Argonne

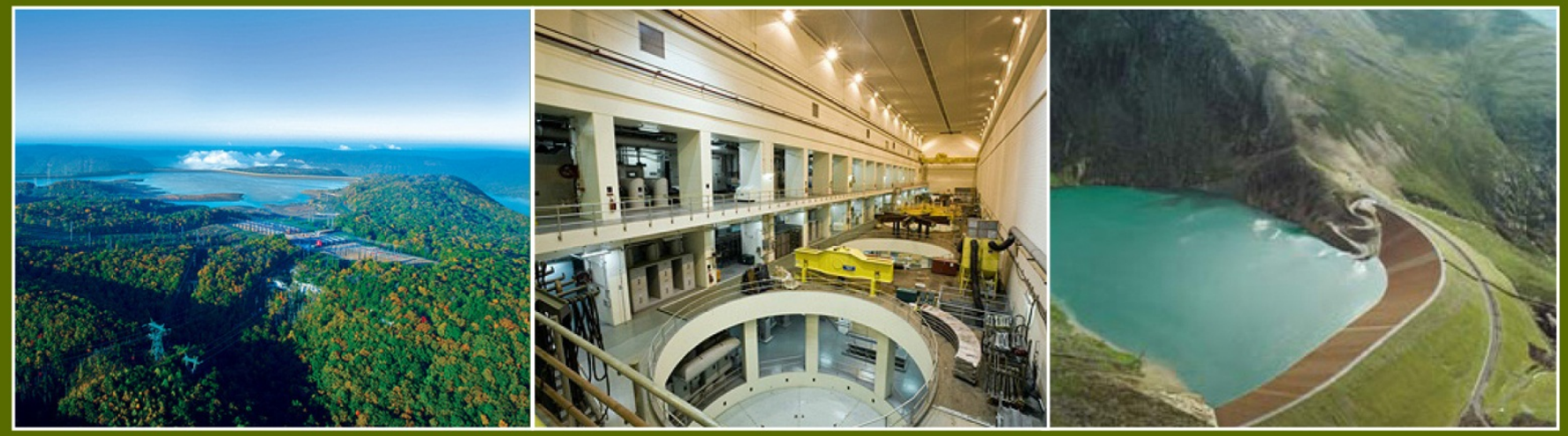

\title{
Modeling and Analysis of Value of Advanced Pumped Storage Hydropower in the United States
}

Decision and Information Sciences 


\author{
About Argonne National Laboratory \\ Argonne is a U.S. Department of Energy laboratory managed by UChicago Argonne, LLC \\ under contract DE-AC02-06CH11357. The Laboratory's main facility is outside Chicago, \\ at 9700 South Cass Avenue, Argonne, Illinois 60439. For information about Argonne \\ and its pioneering science and technology programs, see www.anl.gov.
}

\title{
DOCUMENT AVAILABILITY
}

Online Access: U.S. Department of Energy (DOE) reports produced after 1991 and a growing number of pre-1991 documents are available free via DOE's SciTech Connect (http://www.osti.gov/scitech/)

Reports not in digital format may be purchased by the public from the National Technical Information Service (NTIS):

\section{U.S. Department of Commerce}

National Technical Information Service

5301 Shawnee Rd

Alexandra, VA 22312

www.ntis.gov

Phone: (800) 553-NTIS (6847) or (703) 605-6000

Fax: (703) 605-6900

Email: orders@ntis.gov

Reports not in digital format are available to DOE and DOE contractors from the Office of Scientific and Technical Information (OSTI):

U.S. Department of Energy

Office of Scientific and Technical Information

P.O. Box 62

Oak Ridge, TN 37831-0062

www.osti.gov

Phone: (865) 576-8401

Fax: (865) 576-5728

Email: reports@osti.gov

\section{Disclaimer}

This report was prepared as an account of work sponsored by an agency of the United States Government. Neither the United States Government nor any agency thereof, nor UChicago Argonne, LLC, nor any of their employees or officers, makes any warranty, express or implied, or assumes any legal liability or responsibility for the accuracy, completeness, or usefulness of any information, apparatus, product, or process disclosed, or represents that its use would not infringe privately owned rights. Reference herein to any specific commercial product, process, or service by trade name, trademark, manufacturer, or otherwise, does not necessarily constitute or imply its endorsement, recommendation, or favoring by the United States Government or any agency thereof. The views and opinions of document authors expressed herein do not necessarily state or reflect those of the United States Government or any agency thereof, Argonne National Laboratory, or UChicago Argonne, LLC.

This report is being disseminated by the Department of Energy. As such, this document was prepared in compliance with Section 515 of the Treasury and General Government Appropriations Act for Fiscal Year 2001 (Public Law 106-554) and Information Quality Guidelines issued by the Department of Energy. Although this report does not constitute "influential" information, as that term is defined in DOE's Information Quality Guidelines or the Office of Management and Budget's Information Quality Bulletin for Peer Review, the study was reviewed both internally and externally prior to publication. For purposes of external review, the study benefited from the advice and comments of an advisory working group consisting of more than 30 experts from the industry, government, and research institutions. 


\title{
Modeling and Analysis of Value of Advanced Pumped Storage Hydropower in the United States
}

\author{
prepared by \\ Vladimir Koritarov, Thomas Veselka, John Gasper, Brett Bethke, Audun Botterud, \\ Jianhui Wang, Matthew Mahalik, Zhi Zhou, and Catharina Milostan \\ Argonne National Laboratory \\ James Feltes and Yuriy Kazachkov \\ Siemens PTI \\ Tao Guo and Guangjuan Liu \\ Energy Exemplar \\ Bruno Trouille, Peter Donalek, and Kathleen King \\ MWH Americas \\ Erik Ela, Brendan Kirby (consultant), Ibrahim Krad, and Vahan Gevorgian \\ National Renewable Energy Laboratory
}

June 2014 
This page intentionally left blank. 


\section{Preface}

This report is the last of seven reports developed during the U.S. Department of Energy (DOE) study on the "Modeling and Analysis of Value of Advanced Pumped Storage Hydropower in the United States.” This report is the Final Project Report and provides an overview of all activities and work performed by the project team, as well the key results and findings of the various analyses performed during the study. The study was led by Argonne National Laboratory in collaboration with Siemens PTI, Inc., Energy Exemplar, LLC, MWH Americas, Inc., and the National Renewable Energy Laboratory (NREL). Funding for the study was provided by DOE's Office of Energy Efficiency and Renewable Energy (EERE) through a program managed by the EERE's Wind and Water Power Technologies Office (WWPTO).

The scope of work for the study contained two main components: (1) development of vendorneutral dynamic simulation models for advanced pumped storage hydropower (PSH) technologies, and (2) production cost and revenue analyses to assess the value of advanced PSH in the power system. Throughout the study, the project team was supported and guided by an Advisory Working Group (AWG) consisting of more than 30 experts from a diverse group of organizations within the hydropower industry, including equipment manufacturers, electric power utilities, regional electricity market operators, hydro engineering and consulting companies, national laboratories, universities and research institutions, hydropower industry associations, and government and regulatory agencies.

The development of vendor-neutral dynamic simulation models was carried out by the Advanced Technology Modeling Task Force Group (TFG) led by experts from Siemens PTI, with the participation of other project team experts. As part of this study, the Advanced Technology Modeling TFG first reviewed and prepared a summary of the existing dynamic models of conventional hydro and PSH plants that are currently in use in the United States. The review was conducted to determine the need for improving existing models and developing new ones; the summary is published in the first project report, Review of Existing Hydroelectric TurbineGovernor Simulation Models.

Although existing dynamic models for conventional hydro and PSH plants allow for accurate representation and modeling of these technologies, the Advanced Technology Modeling TFG determined that dynamic models should also be developed for two PSH technologies for which there were no existing models available in the United States. Those two technologies are (1) adjustable speed PSH plants employing doubly-fed induction machines (DFIMs), and (2) ternary PSH units. The Advanced Technology Modeling TFG developed vendor-neutral dynamic models of these two PSH technologies that are published in the following two project reports: (1) Modeling Adjustable Speed Pumped Storage Hydro Units Employing Doubly-Fed Induction Machines, and (2) Modeling Ternary Pumped Storage Units.

Extensive testing of the newly developed models was performed using Siemens PTI's standard test cases for the Power System Simulator for Engineering (PSS ${ }^{\circledR} E$ ) model, as well as the Western Electricity Coordinating Council (WECC) modeling cases for the Western Interconnection that were provided in the $\mathrm{PSS}^{\circledR} \mathrm{E}$ format. The results of model testing are 
presented in the fourth project report, Testing Dynamic Simulation Models for Different Types of Advanced Pumped Storage Hydro Units.

The capabilities of advanced PSH technologies to provide frequency regulation, especially in the pump mode, were analyzed using the Sacramento Municipal Utility District (SMUD) balancing authority as a test bed for analysis. The results are published in the fifth project report, Simulation of the Secondary Frequency Control Capability of the Advanced PSH Technology and Its Application to the SMUD System.

The second component of the study, the analysis of production cost and revenue, was conducted to assess the value of advanced PSH in the power system. The sixth project report provides details on the production cost and revenue simulations performed using the Energy Exemplar's PLEXOS model. The analysis focused on several geographical areas (Western Interconnection, California, and SMUD balancing authority) and was carried out for different levels of renewable energy generation in the system. The analysis examined the benefits and value of advanced PSH plants in both regulated and competitive electricity market environments. The analytical approach and key results of the analyses are provided in the report, Adjustable Speed PumpedStorage Hydro-Generator (PSH) Evaluation by PLEXOS, published by Energy Exemplar. 


\section{Acknowledgments}

The authors would like to acknowledge the support and guidance provided to the project team by the staff and contractors of the U.S. Department of Energy Office of Energy Efficiency and Renewable Energy’s (EERE’s) Wind and Water Power Technologies Office (WWPTO), including Michael Reed, Charlton Clark, Rajesh Dham, Rob Hovsapian, Patrick O’Connor, Richard Gilker, and others. The authors are also grateful to the members of the Advisory Working Group for their excellent collaboration and efforts in advising the project team and guiding the study. The Advisory Working Group included a broad spectrum of global pumped storage hydropower experts, including the following:

\begin{tabular}{|l|l|}
\hline $\begin{array}{l}\text { Michael Reed, Charlton Clark, Rajesh Dham, } \\
\text { Rob Hovsapian, Patrick O'Connor, } \\
\text { Richard Gilker }\end{array}$ & $\begin{array}{l}\text { U.S. Department of Energy Office of Energy } \\
\text { Efficiency and Renewable Energy (DOE/EERE) - } \\
\text { Wind and Water Power Technologies Office } \\
\text { (WWPTO) }\end{array}$ \\
\hline Rachna Handa & $\begin{array}{l}\text { DOE - Office of Electricity Delivery and Energy } \\
\text { Reliability (OE) }\end{array}$ \\
\hline Rahim Amerkhail & Federal Energy Regulatory Commission (FERC) \\
\hline Michael Manwaring, Douglas Divine & National Hydropower Association (NHA) \\
\hline Mark Jones, Elliot Mainzer & Bonneville Power Administration (BPA) \\
\hline Xiaobo Wang & California Independent System Operator (CAISO) \\
\hline Zheng Zhou & Midwest Independent System Operator (MISO) \\
\hline Matt Hunsaker & Western Electricity Coordinating Council (WECC) \\
\hline Tuan Bui & $\begin{array}{l}\text { California Department of Water Resources } \\
\text { (CDWR) }\end{array}$ \\
\hline David Harpman & Bureau of Reclamation (Reclamation) \\
\hline Kyle L. Jones & U.S. Army Corps of Engineers (USACE) \\
\hline Scott Flake, Greg Brownell & Sacramento Municipal Utility District (SMUD) \\
\hline Paul Jacobson, Stan Rosinski & Electric Power Research Institute (EPRI) \\
\hline Alan Soneda & Pacific Gas and Electric Company (PG\&E) \\
\hline Osamu Nagura & Hitachi Mitsubishi Hydro \\
\hline Teruyuki Ishizuki & Toshiba Corporation \\
\hline Rick Miller, Rick Jones & HDR Engineering, Inc. (HDR|DTA) \\
\hline Jiri Koutnik, Maximilian Manderla & Voith Hydro \\
\hline Christophe Nicolet & Power Vision Engineering (PVE) \\
\hline Peter McLaren & Center for Advanced Power System (CAPS) \\
\hline Landis Kannberg & Pacific Northwest National Laboratory (PNNL) \\
\hline Klaus Engels & E.ON Wasserkraft GmbH \\
\hline Kim Johnson & Riverbank Power/eBurton \\
\hline Steve Aubert, Le Tang & ABB Switzerland, Ltd. \\
\hline Debbie Mursch & Alstom \\
\hline Ali Nourai & DNV GL \\
\hline & \\
\hline
\end{tabular}


This page intentionally left blank. 


\section{Contents}

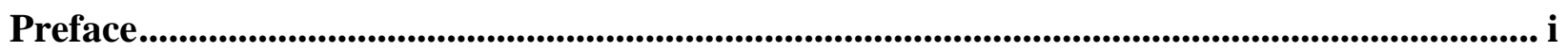

Acknowledgments ................................................................................................................................................... iii

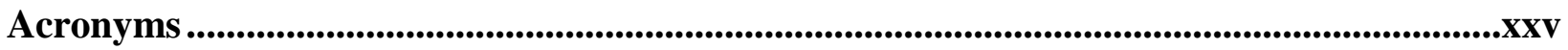

Executive Summary ....................................................................................................................... ES-1

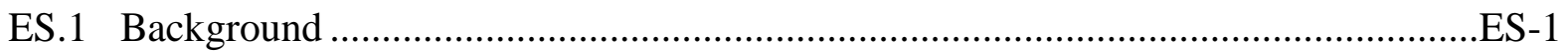

ES.2 Study Objectives ..............................................................................................

ES.3 Technical Approach ............................................................................................

ES.4 Summary of Key Findings and Conclusions.............................................................ES-5

ES.4.1 Advanced Technology Modeling....................................................................

ES.4.2 Production Cost Simulations Using the PLEXOS Model...............................ES-7

ES.4.3 Analysis of Reliability and Costs Using the FESTIV Model ......................ES-18

ES.4.4 Analysis of PSH Operation Using the CHEERS Model..............................ES-19

ES.4.5 Market Issues and Treatment of PSH in Electricity Markets ......................ES-20

ES.4.6 Financial Analysis and Business Models...................................................ES-21

Section 1 Introduction ...................................................................................................................... 1-1

$1.1 \quad$ Background ..................................................................................................... 1-1

1.2 Study Objectives ……………………………….............................................. 1-1

1.3 Technical Approach .......................................................................................... 1-2

1.4 Content of Report .......................................................................................... 1-6

1.5 References ........................................................................................................ 1-6

Section 2 PSH Technology Characteristics........................................................................................ 2-1

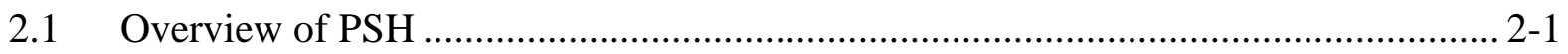

2.2 Pumped Storage Hydro Technology …………......................................................... 2-2

2.3 History of Pumped Storage Hydro ............................................................................ 2-3

2.3.1 Pumped Storage in the United States........................................................... 2-4

2.3.2 Adjustable Speed PSH in Japan and Europe.................................................. 2-4

2.4 Pumped Storage Hydro Capabilities ............................................................... 2-5

2.5 Analysis of Pumped Storage Plants and Units .......................................................... 2-6

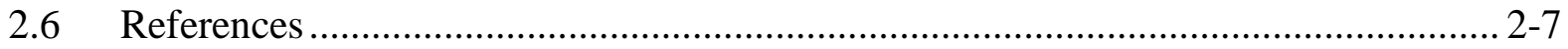

Section 3 Advanced PSH Model Development................................................................................ 3-1

3.1 Review of Existing Hydroelectric Turbine Governor Models ..................................... 3-1

3.2 Modeling Adjustable Speed PSH Units Employing Doubly-Fed Induction

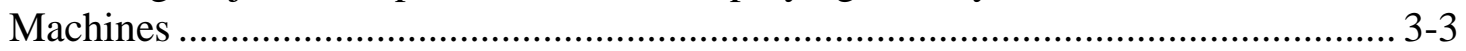

3.2.1 Model of the Adjustable Speed PSH Units Employing a Doubly-Fed Induction Machine ........................................................................................ 3-4 
3.3 Modeling Ternary Pumped Storage Units ................................................................... 3-8

3.3.1 Overview of Ternary Pumped Storage Technology ……............................... 3-9

3.3.2 Modeling of Ternary Pumped Storage Units .................................................. 3-12

3.4 Testing Dynamic Simulation Models for Different Types of Advanced PSH

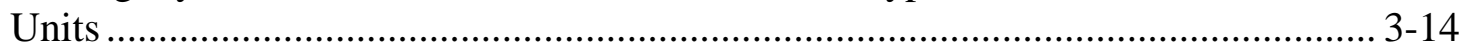

3.5 Simulation of the Secondary Frequency Control Capability of the Advanced PSH Technology and Its Application to the SMUD System ..................................... 3-22

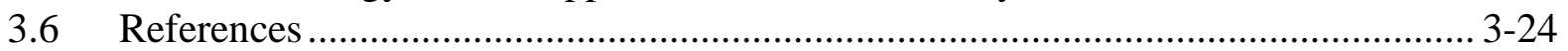

Section 4 Production Cost and Revenue Simulations Using the PLEXOS Model................ 4-1

4.1 WI Database and Modeling Assumptions ................................................................. 4-1

4.1.1 Introduction of WI Database........................................................................ 4-1

4.1.2 Contingency, Flexibility, and Regulation Reserve Requirements ................. 4-3

4.1.3 Modeling Representation of PSH Plants................................................... 4-5

4.1.4 TEPPC Data Modifications................................................................. 4-6

4.2 PLEXOS Modeling Approach ………………................................................... 4-7

4.2.1 PLEXOS SCUC/ED Algorithm............................................................. 4-7

4.2.2 Three-Stage DA-HA-RT Sequential Simulations........................................ 4-8

4.2.3 Scope of PLEXOS Simulations ............................................................. 4-11

$4.3 \quad$ Day-Ahead Simulation Results ......................................................................... 4-12

4.3.1 WI Simulation Results ........................................................................ 4-12

4.3.2 California Simulation Results ........................................................... 4-20

4.3.3 SMUD Simulation Results.................................................................... 4-36

4.4 Three-Stage DA-HA-RT Sequential Simulations ...................................................... 4-42

4.4.1 Variability and Uncertainty of Variable Energy Resources ......................... 4-42

4.4.2 Three-Stage DA-HA-RT Simulation Results for the WI............................. 4-46

4.4.3 Three-Stage DA-HA-RT Simulation Results for California ......................... 4-51

4.4.4 Three-Stage DA-HA-RT Simulation Results for SMUD ............................. 4-56

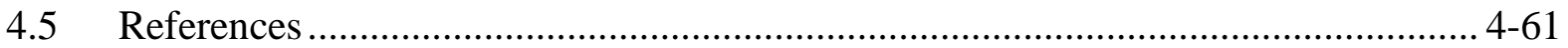

\section{Section 5 Analysis of Steady-State Reliability and Detailed Costs Using the} FESTIV Model ........................................................................................................... 5-1

5.1 Input Data and Assumptions .............................................................................. 5-4

5.2 FESTIV Simulation Results.......................................................................... 5-13

5.3 Sensitivity Studies.......................................................................................... 5-19

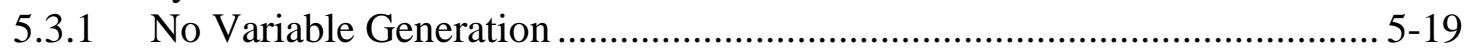

5.3.2 Perfect Variable Generation Forecasts...................................................... 5-20

5.3.3 Fast, Unfiltered Control from Adjustable Speed PSH................................. 5-21

$5.4 \quad$ Summary and Conclusions...................................................................................... 5-24

5.5 References and Bibliography …………………………………………………. 5-25

Section 6 CHEERS Pumped Storage Modeling and Analysis ....................................................... 6-1

6.1 General Description of CHEERS ........................................................................... 6-1

6.2 Objective of the CHEERS Study ......................................................................... 6-2 


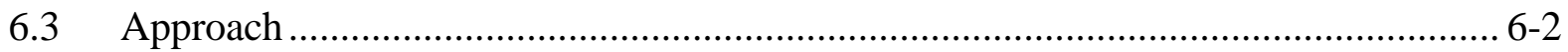

6.3.1 Fixed-Speed Pumped Storage Model............................................................ 6-5

6.3.2 Adjustable Speed Pumped Storage Model................................................... 6-6

6.3.3 Gas Turbine Model .............................................................................. 6-9

6.3.4 Day-Ahead Price Forecasts and Uncertainty …............................................ 6-9

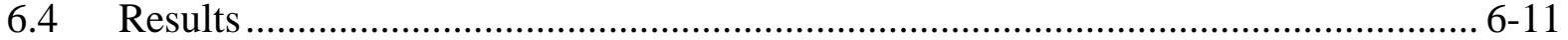

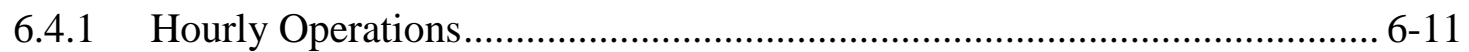

6.4.2 Annual Operating Net Revenue Analysis ..................................................... 6-17

6.4.3 Comparative Net Present Value Analysis.................................................... 6-21

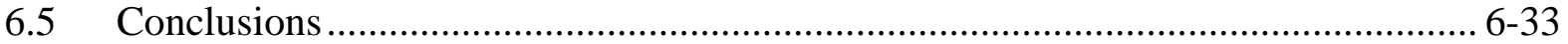

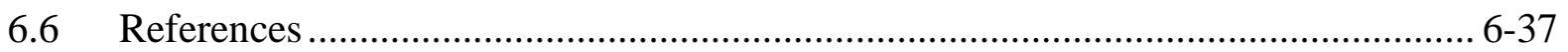

Section 7 Value of PSH in the Power System ........................................................................... 7-1

7.1 PSH Services and Contributions ..........................................................................

7.2 Value of PSH Services and Contributions ............................................................. 7-2

7.2.1 Inertial Response...................................................................................... 7-3

7.2.2 Primary Frequency Control.............................................................. 7-4

7.2.3 Operating Reserves .................................................................................. 7-6

7.2.4 Energy Arbitrage................................................................................. 7-11

7.2.5 Generating Capacity............................................................................ 7-15

7.2.6 Emission Reductions............................................................................ 7-17

7.2.7 Integration of Variable Energy Resources ..................................................... 7-19

7.2.8 Reduced Cycling of Thermal Generating Units............................................ 7-20

7.2.9 Other Portfolio Effects .............................................................................. 7-24

7.2.10 Reduced Transmission Congestion............................................................ 7-25

7.2.11 Transmission Deferral........................................................................... 7-25

7.2.12 Voltage Support .................................................................................... 7-26

7.2.13 Power System Stability …………………................................................ 7-27

7.2.14 Black-Start Capability............................................................................ 7-28

7.2.15 Energy Security..................................................................................... 7-29

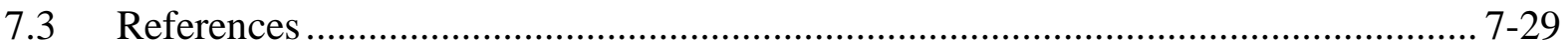

Section 8 Treatment of PSH in Electricity Markets ....................................................................... 8-1

8.1 Energy Arbitrage and Ancillary Services ………...................................................... 8-3

8.2 Capacity Markets and Payments .............................................................................. 8-9

8.2.1 Capacity Market Considerations................................................................... 8-13

8.3 Treatment of PSH in Electricity Markets................................................................ 8-13

8.3.1 Mechanisms for Pricing and Settlement Calculations ................................ 8-15

8.3.2 Need for Flexibility and Storage .............................................................. 8-17

8.3.3 PSH Scheduling in Energy and Ancillary Services Markets ........................ 8-18

8.3.4 Market versus System Value .................................................................... 8-18

8.4 Market Design Issues Affecting the Value of PSH................................................ 8-20

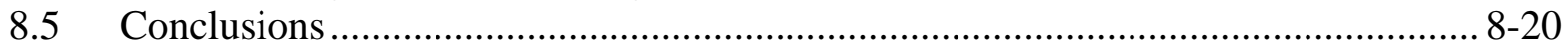

8.6 References and Bibliography …....................................................................... 8-22 
9.1 Modeling the Economic versus the Financial Potential of PSH Facilities .................. 9-1

9.2 Scope of Present Study .................................................................................. 9-2

9.3 Study Terms and Definitions ................................................................................ 9-3

9.3.1 Glossary of Economic and Financial Terms ............................................... 9-3

9.4 Background on PSH Development and Business Models ......................................... 9-4

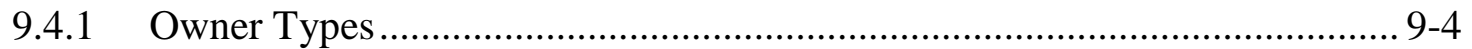

9.4.2 Development Types ................................................................................... 9-5

9.4.3 Contracting Strategies ......................................................................... 9-6

9.4.4 Division of Scope................................................................................ 9-7

9.4.5 Delivery Types........................................................................................ 9-7

9.5 Modeling Methodology........................................................................................ 9-11

9.5.1 Overview of the PSH Financial Model .................................................. 9-15

9.6 Case Studies ………………………………................................................. 9-16

9.6.1 Base Case ....................................................................................... 9-17

9.6.2 Base-Case Results ......................................................................... 9-18

9.6.3 Sensitivity Case 1: Construction Cost........................................................... 9-18

9.6.4 Sensitivity Case 2: Interest Rates................................................................. 9-19

9.6.5 Sensitivity Case 3: Revenues from Energy and Ancillary Services ............ 9-19

9.6.6 Sensitivity Case 4: Real Escalation Rates for All Revenues ....................... 9-19

9.6.7 Sensitivity Case 5: Ancillary Revenues........................................................ 9-22

9.6.8 Sensitivity Case 6: Real Escalation Rates for Ancillary Revenues .............. 9-22

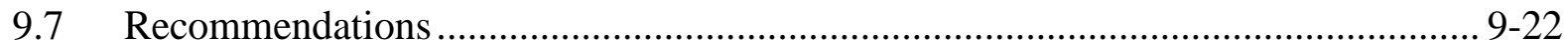

9.8 References and Bibliography …………………............................................... 9-25

Section 10 Key Findings and Conclusions ................................................................................... 10-1

10.1 Advanced Technology Modeling ............................................................................ 10-1

10.1.1 Development and Testing of Dynamic PSH Models .....................................10-1

10.1.2 Power and Speed Control of AS PSH.......................................................10-2

10.1.3 Mode Change Times of PSH Technologies .................................................. 10-2

10.1.4 Additional Capabilities Provided by Advanced PSH Technologies............. 10-3

10.2 Production Cost Simulations with PLEXOS Model .................................................. 10-4

10.2.1 Annual Simulation Results .................................................................... 10-5

10.2.2 Three-Stage DA-HA-RT Simulation Results ..........................................10-15

10.3 Analysis of Reliability and Costs by Using the FESTIV Model ............................. 10-16

10.4 Analysis of PSH Operation by Using the CHEERS Model.................................... 10-17

10.5 Treatment of PSH in Electricity Markets.........................................................10-19

10.6 Financial Analysis and Business Models ........................................................... 10-20

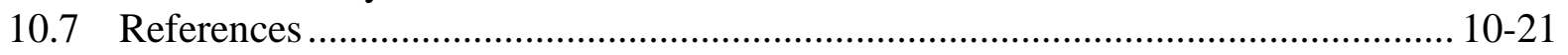

Appendix A: PSH Technology Characteristics ................................................................................ A-1 


\section{Figures}

ES-1 Technical Approach—Schematic Flowchart of Project Activities ..........................ES-3

ES-2 Power System Timeframes and Operational Issues ..............................................ES-4

ES-3 PSH Contributions to WI Operating Reserves in 2022 ...........................................9

ES-4 PSH Contributions to California Operating Reserves in 2022 ...............................ES-9

ES-5 Average Annual PSH Revenues for Operating Reserves per kW of PSH

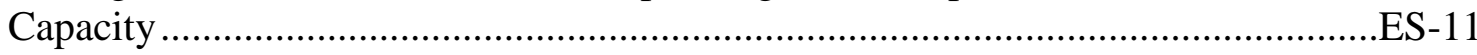

ES-6 Reduction in Thermal Startup Costs Due to PSH Capacity in the WI in 2022 ..........ES-12

ES-7 Reduction in Thermal Startup Costs Due to PSH Capacity in California in 2022....ES-13

ES-8 Reduction in Thermal Startup Costs Due to PSH Capacity in SMUD in 2022 ........ES-13

ES-9 Reductions in Thermal Capacity Ramping Needs in the WI in 2022 Due to PSH Capacity

ES-10 Reductions in Thermal Capacity Ramping Needs in California in 2022 Due to PSH Capacity......

ES-11 Reductions in Thermal Capacity Ramping Needs in SMUD in 2022 Due to PSH

Capacity.

ES-12 Emission Reductions Due to PSH Capacity in the WI in 2022 ...............................ES-15

ES-13 Emission Reductions Due to PSH Capacity in California in 2022 ..........................ES-15

ES-14 Emission Reductions Due to PSH Capacity in the SMUD System in 2022 ..............ES-16

1-1 Technical Approach—Schematic Flowchart of Project Activities ............................ 1-3

1-2 Organization of Project Team ..................................................................... 1-4

1-3 Power System Timeframes and Operational Issues ............................................ 1-5

2-1 Typical Pumped Storage Configuration ............................................................. 2-1

2-2 Goldisthal Pumped Storage Project in Germany .................................................. 2-3

2-3 Preliminary Permits for Pumped Storage Projects Issued by FERC ........................... 2-5

2-4 System Operational Issues and Time Ranges................................................... 2-7 
3-1 Turbine, Governor System, and Generator Functional Relationships......................... 3-2

3-2 Configuration of a DFIM............................................................................ 3-4

3-3 Model of Adjustable Speed PSH Employing DFIM-Turbine Operation .................. 3-6

3-4 Model of AS PSH Employing DFIM—Pump Operation......................................... 3-7

3-5 Ternary Units Demonstrating Hydraulic Short-Circuit Operation ........................... 3-10

3-6 Example of Operation in Pumping Mode with Regulation Capability Using the Hydraulic Short-Circuit Concept....................................................................... 3-10

3-7 Mode Change Times for Various Advanced Pumped Storage Technologies ............. 3-11

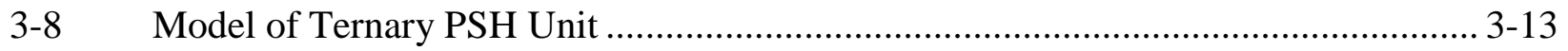

3-9 Comparison of System Frequency with the Conventional and AS PSH Units in Response to the Trip of a Gas Turbine.

3-10 Response of the Power of Units 2, 3, and 4 to a Step Reduction in the Power of Unit 1 with Four Units Sharing a Common Penstock

3-11 Response of Frequency and Mechanical Power of the Turbine and the Mechanical Power of the Pump of the Ternary Unit to the Trip of a Load

3-12 System Frequency with Conventional Units Following System Separation Showing the Impact of Under-Frequency Load Shedding.

3-13 Comparison of System Frequency with Conventional Unit versus AS PSH following System Separation .

3-14 Iowa Hill Pump Input Power and Total Tie Line Flow with Conventional and AS Pumps at Iowa Hill in Response to Wind Power Ramping Up for 2022 Light Load System Conditions.

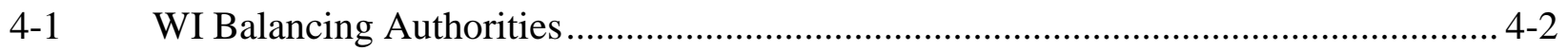

4-2 Average Heat Rates for Coal, CC, CT, and Gas Steam Generators ........................... 4-7

4-3 PLEXOS Security-Constrained Unit Commitment and Economic Dispatch Algorithm

4-4 DA-HA-RT Three-Stage Sequential Simulations

4-5 Comparison of Regional LMPs in Three Cases for the Selected WI Regions in 2022 for the Base Renewable Scenario 
4-6 Comparison of Regional LMPs in Three Cases for the Selected WI Regions in 2022 for the High Wind Renewable Scenario

4-7 Logic Flow for the Transmission Expansion Using the Congestion Shadow Price Approach

4-8 Comparison of Regional LMPs in Three Cases for the Selected Regions in

California in 2022 for the Base Renewable Scenario.

4-9 Comparison of Regional LMPs in Three Cases for the Selected Regions in

California in 2022 for the High Wind Renewable Scenario.

4-10 SCE LMP in the Week of July 17, 2022, in Three Cases for the High Wind Renewable Scenario

4-11 Comparison of SMUD Regional LMP in Two Cases in 2022 for the Base

Renewable Scenario

4-12 Comparison of SMUD Regional LMP in Two Cases in 2022 for the High Wind

Renewable Scenario

4-13 Five-Minute Actual Solar Generation and Hourly DA/HA Forecasts in Southern California in a Typical Winter Week of 2022

4-14 Five-Minute Actual Wind Generation and Hourly DA/HA Forecasts in Southern California in a Typical Winter Week of 2022

4-15 Five-Minute Actual Solar Generation and Hourly DA/HA Forecasts in Southern California in a Typical Summer Week of 2022.

4-16 Five-Minute Actual Wind Generation and Hourly DA/HA Forecasts in Southern California in a Typical Summer Week of 2022.

4-17 Wind and Solar Generation Forecast Error from DA to HA and HA to RT in Southern California in a Typical Winter Week of 2022.

4-18 Wind and Solar Generation Forecast Error from DA to HA and HA to RT in Southern California in a Typical Summer Week of 2022 .....

4-19 WI Production Cost from Three-Stage Simulations for Three Cases and Four Typical Weeks in 2022 for the High Wind Renewable Scenario.

4-20 WI Startup and Shutdown Costs from Three-Stage Simulations for Three Cases and Four Typical Weeks in 2022 for the High Wind Renewable Scenario

4-21 WI Thermal Generator Ramp Up from Three-Stage Simulations for Three Cases and Four Typical Weeks in 2022 for the High Wind Renewable Scenario 
4-22 WI Thermal Generator Ramp Down from Three-Stage Simulations for Three Cases and Four Typical Weeks in 2022 for the High Wind Renewable Scenario ...... 4-50

4-23 California Production Cost from Three-Stage Simulations for Three Cases and Four Typical Weeks in 2022 for the High Wind Renewable Scenario

4-24 California Startup Cost from Three-Stage Simulations for Three Cases and Four

Typical Weeks in 2022 for the High Wind Renewable Scenario

4-25 California Thermal Generator Ramp Up from Three-Stage Simulations for Three Cases and Four Typical Weeks in 2022 for the High Wind Renewable Scenario $4-54$

4-26 California Thermal Generator Ramp Down from Three-Stage Simulations for Three Cases and Four Typical Weeks in 2022 for the High Wind Renewable Scenario 4-55

4-27 SMUD Production Cost from Three-Stage Simulations for Two Cases and Four Typical Weeks in 2022 for the High Wind Renewable Scenario $4-57$

4-28 SMUD Startup Cost from Three-Stage Simulations for Two Cases and Four Typical Weeks in 2022 for the High Wind Renewable Scenario.

4-29 SMUD Thermal Generator Ramp Up from Three-Stage Simulations for Two Cases and Four Typical Weeks in 2022 for the High Wind Renewable Scenario ...... 4-59

4-30 SMUD Thermal Generator Ramp Down from Three-Stage Simulations for Two Cases and Four Typical Weeks in 2022 for the High Wind Renewable Scenario ...... 4-60

5-1 Flow Diagram for FESTIV ………………….................................................. 5-2

5-2 Power Spectrum of Real Data versus Synthetic Wind Data........................................... 5-5

5-3 Timeline for DASCUC, RTSCUC, RTSCED, and AGC in FESTIV ............................. 5-7

5-4 PV Forecasts for RTSCUC with an Optimization Horizon of 3 Hours, Repeating Every 15 Minutes ………………………………………..................................... 5-8

5-5 PV Forecasts for RTSCED with an Optimization Horizon of 1 Hour, Repeating Every 5 Minutes ………………………………………….......................................... 5-9

5-6 Day-Ahead Reserve Requirements for April 16 and July 16 ...................................... 5-11

5-7 Real-Time Dispatch Reserve Requirements for April 16............................................ 5-12

5-8 Power Output of Three FS PSH Units for 1 Day in April............................................ 5-16

5-9 Power Output for Three AS PSH Units for 1 Day in April.......................................... 5-16 
5-10 AS PSH Regulating in Pumping Mode

5-11 Power Output of Three PSH Units as FS in April, AS in April, FS in July, and AS in July $5-18$

5-12 Net Load and Total PSH Output for Perfect and Imperfect Scenarios $5-21$

5-13 Net Load and Total PSH Output for Perfect and Imperfect Scenarios Zoomed on 1 Day .....

5-14 Comparison of Output from AS PSH during Normal AGC and Control

Opposing Unfiltered ACE

6-1 CHEERS Pumped Storage Model Topology

6-2 Generation Efficiency Curves for Pumped Storage Models

6-3 Hourly Operations of FS PSH and Projected Prices for Unit 1 on January 19, 2011.

6-4 Hourly Operations of FS PSH and Projected Prices for Unit 1 on July 27, 2011

6-5 Hourly Operations of AS PSH and Projected Prices for Unit 1 on January 19, 2011.

6-6 Hourly Operations of AS PSH and Projected Prices for Unit 1 on July 27, 2011 ...... 6-15

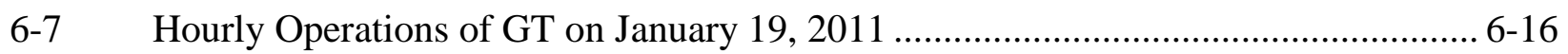

6-8 Hourly Operations of GT on July 27, 2011 _................................................ 6-16

6-9 Annual Net Operating Revenue as a Function of Energy and Ancillary Services Prices

6-10 Annual Net Operating Revenue as a Function of Ancillary Services Prices

6-11 Projecting NPV as a Function of Capital Costs Based on 4.28\% Discount Rate

6-12 Projecting PSH NPV as a Function of Capital Costs: Comparison Using Perfect versus Imperfect Forecasts with PSH Participation in Ancillary Services Markets

6-13 Projecting PSH NPV as a Function of Capital Costs: Comparison Using Perfect versus Imperfect Forecasts without PSH Participation in Ancillary Services Markets .....

6-14 Projecting NPV as a Function of Capital Costs Based on 35\% Lower Energy and Ancillary Services Prices. 
6-15 Projecting NPV as a Function of Capital Costs Based on 35\% Lower Energy and Ancillary Services Prices: Comparison Using Perfect versus Imperfect Forecasts .... 6-28

6-16 Projecting NPV as a Function of Capital Costs Based on 35\% Higher Energy and Ancillary Services Prices

6-17 Projecting NPV as a Function of Capital Costs Based on 35\% Higher Energy and Ancillary Services Prices: Comparison Using Perfect versus Imperfect Forecasts

6-18 EIA 2013 AEO Natural Gas Price Projections. 6-30

6-19 Projecting NPV as a Function of Capital Costs Based on California AEO Baseline Projection

6-20 Projecting NPV as a Function of Capital Costs Based on California AEO Baseline Projection: Comparison Using Perfect versus Imperfect Forecasts

6-21 Sensitivity of Project NPV to Changes in Interest Rate Based on California AEO Baseline Projection.

6-22 Sensitivity of Project NPV on Changes in Ancillary Services Prices Based on California AEO Baseline Projection, with Base Capital Cost and Base Interest Rate.

6-23 Technology NPV under Various Price Scenarios Assuming Participation in Ancillary Services Markets

6-24 Technology NPV under Various Price Scenarios Assuming No Participation in Ancillary Services Markets

6-25 Technology NPV under Various Price Scenarios Assuming Participation in Ancillary Services Markets: Comparison Using Perfect versus Imperfect Forecasts 6-36

6-26 Technology NPV under Various Price Scenarios Assuming No Participation in Ancillary Services Markets: Comparison Using Perfect versus Imperfect Forecasts 6-36

7-1 Response of System Frequency to a Loss of Generation Event ..................................... 7-4

7-2 Speed Governor and Turbine in Relationship to Generator ........................................... 7-5

7-3 Speed/Droop Characteristic .................................................................................... 7-6

7-4 PSH Contributions to WI Operating Reserves in 2022 …............................................ 7-8

7-5 PSH Contributions to California Operating Reserves in 2022 …................................... 7-8 
7-6 Average Annual PSH Revenues for Operating Reserves per Kilowatt of PSH

Capacity

7-7 Annual Net Revenues from Energy Arbitrage in California in 2022 ....................... 7-13

7-8 Net Revenues from Energy Arbitrage per Kilowatt of PSH Capacity ....................... 7-13

7-9 Forward Capacity Market Clearing Prices for ISONE and PJM............................. 7-16

7-10 Emission Reductions Due to PSH Capacity in the WI in 2022 ............................... 7-18

7-11 Emission Reductions Due to PSH Capacity in California in 2022 .......................... 7-18

7-12 Emission Reductions Due to PSH Capacity in the SMUD System in 2022 .............. 7-18

7-13 Reduction in Thermal Startup Costs Due to PSH Capacity in the WI in 2022 .......... 7-21

7-14 Reduction in Thermal Startup Costs Due to PSH Capacity in California in 2022 ...... 7-21

7-15 Reduction in Thermal Startup Costs Due to PSH Capacity in SMUD in 2022 ......... 7-22

7-16 Reductions in Thermal Capacity Ramping Needs in the WI in 2022 Due to PSH Capacity

7-17 Reductions in Thermal Capacity Ramping Needs in California in 2022 Due to PSH Capacity..... $7-23$

7-18 Reductions in Thermal Capacity Ramping Needs in SMUD in 2022 Due to PSH Capacity.... $7-23$

8-1 Operating Reserves, Showing Why and When They Are Needed ............................. 8-5

8-2 Regulation Compensates for Random Minute-to-Minute Variations in Net System Load

8-3 Contingency Reserves Compensate for the Sudden Failure of a Large Generator or Transmission Line 8-8

8-4 CAISO Average Hourly 2011 Prices for Energy and Ancillary Services.................. 8-10

8-5 RTO and ISO Regions in North America......................................................... 8-14

8-6 Market and System Value of Energy Storage as a Function of Total Storage Capacity in the System

10-1 Mode Change Times for Various Advanced Pumped Storage Technologies ............. 10-3

10-2 PSH Contributions to WI Operating Reserves in 2022 ....................................... 10-7 
10-3 PSH Contributions to California Operating Reserves in 2022 …................................ 10-7

10-4 Average Annual PSH Revenues for Operating Reserves per Kilowatt of PSH

Capacity ..................................................................................................... 10-9

10-5 Reduction in Thermal Startup Costs Due to PSH Capacity in the WI in 2022 ......... 10-11

10-6 Reduction in Thermal Startup Costs Due to PSH Capacity in California in 2022 .... 10-11

10-7 Reduction in Thermal Startup Costs Due to PSH Capacity in SMUD in 2022 ........ 10-11

10-8 Reductions in Thermal Capacity Ramping Needs in the WI in 2022 Due to PSH

Capacity ……...................................................................................................... 10-12

10-9 Reductions in Thermal Capacity Ramping Needs in California in 2022 Due to PSH Capacity........................................................................................................ 10-12

10-10 Reductions in Thermal Capacity Ramping Needs in SMUD in 2022 Due to PSH Capacity

10-11 Emission Reductions Due to PSH Capacity in the WI in 2022 ................................. 10-13

10-12 Emission Reductions Due to PSH Capacity in California in 2022 ........................... 10-14

10-13 Emission Reductions Due to PSH Capacity in the SMUD System in 2022 ............. 10-14

A-1 Typical Pumped Storage Configuration ......................................................................... A-1

A-2 Comparison of Single-Speed and AS Electrical Connections........................................ A-3

A-3 Ternary Pumped Storage Plant Configuration …………………………………......... A-5

A-4 Ternary Unit Operating in a Hydraulic Short-Circuit Mode ........................................... A-6

A-5 Operating Range in Pump Mode ................................................................................ A-13

A-6 Operating Range in Generation Mode...................................................................... A-14

A-7 Comparison of Efficiency Curves …………………………............................ A-15

A-8 Operating Mode Transition Times …………………………………….................. A-15

A-9 Comparison of Response Capabilities ..................................................................... A-17

A-10 Comparison of Response of AS PSH and Single-Speed PSH..................................... A-18

A-11 Pump Mode, Discharge, and Head Operating Range .................................................... A-23

A-12 Separate Efficiency Points for Pump and Generation Modes .................................... A-24 
A-13 Efficiency Difference for Single-Speed and AS Operation …………………............ A-25

A-14 Turbine Efficiency Range versus Rated Head.............................................................. A-26

A-15 Turbine Efficiency Range versus Rated Power Output................................................. A-26

A-16 Comparison of Vibrations and Pressure, Yagisawa Pumped Storage Plant ................ A-27

A-17 Cross Section Showing Waterways ...................................................................... A-30

A-18 Historic Capital Cost versus Length to Head Ratio......................................................... A-31

A-19 Synchronous Speed and AS PSH Unit …………................................................. A-33

A-20 Historic Capital Cost versus Project Year ....................................................................... A-36

A-21 Indicative Overnight Construction Cost for Greenfield Pumped Storage Projects.... A-37 


\section{Tables}

ES-1 PSH Services and Contributions …………….......................................................

ES-2 Production Costs Savings in 2022 Due to PSH Capacity.................................................

ES-3 Results for PSH Energy Arbitrage Revenues in California in 2022 ............................ES-8

ES-4 PSH Revenues for Provisions of Operating Reserves in California in 2022 ..............ES-10

ES-5 Average Annual PSH Revenues for Operating Reserves in California in 2022 ........ES-10

ES-6 Summary of PLEXOS Three-Stage Results for the WI, California, and SMUD in 2022

3-1 Hydro Governor Models in PSS ${ }^{\circledR}$ E Software....................................................... 3-2

3-2 Hydro Governor Models in PSLF Software …...................................................... 3-3

3-3 Six Existing PSH Plants Selected for New Model Testing ............................................ 3-22

4-1 Renewable Generation Assumptions by BA in the WI and the U.S. Part of the

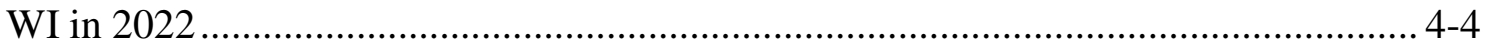

4-2 Characteristics of Three Proposed AS PSH Plants...................................................... 4-5

4-3 Locations and Installed Capacity of Existing FS PHS Plants and Proposed AS PSH Plants in the WI..................................................................................... 4-6

4-4 Simulation Scenario Combinations ........................................................... 4-11

4-5 Three Focus Simulation Areas: WI, California, and SMUD, and the Simulation Settings.................................................................................................. 4-12

4-6 Comparison of WI Production Cost in Three Cases for the Base Renewable Scenario in 2022

4-7 Comparison of WI Production Cost in Three Cases for the High Wind Renewable Scenario in 2022

4-8 Comparison of WI Renewable Curtailment in the Base Renewable Scenario............. 4-13

4-9 Comparison of WI Renewable Curtailment in the High Wind Renewable Scenario

4-10 Comparison of WI Reserve Requirements and Provisions by PSH in Three Cases for the Base Renewable Scenario in 2022. 
4-11 Comparison of WI Reserve Requirements and Provisions by PSH in Three

Cases for the High Wind Renewable Scenario in 2022

4-12 Comparison of WI Emission Production in Three Cases in 2022 for the Base

Renewable Scenario

4-13 Comparison of WI Emission Production in Three Cases in 2022 for the

High Wind Renewable Scenario ....

4-14 Comparison of Number of Starts and Startup Costs of the WI Thermal

Generators in 2022 for the Base Renewable Scenario

4-15 Comparison of Number of Starts and Startup Costs of the WI Thermal

Generators in 2022 for the High Wind Renewable Scenario

4-16 Comparison of Thermal Generator Ramp Up and Down of the WI Thermal

Generators in 2022 for the Base Renewable Scenario

4-17 Comparison of Thermal Generator Ramp Up and Down of the WI Thermal

Generators in 2022 for the High Wind Renewable Scenario

4-18 Comparison of California Production Cost in Three Cases for the Base

Renewable Scenario in 2022

4-19 Comparison of California Production Cost in Three Cases for the High Wind

Renewable Scenario in 2022

4-20 Comparison of California Renewable Curtailment in the Base Renewable

Scenario

4-21 Comparison of California Renewable Curtailment in the High Wind Renewable

Scenario

4-22 Comparison of California Reserve Requirements and Provisions by PSH in

Three Cases for the Base Renewable Scenario in 2022 ....

4-23 Comparison of California Reserve Requirements and Provisions by PSH in

Three Cases for the High Wind Renewable Scenario in 2022 ......

4-24 Comparison of California Emission Productions in Three Cases in 2022 for the Base Renewable Scenario......

4-25 Comparison of California Emission Productions in Three Cases in 2022 for the High Wind Renewable Scenario ....

4-26 Comparison of Number of Starts and Startup Costs of the California Thermal Generators in 2022 for the Base Renewable Scenario 
4-27 Comparison of Number of Starts and Startup Costs of the California Thermal

Generators in 2022 for the High Wind Renewable Scenario

4-28 Comparison of Thermal Generator Ramp Up and Down of the California

Thermal Generators in 2022 for the Base Renewable Scenario

4-29 Comparison of Thermal Generator Ramp Up and Down of the Califoirnia

Thermal Generators in 2022 for the High Wind Renewable Scenario

4-30 California Generator Generation, Generation Cost, Energy Revenue, and

Ancillary Service Revenue for the Base Renewable Scenario in 2022.

4-31 California Generator Generation, Generation Cost, Energy Revenue, and

Ancillary Service Revenue for the High Wind Renewable Scenario in 2022

4-32 California PSH Net Revenues in 2022 under the Base Renewable Scenario:

Simulations with FS PSHs.

4-33 California PSH Net Revenues in 2022 under the Base Renewable Scenario:

Simulations with FS and AS PSHs.

4-34 California PSH Net Revenues in 2022 under the High Wind Renewable

Scenario: Simulations with FS PSHs ....

4-35 California PSH Net Revenues in 2022 under the High Wind Renewable

Scenario: Simulations with FS and AS PSHs.

4-36 Comparison of SMUD Production Cost in Two Cases for the Base Renewable

Scenario in 2022 .

4-37 Comparison of SMUD Production Cost in Two Cases for the High Wind

Renewable Scenario in 2022

4-38 Comparison of SMUD Renewable Curtailment in the High Wind Renewable

Scenario

4-39 Comparison of SMUD Reserve Requirements and Provisions by PSH in Two

Cases for the Base Renewable Scenario in 2022.

4-40 Comparison of SMUD Reserve Requirements and Provisions by PSH in Two

Cases for the High Wind Renewable Scenario in 2022

4-41 Comparison of SMUD Emission Productions in Two Cases in 2022 for the Base

Renewable Scenario

4-42 Comparison of SMUD Emission Productions in Two Cases in 2022 for the High

Wind Renewable Scenario 
4-43 Comparison of Number of Starts and Startup Costs of SMUD Thermal

Generators in 2022 for the Base Renewable Scenario

4-44 Comparison of Number of Starts and Startup Costs of SMUD Thermal

Generators in 2022 for the High Wind Renewable Scenario

4-45 Comparison of Thermal Generator Ramp Up and Down of SMUD Thermal

Generators in 2022 for the Base Renewable Scenario

4-46 Comparison of Thermal Generator Ramp Up and Down of SMUD Thermal

Generators in 2022 for the High Wind Renewable Scenario

4-47 Maximum and Minimum Wind and Solar Forecast Errors in Southern California in a Typical Winter Week of 2022

5-1 Overview of System Details .......................................................................... 5-4

5-2 FESTIV Submodel Timing Parameters ........................................................... 5-7

5-3 Wind and Solar Day-Ahead Forecast Error Characteristics ..................................... 5-9

5-4 Wind and Solar Real-Time Dispatch Forecast Error Characteristics ....................... 5-10

5-5 Requirements for Spinning Reserves ......................................................... 5-11

5-6 Summary of the AS PSH Unit Characteristics …............................................. 5-12

5-7 Summary of April Week Simulations ............................................................ 5-14

5-8 Summary of July Week Simulations ........................................................... 5-14

5-9 Amount of Energy the Three PSH Units Produced and Consumed for

Generating and Pumping ............................................................................... 5-18

5-10 Summary of the April Week Simulations without VER Generation ........................ 5-19

5-11 Amount of Energy the Three PSH Units Produce While Generating and

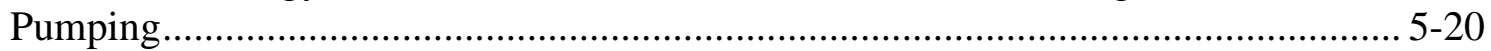

5-12 Reliability and Costs with Perfect VER Generation Forecasts ............................... 5-20

5-13 Study of PSH Providing Fast Unfiltered AGC Regulation Response ........................ 5-22

6-1 CHEERS Assumptions for Ancillary Services of FS and AS PSH Plants.................. 6-8

6-2 Technical Parameters of GT Technologies ...................................................... 6-9

6-3 Absolute Errors of Price Forecast................................................................ 6-11 
6-4 CHEERS Annual Net Revenue Results

6-5 CHEERS Annual Net Revenue Results without an Ancillary Services Market $6-20$

6-6 Assumptions for Comparative Economic Analysis.

6-7 Project Financing Assumptions $6-23$

7-1 PSH Services and Contributions …………............................................................ 7-2

7-2 PSH Revenues for Provisions of Operating Reserves in California in 2022 ................. 7-9

7-3 Average Hourly Prices of Operating Reserves in California in 2022 ............................ 7-9

7-4 Average Annual PSH Revenues for Operating Reserves in California in 2022 ......... 7-10

7-5 Impacts of PSH on ACE and Steady-State Reliability in Third Week of April 2022 ................................................................................................................ 7-11

7-6 Impacts of PSH on ACE and Steady-State Reliability in Third Week of July 2022

7-7 Results for PSH Energy Arbitrage Revenues in California in 2022 ............................ 7-12

7-8 Production Cost Savings Due to PSH Capacity …………………………..................... 7-14

7-9 Production Cost Savings Due to PSH Capacity in BANC ……………………............ 7-15

7-10 Reduction in Thermal Startup Costs Due to PSH Capacity under the Base Renewable Scenario .................................................................................................. 7-20

7-11 Reduction in Thermal Startup Costs Due to PSH Capacity under the High Wind Renewable Scenario ........................................................................... 7-20

7-12 Reduction in Thermal Ramping Needs Due to PSH Capacity ...................................... 7-24

8-1 Operating Reserve Definitions and Common Terms ……............................................... 8-6

8-2 Average Ancillary Services Prices from Each ISO/RTO from 2002 through 2012.

8-3 Forward Capacity Market Clearing Prices for ISONE and PJM.................................... 8-12

8-4 Market Design Topics and Pumped Storage ………................................................... 8-21

9-1 Model Assumptions ........................................................................................... 9-17

9-2 Default Loan Attributes ..................................................................................... 9-18 


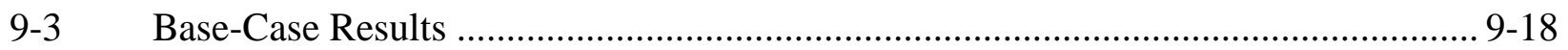

9-4 Results for Sensitivity Case 1, Construction Cost........................................................ 9-20

9-5 Results for Sensitivity Case 2, Interest Rates ....................................................... 9-21

9-6 Results for Sensitivity Case 3, Revenues from Energy and Ancillary Services ......... 9-22

9-7 Results for Sensitivity Case 4, Real Escalation Rates for All Revenues...................... 9-23

9-8 Results for Changes to Ancillary Services Revenue Assumptions ............................... 9-24

9-9 Results for Sensitivity Case 6, Real Escalation Rates for Ancillary Revenues............ 9-24

10-1 Production Costs Savings in 2022 Due to PSH Capacity............................................. 10-5

10-2 Results for PSH Energy Arbitrage Revenues in California in 2022 ........................... 10-6

10-3 PSH Revenues for Provisions of Operating Reserves in California in 2022 ............... 10-8

10-4 Average Annual PSH Revenues for Operating Reserves in California in 2022 ......... 10-9

10-5 Summary of PLEXOS Three-Stage Results for the WI, California, and SMUD

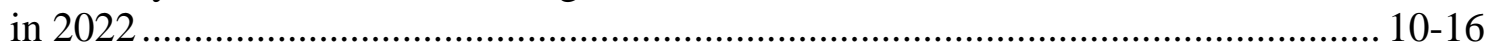

A-1 AS DFIM Pumped Storage Hydro Units.................................................................. A-8

A-2 AS PSH Units in Various Stages of Construction and Installation .............................. A-8

A-3 Primary Benefits of PSH Technologies................................................................. A-9

A-4 Secondary Benefits of Pumped Storage Hydro Technologies ...................................... A-10

A-5 Summary/Comparison of Single-Speed and AS Reversible Pump/Turbine Pumped Storage Units .................................................................................................. A-11

A-6 Composition of a Single-Speed PSH Plant Cycle Efficiency ……………………..... A-21

A-7 Plant Design Issues ............................................................................................ A-34 
This page intentionally left blank. 


\section{Acronyms}

$\begin{array}{ll}\text { AC } & \text { alternating current } \\ \text { ACE } & \text { area control error } \\ \text { AACEE } & \text { absolute area control error in energy } \\ \text { AEO } & \text { Annual Energy Outlook } \\ \text { AGC } & \text { automatic generation control } \\ \text { Argonne } & \text { Argonne National Laboratory } \\ \text { AS } & \text { adjustable speed } \\ \text { A/S } & \text { ancillary service(s) } \\ \text { ASCE } & \text { American Society of Civil Engineers } \\ \text { ASCP } & \text { ancillary service clearing price(s) } \\ \text { AWG } & \text { Advisory Working Group } \\ & \\ \text { BA } & \text { balancing authority } \\ \text { BANC } & \text { Balancing Authority of Northern California } \\ \text { BCR } & \text { benefit/cost ratio } \\ & \\ \text { CA } & \text { California } \\ \text { CAISO } & \text { California ISO } \\ \text { CC } & \text { combined cycle } \\ \text { CCGT } & \text { combined-cycle gas turbine } \\ \text { CEMS } & \text { Continuous Emission Monitoring System } \\ \text { CFE } & \text { Comisión Federal de Electricidad } \\ \text { CFSM } & \text { converter-fed synchronous machine } \\ \text { CH } & \text { conventional hydropower } \\ \text { CHEERS } & \text { Conventional Hydropower Energy and Environmental Systems } \\ \text { CMAR } & \text { construction management at risk } \\ \text { CONE } & \text { cost of new entry } \\ \text { CO } 2 & \text { carbon dioxide } \\ \text { CPLEX } & \text { linear programming optimization solver } \\ \text { CPS } & \text { control performance standard } \\ \text { CPS2 } & \text { control performance standard 2 } \\ \text { CRSP } & \text { Colorado River Storage River Project } \\ \text { CT } & \text { combustion turbine } \\ & \\ \text { DA } & \text { day-ahead } \\ \text { DA-HA-RT } & \text { Day Ahead-Hour Ahead-Real Time } \\ \text { DASCUC } & \text { day-ahead security-constrained unit commitment } \\ \text { DB } & \text { design-build } \\ \text { DBB } & \text { design-bid-build } \\ \text { DC } & \text { direct current } \\ \text { DC-OPF } & \text { direct current optimal power flow } \\ \text { DFIM } & \text { doubly-fed induction machine } \\ \text { DOE } & \text { U.S. Department of Energy } \\ & \end{array}$




\begin{tabular}{|c|c|}
\hline DSCR & debt service coverage ratio \\
\hline $\mathrm{E} \& \mathrm{M}$ & electrical and mechanical \\
\hline EBIT & earnings before income and taxes \\
\hline ED & economic dispatch \\
\hline EERE & Energy Efficiency and Renewable Energy \\
\hline EIA & Energy Information Administration \\
\hline ENTSO-E & European Network of Transmission System Operators for Electricity \\
\hline EPC & engineer, procure, and construct \\
\hline EPCM & engineer, procure, and construction management \\
\hline EPRI & Electric Power Research Institute \\
\hline ERCOT & Electric Reliability Council of Texas \\
\hline FERC & Federal Energy Regulatory Commission \\
\hline $\begin{array}{l}\text { FESTIV } \\
\text { FS }\end{array}$ & $\begin{array}{l}\text { Flexible Energy Scheduling Tool for Integration of Variable generation } \\
\text { fixed speed }\end{array}$ \\
\hline GAMS & General Algebraic Modeling System \\
\hline GMP & guaranteed maximum price \\
\hline GT & gas turbine \\
\hline HA & hour-ahead \\
\hline IAEA & International Atomic Energy Agency \\
\hline IEEE & Institute of Electrical and Electronics Engineers \\
\hline IOU & investor owned utility \\
\hline IPP & independent power producer \\
\hline IRR & internal rate of return \\
\hline ISO & independent system operator \\
\hline ISONE & Independent System Operator New England \\
\hline KEPCO & Kansai Electric Power Company \\
\hline LGIA & large generator interconnection agreement \\
\hline LGIP & large generator interconnection procedure \\
\hline LMP & locational marginal price \\
\hline LSE & load serving entity \\
\hline MAE & mean absolute error \\
\hline MID & Modesto Irrigation District \\
\hline MIP & Mixed Integer Programming \\
\hline MISO & Midcontinent Independent System Operator \\
\hline MWH & MWH Americas \\
\hline NERC & North American Electric Reliability Corporation \\
\hline NETL & National Energy Technology Laboratory \\
\hline
\end{tabular}




\begin{tabular}{|c|c|}
\hline $\mathrm{NO}_{\mathrm{x}}$ & nitrogen oxide \\
\hline NPV & net present value \\
\hline NREL & National Renewable Energy Laboratory \\
\hline NYISO & New York Independent System Operator \\
\hline O\&M & operations and maintenance \\
\hline $\mathrm{OPF}$ & optimal power flow \\
\hline ORNL & Oak Ridge National Laboratory \\
\hline P3 & public private partnership \\
\hline PI & proportional-integral controller \\
\hline PID & proportional-integral-derivative controller \\
\hline PSH & pumped storage hydropower \\
\hline PSLF & Positive Sequence Load Flow \\
\hline PSS ${ }^{\circledR} E$ & Power System Simulator for Engineering \\
\hline PUC & public utility commission \\
\hline PV & photovoltaic \\
\hline PWM & pulse-width modulation \\
\hline $\mathrm{RE}$ & renewable energy \\
\hline ROE & return on equity \\
\hline ROI & return on investment \\
\hline RPS & Renewable Portfolio Standard \\
\hline RT & real time \\
\hline RTO & regional transmission organization \\
\hline RTSCED & real-time security-constrained economic dispatch \\
\hline RTSCUC & real-time security-constrained unit commitment \\
\hline SCE & Southern California Edison \\
\hline SCED & security-constrained economic dispatch \\
\hline SCUC & security-constrained unit commitment \\
\hline SDG\&E & San Diego Gas \& Electric Company \\
\hline SEDS & State Energy Data System \\
\hline SMUD & Sacramento Municipal Utility District \\
\hline $\mathrm{SO}_{2}$ & sulfur dioxide \\
\hline TEPCO & Tokyo Electric Power Company \\
\hline TEPPC & Transmission Expansion Planning Policy Committee \\
\hline TFG & task force group \\
\hline TVA & Tennessee Valley Authority \\
\hline UC & unit commitment \\
\hline $\mathrm{UC} / \mathrm{ED}$ & unit commitment and economic dispatch \\
\hline U.S. & United States \\
\hline USACE & U.S. Army Corps of Engineers \\
\hline
\end{tabular}




$\begin{array}{ll}\text { VER } & \text { variable energy resource } \\ \text { WECC } & \text { Western Electricity Coordinating Council } \\ \text { WI } & \text { Western Interconnection } \\ \text { WUOT } & \text { Water Use Optimization Toolset } \\ \text { WWPTO } & \text { Wind and Water Power Technologies Office } \\ \text { WWSIS2 } & \text { Western Wind and Solar Integration Study - Phase 2 }\end{array}$

\section{Units of Measure}

$\begin{array}{ll}\text { Btu } & \text { British thermal unit(s) } \\ \text { cfs } & \text { cubic foot (feet) per second } \\ \mathrm{ft} & \text { foot (feet) } \\ \mathrm{GW} & \text { gigawatt(s) } \\ \text { GWh } & \text { gigawatt-hour(s) } \\ \mathrm{h} & \text { hour(s) } \\ \mathrm{Hz} & \text { hertz } \\ \mathrm{kV} & \text { kilovolt(s) } \\ \mathrm{kWh} & \text { kilowatt-hour(s) } \\ \text { min } & \text { minute(s) } \\ \text { MMBtu } & \text { 1 million British thermal units } \\ \text { MVA } & \text { megavolt ampere(s) } \\ \text { MW } & \text { megawatt(s) } \\ \text { MWh } & \text { megawatt-hour(s) } \\ \text { sec } & \text { second(s) } \\ \text { VAR } & \text { volt-ampere(s) reactive } \\ \text { Wh } & \text { watt-hour(s) } \\ \text { yr } & \text { year(s) }\end{array}$




\section{Executive Summary}

\section{ES.1 Background}

A project team, led by Argonne National Laboratory (Argonne), was tasked by the U.S. Department of Energy (DOE) to study the role and value of advanced pumped storage hydropower (PSH) in the United States. The study was funded by DOE's Office of Energy Efficiency and Renewable Energy (EERE) through a program managed by the EERE's Wind and Water Power Technologies Office (WWPTO). The project team for the study consisted of five organizations that combined diverse skills and expertise from national laboratories, the hydropower industry, and engineering and consulting companies. In addition to Argonne, the project team included Siemens PTI, Inc., Energy Exemplar, LLC, MWH Americas, Inc., and the National Renewable Energy Laboratory (NREL).

Throughout the study, the project team was supported and guided by an Advisory Working Group (AWG) consisting of 35 experts from a diverse group of organizations, including the hydropower industry and equipment manufacturers, electric power utilities and regional electricity market operators, hydro engineering and consulting companies, national laboratories, universities and research institutions, hydropower industry associations, and government and regulatory agencies.

\section{ES.2 Study Objectives}

The main purpose of the study was to develop detailed simulation models of advanced pumped storage technologies in order to analyze their technical capabilities to provide various grid services and to assess the value of these services under different market structures and for different levels of renewable generation resources integrated within the power system. Specifically, the main objectives of the study can be summarized as follows:

- Improve modeling representation of advanced PSH and conventional hydropower $(\mathrm{CH})$ plants in power system and electricity market models,

- Quantify technical capabilities of advanced PSH plants to provide various grid services,

- Analyze the value of these services under different market conditions and levels of variable renewable generation (wind and solar) in the power system, and

- $\quad$ Provide information on the full range of benefits and value of PSH plants.

Although existing dynamic models for $\mathrm{CH}$ and $\mathrm{PSH}$ plants provide accurate representation and modeling of these technologies, it was necessary to develop dynamic models of advanced PSH technologies (adjustable speed [AS] and ternary PSH units) that are not currently available in the United States (U.S.). Developing these new models would provide accurate modeling of 
dynamic responses of the advanced PSH units to various system disturbances and are required for transmission interconnection studies of new PSH projects.

In addition, one goal of the study was to improve the modeling representation of advanced PSH plants in production cost and electricity market simulation models, especially for high-resolution simulations performed with sub-hourly simulation time steps. While most production cost models can accurately simulate PSH technologies when using an hourly simulation time step, there is a need to improve the modeling representations of PSH plants and properly capture their flexible operating characteristics in high-resolution simulations.

Another goal of the study was to perform production cost and revenue simulations and assess the role and value of various services and contributions that PSH technologies provide to the power system. The production cost and revenue simulations focused on the electric power systems within the Western Interconnection (WI), which covers the western part of the United States, Canadian provinces of British Columbia and Alberta, and the Comisión Federal de Electricidad (CFE) serviced area of northern Mexico. The analysis focused on several geographical areas within the region and was carried out for different levels of renewable energy generation in the power system. The analysis examined the benefits and value of PSH plants in both regulated and competitive electricity market environments.

\section{ES.3 Technical Approach}

The scope of work for the study had two main components:

1. Development of vendor-neutral dynamic simulation models for advanced PSH technologies, and

2. Production cost and revenue analyses to assess the value of PSH in the power system.

Figure ES-1 is a schematic illustration of the technical approach and associated project tasks and activities. To perform these tasks, the project team established several task force groups (TFGs) to focus on specific aspects of the modeling and/or analysis. In addition, the project team closely coordinated the work on the study with DOE and the AWG.

The first component of the study, development of vendor-neutral models, was carried out by the Advanced Technology Modeling TFG led by experts from Siemens PTI, with the participation of experts from other project team organizations. The Advanced Technology Modeling TFG first conducted a review of dynamic PSH and $\mathrm{CH}$ simulation models that are currently in use in the United States to determine whether improvements were needed. It was found that existing dynamic models for conventional PSH and CH plants accurately describe their dynamic behavior and responses to system disturbances. The TFG then focused on the need for new models and developed vendor-neutral models for advanced PSH technologies (AS and ternary PSH units) for which no dynamic models were available in the United States. The new models were integrated into the Power System Simulator for Engineering (PSS ${ }^{\circledR}$ E) software and tested using the standard PSS $^{\circledR} E$ test cases as well as using the dynamic PSS ${ }^{\circledR}$ E cases for the WI developed by the Western 


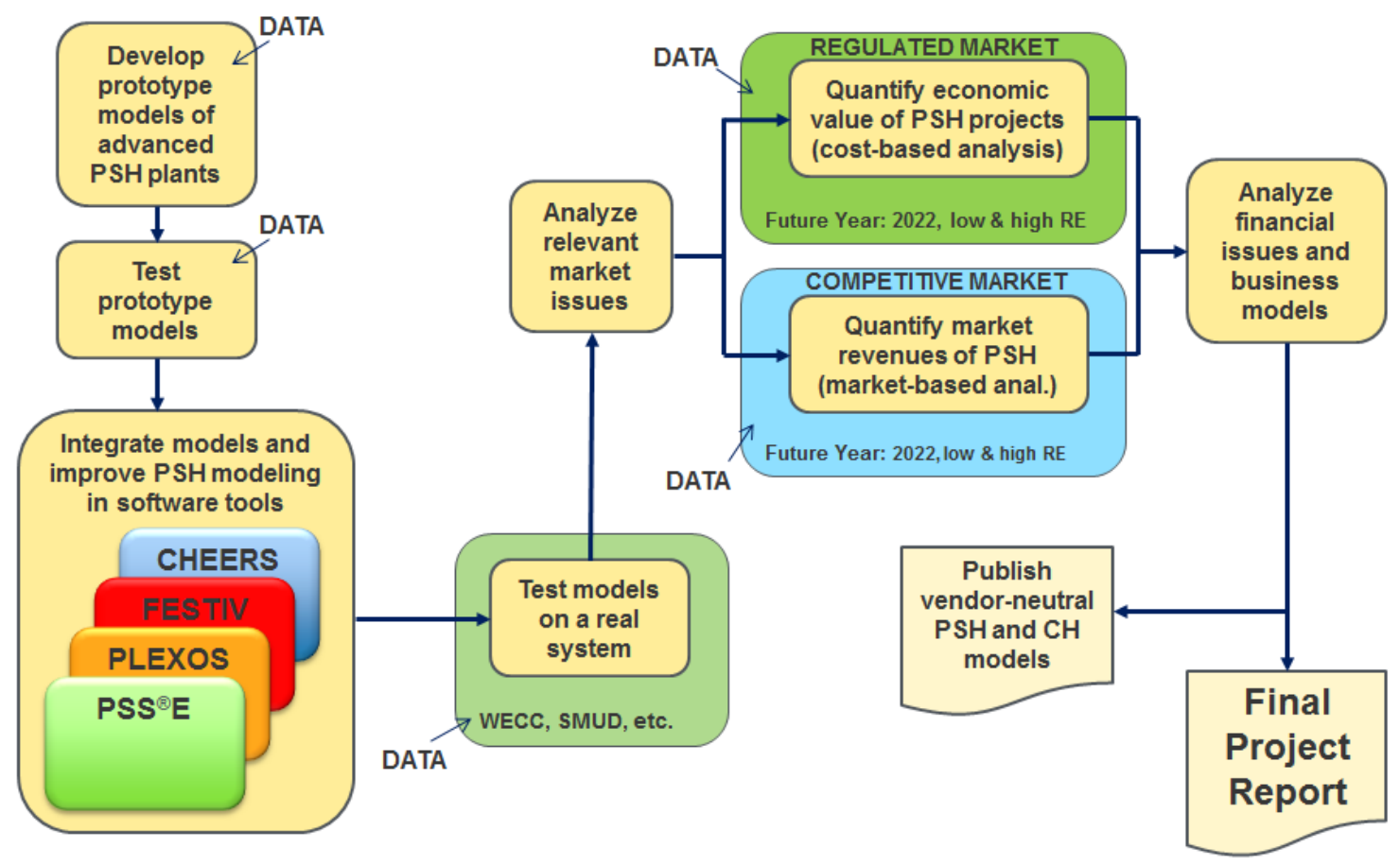

Figure ES-1 Technical Approach-Schematic Flowchart of Project Activities

Electricity Coordinating Council (WECC). The new dynamic models for AS and ternary PSH units were added to the PSS ${ }^{\circledR} \mathrm{E}$ library of dynamic models and are available to all PSS ${ }^{\circledR} \mathrm{E}$ users. In addition, because these models were developed as vendor-neutral, they were published in several of the reports for this project and are now available for integration into other software packages.

The simulations performed during the study addressed a wide range of power system operational issues and timeframes illustrated in Figure ES-2. The analysis aimed to capture PSH behavior and operational characteristics across different timescales-from a fraction of a second for dynamic responses, to annual simulations for production cost simulations. The project team used a suite of four different computer models (PSS ${ }^{\circledR}$ E, FESTIV [Flexible Energy Scheduling Tool for Integration of Variable generation], CHEERS [Conventional Hydropower Energy and Environmental Systems], and PLEXOS) to simulate system operation and analyze various control issues occurring at different timescales. This is illustrated in Figure ES-2, which also shows an approximate zone of wind/solar impacts and the system operational issues that are mostly affected by the variability of these renewable energy resources.

For the production cost and revenue modeling component of the study, the project team first developed a matrix of contributions and services that PSH plants provide to the system. The Market Issues TFG was tasked with analyzing current operation and market treatment of PSH plants in regulated and restructured markets, while the Simulation TFG implemented the design of modeling cases and scenarios to address various PSH contributions and their value in different power systems (Table ES-1). 


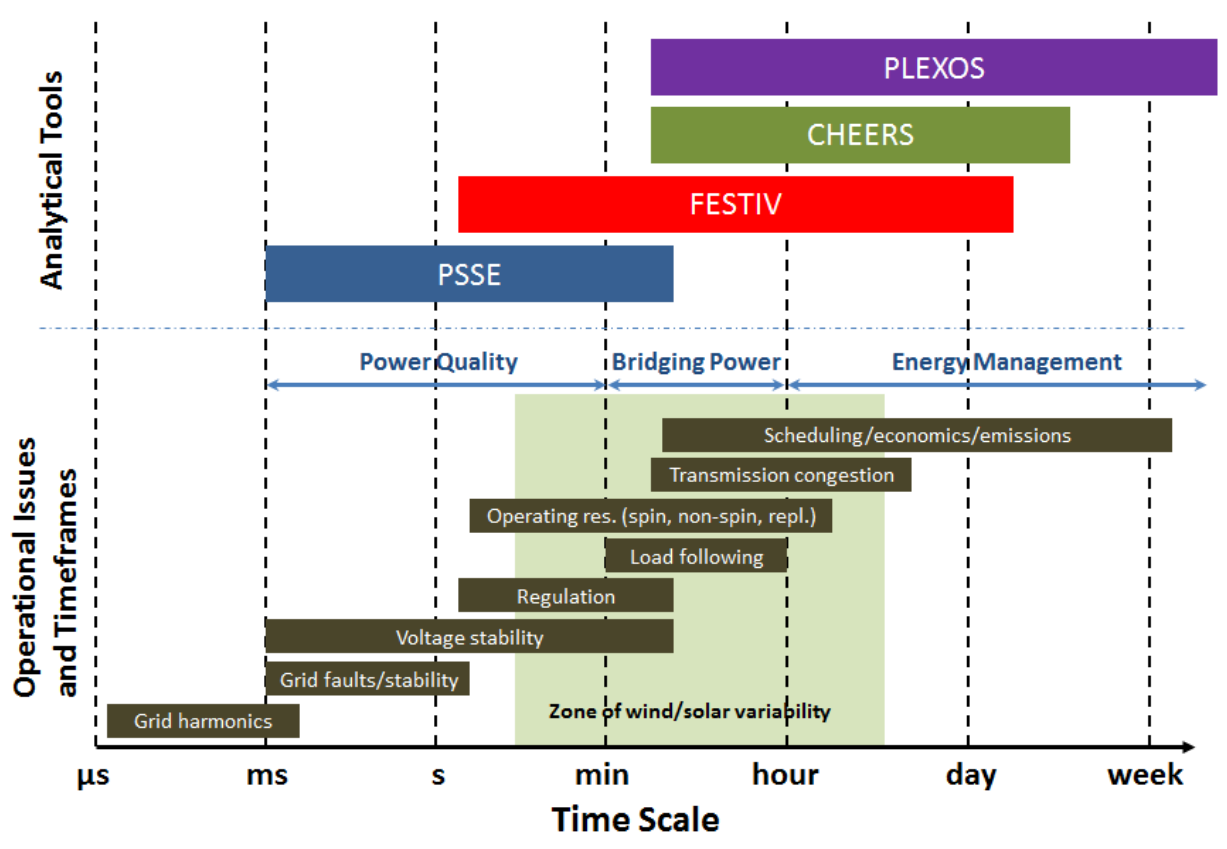

Figure ES-2 Power System Timeframes and Operational Issues

Table ES-1 PSH Services and Contributions

\begin{tabular}{|r|l|}
\hline & \multicolumn{1}{|c|}{ PSH Contribution } \\
\hline $\mathbf{1}$ & Inertial response \\
\hline $\mathbf{2}$ & $\begin{array}{l}\text { Governor response, frequency response, or primary } \\
\text { frequency control }\end{array}$ \\
\hline $\mathbf{3}$ & $\begin{array}{l}\text { Frequency regulation, regulation reserve, or secondary } \\
\text { frequency control }\end{array}$ \\
\hline $\mathbf{4}$ & Flexibility reserve \\
\hline $\mathbf{5}$ & Contingency spinning reserve \\
\hline $\mathbf{6}$ & Contingency non-spinning reserve \\
\hline $\mathbf{7}$ & Replacement/Supplemental reserve \\
\hline $\mathbf{8}$ & Load following \\
\hline $\mathbf{9}$ & Load leveling/Energy arbitrage \\
\hline $\mathbf{1 0}$ & Generating capacity \\
\hline $\mathbf{1 1}$ & Reduced environmental emissions \\
\hline $\mathbf{1 2}$ & Integration of variable energy resources (VERs) \\
\hline $\mathbf{1 3}$ & Reduced cycling and ramping of thermal units \\
\hline $\mathbf{1 4}$ & Other portfolio effects \\
\hline $\mathbf{1 5}$ & Reduced transmission congestion \\
\hline $\mathbf{1 6}$ & Transmission deferral \\
\hline $\mathbf{1 7}$ & Voltage support \\
\hline $\mathbf{1 8}$ & Improved dynamic stability \\
\hline $\mathbf{1 9}$ & Black-start capability \\
\hline $\mathbf{2 0}$ & Energy security \\
\hline &
\end{tabular}


The focus of the study was on the WI; however, the geographical scope included modeling the entire WI, individual balancing authorities within the WI, as well as individual projects. As illustrated in Figure ES-1, both cost-based and market-based approaches were applied in the analysis. The cost-based approach allows for the evaluation of benefits provided by PSH plants to the power system and is typically applied in the case of PSH projects operating in traditionally regulated utilities. On the other hand, the market-based approach allows for the calculation of revenues that a PSH project can realize in a restructured electricity market, where PSH plants compete to provide energy and ancillary services (A/S). Thus, the market-based approach mainly focuses on the revenue streams that a PSH project may realize in a competitive market environment, depending on the available market mechanisms that have been established for different types of services. The main distinction between the cost- and market-based approaches in the evaluation of PSH plants is that the cost-based approach is a system-level approach in which the value of the PSH project is measured by the overall benefits that it provides to the power system in which it operates; the market-based approach, however, focuses on the PSH plant and its potential revenues, thus providing information for the analysis of financial viability of the PSH project in a competitive market environment.

The simulations of system operations were performed for a future year that was largely based on WECC's long-term projections for 2022. WECC's Transmission Expansion Planning Policy Committee (TEPPC) 2022 Common Case served as the foundation for building modeling cases and scenarios, but certain case parameters and data varied depending on the scenario assumptions. Simulations of power system operations were performed for two levels of renewable energy penetration:

1. Baseline Renewable Energy Scenario - Corresponding to mandated Renewable Portfolio Standard (RPS) levels of renewable energy generation, amounting to about $14 \%$ of total generation within the U.S. part of WI in 2022; and

2. High Wind Renewable Energy Scenario - Corresponding to the High Wind Scenario from the Western Wind and Solar Integration Study - Phase 2 (WWSIS-2), amounting to about $33 \%$ renewable energy generation within the U.S. part of the WI in 2022.

For the fine-granularity simulations with time steps on the order of seconds, it was necessary to have high-resolution wind and solar data. Because the highest available resolution of wind and solar data is 10-min data, the project team utilized algorithms for generating synthetic second-bysecond data streams. The algorithm uses techniques like fractal analysis and cubic spline fit to interpolate higher-resolution data points within an existing stream of wind or solar data, using the pattern observed in actual high-resolution samples.

\section{ES.4 Summary of Key Findings and Conclusions}

The study involved numerous simulations and model runs across various timescales. Key findings and conclusions derived from various analyses are summarized in the following subsections. 


\section{ES.4.1 Advanced Technology Modeling}

\section{ES.4.1.1 Development and Testing of Dynamic PSH Models}

On the basis of the review of existing hydroelectric turbine-governor simulation models in use in the United States, it was concluded that existing dynamic models accurately represent the dynamic behavior of PSH and $\mathrm{CH}$ units. However, the review also determined that for new advanced PSH technologies, such as AS and ternary units, there were no dynamic models currently available in the United States. Dynamic models are needed for the generation/transmission interconnection and system dynamic performance studies for new PSH projects employing these technologies, and will be useful to the hydropower industry and PSH project developers. Currently, there are approximately 50 proposed pumped storage projects in the United States in various stages of planning and the Federal Energy Regulatory Commission (FERC) licensing process. Many of these projects are considering the use of AS technology, such as doubly-fed induction machines (DFIMs).

Dynamic models for AS and ternary units were developed as vendor-neutral and described in several project reports that are publicly available. The models were also integrated into the Siemens PTI's PSS ${ }^{\circledR} E$ software and added to the PSS ${ }^{\circledR} E$ library of dynamic models. In addition, the vendor-neutral models (block diagrams and transfer functions) were made publicly available for integration into other software tools.

The project team used the dynamic models of AS and ternary PSH units that were developed during the project to conduct various power system dynamic performance studies and analyze the dynamic behavior of these technologies and their impact on the power system. Also, analyses of conventional fixed speed (FS) and advanced AS PSH technologies and their dynamic responses were studied for various system disturbances, including over- and under-frequency events due to sudden loss of load or generation in the power system, as well as to changes in the power generated by variable renewable energy sources. Compared with the conventional FS PSH plants, the analyses showed that the advanced PSH technologies provide greater flexibility and faster response times to system disturbances.

The testing of the dynamic models demonstrated that the new models performed well and can be used for typical dynamic simulation analyses required by transmission planning and interconnection studies. The tests also demonstrated the new capabilities available in these models, such as the use of AS and ternary PSH plants to provide regulation service in pump mode. For all scenarios and disturbances, the newly developed models of AS and ternary PSH units showed expected performance and allowed demonstration of the expected advantages of the advanced PSH technology, specifically the capability of AS pumps and ternary pumps to participate in the secondary frequency control.

To validate newly developed dynamic models of advanced PSH technologies, the test results were also compared with the behavior of actual generating units in operation. Because there are currently no AS PSH plants operating in the United States, the comparison was made using the data and information that are publicly available for the operation of these technologies in Japan 
and Europe. It was found that the results of dynamic simulation models closely match the actual behavior of AS PSH units in operation.

\section{ES.4.2 Production Cost Simulations Using the PLEXOS Model}

Energy Exemplar's PLEXOS model was used to perform production cost and revenue simulations for the Base and High Wind renewable energy scenarios with and without FS and AS PSH plants modeled in the system. The day-ahead (DA) simulations were performed on an hourly basis for all of 2022 for all cases. However, higher resolution PLEXOS three-stage simulations with a 5-minute simulation time step were performed in each case for four typical weeks in the year: the third week in January, April, July, and October in 2022.

The analysis focused on three areas: WI, California, and the Sacramento Municipal Utility District (SMUD). In the WECC TEPPC database, the load region SMUD represents the Balancing Authority of Northern California (BANC).

Both cost-based and market-based approaches were used in the analysis. While the cost-based approach was applied for the simulation of the entire WI and for the SMUD footprint, a marketbased approach (as a bid-based electricity market) was applied for the simulation of the California footprint.

\section{ES.4.2.1 Annual Simulation Results}

The following sub-sections present some of the key results obtained from the annual PLEXOS simulations of the WI, California, and SMUD for three cases: (1) without any PSH plants, (2) with the existing FS PSH plants, and (3) with existing FS and additional AS PSH plants. All three cases have been run for the Base and High Wind renewable energy scenarios.

\section{Production Cost Savings}

Table ES-2 summarizes the savings in total system production cost in 2022 that can be attributed to PSH capacity and demonstrates that production cost savings are greater for higher penetration of renewable energy resources in the system (High Wind renewable energy scenario).

Table ES-2 Production Costs Savings (\%) in 2022 Due to PSH Capacity

\begin{tabular}{|c|c|c|c|c|c|c|}
\hline \multirow[b]{2}{*}{$\begin{array}{l}\text { Production Cost } \\
\text { Savings Due to } \\
\text { PSH Capacity (\%) }\end{array}$} & \multicolumn{2}{|c|}{ Western Interconnection } & \multicolumn{2}{|c|}{ California } & \multicolumn{2}{|c|}{ SMUD } \\
\hline & $\begin{array}{c}\text { Base } \\
\text { Renewable } \\
\text { Scenario } \\
\end{array}$ & $\begin{array}{l}\text { High Wind } \\
\text { Renewable } \\
\text { Scenario } \\
\end{array}$ & $\begin{array}{c}\text { Base } \\
\text { Renewable } \\
\text { Scenario } \\
\end{array}$ & $\begin{array}{c}\text { High Wind } \\
\text { Renewable } \\
\text { Scenario } \\
\end{array}$ & $\begin{array}{c}\text { Base } \\
\text { Renewable } \\
\text { Scenario } \\
\end{array}$ & $\begin{array}{c}\text { High Wind } \\
\text { Renewable } \\
\text { Scenario } \\
\end{array}$ \\
\hline With FS PSH & 1.14 & 1.96 & 2.18 & 4.52 & - & - \\
\hline With FS \& AS PSH & 2.11 & 3.77 & 3.36 & 9.12 & 8.62 & 16.45 \\
\hline
\end{tabular}

The simulation results for WI show that existing FS PSH plants will reduce total system operating cost in 2022 by about 1.1\% (about $\$ 167$ million) under the Base renewable energy 
scenario, or about 2\% (about \$248 million) under the High Wind scenario. The addition of three proposed AS PSH plants—Eagle Mountain, Iowa Hill, and Swan Lake North—could further reduce total production cost in the WI by an additional 1\%, or \$144 million, under the Base renewable energy scenario and by an additional $1.8 \%$, or $\$ 229$ million, under the High Wind scenario. Percentage-wise, even larger cost savings could be achieved in California, where the FS and AS PSH capacity reduces total system operating costs by $3.4 \%$, or $\$ 171$ million, under the Base renewable scenario, and by a total of 9.1\%, or \$376 million, under the High Wind scenario.

Results for the SMUD area show that the addition of the proposed AS PSH Iowa Hill plant could result in annual production cost savings of about $\$ 23$ million, or 8.6\% of the total SMUD production cost under the Base renewable energy scenario, and in savings of about \$51 million, or $16.45 \%$, under the High Wind scenario.

\section{Energy Arbitrage}

PLEXOS simulations of the California system in 2022 were performed using the market-based approach, which allows for detailed analysis of value of energy arbitrage based on the locational marginal prices (LMPs) of electricity in each hour of the year. It should be noted that PLEXOS simulations were performed using the co-optimization of energy and A/S, so the results for energy arbitrage with A/S are likely different than if the PSH operations were optimized to maximize energy arbitrage revenues only. Table ES-3 gives a summary of key PLEXOS results for the Base and High Wind renewable energy scenarios.

Table ES-3 Results for PSH Energy Arbitrage Revenues in California in 2022

\begin{tabular}{|c|c|c|c|c|}
\hline \multirow[b]{2}{*}{ Parameter } & \multicolumn{2}{|c|}{$\begin{array}{c}\text { Base } \\
\text { Renewable Scenario }\end{array}$} & \multicolumn{2}{|c|}{$\begin{array}{c}\text { High Wind } \\
\text { Renewable Scenario }\end{array}$} \\
\hline & FS PSH & FS \& AS PSH & FS PSH & FS \& AS PSH \\
\hline PSH capacity (MW) & 2,626 & 4,425 & 2,626 & 4,425 \\
\hline Energy generation (GWh) & 2,725 & 5,313 & 5,299 & 9,456 \\
\hline Pumping energy (GWh) & 3,840 & 6,856 & 7,501 & 12,521 \\
\hline PSH capacity factor (\%) & 11.85 & 13.71 & 23.04 & 24.39 \\
\hline Energy revenue $(\$ 1,000)$ & 102,302 & 181,554 & 147,285 & 217,302 \\
\hline Pumping cost $(\$ 1,000)$ & 65,768 & 164,508 & $-13,229$ & 25,045 \\
\hline Net revenue $(\$ 1,000)$ & 36,534 & 17,046 & 160,514 & 192,257 \\
\hline Net revenue $(\$ / k W-y r)$ & 13.9 & 3.9 & 61.1 & 43.4 \\
\hline
\end{tabular}

The high penetration of variable energy resources (VERs) (wind and solar) under the High Wind scenario keeps the average LMPs low, and even negative, when there are curtailments of excess variable generation. The cost of pumping energy for FS PSH plants under the High Wind scenario is negative because it is mostly supplied by the excess VER generation that would have been curtailed. It also shows that the capacity of existing FS PSH plants would not be sufficient for the high level of renewable resources in the system. With the addition of AS PSH plants, the overall pumping cost under the High Wind scenario becomes positive, but its relatively low 
value indicates that the PSH pumping energy is still mostly composed of the VER generation that would have been curtailed.

Table ES-3 also shows that, under the High Wind scenario, the addition of AS PSH plants increases the total annual net revenues from energy arbitrage; however, the net revenues per $\mathrm{kW}$ of PSH capacity are smaller because of much larger PSH capacity in the system.

\section{Operating Reserves}

Figures ES-3 and ES-4 illustrate the contributions of PSH plants to operating reserves in the WI and California power systems in 2022, respectively. The results are presented for both the Base and High Wind renewable energy scenarios. Taking into account that the combined capacity of FS and AS PSH plants represents less than 3\% of the total WI system capacity in 2022, it can be seen that PSH plants provide a significant amount of operating reserves to the system, especially in cases when both FS and AS PSH plants are in operation. Also, it can be noted that PSH contributions to operating reserves increase significantly with the addition of AS PSH plants to the system.

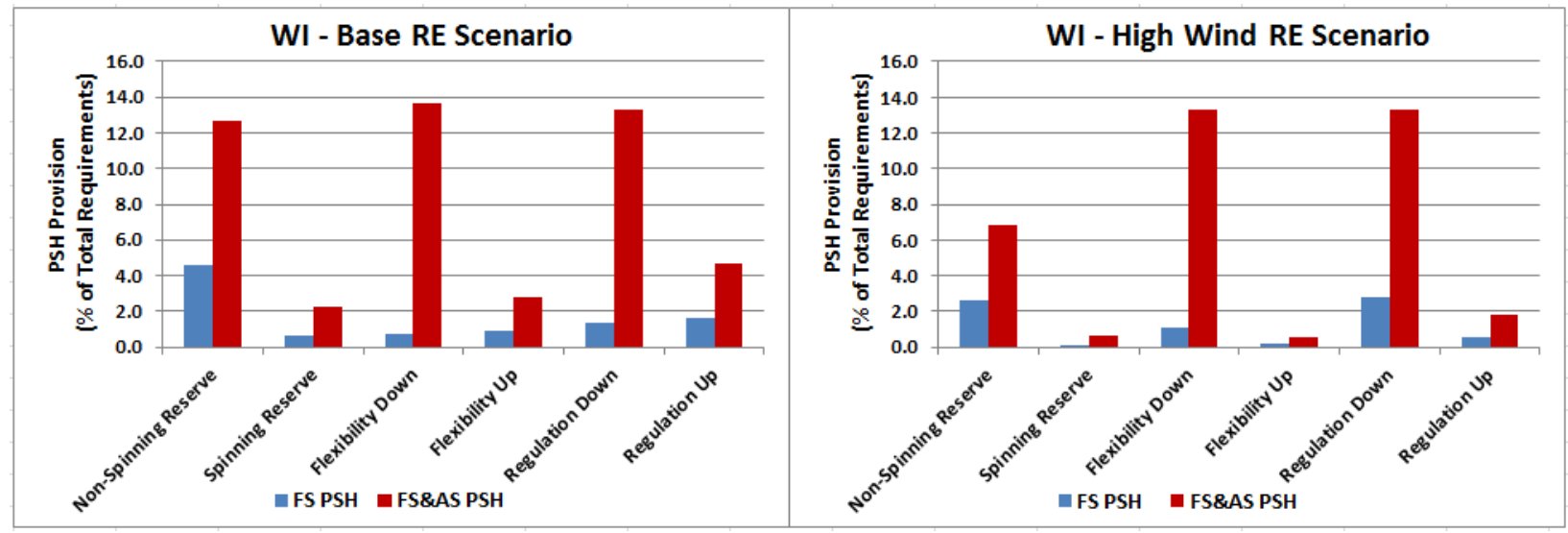

Figure ES-3 PSH Contributions to WI Operating Reserves in 2022
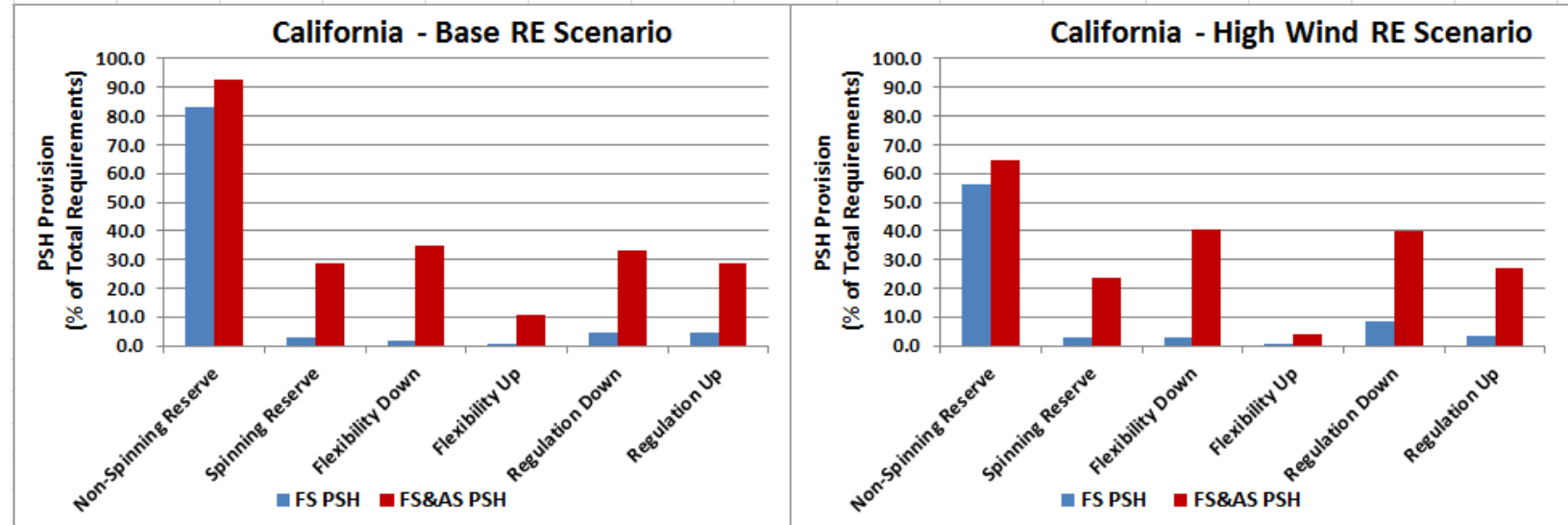

Figure ES-4 PSH Contributions to California Operating Reserves in 2022 
An especially large increase is observed for the regulation down and flexibility down reserves, because the AS PSH can provide these services in the pumping mode of operation as well. These reserves are especially needed during times of low flexibility in the power system, such as during the night.

With regard to the monetary value of PSH contributions to operating reserves, PLEXOS simulations for California were performed using a market-based approach, which allowed for individual pricing and revenue analysis of A/S. A summary of PSH total annual revenues for their provisions of operating reserves in 2022 is provided in Table ES-4.

The revenues of PSH plants for the provisions of operating reserves can also be expressed per $\mathrm{kW}$ of PSH capacity. The results presented in Table ES-5 show that the average annual revenues are highest for the provisions of regulation down service.

Table ES-4 PSH Revenues for Provisions of Operating Reserves in California in 2022

\begin{tabular}{|l|c|c|c|c|}
\hline \multirow{2}{*}{\multicolumn{1}{|c|}{ Operating Reserve }} & \multicolumn{2}{|c|}{ Base } & \multicolumn{2}{c|}{$\begin{array}{c}\text { High Wind } \\
\text { Renewable Scenario }\end{array}$} \\
\cline { 2 - 5 } & $\begin{array}{c}\text { FS PSH } \\
\mathbf{( \$ 1 , 0 0 0 )}\end{array}$ & $\begin{array}{c}\text { FS \& AS PSH } \\
\mathbf{( \$ 1 , 0 0 0 )}\end{array}$ & $\begin{array}{c}\text { FS PSH } \\
\mathbf{( \$ 1 , 0 0 0 )}\end{array}$ & $\begin{array}{c}\text { FS \& AS PSH } \\
(\mathbf{\$ 1 , 0 0 0 )}\end{array}$ \\
\hline Non-spinning reserve & 7,557 & 8,563 & 5,246 & 6,184 \\
\hline Spinning reserve & 1,218 & 8,588 & 1,515 & 6,208 \\
\hline Flexibility down & 389 & 5,728 & 1,626 & 14,934 \\
\hline Flexibility up & 43 & 731 & 80 & 412 \\
\hline Regulation down & 4,562 & 20,360 & 19,511 & 49,885 \\
\hline Regulation up & 4,436 & 7,935 & 4,144 & 8,528 \\
\hline Total & 18,205 & 51,905 & 32,122 & 86,151 \\
\hline
\end{tabular}

Table ES-5 Average Annual PSH Revenues for Operating Reserves in California in 2022

\begin{tabular}{|l|c|c|c|c|}
\hline \multirow{2}{*}{\multicolumn{1}{|c|}{ Operating Reserve }} & \multicolumn{2}{|c|}{ Base } & \multicolumn{2}{c|}{$\begin{array}{c}\text { High Wind } \\
\text { Renewable Scenario }\end{array}$} \\
\cline { 2 - 5 } & $\begin{array}{c}\text { FS PSH } \\
(\mathbf{\$} / \mathbf{k W}-\mathbf{y r})\end{array}$ & $\begin{array}{c}\text { FS \& AS PSH } \\
(\mathbf{\$} / \mathbf{k W}-\mathbf{y r})\end{array}$ & $\begin{array}{c}\text { FS PSH } \\
(\mathbf{\$} / \mathbf{k W}-\mathbf{y r})\end{array}$ & $\begin{array}{c}\text { FS \& AS PSH } \\
(\mathbf{\$} / \mathbf{k W}-\mathbf{y r})\end{array}$ \\
\hline Non-spinning reserve & 2.88 & 1.94 & 2.00 & 1.40 \\
\hline Spinning reserve & 0.46 & 1.94 & 0.58 & 1.40 \\
\hline Flexibility down & 0.15 & 1.29 & 0.62 & 3.37 \\
\hline Flexibility up & 0.02 & 0.17 & 0.03 & 0.09 \\
\hline Regulation down & 1.74 & 4.60 & 7.43 & 11.27 \\
\hline Regulation up & 1.69 & 1.79 & 1.58 & 1.93 \\
\hline Total & $\mathbf{6 . 9 3}$ & $\mathbf{1 1 . 7 3}$ & $\mathbf{1 2 . 2 3}$ & $\mathbf{1 9 . 4 7}$ \\
\hline
\end{tabular}


As illustrated in Figure ES-5, the average annual revenues per $\mathrm{kW}$ of PSH capacity are higher for cases when both FS and AS PSH plants operate in the system.

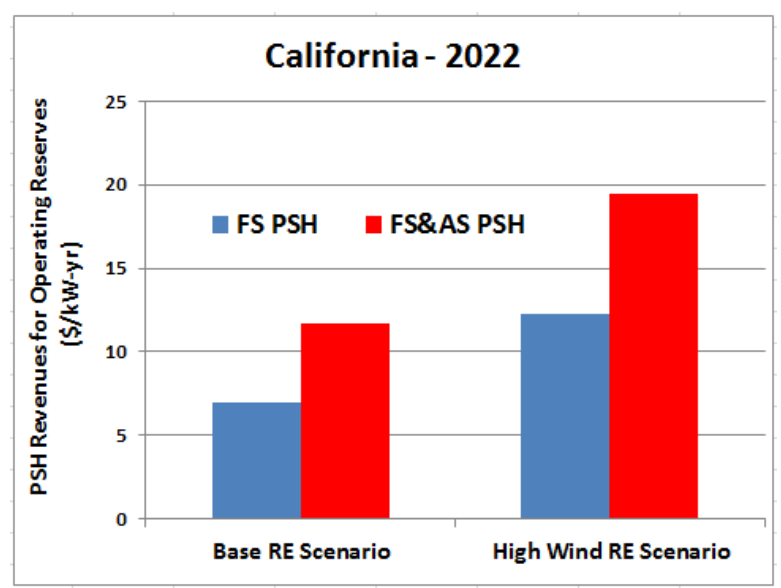

Figure ES-5 Average Annual PSH Revenues for Operating Reserves per kW of PSH Capacity

\section{Integration of Variable Energy Resources}

PLEXOS simulation results for WI under the Base renewable energy scenario show that the FS PSH plants reduce curtailments of VER generation by 565 GWh, or about $29 \%$ of total curtailments if there were no PSH plants operating in the system. With both FS and AS PSH operating in the WI system, the curtailments are reduced by $958 \mathrm{GWh}$, or about $50 \%$ of total curtailments. The amount of curtailed VER generation under the High Wind scenario is much greater and amounts to 56,885 GWh in the case without PSH plants operating in the system. The FS PSH plants reduce this curtailment by 8,482 GWh, or $15 \%$, while when both FS and AS PSH plants are operating in the system, the curtailments are reduced by $12,675 \mathrm{GWh}$, or $22 \%$. Assuming a $30 \%$ capacity factor, the savings of 12,675 GWh roughly corresponds to an average annual generation of almost 5,000 MW of wind capacity.

In California, under the Base renewable energy scenario, the curtailments of VER generation are reduced from $155 \mathrm{GWh}$ in the case without PSH plants to $46 \mathrm{GWh}$ (70\% reduction) if FS PSH plants are operating in the system, and to $14 \mathrm{GWh}$ (91\% reduction) if both FS and AS PSH plants are operating. Under the High Wind scenario, the curtailments are reduced from 618 GWh in the case without PSH plants to 380 GWh (39\% reduction) if FS PSH plants are operating in the system, to 275 GWh (55\% reduction) if both FS and AS PSH plants are operating.

The results for the SMUD footprint show that the addition of the AS PSH Iowa Hill plant reduces renewable energy curtailments from $19 \mathrm{GWh}$ to $1 \mathrm{GWh}$ (95\% reduction) under the High Wind renewable energy scenario. There were no curtailments of VER generation under the Base renewable energy scenario. 


\section{Reduced Cycling of Thermal Generating Units}

The flexibility of PSH capacity, its fast ramping characteristics, and load-leveling operation creates a flatter net load profile for thermal generating units. This allows them to operate in a steadier mode, thus reducing the need for their ramping and frequent startups and shutdowns.

\section{Reduced Startup Costs}

As startups and shutdowns of thermal generating units involve substantial operating cost, as well as increased wear and tear, the reduction in the number of unit startups provides significant savings in system operating costs. PLEXOS results show that under both renewable energy scenarios, the number of starts and startup costs of thermal generators are reduced substantially as more PSH capacity is introduced into the system.

If both FS and AS PSH plants are operating in the system, the annual thermal startup cost savings for WI amount to $\$ 44$ million (about $28.6 \%$ reduction in system startup costs) under the Base renewable energy scenario, and to \$31 million (about 17.7\% savings) under the High Wind scenario. Figure ES-6 illustrates the percentage reductions in thermal startup costs due to PSH capacity in the WI.

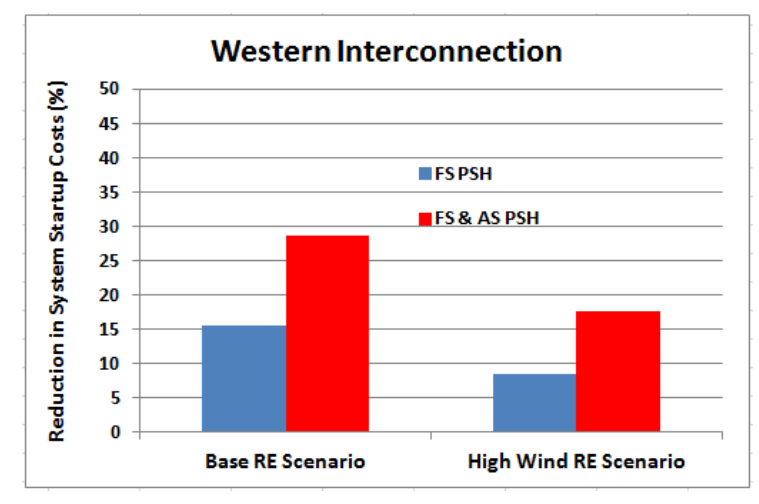

Figure ES-6 Reduction in Thermal Startup Costs Due to PSH Capacity in the WI in 2022

In the case of California, the savings in startup costs are similar under both renewable energy scenarios and amount to about $\$ 10$ million if only the existing FS PSH plants are operating in the system, and to about $\$ 20$ million if both FS and AS PSH plants are operating. The reductions in startup costs, as percentage of total startup costs in California, are illustrated in Figure ES-7.

In the case of SMUD, the addition of the AS PSH plant (Iowa Hill) reduces annual startup costs by about $\$ 2$ million under both renewable energy scenarios. As a percentage of total system startup costs in 2022, the cost savings ( $\$ 2$ million) represent about $45 \%$ of total startup costs under the Base scenario and about $42 \%$ under the High Wind renewable energy scenario. This is illustrated in Figure ES-8. 


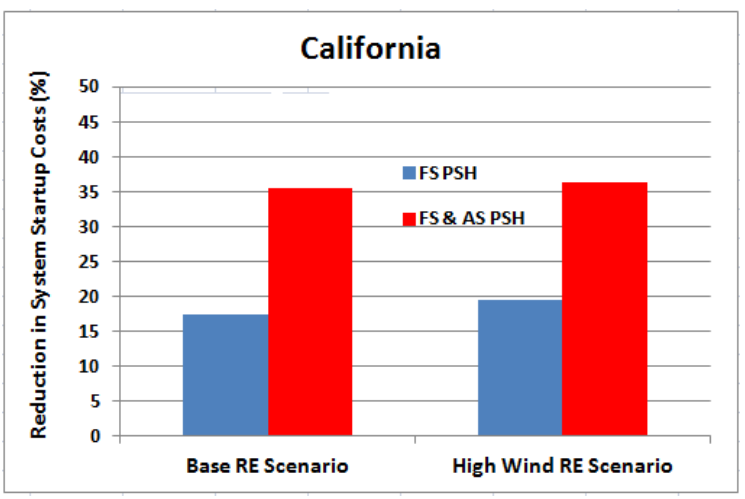

Figure ES-7 Reduction in Thermal Startup Costs Due to PSH Capacity in California in 2022

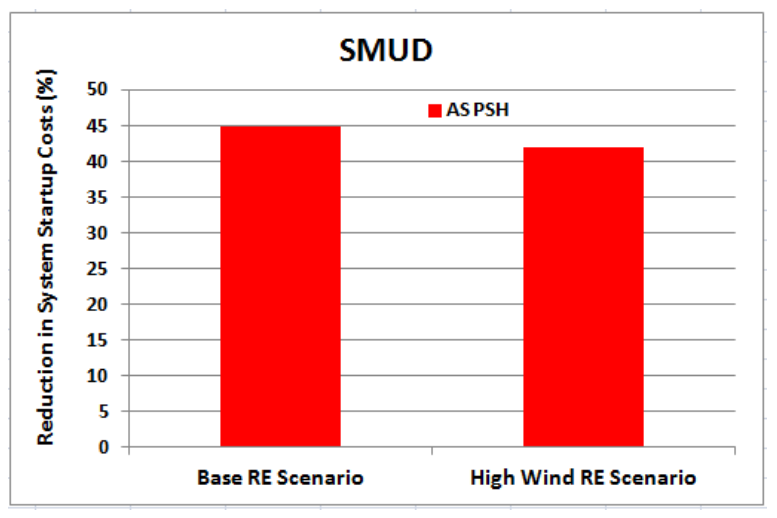

Figure ES-8 Reduction in Thermal Startup Costs Due to PSH Capacity in SMUD in 2022

\section{Reduced Thermal Generator Ramping}

Figures ES-9 through ES-11 present the results for reductions in thermal generator ramping (both up and down) in the WI, California, and SMUD systems, respectively.

PLEXOS simulations for WI in 2022, under the Base renewable energy scenario, show that FS PSH reduces the total ramping of thermal generators during the year by 1,786 GW (aggregated ramping MW), and ramp-down needs by 2,560 GW. If both FS and AS PSH plants are operating in the system, the ramp-up needs of thermal generators are reduced by 3,420 GW and ramp-down needs by 4,817 GW.

Similarly, the results for California in 2022, under the High Wind renewable energy scenario, show that FS PSH reduces the ramp-up needs of thermal generators by $531 \mathrm{GW}$, and ramp-down needs by $945 \mathrm{GW}$. If both FS and AS PSH plants are operating in the system, the ramp-up needs of thermal generators are reduced by 1,214 GW and ramp-down needs by 1,943 GW. 


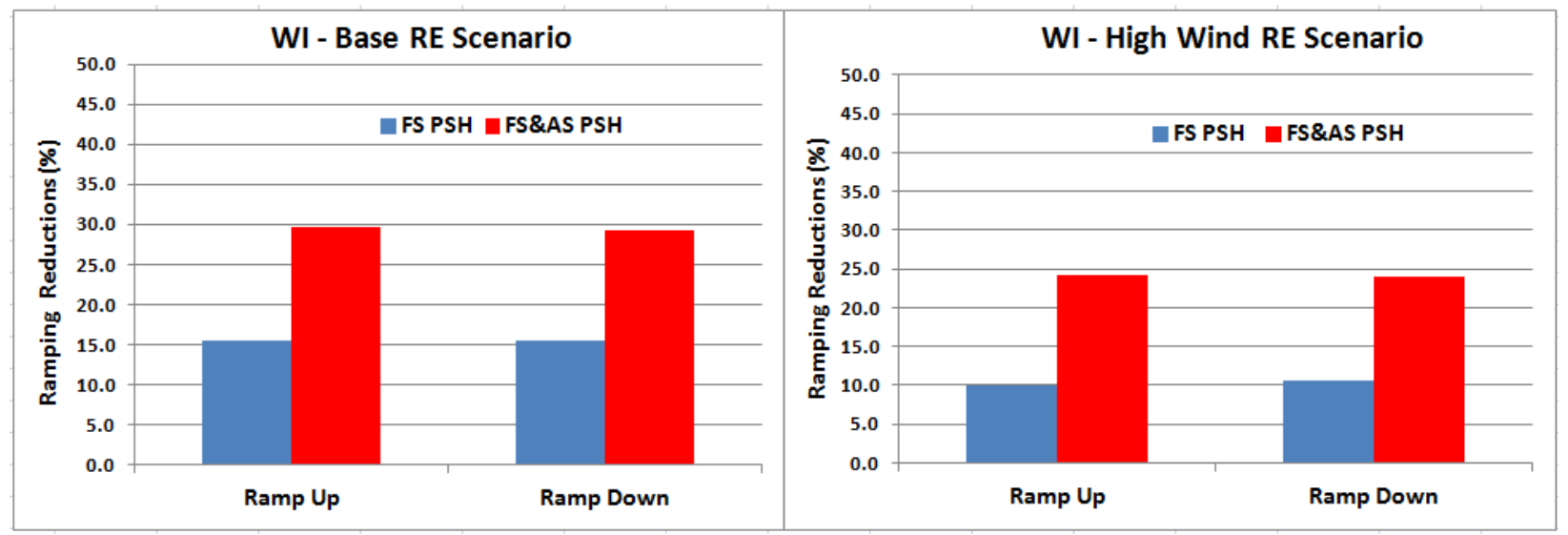

Figure ES-9 Reductions in Thermal Capacity Ramping Needs in the WI in 2022 Due to PSH Capacity

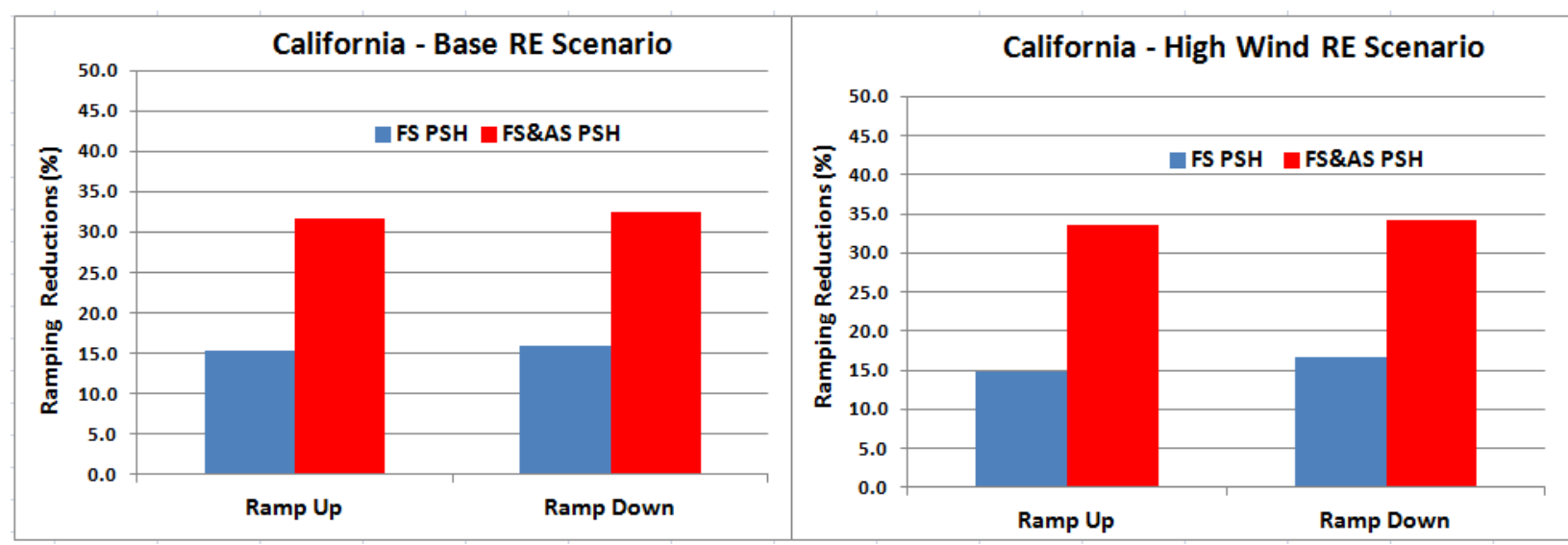

Figure ES-10 Reductions in Thermal Capacity Ramping Needs in California in 2022 Due to PSH Capacity

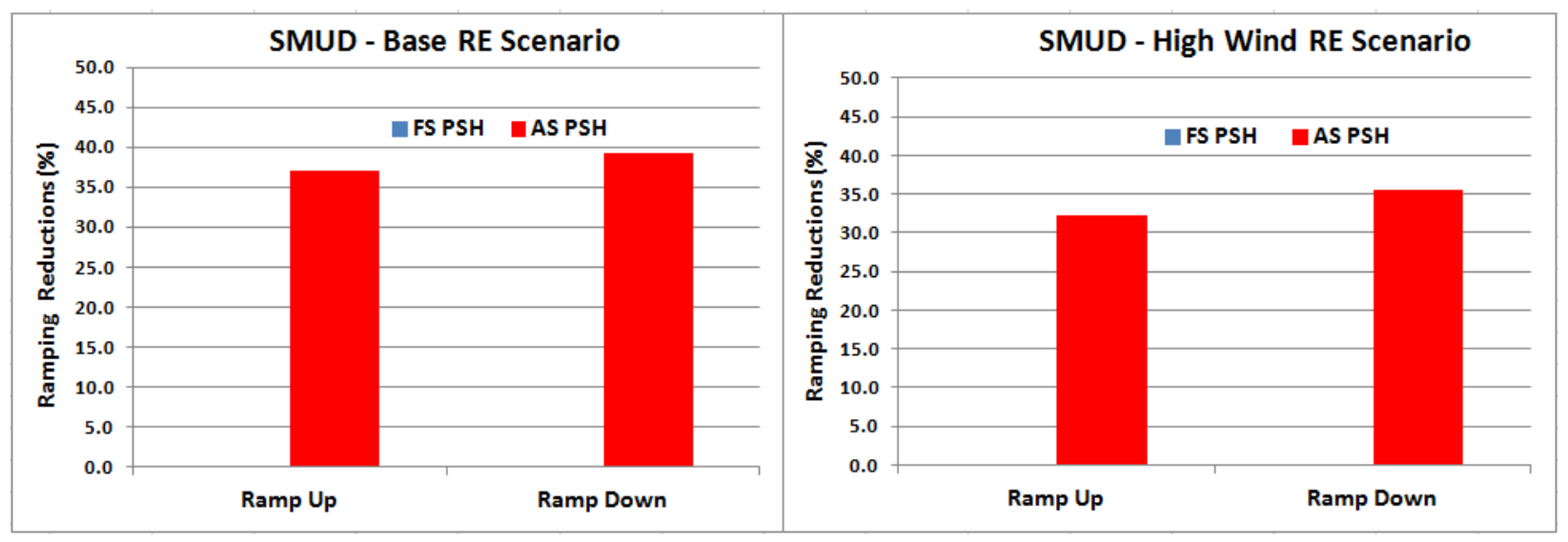

Figure ES-11 Reductions in Thermal Capacity Ramping Needs in SMUD in 2022 Due to PSH Capacity 
In the case of SMUD, the proposed AS PSH plant (Iowa Hill) reduces ramp-up needs by 136 GW and ramp-down needs by 197 GW under the Base renewable energy scenario, and by 119 GW and 174 GW, respectively, under the High Wind scenario.

\section{PSH Impacts on Power System Emissions}

Simulation results for WI (Figure ES-12) show an increase in carbon dioxide $\left(\mathrm{CO}_{2}\right)$, nitrogen oxide $\left(\mathrm{NO}_{\mathrm{x}}\right)$, and sulfur dioxide $\left(\mathrm{SO}_{2}\right)$ emissions under the Base renewable energy scenario, but the operation of PSH plants decreases overall system emissions under the High Wind scenario. This is primarily due to a higher percentage of wind energy that is available for PSH pumping and the PSH impacts on reducing the curtailments of wind energy, which offset the increased emissions of conventional thermal generating units.

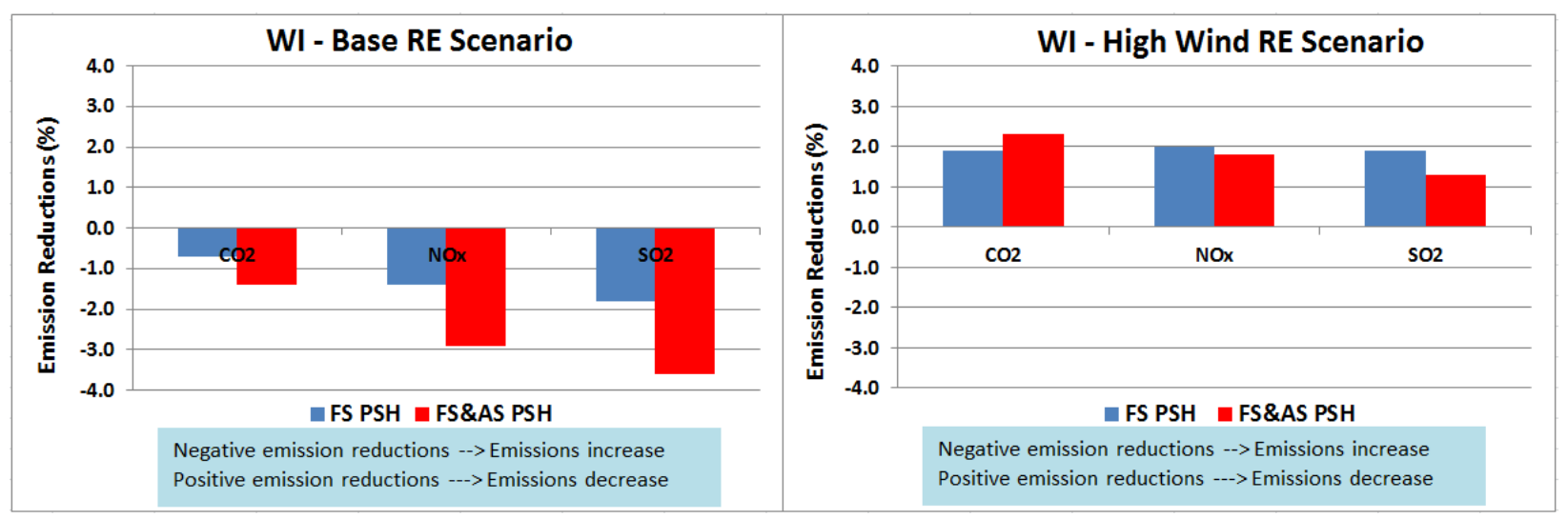

Figure ES-12 Emission Reductions Due to PSH Capacity in the WI in 2022

The results for California (Figure ES-13) show a decrease in $\mathrm{CO}_{2}$ and $\mathrm{NO}_{\mathrm{x}}$ emissions, and an increase in $\mathrm{SO}_{2}$ emissions under both the Base and High Wind renewable energy scenarios. The results for California are different from those obtained for the WI because of the differences in the generation mix of these two systems.

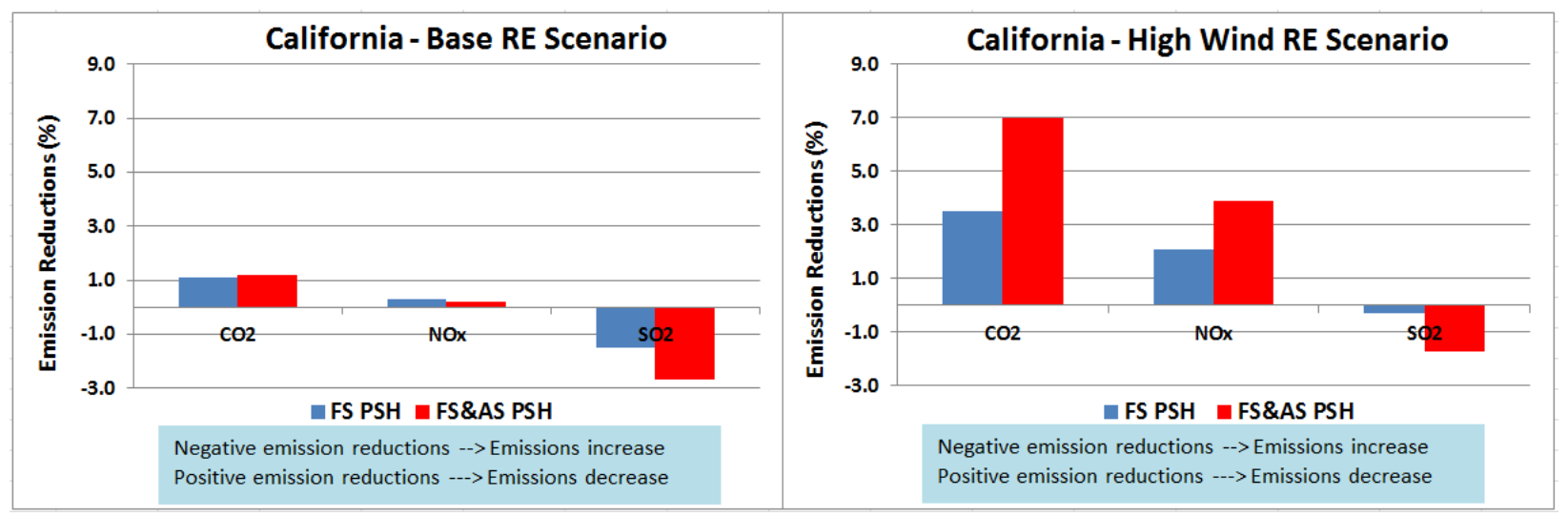

Figure ES-13 Emission Reductions Due to PSH Capacity in California in 2022 
The most significant emission reductions are observed for the SMUD system (Figure ES-14). The introduction of the proposed AS PSH Iowa Hill plant reduces pollutant emissions in the SMUD system under both renewable energy scenarios.

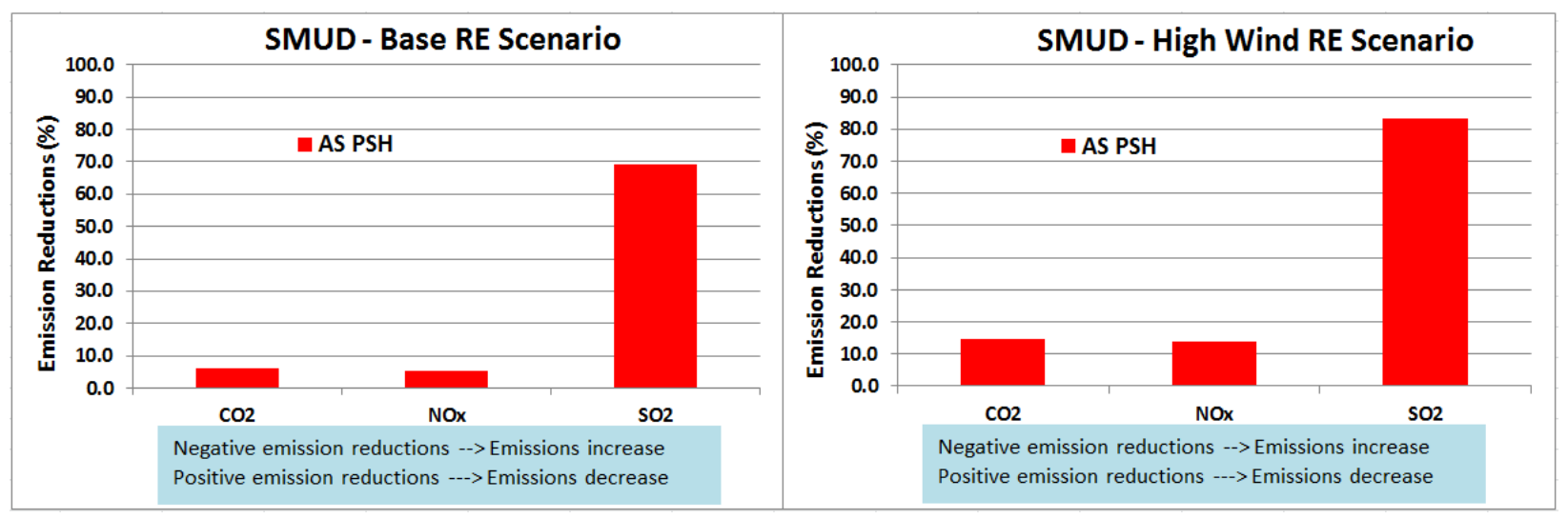

Figure ES-14 Emission Reductions Due to PSH Capacity in the SMUD System in 2022

\section{PSH Impacts on Transmission Congestion}

In markets that use LMP, a component of the price is based on transmission congestion. The transmission congestion price is an indicator of the congestion in the transmission grid. The lower transmission congestion prices obtained in cases with PSH plants indicate that they help mitigate the costs associated with transmission congestion.

PLEXOS simulations of the WI show that under the Base renewable energy scenario, average transmission congestion prices decrease from $\$ 4 / \mathrm{MWh}$ in the case with no PSH plants operating in the system to $\$ 2 / \mathrm{MWh}$ if both FS and AS PSH plants are operating. Because transmission expansion was enacted for the High Wind scenario, little congestion was seen with or without $\mathrm{PSH}$, and therefore no significant reductions of transmission congestion prices were observed under that scenario. However, under both Base and High Wind scenarios, the interface with the significant congestion price reduction was the "P27 Intermountain Power Project DC Line," located in the vicinity of the existing Castaic plant and the proposed Eagle Mountain PSH plant.

In PLEXOS simulations of California for the Base renewable energy scenario, the average transmission congestion prices decrease from \$3.51/MWh in the case with no PSH plants operating in the system, to $\$ 0.4 / \mathrm{MWh}$ in the case with FS PSH plants, and further to $\$ 0.24 / \mathrm{MWh}$ in the case with both FS and AS PSH plants operating in the system. Under the High Wind renewable scenario, the average transmission congestion prices in California decrease from $\$ 1.79 / \mathrm{MWh}$ in the case without PSH plants, to \$0.56/MWh in the case with FS PSHs, and further to $\$ 0.37 / \mathrm{MWh}$ in the case with both FS and AS PSH plants operating in the system. The lower transmission congestion prices obtained under the High Wind renewable scenario are because of transmission expansion planning that was performed for this renewable energy scenario, resulting in additional transmission capacity in the system. Again, under both Base and High Wind renewable scenarios, the interface with the significant congestion price reduction was the 
“P27 Intermountain Power Project DC Line,” located in the vicinity of the existing Castaic plant and the proposed Eagle Mountain PSH plant.

\section{ES.4.2.2 Three-Stage DA-HA-RT Simulation Results}

To capture the uncertainty of renewable energy forecasting and intra-hourly variability of VER, as well as to evaluate system needs for operating reserves and flexible ramping capacity, threestage DA-HA-RT (Day Ahead - Hour Ahead - Real Time) sequential simulations with a 5-min time step in RT were performed for four typical weeks in different seasons of the year. Simulations were performed for the WI, California, and SMUD footprints, and the selected weeks were the third weeks in January, April, July, and October of 2022.

Table ES-6 presents a summary of key results obtained from three-stage simulations for the WI, California, and SMUD power systems. The results shown are for the High Wind renewable energy scenario. SMUD is planning to add an AS PSH plant (Iowa Hill) to its power system; therefore, conventional FS PSH plants were not modeled in the simulations of the SMUD footprint.

The results of these detailed, high-resolution (5-min time step) simulations show that the overall production cost savings due to operation of FS and AS PSH plants in the system amount to about $3.6 \%$ of the total production costs in the WI, to $7.3 \%$ in California, and reach $14.3 \%$ in the SMUD system. Although these are the average cost savings over the four typical weeks in different seasons of 2022, the average annual values can be expected to be in a similar range. PLEXOS annual simulation runs using the hourly time step also provide similar results.

The impacts of PSH plants on the reduction of startup and shutdown cost are also significant. The operation of FS and AS PSH plants in the system reduces overall startup and shutdown costs from about $11 \%$ in SMUD, up to almost $42 \%$ in California.

Similarly, the operation of both FS and AS PSH plants reduces the need for ramping of thermal generating units. Over the four typical weeks in 2022, the ramping up and down of thermal units are reduced by about $22 \%$ to $25 \%$ in the WI and SMUD areas, respectively; the ramping down of thermal units by more than $60 \%$ in California. These results demonstrate that PSH can manage a significant amount of ramping duties to counterbalance the intra-hourly variations in loads and variable renewable generation.

It should be noted that in the three-stage simulations, the results of RT simulations show higher operating costs and ramping needs than those in the DA simulations. This is because the RT simulations capture the intra-hourly variability of VER generation, which is not captured by DA simulations that use an hourly time step. The higher operating cost and ramping needs of thermal generators in RT simulations indicate that they require additional ramping to meet the sub-hourly variability and uncertainties of load and variable renewable generation. 
Table ES-6 Summary of PLEXOS Three-Stage Results for the WI, California, and SMUD in 2022

\begin{tabular}{|c|c|c|c|c|}
\hline \multirow[b]{2}{*}{$\begin{array}{l}\text { High Wind } \\
\text { Renewable } \\
\text { Scenario } \\
\end{array}$} & \multicolumn{4}{|c|}{$\begin{array}{c}\text { Average Cost Savings or Decrease in Ramping Needs Due to PSH Capacity } \\
\text { over the Four Simulated Typical Weeks in } 2022\end{array}$} \\
\hline & $\begin{array}{c}\text { System Production } \\
\text { Costs Savings } \\
(\%) \\
\end{array}$ & $\begin{array}{c}\text { Startup and } \\
\text { Shutdown Costs } \\
\text { Savings } \\
(\%) \\
\end{array}$ & $\begin{array}{c}\text { Ramp Up of } \\
\text { Thermal } \\
\text { Generators } \\
(\%)\end{array}$ & $\begin{array}{c}\text { Ramp Down of } \\
\text { Thermal } \\
\text { Generators } \\
(\%) \\
\end{array}$ \\
\hline \multicolumn{5}{|l|}{\begin{tabular}{|l|} 
Western \\
Interconnection
\end{tabular}} \\
\hline With FS PSH & 2.01 & 11.21 & 5.44 & 8.25 \\
\hline With FS \& AS PSH & 3.60 & 17.71 & 23.25 & 24.86 \\
\hline \multicolumn{5}{|l|}{ California } \\
\hline With FS PSH & 5.01 & 27.58 & 9.76 & 15.10 \\
\hline With FS \& AS PSH & 7.27 & 41.67 & 33.05 & 64.16 \\
\hline \multicolumn{5}{|l|}{ SMUD } \\
\hline With AS PSH & 14.31 & 10.62 & 22.06 & 22.87 \\
\hline
\end{tabular}

\section{ES.4.3 Analysis of Reliability and Costs Using the FESTIV Model}

NREL's FESTIV model was utilized to analyze in high temporal detail how conventional and advanced PSH can assist in reducing total system production costs and improving steady-state reliability. The FESTIV model was used to simulate the BANC, where the SMUD system is located, for two time periods - one with highly volatile variable generation and relatively low load in April, and one with reduced variable generation but significant load in July. In both time periods, the use of FS conventional PSH reduced the total system production costs. When adding AS PSH rather than the conventional FS PSH plant, production costs were additionally reduced. These results bolster those obtained from PLEXOS simulations, and the analysis of detailed power system operations at multiple timescales demonstrates conventional PSH and advanced PSH provide tremendous benefits to systems of this size by reducing production costs.

The FS PSH was able to reduce the amount of Control Performance Standard 2 (CPS2) violations in both time periods, and the addition of AS PSH reduced the violations even further. In both cases, the CPS2 score was already above the required level (although load forecast errors and conventional generator performance were not modeled). The July time period received greater benefit from both the FS and AS PSH plants because its higher costs led to the dispatch selecting PSH more often to provide regulation service utilizing automatic generation control (AGC). The standard deviation and total amount of energy imbalances was reduced in the July period, but not always in the April period. It is possible that the ability to re-optimize the operational mode of PSH could better prepare the system when very large DA variable generation forecast errors would otherwise leave the PSH in the wrong operating mode. Overall, it is evident that conventional FS PSH provides some improvement to steady-state reliability, and that the improvements provided by the AS PSH are even greater. 
When conducting analyses with FESTIV, additional sensitivities were analyzed. Additional simulations were run to determine how much variable generation and variable generation forecast errors impacted the results of how PSH brought value to the system. These studies demonstrated that when steady-state reliability is already very good (i.e., less than three CPS2 violations), it is difficult for the PSH to truly improve the steady-state reliability. This was observed in scenarios without variable generation and with variable generation, but with all variable generation forecasts being perfectly predicted. On the other hand, these FESTIV analyses revealed that even without variable generation or without variable generation forecast errors, PSH plants still reduce overall production costs.

Lastly, FESTIV simulations were run to study how AS PSH plants can provide benefit when following a raw, unfiltered ACE signal, which is a likely scenario because of their extremely fast power ramp rates. This type of study is relevant to recent industry developments related to evaluating the benefits of other limited energy storage resources to provide this type of fast ramping service (e.g., FERC Order 755, "Pay for Performance Regulation”). The results showed that this type of control had a negligible effect in reducing the number of CPS2 violations. However, the total imbalance occurring and the standard deviation of that imbalance were significantly reduced with just the three AS PSH units providing this fast control. Another outstanding result is the reduction in total production costs even further when allowing AS PSH to provide this control. This result, not as intuitive as the reduction in ACE impacts, was caused by the PSH units allowing other ramp-constrained units to stay closer to their most optimal points. These resources were not being asked by the AGC to move too far from their set points and were therefore less constrained by their ramp rates when the dispatch model chose the least cost options to meet the expected load demands. Additional studies should evaluate this effect further, and this type of control should be utilized in operations if future studies demonstrate these results consistently.

\section{ES.4.4 Analysis of PSH Operation Using the CHEERS Model}

The CHEERS study compared the economic performance of AS PSH, FS PSH, and gas turbine (GT) technologies under a wide range of possible futures. Results show that, in general, PSH technologies are competitive with advanced GT technologies and have higher net present values (NPVs) under most, but not all, plausible futures tested. While PSH technologies show higher potential financial gains compared with advanced GT technologies, PSH technologies are also riskier with potentially higher losses. Testing capital cost variances for new projects revealed that PSH technologies have greater downside risks compared with GT technology if capital cost overruns are incurred. Changes in loan interest rates produced similar results in which rising interest rates lowered project returns as higher debt service costs reduced operating profits and net cash flows. Conversely, PSH technologies have a potential for larger net profits over GT technologies if capital costs decline.

The CHEERS results also highlight the advantage that AS PSH has over conventional, FS PSH technologies; especially when market prices are high. In particular, with high A/S prices, the economics of AS PSH further improve over other technologies. Greater AS PSH revenues are due to better efficiencies, a narrower rough zone, and the ability to serve A/S in pump operating mode. Hourly operations tests illustrate the ability of the AS PSH to sell regulation in pumping 
mode, which is the key factor in offsetting higher AS PSH construction costs. When it is assumed that A/S prices are always zero (e.g., no market), there is little difference in net revenues between AS and FS technologies. However, the gap widened as A/S prices increased, illustrating that the key advantage of AS technology is its ability to provide regulation services in pump operating mode.

Recognizing the potential sensitivity of project returns to capital costs, market conditions, and the accuracy of market price forecasts, scenarios were developed to test the implications of these factors. Results of these scenario runs highlighted four key observations. First, revenue recognition for A/S is essential to support profitable operations of PSH plants. Second, favorable (rising) natural gas prices are needed to support revenue growth and subsequent plant profitability. Third, higher costs, such as capital costs and loan interest costs, can negatively impact plant returns and result in lower NPVs over time. Lastly, day-ahead price forecast errors can significantly erode the profitability of PSH technologies.

Analyses highlight the value and importance of market prices for energy and A/S and confirm the need for good mid- and long-term price forecasts when evaluating the economics of not only $\mathrm{PSH}$, but other technologies.

\section{ES.4.5 Market Issues and Treatment of PSH in Electricity Markets}

Much of the nation's $20 \mathrm{GW}$ of pumped hydro storage entered service during the mid to late 1970s. Projects were economically justified for daily energy arbitrage based on high-cost peaking oil and natural gas-fired generation, low-cost coal, and nuclear power during off-peak periods, and based on pumped storage capital costs that were similar to those of combined cycle plants. With natural gas now on the margin much of the time, coupled with the increase in efficiency and decrease in relative capital costs for combustion turbines and combined cycle plants, energy arbitrage is typically not sufficient to justify new pumped storage plants today. Storage provides additional flexibility benefits for the power system, however, and the increase in variable and uncertain wind and solar generation is increasing the need for that flexibility. Moreover, restructuring of the power sector has led FERC to explicitly define A/S that help quantify and price the flexibility requirements. FERC's encouragement of independent system operators (ISOs) and regional transmission operators (RTOs), which now serve two- thirds of the nation's load, has led to the establishment of energy and A/S markets that monetize the value of flexibility. Storage can compete with generators and demand response to provide the flexibility that the system operator requires to maintain reliability. In this context, there is a need to evaluate the benefits that energy storage offers against the generation and demand response alternatives. One of the advantages of storage is its charging capability, which can be used to provide load for excess variable generation. This can be extremely valuable during the off-peak hours (e.g., at night) when the system loads are low, most conventional thermal generating units in operation are base load units operating at their minimum (must run) capacities, and demand response options are limited.

ISOs and RTOs co-optimize energy and A/S provision from generators. Generators simply offer their capabilities (maximum load, minimum load, ramp rate, start time, etc.) and bid costs and let the system operator determine how much energy and each of the A/S they should provide each 
market interval. This generally maximizes the generator's profit while simultaneously minimizing power system costs. Unfortunately, this same concept is not currently fully extended to the charging and discharging of storage. Storage projects typically must guess at their charging and discharging schedules, and only then do they let the power system operator optimize the energy and A/S within that predefined operational mode.

Vertically integrated, regulated, non-market areas require the same types of flexibility to maintain power system reliability. The lack of markets can make it more difficult to quantify the value of storage, especially for a third party proposing a new project because the power system production cost data are typically proprietary. Still, vertically integrated areas currently potentially offer several advantages for storage projects. Vertically integrated utilities may be able to obtain regulatory approval for long-term contracts based on expected benefits for electricity consumers over decades. Markets seldom offer such assurances, and the developer must assume the risk, typically increasing project costs. Similarly, a vertically integrated utility and its regulator may invest in a storage project that flattens on/off peak energy price differentials or that collapses A/S prices if those benefits exceed the project cost; while in a market environment, the price collapse would eliminate the storage project's economic incentive and thereby deny consumers the project's benefits.

A list of 10 topics was proposed that could be limitations of current market designs and system operation procedures. Modifications to these limitations could offer PSH to achieve more revenue than it currently receives. In addition, it could allow for the system and market operator to extract more of the flexibility from PSH than it currently receives, which, with increasing variable renewable penetrations, becomes increasingly important.

\section{ES.4.6 Financial Analysis and Business Models}

The role of PSH projects in the U.S. market has changed in response to increased penetration of variable renewable resources. PSH projects are often operating to maximize the dependable capacity from variable renewables and provide A/S to support interconnected bulk transmission grid reliability and stability. PSH projects have the ability to provide fast response. However, in existing electricity markets many of these services may not be-at present-compensated financially. ${ }^{1}$ The A/S acknowledged with market products vary by ISO and RTO.

PSH's other role, to operate for energy arbitrage, leads to a smoothing of prices between offpeak and on-peak hours, such that PSH operation can greatly reduce price differentials (spread value) and, consequently, their revenues. These market-related barriers significantly impact the financial viability of a PSH project.

As demonstrated in the financial modeling completed as part of this study, developing a new, financially viable PSH project will be a challenge. While this report focuses on a generic case study with associated sensitivity analyses, the results highlight the overarching issue facing

1 The conditions are beginning to change in this regard as evidenced by the recently adopted FERC Order 784, Third-Party Provision of Ancillary Services; Accounting and Financial Reporting for New Electric Storage Technologies, issued July 18, 2013. 
large-scale energy storage-the monetized benefits under current market conditions are not always sufficient to justify the required investment. Lenders often prefer a fast return of investment with lower capital cost projects, while PSH requires financing a high capital cost, low operating cost, long-lived project. 


\section{Section}

1

\section{Introduction}

\subsection{Background}

A project team, led by Argonne National Laboratory (Argonne), was tasked by the U.S. Department of Energy (DOE) to study the role and value of advanced pumped storage hydropower (PSH) in the United States. The study was funded by DOE's Office of Energy Efficiency and Renewable Energy (EERE) through a program managed by the EERE's Wind and Water Power Technologies Office (WWPTO). The project team consisted of five organizations, combining diverse skills and expertise from national laboratories, the hydropower industry, and engineering and consulting companies. In addition to Argonne, the project team included Siemens PTI, Inc., Energy Exemplar, LLC, MWH Americas, Inc., and the National Renewable Energy Laboratory (NREL).

Throughout the study, the project team was supported and guided by an Advisory Working Group (AWG) consisting of 35 experts from a diverse group of organizations, including the hydropower industry and equipment manufacturers, electric power utilities and regional electricity market operators, hydro engineering and consulting companies, national laboratories, universities and research institutions, hydropower industry associations, and government and regulatory agencies.

\subsection{Study Objectives}

The main purpose of the study was to develop detailed simulation models of advanced pumped storage technologies in order to analyze their technical capabilities to provide various grid services and to assess the value of these services under different market structures and for different levels of renewable generation resources in the system. Specifically, the main objectives of the study can be summarized as follows:

- Improve modeling representation of advanced PSH and conventional hydropower $(\mathrm{CH})$ plants in power system and electricity market models,

- Quantify technical capabilities of advanced PSH plants to provide various grid services,

- Analyze the value of these services under different market conditions and levels of variable renewable generation (wind and solar) in the power system, and

- $\quad$ Provide information on the full range of benefits and value of PSH plants. 
Although the existing dynamic models for conventional hydro and pumped storage plants provide accurate representation and modeling of these technologies, it was necessary to develop dynamic models of advanced PSH technologies (adjustable speed [AS] and ternary PSH units) for which no models were available in the United States (U.S.). These new models would provide accurate modeling of dynamic responses of the advanced PSH units to various system disturbances and are required for transmission interconnection studies of new advanced PSH projects.

In addition, one goal of the study was to improve the modeling representation of advanced PSH plants in production cost and electricity market simulation models, especially for high-resolution simulations performed with sub-hourly simulation time steps. While most production cost models can accurately simulate PSH technologies when using an hourly simulation time step, there is a need to improve the modeling representations of PSH plants and properly capture their flexible operating characteristics in high-resolution simulations.

Another goal of the study was to perform production cost and revenue simulations and assess the role and value of various services and contributions that PSH technologies provide to the system. The production cost and revenue simulations focused on the electric power systems within the Western Interconnection (WI), which covers the western part of the United States, the Canadian provinces of British Columbia and Alberta, and the Comisión Federal de Electricidad (CFE) serviced area of northern Mexico. The analysis focused on several geographical areas within the region and was carried out for different levels of renewable energy generation in the system. The analysis examined the benefits and value of PSH plants in both regulated and competitive electricity market environments.

\subsection{Technical Approach}

The technical approach for the study consisted of two main components that can be summarized as follows:

1. Advanced Technology Modeling: Develop and test vendor-neutral dynamic simulation models of advanced PSH plants, including AS and ternary technologies. Integrate these newly developed models into the Power System Simulator for Engineering (PSS ${ }^{\circledR} \mathrm{E}$ ) software developed by Siemens PTI and test them using both PSS ${ }^{\circledR} E$ test cases and cases for the WI. Publish the vendor-neutral models (as block diagrams and transfer functions) and make them publicly available for integration into other software packages.

2. Production Cost and Revenue Modeling: Simulate WI and different balancing authorities (BAs) within the region to quantify the technical capabilities of PSH plants to provide various grid services, quantify economic value and financial revenues of PSH plants if they are co-optimized for energy and ancillary services $(\mathrm{A} / \mathrm{S})$, and to assess the value of other services that these plants bring to the system (e.g., lower system production cost, better integration of variable renewable resources [wind and solar], and reduced cycling of thermal units). Analyze the impacts of different market structures and include both cost-based approaches to determine the 
economic value of hydropower and market-based approaches to determine plant revenues in competitive electricity markets. Investigate the impacts of different penetration levels of variable renewable resources in the system.

Figure 1-1 is a schematic illustration of the technical approach and associated project tasks and activities. To perform these tasks, the project team established several task force groups (TFGs), illustrated in Figure 1-2, to focus on the specific aspects of the modeling and/or analysis. In addition, the project team closely coordinated project work with DOE and the AWG.

The first component of the study, the development of vendor-neutral models, was carried out by the Advanced Technology Modeling TFG led by experts from Siemens PTI, aided by the participation of experts from other project team organizations. The Advanced Technology Modeling TFG first conducted a review of dynamic PSH and CH simulation models that are currently in use in the United States to determine whether improvements were needed. It was found that the existing dynamic models for conventional PSH and $\mathrm{CH}$ plants accurately describe their dynamic behavior and responses to system disturbances. The TFG then focused on the need for new models and developed vendor-neutral models for advanced PSH technologies (AS and ternary PSH units) for which no dynamic models were available in the United States. The new models were integrated into the PSS ${ }^{\circledR} E$ software and tested using the standard PSS ${ }^{\circledR} E$ test cases, as well as using the dynamic PSS ${ }^{\circledR} E$ cases for WI developed by the Western Electricity Coordinating Council (WECC). The new dynamic models for AS and ternary PSH units were added to the PSS ${ }^{\circledR} E$ library of dynamic models and are available to all PSS ${ }^{\circledR} E$ users. In addition,

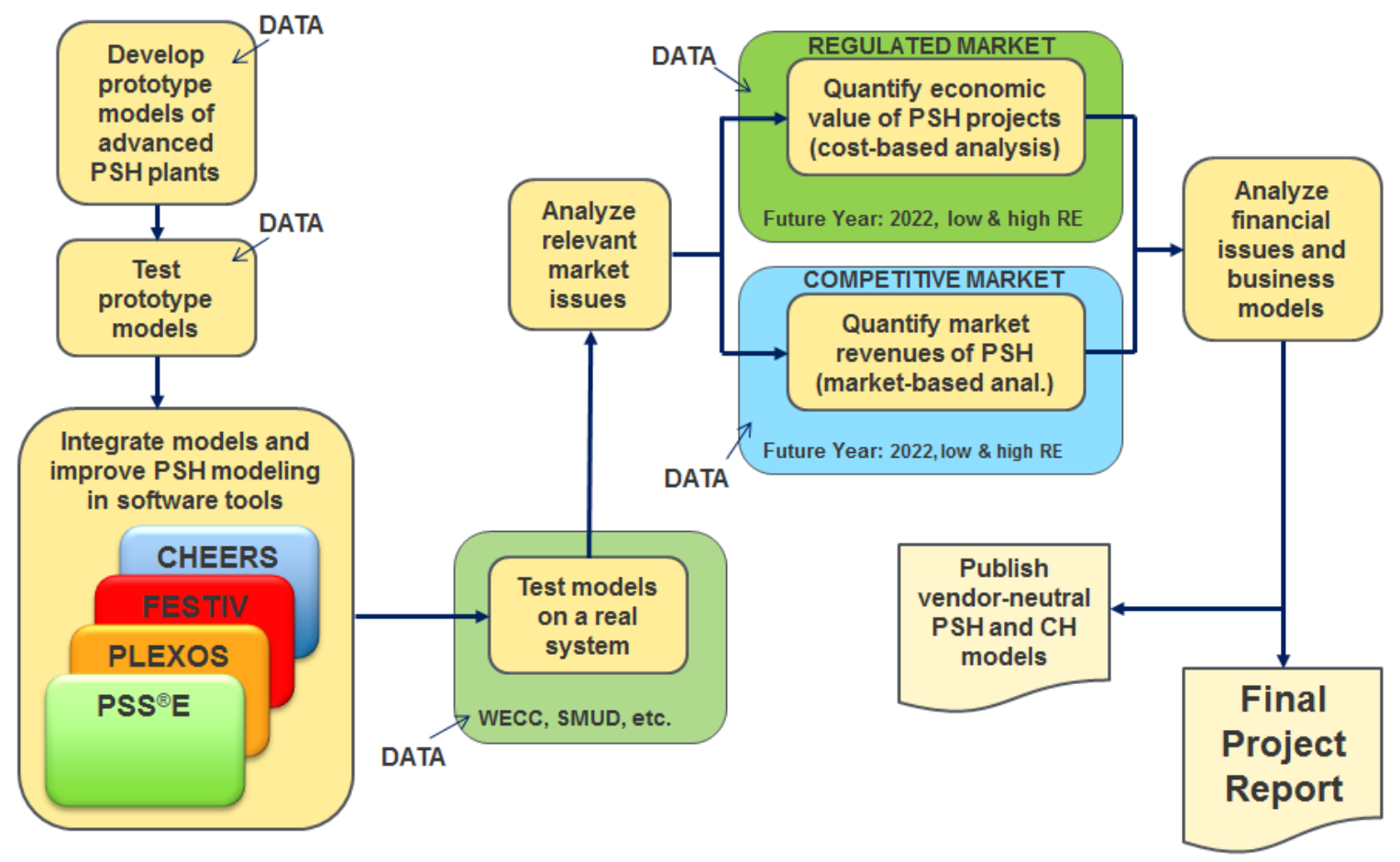

Figure 1-1 Technical Approach-Schematic Flowchart of Project Activities 


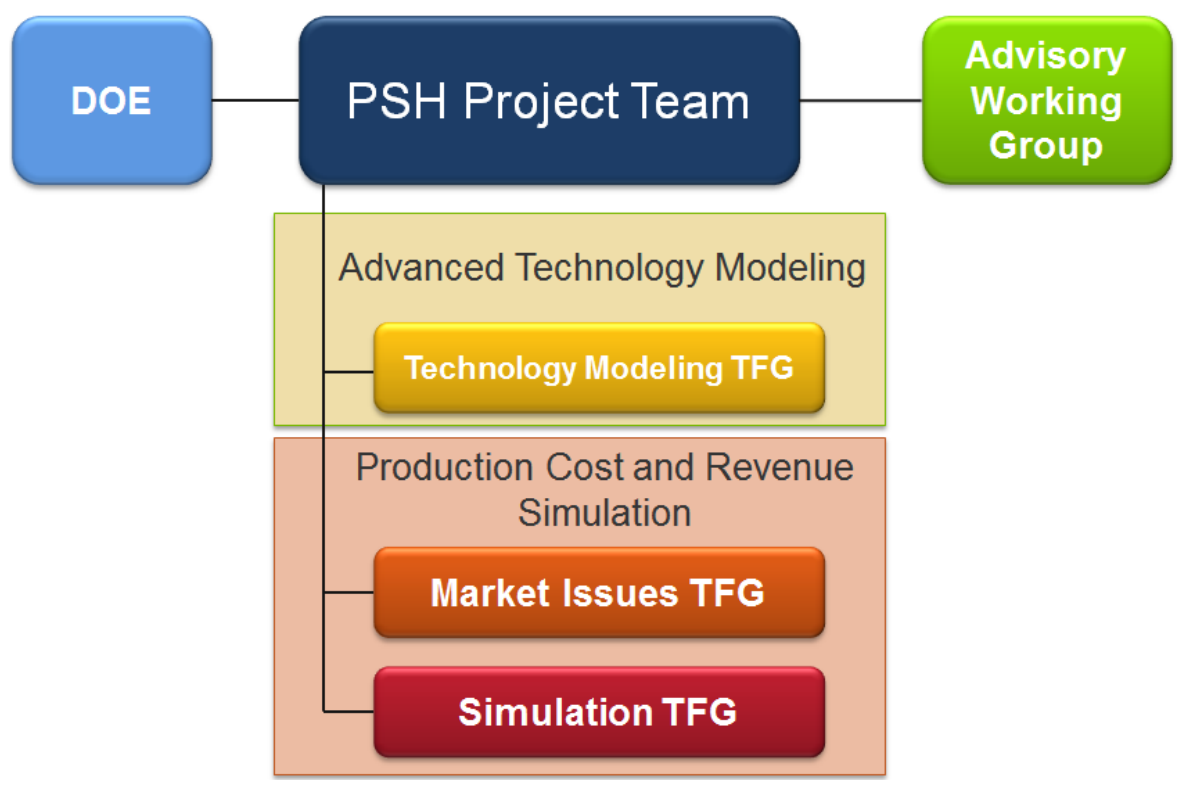

Figure 1-2 Organization of Project Team

because these models were developed as vendor-neutral, they were published in several project reports and are now available for integration into other software packages.

The simulations performed during the study addressed a wide range of power system operational issues and timeframes illustrated in Figure 1-3. The analysis aimed to capture PSH behavior and operational characteristics across different timescales; from a fraction of a second for dynamic responses, to annual simulations for production cost simulations. The project team used a suite of four different computer models to simulate system operation and analyze various control issues occurring at different timescales. This is illustrated in Figure 1-3 which also shows an approximate zone of wind/solar impacts and the system operational issues that are mostly affected by the variability of these renewable energy resources.

For the production cost and revenue modeling task, the project team first developed a matrix of contributions and services that PSH plants provide to the system. The Market Issues TFG was tasked to analyze current operation and market treatment of PSH plants in regulated and restructured markets, while the Simulation TFG worked on the design of modeling cases and scenarios to address various PSH contributions and their value in different power systems.

While the focus of the study was on the WI, there were several levels of geographical scope; from modeling the entire WI, to modeling individual BAs and individual projects. As illustrated in Figure 1-1, both cost-based and market-based approaches were applied in the analysis. The cost-based approach allows for the evaluation of benefits provided by $\mathrm{PSH}$ plants to the power system and is typically applied in the case of PSH projects operating in traditionally regulated utilities. On the other hand, the market-based approach allows for the calculation of revenues that a PSH project can realize in a restructured electricity market, where PSH plants compete to provide energy and ancillary services. Thus, the market-based approach mainly focuses on the 


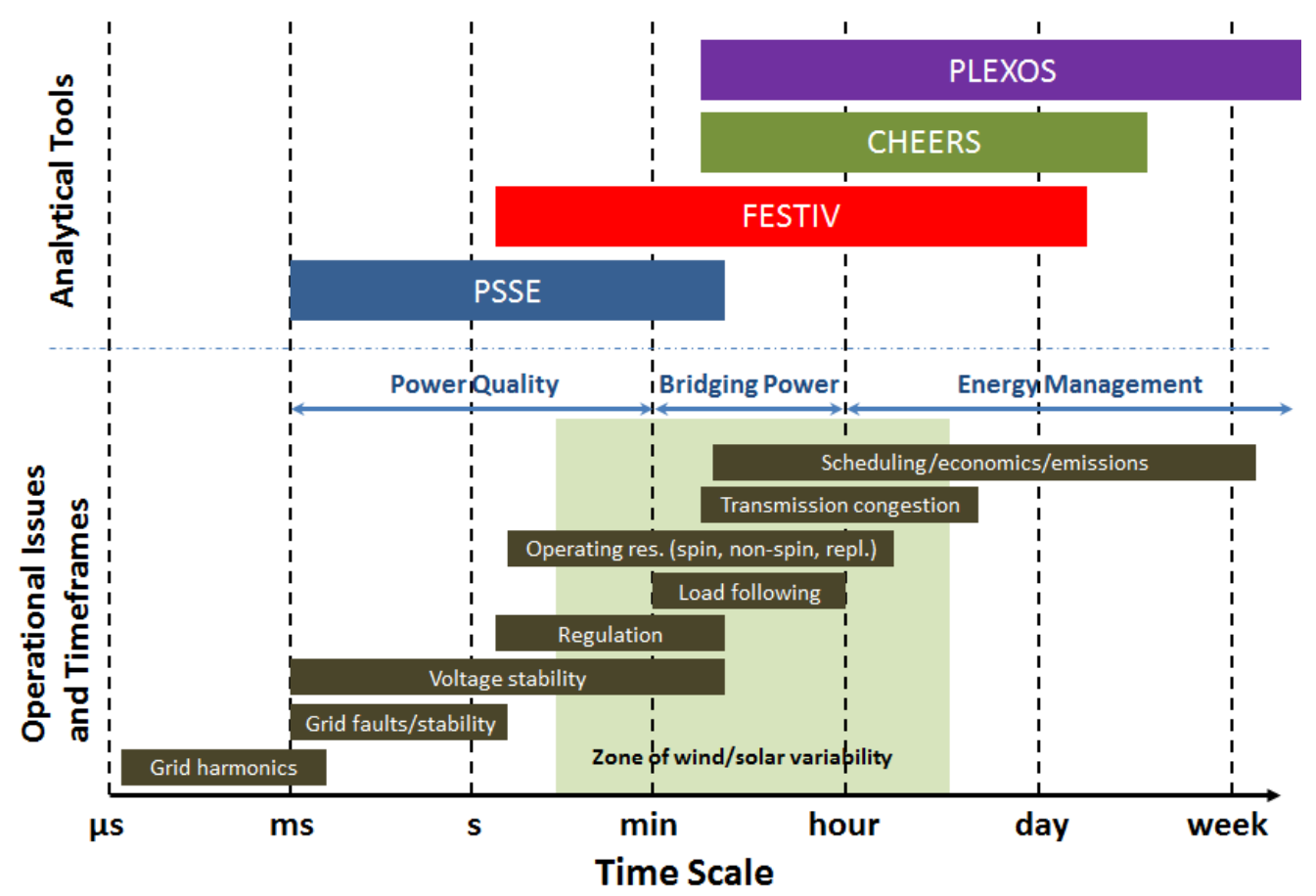

Figure 1-3 Power System Timeframes and Operational Issues

revenue streams that a PSH project may realize in a competitive market environment, depending on the available market mechanisms that have been established for different types of services. The main distinction between the cost- and market-based approaches in the evaluation of PSH plants is that the cost-based approach is a system-level approach where the value of a PSH project is measured by the overall benefits that it provides to the power system in which it operates, while the market-based approach focuses on the PSH plant and its potential revenues, thus providing information for the analysis of the financial viability of the PSH project in a competitive market environment.

The simulations of system operations were performed for a future year that was largely based on WECC's long-term projections for 2022. WECC's Transmission Expansion Planning Policy Committee (TEPPC) 2022 Common Case served as the foundation for building modeling cases and scenarios; however, certain case parameters and data varied depending on the scenario assumptions. Simulations of power system operations were performed for two levels of renewable energy penetration:

- Baseline Renewable Energy Scenario - Corresponding to mandated Renewable Portfolio Standard (RPS) levels of renewable energy generation, amounting to about $14 \%$ of total generation within the U.S. part of the WI in 2022; and

- High Wind Renewable Energy Scenario - Corresponding to the High Wind Scenario from the Western Wind and Solar Integration Study - Phase 2 (WWSIS-2) (Lew et al. 2013), amounting to about 34\% renewable energy generation within the U.S. part of the WI in 2022. 
For the fine-granularity simulations with the time steps on the order of seconds, it was necessary to have high-resolution wind and solar data. Since the highest available resolution of wind and solar data is 10 -min data, the project team developed an algorithm for generating synthetic second-by-second data streams. The algorithm uses a fractal analysis approach to interpolate higher-resolution data points within an existing stream of wind or solar data, using the pattern observed in actual high-resolution samples.

\subsection{Content of Report}

Following this introductory section, Section 2 provides an overview of PSH technologies and their characteristics, with additional technical details provided in Appendix A. Section 3 provides a summary of activities relative to the development and testing of vendor-neutral dynamic models for AS and ternary PSH units. Section 4 summarizes production cost and revenue simulations performed using the PLEXOS model for the WI, California, and Sacramento Municipal Utility District (SMUD) power systems. Section 5 details steady-state reliability and cost simulations performed using the Flexible Energy Scheduling Tool for Integration of Variable generation (FESTIV) model to assess how PSH projects can increase power system reliability and improve control performance standards. Section 6 provides an overview of PSH modeling and co-optimization of PSH energy and ancillary services using the Conventional Hydropower Energy and Environmental Systems (CHEERS) model. Section 7 provides a summary of key study findings and discusses the role and value of various PSH services and contributions to the power system. Section 8 addresses market issues and the treatment of PSH plants in electricity markets in the United States. Section 9 discusses financial analysis and business models for the development of new PSH projects. And, finally, Section 10 provides a summary of key findings and conclusions.

\subsection{References}

Lew, D., G. Brinkman, N. Kumar, P. Besuner, D. Agan, and S. Lefton, 2012, “Impacts of Wind and Solar on Fossil-Fueled Generators," presented at Institute of Electrical and Electronics Engineers (IEEE) Power and Energy Society General Meeting, July 22-26, San Diego, Calif. 


\section{Section}

\section{2}

\section{PSH Technology Characteristics}

This section presents an overview of PSH technologies, including single-speed, AS, and ternary units. Additional discussion about the advanced pumped storage technologies is presented in Appendix A. Background information is provided in support of modeling efforts described in other sections of this report and other reports prepared during the study. An overview of pumped storage is given, along with a brief historical development of PSH from its early beginnings in Europe to the present. The focus is on pumped storage units with AS capabilities and draws on experience with the advanced technology pumped storage units in Japan and Europe.

\subsection{Overview of PSH}

A typical conventional PSH project consists of two interconnected reservoirs (lakes), tunnels that convey water from one reservoir to another (waterways), turbine shutoff valves, hydro machinery (a pump/turbine, a motor/generator, and transformers), a transmission switchyard, and a transmission connection (see Figure 2-1). The product of the total volume of water and the differential height between reservoirs is proportional to the amount of stored electricity; thus, storing $8,800 \mathrm{MWh}$ in a system with an elevation change of 1,000 ft and installed capacity of 800 MW requires a water volume of about 10,000 acre-feet.

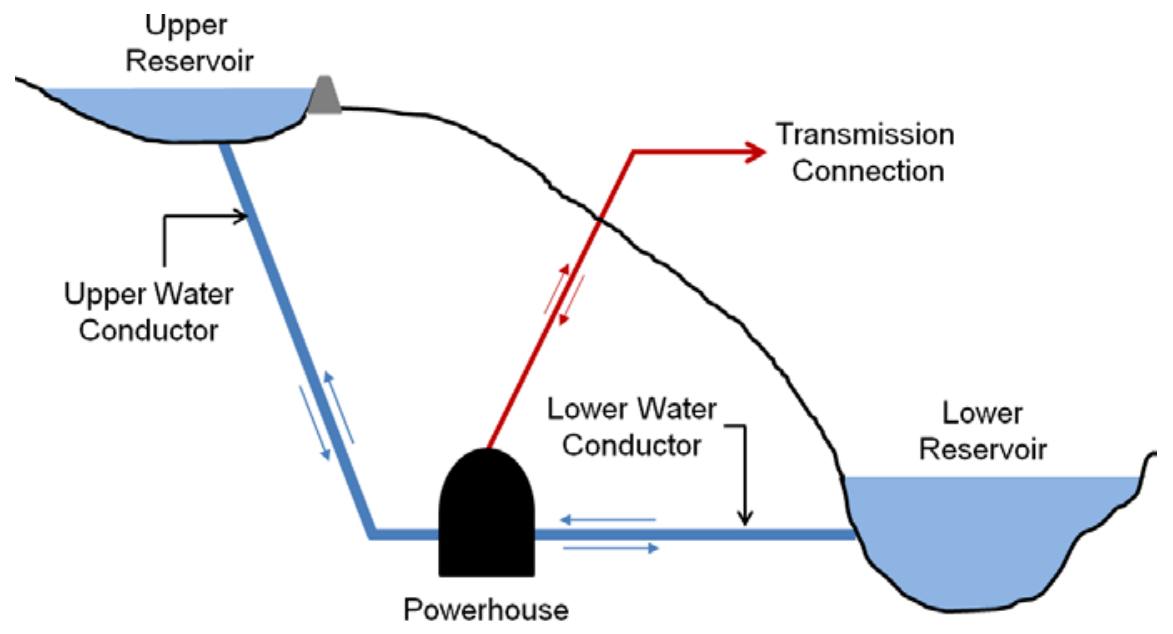

Figure 2-1 Typical Pumped Storage Configuration

In the traditional energy arbitrage mode of operation, inexpensive electricity (which typically occurs overnight, when there is low power demand) is used to pump water from the lower 
reservoir to the upper reservoir. Water stored in the upper reservoir is released during peak demand periods, delivering more valuable electricity to the grid.

Because of the deregulation of the bulk power electric system, which unbundled A/S, it is also possible to earn revenues for supplying A/S. There are concerns regarding the potential impact of increased capacity from variable renewable energy sources-such as wind and solar photovoltaic (PV) — on grid reliability, and the related need for additional operating reserves to balance these variable generation sources. The need for additional A/S has led some developers to consider new pumped storage projects that are focused on providing A/S.

There are a variety of ways that the PSH concept can be implemented within specific geologic and hydrologic constraints. Many early pumped storage projects used existing, conventional hydro facilities to provide the necessary lower reservoir for water storage. These installations form a class of projects known as "on-stream integral pumped storage” or "pump-back pumped storage" projects. The latter uses two reservoirs located in tandem on the same river. They can operate as a conventional hydro plant, but when water flows are low, or when peak demand is high, they are operated in the pumped storage mode. Though operating fewer hours per year than the dedicated PSH system, these units often fit into an effective niche and function very well and economically.

It is also possible to construct pumped storage projects that are independent of a naturally occurring river or lake. Plants of this type are often referred to as "closed-loop" pumped storage systems. In this type of plant, the upper and lower reservoirs are located "off stream.” An advantage of this approach is that there is minimal to no aquatic life interaction; this approach minimizes or avoids the permitting and environmental review process. The development of a closed-loop system requires that a water source be identified to provide the initial charge and water to replace losses from evaporation and leakage. Closed-loop systems may also be advantageous for smaller applications with daily operating cycles.

On the other hand, all recent installations are on a much larger scale, with most installations having multiple units rated $100 \mathrm{MW}$ or greater. These require considerable civil construction, often with the need to build an upper reservoir and dams on an existing water feature for a lower reservoir. Figure 2-2 shows a recent four-unit 1,060-MW installation at Goldisthal, Germany. The facility is known as a greenfield site, not for the surrounding forest, but because there were no hydro facilities there prior to construction.

\subsection{Pumped Storage Hydro Technology}

While the basic pumped storage plant consists of upper and lower reservoirs with interconnecting water tunnels, there are several choices of motor/generator power conversion technologies. With the advent of significant numbers of renewables, such as wind and solar PV, the need for energy storage and regulation services has sparked a renewed interest in pumped storage. While conventional single-speed pumped storage power conversion with single-speed synchronous motor/generators can provide regulation service in generation mode, they cannot be used for regulation in the pump mode. With AS pumped storage technology this deficiency is overcome, and it is now possible to provide regulation services also in the pump mode. 


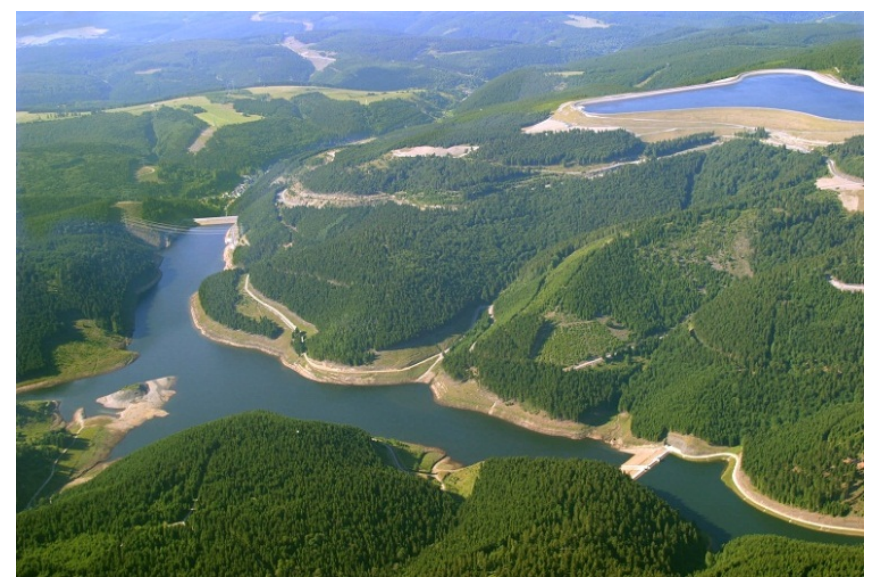

Figure 2-2 Goldisthal Pumped Storage Project in Germany (Source: Vattenfall GmbH)

Since the 1990s, more than 20 AS units have been placed in commercial operation and several more are in design and construction. Existing installations are using the asynchronous machines known as doubly-fed Induction machines (DFIMs). It is also possible to convert single-speed synchronous machines to AS operation. Since the dominant pumped storage technology is based on DFIM AS machines, the discussion of technical characteristics is focused on them; however, ternary and converter-fed synchronous machine (CFSM) power conversion technologies are also discussed.

Another common pumped storage configuration is ternary pumped storage, which uses singlespeed synchronous machines. The ternary pumped storage power conversion technology with single-speed synchronous power conversion also has the limitation of not being able to provide regulation in pump mode. However, in recent years, a variation of the ternary configuration with a hydraulic by-pass has been developed and it provides regulation in pump mode. Another variation of advanced pumped storage is the CFSM. There is a 100-MW CFSM unit in operation at the Grimsel 2 plant in Switzerland. See Appendix A for additional details.

\subsection{History of Pumped Storage Hydro}

One of the earliest known applications of PSH technology was in Zurich, Switzerland, in 1882. For nearly a decade, a pump and turbine operated with a small reservoir as a hydro-mechanical storage system. Beginning in the early 1900s, several small hydroelectric pumped storage plants were constructed in Europe, mostly in Germany. The first unit in North America was the Rocky River pumped storage plant, constructed in 1929 on the Housatonic River in Connecticut.

These early units were relatively basic as they had a motor and pump on one shaft and a separate shaft with a generator and turbine. Subsequent developments through the middle of the 20th century used a configuration with a single vertical shaft with motor/generator at the top, above a pump, with a turbine at the bottom of the shaft. In other applications, separate pump-motor and turbine-generators were used. Both the pump and the turbine in these cases were usually of the 
Francis type. Wicket gates, eventually under hydraulic control, were developed and used to regulate the power output in generation mode.

It was realized early on that a Francis turbine could also operate as a pump, but it was not used for both purposes until the Tennessee Valley Authority (TVA) and Allis Chalmers constructed the Hiwassee Unit 2 in 1956. This unit was a true reversible pump/turbine and, at $59.5 \mathrm{MW}$, was larger than earlier installations. Early pumped storage applications were limited by pump starting requirements. Pump/motor starting was done with pony motors or back-to-back configurations until the advent of solid-state starting devices. Technology and materials developments over the next three decades improved overall efficiency, reduced pump starting issues, and allowed increasingly larger units to be constructed.

The next major breakthrough in pumped storage hydro technology was the introduction of the DFIM with AS (also known as variable speed) capability. The first application of AS technology was a pilot project in a conventional hydro plant. In 1987, Hitachi installed a 22-MVA AS generator at the Kansai Electric Power Company’s (KEPCO) Narude hydro plant. The installation included a three-phase rotor, cycloconverter, power electronics controller, and protective relaying. The unit was initially operated in generation mode to demonstrate the feasibility of AS technology applied to hydro generation. The Narude pilot project was a pioneering accomplishment and led to the development of large AS pumped storage units.

\subsubsection{Pumped Storage in the United States}

In the United States, there are 40 conventional single-speed pumped storage plants in commercial operation. Many of these were constructed in the 1960s to 1980s to optimize the operation of large base load coal and nuclear power plants. In some cases, PSH was part of the off-site backup power supply for cooling water pumps serving nuclear power stations.

The role of PSH and nuclear cooling water is documented in an International Atomic Energy Agency (IAEA) report entitled Electric Grid Reliability and Interface with Nuclear Power Plants (IAEA 2012); the report provides the example of the 1,200-MW, four-unit Guangdong PSH project in China, which was developed to work with the Daya Bay 1,968-MW, two-unit nuclear plant.

At present, there are also about 50 proposed pumped storage projects in the United States that are in various stages of planning and Federal Energy Regulatory Commission (FERC) licensing process (see Figure 2-3). Many of these projects are considering the use of AS DFIMs.

\subsubsection{Adjustable Speed PSH in Japan and Europe}

The first full scale AS technology applied to a pumped storage plant was at Tokyo Electric Power Company's (TEPCO) Yagisawa pumped storage plant. Yagisawa Unit 2 was the first AS pumped storage unit; it was a conversion and was constructed by Toshiba and became operational in 1990. 


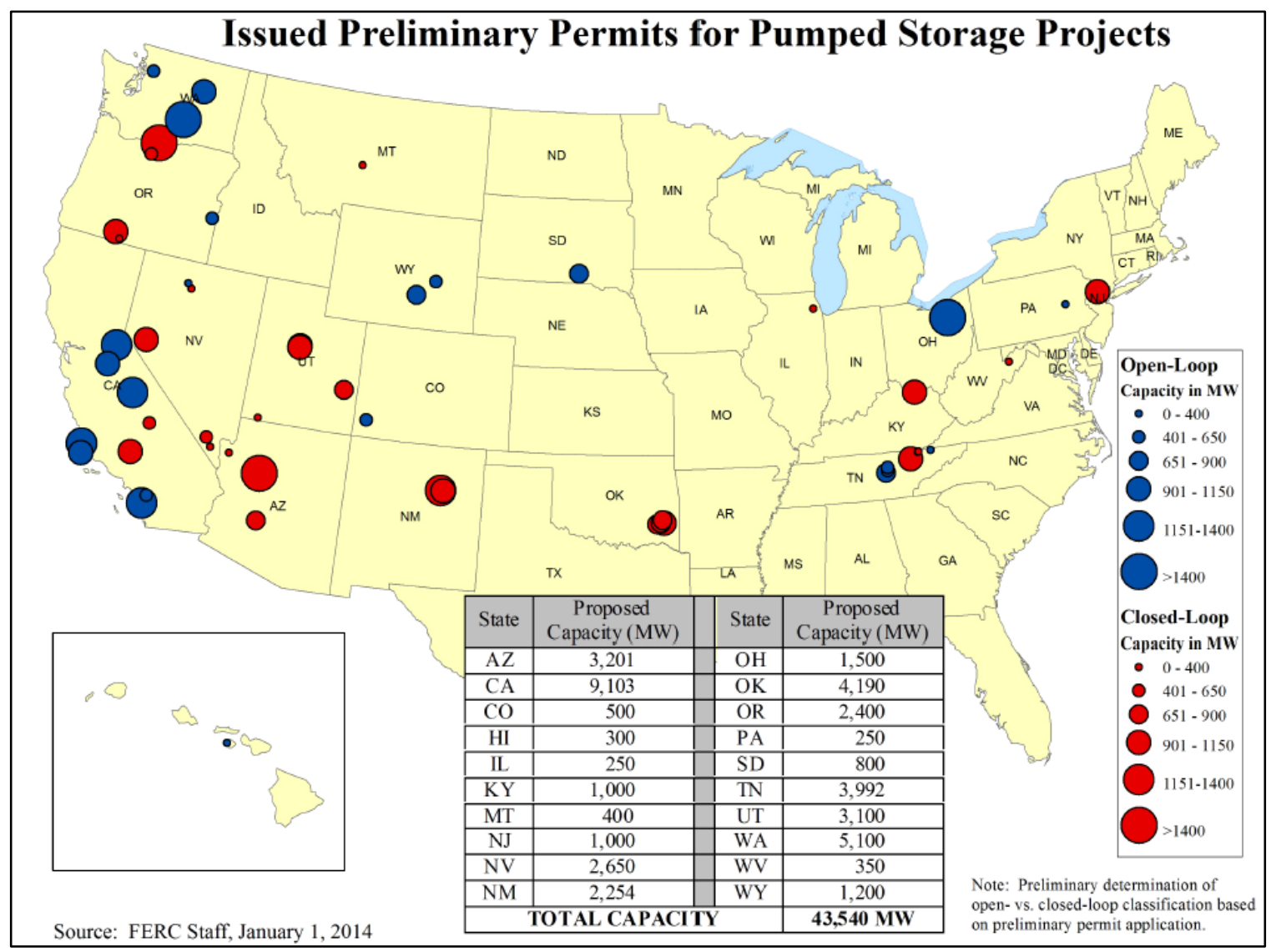

Figure 2-3 Preliminary Permits for Pumped Storage Projects Issued by FERC

The KEPCO Okawachi plant (1993-1995) was the first pumped storage plant designed specifically for units with AS technology. There are four units - two single-speed and two ASeach rated at 395 MVA in generation mode.

Since 1990, several AS units have been constructed in Japan and Europe. Table A-1 in Appendix A gives the names and basic characteristics of AS pumped storage units in commercial operation in Japan and Europe. Table A-2 lists the names of additional units that are in various stages of planning and development.

Manufacturers that have supplied pumps/turbines, motors/generators, rotor excitation and control systems for pumped storage plants with AS units include Toshiba, Hitachi, Mitsubishi, Andritz, Alstom, Converteam/GE, ABB, and Voith.

\subsection{Pumped Storage Hydro Capabilities}

Comparison matrixes of capabilities with technical characteristics for PSH plants and units were developed and are provided in Appendix A of this report (see Tables A-3 and A-4). The matrixes summarize the capabilities for each of the three main pumped storage technologies in terms of primary and secondary benefits. The following capabilities are included: 
- Energy arbitrage,

- Minimum unit capacity rating (MW),

- Maximum unit capacity rating (MW),

- Spinning reserve,

- Efficiency,

- Range of operation (\% of rated capacity),

- Capability to synchronize at less than system frequency,

- Mode change time,

- Change direction of rotation for mode change,

- Hydraulic churning during mode change,

- Regulate frequency in pump mode,

- Load following capability,

- Ramp rates,

- Reactive power,

- Load shedding,

- Flywheel effect,

- Generator dropping as a system stabilizing option,

- Shoulder pumping, and

- Hydraulic churning.

\subsection{Analysis of Pumped Storage Plants and Units}

To accurately represent the values and benefits of PSH, analyses are required to quantify operational capabilities and dynamic responses across different timescales, ranging from a fraction of a second to weeks. With the expected introduction of the AS pumped storage units in the United States, there is a need for new models that can be used for transmission interconnection and system dynamic performance studies as well as for production costing and economic analysis. 
Figure 2-4 shows the time ranges of power system dynamic phenomena, capacity dispatching, and operational planning.

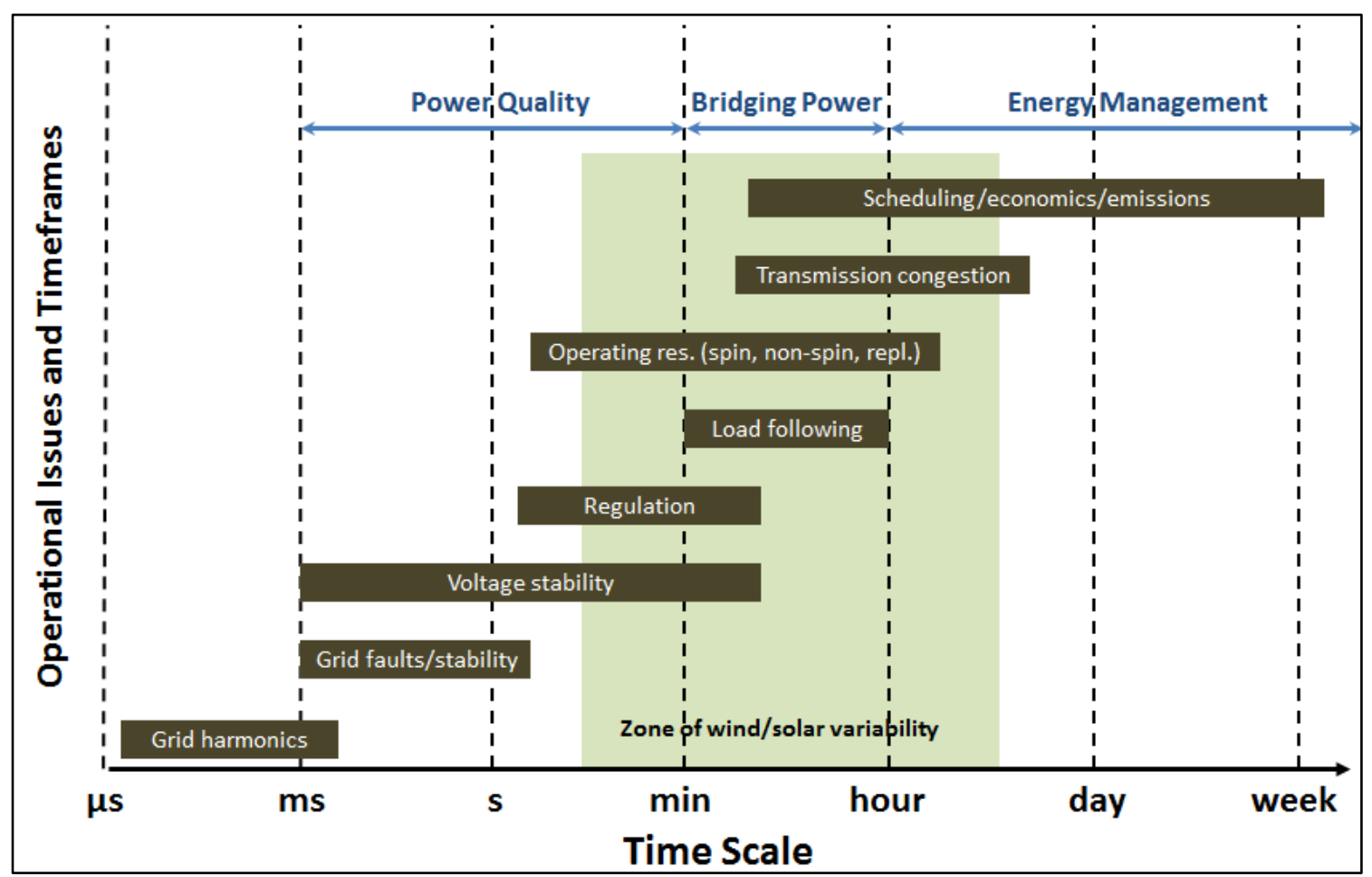

Figure 2-4 System Operational Issues and Time Ranges

The capabilities and benefits of PSH plants that are listed in the primary and secondary benefits tables in Appendix A, Tables A-3 and A-4, were analyzed using two types of software models: (1) short-time bulk power transmission system dynamic aspects (milliseconds to seconds), and (2) production costing and operation planning in the longer term (minutes, hours, days, and weeks).

During this study, dynamic models for AS and ternary pumped storage units were developed for short-time system dynamic and transmission system interconnection analyses, as discussed in Section 3. The models are described and documented in more detail in two reports-Modeling Adjustable Speed Pumped Storage Hydro Units Employing Doubly-Fed Induction Machines (Koritarov et al. 2013a) and Modeling Ternary Pumped Storage Units (Koritarov et al. 2013b). The reports further describe the controls and parameters for these two PSH technologies.

\subsection{References}

International Atomic Energy Agency (IAEA), Electric Grid Reliability and Interface with Nuclear Power Plants, IAEA Nuclear Energy Series Technical Report No. NG-T-3.8, Vienna, Austria, 2012. 
Koritarov, V., L. Guzowski, J. Feltes, Y. Kazachkov, B. Lam, C. Grande-Moran, G. Thomann, L. Eng, B. Trouille, and P. Donalek, 2013a, Review of Existing Hydroelectric Turbine-Governor Simulation Models, Report, Argonne National Laboratory, ANL/DIS-13/05, Argonne, Ill., Aug.

Koritarov, V., L. Guzowski, J. Feltes, Y. Kazachkov, B. Gong, B. Trouille, and P. Donalek, 2013b, Modeling Adjustable Speed Pumped Storage Hydro Units Employing Doubly-Fed Induction Machines, ANL/DIS-13/06, Argonne National Laboratory, Argonne, Ill., Aug. 


\section{Section}

3

\section{Advanced PSH Model Development}

The objective of this project task was to review the existing models of PSH and $\mathrm{CH}$ technologies and develop vendor-neutral dynamic simulation models for technologies for which such models were not available in the United States. This work is described in detail in five reports (Koritarov et al. 2013a,b,c,d,e) published by the project team. The following sections provide a brief summary of the work performed on the development of dynamic PSH models.

\subsection{Review of Existing Hydroelectric Turbine Governor Models}

Before embarking on the development of new dynamic models, the project team reviewed the status of hydro unit modeling in the commercially available software packages used by utilities and system operators for the planning and operation of the U.S. power grid. The two software packages that dominate this market are Siemens PTI's PSS ${ }^{\circledR} E$ and GE's Positive Sequence Load Flow (PSLF) programs; nearly all major U.S. utilities and system operators use one of these two programs.

On the basis of this review, the project team prepared a report that summarizes all turbinegovernor models for hydroelectric units available in these two software packages (Koritarov et al. 2013a). To put the model development work into a wider power system perspective, the report provides a general overview of the control systems and strategies employed to operate the power system. It also describes the models used to simulate the major equipment in the generating stations: generators, excitation systems, and turbine-governors. Figure 3-1 shows the functional relationships among the fundamental components associated with the turbine, its governing system, and the generator in a conventional generating unit.

The report (Koritarov et al. 2013a) also provides a description of the hydro governor models that can be found in commercial software packages that are commonly in use in North America as well as on other continents. These software packages contain a wide variety of models to cover different governor designs, turbine types, and various levels of complexity of the penstock dynamics. Table 3-1 lists the standard library of models used in the PSS ${ }^{\circledR} E$ software, while Table 3-2 lists the models used in the PSLF software. Details of the listed models and their parameters are discussed in Koritarov et al. (2013a.)

A comprehensive discussion on modeling conventional (fixed speed [FS]) PSH units using commercial simulation software is also provided, along with results of simulations using the PSS ${ }^{\circledR}$ E software. Finally, the report discusses the modeling of conventional PSH plants and provides a bibliography of pertinent references. 


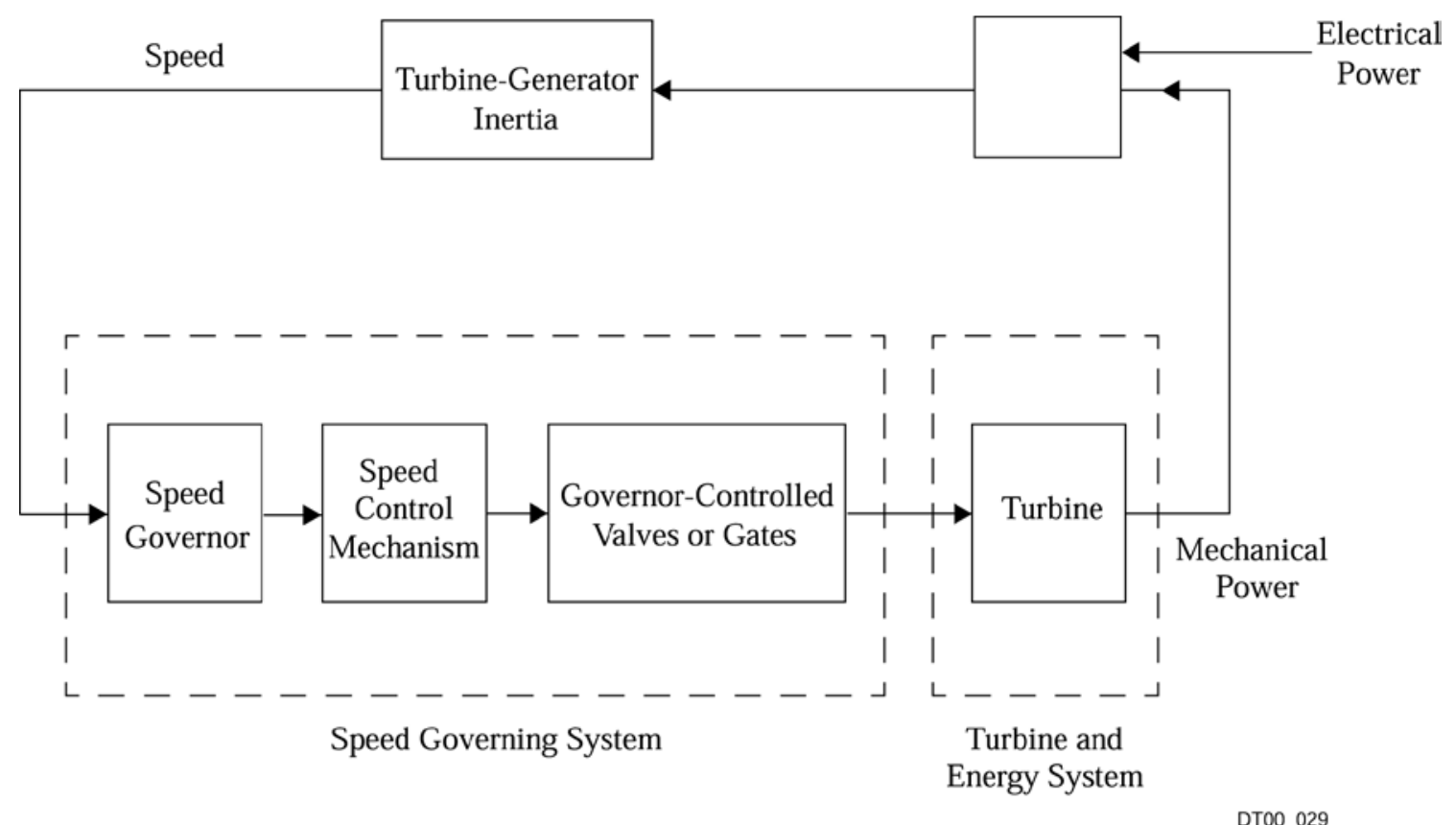

Figure 3-1 Turbine, Governor System, and Generator Functional Relationships

Table 3-1 Hydro Governor Models in PSS ${ }^{\circledR}$ E Software

\begin{tabular}{|l|l|}
\hline \multicolumn{1}{|c|}{ Model Name } & \multicolumn{1}{c|}{ Description } \\
\hline HYGOV & Standard hydro turbine-governor model \\
\hline HYGOV2 & Linearized hydro turbine-governor model \\
\hline HYGOVM & Hydro turbine-governor model with lumped parameters \\
\hline HYGOVT & Hydro turbine-governor model with traveling wave \\
\hline HYGOVRU & Fourth order lead-lag hydro turbine-governor model \\
\hline IEEEG2 & General-purpose linearized turbine-governor model \\
\hline IEEEG3 & General-purpose linearized turbine-governor model \\
\hline PIDGOV & $\begin{array}{l}\text { Hydro turbine-governor model for plants with straightforward penstock } \\
\text { configurations and three-term electro-hydraulic governors }\end{array}$ \\
\hline TURCZT & General-purpose turbine-governor model \\
\hline TWDM1T & Hydro turbine-governor model with tailwater depression \\
\hline TWDM2T & $\begin{array}{l}\text { Hydro turbine-governor model with proportional, integral, and } \\
\text { derivative (PID) controller and tailwater depression }\end{array}$ \\
\hline WEHGOV & Woodward electro-hydraulic hydro turbine-governor model \\
\hline WPIDHY & Woodward PID hydro turbine-governor model \\
\hline WSHYDD & WECC double derivative hydro turbine-governor model \\
\hline WSHYPG & WECC type GP hydro turbine-governor model \\
\hline HYGOV4 & Hydro turbine-governor model \\
\hline
\end{tabular}


Table 3-2 Hydro Governor Models in PSLF Software

\begin{tabular}{|l|l|}
\hline \multicolumn{1}{|c|}{ Model Name } & \multicolumn{1}{c|}{ Description } \\
\hline G2WSCC & Double derivative hydro governor and turbine \\
\hline GPWSCC & PID governor and turbine \\
\hline HYG3 & PID governor, double derivative governor, and turbine \\
\hline HYGOV4 & $\begin{array}{l}\text { Hydro turbine and governor model for plants with straightforward } \\
\text { penstock configurations and traditional dashpot-type hydraulic governors }\end{array}$ \\
\hline HYGOV & $\begin{array}{l}\text { Hydro turbine and governor model for plants with straightforward } \\
\text { penstock configurations and electro-hydraulic governors that mimic the } \\
\text { permanent/temporary droop characteristics of traditional dashpot-type } \\
\text { hydraulic governors }\end{array}$ \\
\hline HYGOVR & $\begin{array}{l}\text { Fourth order lead-lag governor and hydro turbine } \\
\text { Hydro turbine and governor model for plants with straightforward } \\
\text { Includes capability to represent blade angle adjustment of Kaplan and } \\
\text { diagonal flow turbines. }\end{array}$ \\
\hline HYST1 & $\begin{array}{l}\text { Hydro turbine with Woodward electric-hydraulic PID governor, penstock, } \\
\text { surge tank, and inlet tunnel }\end{array}$ \\
\hline IEEEG3 & $\begin{array}{l}\text { Institute of Electrical and Electronics Engineers (IEEE) hydro turbine and } \\
\text { governor model for plants with straightforward penstock configurations } \\
\text { and hydraulic-dashpot governors with optional deadband and nonlinear } \\
\text { gain }\end{array}$ \\
\hline WIDGOV & $\begin{array}{l}\text { Hydro turbine and governor model for plants with straightforward } \\
\text { penstock configurations and three-term electro-hydraulic governors } \\
\text { (Woodward electronic) }\end{array}$ \\
\hline Woodward 2301 governor and basic turbine model \\
\hline
\end{tabular}

\subsection{Modeling Adjustable Speed PSH Units Employing Doubly-Fed Induction Machines}

Since the review of the existing hydroelectric turbine-governor models identified the need to develop dynamic simulation models for AS PSH, the purpose of this task was to propose a model structure for an AS PSH unit employing a DFIM.

The use of a DFIM with its rotor windings controlled by a power converter is the present stateof-the-art design for AS hydro pumped storage units. Fortunately, very significant efforts have been previously applied to determine the proper level of modeling required for DFIMs, albeit not specifically for pumped storage units. Previous efforts to describe the theoretical and modeling aspects of DFIMs were related to the development of models for wind turbines employing doubly-fed induction generators. For a period of more than 10 years, starting from the early 2000s, a significant evolution has been observed in the approach to modeling this type of electrical machine. While the machines for pumped storage units will be much larger than those used for wind units, and thus the higher currents and voltages may require different power electronic devices, the control strategies and overall responses will be similar. 
The project team published the report Modeling Adjustable Speed Pumped Storage Hydro Units Employing Doubly-Fed Induction Machines, which describes the vendor-neutral models of AS PSH units that were developed during the project (Koritarov et al. 2013b). This report includes a comprehensive review of the basics of the operation of a DFIM, including the theory of this operation for dynamic and steady-state modeling. The report provides a discussion on modeling of PSH units employing a DFIM for dynamic stability studies. This discussion takes into account the experience gained in the course of developing PSS ${ }^{\circledR} \mathrm{E}$ dynamic simulation models of wind units.

The report (Koritarov et al. 2013b) provides a detailed description of the vendor-neutral models developed for the modeling of AS PSH units employing a DFIM. While the focus of this report is on how to model these units in the PSS ${ }^{\circledR} E$ program, the information is provided in a manner that is also applicable to modeling such devices in other commercial power system stability simulation programs. A brief summary of this work is provided in the following sections.

\subsubsection{Model of the Adjustable Speed PSH Units Employing a Doubly-Fed Induction Machine}

The basic operation of a DFIM is shown in Figure 3-2. The stator of the machine is connected to the system. The rotor of the machine is connected to the machine terminals through a power converter. The power converter can control the voltage, current, and frequency in the rotor circuit, and hence the machine power and reactive power.

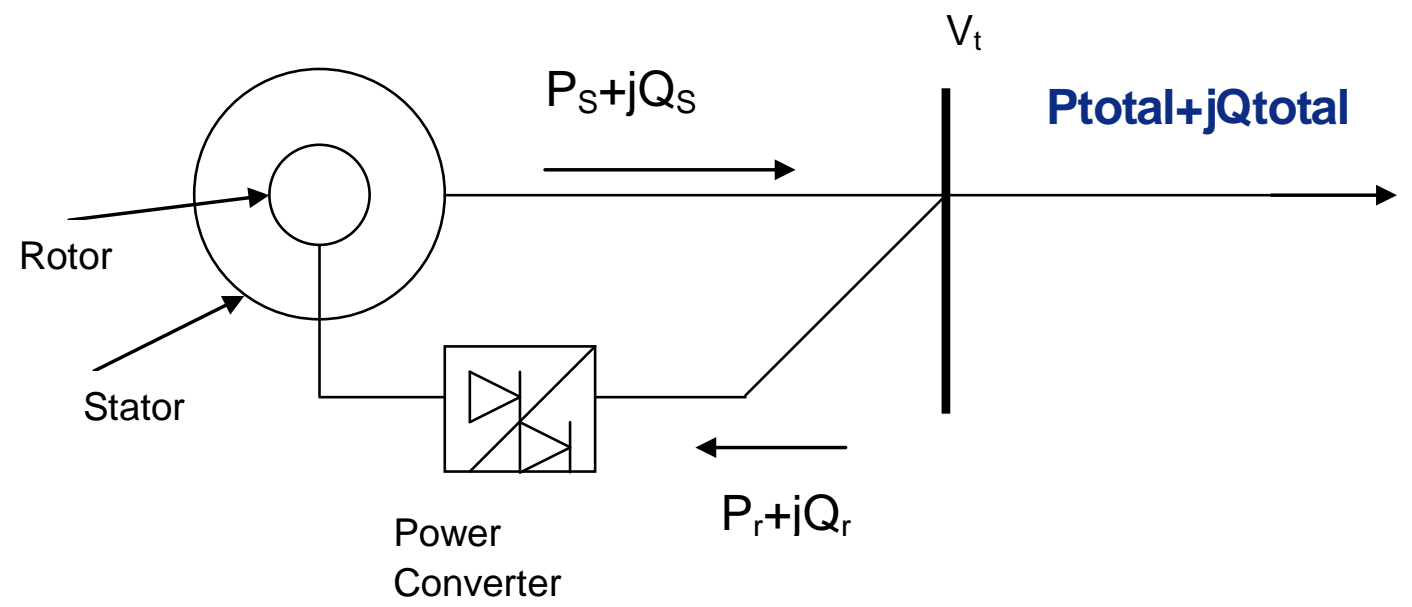

Figure 3-2 Configuration of a DFIM

The full order model of a DFIM described in Section 2 of the report (Koritarov et al. 2013b) is not appropriate for stability studies because it requires a significant reduction of the integration time step. Moreover, it is well known that taking into account the stator flux linkage dynamics is not necessary for stability studies. However, the rotor flux linkage dynamics must be represented in the electrical machine model used for rotor angle and voltage stability studies. 
The vector control provided by a power converter connected to the rotor of the DFIM processes commands in terms of the $\mathrm{d}(\mathrm{R})$ and $\mathrm{q}$ (I) components of the rotor current responsible for controlling the machine voltage across the magnetizing branch and electromagnetic torque. This control is done in a very fast manner by means of high-frequency pulse-width modulation (PWM) electronics. The rotor current follows these commands with negligible delay. As currents of the rotor and stator are closely related, the current injected by the DFIM into the grid may be determined also based on the commands issued by these controls. This fundamental consideration allows us to dramatically change the approach to modeling of the DFIM controlled by a power converter connected to its rotor winding. The model should have a fair representation of the controls whose outputs are applied to a combined machine/converter model, but it does not need to model either the very fast PWM electronics or include a detailed model of the machine. This philosophy has been successfully employed for modeling DFIM wind turbines and was suggested for usage in the advanced pumped storage unit models.

Figures 3-3 and 3-4 illustrate the recommended model structure for a PSH unit employing a DFIM for turbine and pump operation, respectively. The design of this model draws heavily on the control structures described in a paper by Kuwabara et al. (1996), "Design and Dynamic Response Characteristics of 400 MW Adjustable Speed Pumped Storage Unit for Okawachi Power Station.” This approach to modeling, based on the experience of these Japanese authors gained at their Okawachi PSH plant, was found to be the most practical and useful of the many references reviewed. It is also consistent with our understanding and the modeling practices of commercial stability programs. However, there are many other references and ongoing development efforts, thus the selection of this control structure is not to be construed as indicating that other potential control structures are impossible, since they may have advantages for particular installations or technologies.

In a conventional single-speed pumped storage plant, synchronous machines are employed. The input to the governor controls is speed, and the gate position is controlled to adjust power. The machine speed is not controlled; since the machine is a synchronous machine; speed is locked to the system frequency.

In a pumped storage plant employing a DFIM, there are two controllable variables, gate position and speed, as the speed of the machine is no longer locked to system frequency. In the steady state, the controls select the optimum relationship between gate position and speed to get the desired power. In principle, there are three basic control approaches:

1. The electrical power is controlled by the power converter, and the rotating speed is controlled by the turbine-governor adjusting the gate position;

2. The rotating speed is controlled by the power converter, and the electrical power is controlled by the turbine-governor adjusting gate position; and

3. A combination of these two approaches. 
Since the power converter can be adjusted very quickly (tenths of a second) compared with gate position (seconds), control strategy 1 above is labeled as Fast Power Control and control

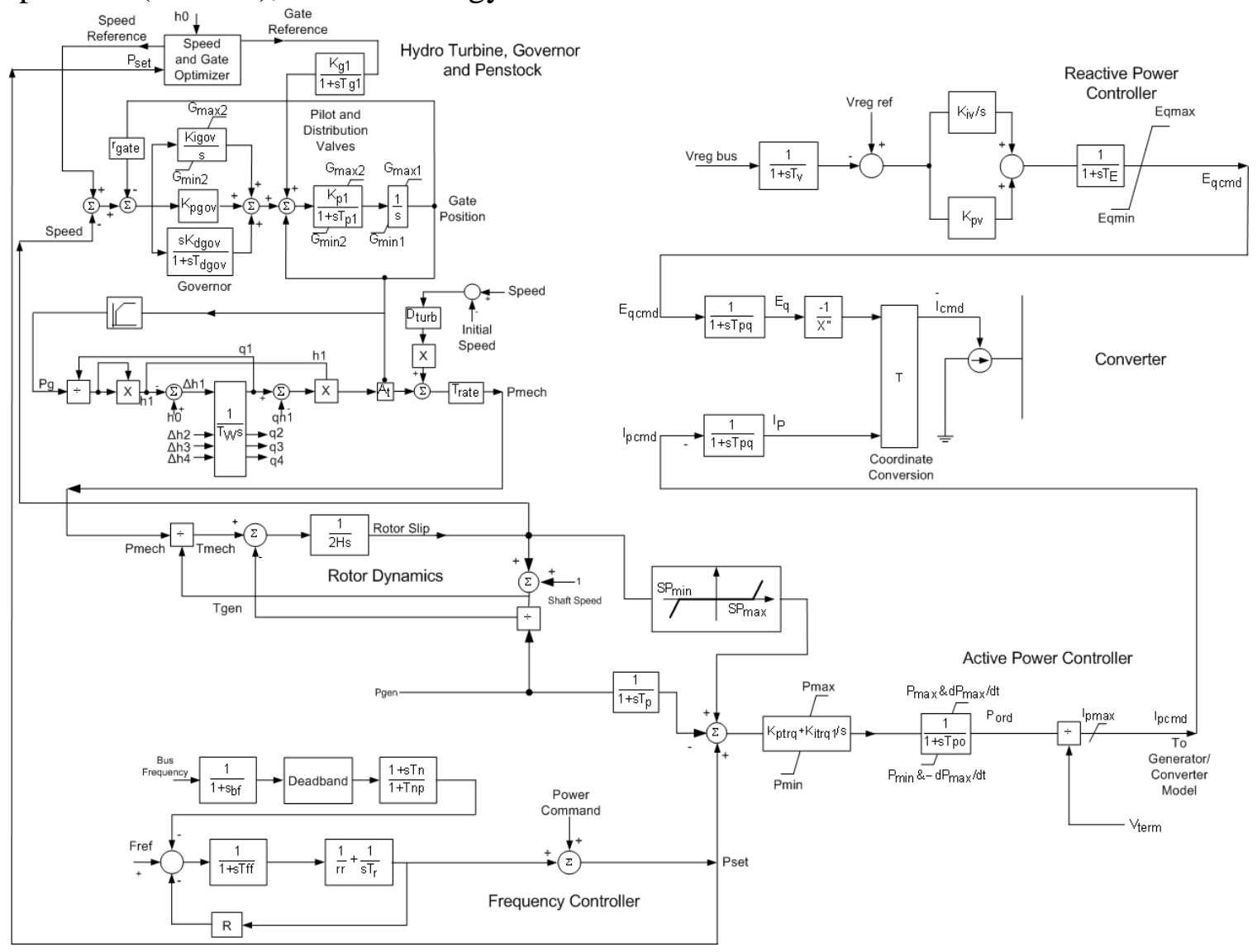

Figure 3-3 Model of Adjustable Speed PSH Employing DFIM-Turbine Operation

strategy 2 as Fast Speed Control. In a general sense, it can be shown that both approaches work, although the transient response of the units to events occurring on the system is very different.

The control investigations that are related to the design of the Okawachi power plant in Japan showed the response employing both control strategies (Nagura and Yoshida 2011). The authors show that Fast Power Control is a superior approach compared with Fast Speed Control. The two control strategies are also compared in Pannatier et al. (2008). The authors conclude that the Fast Speed Control strategy is detrimental to grid stability and that the Fast Power Control strategy is capable of following changes of the power set point very quickly, about 84 times quicker than using the alternate strategy, and results in very acceptable transient behavior. The findings of a third reference Kopf et al. (2004) based on the experience gained at the Goldisthal pumped storage plant in Germany are similar. Both control strategies were investigated and the Fast Power Control strategy was shown to be superior and was selected as the preferred strategy. There are other PSH plants, such as the Yagisawa and Shiobara plants in Japan, where a third control strategy is employed, using a combination of Fast Power Control and Fast Speed Control (personal communication with T. Ishizuki, Toshiba Corporation, 2013). The output power of these units is normally controlled by adjusting the guide vane opening, and the converter controls 
adjust to maintain the optimal rotating speed, essentially a Fast Speed Control strategy. However, in the case of a large disturbance causing a significant frequency deviation, the controls respond very quickly due to an additional compensation signal applied to both the converter control and the gate controls. Thus, for large disturbances, the response is similar to Fast Power Control. The stated advantage of this approach is that it meets both electrical and mechanical requirements in that it reduces the movement of the guide vane and the adjustment of the rotating speed of the units, while still maintaining the ability to make a quick response under conditions where it is needed.

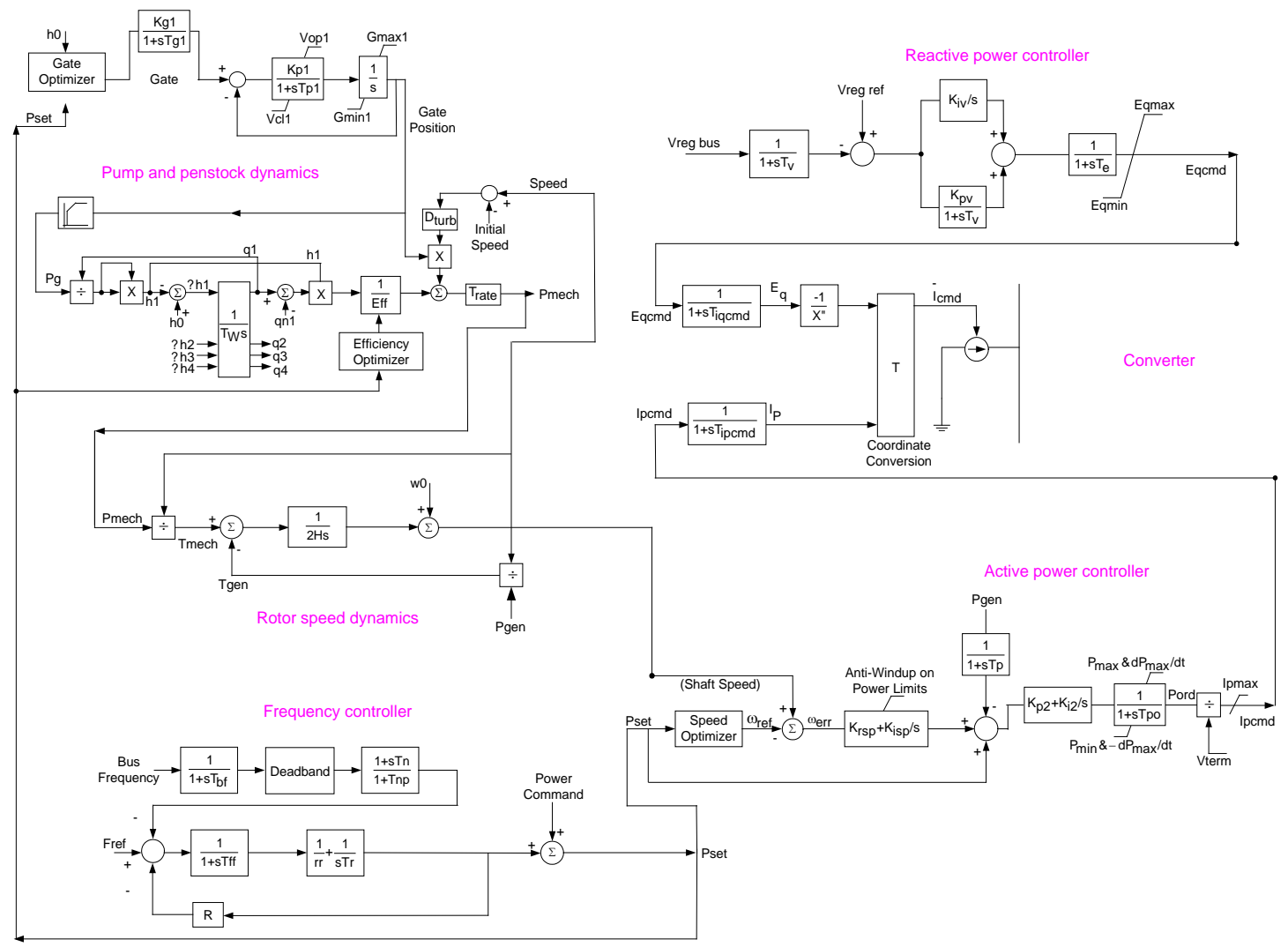

Figure 3-4 Model of AS PSH Employing DFIM-Pump Operation

In the modeling effort through this project, the Fast Power Control strategy was employed. The pump and turbine models shown in Figure 3-3 and Figure 3-4 share similar characteristics, although there are also significant differences.

In both models, the converter control is responsible for controlling active power and voltage. The power command is combined with the command from the frequency control to form the total power command Pset. The power error is processed by a proportional-integral-derivative (PI) regulator. The power reference from the active power controller and the voltage reference from the reactive power controller are used to determine the desired current command; and thus, the desired generator active and reactive power. The generator/converter model also includes the rotor inertial dynamics. 
Figure 3-3 shows the model for the governor, turbine, and penstock dynamics. While the model of the physics of the turbine and penstock are similar to that of conventional hydro units, this model addresses the extra degree of freedom in control of the AS unit. The mechanical power can be adjusted by either a change in turbine speed or in a change in gate position or in a combination of both. The speed and gate optimizers select the proper coordination of speed and gate position to maximize efficiency. Note that the optimization process itself is not modeled; however, the optimal mechanical power/gate/speed relationships supplied by the manufacturer are represented through simplified functional characteristics.

The major differences between the model for pumping operation and the model for turbine operation are in the active power controller and the modeling of the physics of the gate, pump, and penstock relationships. Figure 3-4 shows the model for pump operation. The desired speed at power Pset is determined from the speed optimizer and compared with the actual speed. A PI controller determines the desired power, which is then compared with the power absorbed by the unit, and then another PI controller determines the active current command. The active current command, along with the reactive current command from the voltage regulator, is fed to the power converter control. The total power command Pset is also used by the gate optimizer to determine the desired gate position. The generator/converter controls and the reactive power controls are identical to those for the turbine mode of operation.

The potential for the AS units to share a common penstock is included in the models. The model is structured to account for up to four units sharing the same penstock and models the hydraulic coupling between the units; that is, a change in the flow through one unit results in a change in the dynamic head at the bifurcation point and thus impacts the flow through the other units. The relationship between head and flow is defined by a matrix of water time constants, using a nonlinear model assuming a non-elastic water column and suitable for short- to medium-length penstocks.

\subsection{Modeling Ternary Pumped Storage Units}

The review of existing hydroelectric turbine-governor models in use in North America also identified the need to develop dynamic simulation models for the ternary PSH technology. Therefore, the purpose of this task was to propose a power system dynamic simulation model structure for a ternary PSH unit employing a separate turbine and pump on a single shaft with the generator/motor.

The project team has published a companion report Modeling Ternary Pumped Storage Units that describes this work in detail (Koritarov et al. 2013c). This report gives an overview of the ternary technology and the basics of the operation of a ternary PSH unit, including both dynamic and steady-state operation. It also provides a discussion on the dynamic modeling of these ternary pumped storage units. While the focus of this report is on how to model these units in the PSS ${ }^{\circledR} E$ software, the information is provided in a manner that is also applicable to modeling such devices in other commercial power system stability simulation programs. A brief summary of this work is provided in the following sections. 


\subsubsection{Overview of Ternary Pumped Storage Technology}

Conventional PSH units have many similarities with conventional hydro plants. The major difference is, of course, that the flow is bidirectional for conventional PSH units. Usually, but not always, the same equipment is used for both generation and pumping; thus, the synchronous generator also operates as a motor, and the hydro turbine also operates as a pump. Both components are therefore reversible in their functionality. Some plants, particularly those with very high heads (head is the effective height between the water source and the turbine), may require separate turbines and pumps.

In practical applications, the transition from a generating to a pumping mode of operation (or vice versa) is performed by the operator and takes several minutes (i.e., it is usually not a subject of power system dynamic simulation studies, except possibly for those used in the initial design of the plant). Thus, in most power system simulation studies, the generating and pumping modes of operation for conventional PSH units are studied separately. The system conditions being analyzed are appropriate for one mode or the other; for example, studies performed at peak load would model the units as generating, while light-load studies would model the units as pumping.

The major difference between a ternary plant and other types of pumped storage plants is that the ternary plant can simultaneously operate both the pump and turbine. All other pumped storage plant designs operate either in a generating mode or a pumping mode, and the shaft rotates in opposite directions in these two modes.

The ability of the pump and turbine to operate simultaneously provides added flexibility in the plant's operation. The flexibility of the ternary plant is also improved by having the pump and turbine on the same shaft and thus rotating in the same direction, thereby eliminating the need to reverse the rotation to transition from pumping to generating or vice versa.

Because the pump and turbine are able to operate simultaneously, the hydraulic flow is more complex than it is in a conventional pumped storage unit. The ternary unit can operate with what is referred to as a "hydraulic short circuit," which is shown in Figure 3-5. The flow in the penstock is, of course, bi-directional; it goes from the headwater to the tailwater when the unit is generating electrical power, and from the tailwater to the headwater when the unit is absorbing electrical power (motoring).

The flow in the penstock is the net of the flow to the turbine and flow from the pump. The flow to the tailrace is this same net flow. One can think of a component of the flow circulating from the turbine to the pump (or vice versa), which is the hydraulic short circuit referred to above.

If the plant is operating in a pure pumping mode, the guide vanes to the turbine are closed, and the clutch is enabled. In this mode, the pump guide vanes are wide open, and there is no regulation capability. 


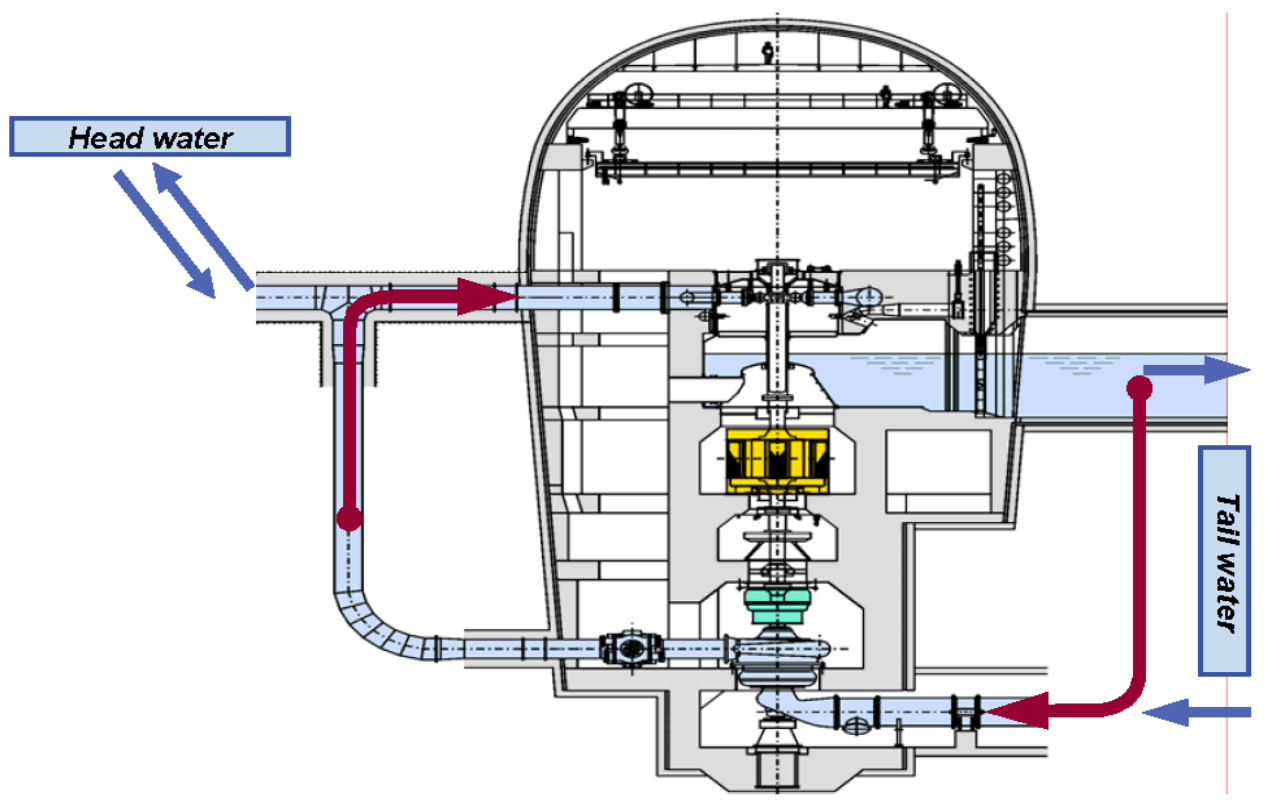

Figure 3-5 Ternary Units Demonstrating Hydraulic Short-Circuit Operation (Source: Spitzer and Penninger 2008)

If the plant is in the pumping mode and regulation is needed, both the pump and the turbine operate (i.e., employing the hydraulic short circuit). An example of this mode of operation is illustrated in Figure 3-6. The flow through the pump and the resulting torque applied to the shaft from the pump correspond to an electrical energy of $150 \mathrm{MW}$ drawn from the power system. However, the turbine guide vanes are adjusted so that the flow through the turbine and the resulting torque applied to the shaft from the turbine correspond to an electrical energy of 100 MW supplied to the power system. The net result is that $50 \mathrm{MW}$ is drawn from the power system, and the flow pumped up to the reservoir is equivalent to $50 \mathrm{MW}$. Of course, there are some hydraulic losses in the loop owing to the circulating component of the flow, and careful hydraulic design is required. In this mode of operation, the guide vanes of the turbine are adjusted to provide the desired regulation.

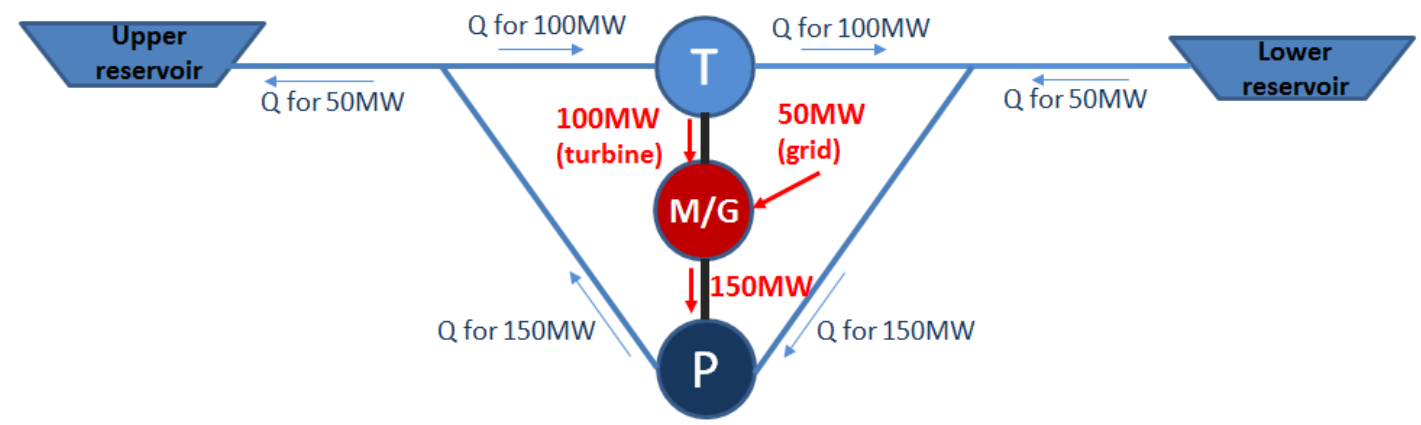

Figure 3-6 Example of Operation in Pumping Mode with Regulation Capability Using the Hydraulic Short-Circuit Concept 
One major advantage of the ternary design is that the rotational direction of the motor/generator is the same for both operational modes (i.e., there is no change in the direction of water flow to change from pumping to generating). The impacts from hydraulic transients are thus significantly reduced, and the machine can move rapidly from the full pumping mode to the full generating mode, unlike a reversible machine, which must stop before restarting in the opposite direction.

Figure 3-7 gives typical startup and transition times and illustrates this advantage. The transition time from generating mode to pumping mode for a reversible pump/turbine is seen to range from 4 to $8 \mathrm{~min}$, even for units employing advanced technologies. The transition time for the ternary units is much less, on the order of 0.5 to $0.75 \mathrm{~min}$.

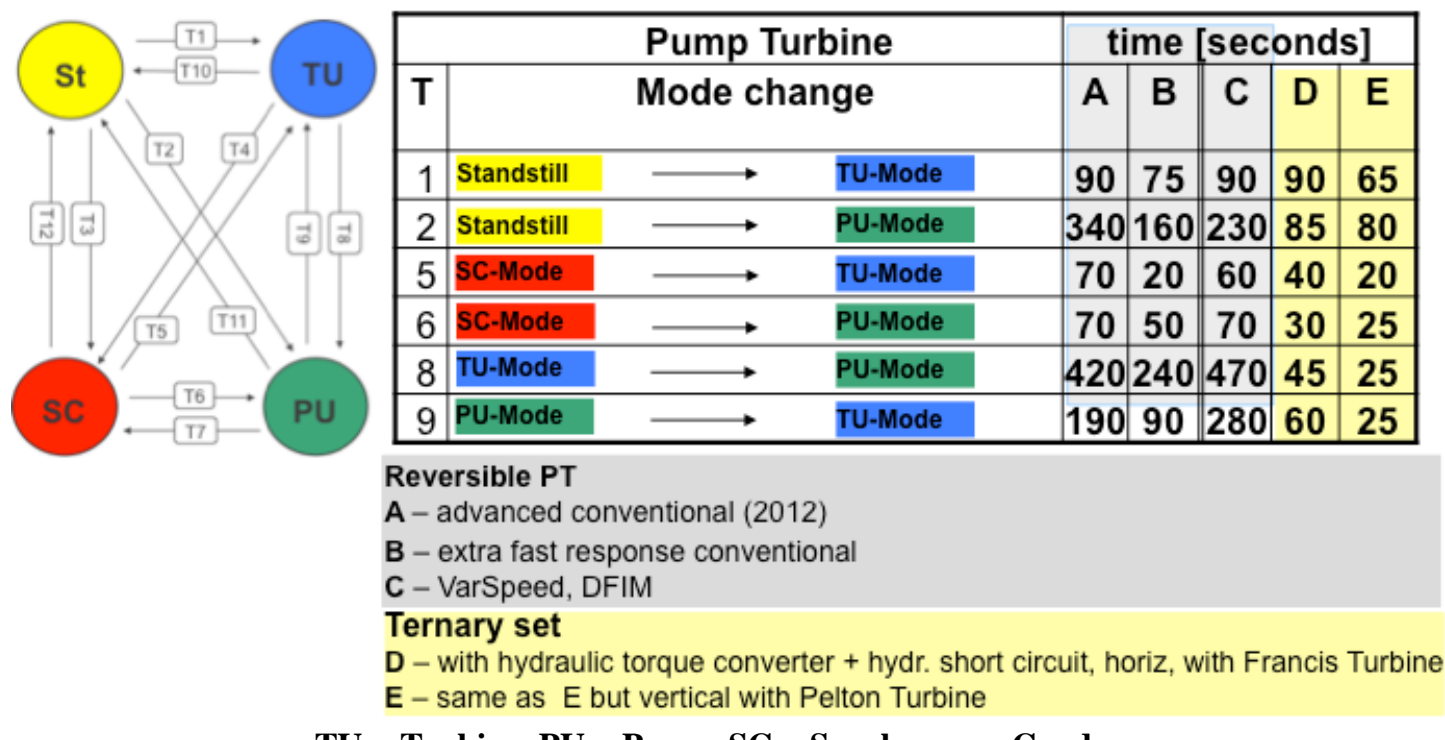

TU $=$ Turbine, $\mathbf{P U}=$ Pump, $\mathrm{SC}=$ Synchronous Condenser

Figure 3-7 Mode Change Times for Various Advanced Pumped Storage Technologies

(Source: Fisher et al. 2012)

The transition time for a reversible pump/turbine in the opposite direction, from pumping mode to generating mode, ranges from 1.5 to $5 \mathrm{~min}$, while the transition time for the ternary units is again significantly less, on the order of 0.5 to $1 \mathrm{~min}$.

Depending on the system requirements, this decrease in transition time could be very advantageous. For example, consider a pumped storage unit operating in pumping mode at night when a large amount of wind-powered generation is occurring. If there is a significant and fast drop in the wind energy, the ability of the pumped storage plant to transition quickly from pumping (and thus a system load) to generating could have a large impact on mitigating any resulting frequency deviations experienced by the system. 
A second advantage of ternary units over reversible pump-turbines is improved efficiency. In a ternary unit, the pump and turbine are both optimized for efficiency. In a reversible unit, the design is necessarily a compromise to allow for operation as both a pump and a turbine.

Another advantage of a ternary unit is its ability to employ different turbine technologies for the pump and turbine; in particular, to employ a Pelton turbine for high-head installations.

Since the ternary unit does not employ power electronics, such as those used in DFIM-based designs, it does not have an impact on power quality, which can be a concern with regard to any design that employs power electronics.

A ternary unit also has a better natural response to system disturbances for which transient stability is a concern. A ternary unit inherently has a higher total inertia, since this inertia includes both a pump and a turbine in addition to the generator. This extra inertia also has a positive impact on the initial rate of frequency change for a system event, resulting in an imbalance of generation and load.

On the other hand, there are also some disadvantages of the ternary design. In general, it will have a higher first cost because the hydraulic design is more complex and because more equipment is required. The hydro plant will also be larger because of the additional equipment, and that additional equipment will probably result in increased operating and maintenance costs.

\subsubsection{Modeling of Ternary Pumped Storage Units}

A ternary PSH unit employs a separate turbine and pump on a single shaft with the generator/motor. The modeling of the generator/motor and its excitation system is exactly like the modeling of a conventional PSH unit. Commercial power system simulation software packages, such as Siemens PTI's PSS ${ }^{\circledR} E$ and GE's PSLF, include models that represent the salient pole machine and many types of excitation systems. For more details on these models, please see the companion report, Review of Existing Hydroelectric Turbine-Governor Simulation Models (Koritarov et al. 2013a).

The model for the prime mover and governor of a ternary PSH unit must include models of the turbine and pump, which are on a single shaft with the generator/motor. The modeling of this equipment is the primary focus of the companion report Modeling Ternary Pumped Storage Units (Koritarov et al. 2013c).

In practical applications, the transition from a generating mode to a pumping mode of operation (or vice versa) is performed by the operator. It usually is not a subject of dynamic simulation studies, except possibly for those used in the initial design of the plant. Thus, in most simulation studies, the modes of operation of a pumped storage unit are studied separately. The system conditions being analyzed are appropriate for one mode or the other; for example, studies performed at peak load would model the units in a generating mode.

The representation is a bit more complex for a ternary unit, since in one mode of operation, both the turbine and pump are active simultaneously. However, the models proposed are still based on 
the assumption that the mode of operation does not change (i.e., the unit has the turbine in operation, has the pump in operation, or has both the pump and turbine in operation). The model does not include logic enabling a transition from, for example, operation with only the turbine in operation to operation with only the pump in operation.

While the model for a conventional pumped storage plant requires separate models for turbine and pump operation, the model for the ternary unit incorporates all three modes (turbine operation only, pump operation only, or both turbine and pump operation) in a single model. Figure 3-8 shows the model structure for the ternary unit.

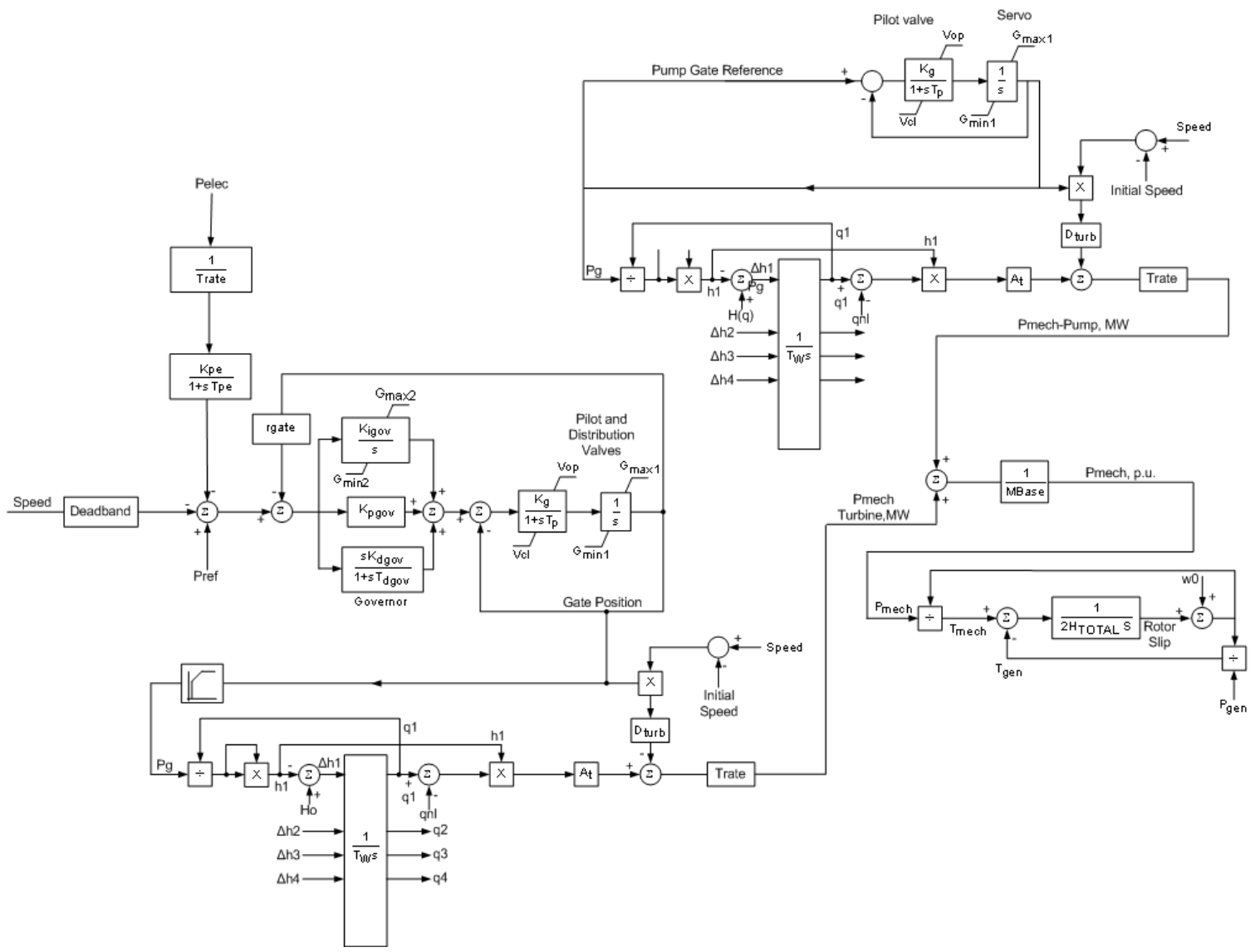

Figure 3-8 Model of Ternary PSH Unit

In generating mode with only the turbine in operation, the model of the ternary unit is similar to that of a conventional hydro unit. Conventional models are used for the salient pole machine and the excitation system. The machine will participate in the usual governor speed control, similar to the other generators on the system.

In pumping mode with only the pump in operation, the model of the ternary unit is again similar to that of a conventional hydro unit. Conventional models are used for the salient pole machine and the excitation system. The machine will not participate in governor speed control. 
The third mode of operation is pumping mode with the unit employing the hydraulic short circuit (ternary operation). For the hydraulic short-circuit mode, the model includes the following:

- Conventional models are used for the salient pole machine and the excitation system.

- The unit will adjust the gate position to participate in the usual governor speed control.

- The main inlet valve for the pump is adjusted to obtain maximum pump efficiency. The pump controls do not participate in the speed (frequency) control.

- The hydro and pump models include the logic to account for a design in which two ternary units (two sets of turbines and pumps) share the same penstock.

In ternary operation, the mechanical powers of the turbine and the pump provided by governor and pump models are summed to find the total mechanical power transferred to or from the common shaft. The rotor speed is determined by using the total inertia constant of the shaft, including all three components (i.e., the machine, the turbine, and the pump).

The operating mode (turbine operation only, pump operation only, or both turbine and pump operation) is selected via the proper setting of model constants.

The potential for ternary units to share a common penstock is included in the model. The model is structured to account for two ternary units sharing the same penstock, with each unit including a turbine, a pump, and a generator/motor, and models the hydraulic coupling between the units; that is, a change in the flow through one unit results in a change in the dynamic head at the bifurcation point and thus impacts the flow through the other units. The relationship between head and flow is defined by a matrix of water time constants, using a non-linear model assuming a non-elastic water column and suitable for short- to medium-length penstocks.

\subsection{Testing Dynamic Simulation Models for Different Types of Advanced PSH Units}

Testing of the new dynamic simulation models that were developed to represent advanced PSH technologies was performed to demonstrate the performance of these simulation models and illustrate how these models can now be used in analyses required for investigations into applications of these technologies.

The following new dynamic simulation models have been developed during the project:

1. A model of an AS PSH unit employing a DFIM and operating as a turbine.

2. A model of an AS PSH unit operating as a pump.

3. A combined model of a ternary PSH unit that can be used for simulation of any of three modes of operation of this type of unit, namely: 
- As a conventional hydro turbine,

- As a conventional hydro pump, or

- As a ternary unit operating in the hydraulic short-circuit mode.

Earlier reports (Koritarov et al. 2013b,c) published by the project team during the study described the performance of these technologies, the approach to their modeling, and details of the models' designs. The project team performed extensive testing of these newly developed models and described this work in detail in Testing Dynamic Simulation Models for Different Types of Advanced Pumped Storage Hydro Units (Koritarov et al. 2013d). The following is a brief summary of the testing of these dynamic models.

Several test systems were developed to illustrate different characteristics and control capabilities of the models:

- A 12-bus system with three machines in which the PSH is the dominant machine. Thus, the capabilities of the PSH unit are clearly shown, albeit in an exaggerated manner from a system impact standpoint.

- A 23-bus system with six machines. In this case, the PSH unit still represents a large portion of the system generation, but the case can be used to demonstrate the faster frequency control of the AS PSH technology.

- The full WI system. This is a large system model containing nearly 20,000 buses that represents the western portion of the North American power grid, approximately the western third of the United States from the Rocky Mountains west to the Pacific Ocean and the Western provinces of Canada. The present conventional PSH units in WI are modeled in this case. A revised WI model was created in which these existing installations are modeled using the new models, thus showing the response using the new technologies in real PSH locations and also allowing for a comparison of the response with the advanced technologies to that with conventional technologies.

These test systems were used to demonstrate that the new models were robust and showed the expected performance for different disturbances. In some cases, it is shown that the advanced PSH technologies have advantages (e.g., the ability to respond faster to frequency events compared with conventional units).

Simulations using the WI system demonstrate that the new models can be used for planning and interconnection studies for practical systems and can be tuned to local conditions. In general, throughout the course of testing described in this report, we performed many different simulations, created various frequency events, applied different types of faults, and, in general, put the models through all of the usual activities that would be encountered in studies using a tool such as PSS ${ }^{\circledR} E$. Thus, the tests documented below have confirmed and demonstrated the expected capabilities of the advanced PSH technology, such as riding through faults, voltage control, and participation in frequency control. 
The small 12-bus sample test system was used to make sure that the models showed adequate performance responding to different disturbances such as under-frequency and over-frequency events caused by the loss of generation or load, and three-phase and single-line-to-ground faults in the vicinity of the plant under study. This test system allowed for variation in the level of penetration of the advanced technology. The following types of PSH units were tested:

- Conventional turbines, to have a basis for comparison;

- Conventional pumps, to have a basis for comparison;

- $\quad$ AS PSH turbine;

- Up to four AS PSH turbines sharing a common penstock;

- $\quad$ AS PSH pump;

- Up to four AS PSH pumps sharing a common penstock;

- Ternary unit in the pump mode of operation;

- $\quad$ Ternary unit in the turbine mode of operation; and

- Ternary unit in the hydraulic short-circuit mode of operation.

Simulations were performed to test transient stability response and voltage control/reactive power control capabilities, and to demonstrate fast frequency regulation for events involving loss of generation or other events that result in an imbalance between system load and generation. These tests ensured that the newly developed models can be used to simulate the PSH unit's response to different disturbances and to demonstrate the potential for fast frequency control of the AS PSH units. Only a few examples of these tests are shown here.

Figure 3-9 compares the resulting system frequency with a conventional unit (black curve) and the AS unit (red curve) as a response to an under-frequency event resulting from loss of generation. Note that the under-frequency is controlled quicker with the AS unit. The maximum under-frequency reached is less than that with the AS unit, and the final frequency is reached faster. The PSH power electronics and turbine controls provide significantly different capabilities for frequency control versus conventional units. Tuning of these controllers depends on system needs in terms of initial frequency decay rate, frequency nadir, and frequency recovery rate. It should also be noted that in this test system, where the PSH unit represents the majority of the generation, the change in system inertia is very significant when the PSH machine is connected to the system through power electronics rather than being directly connected as a conventional machine. The AS PSH unit does not contribute to the total system inertia, as its machine speed is not synchronously connected to system frequency. This significantly impacts the initial system response to the generation/load imbalance in these simulations, as well as the potential rate of change in frequency possible through control action to recover from the event. This impact 


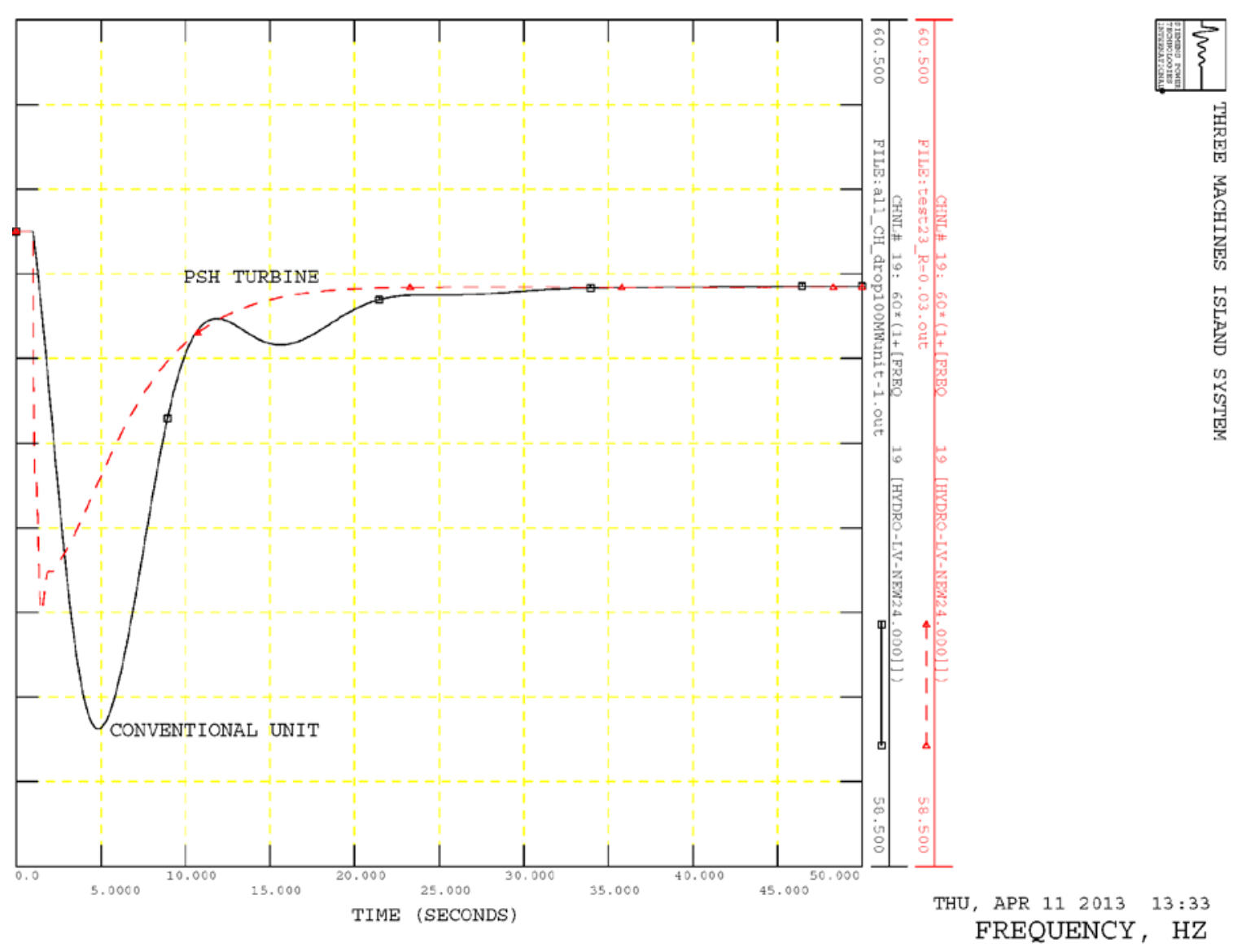

Figure 3-9 Comparison of System Frequency with the Conventional and AS PSH Units in Response to the Trip of a Gas Turbine

would not be as pronounced for the usual situation in which the AS PSH unit is part of a much larger power system.

Figure 3-10 illustrates the impact of the flow of an individual unit on the flows of other units sharing the common penstock with it; that is, the cross coupling of the flows modeled by the matrix of water time constants. The test simulated the reduction in the power output of Unit 1 in a stepwise manner. The dynamics of the model results in a reduction of the gate position of Unit 1 to bring the unit's electrical and mechanical power back into equilibrium.

Results of testing the ternary unit operating in the hydraulic short-circuit mode provided in Figure 3-11 clearly illustrate the main advantage of the ternary unit, namely, the capability of the unit operating in the hydraulic short-circuit mode to control the rotor speed and contribute to the control of system frequency. Figure 3-11 shows the response of turbine mechanical power and system frequency to the over-frequency caused by trip of a load. The ternary unit contributes to frequency control by closing the ternary unit's turbine gates and reducing mechanical power in a smoothly controlled manner. 


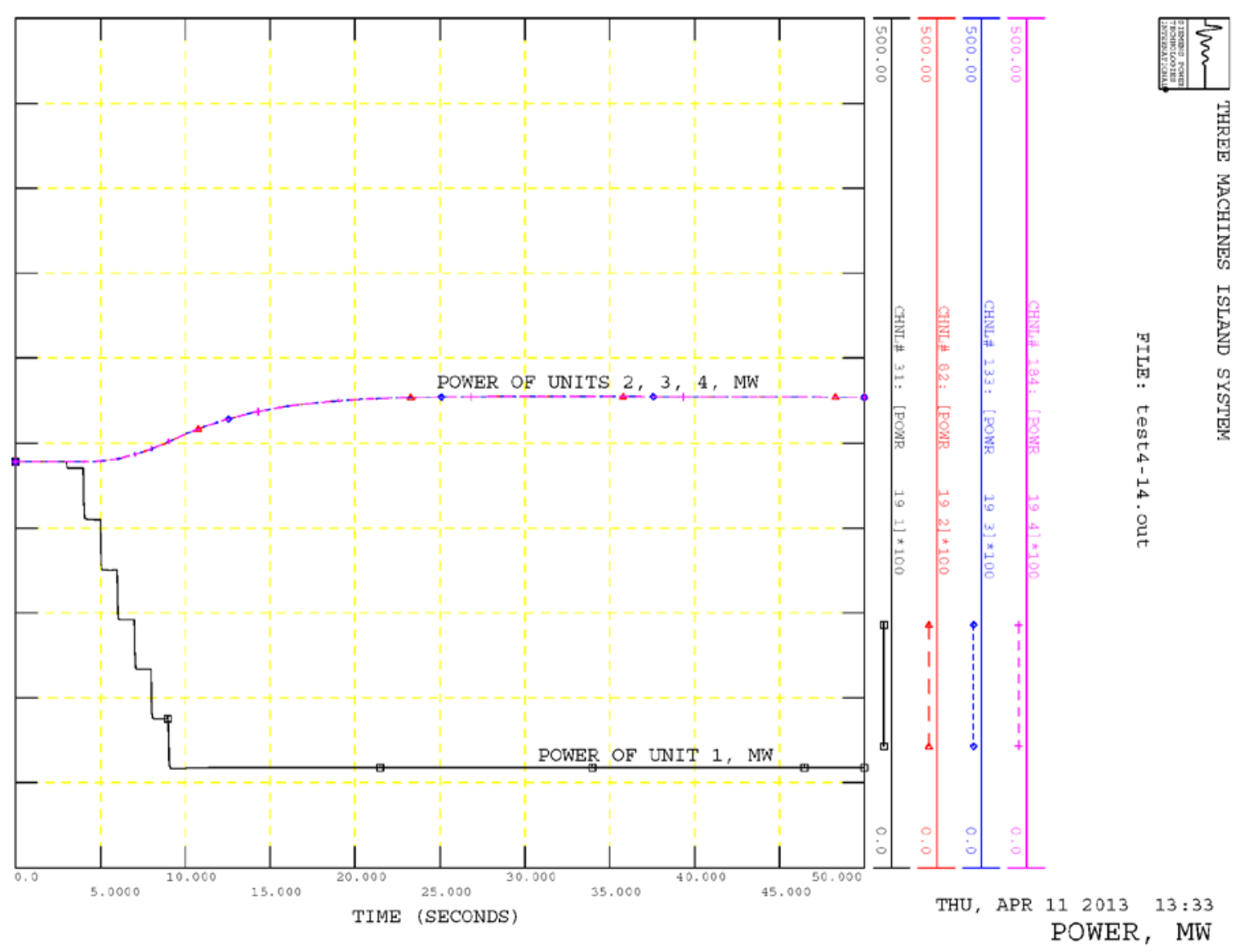

Figure 3-10 Response of the Power of Units 2, 3, and 4 to a Step Reduction in the Power of Unit 1 with Four Units Sharing a Common Penstock

A second series of tests was performed using another small sample test system to demonstrate the potential benefits of the faster frequency control capability of the AS PSH technology. Trip of the tie lines resulted in an area being deficient in power and thus experiencing a significant drop in frequency. With all conventional units, a frequency nadir of $58.26 \mathrm{~Hz}$ was reached at time equal to $4.6 \mathrm{sec}$. Frequency recovers and settles to $59.68 \mathrm{~Hz}$ in accordance with the permanent droop of the hydro governors. The local system would likely be equipped with underfrequency load shedding protection. An under-frequency load shedding model was added with three stages of protection: $59.3 \mathrm{~Hz}, 59.0 \mathrm{~Hz}$, and $58.7 \mathrm{~Hz}$. After the system frequency crosses any of these levels, $33.3 \%$ of the original load would be shed.

Plots in Figure 3-12 compare the response of system frequency for simulations of the loss of the tie lines without (black) and with load shedding (red). The blue trace shows the MW consumption of a large load in the system. Two stages of load shedding are clearly seen. As a result of load shedding, the nadir of the system frequency turned out to be $0.4 \mathrm{~Hz}$ greater than without load shedding. 


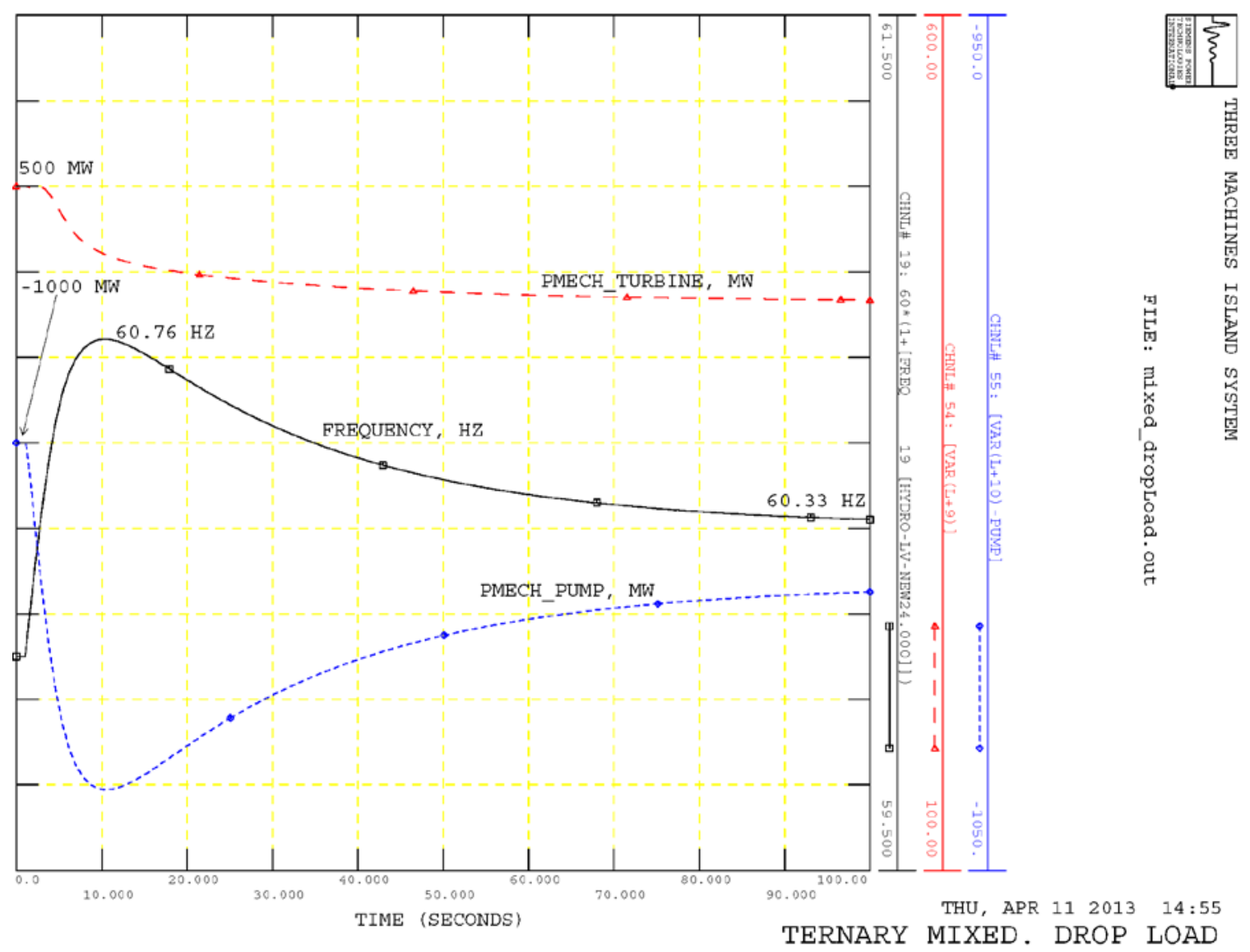

Figure 3-11 Response of Frequency and Mechanical Power of the Turbine and the Mechanical Power of the Pump of the Ternary Unit to the Trip of a Load

The set of models for the hydro unit was replaced by the new model of the AS PSH turbine. The data conversion from the conventional unit models to the AS PSH turbine model retained key parameters such as rotor inertia, water time constant, and permanent droop. The trip of the tie lines with the AS PSH turbine did not cause a drop in the system frequency below the first load shedding threshold of $59.3 \mathrm{~Hz}$. Figure 3-13 compares the response of system frequency for the conventional and AS PSH turbine, both with no load shedding protection. It should be noted that these simulations are not intended to represent any particular system or events, and the impact of a PSH unit would be less in a larger system where it is only one component of a much larger overall response. However, the simulation tests demonstrate the capabilities of the new PSH models and how these technologies could, in particular circumstances, make a significant impact on system performance following severe events.

The use of the models as part of a large U.S. system was demonstrated through tests performed using the WI power system that has about $190 \mathrm{GW}$ of generation capacity. Power system data for modeling of the WI were obtained from WECC. 


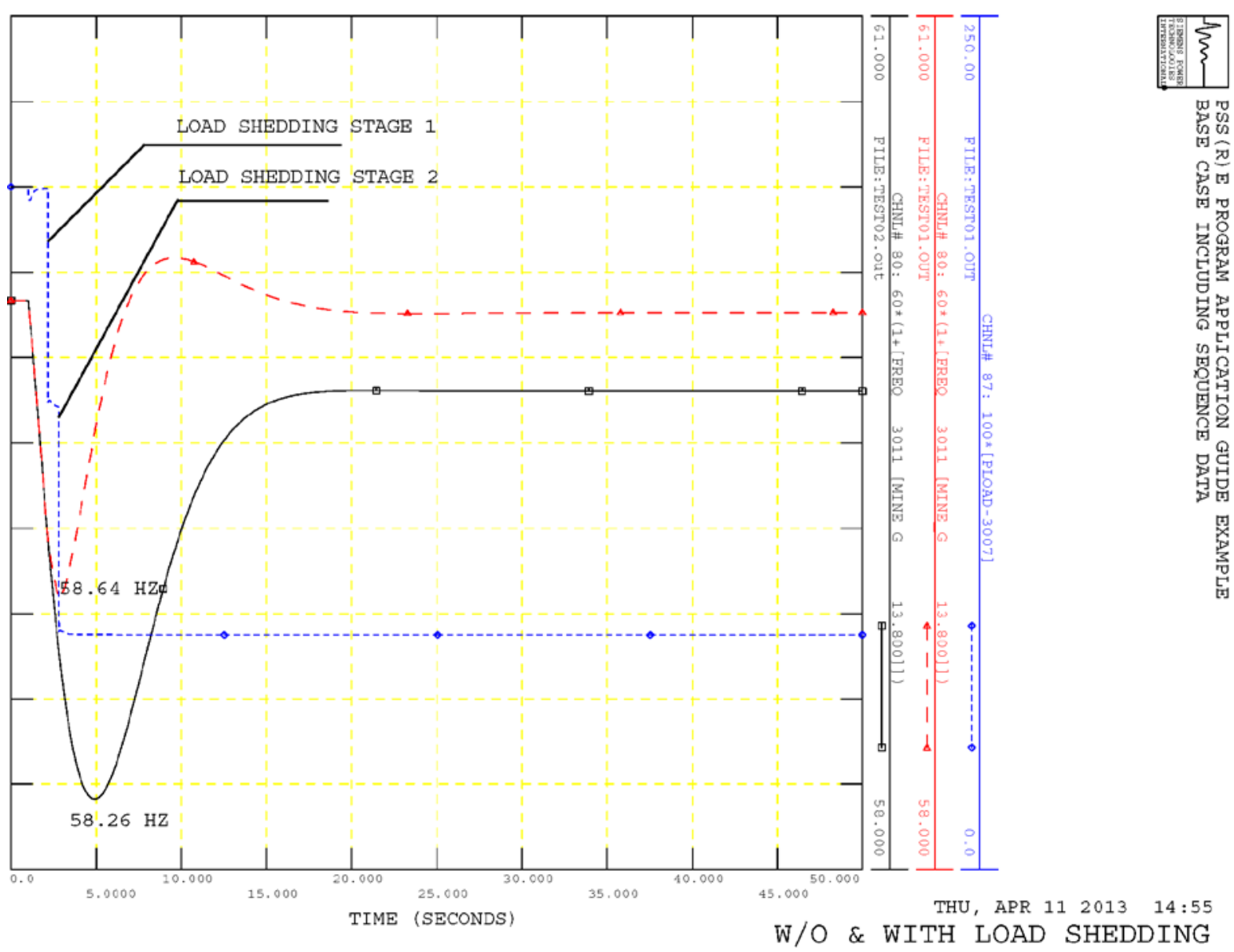

Figure 3-12 System Frequency with Conventional Units Following System Separation Showing the Impact of Under-Frequency Load Shedding

Six existing PSH plants, totaling about 3,200 MW of installed capacity, were simulated using the newly developed models as well as their original conventional PSH models. The dispatch of these units was modified from that in the original WECC case, as shown in Table 3-3, by putting all of the units at the plant on-line and at a uniform output. ${ }^{2}$

The response of these units (and of the system with these units) was simulated for a wide variety of typical disturbances, including the response to changes in the power generated by renewable energy sources. These tests ensured that the newly developed models could be used for practical analyses of real systems.

2 The six PSH plants were assumed to be fully dispatchable in both the turbine and the pumping mode in this analysis. However, some of the PSH units presently have operating restrictions, so this may not be representative of actual operation. Also, there are PSH units in the WI in addition to the six PSH plants chosen for this analysis. 


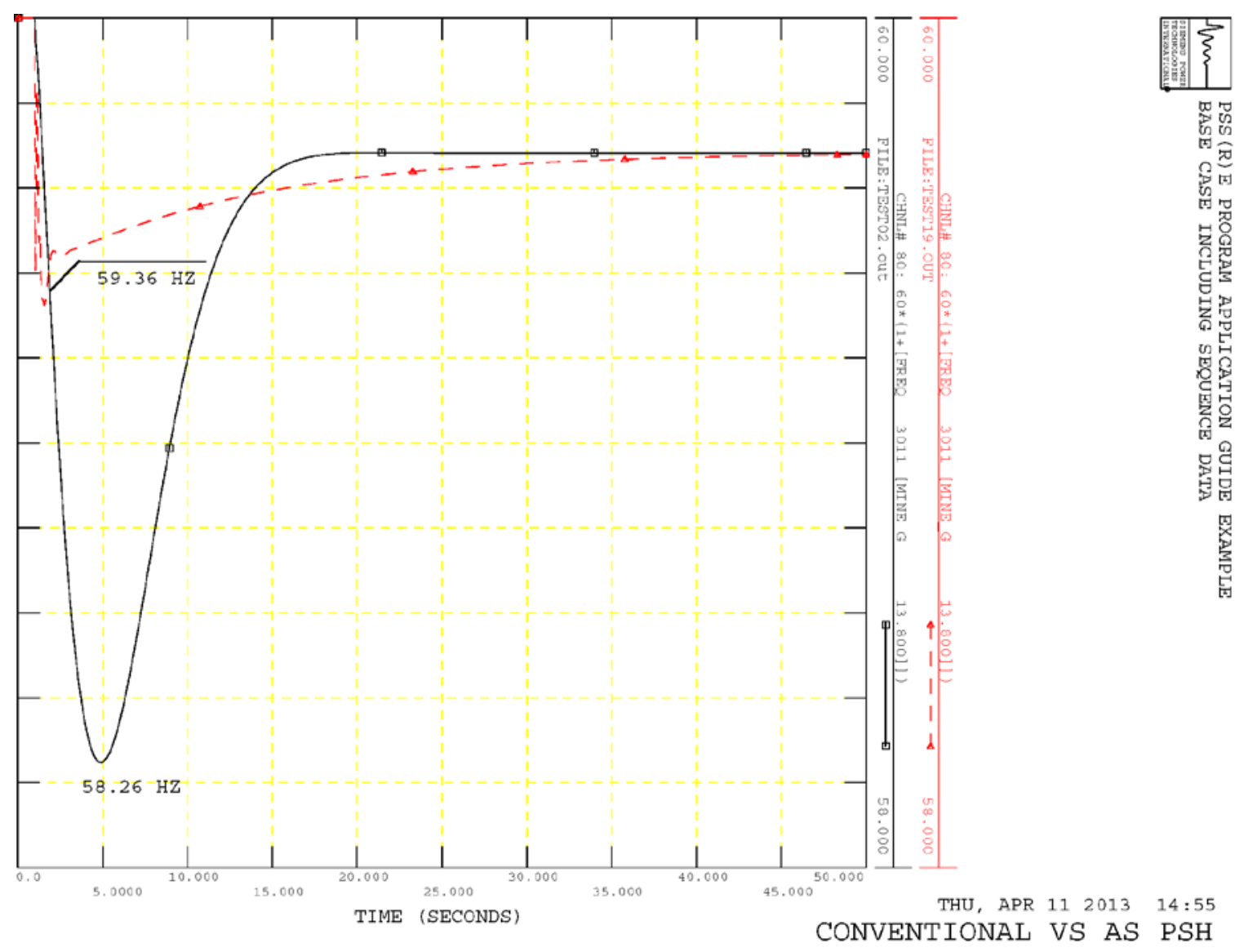

Figure 3-13 Comparison of System Frequency with Conventional Unit versus AS PSH following System Separation

Thus, the tests demonstrated that the new models performed well and can be used for the typical dynamic simulation analyses required by planning and interconnection studies. The tests also demonstrated the new capabilities available in these models (e.g., the use of an AS PSH plant to provide regulation services in pump mode). The tests showed the improved capabilities of the equipment, such as the faster response to system events.

These new models fill a major need in the transmission system interconnection activity with regard to system dynamic performance studies for new pumped storage plants with AS or ternary pumped storage units. These models will be very useful in studies investigating how these PSH technologies can be utilized to enable a larger share of wind and solar PV resources in the power system.

\section{Validation of New Dynamic Models}

To validate newly developed dynamic models of advanced PSH technologies, the test results were compared with the behavior of actual generating units in operation. Since currently there are no AS PSH plants operating in the United States, the comparison was made using the 
Table 3-3 Six Existing PSH Plants Selected for New Model Testing

\begin{tabular}{|c|l|c|c|c|c|}
\hline $\begin{array}{c}\text { Plant } \\
\text { Number }\end{array}$ & \multicolumn{1}{|c|}{ PSH Plant } & $\begin{array}{c}\text { Number } \\
\text { of Units }\end{array}$ & $\begin{array}{c}\text { Unit } \\
\text { MVA }\end{array}$ & $\begin{array}{c}\text { Original Plant } \\
\text { Dispatch } \\
\text { (MW) }\end{array}$ & $\begin{array}{c}\text { Plant } \\
\text { Re-dispatched } \\
\text { (MW) }\end{array}$ \\
\hline $\mathbf{1}$ & Castaic & 5 & 250 & $1 \times 232$ & $5 \times 212.5$ \\
\hline $\mathbf{2}$ & Helms & 3 & 390 & $2 \times 404$ & $3 \times 350$ \\
\hline $\mathbf{3}$ & Edward G. Hyatt & 3 & 123 & $5 \times 105$ & $6 \times 100$ \\
\hline $\mathbf{4}$ & Cabin Creek & 2 & 115 & & $2 \times 150$ \\
\hline $\mathbf{5}$ & San Luis & 8 & 53 & $8 \times 17$ & $8 \times 45$ \\
\hline $\mathbf{6}$ & Mount Elbert & 2 & 105 & $2 \times 90$ & $2 \times 90$ \\
\hline & Total & $\mathbf{2 6}$ & & $\mathbf{1 , 9 2 6}$ & $\mathbf{3 , 3 7 2 . 5}$ \\
\hline
\end{tabular}

publicly available data and information for the operation of these technologies in Japan (Kuwabara et al. 1994) and Europe (Simond et al. 2014). It was found that the results of dynamic simulation models closely match the actual behavior of AS PSH units in operation.

\subsection{Simulation of the Secondary Frequency Control Capability of the Advanced PSH Technology and Its Application to the SMUD System}

The SMUD, as a typical BA and a member of the project advisory group, was suggested by the Advanced Technology Modeling TFG as an appropriate example system to be used for testing of the models of the advanced PSH technology developed in the course of the DOE project and for demonstration of the potential benefits of this technology (Koritarov et al. 2013e).

On the basis of the 2017 Summer Peak Load WI case, an equivalent was created comprising the full model of SMUD connected to a single machine equivalent of the WI system, with all 230-kV tie lines to WI retained. All machines of the SMUD system were retained including the hydro units of the Upper American River hydro plants.

A dynamic simulation model of the automatic generation control (AGC) was added to this case, with the capability to control both the conventional generating units and also those employing the newly developed models of the advanced PSH units.

Taking into consideration the size of the WI, a significant frequency deviation does not occur as a result of a large load or generating unit in SMUD turning on or off. Thus from the two components of the AGC area control error (ACE), namely frequency and intertie power flow, the latter component can be considered as the major criterion of AGC performance quality.

A list of disturbances that was used to demonstrate AGC performance included: 
- Drop of generating units of different sizes in SMUD,

- Ramping down the generation in SMUD, and

- Ramping up the generation in SMUD.

The two latter disturbances can be construed as a change in renewable power (e.g., a drop or an increase in wind or solar generation power).

The following scenarios in terms of SMUD hydro units have been considered:

- All conventional hydro turbines (present condition),

- All conventional hydro turbines plus two conventional pumps,

- All conventional hydro turbines plus two AS pumps, and

- All conventional hydro turbines plus two ternary pumps in hydraulic short-circuit mode of operation.

The proposed Iowa Hill PSH plant was also added to the SMUD system. Its three AS PSH units were tested as pumps for two WI system conditions, namely the 2017 summer peak load case and 2022 light load case. Wind power ramping up from zero to $400 \mathrm{MW}$ over 50 sec (i.e., at $8 \mathrm{MW} / \mathrm{sec}$ ) was used as a disturbance.

As an example, Figure 3-14 compares the response of the Iowa Hill pump output and the total tie line flow for conventional and AS pumps modeled at Iowa Hill for the light load case. AGC action results in a reduction of the AS pump input power from -27 MW to $-52 \mathrm{MW}$. For this specific example, it did not noticeably affect the secondary control because the AGC control action was adequate even with conventional pumps at Iowa Hill. However for some applications, the AS PSH unit's capability to change the input power while pumping could be essential.

For all scenarios and disturbances, the newly developed models of AS PSH units and ternary units showed expected performance and allowed demonstration of the expected advantages of the advanced PSH technology, specifically the capability of AS pumps and ternary pumps to participate in the secondary frequency control. 


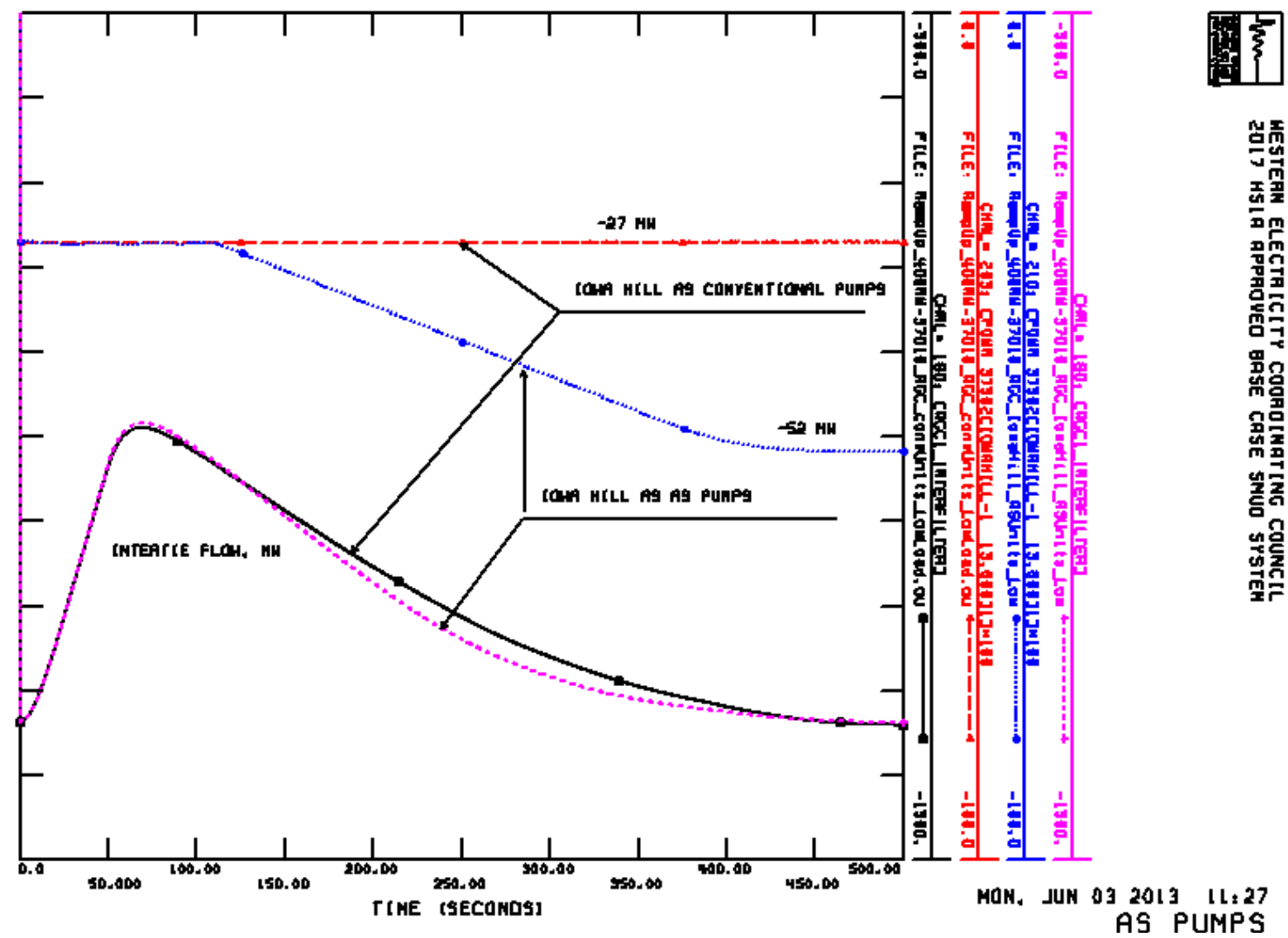

Figure 3-14 lowa Hill Pump Input Power (red and blue) and Total Tie Line Flow (black and pink) with Conventional (black and red) and AS (pink and blue) Pumps at lowa Hill in Response to Wind Power Ramping Up for 2022 Light Load System Conditions

\subsection{References}

Fisher, R.K., J. Koutnik, L. Meier, V. Loose, K. Engels, and T. Beyer, 2012, “A Comparison of Advanced Pumped Storage Equipment Drivers in the US and Europe,” HydroVision International.

Kopf, E., et al., 2004, “Optimized Control Strategies for Variable Speed Machines,” 22nd IAHR Symposium on Hydraulic Machinery and Systems, June.

Koritarov, V., L. Guzowski, J. Feltes, Y. Kazachkov, B. Lam, C. Grande-Moran, G. Thomann, L. Eng, B. Trouille, and P. Donalek, 2013a, Review of Existing Hydroelectric Turbine-Governor Simulation Models, Report, Argonne National Laboratory, ANL/DIS-13/05, Argonne, Ill., Aug.

Koritarov, V., L. Guzowski, J. Feltes, Y. Kazachkov, B. Gong, B. Trouille, and P. Donalek, 2013b, Modeling Adjustable Speed Pumped Storage Hydro Units Employing Doubly-Fed Induction Machines, ANL/DIS-13/06, Argonne National Laboratory, Argonne, Ill., Aug. 
Koritarov, V., L. Guzowski, J. Feltes, Y. Kazachkov, B. Gong, B. Trouille, P. Donalek, and V. Gevorgian, 2013c, Modeling Ternary Pumped Storage Units, ANL/DIS-13/07, Argonne National Laboratory, Argonne, Ill., Aug.

Koritarov, V., J. Feltes, Y. Kazachkov, B. Gong, P. Donalek, and V. Gevorgian, 2013d, Testing Dynamic Simulation Models for Different Types of Advanced Pumped Storage Hydro Units, ANL/DIS-13/08, Argonne National Laboratory, Argonne, Ill., Aug.

Koritarov, V., J. Feltes, and Y. Kazachkov, 2013e, Simulation of the Secondary Frequency Control Capability of the Advanced PSH Technology and Its Application to the SMUD System, ANL/DIS-13/10, Argonne National Laboratory, Argonne, Ill., Nov.

Kuwabara, T., A. Shibuya, and H. Furuta, 1996, "Design and Dynamic Response Characteristics of 400 MW Adjustable Speed Pumped Storage Unit for Okawachi Power Station,” pp. 376-384 in IEEE Transactions on Energy Conversion, Vol. 11, No. 2, June.

Nagura, O., and M. Yoshida, 2011, “Transient Behavior Analysis of Adjustable Speed Pumped Storage System,” presented at Hydro Vision International 2011, Session No. 414, Sacramento, Calif., July 20.

Pannatier, Y., et al., 2008, “Transient Behavior of Variable Speed Pumped-Turbine Units,” International Association for Hydro-Environment Engineering (IAHR), 24th Symposium on Hydraulic Machines and Systems, Oct.

Simond, J.-J., A.A. Sapin, and D. Shafer, 2014, Expected Benefits of Adjustable Speed Pumped Storage in the European Network.” Available at http://infoscience.epfl.ch/record/134070/files/ eboaspsiten.pdf. Accessed May 2014.

Spitzer, F., and G. Penninger, 2008, "Pumped Storage Power Plants-Different Solutions for Improved Ancillary Services through Rapid Response to Power Needs,” Hydro Vision 2008 Session 4H2, Sacramento, Calif., July 17. 
This page intentionally left blank. 


\section{Section}

4

\section{Production Cost and Revenue Simulations Using the PLEXOS Model}

Energy Exemplar was engaged in this project to perform the simulations of power system operation and evaluate the FS and AS pumped storage plants in the areas of:

1. Quantifying the value of the FS and AS PSH under different market conditions and for different levels of variable renewable generation (wind and solar) in the system; and

2. Providing information about the full range of benefits and value of $\mathrm{PSH}$ and $\mathrm{CH}$ plants and recommendations for appropriate business models for future PSH projects.

This section of the report describes the database used for the simulation of power system operation, the approach used for modeling of the power system, the simulation results for different renewable energy generation scenarios, and key findings of the analysis. Section 4.1 describes the database used for the simulations and key modeling assumptions; Section 4.2 presents PLEXOS modeling approaches; Section 4.3 presents the DA simulation results; and Section 4.4 presents the three-stage Day Ahead-Hour Ahead-Real Time (DA-HA-RT) sequential simulation results for four typical weeks in a year.

Additional details of the analysis presented in this section, are provided in the report Adjustable Speed Pumped-Storage Hydro-Generator (PSH) Evaluation by PLEXOS (Guo et al. 2013).

\subsection{WI Database and Modeling Assumptions}

\subsubsection{Introduction of WI Database}

The simulations in this study focused on the WI. The WECC's TEPPC 2022 Common Case database (WECC TEPPC 2012a, 2012b) was translated into PLEXOS to develop a modeling representation of the WI for a future year. The WECC TEPPC 2022 Common Case database covers power systems in 38 BAs (identified in Figure 4-1) in the western United States, the Canadian provinces of British Columbia and Alberta, and an area in northern Mexico serviced by the CFE.

The BA areas in the WI operate independently in terms of unit commitment to meet their own demand while performing economic exchanges with each other. 


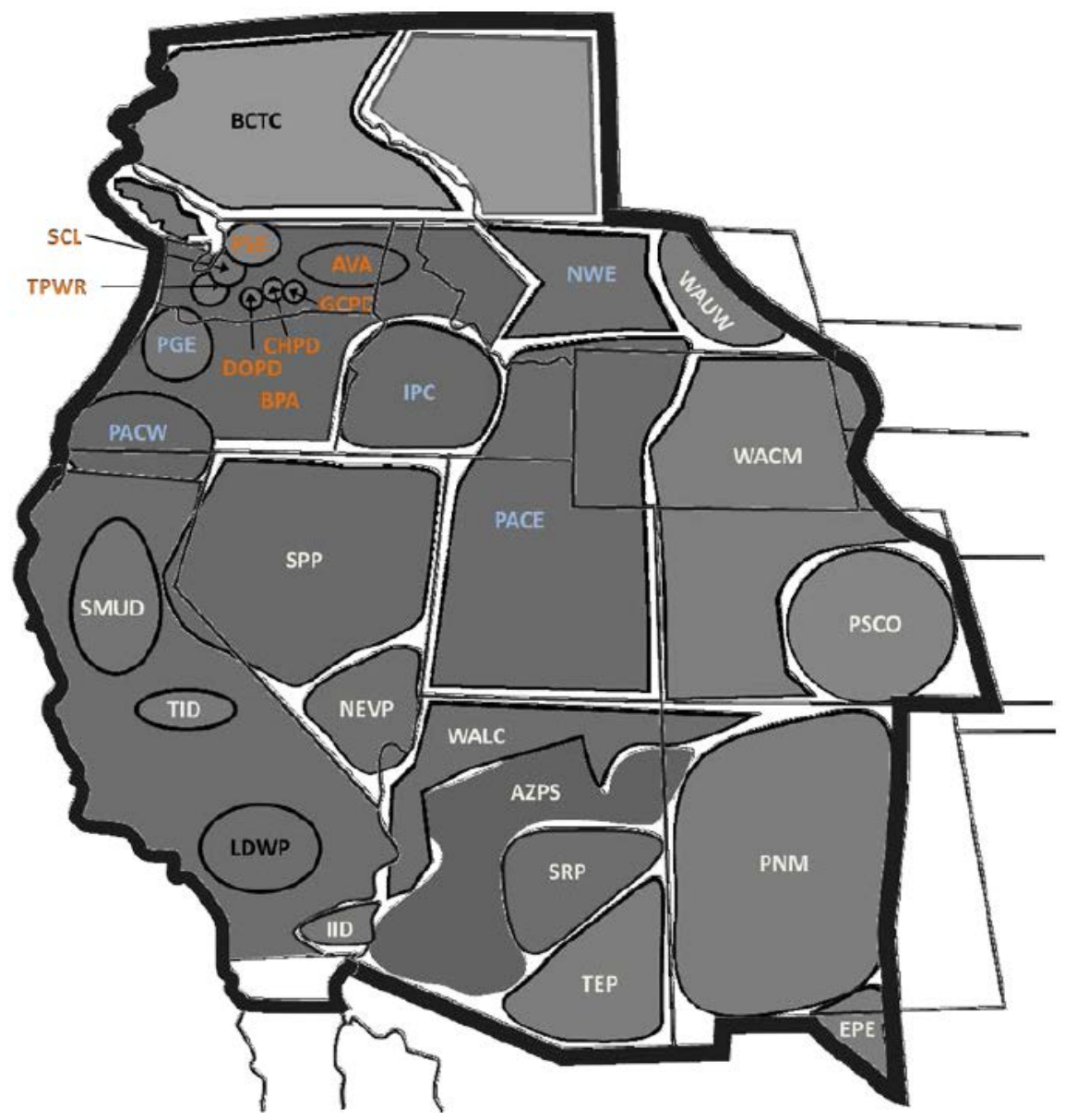

Figure 4-1 WI Balancing Authorities (Source: King et al. 2012)

Assumptions for the PLEXOS model simulations included the following:

The WI network consists of:

- More than 17,000 buses,

- More than 22,000 transmission lines (1,045 lines are enforced), and

- 91 interfaces (enforced) and 33 nomograms (enforced).

The generation facilities include:

- More than 3,700 generators (including renewables),

- 8 existing PSH plants (20 units), and

- 3 new PSH plants (11 units). 
The projected price of natural gas in 2022 is \$4.6/MMBtu.

The forecasted energy demand (includes transmission losses), and peak loads for the WI in 2022 are:

- $\quad$ Energy demand for the WI $=985,457$ GWh; energy demand for the U.S. part of the WI is 786,275 GWh;

- $\quad$ Coincident peak for the WI = 168,972 MW; coincident peak for the U.S. part of the WI is $146,718 \mathrm{MW}$.

Two renewable energy penetration scenarios were used in the analysis:

- Base Renewable Generation Scenario: Corresponding to mandated RPS levels of renewable energy generation, amounting to about 14\% (108,993 GWh) of total generation within the U.S. part of the WI in 2022; and

- High Wind Renewable Generation Scenario: Corresponding to the High Wind scenario from the WWSIS-2, amounting to about 34\% renewable energy generation (273,842 GWh) within the U.S. part of the WI in 2022.

Table 4-1 lists the wind and solar energy generation assumptions by BA for the Base and High Wind renewable generation scenarios.

\subsubsection{Contingency, Flexibility, and Regulation Reserve Requirements}

The requirements of contingency reserves (i.e., spinning and non-spinning reserves) were defined for eight spinning reserve sharing groups. The spinning reserve requirement in a contingency reserve sharing group was specified as $3 \%$ of the load in the group. The spinning reserve is provided by the eligible on-line generators in the group.

The non-spinning reserve requirement in a contingency reserve sharing group was specified as $3 \%$ of the load in the group. The non-spinning reserve is provided by the eligible on-line generators and the off-line quick startup generators in the group.

The flexibility and regulation reserve requirements were defined for 20 flexibility/regulation reserve sharing groups. The hourly flexibility and regulation reserve requirements for the DA, 4-HA simulations and 5-min regulation reserve requirements in 2020 for the Base and High Wind renewable scenarios were provided by NREL from the NREL WWSIS-2 study (Lew et al. 2013). These reserve requirements for 2020 were then translated to 2022, with the weekly patterns synchronized in these two years. 
Table 4-1 Renewable Generation Assumptions by BA in the WI and the U.S. Part of the WI in 2022

\begin{tabular}{|c|c|c|c|c|c|}
\hline \multirow[b]{2}{*}{ BA } & \multirow[b]{2}{*}{$\begin{array}{c}\text { Sum of Net } \\
\text { Load } \\
\text { (GWh) }\end{array}$} & \multicolumn{2}{|c|}{$\begin{array}{c}\text { High Wind } \\
\text { Renewable Scenario }\end{array}$} & \multicolumn{2}{|c|}{$\begin{array}{c}\text { Base } \\
\text { Renewable Scenario }\end{array}$} \\
\hline & & $\begin{array}{c}\text { Wind and } \\
\text { Solar Energy } \\
\text { (GWh) }\end{array}$ & $\begin{array}{c}\text { Ratio of } \\
\text { Renewable } \\
\text { Energy and Load } \\
\text { (\%) }\end{array}$ & $\begin{array}{c}\text { Wind and } \\
\text { Solar Energy } \\
\text { (GWh) }\end{array}$ & $\begin{array}{c}\text { Ratio of } \\
\text { Renewable } \\
\text { Energy and Load } \\
\text { (\%) }\end{array}$ \\
\hline AESO & 114,066 & 0 & 0.0 & 0 & 0.0 \\
\hline APS & 43,062 & 11,582 & 26.9 & 5,355 & 12.4 \\
\hline AVA & 14,237 & 6,007 & 42.2 & 5,566 & 39.1 \\
\hline BANC & 16,442 & 6,512 & 39.6 & 536 & 3.3 \\
\hline BCTC & 66,095 & 0 & 0.0 & 0 & 0.0 \\
\hline BPA & 60,804 & 18,153 & 29.9 & 9,848 & 16.2 \\
\hline CAISO & 222,675 & 45,771 & 20.6 & 30,482 & 13.7 \\
\hline CFE & 19,021 & 709 & 3.7 & 686 & 3.6 \\
\hline CHPD & 4,077 & 0 & 0.0 & 0 & 0.0 \\
\hline DOPD & 2,047 & 0 & 0.0 & 0 & 0.0 \\
\hline EPE & 11,161 & 583 & 5.2 & 150 & 1.3 \\
\hline GCPD & 4,924 & 1,035 & 21.0 & 0 & 0.0 \\
\hline IID & 4,541 & 4,835 & 106.5 & 3,772 & 83.1 \\
\hline IPC & 21,031 & 2,528 & 12.0 & 1,160 & 5.5 \\
\hline LDWP & 37,118 & 6,629 & 17.9 & 5,461 & 14.7 \\
\hline NEVP & 28,523 & 7,118 & 25.0 & 1,903 & 6.7 \\
\hline NWMT & 11,175 & 19,994 & 178.9 & 2,338 & 20.9 \\
\hline PACE & 56,175 & 24,830 & 44.2 & 6,288 & 11.2 \\
\hline PACW & 21,128 & 9,607 & 45.5 & 8,643 & 40.9 \\
\hline PGN & 23,163 & 55 & 0.2 & 0 & 0.0 \\
\hline PNM & 16,695 & 18,066 & 108.2 & 2,149 & 12.9 \\
\hline PSC & 39,347 & 11,330 & 28.8 & 6,036 & 15.3 \\
\hline PSE & 26,308 & 2,813 & 10.7 & 704 & 2.7 \\
\hline SCL & 10,926 & 118 & 1.1 & 0 & 0.0 \\
\hline SPP & 12,927 & 8,575 & 66.3 & 921 & 7.1 \\
\hline SRP & 34,546 & 7,795 & 22.6 & 2,413 & 7.0 \\
\hline TEP & 15,087 & 3,244 & 21.5 & 696 & 4.6 \\
\hline TIDC & 2,718 & 14 & 0.5 & 0 & 0.0 \\
\hline TPWR & 5,605 & 28 & 0.5 & 0 & 0.0 \\
\hline WACM & 31,332 & 45,541 & 145.3 & 8,321 & 26.6 \\
\hline WALC & 7,664 & 9,696 & 126.5 & 5,890 & 76.9 \\
\hline WAUW & 837 & 1,386 & 165.6 & 361 & 43.1 \\
\hline WI & 985,457 & 274,551 & 27.9 & 109,679 & 11.1 \\
\hline WI-USA & 786,275 & 273,842 & 34.8 & 108,993 & 13.9 \\
\hline
\end{tabular}




\subsubsection{Modeling Representation of PSH Plants}

Eight existing FS PSH plants were simulated in the PLEXOS modeling of WI. The existing PSH plants have the ability to pump only at the full pumping capacity and, therefore, cannot provide regulation reserve in the pumping mode of operation. For the generating mode of operation, the minimum generating capacity of existing FS PSH plants was specified as $70 \%$ of their maximum generating capacity. Therefore, in the generating mode, the existing FS PSHs can provide operating reserves in the dispatchable generating capacity range of $30 \%$ of their maximum generating capacity.

Three AS PSH plants proposed to be built within the WI were modeled in this project. Table 4-2 provides key technical characteristics of these proposed PSH plants as they were specified in PLEXOS simulation runs. Because these PSH projects are still in the planning stage, their final technical characteristics may be different.

Table 4-2 Characteristics of Three Proposed AS PSH Plants

\begin{tabular}{|l|c|c|c|}
\hline \multicolumn{1}{|c|}{ Properties } & lowa Hill & Eagle Mountain & Swan Lake North \\
\hline Units & 3 & 4 & 4 \\
\hline Max cap per unit (MW) & 133 & 350 & 345 \\
\hline Min cap per unit (MW) & 39.9 & 105 & 103.5 \\
\hline Max pump load (MW) & 133 & 350 & 345 \\
\hline Min pump load (MW) & 79.8 & 210 & 207 \\
\hline Upper storage (GWh) & 5 & 25.5 & 10 \\
\hline Lower storage (GWh) & 5 & 25.5 & 10 \\
\hline Cycle efficiency (\%) & 80.472 & 80.472 & 80.472 \\
\hline Connected bus & $\begin{array}{c}\text { 37001_CAMINO S } \\
(230 \mathrm{KV})\end{array}$ & $\begin{array}{c}28195 \_R e d ~ B l u f f \\
\text { (500 KV) }\end{array}$ & $\begin{array}{c}\text { 45035_CAPTJACK } \\
\text { (500 KV) }\end{array}$ \\
\hline
\end{tabular}

The AS PSHs have the minimum pumping capacity at $70 \%$ of the maximum pumping capacity. Therefore, in the pumping mode of operation, the AS PSHs can provide operating reserves in the dispatchable pumping capacity range of $30 \%$ of the maximum pumping capacity. In the generating mode of operation, the AS PSHs have the minimum generating capacity at $30 \%$ of the maximum generating capacity. Therefore, the AS PSHs can provide operating reserves in the dispatchable generating capacity range of $70 \%$ of the maximum generating capacity.

Table 4-3 summarizes the locations and installed capacity of the existing FS PSH plants and proposed AS PSH plants. 
Table 4-3 Locations and Installed Capacity of Existing FS PHS Plants and Proposed AS PSH Plants in the WI

\begin{tabular}{|l|l|l|l|c|c|c|}
\hline \multicolumn{1}{|c|}{ PSH Plant } & $\begin{array}{c}\text { Location } \\
\text { Region }\end{array}$ & $\begin{array}{c}\text { Spinning } \\
\text { Reserve } \\
\text { Sharing Group }\end{array}$ & $\begin{array}{c}\text { Regulation } \\
\text { Reserve } \\
\text { Sharing Group }\end{array}$ & $\begin{array}{c}\text { Number } \\
\text { of Units }\end{array}$ & $\begin{array}{c}\text { Total } \\
\text { Capacity } \\
\text { (MW) }\end{array}$ & $\begin{array}{c}\text { Generator } \\
\text { Type }\end{array}$ \\
\hline Cabin Creek & PSC & RMPP & Colorado & 2 & 324 & FS \\
\hline Castaic & LDWP & CALIF_SOUTH & LDWP & 6 & 1,175 & FS \\
\hline Eastwood & SCE & CALIF_SOUTH & SCE & 1 & 199 & FS \\
\hline Elbert & WACM & RMPP & Colorado & 2 & 200 & FS \\
\hline Helms & PG\&E_VLY & CALIF_NORTH & PG\&E Valley & 3 & 1,212 & FS \\
\hline Horse Mesa & SRP & AZNMNV & Arizona & 3 & 96 & FS \\
\hline Lake Hodge & SDGE & CALIF_SOUTH & SDGE & 2 & 40 & FS \\
\hline Mormon Flat & SRP & AZNMNV & Arizona & 1 & 50 & FS \\
\hline Eagle Mt. & SCE & CALIF_SOUTH & SCE & 4 & 1,400 & AS \\
\hline lowa Hill & SMUD & CALIF_NORTH & SMUD & 3 & 399 & AS \\
\hline Swan Lake & BPA & NWPP & NWPP & 4 & 1,380 & AS \\
\hline Total & & & & 31 & 6,475 & \\
\hline
\end{tabular}

\subsubsection{TEPPC Data Modifications}

The WI database for 2022 was created by applying the relevant information from the WECC TEPPC 2022 Common Case database into PLEXOS. Per stakeholder meetings, a few data modifications were performed to ensure that the assumptions in the database are close to real world operation. The list of all data modifications is provided in Guo et al. (2013)

In addition, in PLEXOS simulations the incremental heat rate curves were used rather than a single average heat rate value for the coal, combined cycle (CC), and combustion turbine (CT) generators. For these generating units, the heat rates were defined at 50\%, 80\%, and 100\%, respectively, of their maximum operating capacities. In PLEXOS simulations, the heat rates were then linearly interpolated among those load points. The typical average heat rate curves for different thermal technologies were derived from the Continuous Emission Monitoring System (CEMS) and were the same as those used in the WWSIS-2 study (Lew et al. 2013).

The typical heat rate curves are shown in Figure 4-2. These generator heat rate curves were scaled for individual generating units using their average heat rates at maximum generating capacity from the WECC TEPPC 2022 database.

The maintenance outages of thermal generating units were scheduled using the PLEXOS Projected Assessment of Supply Adequacy (PASA) module. The approach applies user-defined maintenance rates and durations to maximize regional capacity reserve margins on a daily basis and for all of 2022. The forced outages of generating units were modeled using random draws on the user-defined annual forced outage rates and durations. 


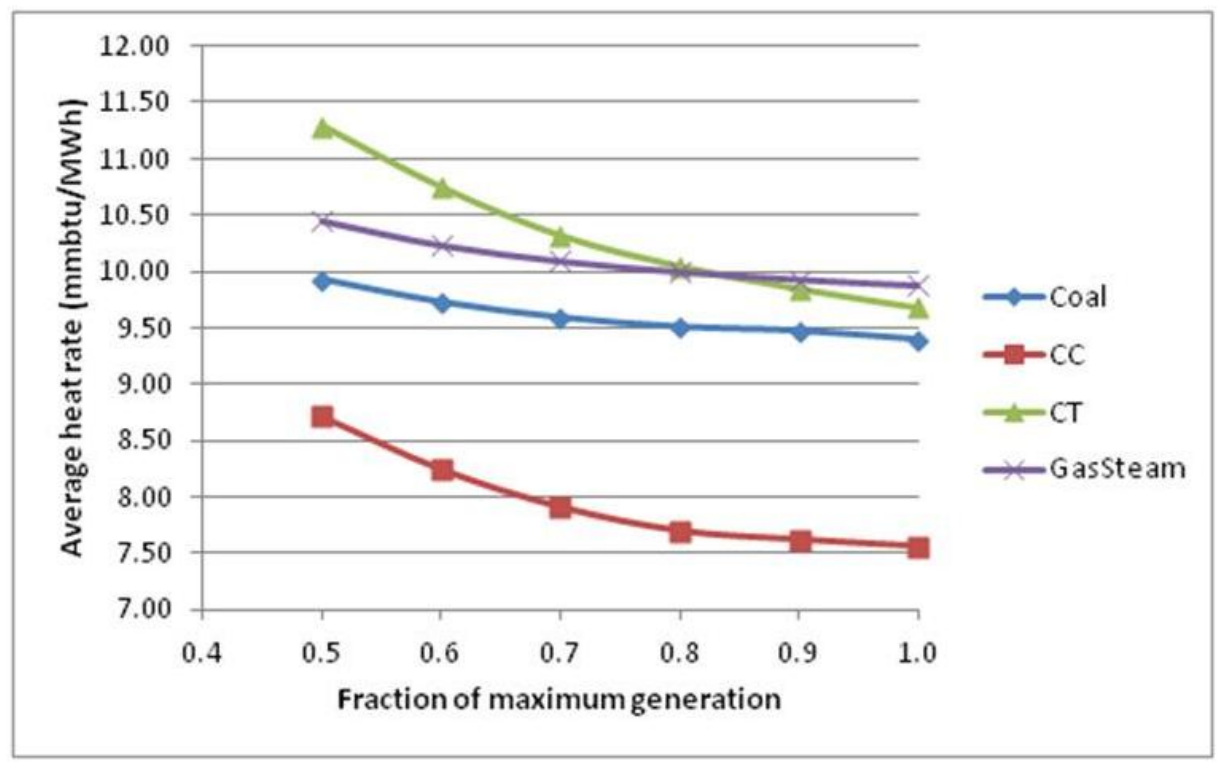

Figure 4-2 Average Heat Rates for Coal, CC, CT, and Gas Steam Generators (Source: Lew et al. 2013)

\subsection{PLEXOS Modeling Approach}

\subsubsection{PLEXOS SCUC/ED Algorithm}

PLEXOS' Security Constrained Unit Commitment (SCUC) algorithm consists of two major logics: (1) Unit Commitment using Mixed Integer Programming (MIP), and (2) Network Applications. The SCUC/economic dispatch (ED) simulation algorithm is illustrated in Figure 4-3.

The Unit Commitment and Economic Dispatch (UC/ED) logic performs co-optimization of energy and A/S using MIP, while enforcing all resource and operational constraints. The UC/ED logic commits and dispatches resources to balance the system energy demand and meet the system reserve requirements.

The resource schedules from the UC/ED logic are passed to the Network Applications logic in $24 \mathrm{~h}$ for DA and HA simulations or in 5 min for real-time (RT) simulations. The Network Applications logic solves the direct current optimal power flow (DC-OPF) to enforce the power flow limits and nomograms. The Network Applications logic also performs the contingency analysis if the contingencies are defined. For example, any transmission line limit violations are passed to the UC/ED logic for the re-run of UC/ED. The iteration continues until all transmission limit violations are resolved. Thus the co-optimization solution of Energy-A/S DC-OPF is achieved. 


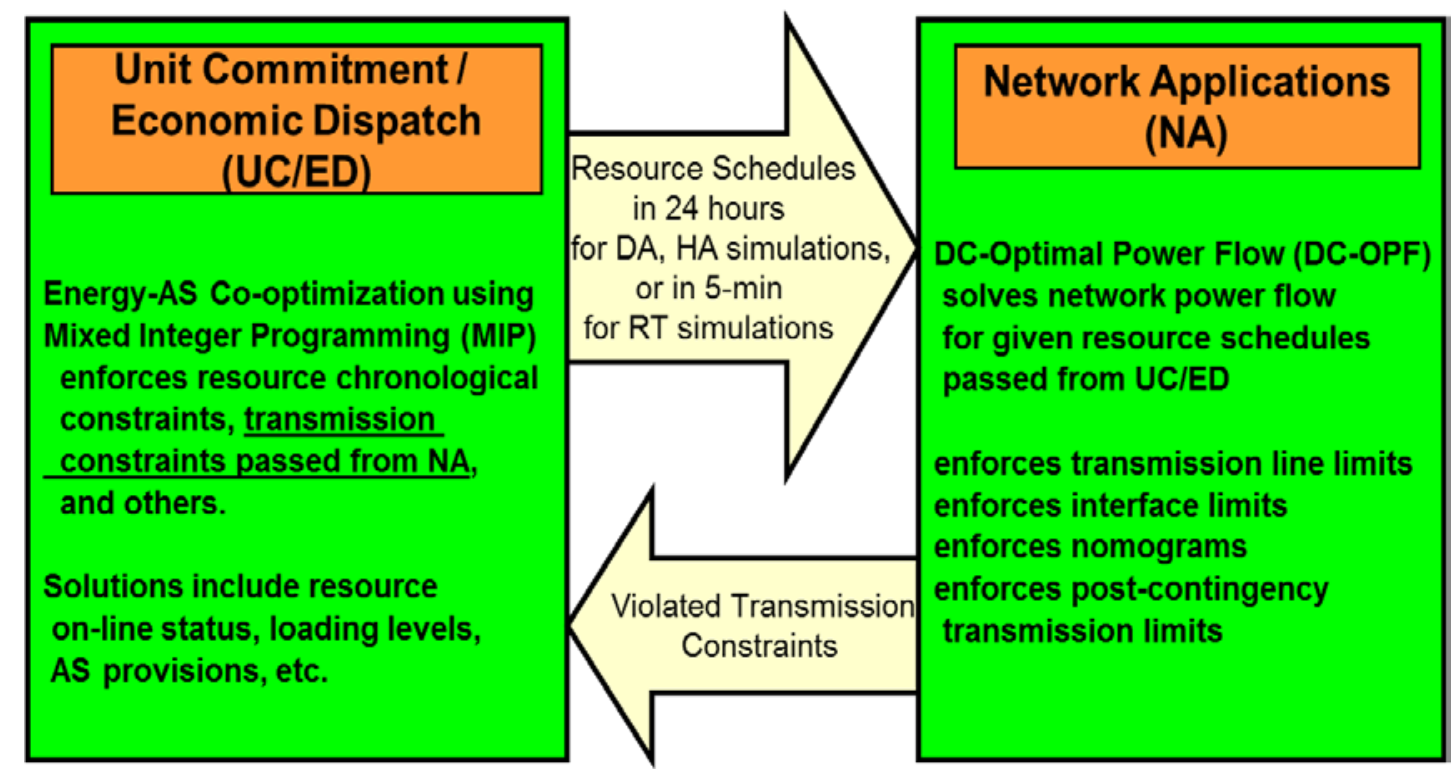

Figure 4-3 PLEXOS Security-Constrained Unit Commitment and Economic Dispatch Algorithm

The same SCUC/ED algorithm is used by many independent system operator (ISO) market scheduling software (some ISO market scheduling software may use alternating current optimal power flow, or alternating current (AC)-OPF, in the Network Applications).

One of the advantages of the MIP algorithm is its transparency. Any cost component or constraint in the MIP formula can be examined and explained. Guo et al. (2013) include an illustration of the MIP formulation of the SCUC/ED algorithm.

The pumping and generation of PSH plants are included in the system energy balance constraints and ancillary reserve provision constraints. By so doing, the PSH operation is co-optimized with other variables such as energy, A/S, and power flow.

\subsubsection{Three-Stage DA-HA-RT Sequential Simulations}

PLEXOS is capable of simulating power markets at a sub-hourly interval. This feature is very useful when evaluating the adequacy of system ramping capabilities to compensate for renewable generation variability and uncertainty. Usually, the sub-hourly economic dispatch capability works in conjunction with the DA and HA unit commitment to mimic real world market operation. The three-stage DA-HA-RT sequential simulation approach is illustrated in Figure 4-4 and described below. 


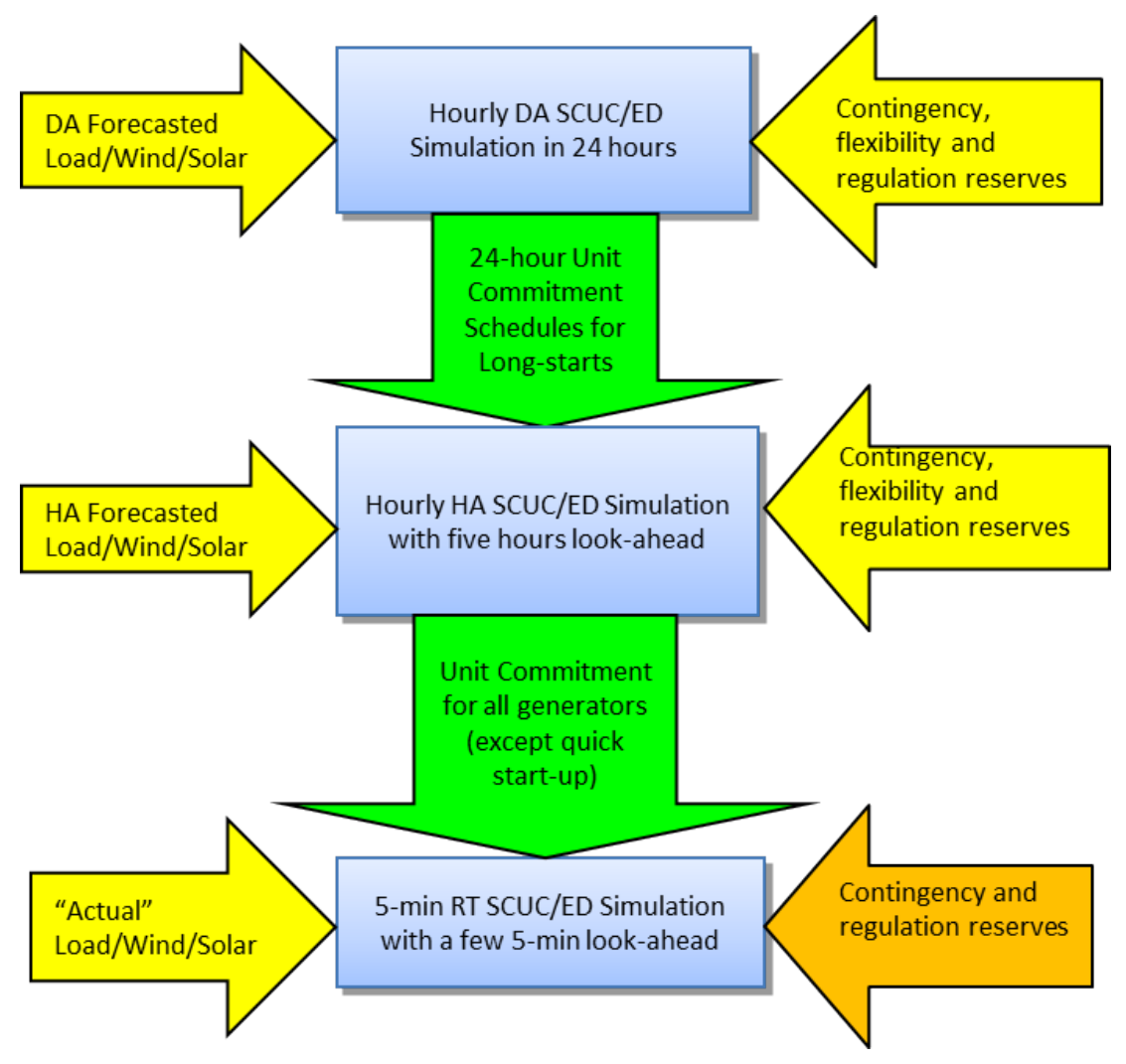

Figure 4-4 DA-HA-RT Three-Stage Sequential Simulations

- In the first stage, the DA simulation mimics the DA SCUC/ED and includes the following:

- DA forecasted load/wind/solar generation time series are used.

- $\quad$ The SCUC/ED optimization window is $24 \mathrm{~h}$ at an hourly interval.

- $\quad$ The transmission network is modeled at the nodal level.

- $\quad$ The contingency, flexibility up/down, and regulation up/down reserves are modeled.

- In the second stage, HA simulation mimics the intra-day SCUC/Security-Constrained Economic Dispatch (SCED) and includes the following:

- $\quad$ The 4-h-ahead forecasted wind/solar generation time series are used.

- $\quad$ The HA forecasted load time series are used.

- $\quad$ The SCUC/ED optimization window is 4-h plus 20-h look-ahead with a 2-h interval. 
- $\quad$ The UC patterns from the DA simulation are frozen for generators with Min Up/Down Time greater than $4 \mathrm{~h}$.

- The transmission network is modeled at the nodal level.

- The contingency, flexibility up/down, and regulation up/down reserves are modeled.

- In the third stage, RT simulation mimics the 5-min RT SCED and includes the following:

- The “Actual” 5-min load/wind/solar generation time series are used.

- $\quad$ The SCED optimization window is twelve 5-min plus 23-h look-ahead with an hourly interval.

- $\quad$ The UC patterns from the HA simulation are frozen.

- $\quad$ The transmission network is modeled at the nodal level.

- The contingency and regulation up/down reserves are modeled. However, the flexibility up/down reserves are not modeled. The implication is that the capacity held in the HA simulation for the flexibility reserves is deployed to cover the load and renewable generation variability and uncertainty at the 5-min interval.

- CT with max capacity less than $100 \mathrm{MW}$ could be committed or de-committed in the 5-min RT simulation.

\section{PSH Storage Modeling in Three-Stage Sequential Simulations}

In the DA simulation, the SCUC/ED is performed in a 24-h window. The PSHs are dispatched by PLEXOS SCUC/ED according to the formulation in Section 4.2.1, PLEXOS SCUC/ED Algorithm. The storage volume of PSH plants at the end of the 24-h optimization window is constrained to the storage volume at the beginning of the optimization window.

In the HA simulation, the SCUC/ED is performed in a 4-h plus 20-h look-ahead window. The simulation solution in the first $4 \mathrm{~h}$ is saved; then the SCUC/ED is performed for the next 4-h in a 4-h plus 20-h look-ahead window, and so on. The PSHs are re-dispatched in the HA simulation according to the formulation in Section 4.2.1, PLEXOS SCUC/ED Algorithm. The storage volume of a PSH at the end of the optimization window is constrained to the storage volume from the DA simulation.

In the 5-min RT simulation, the SCUC/ED is performed in twelve 5-min periods plus a 23-h look-ahead window. The simulation solution in the first twelve 5-min is saved; then the SCUC/ED is performed for the next twelve 5-min periods in a twelve 5-min plus 23-h lookahead window, and so on. The PSHs are re-dispatched in the RT simulation according to the formulation in Section 4.2.1, PLEXOS SCUC/ED Algorithm. The storage volume of a PSH at the end of the optimization window is constrained to the storage volume from the HA simulation. 


\subsubsection{Scope of PLEXOS Simulations}

PLEXOS simulations were performed for the Base and High Wind renewable generation scenarios with and without FS and AS PSH plants modeled in the system. Table 4-4 lists the simulation scenario combinations.

Table 4-4 Simulation Scenario Combinations

\begin{tabular}{|l|c|c|c|}
\hline \multicolumn{1}{|c|}{ Case } & $\begin{array}{c}\text { Renewable Energy } \\
\text { Scenario }\end{array}$ & $\begin{array}{c}\text { FS PSHs } \\
\text { Modeled }\end{array}$ & $\begin{array}{c}\text { AS PSHs } \\
\text { Modeled }\end{array}$ \\
\hline Base 1 & Base & No & No \\
\hline Base 2 & Base & Yes & No \\
\hline Base 3 & Base & Yes & Yes \\
\hline High Wind 1 & High Wind & No & No \\
\hline High Wind 2 & High Wind & Yes & No \\
\hline High Wind 3 & High Wind & Yes & Yes \\
\hline
\end{tabular}

The DA simulations were performed on an hourly basis for all of 2022 for all cases. However, the three-stage simulations with a 5-min simulation time step were performed in each case for four typical weeks in the year: the third week in January, April, July, and October in 2022.

This study focused on three areas: WI, California, and SMUD. In the WECC TEPPC database, the load region SMUD represents the Balancing Authority of Northern California (BANC), which includes:

- Sacramento Municipal Utility District (SMUD),

- Modesto Irrigation District (MID),

- Roseville Electric, and

- Redding Electric Utility.

For consistency, SMUD is used in the remainder of Section 4 when referring to the BANC.

The simulation footprints for California and SMUD were developed by extracting them from the WI simulation footprint. As for the WI, the simulations of Base and High Wind cases were also performed for California and SMUD footprints. Both cost-based and market-based approaches were used in the analysis. While the cost-based approach was applied for the simulation of the entire WI and for the SMUD footprint, a market-based approach (as a bid-based electricity market) was applied for the simulation of the California footprint. The system information and modeling representations of the WI, California, and SMUD footprints are provided in Table 4-5. 
Table 4-5 Three Focus Simulation Areas: WI, California, and SMUD, and the Simulation Settings

\begin{tabular}{|c|c|c|c|}
\hline & $\begin{array}{c}\text { Western } \\
\text { Interconnection }\end{array}$ & California & SMUD \\
\hline Load regions & 39 & 9 & 1 \\
\hline Buses & more than 17,000 & more than 4,000 & more than 250 \\
\hline Transmission lines & more than 22,000 & more than 5,952 & more than 300 \\
\hline Interfaces & 91 & 31 & 0 \\
\hline Generator & more than 3,700 & more than 700 & more than 60 \\
\hline Existing FS PSHs & 8 & 4 & 0 \\
\hline New AS PSHs & 3 & 2 & 1 \\
\hline Network representation & Nodal & Nodal & Zonal \\
\hline DA simulation step & \multicolumn{3}{|c|}{ 24-h (hourly interval) } \\
\hline 4-HA simulation step & \multicolumn{3}{|c|}{$4 \mathrm{~h}$ plus $20-\mathrm{h}$ look-ahead period (hourly Interval) } \\
\hline RT simulation step & \multicolumn{3}{|c|}{$\begin{array}{l}\text { Twelve 5-min periods (5-min interval) plus 23-h look-ahead } \\
\text { (hourly interval) }\end{array}$} \\
\hline Simulation approach & Cost-based & Bid-based & Cost-based \\
\hline
\end{tabular}

\subsection{Day-Ahead Simulation Results}

The simulation results for the three focus areas-WI, California, and SMUD—are presented in this section for cases (1) without any PSH plants, (2) with existing FS PSH plants, and (3) with existing FS and additional AS PSH plants. All three cases have been run for the Base and High Wind renewable energy scenarios.

\subsubsection{WI Simulation Results}

This subsection presents PLEXOS results for the simulations of the entire WI.

\section{WI System Production Costs}

The production cost of the three cases for 2022: (1) without PSHs, (2) with the existing FS PSHs, and (3) with additional AS PSHs, are listed in Table 4-6 for the Base renewable scenario and in Table 4-7 for the High Wind renewable scenario. Annual cost reduction information is also provided in these tables.

With the existing PSH plants, the total annual production cost in the WI is reduced by $1.14 \%$ and 1.96\% under the Base and High Wind renewable scenarios, respectively. With the additional AS PSH introduced into the system, the total annual production cost in the WI is reduced by $2.11 \%$ and $3.77 \%$ for the Base and High Wind renewable scenarios, respectively.

It should be noted that with the higher penetration of renewable energy generation (approximately 33\% of WI demand under the High Wind scenario), the production cost reduction due to the PSH operation is even greater. Compared with the Base renewable energy 
Table 4-6 Comparison of WI Production Cost in Three Cases for the Base Renewable Scenario in 2022

\begin{tabular}{|c|c|c|c|c|c|c|c|}
\hline \multirow{2}{*}{$\begin{array}{c}\text { Base } \\
\text { Renewable } \\
\text { Scenario }\end{array}$} & \multirow{2}{*}{$\begin{array}{l}\text { Total } \\
\text { Generation } \\
\text { (GWh) }\end{array}$} & \multirow{2}{*}{$\begin{array}{c}\text { PSH } \\
\text { Generation } \\
\text { (GWh) }\end{array}$} & \multirow{2}{*}{$\begin{array}{l}\text { Production } \\
\text { Cost } \\
\text { (\$ million) }\end{array}$} & \multicolumn{2}{|c|}{$\begin{array}{c}\text { Annual Cost } \\
\text { Reduction }\end{array}$} & \multicolumn{2}{|c|}{\begin{tabular}{|c|} 
Annual Cost \\
Reduction per kW of \\
PSH Capacity \\
\end{tabular}} \\
\hline & & & & (\$ million) & (\%) & $\begin{array}{c}\text { Total PSH } \\
\text { MW }\end{array}$ & $(\$ / k w-y r)$ \\
\hline No PSH & 997,546 & - & 14,737 & - & - & - & - \\
\hline With FS PSH & $1,003,204$ & 4,106 & 14,569 & 167 & $1.14 \%$ & 3,296 & 50.82 \\
\hline $\begin{array}{l}\text { With FS \& AS } \\
\text { PSH }\end{array}$ & $1,008,135$ & 8,244 & 14,426 & 311 & $2.11 \%$ & 6,475 & 48.06 \\
\hline
\end{tabular}

Table 4-7 Comparison of WI Production Cost in Three Cases for the High Wind Renewable Scenario in 2022

\begin{tabular}{|c|c|c|c|c|c|c|c|}
\hline \multirow{2}{*}{$\begin{array}{l}\text { High Wind } \\
\text { Renewable } \\
\text { Scenario } \\
\end{array}$} & \multirow{2}{*}{$\begin{array}{c}\text { Total } \\
\text { Generation } \\
\text { (GWh) }\end{array}$} & \multirow{2}{*}{$\begin{array}{c}\text { PSH } \\
\text { Generation } \\
\text { (GWh) }\end{array}$} & \multirow{2}{*}{$\begin{array}{c}\text { Production } \\
\text { Cost } \\
\text { (\$ million) }\end{array}$} & \multicolumn{2}{|c|}{$\begin{array}{c}\text { Annual Cost } \\
\text { Reduction }\end{array}$} & \multicolumn{2}{|c|}{$\begin{array}{c}\text { Annual Cost } \\
\text { Reduction per kW of } \\
\text { PSH Capacity }\end{array}$} \\
\hline & & & & (\$ million) & (\%) & $\begin{array}{c}\text { Total PSH } \\
\text { (MW) }\end{array}$ & $(\$ / k w-y r)$ \\
\hline No PSH & 997,538 & - & 12,646 & - & - & - & - \\
\hline With FS PSH & $1,007,140$ & 6,925 & 12,398 & 248 & $1.96 \%$ & 3,296 & 75.29 \\
\hline $\begin{array}{l}\text { With FS \& AS } \\
\text { PSH }\end{array}$ & $1,015,512$ & 13,811 & 12,169 & 477 & $3.77 \%$ & 6,475 & 73.67 \\
\hline
\end{tabular}

scenario, the increased PSH capacity results in about 50\% additional annual cost reduction under the High Wind scenario.

\section{WI Curtailments of Renewable Generation}

The operation of PSH plants in the system allows for significant reduction of curtailments of variable energy resources (VERs). Tables 4-8 and 4-9 present the results obtained for the contributions of PSH plants in reducing the curtailments of renewable generation in the WI under the Base and High Wind scenarios, respectively.

Table 4-8 Comparison of WI Renewable Curtailment in the Base Renewable Scenario

\begin{tabular}{|l|c|c|c|}
\hline \multicolumn{1}{|c|}{$\begin{array}{c}\text { Base Renewable } \\
\text { Scenario }\end{array}$} & $\begin{array}{c}\text { Curtailed Energy } \\
\text { (GWh) }\end{array}$ & \multicolumn{2}{c|}{ Renewable Curtailment Reduction } \\
\cline { 3 - 4 } & 1,921 & 0 & (GWh) \\
\hline No PSH & 1,356 & 565 & 29 \\
\hline With FS PSH & 964 & 958 & 50 \\
\hline With FS \& AS PSH & & & \\
\hline
\end{tabular}


Table 4-9 Comparison of WI Renewable Curtailment in the High Wind Renewable Scenario

\begin{tabular}{|l|c|c|c|}
\hline \multirow{2}{*}{$\begin{array}{c}\text { High Wind Renewable } \\
\text { Scenario }\end{array}$} & $\begin{array}{c}\text { Curtailed Energy } \\
\text { (GWh) }\end{array}$ & \multicolumn{2}{c|}{ Renewable Curtailment Reduction } \\
\cline { 3 - 4 } & 56,885 & (GWh) & (\%) \\
\hline No PSH & 48,403 & 0 & 0 \\
\hline With FS PSH & 44,211 & 8,482 & 15 \\
\hline With FS \& AS PSH & 12,675 & 22 \\
\hline
\end{tabular}

\section{WI System Reserve Provisions by PSH}

Tables 4-10 and 4-11 present WI system requirements for various types of operating reserves and reserve provisions by PSH plants, for the three cases, under the Base and High Wind renewable scenarios.

Table 4-10 Comparison of WI Reserve Requirements and Provisions by PSH in Three Cases for the Base Renewable Scenario in $\mathbf{2 0 2 2}$

\begin{tabular}{|l|c|c|c|c|c|c|}
\hline \multirow{2}{*}{$\begin{array}{l}\text { Base Renewable } \\
\text { Scenario }\end{array}$} & \begin{tabular}{c}
$|c|$ \\
\cline { 2 - 7 } \\
\cline { 2 - 7 } \\
Total Req.
\end{tabular} & $\begin{array}{c}\text { PSH } \\
\text { Provision } \\
\text { (GWh) }\end{array}$ & $\begin{array}{c}\text { Whith FS PSH } \\
\text { Total Req. } \\
\text { (GWh) }\end{array}$ & $\begin{array}{c}\text { PSH } \\
\text { Provision } \\
\text { (GWh) }\end{array}$ & $\begin{array}{c}\text { With FS \& AS PSH } \\
\text { Total Req. } \\
\text { (GWh) }\end{array}$ & $\begin{array}{c}\text { PSH } \\
\text { Provision } \\
\text { (GWh) }\end{array}$ \\
\hline $\begin{array}{l}\text { Non-spinning } \\
\text { reserve }\end{array}$ & 29,564 & - & 29,564 & 1,364 & 29,564 & 3,757 \\
\hline Spinning reserve & 29,564 & - & 29,564 & 182 & 29,564 & 679 \\
\hline Flexibility down & 10,732 & - & 10,732 & 74 & 10,732 & 1,463 \\
\hline Flexibility up & 10,732 & - & 10,732 & 100 & 10,732 & 299 \\
\hline Regulation down & 12,423 & - & 12,423 & 163 & 12,423 & 1,652 \\
\hline Regulation up & 12,441 & - & 12,441 & 205 & 12,441 & 580 \\
\hline
\end{tabular}

"_" = not applicable

Table 4-11 Comparison of WI Reserve Requirements and Provisions by PSH in Three Cases for the High Wind Renewable Scenario in 2022

\begin{tabular}{|l|c|c|c|c|c|c|}
\hline \multirow{2}{*}{$\begin{array}{c}\text { High Wind } \\
\text { Renewable } \\
\text { Scenario }\end{array}$} & \multicolumn{2}{|c|}{ No PSH } & \multicolumn{2}{c|}{ With FS PSH } & \multicolumn{2}{c|}{ With FS \& AS PSH } \\
\cline { 2 - 7 } & $\begin{array}{c}\text { Total Req. } \\
\text { (GWh) }\end{array}$ & $\begin{array}{c}\text { PSH } \\
\text { Provision } \\
\text { (GWh) }\end{array}$ & $\begin{array}{c}\text { Total Req. } \\
\text { (GWh) }\end{array}$ & $\begin{array}{c}\text { PSH } \\
\text { Provision } \\
\text { (GWh) }\end{array}$ & $\begin{array}{c}\text { PSH } \\
\text { Total Req. } \\
\text { (GWh) }\end{array}$ & $\begin{array}{c}\text { Provision } \\
\text { (GWh) }\end{array}$ \\
\hline $\begin{array}{l}\text { Non-spinning } \\
\text { reserve }\end{array}$ & 29,564 & - & 29,564 & 766 & 29,564 & 2,017 \\
\hline Spinning reserve & 29,564 & - & 29,564 & 22 & 29,564 & 187 \\
\hline Flexibility down & 23,062 & - & 23,062 & 240 & 23,062 & 3,072 \\
\hline Flexibility up & 23,062 & - & 23,062 & 35 & 23,062 & 119 \\
\hline Regulation down & 17,487 & - & 17,487 & 485 & 17,487 & 2,333 \\
\hline Regulation up & 17,448 & - & 17,448 & 95 & 17,448 & 319 \\
\hline
\end{tabular}

"_" = not applicable 
The addition of AS PSH plants substantially increases the amount of operating reserves provided by PSH plants to the system. The greatest increase is observed in provisions of regulation down and flexibility-down reserves. Two key characteristics of AS PSH that contribute to this increase are:

1. Larger operating capacity range in the generating mode, and

2. The capability to provide regulation reserve in the pumping mode.

\section{WI System Emissions}

Tables 4-12 and 4-13 show air pollutant emissions in the WI system for the three simulated cases under the Base and High Wind renewable scenarios, respectively.

Table 4-12 Comparison of WI Emission Production in Three Cases in 2022 for the Base Renewable Scenario

\begin{tabular}{|c|c|c|c|c|c|c|c|c|c|}
\hline \multirow{2}{*}{$\begin{array}{c}\text { Base Renewable } \\
\text { Scenario }\end{array}$} & \multirow{2}{*}{$\begin{array}{c}\mathrm{CO}_{2} \\
\text { (ton) }\end{array}$} & \multirow{2}{*}{$\begin{array}{l}\mathrm{NO}_{\mathrm{x}} \\
\text { (ton) }\end{array}$} & \multirow{2}{*}{$\begin{array}{c}\mathrm{SO}_{2} \\
\text { (ton) } \\
\end{array}$} & \multicolumn{3}{|c|}{ Emission Reduction (ton) } & \multicolumn{3}{|c|}{$\begin{array}{c}\text { Emission } \\
\text { Reduction (\%) }\end{array}$} \\
\hline & & & & $\mathrm{CO}_{2}$ & $\mathbf{N O}_{*}$ & $\mathrm{SO}_{2}$ & $\mathrm{CO}_{2}$ & $\mathrm{NO}_{\mathrm{x}}$ & $\mathrm{SO}_{2}$ \\
\hline No PSH & $388,463,385$ & 573,025 & 410,404 & 0 & 0 & 0 & 0.0 & 0.0 & 0.0 \\
\hline With FS PSH & $391,262,476$ & 581,329 & 417,728 & $-2,799,091$ & $-8,304$ & $-7,324$ & -0.7 & -1.4 & -1.8 \\
\hline Nith FS & 393,954 & 0 & 425,15 & $-5,491,01$ & $-16,888$ & $-14,747$ & -1 & -2. & -3.6 \\
\hline
\end{tabular}

Table 4-13 Comparison of WI Emission Production in Three Cases in 2022 for the High Wind Renewable Scenario

\begin{tabular}{|c|c|c|c|c|c|c|c|c|c|}
\hline \multirow{2}{*}{$\begin{array}{c}\text { High Wind } \\
\text { Renewable } \\
\text { Scenario }\end{array}$} & \multirow{2}{*}{$\begin{array}{c}\mathrm{CO}_{2} \\
\text { (ton) } \\
\end{array}$} & \multirow{2}{*}{$\begin{array}{l}\mathrm{NO}_{\mathrm{x}} \\
\text { (ton) } \\
\end{array}$} & \multirow{2}{*}{$\begin{array}{c}\mathrm{SO}_{2} \\
\text { (ton) } \\
\end{array}$} & \multicolumn{3}{|c|}{ Emission Reduction (ton) } & \multicolumn{3}{|c|}{$\begin{array}{c}\text { Emission } \\
\text { Reduction (\%) }\end{array}$} \\
\hline & & & & $\mathrm{CO}_{2}$ & $\mathrm{NO}_{\mathrm{x}}$ & $\mathrm{SO}_{2}$ & $\mathrm{CO}_{2}$ & $\mathrm{NO}_{\mathrm{x}}$ & $\mathrm{SO}_{2}$ \\
\hline No PSH & $318,768,466$ & 467,931 & 326,318 & 4 & 0 & 0 & 0.0 & 0.0 & 0.0 \\
\hline With FS PSH & $312,657,135$ & 458,360 & 320,234 & $6,111,331$ & 9,571 & 6,084 & 1.9 & 2.0 & 1.9 \\
\hline With FS \& AS PSH & $311,549,087$ & 459,379 & 322,211 & $7,219,379$ & 8,552 & 4,107 & 2.3 & 1.8 & 1.3 \\
\hline
\end{tabular}

Under the Base renewable energy scenario, the coal generation increases during the night to provide pumping energy, which increases overall system emissions. Under the High Wind renewable scenario, the overall thermal generation is lower due to a higher share of renewable resources in the system, which results in lower overall level of system emissions. The addition of FS and AS PSH plants to the system provides additional emission reduction in the case of high penetration of renewable energy resources, mainly by providing for better integration of variable renewable resources (e.g., reducing curtailments). 


\section{WI Thermal Generator Cycling}

Tables 4-14 and 4-15 provide the number of starts and startup costs of thermal generators for three PSH cases under the Base and High Wind renewable scenarios, respectively.

Table 4-14 Comparison of Number of Starts and Startup Costs of the WI Thermal Generators in 2022 for the Base Renewable Scenario

\begin{tabular}{|l|c|c|c|c|}
\hline \multirow{2}{*}{$\begin{array}{c}\text { Base Renewable } \\
\text { Scenario }\end{array}$} & Total Number of & Total Thermal & \multicolumn{2}{|c|}{$\begin{array}{c}\text { Cost Reduction } \\
\text { Start Cost }\end{array}$} \\
\cline { 4 - 5 } & Thermal Starts & (million \$) & (million \$) & (\%) \\
\hline No PSH & 37,804 & 153 & 0 & 0 \\
\hline With FS PSH & 31,797 & 130 & 24 & 15.46 \\
\hline With FS \& AS PSH & 27,548 & 109 & 44 & 28.57 \\
\hline
\end{tabular}

Table 4-15 Comparison of Number of Starts and Startup Costs of the WI Thermal Generators in 2022 for the High Wind Renewable Scenario

\begin{tabular}{|l|c|c|c|c|}
\hline \multirow{2}{*}{$\begin{array}{c}\text { High Wind } \\
\text { Renewable } \\
\text { Scenario }\end{array}$} & Total Number of & $\begin{array}{c}\text { Total Thermal } \\
\text { Start Cost } \\
\text { (million \$) }\end{array}$ & \multicolumn{2}{|c|}{ Cost Reduction } \\
\cline { 4 - 5 } & Thermal Starts & (million \$) & (\%) \\
\hline No PSH & 40,852 & 176 & 0 & 0 \\
\hline With FS PSH & 36,024 & 161 & 15 & 8.48 \\
\hline With FS \& AS PSH & 31,925 & 145 & 31 & 17.70 \\
\hline
\end{tabular}

In both the Base and High Wind renewable scenarios, the number of starts and startup costs of thermal generators are reduced substantially as more PSHs are introduced into the system. The total number of starts and startup costs are higher under the High Wind renewable scenario because of a larger share of variable energy generation (wind and solar) that is characterized by short-term fluctuations.

\section{WI Thermal Generator Ramping}

Tables 4-16 and 4-17 list the results for ramping up and down of thermal generators in the three cases under the Base and High Wind renewable scenarios, respectively.

Under both Base and High Wind renewable scenarios, the needs for ramping up and down of thermal generators are significantly reduced if more PSH capacity is available in the system.

\section{Selected WI Regional Location Marginal Prices (LMPs)}

Figure 4-5 shows the comparison of average regional LMPs in selected WI regions under the Base renewable scenario. This figure demonstrates that as more PSH capacity is introduced into the system, the average regional LMPs decrease uniformly in all selected regions. 
Table 4-16 Comparison of Thermal Generator Ramp Up and Down of the WI Thermal Generators in $\mathbf{2 0 2 2}$ for the Base Renewable Scenario

\begin{tabular}{|l|c|c|c|c|c|c|}
\hline & $\begin{array}{c}\text { Total } \\
\text { Thermal } \\
\text { Generator } \\
\text { Ramp Up } \\
\text { Base Renewable } \\
\text { Scenario }\end{array}$ & $\begin{array}{c}\text { Total } \\
\text { Thermal } \\
\text { Generator } \\
\text { Ramp Down } \\
\text { (GW) }\end{array}$ & \multicolumn{2}{|c|}{\begin{tabular}{c} 
Ramp-Up Reduction \\
\cline { 4 - 8 }
\end{tabular}} & $\begin{array}{c}\text { Ramp-Down } \\
\text { Reduction }\end{array}$ \\
\hline No PSH & 11,501 & 16,508 & 0 & 0 & 0 & 0 \\
\hline With FS PSH & 9,716 & 13,948 & 1,786 & 15.53 & 2,560 & 15.51 \\
\hline With FS \& AS PSH & 8,081 & 11,691 & 3,420 & 29.74 & 4,817 & 29.18 \\
\hline
\end{tabular}

Table 4-17 Comparison of Thermal Generator Ramp Up and Down of the WI Thermal Generators in $\mathbf{2 0 2 2}$ for the High Wind Renewable Scenario

\begin{tabular}{|c|c|c|c|c|c|c|}
\hline \multirow{2}{*}{$\begin{array}{l}\text { High Wind } \\
\text { Renewable } \\
\text { Scenario }\end{array}$} & \multirow{2}{*}{$\begin{array}{c}\text { Total } \\
\text { Thermal } \\
\text { Generator } \\
\text { Ramp Up } \\
\text { (GW) }\end{array}$} & \multirow{2}{*}{$\begin{array}{c}\text { Total } \\
\text { Thermal } \\
\text { Generator } \\
\text { Ramp Down } \\
\text { (GW) }\end{array}$} & \multicolumn{2}{|c|}{ Ramp-Up Reduction } & \multicolumn{2}{|c|}{$\begin{array}{l}\text { Ramp-Down } \\
\text { Reduction }\end{array}$} \\
\hline & & & (GW) & (\%) & (GW) & (\%) \\
\hline No PSH & 9,325 & 14,188 & 0 & 0 & 0 & 0 \\
\hline With FS PSH & 8,394 & 12,682 & 931 & 9.98 & 1,506 & 10.62 \\
\hline With FS \& AS PSH & 7,060 & 10,778 & 2,265 & 24.29 & 3,410 & 24.04 \\
\hline
\end{tabular}

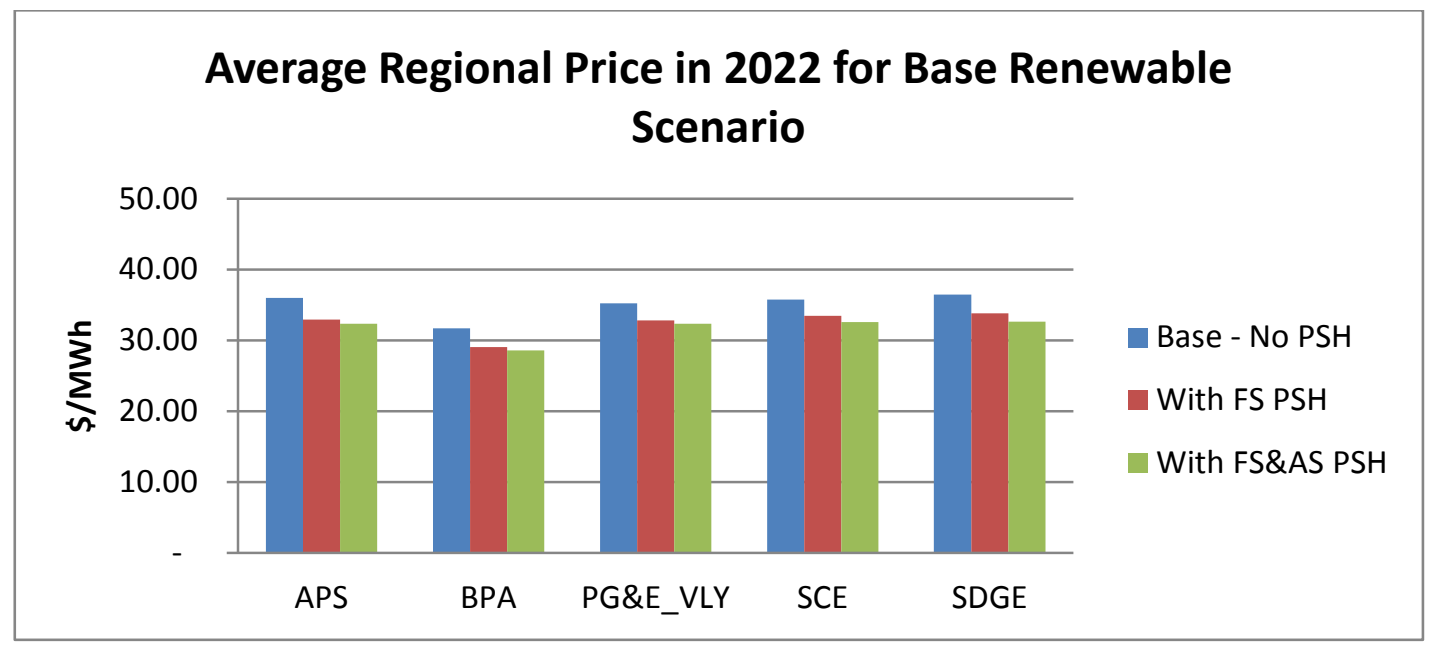

Figure 4-5 Comparison of Regional LMPs in Three Cases for the Selected WI Regions in 2022 for the Base Renewable Scenario 
Figure 4-6 presents the comparison of average regional LMPs in selected regions under the High Wind renewable scenario. The average LMPs increase in some regions and decrease in others as more PSH is introduced into the WI system. Compared with the Base renewable energy scenario, the High Wind renewable scenario regional LMPs are substantially lower because of the much greater share of variable energy generation.

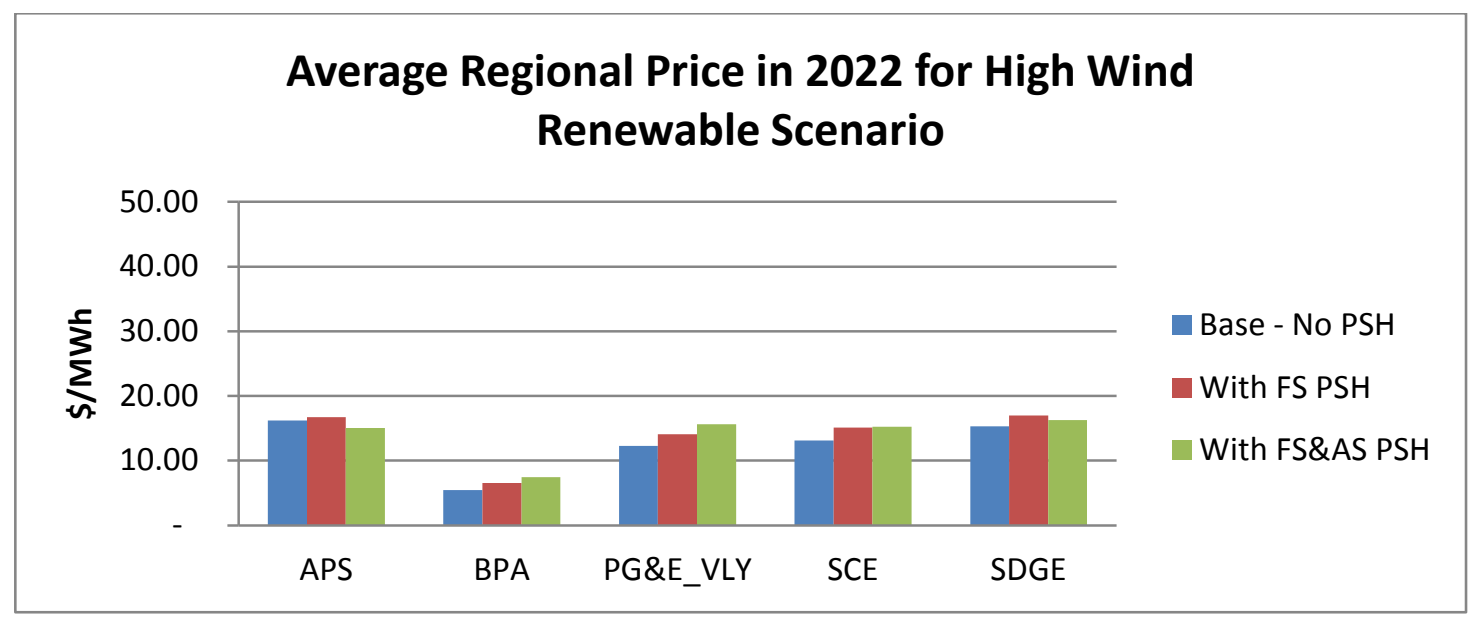

Figure 4-6 Comparison of Regional LMPs in Three Cases for the Selected WI Regions in 2022 for the High Wind Renewable Scenario

\section{WI Transmission Congestion}

Transmission Congestion under the Base Renewable Scenario

The simulation of the WI system for the Base renewable scenario shows that the average WI interface forward congestion shadow price is reduced from \$4/MWh to \$2/MWh as the FS and AS PSH plants are introduced into the system. Similarly, the average WI interface backward congestion shadow price is reduced from \$2/MWh to \$1/MWh as the FS and AS PSH plants are introduced into the system.

The most congested interfaces are:

- Interstate WA-BC East,

- Intrastate AB DC2,

- P18 Montana-Idaho,

- $\quad$ P27 Intermountain Power Project DC Line,

- $\quad$ P45 SDG\&E-CFE, and

- $\quad$ P52 Silver Peak-Control 55 kV. 
Comparing the congestion prices of the three cases (no PSHs, with FS PSH, and with FS and AS $\mathrm{PSH}$ ), the greatest reduction in transmission congestion prices occurs for the following three interfaces:

- P27 Intermountain Power Project DC Line,

- P45 SDG\&E-CFE, and

- $\quad$ P52 Silver Peak-Control 55 kV.

These interfaces are located near the Castaic, Eagle Mountain, and Lake Hodge PSH plants.

Transmission Congestion for the High Wind Renewable Scenario

Because the transmission network in the existing TEPPC 2022 case was not adequate to accommodate the High Wind renewable scenario, some transmission expansion assumptions had to be made. The transmission expansion assumptions were added to allow the grid to deliver the renewable energy quantities required under the High Wind renewable scenario. Without transmission expansion assumptions, PLEXOS simulation could not generate results for the High Wind renewable scenario.

This analysis is not a transmission expansion study, and it is important to note that the methodology applied for transmission expansion was rather simplistic. The transmission expansion methodology did not include detailed economic or reliability analyses, nor did it take into account issues such as rights-of-way, environmental concerns, policy constraints, and many other factors that are typically considered in detailed transmission planning activities.

The following steps were performed during the transmission expansion analysis and are shown in Figure 4-7:

1. Perform PLEXOS nodal simulation with the renewable generation at the High Wind renewable penetration level;

2. For any congested transmission line with the annual average shadow price greater than $\$ 10 / \mathrm{MWh}$, build a parallel transmission line with identical characteristics as the existing transmission line;

3. For a congested transmission interface with the annual average shadow price greater than $\$ 10 / \mathrm{MWh}$, increase the transmission interface rating by $500 \mathrm{MW}$ and build a parallel transmission line in the transmission interface if necessary;

4. Perform PLEXOS nodal simulation again and repeat the process until all monitored transmission lines and interfaces have congestion prices less than \$10/MWh.

These transmission expansion steps are illustrated in the following diagram. 


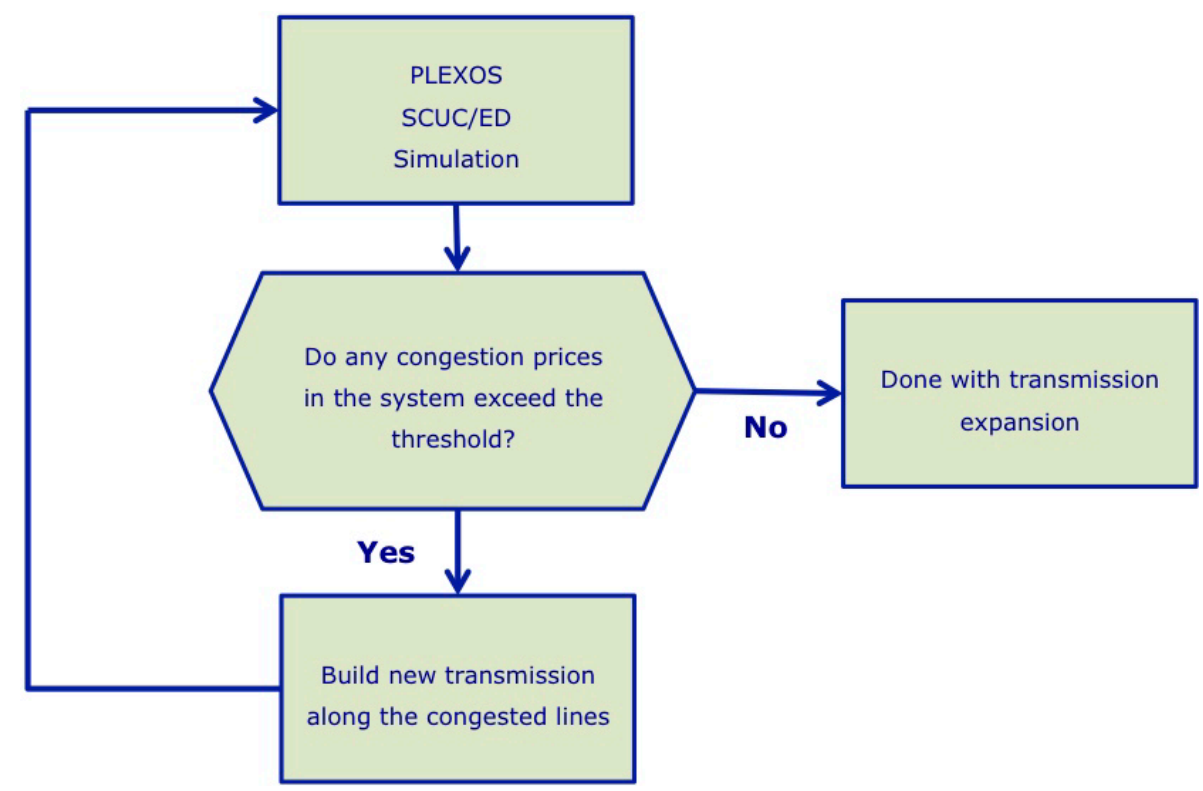

Figure 4-7 Logic Flow for the Transmission Expansion Using the Congestion Shadow Price Approach

The results of the transmission expansion analysis indicate that additional transfer capacity is needed to deliver renewable generation to load centers under the High Wind renewable scenario.

The simulation of the WI system with the transmission expansion for the High Wind renewable scenario determined that the most congested interfaces are:

- P08 Montana to Northwest,

- P27 Intermountain Power Project DC Line,

- $\quad$ P30 TOT 1A, and

- $\quad$ P33 Bonanza West.

Comparing the congestion prices of the three cases (no PSHs, with FS PSH, and with FS and AS $\mathrm{PSH}$ ), the greatest reduction in transmission congestion prices occurs for the interface "P27 Intermountain Power Project DC Line.” This interface is located near the Castaic and Eagle Mountain PSH plants.

\subsubsection{California Simulation Results}

Before simulating the California footprint, the entire WI was simulated to produce the power flows for all transmission lines crossing the border of California to the rest of the WI. The California grid was extracted from the WI grid and the power flow exchanges between California and the rest of the WI, determined from PLEXOS runs for the entire WI, were kept frozen for 
California simulations. Both the WI and California simulation runs were performed for the Base and High Wind renewable scenarios.

The main purpose of the California simulations was to analyze the impact of PSH plants in an electricity market environment. Although a few California utilities, such as SMUD and the Los Angeles Department of Water and Power (LADWP), are not part of the California ISO (CAISO), the entire California footprint was modeled since the transmission grids of these nonCAISO utilities are intertwined with the CAISO grid.

\section{Electricity Market Bidding Prices}

A critical factor in the simulation of electricity markets is to determine generator bidding prices for energy and A/S. The approach adopted in this study for the determination of bidding prices was to benchmark the market prices from PLEXOS simulations against the CAISO historical market prices.

\section{Energy Market Bidding Prices}

The CAISO 2012 annual market report (CAISO 2013) was reviewed for historical price levels for energy in the CAISO electricity market. Section 2.2, "Overall Market Competitiveness," of the report shows that the average energy market prices are close to the cost-based simulations performed by the CAISO department of market monitoring. Therefore, for the energy market simulations, the generator marginal cost prices were used as energy bidding prices.

\section{Ancillary Service Market Bidding Prices}

The historical A/S market clearing prices in year 2012 were analyzed to determine the historical price levels of $\mathrm{A} / \mathrm{S}$ in the CAISO electricity market. The analysis shows that $\mathrm{A} / \mathrm{S}$ clearing prices are closely correlated with the energy market LMPs, which, in turn, are closely correlated with the regional load.

Based on this analysis, the following approach was adopted to mimic the generator bidding prices for A/S in PLEXOS simulations.

1. The hourly upward A/S bidding prices follow the hourly California load profiles, and the hourly downward A/S bidding prices follow the inverse of the hourly California load profiles.

2. The generators with a higher marginal cost have lower A/S bidding prices, and the generators with a lower marginal cost have higher A/S bidding prices. The reason is that the generators with higher marginal cost have a lower energy profit margin, and the generators with lower marginal cost have a higher energy profit margin.

3. The final hourly A/S bidding prices for a generator are the normalized hourly A/S bidding price profiles multiplied by the A/S bidding price scaling factor. The normalized hourly A/S bidding price profiles are the normalized hourly California load profile for the upward $\mathrm{A} / \mathrm{S}$, and the inverse of the normalized hourly California load profile for the downward A/S. 
4. The generator A/S bidding price scaling factor has a higher value for higher-quality reserves.

5. Hydro generators and PSH plants are characterized by fast ramping capabilities and are assumed to provide A/S before thermal generators.

The California simulations were performed for three cases (no PSH, with existing FS PSH, and with existing FS and new AS PSH) and for both the Base and High Wind renewable scenarios.

\section{California System Production Costs}

Tables 4-18 and 4-19 list the production cost results for the three simulated cases in 2022 for the Base and High Wind renewable scenarios, respectively.

Table 4-18 Comparison of California Production Cost in Three Cases for the Base Renewable Scenario in 2022

\begin{tabular}{|c|c|c|c|c|c|c|c|}
\hline \multirow[b]{2}{*}{$\begin{array}{c}\text { Base Renewable } \\
\text { Scenario }\end{array}$} & \multirow{2}{*}{$\begin{array}{l}\text { Total } \\
\text { Generation } \\
\text { (GWh) }\end{array}$} & \multirow{2}{*}{$\begin{array}{c}\text { PSH } \\
\text { Generation } \\
\text { (GWh) }\end{array}$} & \multirow{2}{*}{$\begin{array}{l}\text { Production } \\
\text { Cost } \\
\text { (\$ million) }\end{array}$} & \multicolumn{2}{|c|}{$\begin{array}{c}\text { Annual Cost } \\
\text { Reduction }\end{array}$} & \multicolumn{2}{|c|}{$\begin{array}{c}\text { Annual Cost } \\
\text { Reduction per kW of } \\
\text { PSH Capacity }\end{array}$} \\
\hline & & & & (\$ million) & $(\%)$ & $\begin{array}{c}\text { Total PSH } \\
\text { (MW) }\end{array}$ & $(\$ / k w-y r)$ \\
\hline No PSH & 265,538 & 0 & 5,078 & 0 & 0.00 & 0 & 0.00 \\
\hline With FS PSH & 267,001 & 2,725 & 4,967 & 111 & 2.18 & 2,626 & 42.10 \\
\hline With FS \& AS PSH & 269,374 & 5,313 & 4,907 & 171 & 3.36 & 4,425 & 38.60 \\
\hline
\end{tabular}

Table 4-19 Comparison of California Production Cost in Three Cases for the High Wind Renewable Scenario in 2022

\begin{tabular}{|c|c|c|c|c|c|c|c|}
\hline \multirow{2}{*}{$\begin{array}{l}\text { High Wind } \\
\text { Renewable } \\
\text { Scenario }\end{array}$} & \multirow{2}{*}{$\begin{array}{c}\text { Total } \\
\text { Generation } \\
\text { (GWh) }\end{array}$} & \multirow{2}{*}{$\begin{array}{c}\text { PSH } \\
\text { Generation } \\
\text { (GWh) }\end{array}$} & \multirow{2}{*}{$\begin{array}{l}\text { Production } \\
\text { Cost } \\
\text { (\$ million) }\end{array}$} & \multicolumn{2}{|c|}{$\begin{array}{c}\text { Annual Cost } \\
\text { Reduction }\end{array}$} & \multicolumn{2}{|c|}{$\begin{array}{c}\text { Annual Cost } \\
\text { Reduction per kW of } \\
\text { PSH Capacity }\end{array}$} \\
\hline & & & & (\$ million) & $(\%)$ & $\begin{array}{c}\text { Total PSH } \\
\text { (MW) }\end{array}$ & $(\$ / k w-y r)$ \\
\hline No PSH & 253,872 & 0 & 4,120 & 0 & 0.00 & 0 & 0.00 \\
\hline With FS PSH & 256,069 & 5,299 & 3,934 & 186 & 4.52 & 2626 & 70.91 \\
\hline With FS \& AS PSH & 257,018 & 9,456 & 3,745 & 376 & 9.12 & 4425 & 84.97 \\
\hline
\end{tabular}

With the existing FS PSH plants, the total annual production costs in California are reduced by 2.18\% and $4.52 \%$ under the Base and High Wind renewable scenarios, respectively. With the additional AS PSH plants, the California system production cost reductions amount to $3.36 \%$ and 9.12\% under the Base and the High Wind renewable scenarios, respectively.

With the higher penetration of renewable generation under the High Wind scenario, the production cost savings due to PSH operation increase significantly. Compared with the Base 
renewable energy scenario, the PSH capacity is almost twice as valuable under the High Wind scenario.

\section{California Curtailments of Renewable Generation}

Because of the PSH operation, the curtailments of renewable generation in California under the Base and High Wind renewable scenarios are reduced as shown in Tables 4-20 and 4-21, respectively.

Table 4-20 Comparison of California Renewable Curtailment in the Base Renewable Scenario

\begin{tabular}{|l|c|c|c|}
\hline \multicolumn{4}{|c|}{ CA Renewable Curtailment in the Base Renewable Scenario } \\
\cline { 1 - 2 } & $\begin{array}{c}\text { Renewable Curtailment } \\
\text { (GWh) }\end{array}$ & Renewable Curtailment Reduction \\
\cline { 1 - 3 } \multicolumn{1}{|c|}{ Case } & 155 & 0 & (GWh) \\
\hline No PSH & 46 & 108 & 0 \\
\hline With FS PSH & 14 & 141 & 70 \\
\hline With FS \& AS PSH & & & 91 \\
\hline
\end{tabular}

Table 4-21 Comparison of California Renewable Curtailment in the High Wind Renewable Scenario

\begin{tabular}{|l|c|c|c|}
\hline \multicolumn{4}{|c|}{ CA Renewable Curtailment in the High Wind Renewable Scenario } \\
\hline \multicolumn{1}{|c|}{ Case } & $\begin{array}{c}\text { Renewable Curtailment } \\
\text { (GWh) }\end{array}$ & \multicolumn{2}{c|}{ Renewable Curtailment Reduction } \\
\cline { 3 - 4 } & 618 & (GWh) & (\%) \\
\hline No PSH & 380 & 0 & 0 \\
\hline With FS PSH & 275 & 238 & 39 \\
\hline With FS \& AS PSH & & 343 & 55 \\
\hline
\end{tabular}

\section{California System Reserves and Provision by PSHs}

Tables 4-22 and 4-23 provide system reserve requirements and their provisions by PSH plants for the three simulated cases under the Base and High Wind renewable scenarios, respectively.

Table 4-22 Comparison of California Reserve Requirements and Provisions by PSH in Three Cases for the Base Renewable Scenario in 2022

\begin{tabular}{|l|c|c|c|c|c|c|}
\hline \multirow{2}{*}{$\begin{array}{l}\text { Base Renewable } \\
\text { Scenario }\end{array}$} & \multicolumn{2}{|c|}{ Base - No PSH } & \multicolumn{2}{c|}{ With FS PSH } & \multicolumn{2}{c|}{ With FS \& AS PSH } \\
\cline { 2 - 7 } & $\begin{array}{c}\text { Total Req. } \\
\text { (GWh) }\end{array}$ & $\begin{array}{c}\text { PSH } \\
\text { Provision } \\
\text { (GWh) }\end{array}$ & $\begin{array}{c}\text { Total Req. } \\
\text { (GWh) }\end{array}$ & $\begin{array}{c}\text { PSH } \\
\text { Provision } \\
\text { (GWh) }\end{array}$ & $\begin{array}{c}\text { PSH } \\
\text { Total Req. } \\
\text { (GWh) }\end{array}$ & $\begin{array}{c}\text { Provision } \\
\text { (GWh) }\end{array}$ \\
\hline $\begin{array}{l}\text { Non-spinning } \\
\text { Reserve }\end{array}$ & 8,505 & - & 8,505 & 7,090 & 8,505 & 7,905 \\
\hline Spinning reserve & 8,505 & - & 8,505 & 224 & 8,505 & 2,463 \\
\hline Flexibility down & 3,130 & - & 3,130 & 47 & 3,130 & 1,098 \\
\hline Flexibility up & 3,130 & - & 3,130 & 13 & 3,130 & 341 \\
\hline Regulation down & 3,810 & - & 3,810 & 171 & 3,810 & 1,264 \\
\hline Regulation up & 3,839 & - & 3,839 & 164 & 3,839 & 1,109 \\
\hline
\end{tabular}

"_" = not applicable 
Table 4-23 Comparison of California Reserve Requirements and Provisions by PSH in Three Cases for the High Wind Renewable Scenario in 2022

\begin{tabular}{|l|c|c|c|c|c|c|}
\hline \multirow{2}{*}{$\begin{array}{c}\text { High Wind } \\
\begin{array}{c}\text { Renewable } \\
\text { Scenario }\end{array}\end{array}$} & \multicolumn{2}{|c|}{ Base - No PSH } & \multicolumn{2}{c|}{ With FS PSH } & \multicolumn{2}{c|}{ With FS \& AS PSH } \\
\cline { 2 - 7 } & $\begin{array}{c}\text { Total Req. } \\
\text { (GWh) }\end{array}$ & $\begin{array}{c}\text { PSH } \\
\text { Provision } \\
\text { (GWh) }\end{array}$ & $\begin{array}{c}\text { Total Req. } \\
\text { (GWh) }\end{array}$ & $\begin{array}{c}\text { PSH } \\
\text { Provision } \\
\text { (GWh) }\end{array}$ & $\begin{array}{c}\text { Total Req. } \\
\text { (GWh) }\end{array}$ & $\begin{array}{c}\text { PSH } \\
\text { Provision } \\
\text { (GWh) }\end{array}$ \\
\hline $\begin{array}{l}\text { Non-spinning } \\
\text { Reserve }\end{array}$ & 8,505 & - & 8,505 & 4,774 & 8,505 & 5,492 \\
\hline Spinning reserve & 8,505 & - & 8,505 & 247 & 8,505 & 2,022 \\
\hline Flexibility down & 4,804 & - & 4,804 & 141 & 4,804 & 1,934 \\
\hline Flexibility up & 4,804 & - & 4,804 & 26 & 4,804 & 200 \\
\hline Regulation down & 4,394 & - & 4,394 & 377 & 4,394 & 1,761 \\
\hline Regulation up & 4,442 & - & 4,442 & 144 & 4,442 & 1,201 \\
\hline
\end{tabular}

"_" = not applicable

Under both renewable energy scenarios, the FS and AS PSH plants provide a significant amount of total system needs for A/S in California. The addition of AS PSH substantially increases the provision of certain operating reserves such as regulation down and flexibility down. This is mainly due to operating characteristics of AS PSH which are characterized by:

1. Larger operating capacity range in the generating mode, and

2. The capability to provide regulation reserve in the pumping mode.

Detailed results for energy and A/S revenues of PSH are presented later in this section in Tables 4-30 and 4-31 for both the Base and High Wind renewable scenarios.

\section{California System Emissions}

Tables 4-24 and 4-25 give air pollutant emissions in California for three simulated cases under the Base and High Wind renewable scenarios, respectively.

Table 4-24 Comparison of California Emission Productions in Three Cases in 2022 for the Base Renewable Scenario

\begin{tabular}{|c|c|c|c|c|c|c|c|c|c|}
\hline \multirow{2}{*}{$\begin{array}{c}\text { Base Renewable } \\
\text { Scenario }\end{array}$} & \multirow{2}{*}{$\begin{array}{c}\mathrm{CO}_{2} \\
\text { (ton) }\end{array}$} & \multirow{2}{*}{$\begin{array}{l}\mathrm{NO}_{\mathrm{x}} \\
\text { (ton) }\end{array}$} & \multirow{2}{*}{$\begin{array}{l}\mathrm{SO}_{2} \\
\text { (ton) }\end{array}$} & \multicolumn{3}{|c|}{ Emission Reduction (ton) } & \multicolumn{3}{|c|}{$\begin{array}{c}\text { Emission } \\
\text { Reduction (\%) }\end{array}$} \\
\hline & & & & $\mathrm{CO}_{2}$ & $\mathrm{NO}_{\mathrm{x}}$ & $\mathrm{SO}_{2}$ & $\mathrm{CO}_{2}$ & $\mathrm{NO}_{\mathrm{x}}$ & $\mathrm{SO}_{2}$ \\
\hline No PSH & $65,429,529$ & 53,681 & 6,006 & 0 & 0 & 0 & 0.0 & 0.0 & 0.0 \\
\hline With FS PSH & $64,741,362$ & 53,512 & 6,093 & 688,166 & 170 & -87 & 1.1 & 0.3 & -1.5 \\
\hline With FS \& AS PSH & $64,625,964$ & 53,568 & 6,165 & 803,565 & 113 & -160 & 1.2 & 0.2 & -2.7 \\
\hline
\end{tabular}


Table 4-25 Comparison of California Emission Productions in Three Cases in 2022 for the High Wind Renewable Scenario

\begin{tabular}{|c|c|c|c|c|c|c|c|c|c|}
\hline \multirow{2}{*}{$\begin{array}{l}\text { High Wind } \\
\text { Renewable } \\
\text { Scenario }\end{array}$} & \multirow{2}{*}{$\begin{array}{c}\mathrm{CO}_{2} \\
\text { (ton) }\end{array}$} & \multirow{2}{*}{$\begin{array}{c}\mathrm{NO}_{\mathrm{x}} \\
\text { (ton) }\end{array}$} & \multirow{2}{*}{$\begin{array}{c}\mathrm{SO}_{2} \\
\text { (ton) }\end{array}$} & \multicolumn{3}{|c|}{ Emission Reduction (ton) } & \multicolumn{3}{|c|}{$\begin{array}{c}\text { Emission } \\
\text { Reduction (\%) }\end{array}$} \\
\hline & & & & $\mathrm{CO}_{2}$ & $\mathrm{NO}_{\mathrm{x}}$ & $\mathrm{SO}_{2}$ & $\mathrm{CO}_{2}$ & $\mathrm{NO}_{\mathrm{x}}$ & $\mathrm{SO}_{2}$ \\
\hline No PSH & $51,515,736$ & 44,936 & 5,334 & 0 & 0 & 0 & 0.0 & 0.0 & 0.0 \\
\hline With FS PSH & $49,692,105$ & 44,010 & 5,350 & $1,823,631$ & 925 & -16 & 3.5 & 2.1 & -0.3 \\
\hline With FS \& AS PSH & $47,904,187$ & 43,177 & 5,427 & $3,611,549$ & 1,759 & -93 & 7.0 & 3.9 & -1.7 \\
\hline
\end{tabular}

Carbon dioxide $\left(\mathrm{CO}_{2}\right)$ and nitrogen oxide $\left(\mathrm{NO}_{x)}\right.$ emissions decrease and sulfur dioxide $\left(\mathrm{SO}_{2}\right)$ emissions increase under both the Base and High Wind renewable scenarios. However, compared with the Base case, the total emission levels are significantly lower under the High Wind scenario.

\section{California Thermal Generator Cycling}

The number of starts and startup costs of thermal generators in three simulated cases under the two renewable scenarios are presented in Tables 4-26 and 4-27.

Table 4-26 Comparison of Number of Starts and Startup Costs of the California Thermal Generators in $\mathbf{2 0 2 2}$ for the Base Renewable Scenario

\begin{tabular}{|l|c|c|c|c|}
\hline & & Total Thermal & \multicolumn{2}{|c|}{ Cost Reduction } \\
\cline { 4 - 5 } $\begin{array}{c}\text { Base Renewable } \\
\text { Scenario }\end{array}$ & Total Number of & $\begin{array}{c}\text { Start Cost } \\
\text { (\$ million) }\end{array}$ & (\$ million) & (\%) \\
\hline No PSH & 18,514 & 56 & 0 & 0 \\
\hline With FS PSH & 14,646 & 46 & 10 & 17.35 \\
\hline With FS \&AS PSH & 12,134 & 36 & 20 & 35.40 \\
\hline
\end{tabular}

Table 4-27 Comparison of Number of Starts and Startup Costs of the California Thermal Generators in $\mathbf{2 0 2 2}$ for the High Wind Renewable Scenario

\begin{tabular}{|l|c|c|c|c|}
\hline & & Total Thermal & \multicolumn{2}{|c|}{ Cost Reduction } \\
\cline { 4 - 5 } $\begin{array}{c}\text { High Wind } \\
\text { Renewable Scenario }\end{array}$ & Total Number of & $\begin{array}{c}\text { Start Cost } \\
\text { (\$ million) }\end{array}$ & (\$ million) & (\%) \\
\hline The PSH & 17,862 & 54 & 0 & 0 \\
\hline With FS PSH & 14,351 & 44 & 11 & 19.56 \\
\hline With FS \& AS PSH & 11,864 & 35 & 20 & 36.42 \\
\hline
\end{tabular}

In both the Base and High Wind renewable scenarios, the number of generating unit starts and total startup costs of thermal generators are reduced substantially as more PSH plants are introduced into the system. 


\section{California Thermal Generator Ramping}

Tables 4-28 and 4-29 show the comparisons of the ramp up and down of thermal generators for the three simulated cases under the Base and High Wind renewable scenarios, respectively.

Table 4-28 Comparison of Thermal Generator Ramp Up and Down of the California Thermal Generators in $\mathbf{2 0 2 2}$ for the Base Renewable Scenario

\begin{tabular}{|c|c|c|c|c|c|c|}
\hline \multirow[b]{2}{*}{$\begin{array}{c}\text { Base Renewable } \\
\text { Scenario }\end{array}$} & \multirow{2}{*}{$\begin{array}{c}\text { Total } \\
\text { Thermal } \\
\text { Generator } \\
\text { Ramp Up } \\
\text { (GW) }\end{array}$} & \multirow{2}{*}{\begin{tabular}{|c|} 
Total \\
Thermal \\
Generator \\
Ramp Down \\
(GW)
\end{tabular}} & \multicolumn{2}{|c|}{ Ramp-Up Reduction } & \multicolumn{2}{|c|}{$\begin{array}{l}\text { Ramp-Down } \\
\text { Reduction }\end{array}$} \\
\hline & & & $(G W)$ & $(\%)$ & $(G W)$ & (\%) \\
\hline No PSH & 4,273 & 6,603 & 0 & 0 & 0 & 0 \\
\hline With FS PSH & 3,623 & 5,552 & 650 & 15.20 & 1,052 & 15.93 \\
\hline With FS \& AS PSH & 2,924 & 4,456 & 1,349 & 31.56 & 2,147 & 32.51 \\
\hline
\end{tabular}

Table 4-29 Comparison of Thermal Generator Ramp Up and Down of the Califoirnia Thermal Generators in $\mathbf{2 0 2 2}$ for the High Wind Renewable Scenario

\begin{tabular}{|c|c|c|c|c|c|c|}
\hline \multirow{2}{*}{$\begin{array}{l}\text { High Wind } \\
\text { Renewable } \\
\text { Scenario }\end{array}$} & \multirow{2}{*}{$\begin{array}{c}\text { Total } \\
\text { Thermal } \\
\text { Generator } \\
\text { Ramp Up } \\
\text { (GW) }\end{array}$} & \multirow{2}{*}{$\begin{array}{c}\text { Total } \\
\text { Thermal } \\
\text { Generator } \\
\text { Ramp Down } \\
\text { (GW) }\end{array}$} & \multicolumn{2}{|c|}{ Ramp-Up Reduction } & \multicolumn{2}{|c|}{$\begin{array}{l}\text { Ramp-Down } \\
\text { Reduction }\end{array}$} \\
\hline & & & $(G W)$ & $(\%)$ & $(G W)$ & $(\%)$ \\
\hline No PSH & 3,609 & 5,681 & 0 & 0 & 0 & 0 \\
\hline With FS PSH & 3,078 & 4,737 & 531 & 14.71 & 945 & 16.63 \\
\hline With FS\&AS PSH & 2,396 & 3,738 & 1,214 & 33.63 & 1,943 & 34.20 \\
\hline
\end{tabular}

Under both renewable energy scenarios, the ramping up and down of thermal generators is reduced substantially as more PSHs are introduced into the system.

\section{California Regional LMPs}

Figure 4-8 shows a comparison of average regional LMPs for the selected regions in California under the Base renewable energy scenario. As more PSH plants are introduced into the system, the average regional LMPs increase in all regions.

Figure 4-9 shows the average regional LMPs under the High Wind renewable scenario. Again, the average regional LMPs increase as more PSH capacity is introduced into the system. However, it should be noted that the level of regional LMPs under the High Wind renewable scenario is much lower (about 50\%) than under the Base renewable scenario. 


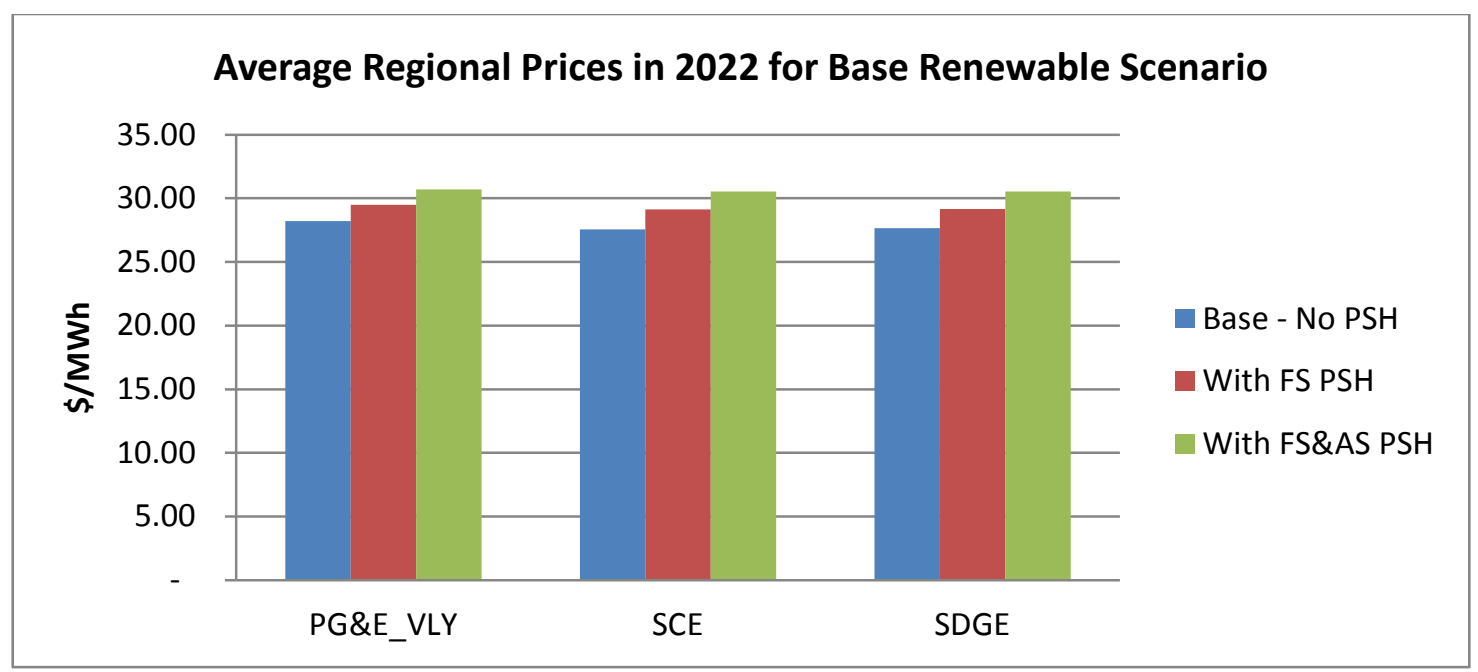

Figure 4-8 Comparison of Regional LMPs in Three Cases for the Selected Regions in California in 2022 for the Base Renewable Scenario

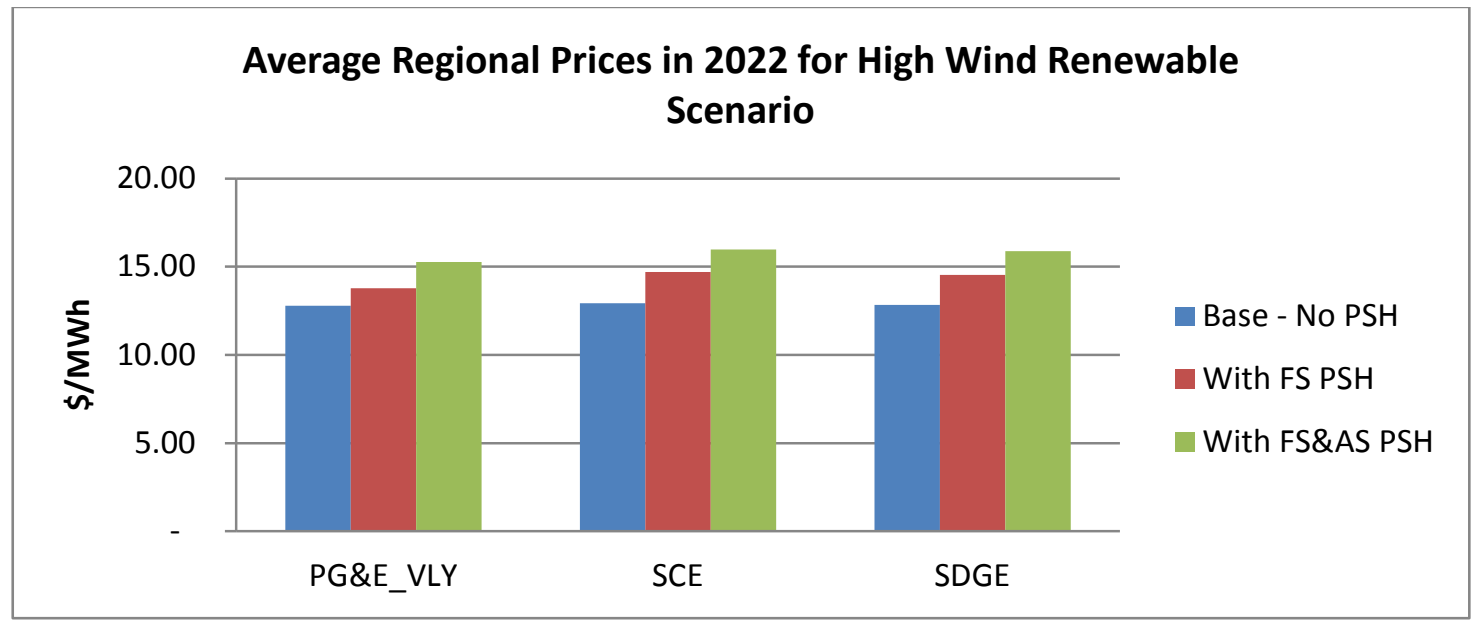

Figure 4-9 Comparison of Regional LMPs in Three Cases for the Selected Regions in California in $\mathbf{2 0 2 2}$ for the High Wind Renewable Scenario

By examining simulation results for hourly LMPs in Southern California Edison (SCE) during the week of July 17, 2022, as shown in Figure 4-10, it can be seen that PSH plants are in the pumping mode during the low-LMP hours, which increases electricity prices in those hours. While there are some price reductions during the high-LMP hours because of the PSH generation, the magnitude of the price increase during the pumping hours is much higher than the magnitude of the price decrease during the PSH generating hours. Therefore, the average regional LMPs increase as more PSHs are introduced into the California system. 


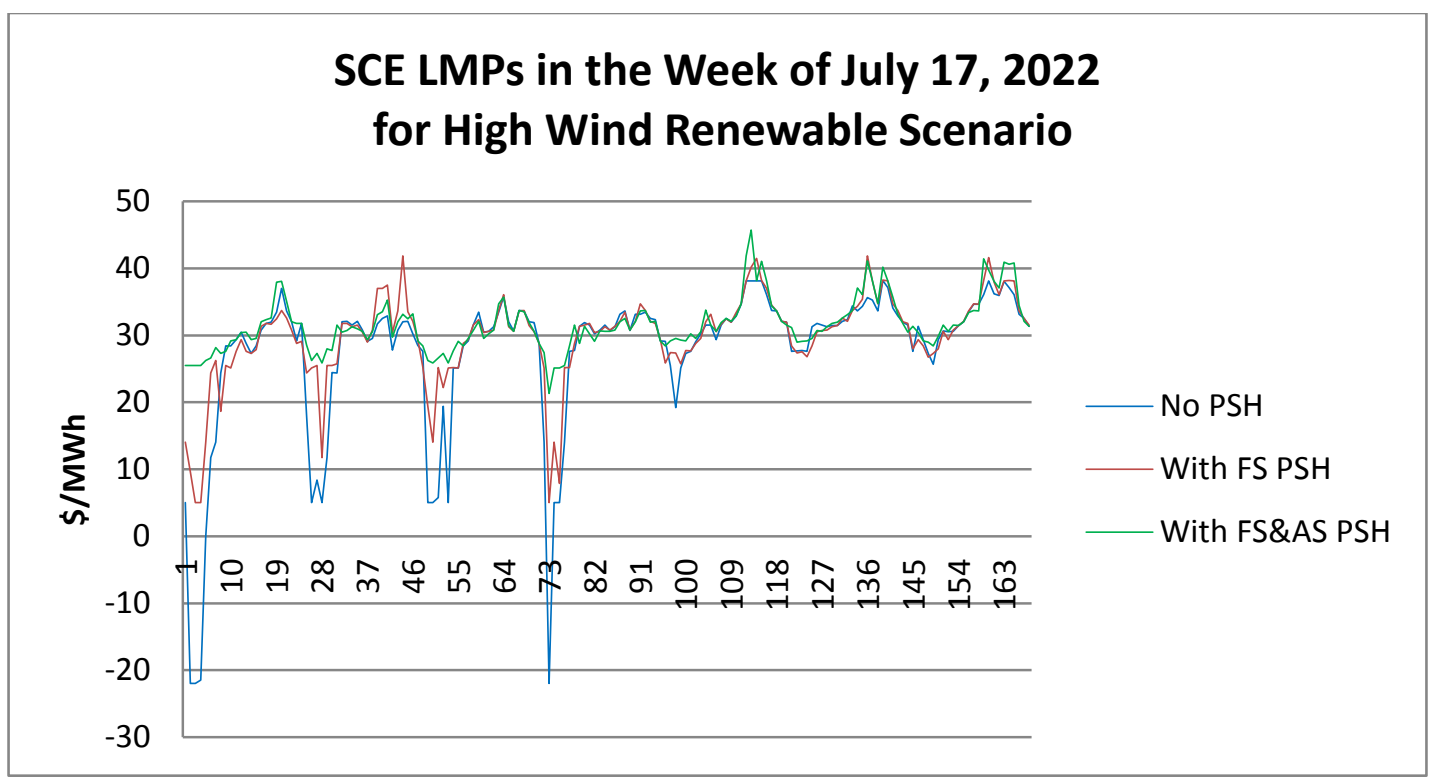

Figure 4-10 SCE LMP in the Week of July 17, 2022, in Three Cases for the High Wind Renewable Scenario

\section{California Generator Energy and Ancillary Services Revenue}

The impacts of PSH plants on California generation and A/S revenues under the Base and High Wind renewable scenarios are shown in Tables 4-30 and 4-31, respectively.

The power exchanges between California and the rest of WI are not included in Tables 4-30 and 4-31. Also, the A/S revenues may be higher than expected because of the introduction of the flexibility up and down reserves. The flexibility reserves are currently not administered in CAISO, but are expected to be introduced in the future.

The simulations are performed for the entire California footprint. The revenue calculations also include the non-CAISO utilities operating within the California footprint. The forecasted generation costs and revenues should be treated as an indicator of how PSH plants may impact a bid-based electricity market.

From PLEXOS simulation results, it can be observed that:

1. Under both the Base and High Wind renewable scenarios, the CA system net revenues (defined here as the total energy and A/S revenues minus the total generation cost) increase as more PSH capacity is introduced into the system.

2. The energy revenue also increases as more PSH plants are introduced into the system due to the average LMPs increasing as more PSHs are introduced into the system. 
Table 4-30 California Generator Generation, Generation Cost, Energy Revenue, and Ancillary Service Revenue for the Base Renewable Scenario in 2022

\begin{tabular}{|c|c|c|c|c|c|c|c|c|c|c|c|c|c|c|c|}
\hline \multirow[b]{2}{*}{$\begin{array}{c}\text { Generator } \\
\text { Type }\end{array}$} & \multicolumn{5}{|c|}{ No PSH } & \multicolumn{5}{|c|}{ With FS PSH } & \multicolumn{5}{|c|}{ With FS \& AS PSH } \\
\hline & $\begin{array}{c}\text { Generation } \\
\text { (GWh) }\end{array}$ & \begin{tabular}{|c|} 
Total \\
Generation \\
Cost \\
$(\$ 1,000)$ \\
\end{tabular} & $\begin{array}{c}\text { Energy } \\
\text { Revenue } \\
(\$ 1,000)\end{array}$ & $\begin{array}{l}\text { Reserves } \\
\text { Revenue } \\
(\$ 1,000)\end{array}$ & $\begin{array}{c}\text { Net } \\
\text { Revenue } \\
(\$ 1,000)\end{array}$ & $\begin{array}{c}\text { Generation } \\
\text { (GWh) }\end{array}$ & $\begin{array}{c}\text { Total } \\
\text { Generation } \\
\text { Cost } \\
(\$ 1,000) \\
\end{array}$ & $\begin{array}{c}\text { Energy } \\
\text { Revenue } \\
(\$ 1,000)\end{array}$ & $\begin{array}{l}\text { Reserves } \\
\text { Revenue } \\
(\$ 1,000)\end{array}$ & $\begin{array}{c}\text { Net } \\
\text { Revenue } \\
(\$ 1,000)\end{array}$ & $\begin{array}{c}\text { Generation } \\
\text { (GWh) }\end{array}$ & $\begin{array}{c}\text { Total } \\
\text { Generation } \\
\text { Cost } \\
(\$ 1,000) \\
\end{array}$ & $\begin{array}{c}\text { Energy } \\
\text { Revenue } \\
(\$ 1,000)\end{array}$ & $\begin{array}{l}\text { Reserves } \\
\text { Revenue } \\
(\$ 1,000)\end{array}$ & $\begin{array}{c}\text { Net } \\
\text { Revenue } \\
(\$ 1,000)\end{array}$ \\
\hline CC & 76,184 & \begin{tabular}{|r|}
$2,889,437$ \\
\end{tabular} & $2,398,856$ & 449,040 & $(41,541)$ & 74,151 & $2,785,726$ & $2,384,914$ & 461,270 & 60,458 & 73,279 & $2,725,054$ & $2,388,034$ & 411,989 & 74,96 \\
\hline Coal & 15,459 & 192,999 & 605,524 & 7,925 & 420,450 & 15,588 & 194,690 & 918,118 & 7,860 & 731,289 & 15,632 & 195,320 & 800,265 & 8,865 & 613,81 \\
\hline CoGen & 8,134 & 246,545 & 237,723 & 0 & $(8,822)$ & 8,185 & 247,069 & 247,283 & 0 & 214 & 8,376 & 251,955 & 260,483 & 0 & $8,52 \varepsilon$ \\
\hline CT & 6,535 & 480,617 & 189,683 & 187,170 & $(103,764)$ & 6,158 & 461,234 & 184,953 & 171,255 & $(105,026)$ & 5,804 & 445,010 & 180,763 & 163,484 & $(100,76$ \\
\hline Hydro & 38,682 & 1,048 & $1,077,887$ & 102,187 & $1,179,026$ & 38,702 & 964 & $1,125,789$ & 98,138 & $1,222,963$ & 38,710 & 901 & $1,184,057$ & 53,831 & $1,236,98 \varepsilon$ \\
\hline Nuclear & 37,271 & 524,535 & $1,015,093$ & 0 & 490,559 & 37,465 & 527,262 & $1,074,099$ & 0 & 546,836 & 37,638 & 529,702 & $1,134,143$ & 0 & 604,441 \\
\hline Other & 7,398 & 4,314 & 200,984 & 1,123 & 197,792 & 7,397 & 4,163 & 211,870 & 740 & 208,447 & 7,378 & 3,240 & 222,362 & 313 & 219,435 \\
\hline RPS & 67,161 & 258,062 & $1,729,433$ & 0 & $1,471,371$ & 67,908 & 266,297 & $1,862,716$ & 0 & $1,596,420$ & 68,537 & 277,600 & $1,999,881$ & 0 & $1,722,281$ \\
\hline Steam & 8,712 & 478,901 & 238,647 & 49,994 & $(190,260)$ & 8,722 & 479,213 & 251,879 & 49,946 & $(177,389)$ & 8,705 & 477,742 & 263,563 & 44,300 & $(169,880)$ \\
\hline DR & 2 & 1,054 & 1,054 & 17,412 & 17,412 & 1 & 330 & 330 & 13,873 & 13,873 & 0 & 178 & 178 & 1,890 & 1,89 \\
\hline FS PSH & & & & & 0 & 2,725 & 0 & 102,302 & 18,205 & 120,507 & 1,551 & 0 & 53,826 & 14,831 & 68,657 \\
\hline AS PSH & & & & & 0 & & & & & 0 & 3,763 & 0 & 127,728 & 37,074 & 164,802 \\
\hline Total & 265,538 & 5,077,510 & $7,694,883$ & 814,849 & $3,432,222$ & 267,001 & \begin{tabular}{|l|}
$4,966,947$ \\
\end{tabular} & $8,364,252$ & 821,287 & $4,218,593$ & 269,374 & $4,906,701$ & $8,615,283$ & 736,576 & $4,445,158$ \\
\hline
\end{tabular}


Table 4-31 California Generator Generation, Generation Cost, Energy Revenue, and Ancillary Service Revenue for the High Wind Renewable Scenario in 2022

\begin{tabular}{|c|c|c|c|c|c|c|c|c|c|c|c|c|c|c|c|}
\hline \multirow[b]{2}{*}{$\begin{array}{c}\text { Generator } \\
\text { Type }\end{array}$} & \multicolumn{5}{|c|}{ No PSH } & \multicolumn{5}{|c|}{ With FS PSH } & \multicolumn{5}{|c|}{ With FS \& AS PSH } \\
\hline & \begin{tabular}{|c|}
$\begin{array}{c}\text { Generation } \\
\text { (GWh) }\end{array}$ \\
\end{tabular} & \begin{tabular}{|c|} 
Total \\
Generation \\
Cost \\
$(\$ 1,000)$ \\
\end{tabular} & $\begin{array}{c}\text { Energy } \\
\text { Revenue } \\
(\$ 1,000) \\
\end{array}$ & $\begin{array}{l}\text { Reserves } \\
\text { Revenue } \\
(\$ 1,000) \\
\end{array}$ & $\begin{array}{c}\text { Net } \\
\text { Revenue } \\
(\$ 1,000) \\
\end{array}$ & $\begin{array}{c}\text { Generation } \\
\text { (GWh) }\end{array}$ & \begin{tabular}{|c|} 
Total \\
Generation \\
Cost \\
$(\$ 1,000)$ \\
\end{tabular} & $\begin{array}{c}\text { Energy } \\
\text { Revenue } \\
(\$ 1,000) \\
\end{array}$ & $\begin{array}{l}\text { Reserves } \\
\text { Revenue } \\
(\$ 1,000) \\
\end{array}$ & $\begin{array}{c}\text { Net } \\
\text { Revenue } \\
(\$ 1,000) \\
\end{array}$ & $\begin{array}{c}\text { Generation } \\
\text { (GWh) }\end{array}$ & \begin{tabular}{|c|} 
Total \\
Generation \\
Cost \\
$(\$ 1,000)$ \\
\end{tabular} & $\begin{array}{c}\text { Energy } \\
\text { Revenue } \\
(\$ 1,000) \\
\end{array}$ & $\begin{array}{l}\text { Reserves } \\
\text { Revenue } \\
(\$ 1,000) \\
\end{array}$ & $\begin{array}{c}\text { Net } \\
\text { Revenue } \\
(\$ 1,000) \\
\end{array}$ \\
\hline CC & 52,802 & $2,053,833$ & $1,081,713$ & 655,103 & $(317,017)$ & 48,666 & \begin{tabular}{|l|}
$1,873,071$ \\
\end{tabular} & $1,070,992$ & 677,108 & $(124,970)$ & 44,339 & $1,692,346$ & $1,055,120$ & 542,556 & $(94,670)$ \\
\hline Coal & 13,518 & 170,464 & 455,827 & 26,231 & 311,594 & 13,496 & 169,973 & 215,339 & 25,965 & 71,332 & 13,508 & 170,130 & 290,909 & 26,634 & 147,413 \\
\hline CoGen & 6,715 & 207,040 & 115,144 & 0 & $(91,896)$ & 6,636 & 203,757 & 121,289 & 0 & $(82,468)$ & 6,599 & 200,964 & 127,397 & 0 & $(73,567)$ \\
\hline CT & 6,641 & 497,018 & 84,280 & 278,700 & $(134,039)$ & 6,519 & 491,018 & 85,483 & 268,850 & $(136,685)$ & 6,279 & 478,730 & 91,018 & 264,313 & $(123,399)$ \\
\hline Hydro & 37,805 & 2,755 & 517,907 & 179,687 & 694,839 & 37,983 & 2,799 & 555,414 & 200,595 & 753,210 & 38,228 & 3,359 & 626,609 & 86,044 & 709,294 \\
\hline Nuclear & 36,164 & 508,959 & 439,944 & 0 & $(69,015)$ & 36,338 & 511,405 & 490,219 & 0 & $(21,187)$ & 36,718 & 516,753 & 542,632 & 0 & 25,879 \\
\hline Other & 7,242 & 4,730 & 89,704 & 2,524 & 87,498 & 7,257 & 4,895 & 99,163 & 2,117 & 96,386 & 7,258 & 3,893 & 109,737 & 1,624 & 107,468 \\
\hline RPS & 84,324 & 193,104 & 796,763 & 0 & 603,659 & 85,218 & 195,940 & 909,511 & 0 & 713,572 & 86,058 & 201,095 & $1,061,961$ & 0 & 860,865 \\
\hline Steam & 8,659 & 480,878 & 109,182 & 76,998 & $(294,698)$ & 8,656 & 481,331 & 123,460 & 77,732 & $(280,139)$ & 8,574 & 476,971 & 135,780 & 71,432 & $(269,759)$ \\
\hline DR & 3 & 1,655 & 1,655 & 27,858 & 27,858 & 0 & 30 & 30 & 25,083 & 25,083 & 1 & 384 & 384 & 9,990 & 9,990 \\
\hline FS PSH & & & & & & 5,299 & 0 & 147,285 & 32,122 & 179,407 & 4,480 & 0 & 98,534 & 27,166 & 125,700 \\
\hline AS PSH & & & & & & & & & & & 4,976 & 0 & 118,769 & 58,985 & 177,754 \\
\hline Total & \begin{tabular}{|l|}
253,872 \\
\end{tabular} & \begin{tabular}{|l|}
$4,120,437$ \\
\end{tabular} & $3,692,120$ & $1,247,100$ & 818,783 & 256 & \begin{tabular}{|r|}
$3,934,218$ \\
\end{tabular} & $3,818,185$ & \begin{tabular}{|l|}
$1,309,572$ \\
\end{tabular} & $1,193,539$ & 257,018 & $3,744,626$ & $4,258,850$ & $1,088,744$ & $1,602,968$ \\
\hline
\end{tabular}


3. The total A/S revenues for the California system as a whole remain approximately the same as more PSH plants are introduced into the system. However, the share of A/S revenues of PSH plants increases as more PSH capacity is introduced into the system.

4. The total energy revenues for the entire system are lower under the High Wind renewable scenario as opposed to the Base renewable scenario. This is because the average LMPs are significantly lower under the High Wind renewable scenario.

5. The reserve revenues are higher under the High Wind renewable scenario than under the Base renewable scenario. The reason is that greater needs for flexibility and regulation reserves under the High Wind renewable scenario yield higher A/S prices.

6. The reserve revenue is less than $10 \%$ of the total market revenue (energy revenue plus reserve revenue) under the Base renewable scenario. The reserve revenue increases to about $25 \%$ of the total market revenue for the High Wind renewable scenario because of higher flexibility and regulation reserve requirements under this scenario.

7. It should be noted that, especially in the High Wind scenario, there are many generators that have negative net revenues. Such units include CCs, CTs, steam units, and even nuclear units. The reason is that there are many hours with excess generation available in the system, which causes negative LMPs to occur, especially under the High Wind renewable scenario. Also, the calculated LMPs do not reflect generator startup cost and no-load cost, while CAISO compensates these generators for the startup and no-load cost (CAISO 2013). Therefore, the net revenues shown in the following tables do not include this type of compensation.

Please note that, in Tables 4-30 and 4-31, the pumping cost is not subtracted from the PSH revenues. However, the pumping cost is subtracted from the PSH revenues in Tables 4-32 through 4-35.

Tables 4-32 through 4-35 list the net revenues of the FS and AS PSHs for the Base and High Wind renewable scenarios, respectively. 
Table 4-32 California PSH Net Revenues in 2022 under the Base Renewable Scenario: Simulations with FS PSHs

\begin{tabular}{|c|c|}
\hline Product & FS PSHs \\
\hline \multicolumn{2}{|l|}{ Energy: } \\
\hline Energy generation (GWh) & 2,725 \\
\hline Pump energy (GWh) & 3,840 \\
\hline Generation cost $(\$ 1,000)$ & 0 \\
\hline Pump cost $(\$ 1,000)$ & 65,768 \\
\hline Energy revenue $(\$ 1,000)$ & 102,302 \\
\hline Subtotal Energy Net Revenue $(\$ 1,000)$ & 36,533 \\
\hline \multicolumn{2}{|l|}{ Ancillary Services (A/S): } \\
\hline \multicolumn{2}{|l|}{ Non-Spinning Reserve } \\
\hline A/S Provision (GWh) & 7,090 \\
\hline A/S Revenue $(\$ 1,000)$ & 7,557 \\
\hline \multicolumn{2}{|l|}{ Spinning Reserve } \\
\hline A/S Provision (GWh) & 224 \\
\hline A/S Revenue $(\$ 1,000)$ & 1,218 \\
\hline \multicolumn{2}{|l|}{ Flexibility Down } \\
\hline A/S Provision (GWh) & 47 \\
\hline A/S Revenue $(\$ 1,000)$ & 389 \\
\hline \multicolumn{2}{|l|}{ Flexibility Up } \\
\hline A/S Provision (GWh) & 13 \\
\hline A/S Revenue $(\$ 1,000)$ & 43 \\
\hline \multicolumn{2}{|l|}{ Regulation Down } \\
\hline A/S Provision (GWh) & 171 \\
\hline A/S Revenue $(\$ 1,000)$ & 4,562 \\
\hline \multicolumn{2}{|l|}{ Regulation Up } \\
\hline A/S Provision (GWh) & 164 \\
\hline A/S Revenue $(\$ 1,000)$ & 4,436 \\
\hline Total A/S Provision (GWh) & 7,709 \\
\hline Subtotal A/S Revenue $(\$ 1,000)$ & 18,205 \\
\hline Total Net Revenue $(\$ 1,000)$ & 54,739 \\
\hline Total PSH Capacity (MW) & 2,626 \\
\hline Annual Net Revenue Rate (\$/kW-yr) & 20.84 \\
\hline
\end{tabular}


Table 4-33 California PSH Net Revenues in 2022 under the Base Renewable Scenario: Simulations with FS and AS PSHs

\begin{tabular}{|c|c|c|c|}
\hline Product & FS PSHs & AS PSHs & Total \\
\hline \multicolumn{4}{|l|}{ Energy: } \\
\hline Energy generation (GWh) & 1,551 & 3,763 & 5,313 \\
\hline Pump energy (GWh) & 2,180 & 4,676 & 6,856 \\
\hline Generation cost $(\$ 1,000)$ & 0 & 0 & 0 \\
\hline Pump cost $(\$ 1,000)$ & 43,985 & 120,523 & 164,508 \\
\hline Energy revenue $(\$ 1,000)$ & 53,826 & 127,728 & 181,554 \\
\hline Subtotal Energy Net Revenue $(\$ 1,000)$ & 9,841 & 7,205 & 17,046 \\
\hline \multicolumn{4}{|l|}{ Ancillary Services (A/S): } \\
\hline \multicolumn{4}{|l|}{ Non-Spinning Reserve } \\
\hline A/S Provision (GWh) & 7,469 & 436 & 7,905 \\
\hline A/S Revenue $(\$ 1,000)$ & 8,310 & 253 & 8,563 \\
\hline \multicolumn{4}{|l|}{ Spinning Reserve } \\
\hline A/S Provision (GWh) & 126 & 2,337 & 2,463 \\
\hline A/S Revenue $(\$ 1,000)$ & 769 & 7,819 & 8,588 \\
\hline \multicolumn{4}{|l|}{ Flexibility Down } \\
\hline A/S Provision (GWh) & 20 & 1,078 & 1,098 \\
\hline A/S Revenue $(\$ 1,000)$ & 165 & 5,564 & 5,728 \\
\hline \multicolumn{4}{|l|}{ Flexibility Up } \\
\hline A/S Provision (GWh) & 19 & 322 & 341 \\
\hline A/S Revenue $(\$ 1,000)$ & 74 & 657 & 731 \\
\hline \multicolumn{4}{|l|}{ Regulation Down } \\
\hline A/S Provision (GWh) & 103 & 1,161 & 1,264 \\
\hline A/S Revenue $(\$ 1,000)$ & 2,661 & 17,698 & 20,360 \\
\hline \multicolumn{4}{|l|}{ Regulation Up } \\
\hline A/S Provision (GWh) & 104 & 1,005 & 1,109 \\
\hline A/S Revenue $(\$ 1,000)$ & 2,852 & 5,083 & 7,935 \\
\hline Total A/S Provision (GWh) & 7,841 & 6,339 & 14,180 \\
\hline Subtotal A/S Revenue $(\$ 1,000)$ & 14,831 & 37,074 & 51,905 \\
\hline Total Net Revenue $(\$ 1,000)$ & 24,671 & 44,279 & 68,951 \\
\hline Total PSH Capacity (MW) & 2,626 & 1,799 & 4,425 \\
\hline Annual Net Revenue Rate (\$/kW-yr) & 9.40 & 24.61 & 15.58 \\
\hline
\end{tabular}


Table 4-34 California PSH Net Revenues in 2022 under the High Wind Renewable Scenario: Simulations with FS PSHs

\begin{tabular}{|c|c|}
\hline Product & FS PSHs \\
\hline \multicolumn{2}{|l|}{ Energy: } \\
\hline Energy generation (GWh) & 5,299 \\
\hline Pump energy (GWh) & 7,501 \\
\hline Generation cost $(\$ 1,000)$ & 0 \\
\hline Pump cost $(\$ 1,000)$ & $(13,229)$ \\
\hline Energy revenue $(\$ 1,000)$ & 147,285 \\
\hline Subtotal Energy Net Revenue $(\$ 1,000)$ & 160,514 \\
\hline \multicolumn{2}{|l|}{ Ancillary Services (A/S): } \\
\hline \multicolumn{2}{|l|}{ Non-Spinning Reserve } \\
\hline A/S Provision (GWh) & 4,774 \\
\hline A/S Revenue $(\$ 1,000)$ & 5,246 \\
\hline \multicolumn{2}{|l|}{ Spinning Reserve } \\
\hline A/S Provision (GWh) & 247 \\
\hline A/S Revenue $(\$ 1,000)$ & 1,515 \\
\hline \multicolumn{2}{|l|}{ Flexibility Down } \\
\hline A/S Provision (GWh) & 141 \\
\hline A/S Revenue $(\$ 1,000)$ & 1,626 \\
\hline \multicolumn{2}{|l|}{ Flexibility Up } \\
\hline A/S Provision (GWh) & 26 \\
\hline A/S Revenue $(\$ 1,000)$ & 80 \\
\hline \multicolumn{2}{|l|}{ Regulation Down } \\
\hline A/S Provision (GWh) & 377 \\
\hline A/S Revenue $(\$ 1,000)$ & 19,511 \\
\hline \multicolumn{2}{|l|}{ Regulation Up } \\
\hline A/S Provision (GWh) & 144 \\
\hline A/S Revenue $(\$ 1,000)$ & 4,144 \\
\hline Total A/S Provision (GWh) & 5,709 \\
\hline Subtotal A/S Revenue $(\$ 1,000)$ & 32,122 \\
\hline Total Net Revenue $(\$ 1,000)$ & 192,636 \\
\hline Total PSH Capacity (MW) & 2,626 \\
\hline Annual Net Revenue Rate (\$/kW-yr) & 73.36 \\
\hline
\end{tabular}


Table 4-35 California PSH Net Revenues in 2022 under the High Wind Renewable Scenario: Simulations with FS and AS PSHs

\begin{tabular}{|c|c|c|c|}
\hline Product & FS PSHs & AS PSHs & Total \\
\hline \multicolumn{4}{|l|}{ Energy: } \\
\hline Energy generation (GWh) & 4,480 & 4,976 & 9,456 \\
\hline Pump energy (GWh) & 6,338 & 6,183 & 12,521 \\
\hline Generation cost $(\$ 1,000)$ & 0 & 0 & 0 \\
\hline Pump cost $(\$ 1,000)$ & $(6,028)$ & 31,074 & 25,045 \\
\hline Energy revenue $(\$ 1,000)$ & 98,534 & 118,769 & 217,302 \\
\hline Subtotal Energy Net Revenue $(\$ 1,000)$ & 104,562 & 87,695 & 192,257 \\
\hline \multicolumn{4}{|l|}{ Ancillary Services (A/S): } \\
\hline \multicolumn{4}{|l|}{ Non-Spinning Reserve } \\
\hline A/S Provision (GWh) & 5,359 & 133 & 5,492 \\
\hline A/S Revenue $(\$ 1,000)$ & 6,125 & 59 & 6,184 \\
\hline \multicolumn{4}{|l|}{ Spinning Reserve } \\
\hline A/S Provision (GWh) & 254 & 1,768 & 2,022 \\
\hline A/S Revenue $(\$ 1,000)$ & 1,501 & 4,707 & 6,208 \\
\hline \multicolumn{4}{|l|}{ Flexibility Down } \\
\hline A/S Provision (GWh) & 139 & 1,795 & 1,934 \\
\hline A/S Revenue $(\$ 1,000)$ & 1,695 & 13,239 & 14,934 \\
\hline \multicolumn{4}{|l|}{ Flexibility Up } \\
\hline A/S Provision (GWh) & 45 & 155 & 200 \\
\hline A/S Revenue $(\$ 1,000)$ & 148 & 265 & 412 \\
\hline \multicolumn{4}{|l|}{ Regulation Down } \\
\hline A/S Provision (GWh) & 272 & 1,489 & 1,761 \\
\hline A/S Revenue $(\$ 1,000)$ & 13,830 & 36,055 & 49,885 \\
\hline \multicolumn{4}{|l|}{ Regulation Up } \\
\hline A/S Provision (GWh) & 137 & 1,064 & 1,201 \\
\hline A/S Revenue $(\$ 1,000)$ & 3,868 & 4,660 & 8,528 \\
\hline Total A/S Provision (GWh) & 6,206 & 6,405 & 12,611 \\
\hline Subtotal A/S Revenue $(\$ 1,000)$ & 27,166 & 58,985 & 86,151 \\
\hline Total Net Revenue $(\$ 1,000)$ & 131,728 & 146,680 & 278,408 \\
\hline Total PSH Capacity (MW) & 2,626 & 1,799 & 4,425 \\
\hline Annual Net Revenue Rate $(\$ / k W-y r)$ & 50.16 & 81.53 & 62.92 \\
\hline
\end{tabular}

From the above tables the following can be observed:

1. The pumping energy cost is negative for the High Wind renewable scenario. This indicates that PSH plants mostly use curtailed renewable energy for pumping. This pumping load helps the integration of a larger share of variable renewable energy generation into the system. 
2. Compared with the FS PSH plants, the AS ones have much higher reserve revenues because AS PSH plants can also provide reserves in the pumping mode of operation, and they have a wider range of operating capacity than the FS PSH plants.

\section{California Transmission Congestions}

The simulations for the California footprint performed under the Base renewable generation scenario show that the average transmission congestion price in California decreases from \$3.51/MWh in the case of "no PSHs" to \$0.4/MWh in the case of "with FS PSHs," and further to $\$ 0.24 / \mathrm{MWh}$ in the case of "with FS and AS PSHs." The greatest congestion price reduction is observed for the interface "P27 Intermountain Power Project DC Line."

As for the simulations of the WI system, a simplified transmission expansion analysis was performed for California for the High Wind renewable generation scenario so that the power can be delivered from renewable generation buses to load buses. The approach used for transmission expansion in California was the same as that applied for WI.

The simulations for the California footprint performed for the High Wind renewable scenario show that the average California transmission congestion price decreases from \$1.79/MWh in the case of "No PSHs" to $\$ 0.56 / \mathrm{MWh}$ in the case of "with FS PSHs," and further to $\$ 0.37 / \mathrm{MWh}$ in the case of "with FS and AS PSHs." Again, the greatest congestion price reduction is observed for the interface "P27 Intermountain Power Project DC Line."

\subsubsection{SMUD Simulation Results}

Before simulating the SMUD footprint, the entire WI system was simulated to determine the power flows in all transmission lines crossing the border of SMUD and the rest of the WI grid. The WI system was simulated for both the Base and the High Wind renewable scenarios.

Then the SMUD system was extracted from the WI grid. The power exchanges between SMUD and the rest of the WI were determined from the simulations of the entire WI system and were kept the same for SMUD simulations. Since there is no significant transmission congestion within the SMUD footprint, the SMUD grid was modeled at a regional (zonal) level; that is, the SMUD grid was represented by a single node.

The key objective of SMUD simulations was to examine the impact of PSH capacity on a utility portfolio. SMUD is considering the development of an AS PSH project (Iowa Hill, $400 \mathrm{MW}$ ). Because the exchange flows between SMUD and the rest of WI were frozen for SMUD simulations, the power exchanges are not included in the simulation results presented in the following subsections.

\section{SMUD System Production Costs}

Since SMUD is planning on constructing an AS PSH plant, the PLEXOS simulations were performed for two cases in 2022: (1) no PSH plants, and (2) with an AS PSH plant. Both cases were simulated for the Base and High Wind renewable generation scenarios. The key production cost results for both scenarios are presented in Tables 4-36 and 4-37, respectively. 
Table 4-36 Comparison of SMUD Production Cost in Two Cases

for the Base Renewable Scenario in 2022

\begin{tabular}{|c|c|c|c|c|c|c|c|}
\hline \multirow{2}{*}{$\begin{array}{c}\text { Base } \\
\text { Renewable } \\
\text { Scenario }\end{array}$} & \multirow{2}{*}{$\begin{array}{c}\text { Total } \\
\text { Generation } \\
\text { (GWh) }\end{array}$} & \multirow{2}{*}{$\begin{array}{c}\text { PSH } \\
\text { Generation } \\
\text { (GWh) }\end{array}$} & \multirow{2}{*}{$\begin{array}{l}\text { Production } \\
\text { Cost } \\
\text { (\$ million) }\end{array}$} & \multicolumn{2}{|c|}{$\begin{array}{l}\text { Annual Cost } \\
\text { Reduction }\end{array}$} & \multicolumn{2}{|c|}{$\begin{array}{c}\text { Annual Cost } \\
\text { Reduction per kW of } \\
\text { PSH Capacity }\end{array}$} \\
\hline & & & & (\$ million) & $(\%)$ & $\begin{array}{c}\text { Total PSH } \\
\text { (MW) }\end{array}$ & (\$/kw-yr) \\
\hline No PSH & 16,100 & - & 269 & - & - & - & - \\
\hline With AS PSH & 16,273 & 467 & 246 & 23 & 8.62 & 400 & 58.04 \\
\hline
\end{tabular}

"_" = not applicable

Table 4-37 Comparison of SMUD Production Cost in Two Cases for the High Wind Renewable Scenario in 2022

\begin{tabular}{|c|c|c|c|c|c|c|c|}
\hline \multirow{2}{*}{$\begin{array}{l}\text { High Wind } \\
\text { Renewable } \\
\text { Scenario } \\
\end{array}$} & \multirow{2}{*}{$\begin{array}{c}\text { Total } \\
\text { Generation } \\
\text { (GWh) } \\
\end{array}$} & \multirow{2}{*}{$\begin{array}{c}\text { PSH } \\
\text { Generation } \\
\text { (GWh) } \\
\end{array}$} & \multirow{2}{*}{$\begin{array}{l}\text { Production } \\
\text { Cost } \\
\text { (\$ million) }\end{array}$} & \multicolumn{2}{|c|}{$\begin{array}{c}\text { Annual Cost } \\
\text { Reduction }\end{array}$} & \multicolumn{2}{|c|}{$\begin{array}{c}\text { Annual Cost } \\
\text { Reduction per kW of } \\
\text { PSH Capacity }\end{array}$} \\
\hline & & & & (\$ million) & $(\%)$ & $\begin{array}{c}\text { Total PSH } \\
\text { (MW) }\end{array}$ & $(\$ / k w-y r)$ \\
\hline No PSH & 20,318 & - & 308 & - & - & - & - \\
\hline With AS PSH & 19,952 & 440 & 258 & 51 & 16.45 & 400 & 126.83 \\
\hline
\end{tabular}

"_" = not applicable

Compared with the case without PSH capacity, the SMUD production cost decreases by 8.62\%, with the AS PSH plant operating in the system under the Base renewable generation scenario, and by $16.45 \%$ under the High Wind renewable scenario.

In monetary terms, annual production cost savings amount to about \$23 million under the Base renewable generation scenario and increase to \$51 million under the High Wind scenario, which has approximately 33\% of renewable generation within the SMUD system. Obviously, the value of PSH capacity is greater for a higher penetration level of variable renewable resources in the system.

\section{SMUD Curtailments of Renewable Generation}

There are no curtailments of renewable generation in the SMUD system under the Base renewable generation scenario. Under the High Wind scenario, if there are no PSH plants operating in the system, there are 19 GWh of renewable energy curtailments (see Table 4-38). The addition of a PSH plant reduces curtailments by 95\%, to $1 \mathrm{GWh}$. 
Table 4-38 Comparison of SMUD Renewable Curtailment in the High Wind Renewable Scenario

\begin{tabular}{|l|c|c|c|}
\hline \multicolumn{4}{|c|}{ SMUD Renewable Curtailment in the High Wind Renewable Scenario } \\
\hline \multicolumn{1}{|c|}{ Case } & (GWh) & Renewable Curtailment Reduction \\
\hline No PSH & 19 & (GWh) & (\%) \\
\hline With AS PSH & 1 & 0 & 0 \\
\hline
\end{tabular}

\section{SMUD System Reserves}

Tables 4-39 and 4-40 present system reserve requirements and their provisions by PSH capacity under the Base and High Wind renewable generation scenarios, respectively.

Table 4-39 Comparison of SMUD Reserve Requirements and Provisions by PSH in Two Cases for the Base Renewable Scenario in 2022

\begin{tabular}{|l|c|c|c|c|}
\hline \multirow{2}{*}{$\begin{array}{c}\text { Base Renewable } \\
\text { Scenario }\end{array}$} & \multicolumn{2}{|c|}{ Base - No PSH } & \multicolumn{2}{c|}{ With AS PSH } \\
\cline { 2 - 5 } & $\begin{array}{c}\text { Total Req. } \\
\text { (GWh) }\end{array}$ & $\begin{array}{c}\text { PSH Provision } \\
\text { (GWh) }\end{array}$ & $\begin{array}{c}\text { Total Req. } \\
\text { (GWh) }\end{array}$ & $\begin{array}{c}\text { PSH Provision } \\
\text { (GWh) }\end{array}$ \\
\hline Non-spinning reserve & 493 & - & 493 & 78 \\
\hline Spinning reserve & 493 & - & 493 & 21 \\
\hline Flexibility down & 156 & - & 156 & 46 \\
\hline Flexibility up & 156 & - & 156 & 6 \\
\hline Regulation down & 238 & - & 238 & 56 \\
\hline Regulation up & 237 & - & 237 & 8 \\
\hline
\end{tabular}

“_" = not applicable

Table 4-40 Comparison of SMUD Reserve Requirements and Provisions by PSH in Two Cases for the High Wind Renewable Scenario in 2022

\begin{tabular}{|l|c|c|c|c|}
\hline \multirow{2}{*}{$\begin{array}{c}\text { High Wind Renewable } \\
\text { Scenario }\end{array}$} & \multicolumn{2}{|c|}{ Base - No PSH } & \multicolumn{2}{c|}{ With AS PSH } \\
\cline { 2 - 5 } & $\begin{array}{c}\text { Total Req. } \\
\text { (GWh) }\end{array}$ & $\begin{array}{c}\text { PSH Provision } \\
\text { (GWh) }\end{array}$ & $\begin{array}{c}\text { Total Req. } \\
\text { (GWh) }\end{array}$ & $\begin{array}{c}\text { PSH Provision } \\
\text { (GWh) }\end{array}$ \\
\hline Non-spinning reserve & 493 & - & 493 & 87 \\
\hline Spinning reserve & 493 & - & 493 & 12 \\
\hline Flexibility down & 601 & - & 601 & 86 \\
\hline Flexibility up & 601 & - & 601 & 12 \\
\hline Regulation down & 439 & - & 439 & 90 \\
\hline Regulation up & 467 & - & 467 & 9 \\
\hline
\end{tabular}

"-“ = not applicable

\section{SMUD System Emissions}

The SMUD system emissions for the two simulated cases under the Base and High Wind renewable scenarios are provided in Tables 4-41 and 4-42. 
Table 4-41 Comparison of SMUD Emission Productions in Two Cases in 2022 for the Base Renewable Scenario

\begin{tabular}{|c|c|c|c|c|c|c|c|c|c|}
\hline \multirow{2}{*}{$\begin{array}{c}\text { Base } \\
\text { Renewable } \\
\text { Scenario }\end{array}$} & \multirow{2}{*}{$\begin{array}{l}\mathrm{CO}_{2} \\
\text { (ton) }\end{array}$} & \multirow{2}{*}{$\begin{array}{l}\mathrm{NO}_{\mathrm{x}} \\
\text { (ton) }\end{array}$} & \multirow{2}{*}{$\begin{array}{r}\mathrm{SO}_{2} \\
\text { (ton) }\end{array}$} & \multicolumn{3}{|c|}{ Emission Reduction (ton) } & \multicolumn{3}{|c|}{$\begin{array}{c}\text { Emission Reduction } \\
(\%)\end{array}$} \\
\hline & & & & $\mathrm{CO}_{2}$ & $\mathrm{NO}_{\mathrm{x}}$ & $\mathrm{SO}_{2}$ & $\mathrm{CO}_{2}$ & $\mathrm{NO}_{\mathrm{x}}$ & $\mathrm{SO}_{2}$ \\
\hline o PSH & $2,856,489$ & 1,880 & 3 & 0 & 0 & 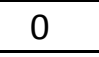 & 0.0 & 0.0 & 0.0 \\
\hline Vith AS PSH & $2,683,737$ & 1,777 & 1 & 172,752 & 103 & 2 & 6.0 & 5.5 & 69.3 \\
\hline
\end{tabular}

Table 4-42 Comparison of SMUD Emission Productions in Two Cases in 2022 for the High Wind Renewable Scenario

\begin{tabular}{|c|c|c|c|c|c|c|c|c|c|}
\hline \multirow{2}{*}{$\begin{array}{c}\text { High Wind } \\
\text { Renewable } \\
\text { Scenario }\end{array}$} & \multirow{2}{*}{$\begin{array}{c}\mathrm{CO}_{2} \\
\text { (ton) }\end{array}$} & \multirow{2}{*}{$\begin{array}{l}\mathrm{NO}_{x} \\
\text { (ton) }\end{array}$} & \multirow{2}{*}{$\begin{array}{c}\mathrm{SO}_{2} \\
\text { (ton) }\end{array}$} & \multicolumn{3}{|c|}{ Emission Reduction (ton) } & \multicolumn{3}{|c|}{$\begin{array}{c}\text { Emission Reduction } \\
(\%)\end{array}$} \\
\hline & & & & $\mathrm{CO}_{2}$ & $\mathrm{NO}_{\mathrm{x}}$ & $\mathrm{SO}_{2}$ & $\mathrm{CO}_{2}$ & $\mathrm{NO}_{\mathrm{x}}$ & $\mathrm{SO}_{2}$ \\
\hline No PSH & $3,299,928$ & 2,168 & 3 & 0 & 0 & 0 & 0.0 & 0.0 & 0.0 \\
\hline Jith AS PSH & $2,814,536$ & 1,872 & 1 & 485,392 & 296 & 3 & 14.7 & 13.7 & 83.2 \\
\hline
\end{tabular}

It can be observed that, under both renewable energy scenarios, emissions significantly decrease as the PSH plant is introduced into the SMUD system.

\section{SMUD Thermal Generator Cycling}

Tables 4-43 and 4-44 provide PLEXOS modeling results for the number of starts and startup costs of thermal generators for the two simulated cases under two renewable energy scenarios.

Table 4-43 Comparison of Number of Starts and Startup Costs of SMUD Thermal Generators in 2022 for the Base Renewable Scenario

\begin{tabular}{|l|c|c|c|c|}
\hline \multirow{2}{*}{$\begin{array}{c}\text { Base Renewable } \\
\text { Scenario }\end{array}$} & Total Number of & Total Thermal & \multicolumn{2}{|c|}{ Cost Reduction } \\
\cline { 4 - 5 } & Start Cost & & & \\
\cline { 5 - 5 } & Thermal Starts & (million \$) & (million \$) & (\%) \\
\hline No PSH & 1,812 & 5 & 0 & 0.00 \\
\hline With AS PSH & 828 & 3 & 2 & 44.83 \\
\hline
\end{tabular}

Table 4-44 Comparison of Number of Starts and Startup Costs of SMUD Thermal Generators in 2022 for the High Wind Renewable Scenario

\begin{tabular}{|l|c|c|c|c|}
\hline & & Total Thermal & \multicolumn{2}{c|}{ Cost Reduction } \\
\cline { 4 - 5 } $\begin{array}{c}\text { High Wind } \\
\text { Renewable Scenario }\end{array}$ & Total Number of & $\begin{array}{c}\text { Start Cost } \\
\text { (million \$) }\end{array}$ & (million \$) & (\%) \\
\hline No PSH & 2,159 & 5 & 0 & 0.00 \\
\hline With AS PSH & 773 & 3 & 2 & 41.87 \\
\hline
\end{tabular}


Under both the Base and High Wind renewable scenarios, the number of starts and startup costs of thermal generators decrease substantially as the PSH plant is introduced into the SMUD system.

\section{SMUD Thermal Generator Ramping}

Tables 4-45 and 4-46 provide the results for thermal generator ramping up and down for the two cases under two renewable energy scenarios.

Table 4-45 Comparison of Thermal Generator Ramp Up and Down of SMUD Thermal Generators in $\mathbf{2 0 2 2}$ for the Base Renewable Scenario

\begin{tabular}{|c|c|c|c|c|c|c|}
\hline \multirow[b]{2}{*}{ Base Renewable } & \multirow{2}{*}{$\begin{array}{c}\text { Total } \\
\text { Thermal } \\
\text { Generator } \\
\text { Ramp Up } \\
\text { (GW) }\end{array}$} & \multirow{2}{*}{$\begin{array}{c}\text { Total } \\
\text { Thermal } \\
\text { Generator } \\
\text { Ramp Down } \\
\text { (GW) }\end{array}$} & \multicolumn{2}{|c|}{ Ramp-Up Reduction } & \multicolumn{2}{|c|}{$\begin{array}{c}\text { Ramp-Down } \\
\text { Reduction }\end{array}$} \\
\hline & & & (GW) & (\%) & (GW) & (\%) \\
\hline No PSH & 367 & 502 & 0 & 0.00 & 0 & 0.00 \\
\hline With AS PSH & 231 & 305 & 136 & 37.03 & 197 & 39.29 \\
\hline
\end{tabular}

Table 4-46 Comparison of Thermal Generator Ramp Up and Down of SMUD Thermal Generators in 2022 for the High Wind Renewable Scenario

\begin{tabular}{|c|c|c|c|c|c|c|}
\hline \multirow{2}{*}{$\begin{array}{c}\text { High Wind } \\
\text { Renewable } \\
\text { Scenario }\end{array}$} & \multirow{2}{*}{$\begin{array}{c}\text { Total } \\
\text { Thermal } \\
\text { Generator } \\
\text { Ramp Up } \\
\text { (GW) }\end{array}$} & \multirow{2}{*}{$\begin{array}{c}\text { Total } \\
\text { Thermal } \\
\text { Generator } \\
\text { Ramp Down } \\
\text { (GW) }\end{array}$} & \multicolumn{2}{|c|}{ Ramp-Up Reduction } & \multicolumn{2}{|c|}{$\begin{array}{l}\text { Ramp-Down } \\
\text { Reduction }\end{array}$} \\
\hline & & & (GW) & $(\%)$ & (GW) & $(\%)$ \\
\hline No PSH & 369 & 489 & 0 & 0.00 & 0 & 0.00 \\
\hline With AS PSH & 250 & 315 & 119 & 32.16 & 174 & 35.59 \\
\hline
\end{tabular}

As can be seen, thermal generator ramping is significantly reduced as PSH capacity is added to the SMUD system.

\section{SMUD Regional LMPs}

The comparison of the average SMUD LMPs for two cases under the Base renewable energy scenario is shown in Figure 4-11. The average SMUD LMP declines as the AS PSH is introduced into the SMUD system.

On the other hand, for the High Wind scenario, the average SMUD LMP increases as the AS PSH plant is introduced into the system as shown in Figure 4-12. This is mainly because the PSH reduces curtailments of VERs, therefore reducing the number of hours in which the LMPs are equal to zero or negative. 


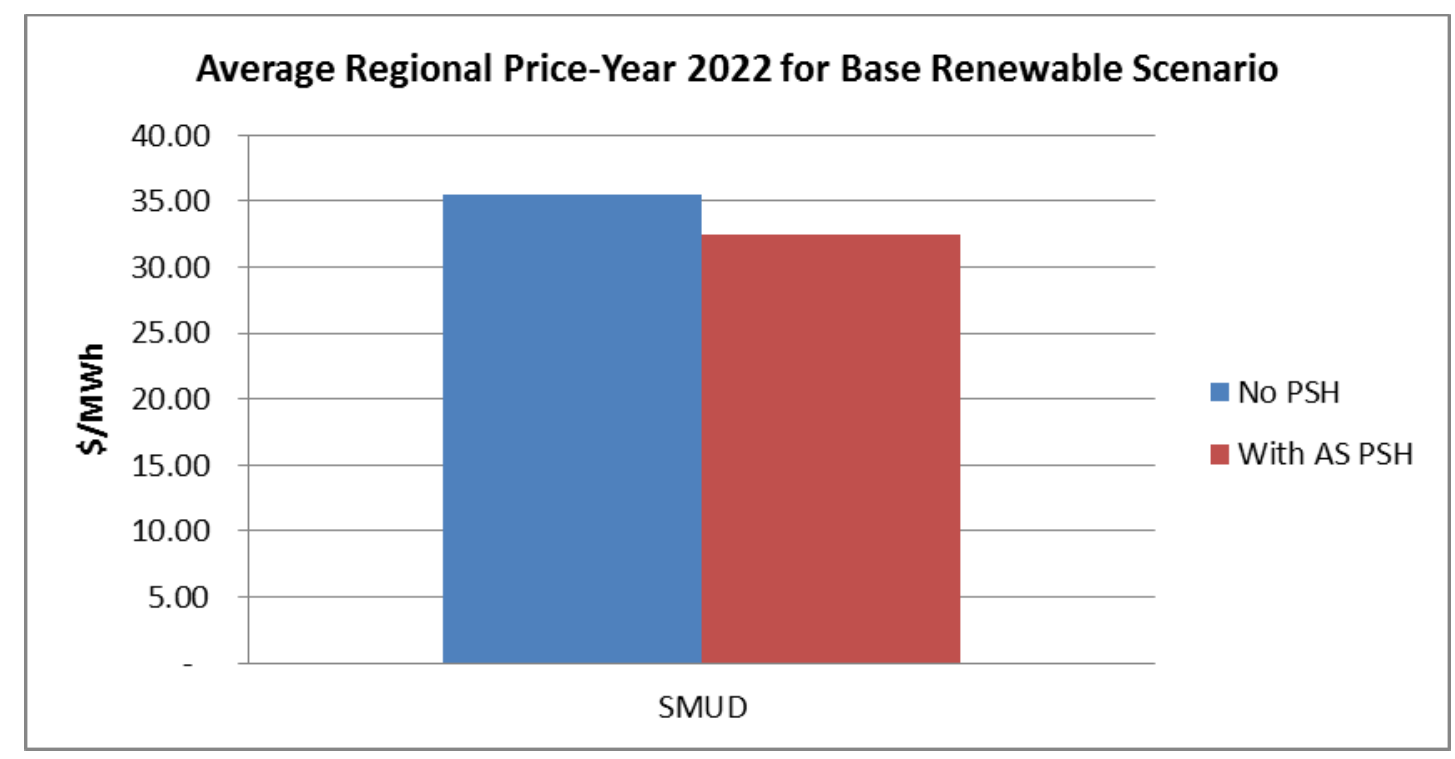

Figure 4-11 Comparison of SMUD Regional LMP in Two Cases in 2022 for the Base Renewable Scenario

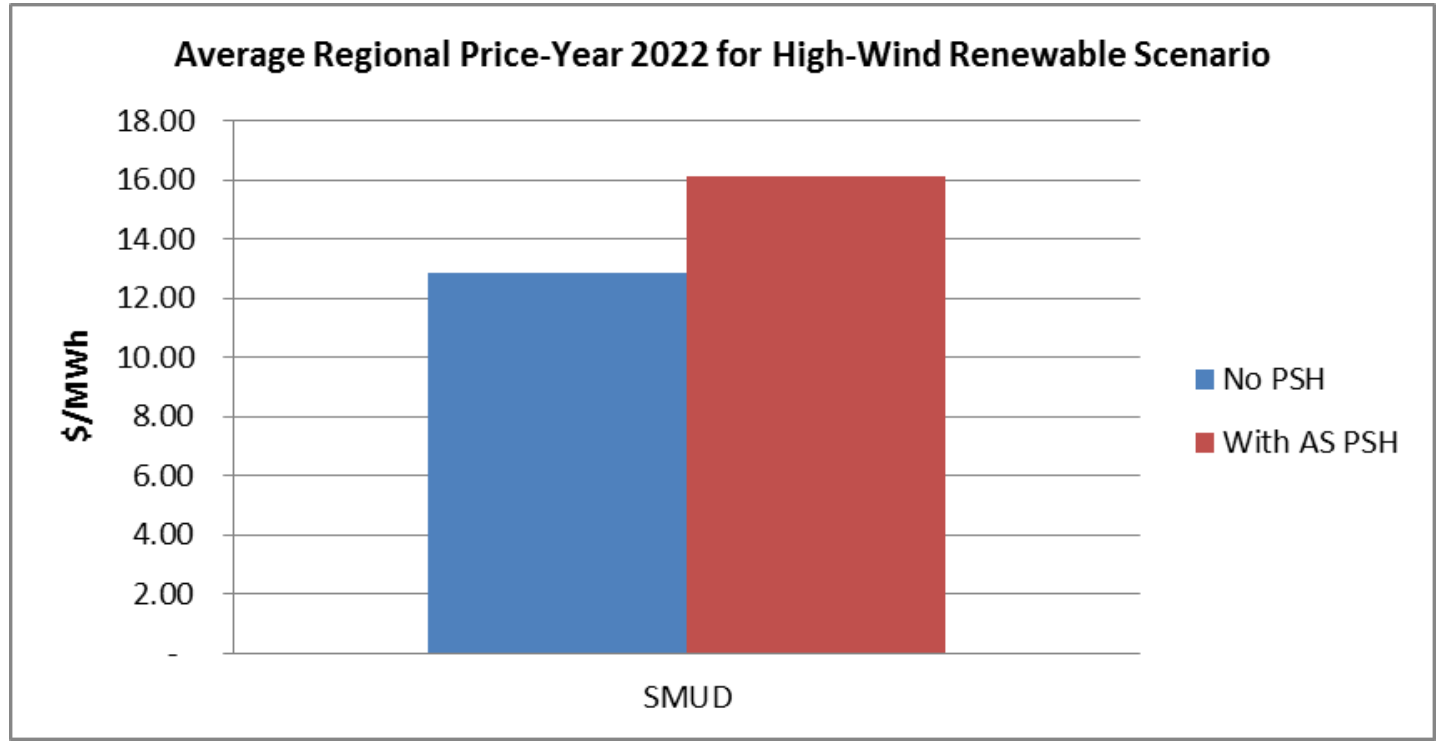

Figure 4-12 Comparison of SMUD Regional LMP in Two Cases in 2022 for the High Wind Renewable Scenario

It should be noted that the overall level of LMPs is much lower under the High Wind scenario compared with the Base renewable generation scenario.

\section{SMUD Transmission Congestion}

Since the SMUD was modeled at the regional level, no transmission interfaces and lines were modeled. 


\subsection{Three-Stage DA-HA-RT Sequential Simulations}

To capture the uncertainty of renewable energy forecasting and intra-hourly variability of VER, as well as to evaluate system needs for operating reserves and flexible ramping capacity, threestage DA-HA-RT sequential simulations with a 5-min time step in RT were performed for four typical weeks in different seasons of the year. Simulations were performed for the WI, California, and SMUD footprints, and the selected weeks were the third weeks in January, April, July, and October of 2022.

\subsubsection{Variability and Uncertainty of Variable Energy Resources}

The variability and uncertainty of renewable generation presents some challenges for power system planning and operation. A key question concerns the impact of intra-hourly variability and uncertainty of renewable generation on system operation.

The following four charts (Figures 4-13 through 4-16) show the 5-min variability and uncertainty of solar and wind generation in Southern California under the High Wind renewable generation scenario. The charts illustrate typical winter and summer weeks in 2022. The source of the data is the WWSIS-2 study by NREL (Lew et al. 2013).

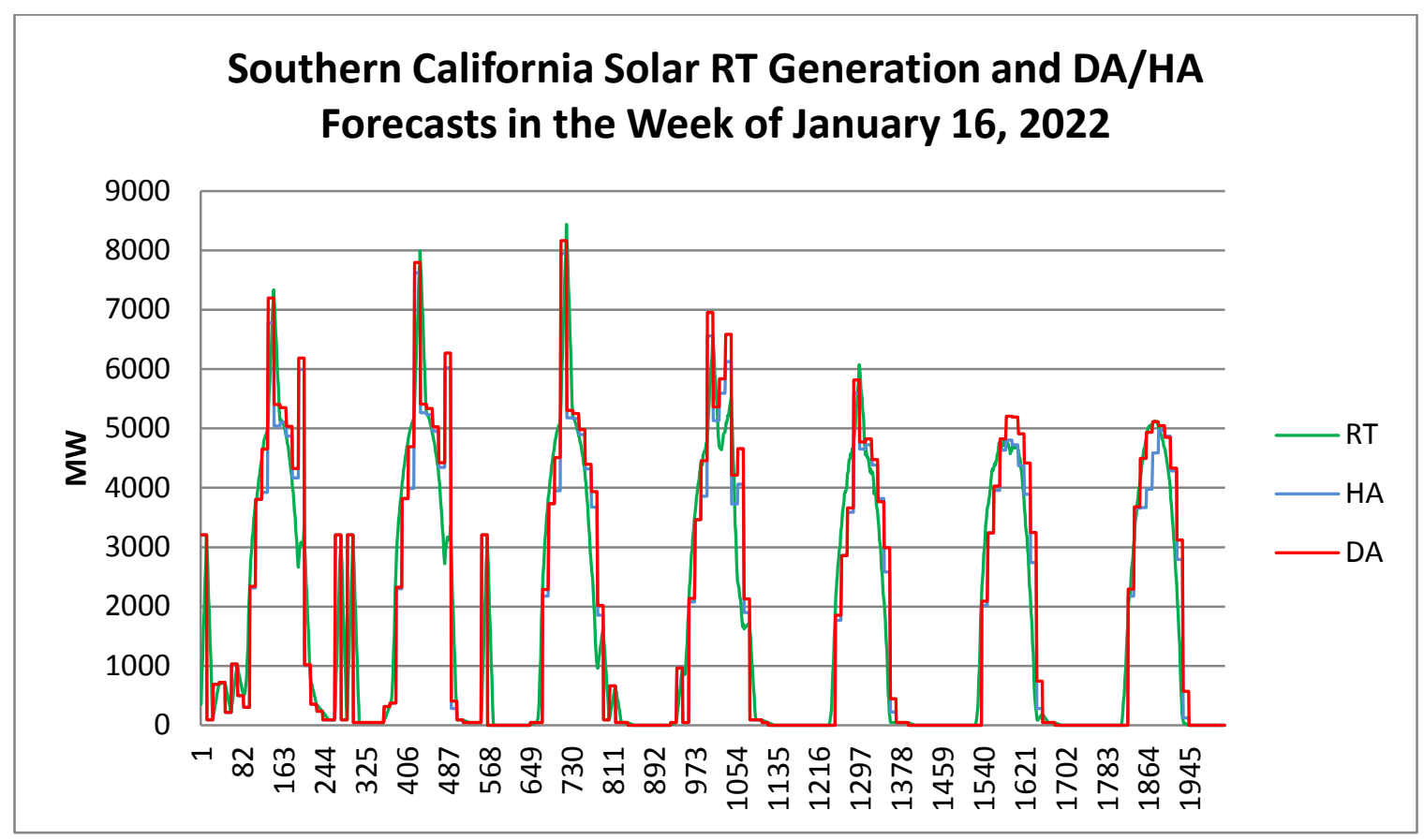

Figure 4-13 Five-Minute Actual Solar Generation and Hourly DA/HA Forecasts in Southern California in a Typical Winter Week of 2022 


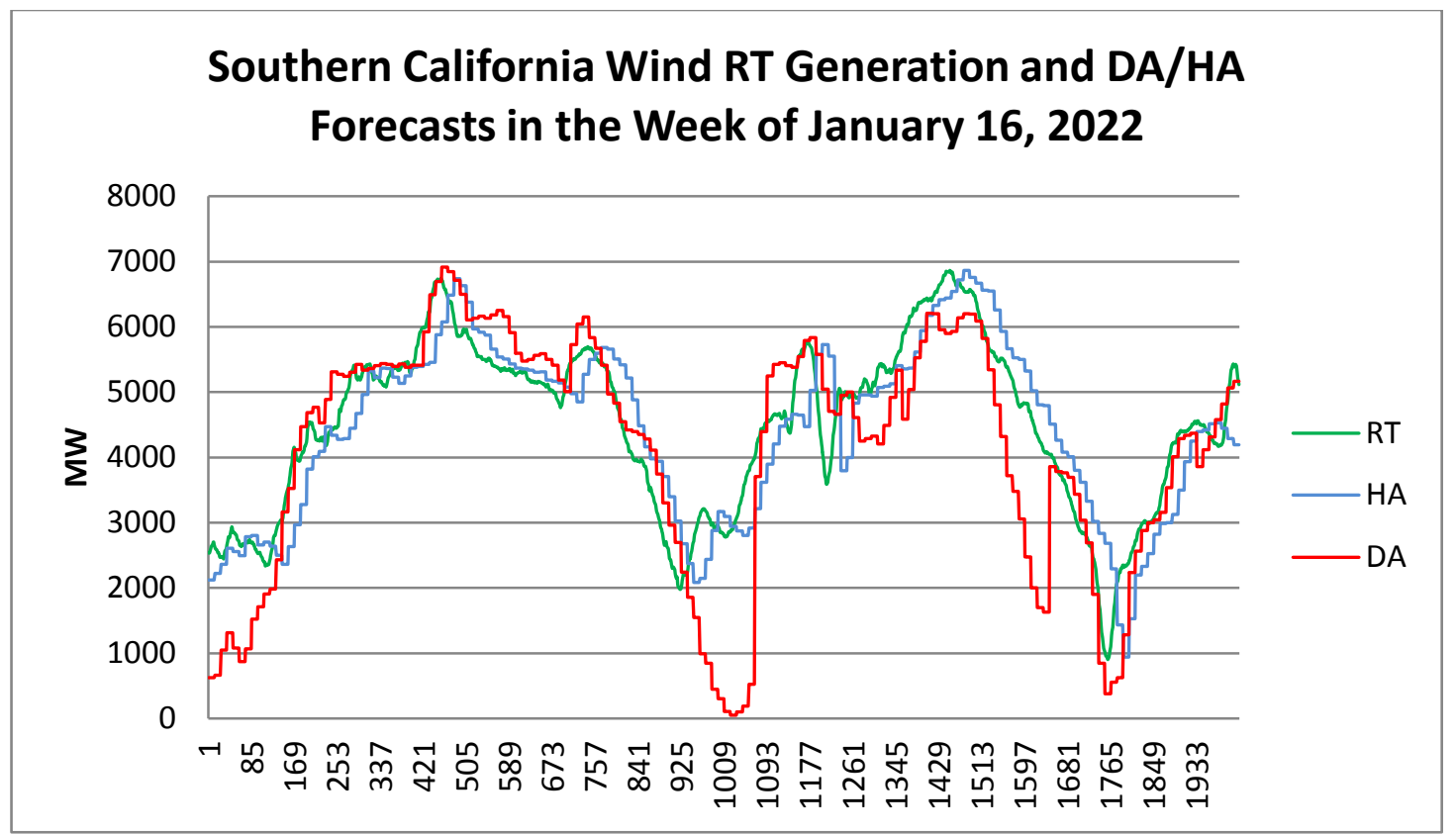

Figure 4-14 Five-Minute Actual Wind Generation and Hourly DA/HA Forecasts in Southern California in a Typical Winter Week of 2022

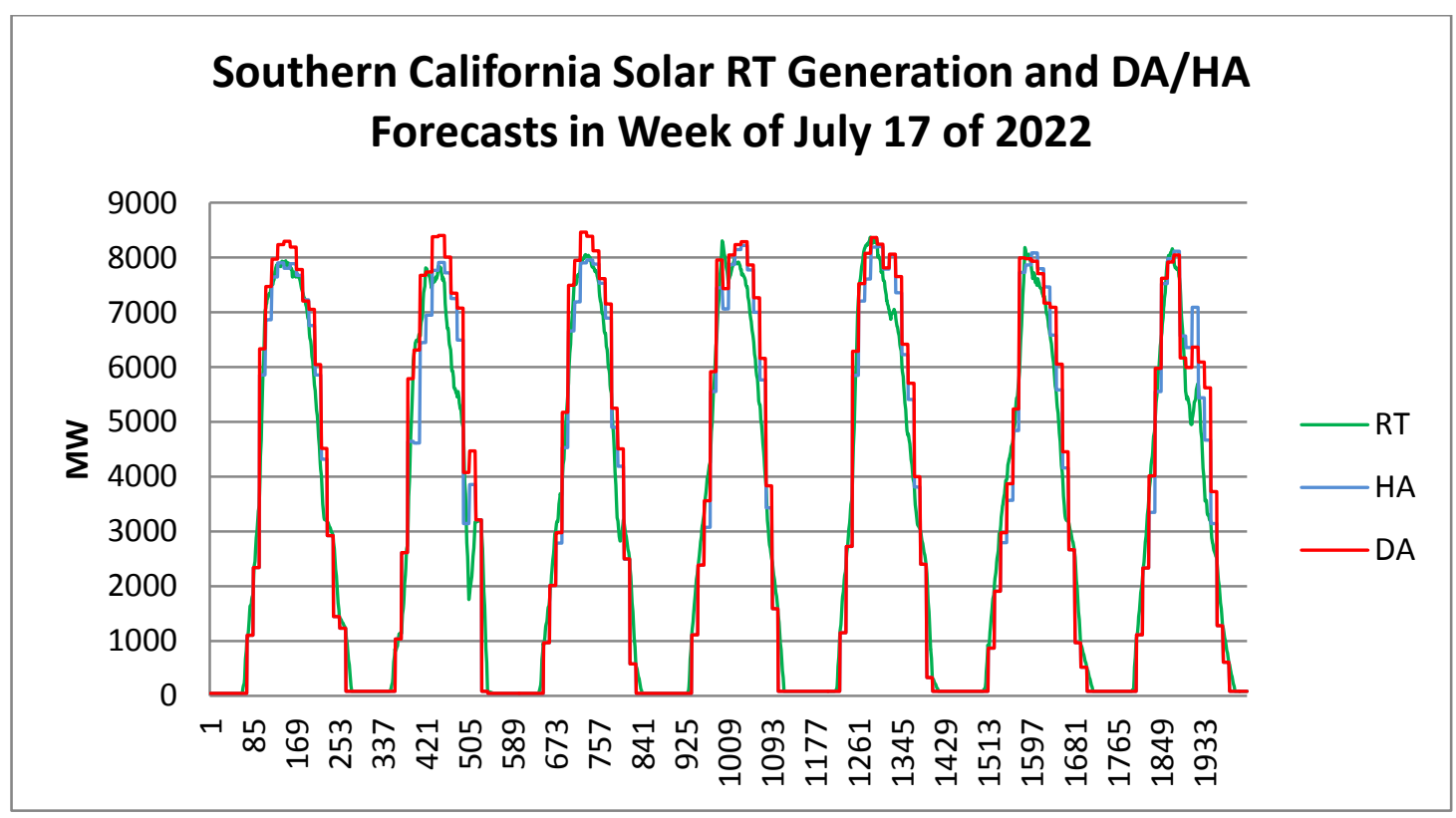

Figure 4-15 Five-Minute Actual Solar Generation and Hourly DA/HA Forecasts in Southern California in a Typical Summer Week of 2022 


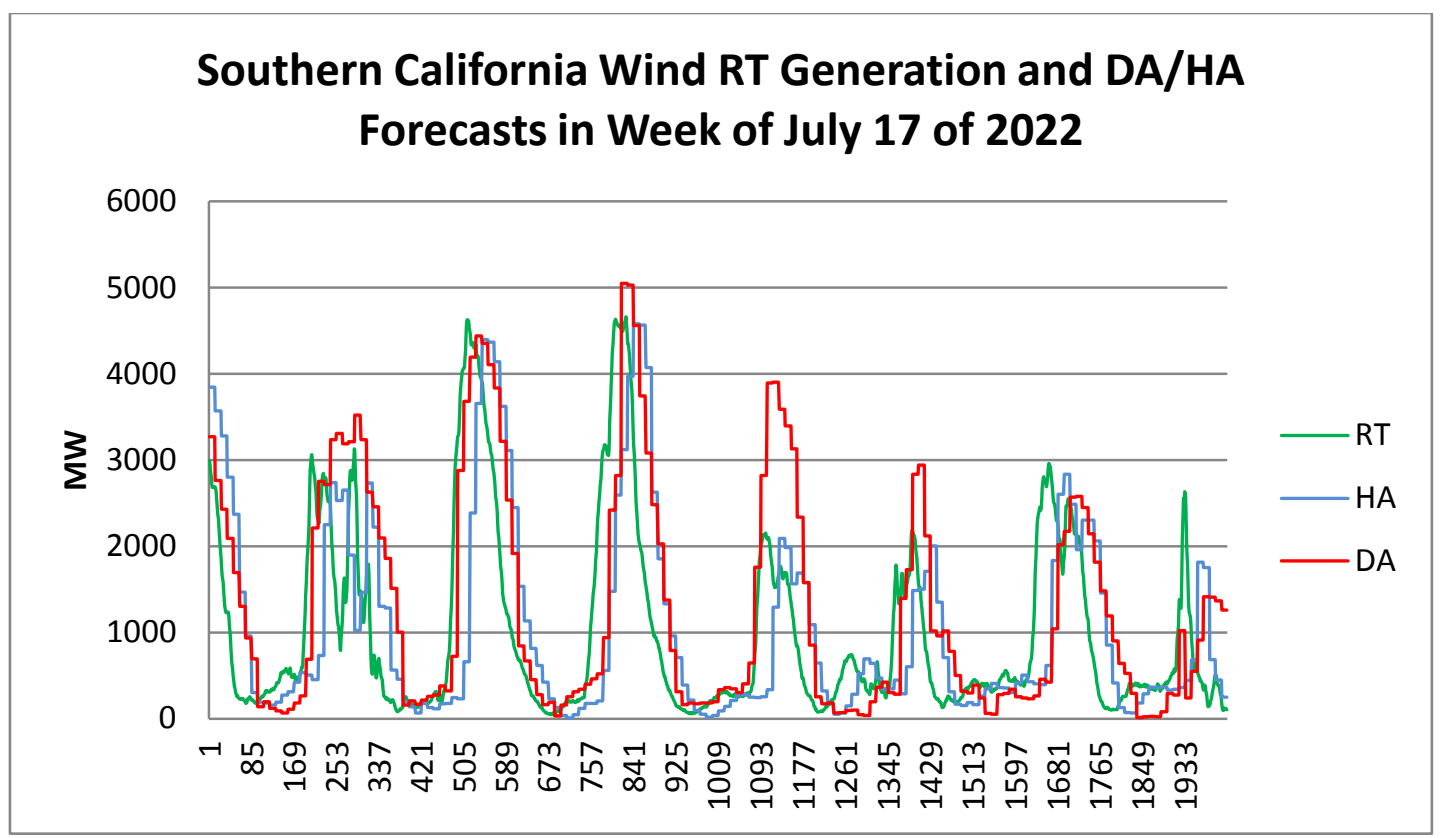

Figure 4-16 Five-Minute Actual Wind Generation and Hourly DA/HA Forecasts in Southern California in a Typical Summer Week of 2022

Table 4-47 lists the maximum and minimum forecast errors during the typical winter and summer weeks.

Table 4-47 Maximum and Minimum Wind and Solar Forecast Errors in Southern California in a Typical Winter Week of 2022

\begin{tabular}{|c|c|r|r|r|r|r|r|r|}
\hline & \multicolumn{4}{|c|}{$\begin{array}{c}\text { Forecast Error(MW) in a Typical Winter } \\
\text { Week }\end{array}$} & \multicolumn{4}{c|}{$\begin{array}{r}\text { Forecast Error(MW) in a Typical Summer } \\
\text { Week }\end{array}$} \\
\hline & \multicolumn{2}{|c|}{ Solar Generation } & \multicolumn{1}{|c|}{ Wind Generation } & \multicolumn{2}{|c|}{ Solar Generation } & \multicolumn{2}{|c|}{ Wind Generation } \\
\hline & RT-HA & HA-DA & RT-HA & HA-DA & RT-HA & HA-DA & RT-HA & HA-DA \\
\hline Max & 3002 & 53 & 1,524 & 3,167 & 2,863 & 727 & 3,969 & 991 \\
\hline Min & -3220 & -995 & $-2,142$ & $-1,353$ & $-2,163$ & $-1,697$ & $-2,969$ & $-3,558$ \\
\hline
\end{tabular}

The following two figures (Figures 4-17 and 4-18) show the wind and solar forecast errors between the HA and RT forecasting, and between the DA and HA forecasting in typical winter and summer weeks of 2022. These figures clearly demonstrate that the forecast error from HA to RT (blue curve) has a higher frequency and magnitude than the one from DA to HA. 


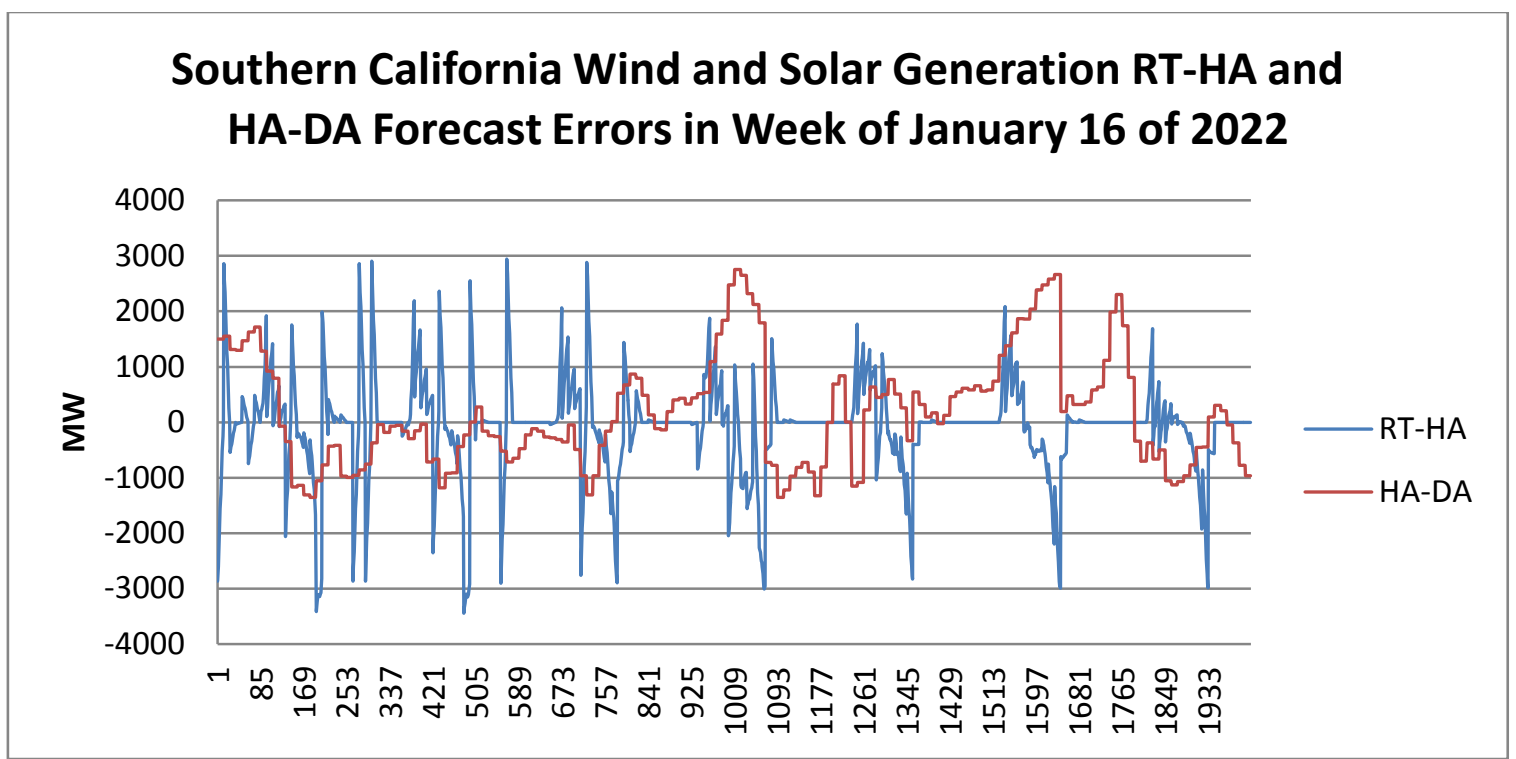

Figure 4-17 Wind and Solar Generation Forecast Error from DA to HA and HA to RT in Southern California in a Typical Winter Week of 2022

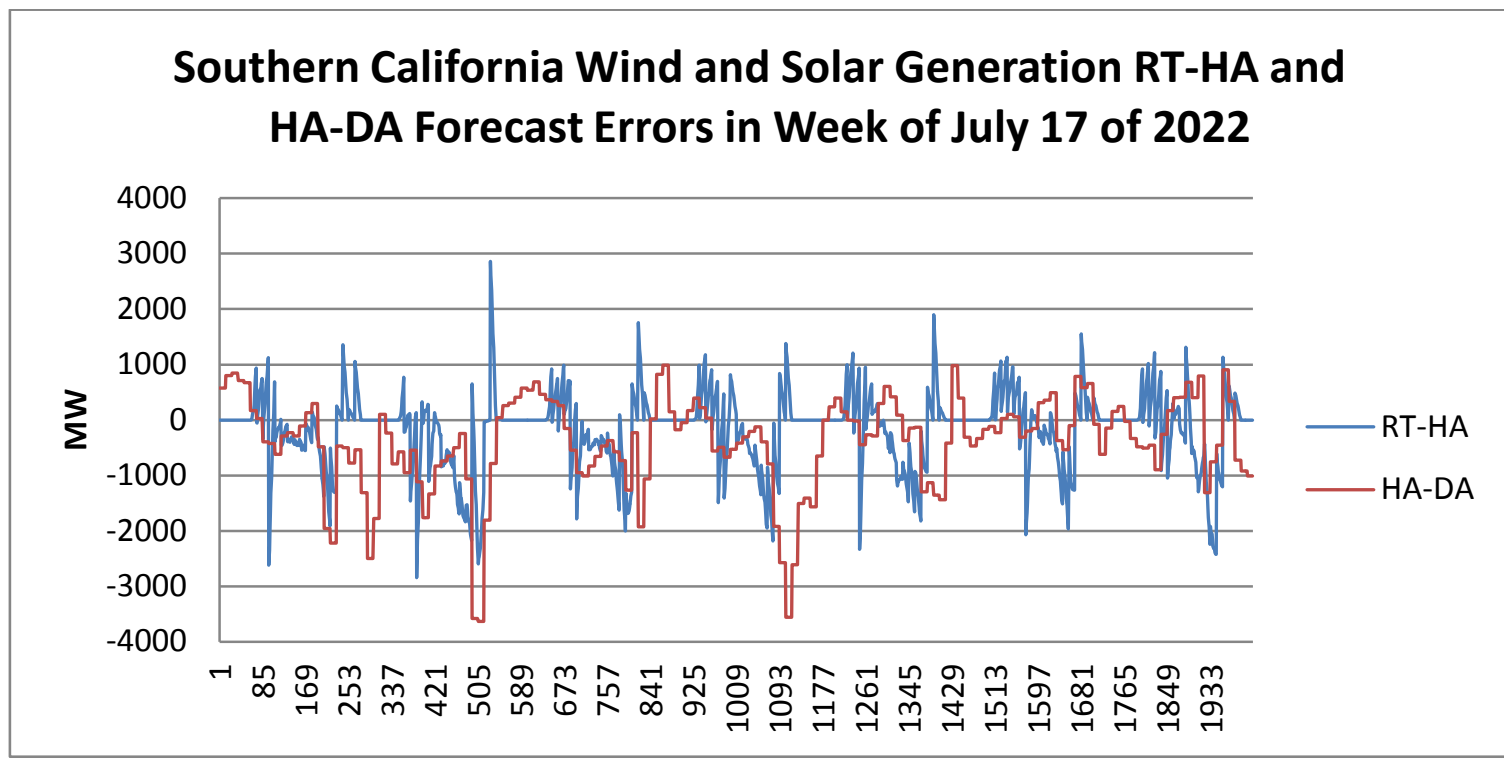

Figure 4-18 Wind and Solar Generation Forecast Error from DA to HA and HA to RT in Southern California in a Typical Summer Week of 2022

To compensate for the sub-hourly variability and uncertainty of renewable generation, the system needs to ramp generators more and/or to cycle the quick-startup generators more. This project task examined the hourly security constrained UC and the sub-hourly security constrained dispatch to quantify the impact of the PSH plant on the overall system production costs and on the sub-hourly ramping and cycling of thermal generators. The simulation approach adopted for this modeling was the three-stage DA-HA-RT sequential simulation as described in 
Guo et al. (2013) The three-stage simulations were performed for three cases (no PSH, with FS PSH, and with FS \& AS PSH) under the Base and High Wind renewable energy scenarios. The three-stage simulations covered three study footprint areas-WI, California, and SMUD.

Sections 4.4.2, 4.4.3, and 4.4.4 present key results obtained for the system production costs and thermal generator ramping and cycling. The results of DA-HA-RT simulations are first presented for the WI footprint.

\subsubsection{Three-Stage DA-HA-RT Simulation Results for the WI}

PLEXOS simulation runs were performed for four typical weeks in 2022. The selected weeks were the third weeks of January, April, July, and October. Three PSH cases: (1) no PSH, (2) with existing FS PSHs, and (3) with existing FS PSH and three proposed AS PSH plants (Swan Lake, Iowa Hill, and Eagle Mountain) were simulated using the cost-based approach.

\section{WI Three-Stage Simulation Results for Four Typical Weeks in 2022}

Figures 4-19 through 4-22 show the results for production costs, startup and shutdown costs, and thermal generator ramping up and down from the three-stage WI DA-HA-RT simulations for the four typical weeks under the High Wind renewable energy scenario.

The results for system production costs, startup and shutdown costs, and unit ramping needs, typically increase if a higher-resolution simulation is performed (e.g., RT as opposed to DA simulations). The reason is that RT simulations are performed with a 5-min time step and capture more details regarding the system operation within the hour compared with the DA simulations that are performed with an hourly time step. As PSH plants represent a very fast and flexible system capacity, their true impact on power system operation and costs can be seen from the RT simulations of system operation.

Figure 4-19 illustrates the total WI system production costs in four simulated weeks of 2022. Comparing the RT simulation results for the three PSH cases (no PSH, with FS PSH, and with FS \& AS PSH), it can be observed that the average WI system production costs over the four simulated weeks are lower if there is more PSH capacity in the system. Specifically, compared with the case without any PSH capacity, the average production costs of the WI system are 2.01\% lower in the case with FS PSH, and 3.60\% lower in the case with FS and AS PSH plants operating in the system.

Figure 4-20 shows the startup and shutdown costs for the WI system in the four simulated weeks of 2022. Compared with the RT simulation results for the case without PSH capacity, the average startup and shutdown costs over four simulated weeks are $11.21 \%$ lower in the case with FS PSH plants and 17.71\% lower with both FS and AS PSH plants operating in the system.

Figures 4-21 and 4-22 show the results for the ramping of thermal generators. It can be observed that both ramp ups and ramp downs are increased substantially in RT simulations, compared with DA simulations. The reason is that the 5-min simulation time step captures not only ramping needs from hour to hour, but also within the hour. With regard to the impact of PSH 


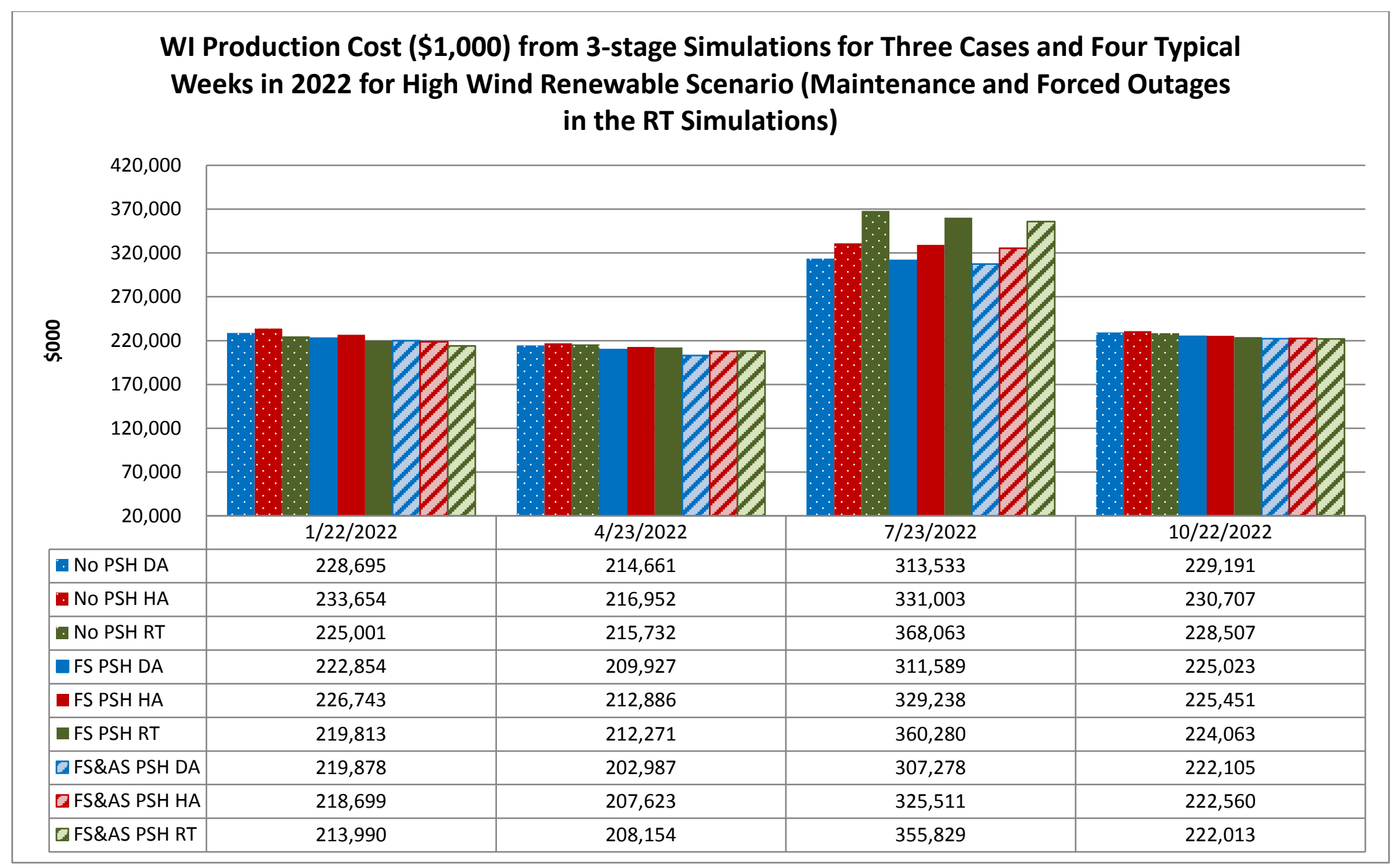

Figure 4-19 WI Production Cost $(\$ 1,000)$ from Three-Stage Simulations for Three Cases and Four Typical Weeks in 2022 for the High Wind Renewable Scenario (Maintenance and Forced Outages in the RT Simulations) 


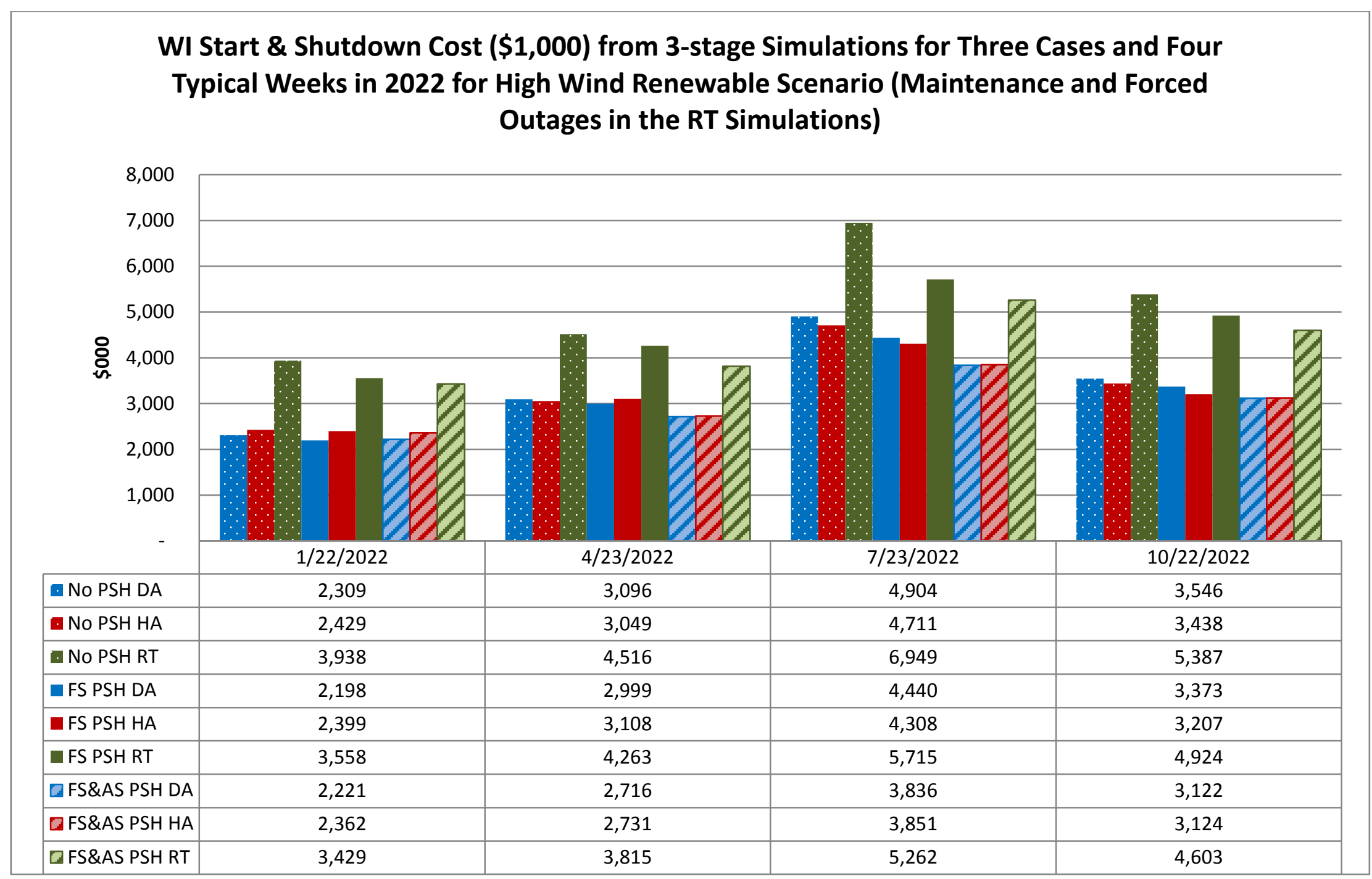

Figure 4-20 WI Startup and Shutdown Costs $(\$ 1,000)$ from Three-Stage Simulations for Three Cases and Four Typical Weeks in 2022 for the High Wind 


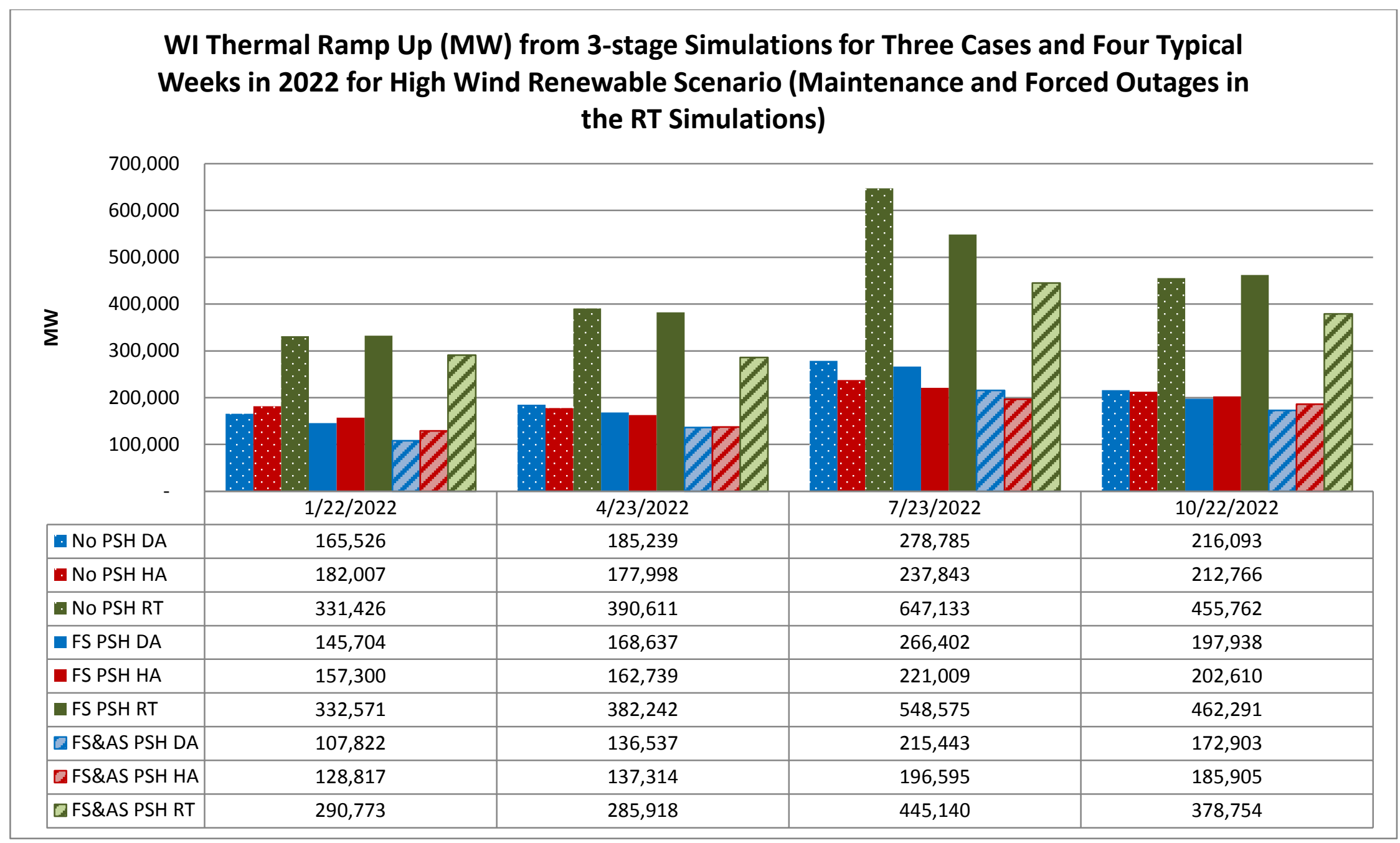

Figure 4-21 WI Thermal Generator Ramp Up (MW) from Three-Stage Simulations for Three Cases and Four Typical Weeks in 2022 for the High Wind Renewable Scenario (Maintenance and Forced Outages in the RT Simulations) 


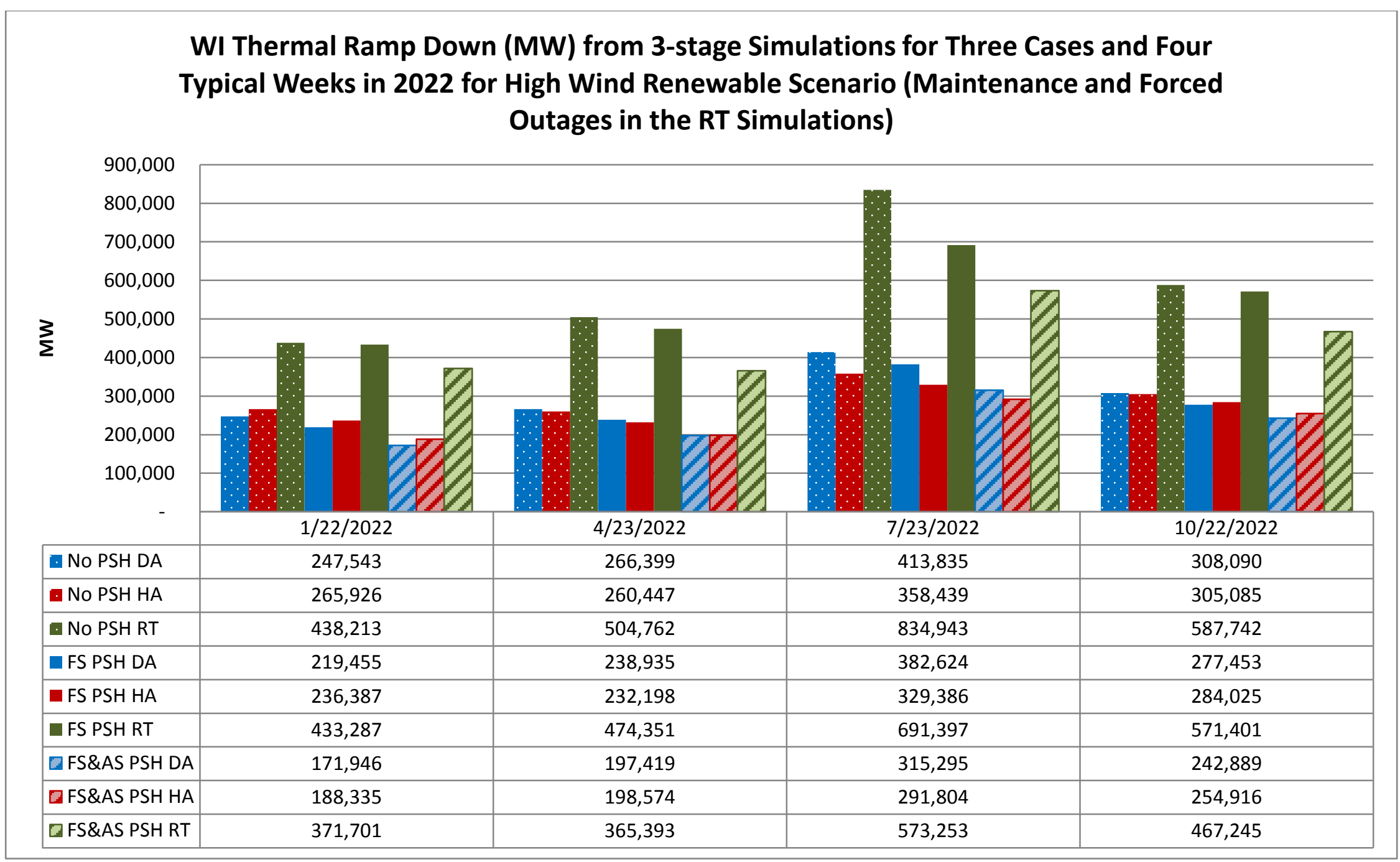

Figure 4-22 WI Thermal Generator Ramp Down (MW) from Three-Stage Simulations for Three Cases and Four Typical Weeks in 2022 for the High Wind Renewable Scenario (Maintenance and Forced Outages in the RT Simulations) 
plants, they are able to significantly reduce the ramping of thermal generating units. Compared with the RT simulation results for the case with no PSH plants in the system, the average ramping up of thermal generators is 5.44\% lower in the case with FS PSH, and $23.25 \%$ lower in the case with FS and AS PSH plants in the system. Similarly, the average ramping down of thermal generators is lower by an average of $8.25 \%$ in the case with FS PSH, and by an average of $24.86 \%$ in the case with both FS and AS PSH in the system.

\subsubsection{Three-Stage DA-HA-RT Simulation Results for California}

Before simulating the California system, the WI simulations were performed to determine the power flows for the interties between California and the rest of WI under both the Base and High Wind renewable scenarios. These power flows on intertie lines were then frozen for California DA, HA, and RT simulations. Four typical weeks were simulated for the California footprint: the third weeks of January, April, July, and October. Three cases-no PSH, with existing FS PSHs, with existing FS PSHs - and two new AS PSHs (Iowa Hill and Eagle Mountain) were simulated using the market-based (bid-based) approach.

\section{California - Three-Stage Simulation Results for Four Typical Weeks in 2022}

The results obtained from the three-stage DA-HA-RT simulations for production costs, startup costs, and thermal generator ramping up and down in California during the four typical weeks in 2022 under the High Wind renewable scenario are presented in Figures 4-23 through 4-26. The following are some of the key observations resulting from these simulation runs.

Figure 4-23 illustrates the total system production costs for California in the four simulated weeks of 2022. Comparing the RT simulation results for the three PSH cases (no PSH, with FS PSH, and with FS \& AS PSH), it can be seen that the average system production costs over the four simulated weeks are lower if there is more PSH capacity in the system. Specifically, compared with the case without any PSH capacity, the average production costs in California are $5.01 \%$ lower in the case with FS PSH, and 7.27\% lower in the case with FS and AS PSH plants operating in the system.

Figure 4-24 presents the startup and shutdown costs for the California system in the four simulated weeks of 2022. Compared with the RT simulation results for the case without PSH capacity, the average startup and shutdown costs over the four simulated weeks decrease by $27.58 \%$ if FS PSH plants are added to the system, and by $41.67 \%$ if both FS and AS PSH plants are operating in the system.

Figures 4-25 and 4-26 show the results for the ramping of thermal generators. As can be seen, both ramp ups and ramp downs are increased substantially in RT simulations, compared with DA simulations. The reason is that the 5-min simulation time step captures not only ramping needs from hour to hour, but also within the hour. With regard to the impact of PSH plants, they are able to significantly reduce the ramping of thermal generating units. Compared with the RT simulation results for the case with no PSH plants in the system, the average ramping up of thermal generators is 9.76\% lower in the case with FS PSH, and 33.05\% lower in the case with FS and AS PSH plants in the system. Similarly, the average ramping down of thermal generators 


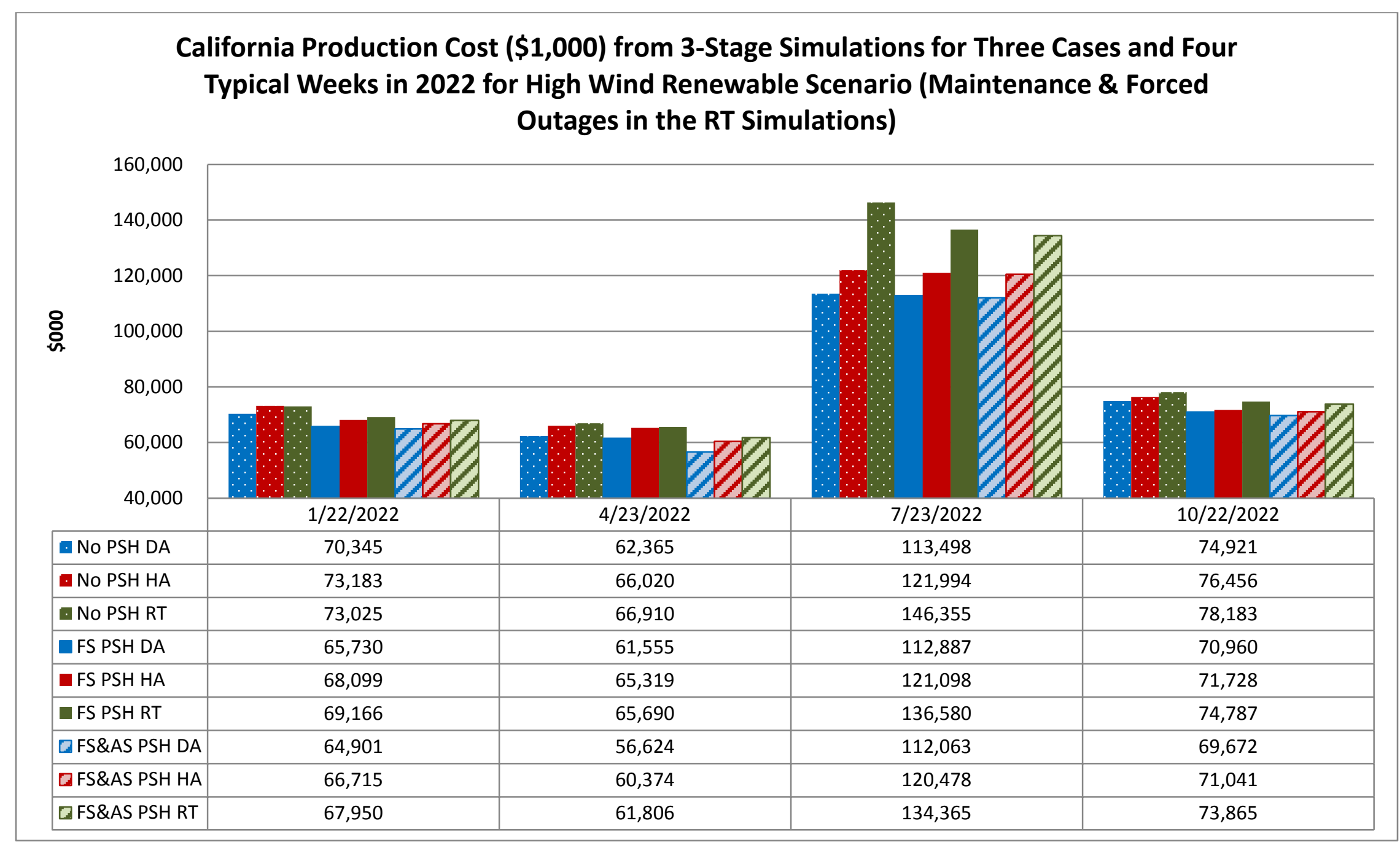

Figure 4-23 California Production Cost $(\$ 1,000)$ from Three-Stage Simulations for Three Cases and Four Typical Weeks in 2022 for the High Wind Renewable Scenario (Maintenance and Forced Outages in the RT Simulations) 


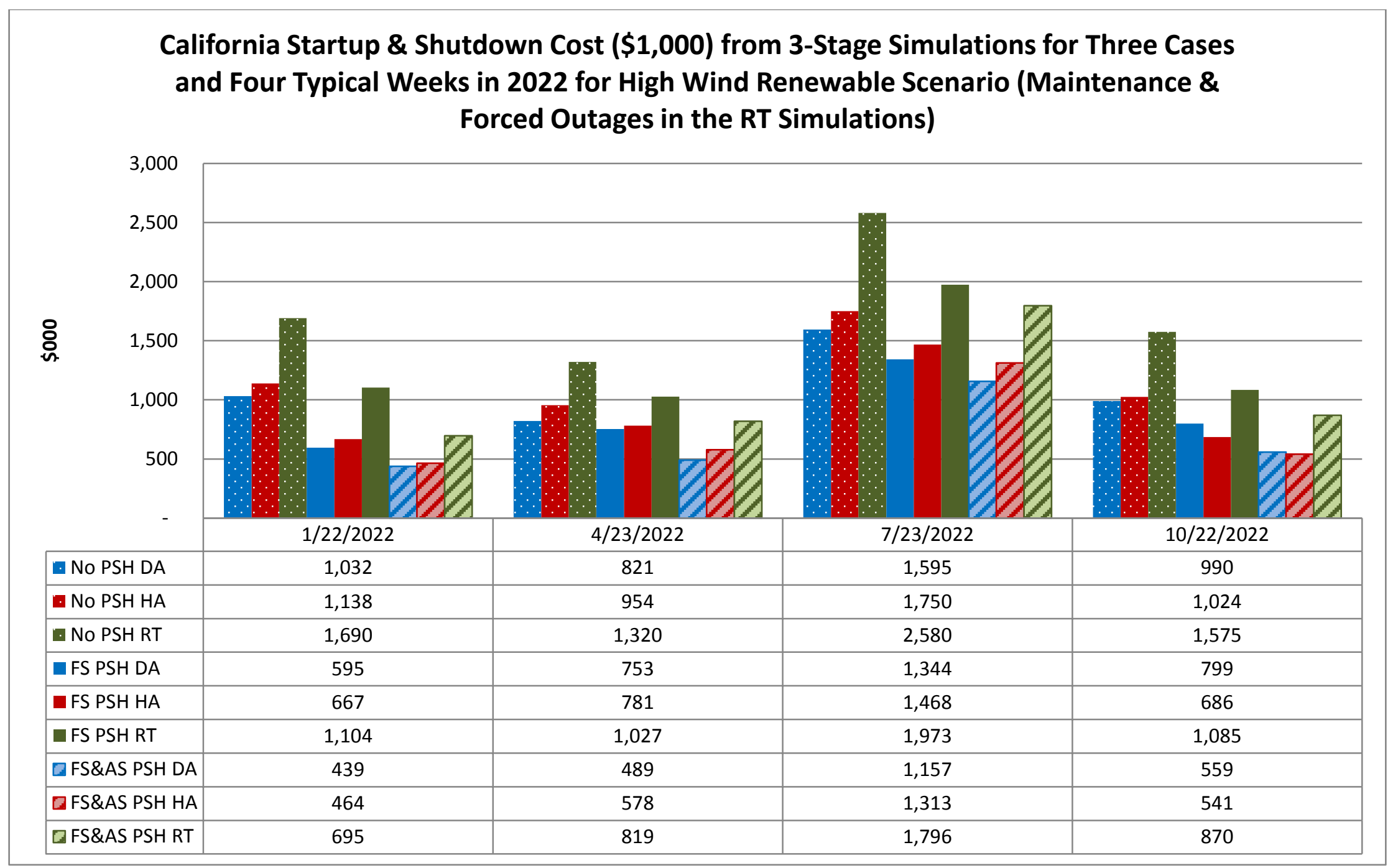

Figure 4-24 California Startup Cost $(\$ 1,000)$ from Three-Stage Simulations for Three Cases and Four Typical Weeks in 2022 for the High Wind Renewable Scenario (Maintenance and Forced Outages in the RT Simulations) 


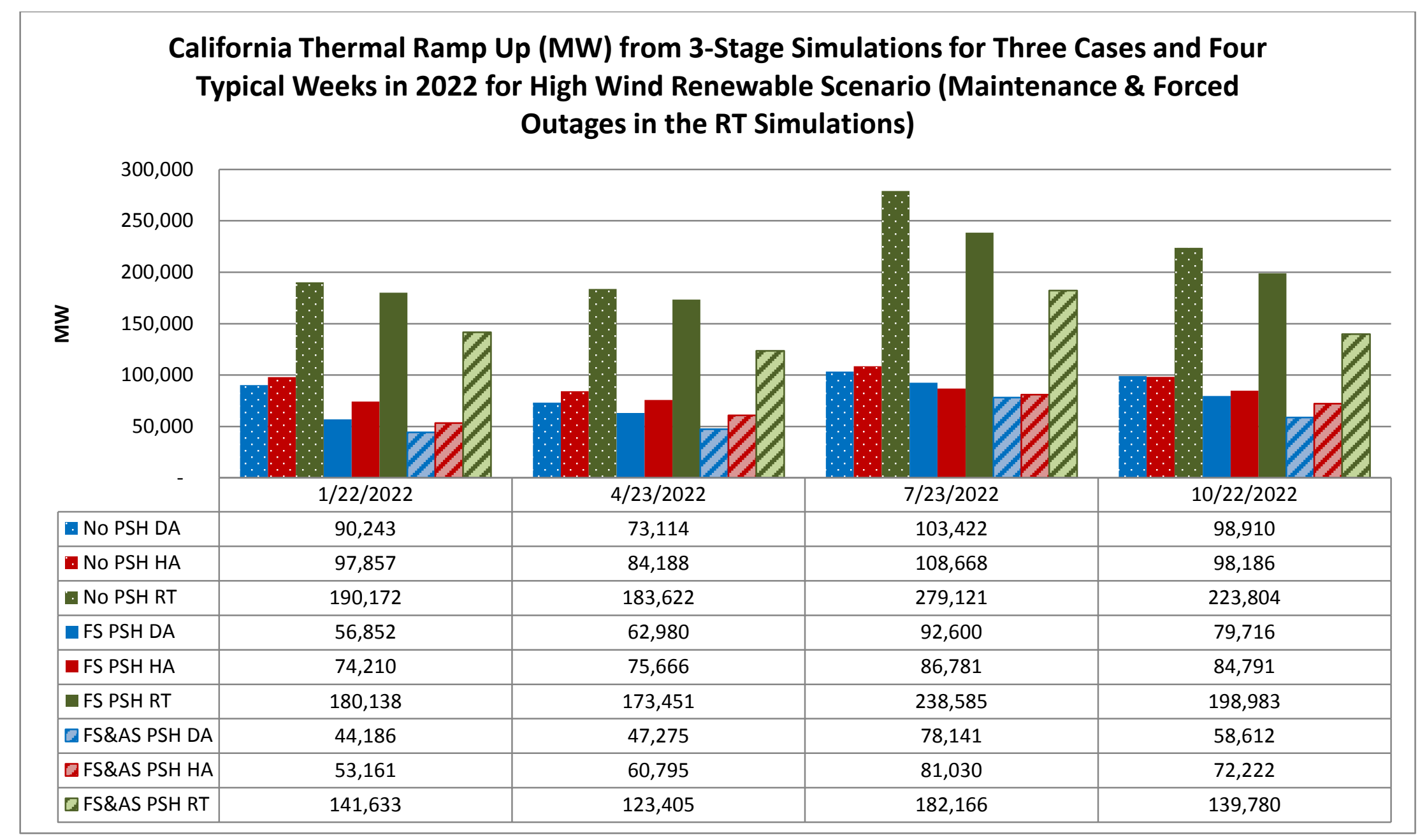

Figure 4-25 California Thermal Generator Ramp Up (MW) from Three-Stage Simulations for Three Cases and Four Typical Weeks in 2022 for the High Wind Renewable Scenario (Maintenance and Forced Outages in the RT Simulations) 


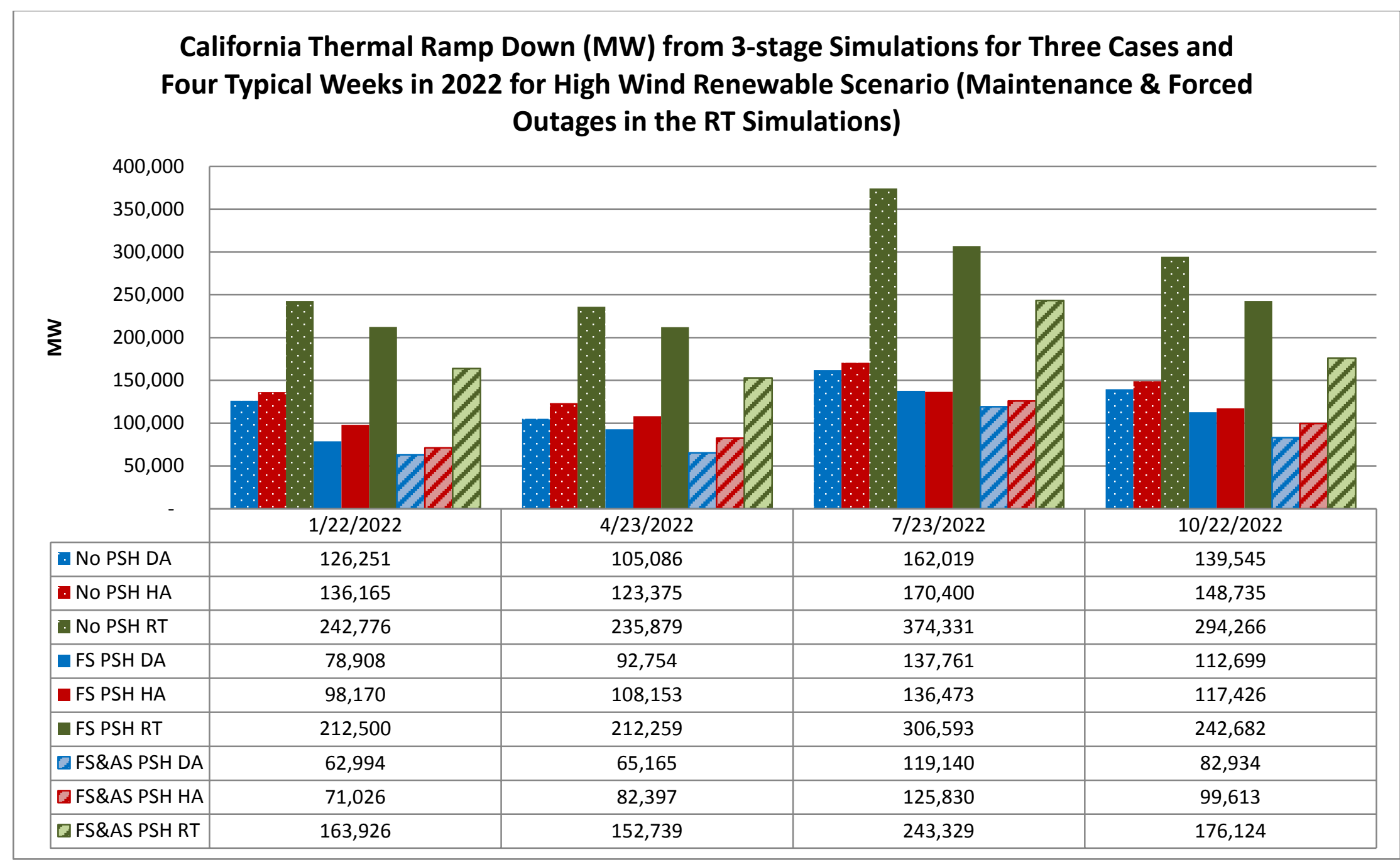

Figure 4-26 California Thermal Generator Ramp Down (MW) from Three-Stage Simulations for Three Cases and Four Typical Weeks in 2022 for the High Wind Renewable Scenario (Maintenance and Forced Outages in the RT Simulations) 
is lower by an average of $15.10 \%$ in the case with FS PSH, and by an average of $64.16 \%$ in the case with both FS and AS PSH in the system.

\subsubsection{Three-Stage DA-HA-RT Simulation Results for SMUD}

Four typical weeks, the third week in January, April, July, and October of 2022, were simulated for the SMUD footprint. Two cases, no PSH, and the proposed new AS PSH plant (Iowa Hill), were simulated using the cost-based approach.

\section{SMUD Three-stage Simulation Results for Four Typical Weeks in 2022}

The results obtained from the three-stage DA-HA-RT simulations for production costs, startup cost, and thermal generator ramping up and down for the four typical weeks under the High Wind renewable scenario are presented in Figures 4-27 through 4-30. The following are some key observations that can be derived from these simulations regarding the impact of PSH plants on the system operation and costs.

Figure 4-27 illustrates total system production costs for the SMUD area in four simulated weeks of 2022. Again, comparing the RT simulation results, it can be observed that the average system production costs over the four simulated weeks are lower if there is AS PSH capacity in the system. Specifically, compared with the case without PSH capacity, the average production costs are 14.31\% lower in the case with the AS PSH plant operating in the SMUD system.

Figure 4-28 shows the startup and shutdown costs for the SMUD system in four simulated weeks of 2022. Compared with the case without any PSH capacity, the average startup and shutdown costs over the four simulated weeks decrease by $10.62 \%$ if the AS PSH plant is added to the system.

Figures 4-29 and 4-30 show the results for the ramping of thermal generators within the SMUD system. It can be observed that both ramp ups and ramp downs are increased substantially in RT simulations, compared with DA simulations. The reason is that the 5-min simulation time step captures not only ramping needs from hour to hour, but also within the hour. With regard to the impact of PSH capacity, compared with the RT simulation results for the case with no PSH plants in the SMUD system, the addition of the proposed 400-MW AS PSH plant reduces the average ramping up of thermal generators by $22.06 \%$, and ramping down by $22.87 \%$. 


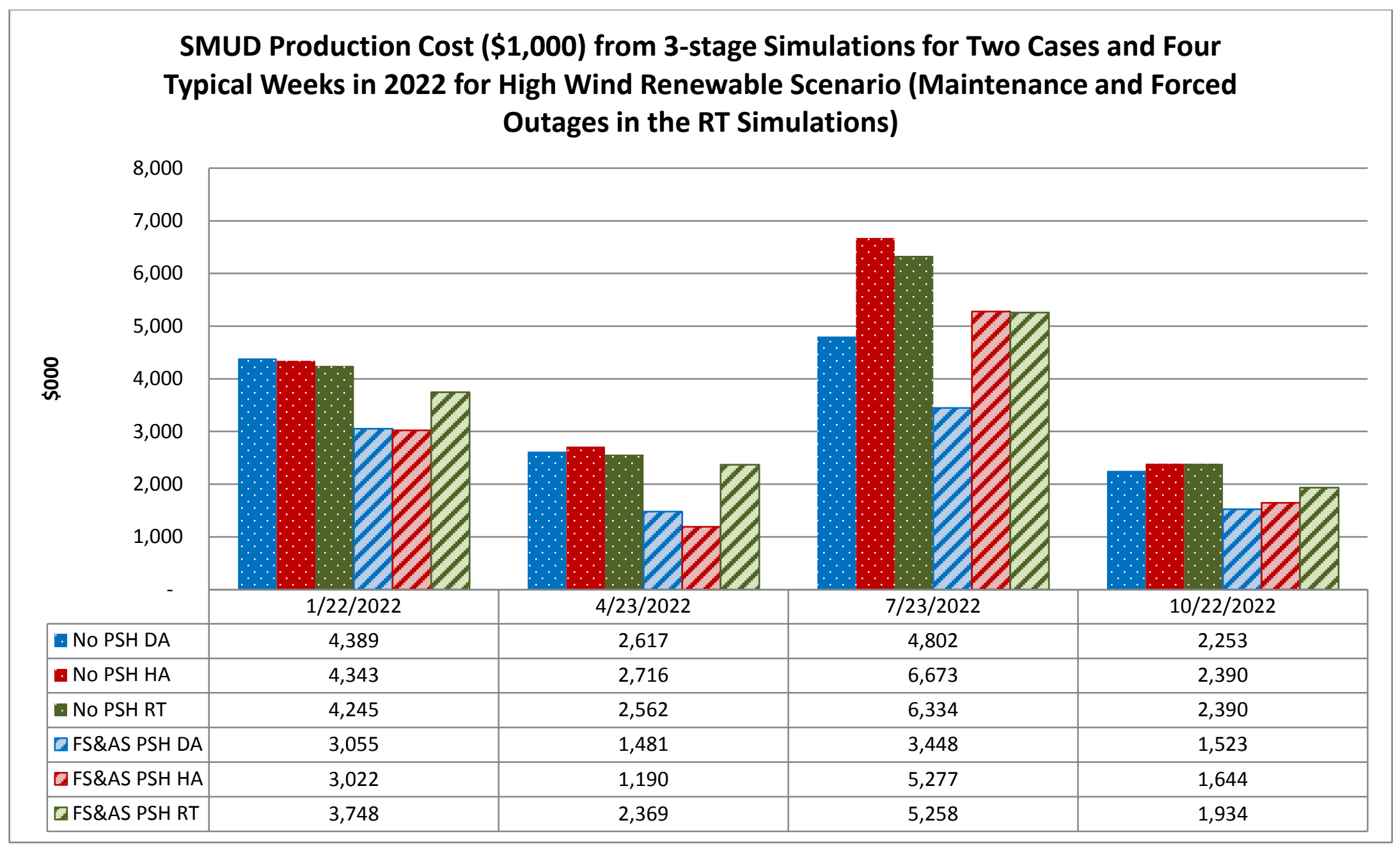

Figure 4-27 SMUD Production Cost $(\$ 1,000)$ from Three-Stage Simulations for Two Cases and Four Typical Weeks in 2022 for the High Wind Renewable Scenario (Maintenance and Forced Outages in the RT Simulations) 


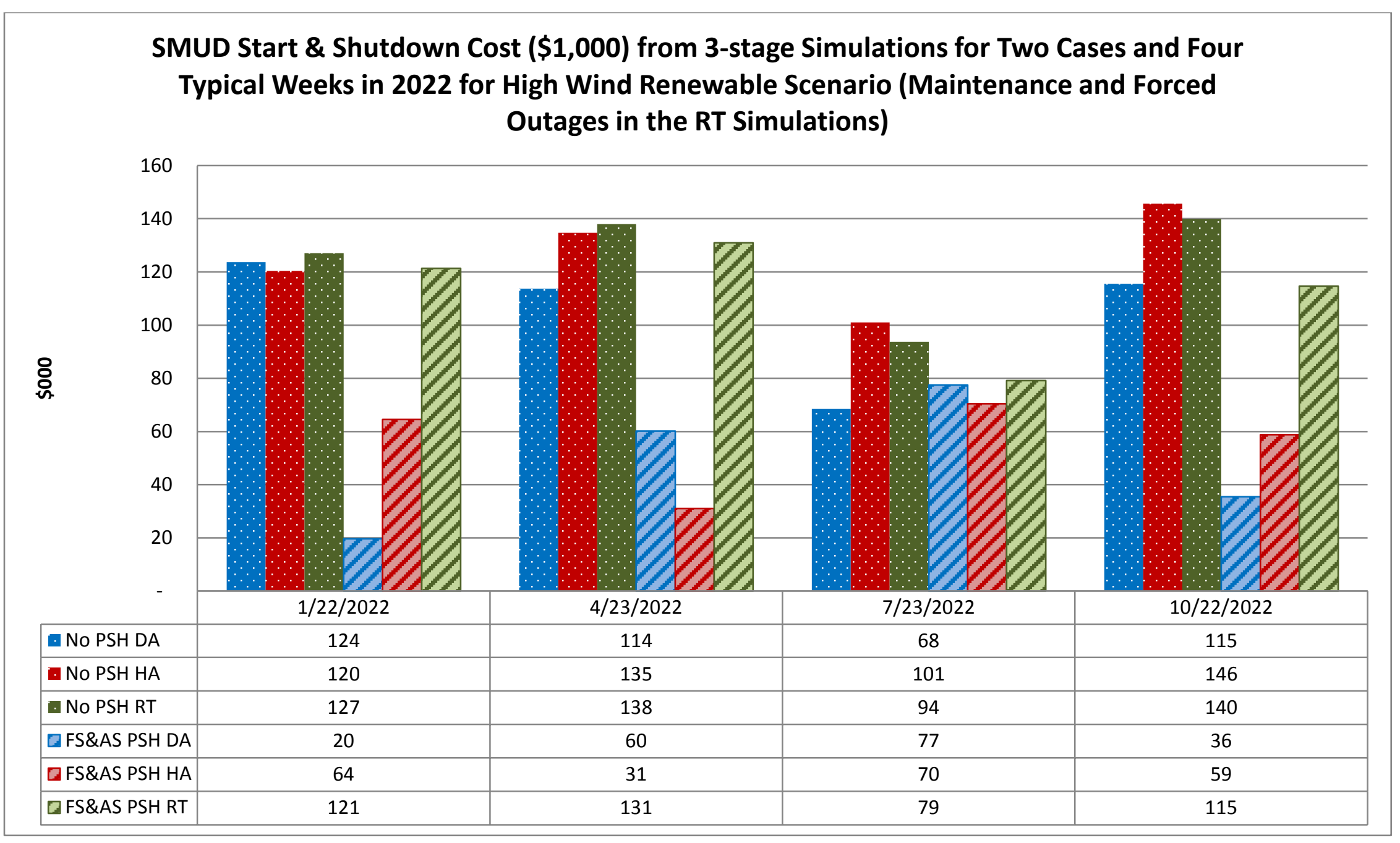

Figure 4-28 SMUD Startup Cost $(\$ 1,000)$ from Three-Stage Simulations for Two Cases and Four Typical Weeks in 2022 for the High Wind Renewable Scenario (Maintenance and Forced Outages in the RT Simulations) 


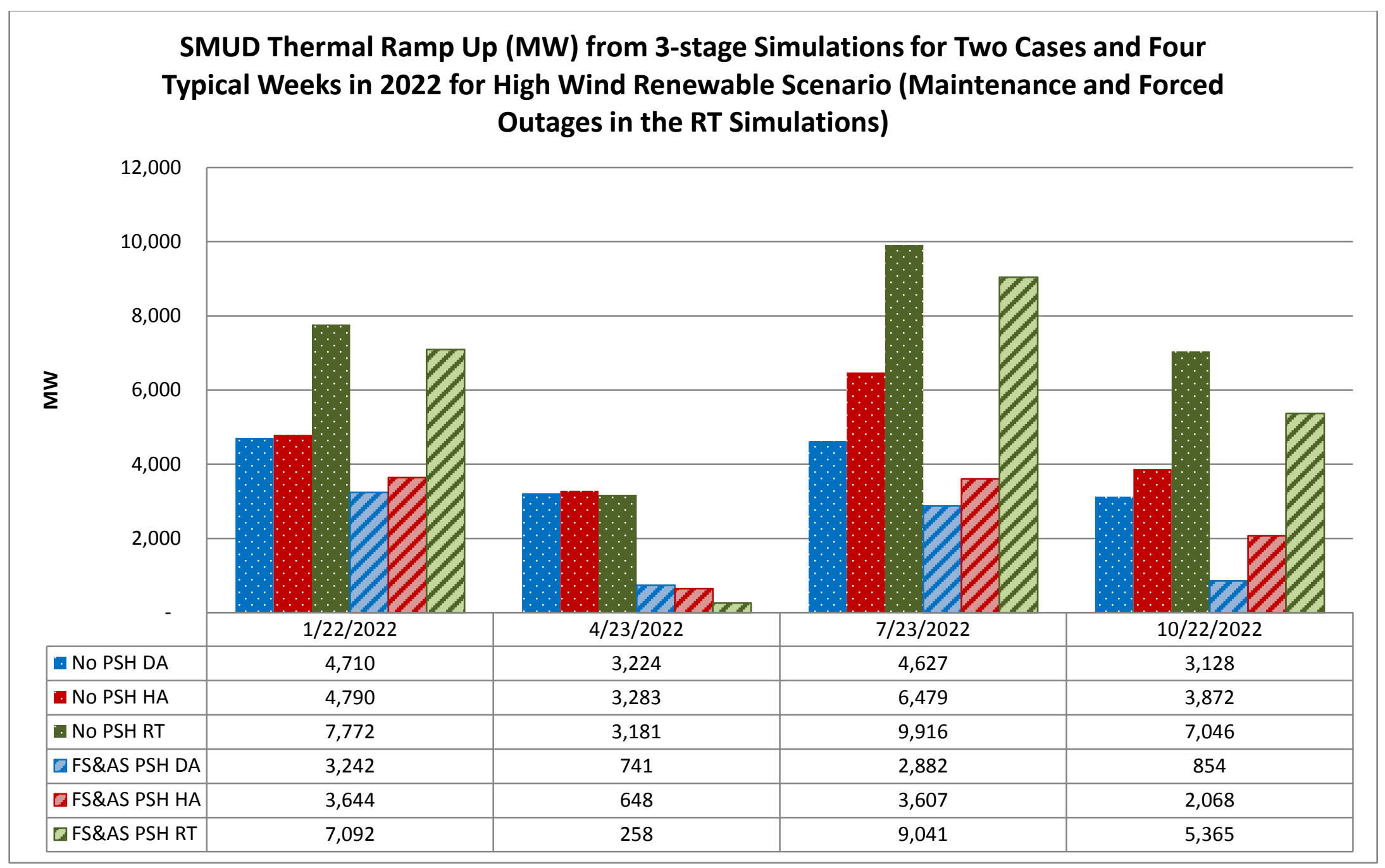

Figure 4-29 SMUD Thermal Generator Ramp Up (MW) from Three-Stage Simulations for Two Cases and Four Typical Weeks in 2022 for the High Wind Renewable Scenario (Maintenance and Forced Outages in the RT Simulations) 


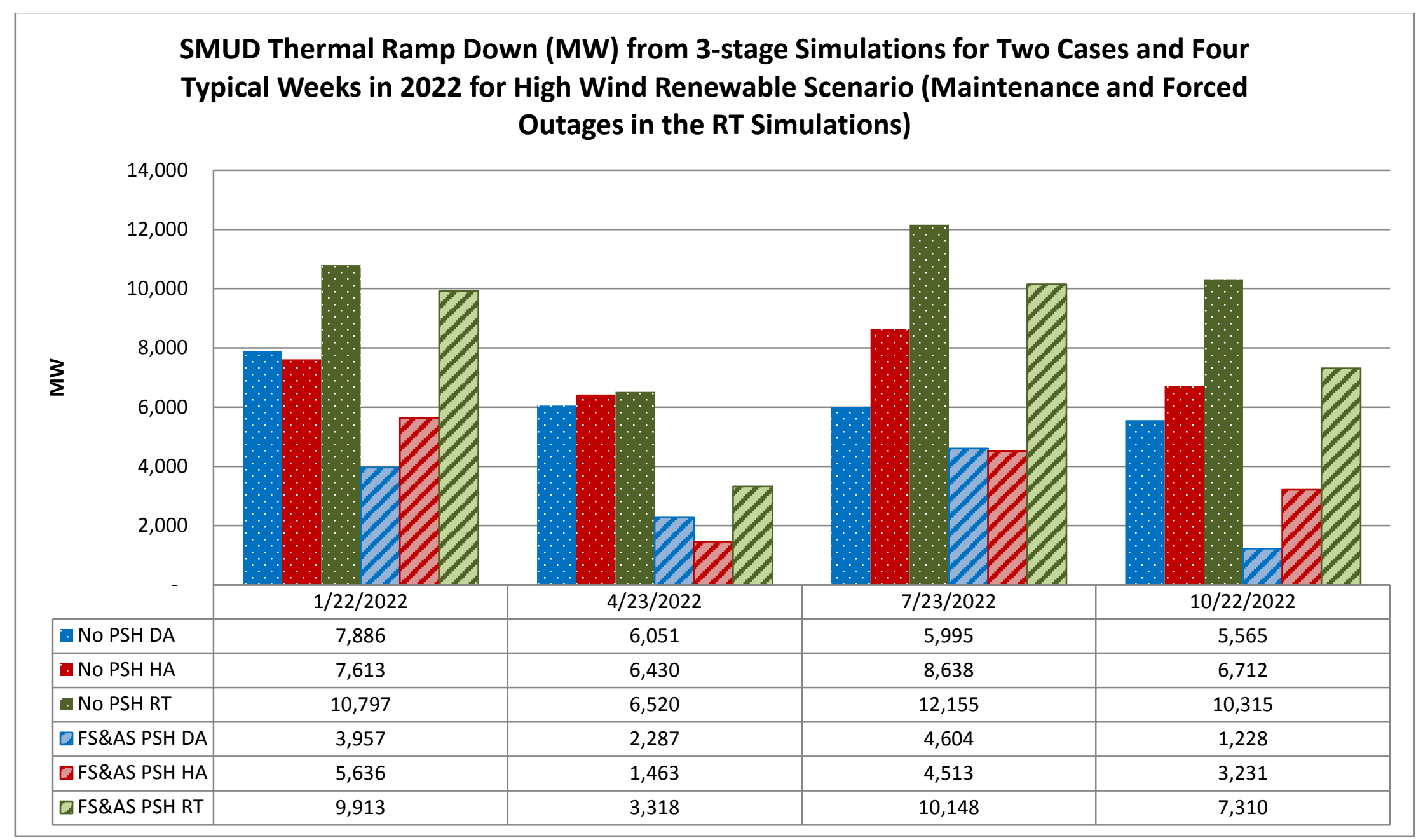

Figure 4-30 SMUD Thermal Generator Ramp Down (MW) from Three-Stage Simulations for Two Cases and Four Typical Weeks in 2022 for the High Wind Renewable Scenario (Maintenance and Forced Outages in the RT Simulations) 


\subsection{References}

WECC TEPPC, 2012a, “Assumptions Matrix for the 2020 TEPPC Dataset.pdf.” Available at https://www.wecc.biz/library/StudyReport/Documents/Assumptions\%20Matrix\%20for\%20the\% 202020\%20TEPPC\%20Dataset.pdf

WECC TEPPC, 2012b, “2022_CommonCase_InputAssumptions.doc.“Available at https://www.wecc.biz/Lists/Calendar/Attachments/4084/2022_CommonCase_InputAssumptions. docx.

CAISO (California Independent System Operator, CAISO, 2013, 2012 Annual Report on Market Issues and Performance, Department of Market Monitoring, April. Available at http://www.caiso.com/Documents/2012AnnualReport-MarketIssues-Performance.htm

Lew, D., G. Brinkman, N. Kumar, P. Besuner, D. Agan, and S. Lefton, 2012, “Impacts of Wind and Solar on Fossil-Fueled Generators," presented at Institute of Electrical and Electronics Engineers (IEEE) Power and Energy Society General Meeting, July 22-26, San Diego, Calif.

King, J., B. Kirby, M. Milligan, and S. Beuning, 2012, Operating Reserve Reductions From a Proposed Energy Imbalance Market With Wind and Solar Generation in the Western Interconnection, NREL/TP-5500-54660, National Renewable Energy Laboratory, Golden, Colo.

Lew, D., G. Brinkman, E. Ibanez, A. Florita, M. Heaney, B.-M Hodge, M. Hummon, G. Stark, J. King, S. Lefton, N. Kumar, D. Agan, G. Jordan, and S. Venkataraman, 2013, The Western Wind and Solar Integration Study Phase 2, NREL/TP-5500-55588, National Renewable Energy Laboratory, Golden, Colo.

Hunsaker, M., N. Samaan, M. Milligan, T. Guo, G. Liu, and J. Toolson, 2013, Balancing Authority Cooperation Concepts To Reduce Variable Generation Integration Costs in the Western Interconnection: Intra-Hour Scheduling, Western Electricity Coordinating Council (WECC) Variable Generation Subcommittee Project Report, March 29.

Guo, T., G. Liu, L. Yu, and V. Koritarov, 2013, Adjustable Speed Pumped-Storage HydroGenerator (PSH) Evaluation by PLEXOS, Energy Exemplar, LLC, Roseville, CA. 
This page intentionally left blank. 


\section{Section}

5

\section{Analysis of Steady-State Reliability and Detailed Costs Using the FESTIV Model}

An important component of understanding the full value of PSH is how it can support the reliability of the power system and how it can reduce the impact of variability and uncertainty of variable generation. With increased penetration of variable generation, the imbalance between generation and load can be more significant, leading to increased deviations in frequency or increased ACE. In this section, we evaluate how PSH and advanced PSH can provide incremental benefits to the steady-state reliability of the power system, while still recognizing any apparent costs savings. FESTIV is used to quantify both cost and reliability metrics, with a focus on how PSH and advanced PSH can increase reliability and improve control performance standards.

FESTIV integrates SCUC, SCED, and AGC into a multi-timescale simulation tool. These are the three modes of power system scheduling that are used to meet the changing net demand. Each of these submodels has different time characteristics and is used to meet the changing demand at different time resolutions and horizons. This allows multiple timescales to be studied where FESTIV accounts for intertemporal coupling between each submodel and the submodels themselves. It does this while having different objectives among the submodels; i.e., commitment of resources, dispatch and reserve commitment, and finally control of imbalance. Figure 5-1 is a flow diagram of FESTIV. Further description of the model can be found in Ela et al. (2011), and methods using FESTIV for studying variable generation impacts in Ela et al. (2012).

The FESTIV model was used to quantitatively assess the reliability impacts, while also understanding the costs and pricing impacts. For reliability analysis, the focus is on the ACE. In practice, the ACE is given as in Equation (1) (NERC 2012).

$$
A C E=\left(N I_{A}-N I_{S}\right)-10 B\left(F_{A}-F_{S}\right)
$$

where:

$$
\begin{aligned}
& N I_{A}=\text { the actual net interchange, } \\
& N I_{S}=\text { the scheduled net interchange, } \\
& B=\text { the frequency bias in } \mathrm{MW} / 0.1 \mathrm{~Hz},
\end{aligned}
$$


$F_{A}=$ the actual frequency, and

$F_{S}=$ the scheduled frequency.

This calculates the imbalance of a single balancing area while ensuring that it is also meeting its frequency response obligation for the interconnection. In FESTIV, frequency is not being modeled, and, therefore, ACE is calculated as the imbalance between generation and load. In practice, this approximation is reflective of ACE for an area that is part of a large interconnection where frequency is close to its scheduled value, and for all areas, if the balancing area frequency bias is assumed to be equal to its frequency response. FESTIV is being run at multiple timescales, the fastest of which is the AGC interval, which in the United States, runs at least every 6 sec (Standard BAL-005; Automatic Generation Control). During every AGC interval, the ACE is calculated. This gives a full time series of ACE data for which other reliability criteria can be assessed.

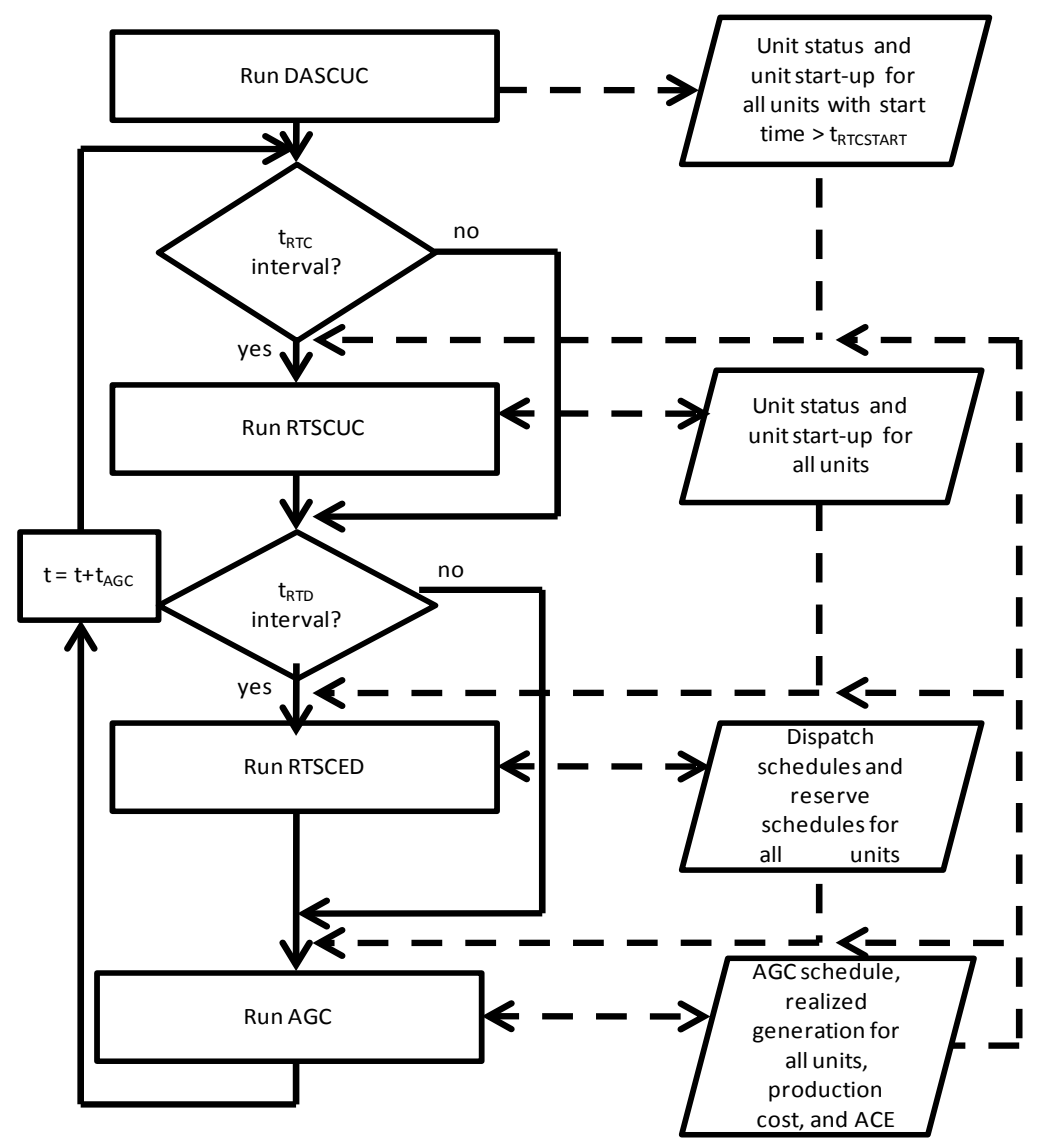

Notes: DASCUC, day-ahead SCUC; RTSCUC, real-time SCUC; RTSCED, real-time SCED

Figure 5-1 Flow Diagram for FESTIV (Solid lines represent process flow, dashed lines represent data flow.) 
ACE is a result of the system resources not being able to meet the changing net load demands, or because forecasts have predicted inaccurate net load demands. For example, variability of variable generation or load occurring at speeds that exceed the capabilities of regulating resources would cause ACE. In addition, when resources are moving toward an anticipated schedule that was forecast inaccurately, this would result in ACE as well. Reduction in variability, reduction in uncertainty, and improvement in resource flexibility (e.g., PSH capabilities) could all result in reduced ACE. In the analysis of this section, we focus on the following three ACE metrics:

- Absolute ACE in Energy (AACEE): This is the sum of the absolute value of ACE at every AGC interval for the study period, calculated in units of MWh.

- Control performance standard 2 (CPS2) violations and CPS2 score: This is the North American Electric Reliability Corporation (NERC) criteria under Standard BAL-001 (Real Power Balancing Control Performance) that signifies the number of 10-min periods that exceed the balancing area's ACE threshold, called L10. Any time the 10-min average ACE exceeds the L10, it is counted as 1 violation. The score is the percentage of 10-min intervals which do not violate the CPS2 criteria. According to BAL-001, a balancing area must score above $90 \%$ to be compliant.

- $\sigma_{\mathrm{ACE}}$ : the standard deviation of ACE for the study period, in MW.

These three metrics show tremendous information on how well the system is balancing its generation and load. It can show the general amount of imbalance, the amount of extreme imbalances, and the variation of that imbalance. In some cases, the amount of extreme imbalances (CPS2 violations) may be reduced with an improved scheduling strategy or the addition of a new resource, while potentially increasing the total imbalances (AACEE). In these scenarios, it is important that the balancing areas assess which of the metrics is most critical to them.

Production costs are also calculated at the AGC interval, so a detailed analysis of the cost of providing energy and regulating the ACE would be captured in these simulations. To compare scenarios properly, any negative bias in the ACE (i.e., the cumulative under-generating ACE for the study period), similar to inadvertent interchange, is bought back. Since both the production costs and ACE are being calculated at such a fine time resolution, the results can be used together to understand trade-offs. Often a strategy that improves reliability (reduces ACE) can increase the total production costs. The two metrics cannot be studied independently.

The FESTIV model is developed in Matlab and uses GAMS (Generic Algebraic Modeling System) with CPLEX (solver linear programming optimization solver) (GAMS 2012) for the DASCUC (day-ahead security-constrained unit commitment), RTSCUC (real-time securityconstrained unit commitment), and RTSCED (real-time security-constrained economic dispatch) algorithms. The interface between the software programs is modeled after work done by Ferris et al. (2005). 


\subsection{Input Data and Assumptions}

In order to study the impact of PSH and advanced PSH, the project team wanted a test system with a significant amount of variable generation. The system must also be large enough to produce meaningful results that may be extrapolated to determine the impact of a PSH plant on a system. As a result, the test system was modeled after BANC. BANC is an independent balancing area within the boundaries of California, including SMUD. Because of its sparse, interconnected nature with California, it was decided that the system would be simulated with internal transmission constraints ignored. SMUD is also in the developmental stages of installing a new PSH plant. The plant is proposed to be an AS technology, which furthermore makes it a perfect testbed for this part of the analysis.

The study periods were determined based on the preliminary results produced from the yearly PLEXOS simulations previously discussed. It was decided that two weeks would be investigated. The first week was the third week in July (July 16-22) due to the occurrence of the system's peak period. The second week was determined based on the variability of the wind and solar generator outputs during the months of January, April, and October. April showed the most variability from the PLEXOS time resolutions and as a result, the third week of April was used (April 16-22).

The input data were based on WECC's TEPPC (Transmission). The data are based on TEPPC's simulation of operating conditions in 2022 based on the TEPPC common case (Matrix). Profiles of the wind and PV resource data were derived from the second phase of the WWSIS-2 (Lew et al. 2013) and the NREL western renewable production database (NREL Wind Integration Datasets). The test case used the "Hi Mix" scenario from the WWSIS-2 study. Table 5-1 gives an overview of the system data.

Table 5-1 Overview of System Details (in MW)

\begin{tabular}{|l|r|}
\hline Peak load & 4,207 \\
\hline Total installed capacity & 6,975 \\
\hline Total installed wind capacity & 1,738 \\
\hline Total installed solar capacity & 325 \\
\hline Total installed hydro capacity & 2,509 \\
\hline Total installed combined cycle capacity & 1,482 \\
\hline Total installed combustion turbine capacity & 372 \\
\hline
\end{tabular}

As was previously mentioned, the system was to be modeled as a single point of injection and withdrawal (i.e., the internal transmission network is ignored). However, the interaction of BANC with the surrounding areas in California needed to be represented. In order to accomplish this, the BANC system was isolated from the PLEXOS simulations that incorporated the entire WI to determine both the net power flow into (power imports) and net power flow out of (power exports) BANC. These import and export schedules were then added to the load data in order to determine the net load on the system to be used in the simulations. The interchange schedules 
were ramped from one hour to the next during the period of 10 min before the hour, to $10 \mathrm{~min}$ after the hour to match what is done in practice.

In most balancing areas in the WI, the AGC is run at 4-sec intervals. This AGC interval resolution was also modeled in FESTIV. In order to convert the 1-min wind data provided by the Western Wind and Solar Integration Study into data at 4-sec intervals, a fractal interpolation method was used that Argonne developed. The basic premise of the interpolation technique is to generate synthetic interpolation data as a fractal in the form of fractional Gaussian noise signal with the proper fractal statistics. Wind speed variation is well known to have a fractal nature and is thus well described by fractal statistics, and synthetic wind signals can be generated as fractals (Chang et al. 2012; Harrouni 2010; Hurst and Vassilicos 2007). An interpolation method was developed using the methods of Morales et al. (2012) and Kroese and Botev (2013) and estimating the Hurst exponent from available 4-sec measured output. This noise was scaled to match the amplitude variations of the low-resolution data to interpolate. Finally, a linear function was then added to the noise to match the end points of the interpolation (e.g., the data points between which we were interpolating). Figure 5-2 shows a plot of a small section of the time history of the real and synthetic data.

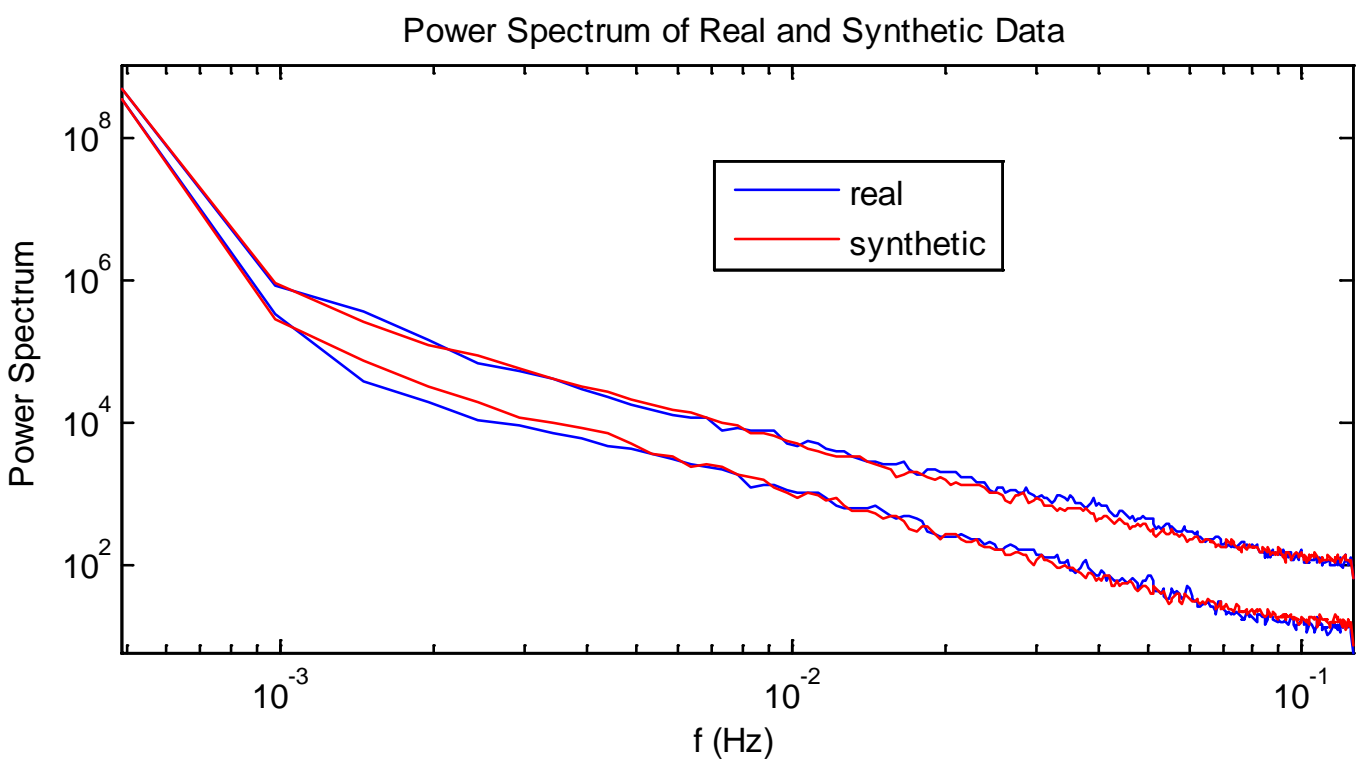

Figure 5-2 Power Spectrum of Real Data versus Synthetic Wind Data

The solar data available were also at 1-min intervals, needing to be adapted to 4-sec temporal resolution. Synthetic high rate solar irradiance time series data were created using a linear combination of spectral and time-series techniques. The downscaling method should introduce appropriate random variability in the sub-minute timescale as measured by a distribution of ramps (i.e., point-to-point differences). One possible approach is to interpolate the data using a technique such as a spline fit; however, this technique will not create synthetic data with the appropriate ramp distribution. Another approach is to extrapolate the amplitude of the 1-min spectra to higher frequencies by calculating a linear fit to the spectra (in log-log space). The 
phase of the spectra is extended to higher frequencies using a uniform random distribution. A synthetic time series can be found by taking the inverse fast Fourier transform (FFT) of the hybrid spectra. Different techniques are applied to extrapolate the spectral amplitude to higher frequencies, specifically, a fit over a subset of frequencies, a fit over all the frequencies, and a template for the spectral amplitude found from measured high rate data. A final synthetic time series is created by taking a weighted average of the different techniques. The weights are found such that the distribution of ramps from the synthetic data was as close as possible to the measured distribution of ramps (i.e., minimize the mean square error of the differences between the distributions). More information can be found in Hummon et al. (2013).

The load data are also based on the WWSIS-2 study mentioned earlier. The data are provided with 1-min temporal resolution. In order to obtain the 4-sec temporal resolution used by FESTIV, the points were linearly interpolated (i.e., it was assumed there is no variability within 1-min intervals in system load).

Once all of the data were developed, the simulation parameters were determined. FESTIV has a number of timing parameters that define how system operation is modeled, as can be seen in Figure 5-3. Because of the variance in timescales between FESTIV's submodels, it is important to carefully treat the intertemporal coupling between the submodels to ensure the most realistic results possible. FESTIV has four important timing parameters that can all be configured to any value: the interval resolution, I; the submodel update frequency, t; the scheduling horizon, $\mathrm{H}$; and the submodel processing time, $\mathrm{P}$. As an example, the RTSCUC model is updated every $\mathrm{t}_{\mathrm{RTC}}$ minutes, optimizes $\mathrm{H}_{\mathrm{RTC}}$ schedules at $\mathrm{I}_{\mathrm{RTC}}$ resolution during each update, and takes $\mathrm{P}_{\mathrm{RTC}}$ minutes to solve and send its directions to all of the resources. Table 5-2 shows the timing parameters used for the FESTIV simulation in this study.

To correctly model the uncertainty of variable generation and how PSH and advanced PSH can help reduce the impacts of uncertainty, the forecasts of the variable generation had to be realistically modeled. Forecasts were used for each of the sub-models, with the AGC using the "realized" 4-sec data. The DA wind and solar forecasts were also taken from the WWSIS-2 database and reflect realistic DA forecast errors. For the RT UC and RT ED, the wind generators would be forecast with a persistence wind forecast. This means that the current wind generator output at every dispatch/commitment interval was used as the output forecast for the next interval. The time it takes for the models to solve (in practice) and the scheduling interval resolution both determine the forecast horizon for the persistence wind forecast. For example, it was assumed that the 5-min RT dispatch model also took 5 min to solve giving a 10-min-ahead forecast horizon.

PV solar output is somewhat easier to predict in the short-term because of the predictable ramp up in the morning and ramp down in the evening. A persistence forecast for PV during either of these periods would cause unnecessary forecast errors. Therefore, the solar PV forecasts for the RT commitment and dispatch used a "constant cloudiness" forecast. The constant cloudiness forecast assumes the current cloud level will remain the same, but the power output of the solar PV will contain typical rise and fall based on the expected position of the sun. The cloudiness is therefore treated similar to the persistence wind forecast, but the expected clear sky ramping 


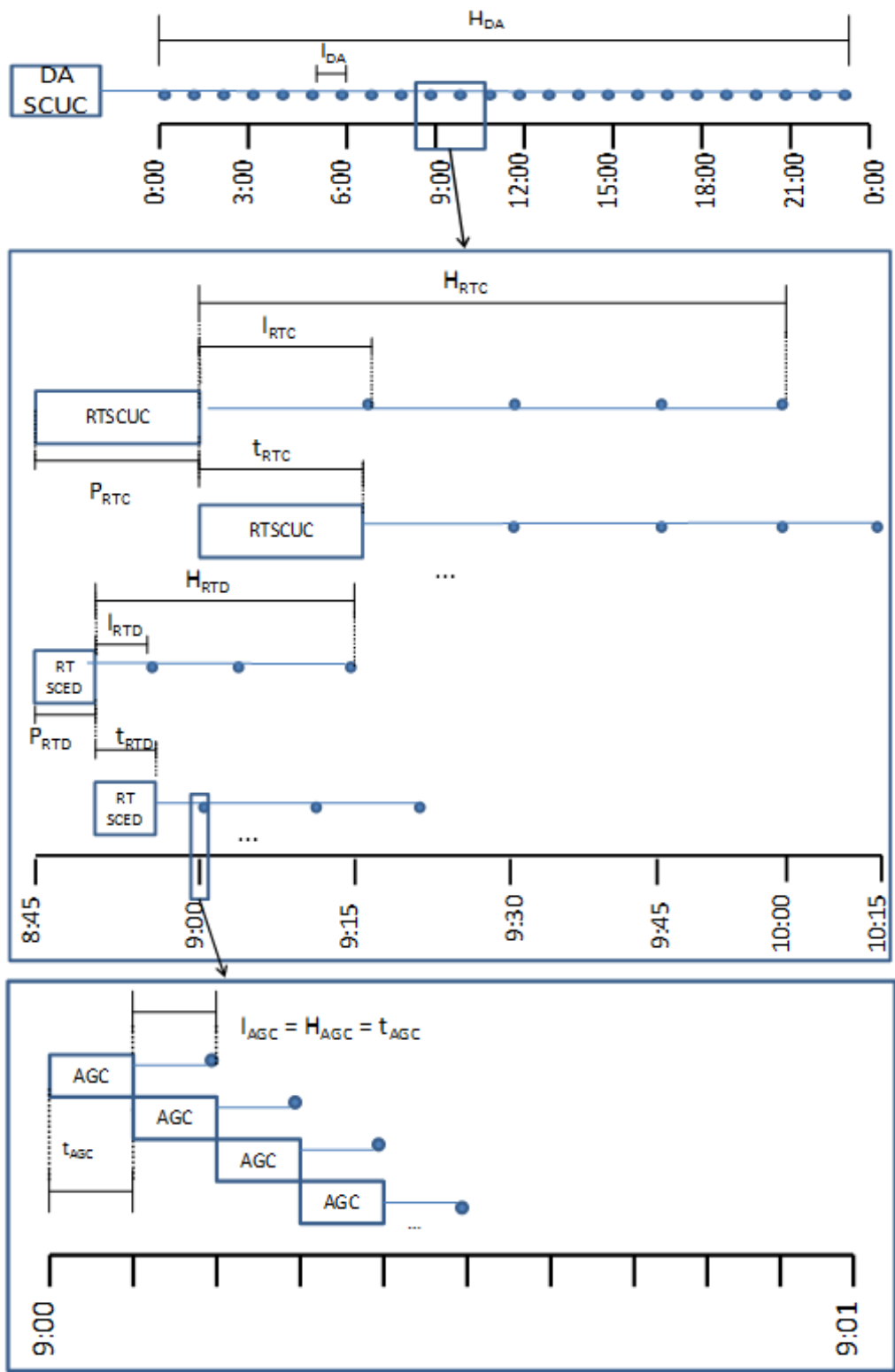

Figure 5-3 Timeline for DASCUC, RTSCUC, RTSCED, and AGC in FESTIV

Table 5-2 FESTIV Submodel Timing Parameters

\begin{tabular}{|l|l|}
\hline Day-Ahead Unit Commitment Optimization Horizon $\left(\mathrm{H}_{\mathrm{DAC}}\right)$ & $24 \mathrm{~h}$ \\
\hline Day-Ahead Unit Commitment Optimization Interval $\left(\mathrm{I}_{\mathrm{DAC}}\right)$ & $1 \mathrm{~h}$ \\
\hline Day-Ahead Unit Commitment Optimization Update Frequency $\left(\mathrm{t}_{\mathrm{DAC}}\right)$ & $24 \mathrm{~h}$ \\
\hline Real-Time Unit Commitment Optimization Horizon $\left(\mathrm{H}_{\mathrm{RTC}}\right)$ & $3 \mathrm{~h}$ \\
\hline Real-Time Unit Commitment Optimization Interval $\left(\mathrm{I}_{\mathrm{RTC}}\right)$ & $15 \mathrm{~min}$ \\
\hline Real-Time Unit Commitment Optimization Update Frequency $\left(\mathrm{t}_{\mathrm{RTC}}\right)$ & $15 \mathrm{~min}$ \\
\hline Real-Time Economic Dispatch Optimization Horizon $\left(\mathrm{H}_{\mathrm{RTD}}\right)$ & $1 \mathrm{~h}$ \\
\hline Real-Time Economic Dispatch Optimization Interval $\left(\mathrm{I}_{\mathrm{RTD}}\right)$ & $5 \mathrm{~min}$ \\
\hline Real-Time Economic Dispatch Optimization Update Frequency $\left(\mathrm{t}_{\mathrm{RTD}}\right)$ & $5 \mathrm{~min}$ \\
\hline Automatic Generation Control Temporal Resolution & $4 \mathrm{sec}$ \\
\hline
\end{tabular}


output is added. The equation used is from Ibanez et al. (2012) and is shown in Equation (2). Solar power index (SPI) is the ratio of power output and clear sky power output $\left(\mathrm{P} / \mathrm{P}_{\mathrm{CS}}\right)$.

$$
P_{F}(t+\Delta t)=P(t)+S P I(t) *\left[P_{C S}(t+\Delta t)-P_{C S}(t)\right]
$$

Where:

$$
\begin{aligned}
& P_{F}=\text { the forecast for the period in the future, } \\
& P(t)=\text { the current PV output, } \\
& S P I=\text { the solar power index, and } \\
& P_{C S}=\text { the power output if there were a clear sky. }
\end{aligned}
$$

Figures 5-4 and 5-5 show the PV forecasts for the first two days of the week in April for RTSCUC and RTSCED, respectively. The RTSCUC forecast has a longer horizon than RTSCED (3 h vs. $1 \mathrm{~h}$ ); however, the RTSCED is repeated every 5 min whereas the RTSCUC is repeated every $15 \mathrm{~min}$. These figures also show how forecasts look during normal sunny days (April 16) and how the forecasts appear during relatively cloudy days (April 17).

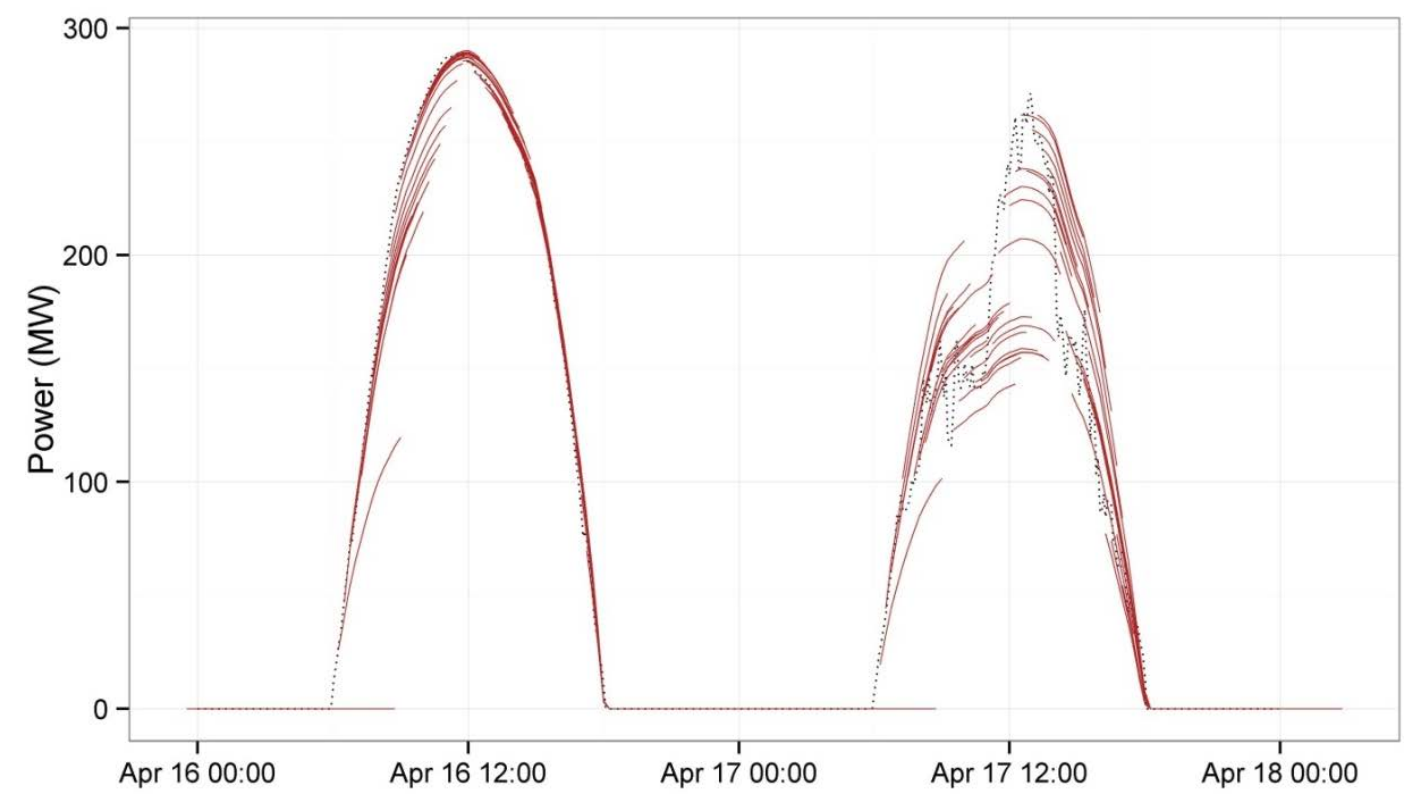

Figure 5-4 PV Forecasts for RTSCUC with an Optimization Horizon of 3 Hours, Repeating Every 15 Minutes 


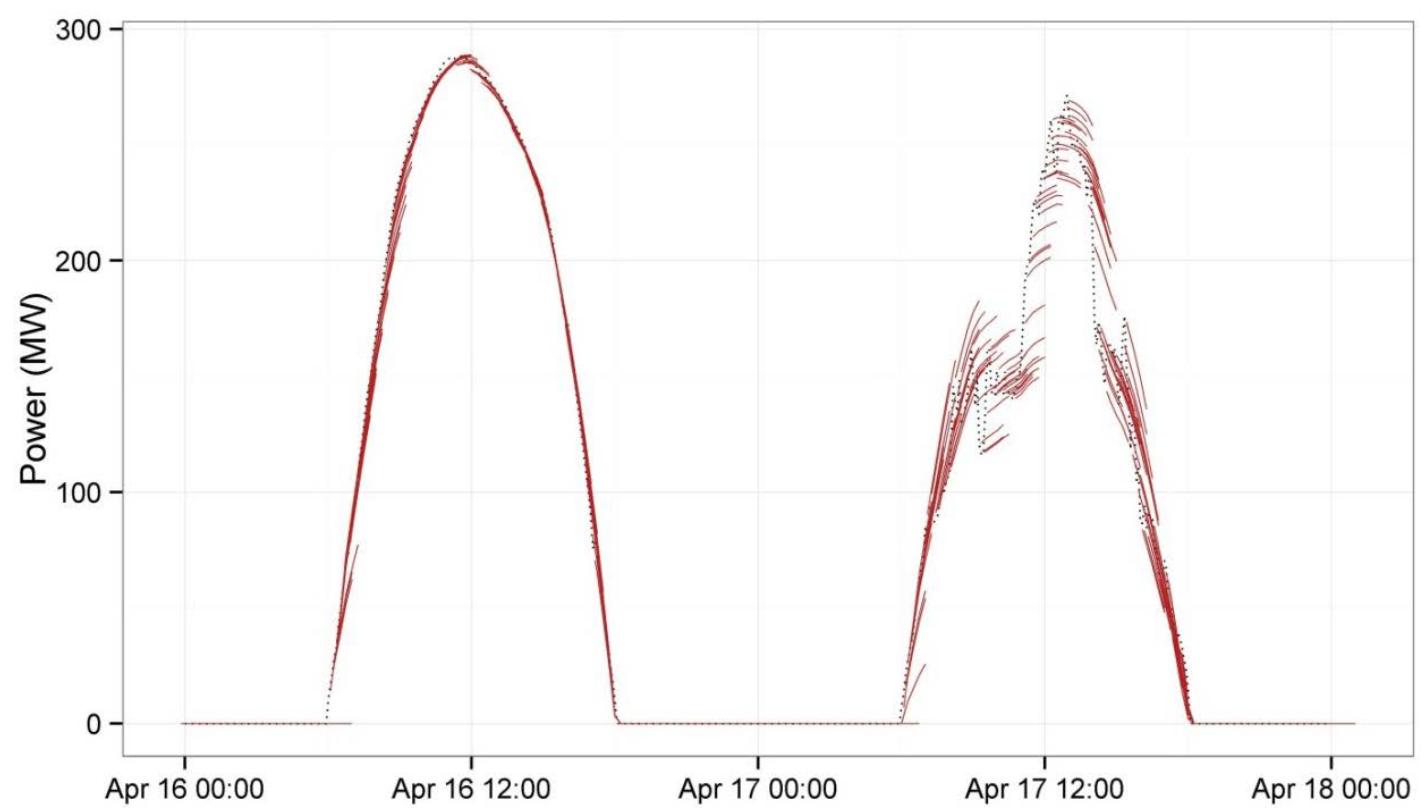

Figure 5-5 PV Forecasts for RTSCED with an Optimization Horizon of 1 Hour, Repeating Every 5 Minutes

Tables 5-3 and 5-4 summarize the mean absolute error (MAE) and the standard deviations $\left(\sigma_{\mathrm{FE}}\right)$ of the RT dispatch and DA forecasts, respectively, for wind and solar. The values shown were derived from the dispatch and forecast schedules of the different wind and solar plants at a 5-min temporal resolution. In the DA forecasting, wind forecast errors tend to be much larger than for $\mathrm{PV}$, as it is fairly easy to predict a daily solar pattern. However, in RT, cloudy days skew results of the PV forecasts so that they have relatively high errors.

In this study, the load demand forecasts were modeled as perfect average forecasts for each of the sub-models (e.g., perfect DA load in DASCUC, perfect 10-min ahead for RTSCED). This is unrealistic and will underestimate the ACE and production costs that result in the simulations. However, the team was not able to get valid data to use for appropriate forecasts for load.

Table 5-3 Wind and Solar Day-Ahead Forecast Error Characteristics

\begin{tabular}{|c|c|c|c|c|c|c|c|c|}
\hline \multirow[b]{2}{*}{ Forecast } & \multicolumn{4}{|c|}{ April } & \multicolumn{4}{|c|}{ July } \\
\hline & $\sigma(M W)$ & $\begin{array}{c}\sigma \text { as } \% \\
\text { Capacity }\end{array}$ & $\begin{array}{l}\text { MAE } \\
\text { (MW) }\end{array}$ & $\begin{array}{c}\text { MAE as } \\
\% \\
\text { Capacity }\end{array}$ & $\begin{array}{c}\sigma \\
(\mathrm{MW})\end{array}$ & $\begin{array}{c}\sigma \text { as } \% \\
\text { Capacity }\end{array}$ & $\begin{array}{c}\text { MAE } \\
(\mathrm{MW})\end{array}$ & $\begin{array}{c}\text { MAE as } \\
\% \\
\text { Capacity }\end{array}$ \\
\hline Wind & 358.64 & 20.6 & 267.36 & 15.4 & 248.56 & 14.3 & 287.16 & 16.5 \\
\hline Solar & 54.09 & 16.6 & 30.47 & 9.4 & 28.44 & 8.7 & 16.94 & 5.2 \\
\hline
\end{tabular}


Table 5-4 Wind and Solar Real-Time Dispatch Forecast Error Characteristics

\begin{tabular}{|c|c|c|c|c|c|c|c|c|}
\hline & \multicolumn{4}{|c|}{ April } & \multicolumn{4}{c|}{ July } \\
\hline Forecast & $\boldsymbol{\sigma}(\mathbf{M W})$ & $\begin{array}{c}\boldsymbol{\sigma} \text { as \% } \\
\text { Capacity }\end{array}$ & $\begin{array}{c}\text { MAE } \\
(\mathbf{M W})\end{array}$ & $\begin{array}{c}\text { MAE as } \\
\% \\
\text { Capacity }\end{array}$ & $\boldsymbol{\sigma}(\mathbf{M W})$ & $\begin{array}{c}\text { M as \% } \\
\text { Capacity }\end{array}$ & $\begin{array}{c}\text { MAE } \\
\text { (MW) }\end{array}$ & $\begin{array}{c}\% \\
\text { Capacity }\end{array}$ \\
\hline Wind & 26.89 & 1.5 & 17.27 & 1.0 & 13.56 & 0.8 & 10.14 & 0.6 \\
\hline Solar & 6.66 & 2.0 & 4.12 & 1.3 & 5.20 & 1.6 & 3.81 & 1.2 \\
\hline
\end{tabular}

Operating reserve requirements have always been decided based on traditional rules but are evolving with the consideration of how variable generation will affect these requirements (Ela et al. 2011a). The reserve requirements of this study were determined based on the methodology developed in WWSIS-2 (Lew et al. 2013). Requirements for wind power were calculated based on the analysis of short-term persistence forecast error distributions. Likewise, PV requirements were determined after examining the constant cloudiness forecast errors (Ibanez et al. 2012). These requirements for wind/solar were used, along with the base requirements for contingency and regulation reserves (as determined by WECC's TEPPC). Three types of operating reserves were considered in this study and the total requirements were calculated as follows:

- Contingency (spinning) reserves: 3\% of the load with no consideration of wind/solar generation. Resources must be on-line and be able to respond within $10 \mathrm{~min}$.

- Regulation reserves: Geometric sum of base requirement (1\% of load) and contribution of wind and PV (which cover 95\% of 10-min-ahead forecast errors). Resources must be on-line, have connection with the energy management system (EMS), and be able to respond within $5 \mathrm{~min}$. This was separated as regulation-up and regulation-down requirements so that some resources provided upward capacity and others provided downward capacity.

- $\quad$ Flexibility (load following) reserves: Geometric sum of wind and PV forecast errors (covering 70\% of 1-h-ahead forecast errors). No load forecast was available, so load did not contribute to this requirement. Resources must be on-line and available to respond within 30 min in both upward and downward directions.

The different requirements were added geometrically with the assumption that for short time steps, the forecast errors were considered to be uncorrelated. Table 5-5 summarizes the requirements for all operating reserves used in the study. 
Table 5-5 Requirements for Spinning Reserves

\begin{tabular}{|c|c|c|}
\hline Reserve & Calculation & $\begin{array}{c}\text { Response Time } \\
\text { (min) }\end{array}$ \\
\hline Contingency & $3 \%$ load & 10 \\
\hline Regulation & $\sqrt{(1 \% \text { load })^{2}+(\text { Wind rqt })^{2}+(P V r q t)^{2}}$ & 5 \\
\hline Flexibility & $\sqrt{(\text { Wind rqt })^{2}+(P V r q t)^{2}}$ & 30 \\
\hline
\end{tabular}

The DA reserve schedules for April 16 are shown in Figure 5-6 for both an April day (left) and July day (right). Figure 5-7 shows the reserve schedules for the binding intervals of the 5-min ED optimization for April 16. The flexibility reserves are assumed to be reserves procured in the DA and RT unit commitment and released for deployment in the RT dispatch to address variability and uncertainty issues. This is why the flexibility reserve schedule in Figure 5-7 is zero throughout the entire day. The contingency reserve tended to be the most significant requirement for both spring and summer periods. In the July case, the flexibility reserve need tends to drop during the middle of the day, likely because solar can be forecast quite well in the summer. These magnitudes are fairly consistent throughout the week in both the April and July periods.

The hydro generator profiles were assumed to follow the dispatch schedules as determined by the PLEXOS simulations, since hydrothermal coordination modeling is not suitable for the short time horizons simulated by FESTIV. The hydro generators could be curtailed by FESTIV and would be curtailed before the variable generation if over-generation situations occurred. In addition, selected large hydro plants were also available on AGC to provide regulation if needed.
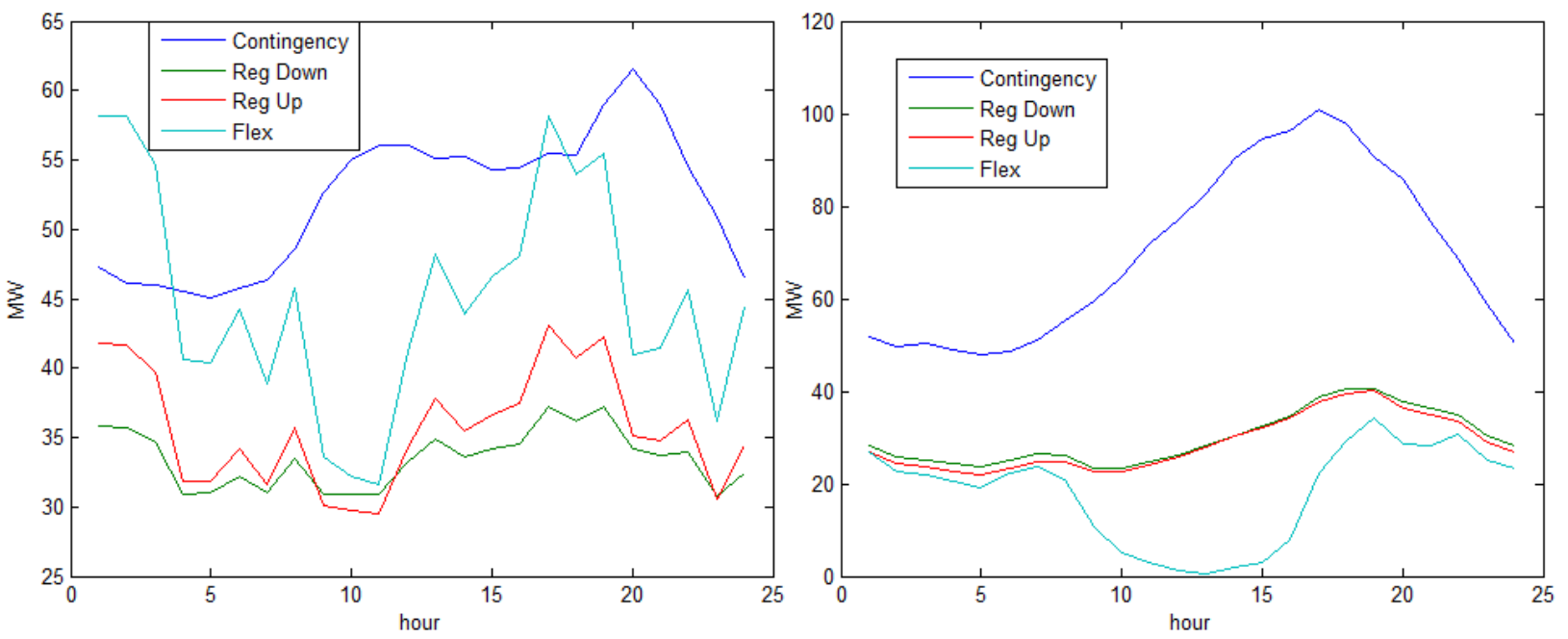

Figure 5-6 Day-Ahead Reserve Requirements for April 16 (left) and July 16 (right) 


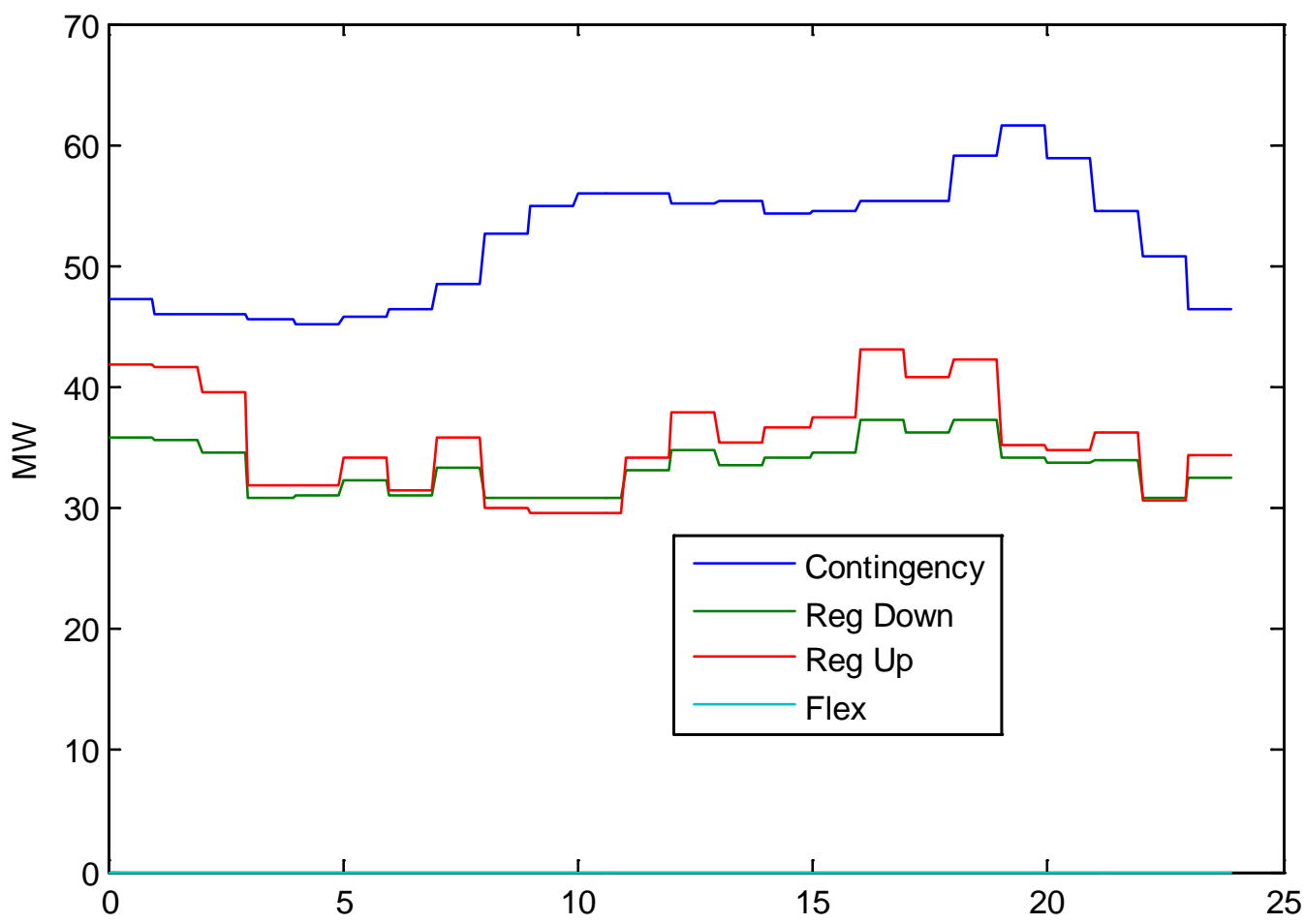

Figure 5-7 Real-Time Dispatch Reserve Requirements for April 16

The modeling of the pumped storage plant was based on the discussion found in Section 2.1 of this report. Table 5-6 is a summary of the characteristics for the AS pumped storage units used in this study. For a conventional FS unit, the major difference is that the minimum output in pumping mode is equal to its maximum output, $133 \mathrm{MW}$. In all simulations involving the pumped storage plant type, there are three units that represent the PSH plant.

Table 5-6 Summary of the AS PSH Unit Characteristics

\begin{tabular}{|l|r|}
\hline Maximum output in pumping mode (MW) & 133 \\
\hline Maximum output in generating mode (MW) & 133 \\
\hline Minimum output in pumping mode (MW) & 79.8 \\
\hline Minimum output in generating mode (MW) & 39.9 \\
\hline Minimum pumping time (h) & 0 \\
\hline Minimum generating time (h) & 0 \\
\hline Time to start pumping (min) & 15 \\
\hline Time to start generating (min) & 15 \\
\hline Ramp rate in pumping mode (MW/sec) & 7 \\
\hline Ramp rate in generating mode (MW/sec) & 7 \\
\hline Pumping efficiency (\%) & 80.4 \\
\hline Total maximum reservoir capacity (MWh) & 5,000 \\
\hline Initial reservoir level (MWh) & 2,500 \\
\hline
\end{tabular}


In order to value the amount of storage left in the reservoir, an additional constraint was used to ensure that the storage level at the end of the optimization of each DA UC is the same as the level at the beginning of the optimization. The RT operating status of the pumped storage plant is also determined by the DA optimization. This means that the DA optimization determines when the pumped storage plant will be generating and when it will be pumping. The RT models then attempt to end the storage level close to where the DA model solution determined the level should be at each time interval, interpolated when the end of the RT horizon was within the hour. However, if the RT optimization favored either more or less generation or pumping to be used, that option is also available. The dual variable from the equation in the DA model that ensures the storage level at the end of the day, equal the storage level from the beginning, is then used as a penalty cost for violating the storage level in RT, as shown in Equation (3).

$S T L_{i, t}^{R T}=S T L_{i, \tilde{t}}^{D A}+\sigma_{i}^{+}-\sigma_{i}^{-}, \forall i \in$ All PSH, $\forall t=$ last interval in $R T$ model Horizon

where:

$S T L=$ the storage level,

$R T=$ the RT model (either RTSCUC or RTSCED),

$S T L^{D A}=$ the storage level as already decided in the DASCUC,

$\tilde{t}=$ the time from DASCUC that corresponds to $t$ in the RT model, and

$\sigma^{+}$and $\sigma^{-}=$the penalty variables for adding more or less storage to the reservoir in the RT models.

The penalty variables are also part of the objective function and are multiplied by the dual variable from the DASCUC. This ensures that PSH is not used too differently in the RT from how it was decided to be used in the DA optimization, unless forecast errors cause it to be used differently.

\subsection{FESTIV Simulation Results}

The FESTIV model was used to analyze the effects of conventional PSH and advanced PSH on the detailed production costs and reliability of the power system. In these cases, typical generating unit constraints, load balance, and all four reserve constraints (spin, regulation up, regulation down, and flexibility reserves) were modeled with the additional constraints needed for PSH. The DASCUC was the only model that decided on the mode that the PSH would operate in, but all models could adjust the output. The AGC model used a 3-min integral term when following the ACE, which is typical of many AGC programs (European Network of Transmission System Operators for Electricity [ENTSO-E]). The BANC system was simulated for one week in April (April 16-22) and one week in July (July 16-22). Each week was simulated for three different scenarios. Scenario one is the base case system without any PSH generators. Scenario two is the base case system with a conventional FS PSH plant added to the 
system. Scenario three is the base case system with an advanced AS PSH plant added to the system. All data, including generation, variable generation realized outputs and forecasts for every model, and load and load forecasts for every model, are identical with the exception of the PSH plants. In scenarios 2 and 3, the pumped storage plant consisted of three PSH units with parameters as shown in Section 5.1. A summary of simulation results for April is shown in Table 5-7, and a summary of simulation results for July is shown in Table 5-8. ${ }^{3}$ The L10 limit used for BANC was 35.6, which is the L10 of the BANC balancing area in 2012 (NERC 2012). ${ }^{4}$

Table 5-7 Summary of April Week Simulations

\begin{tabular}{|l|r|r|r|}
\hline & \multicolumn{1}{|c|}{ No PSH } & With FS PSH & With AS PSH \\
\hline Total production cost (\$ million) & 3.449 & 3.169 & 3.032 \\
\hline Number of CPS2 violations & 49 & 47 & 45 \\
\hline CPS2 Score (\%) & 95.1 & 95.3 & 95.5 \\
\hline Absolute ACE in Energy (AACEE) (MWh) & 2,583 & 2,620 & 2,644 \\
\hline$\sigma_{\text {ACE }}(\mathbf{M W )}$ & 23.8 & 25.1 & 23.0 \\
\hline
\end{tabular}

Table 5-8 Summary of July Week Simulations

\begin{tabular}{|l|r|r|r|}
\hline & \multicolumn{1}{|c|}{ No PSH } & With FS PSH & With AS PSH \\
\hline Total production cost (\$ million) & 5.394 & $\$ 5.101$ & $\$ 5.021$ \\
\hline Number of CPS2 Violations & 40 & 16 & 15 \\
\hline CPS2 Score (\%) & 96.0 & 98.4 & 98.5 \\
\hline Absolute ACE in Energy (AACEE) (MWh) & 3,201 & 2,736 & 2,593 \\
\hline$\sigma_{\text {ACE }}(\mathbf{M W )}$ & 29.3 & 21.3 & 20.2 \\
\hline
\end{tabular}

As is evident from Tables 5-7 and 5-8, there are immediate benefits of both a conventional FS $\mathrm{PSH}$ plant as well as an advanced AS PSH plant in terms of cost reduction. In April, the FS PSH plant reduces total production costs by about $8 \%$. The AS PSH reduces costs $4 \%$ more to a total of a $12 \%$ reduction in costs from the base case. In July, the cost savings are approximately $5 \%$ and 7\%, respectively. The absolute cost savings in July are similar to those from April. These results mirror the PLEXOS results in Section 4.3.3 and signify that the detailed costs of controlling for the ACE and measuring at such a fine timescale do not substantially change the results found from the annual simulations of the production cost simulation model. In April, the addition of the FS PSH units reduced the number of CPS2 violations from 49 to 47. However, the standard deviation and absolute amount of ACE were not reduced. At certain times

3 Total production cost is adjusted slightly in these simulations to account for inadvertent interchange and remaining reservoir level at the end of the 1-week period. Inadvertent interchange is paid back, when negative, or paid to, if positive, at the average RT LMP. For reservoir levels that are equal to the target, no cost adjustment is made, storage above (below) the target will add (subtract) from the total at the average dual value from the PSH storage equation in the DA model.

4 http://www.nerc.com/docs/oc/rs/2012\%20CPS2\%20Bounds\%20Report\%20Final\%28Update20120821\%29.pdf. 
of the year when the PSH plant is pumping and not able to regulate ACE, it may change the mix of resources that are available to improve the ACE results. For example, it is possible that the addition of pumped storage can allow more inflexible baseload units online and reduce the commitment of expensive, yet flexible plants. Since the CPS2 violations were reduced, and the AACEE and $\sigma_{\mathrm{ACE}}$ were only slightly increased, this is likely not a significant effect. In July, all reliability metrics were improved significantly. During high peak times, other flexible units were still needed with the higher load to also help in regulating the ACE.

The addition of the AS PSH unit consistently improved ACE metrics in both weeks of study. The exception is the increase in AACEE in April. Since all units are regulating the filtered ACE in these cases, this slight increase is also not substantial. The AS PSH units always performed better for reliability than the FS units. However, the magnitude at which they performed better was not always substantial.

An important factor of these studies is the amount of conventional hydro that is available in the BANC system. With so much hydro, along with wind and solar, there are a lot of resources that cost very little to regulate. The hydro plants are quite flexible themselves when providing regulation. In Scenario 3, with the AS units for the week of April, the three PSH units were asked to provide regulation between $12 \%$ and $15 \%$ of the time, due to economics. In the July case, the three units were asked to regulate between $21 \%$ and $23 \%$ of the time. This is likely the reason for the July case having a larger improvement in its reliability performance.

Figures 5-8 and 5-9 show the power output for the three pumped storage units in the system as FS pumped storage generators and AS pumped storage, respectively. Notice the main benefit of the AS PSH units is their ability to provide regulation support in pumping mode.

Focusing on hours 57 to 64 of Figure 5-9 shows significant ACE regulation occurring while the AS unit is pumping, as is shown in Figure 5-10.

Figure 5-11 shows the weekly power production of the three PSH units. While both cases for each week are operating on the same system with the same load and variable generation output, the operations of the FS and AS units are sometimes different. There are certain hours that the FS units were asked to pump or generate, and the AS units were not asked to do the same, and vice versa. Because of the differing parameters, the entire UC and dispatch can change quite substantially. In July, there are more periods where both scenarios ask the PSH units consistently to generate or pump. With higher loads and lower variable generation (lower wind power), the high net load and low net load periods are more disparate from one another than in the April case. 


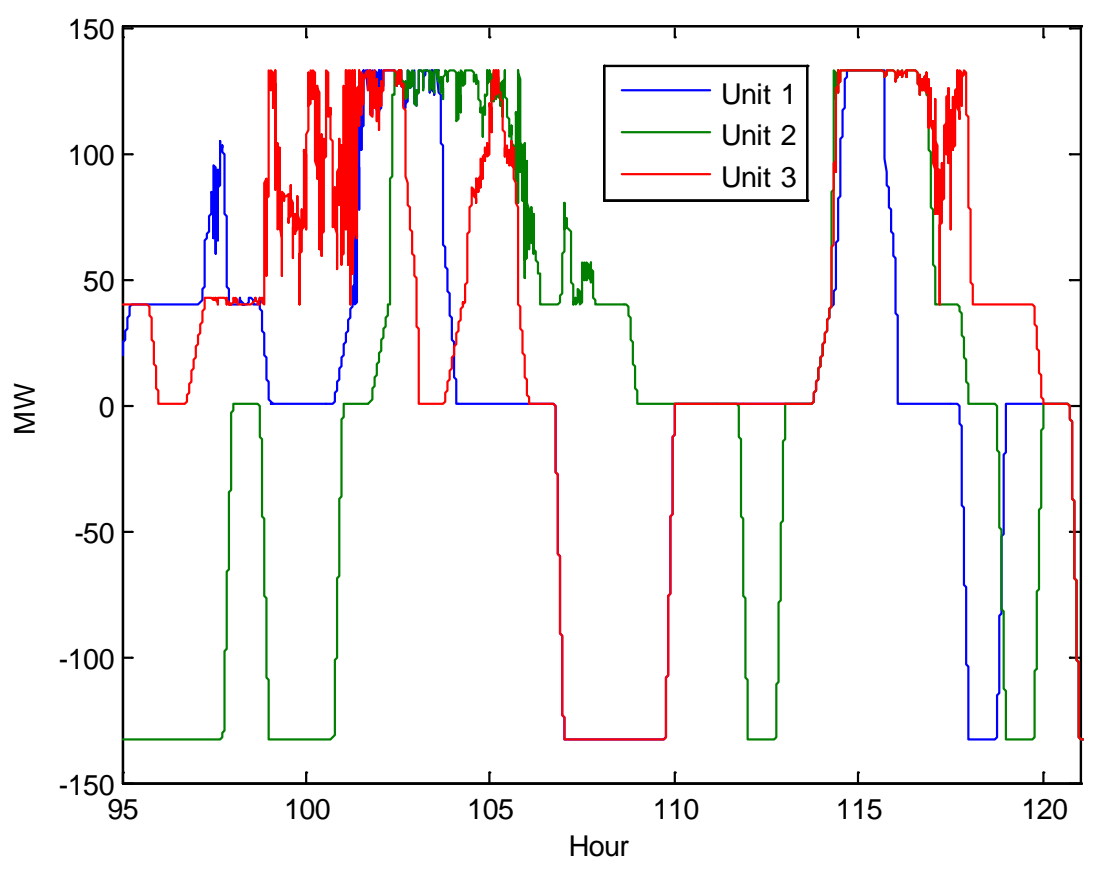

Figure 5-8 Power Output of Three FS PSH Units for 1 Day in April

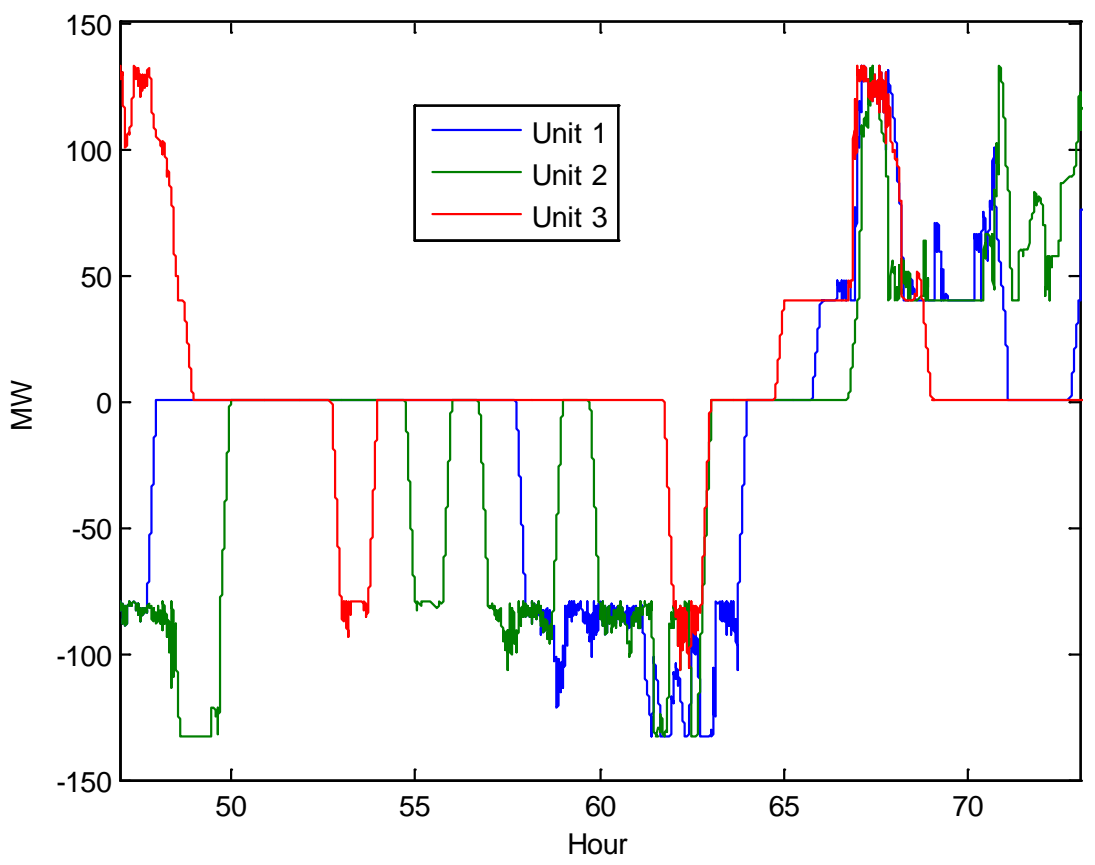

Figure 5-9 Power Output for Three AS PSH Units for 1 Day in April 


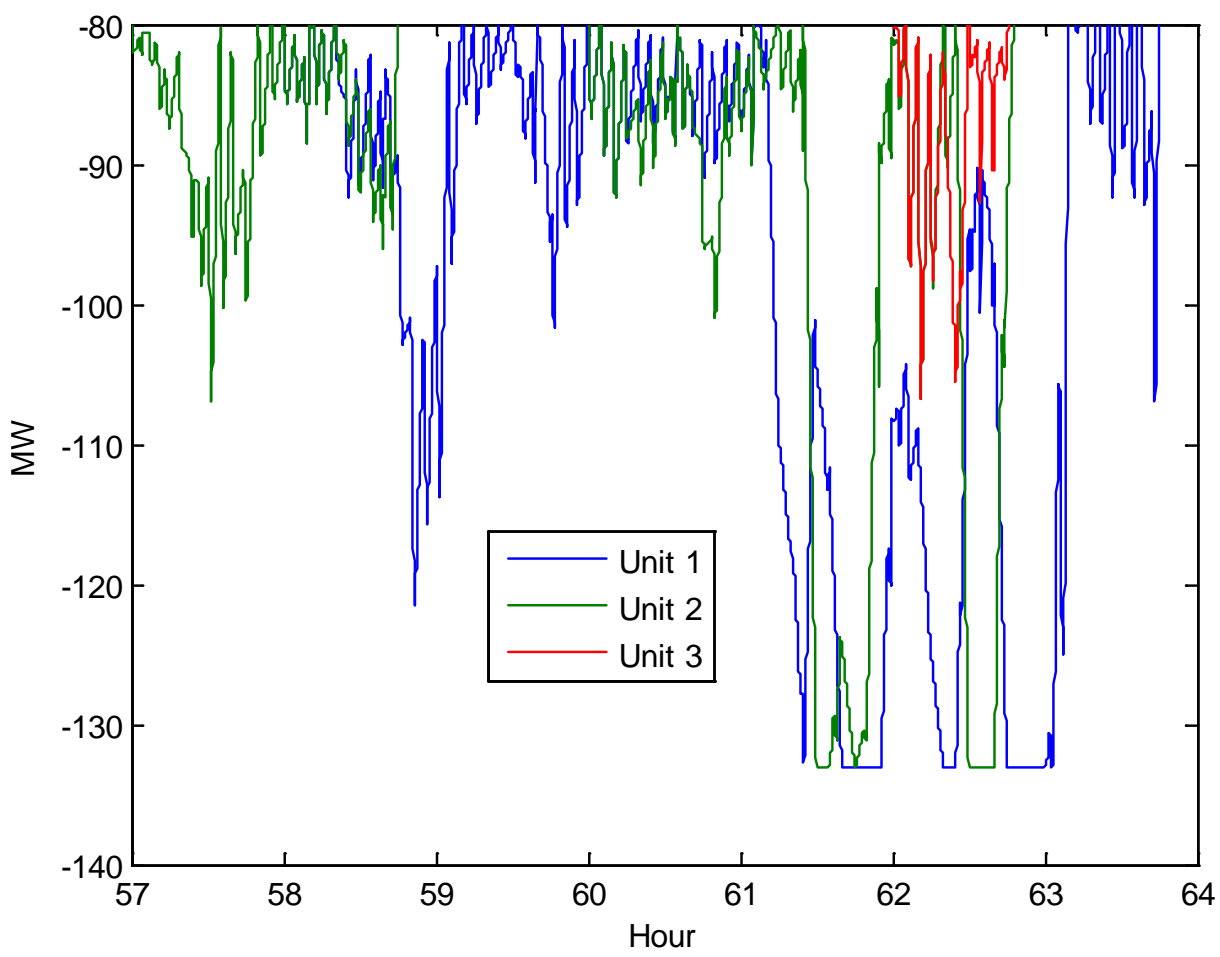

Figure 5-10 AS PSH Regulating in Pumping Mode

Table 5-9 shows the amount of energy the three PSH units produced and consumed while generating and pumping, respectively. It also shows the percentage of energy generated compared with the energy consumed from pumping.

If the final reservoir level were to exactly match the initial reservoir level, the percentage generating would equal the PSH round-trip efficiency, that is, $80.4 \%$. The only case that did was the July case with FS PSH. The July case in general provided more generation than April, due to the higher energy cost in that period. In both cases, the AS PSH scenario had less generation than pumping. In some ways this is counterintuitive since the AS PSH has the ability to reduce its pumping output where the FS PSH plant does not. However, since the cost-minimization tools have this information, they use this to better optimize the use of the AS PSH output. When the AS PSH units were in pumping mode, they provided significantly more regulation services, which are not deployed based on costs, nor does the AGC have any goal to ensure the reservoir level meets its end-of-day goal. 


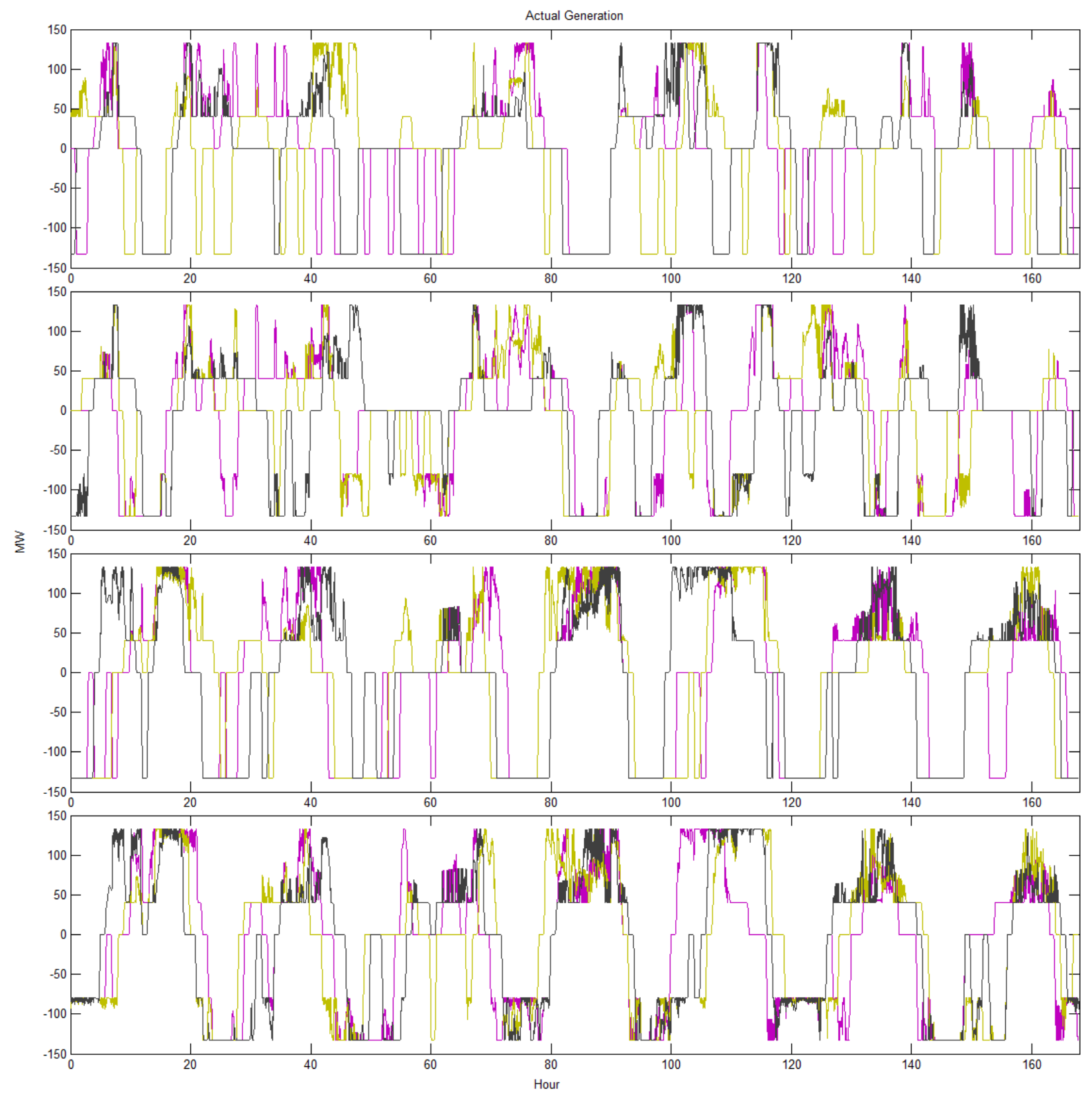

Figure 5-11 Power Output of Three PSH Units as (a) FS in April, (b) AS in April, (c) FS in July, and (d) AS in July

Table 5-9 Amount of Energy the Three PSH Units Produced and Consumed for Generating and Pumping

\begin{tabular}{|l|c|c|c|c|c|c|}
\hline & \multicolumn{3}{|c|}{ Week in April } & \multicolumn{3}{c|}{ Week in July } \\
\cline { 2 - 7 } & $\begin{array}{c}\text { Generating } \\
\text { Mode } \\
\text { Technology }\end{array}$ & $\begin{array}{c}\text { Pumping } \\
\text { Mode } \\
\text { (MWh) }\end{array}$ & $\begin{array}{c}\text { Pumping/ } \\
\text { Generating } \\
\text { (\%) }\end{array}$ & $\begin{array}{c}\text { Generating } \\
\text { Mode (MWh) }\end{array}$ & $\begin{array}{c}\text { Pumping } \\
\text { Mode } \\
\text { (MWh) }\end{array}$ & $\begin{array}{c}\text { Pumping/ } \\
\text { Generating } \\
\text { (\%) }\end{array}$ \\
\hline FS PSH & 11,951 & 15,328 & 78.0 & 17,543 & 21,823 & 80.4 \\
\hline AS PSH & 11,736 & 16,029 & 73.2 & 16,606 & 20,897 & 79.5 \\
\hline
\end{tabular}




\subsection{Sensitivity Studies}

\subsubsection{No Variable Generation}

The team ran a number of sensitivities to better understand the nature of how PSH and advanced PSH were contributing to reducing costs and improving the steady-state reliability of the power system. First, while the studies above analyze the benefits of PSH on high VER penetrations, the PSHs that are being installed are likely to be installed before the VER penetrations reach this high level. Therefore, we studied the same systems where there are no VERs present. Without VER, there is less imbalance occurring on the system. ${ }^{5}$ This may lead to less value for PSH contributions in improving the reliability. It also may mean reduced price volatility where PSH can assist in energy arbitrage. Finally, the regulation and flexibility reserve A/S would likely be a smaller market for which PSH can contribute, because the A/S needs are reduced without the VER on the system. Similar to the base case, three scenarios were run: base case without PSH; conventional, FS PSH; and AS PSH. These cases were identical to the previous cases with the exception that all of the wind and solar plants were no longer available. Interchange schedules were kept identical to previous ones to ensure a fair comparison with the previous cases. We focused only on April in this sensitivity. Table 5-10 presents the results.

Table 5-10 Summary of the April Week Simulations without VER Generation

\begin{tabular}{|l|r|r|r|}
\hline & Base Case & FS PSH Case & AS PSH Case \\
\hline Total production cost (\$ million) & 6.226 & 5.582 & 5.616 \\
\hline Number of CPS2 violations & 3 & 1 & 0 \\
\hline CPS2 score (\%) & 99.7 & 99.9 & 100 \\
\hline AACEE (MWh) & 2,112 & 2,268 & 2,176 \\
\hline$\sigma_{\text {ACE }}(\mathrm{MW})$ & 16.7 & 17.5 & 16.8 \\
\hline
\end{tabular}

Both cases reduce costs by about $10 \%$ compared with the base case. This time the AS case cost higher than the FS case. Without VER variability and uncertainty, and only the load variability (the reason to cause reliability issues), all cases perform very well in terms of all ACE metrics. While both PSH scenarios reduce the already low CPS2 violations, there is a slight increase in AACEE and $\sigma_{\mathrm{ACE}}$. It could be that the additional control when little imbalance is occurring can have the opposite effect.

Table 5-11 summarizes the amount of energy the three PSH units produced and consumed in the generating and pumping mode during the April simulation with no renewable generators. It includes the case with renewables for easy comparison.

5 Our assumptions of perfect load forecasts, perfect conventional generator behavior, and no intra-minute variability make imbalance even less likely. Unfortunately, unavailability of the relevant data prevented us from being able to model these important outcomes. 
Table 5-11 Amount of Energy the Three PSH Units Produce While Generating and Pumping

\begin{tabular}{|l|c|c|c|c|c|c|}
\hline & \multicolumn{3}{|c|}{ With Renewables } & \multicolumn{3}{c|}{ Without Renewables } \\
\cline { 2 - 7 } & $\begin{array}{c}\text { Generating } \\
\text { Mode } \\
\text { (MWh) }\end{array}$ & $\begin{array}{c}\text { Pumping } \\
\text { Mode } \\
\text { (MWh) }\end{array}$ & $\begin{array}{c}\text { Pumping/ } \\
\text { Generating } \\
\text { (\%) }\end{array}$ & $\begin{array}{c}\text { Generating } \\
\text { Mode } \\
\text { (MWh) }\end{array}$ & $\begin{array}{c}\text { Pumping } \\
\text { Mode } \\
\text { (MWh) }\end{array}$ & $\begin{array}{c}\text { Pumping/ } \\
\text { Generating } \\
\text { (\%) }\end{array}$ \\
\hline FS PSH & 11,951 & 15,328 & 78.0 & 12,084 & 14,879 & 81.2 \\
\hline AS PSH & 11,736 & 16,029 & 73.2 & 12,162 & 15,132 & 80.4 \\
\hline
\end{tabular}

Without renewables, the PSH is generating quite more than in the case with renewables. This is expected, since without the variable generators, there is a much higher need for generation compared with pumping load. The FS PSH case generated at a percentage higher than its efficiency, meaning that the final reservoir level was lower than at the beginning of the simulation.

\subsubsection{Perfect Variable Generation Forecasts}

The main study simulated the system with significant variable generation forecast errors in each of the modeling stages. Day-ahead, hour-ahead, and 10-min forecast errors for wind and solar caused significant ACE and need for regulating resources to correct ACE. With the same variable generation resources on the system, but hypothetical perfect forecasts for each scheduling model, we can see how much conventional PSH and advanced PSH are assisting in reducing the impacts of variable generation variability, as opposed to uncertainty (Ela and O’Malley 2012). The forecasts in these scenarios are exactly equal to the average output of VER for the relevant time resolution. The DASCUC forecasts are equal to the average output for the hour, based on $\mathrm{I}_{\mathrm{DAC}}$. The RTSCED forecasts are exactly equal to the average output for a 5-min period, based on $\mathrm{I}_{\mathrm{RTD}}$. Since the output of the VER, and also the load, is varying every 4 sec, there is variability that is occurring inside each of those intervals, and thus ACE and the need to regulate ACE are still present. Table 5-12 shows the results.

Table 5-12 Reliability and Costs with Perfect VER Generation Forecasts

\begin{tabular}{|l|c|c|c|c|c|c|}
\hline & \multicolumn{3}{|c|}{ Perfect } & \multicolumn{3}{c|}{ Imperfect } \\
\cline { 2 - 7 } & Base Case & FS PSH & AS PSH & Base Case & FS PSH & AS PSH \\
\hline $\begin{array}{l}\text { Total production } \\
\text { cost (\$ million) }\end{array}$ & 3.296 & $\$ 3.058$ & $\$ 2.880$ & $\$ 3.449$ & $\$ 3.169$ & $\$ 3.032$ \\
\hline $\begin{array}{l}\text { Number of CPS2 } \\
\text { violations }\end{array}$ & 2 & 1 & 2 & 49 & 47 & 45 \\
\hline CPS2 score (\%) & 99.8 & 99.9 & 99.8 & 95.1 & 95.3 & 95.5 \\
\hline AACEE (MWh) & 2,199 & 2,208 & 2,222 & 2,583 & 2,620 & 2,644 \\
\hline$\sigma_{\text {ACE }}$ (MW) & 16.7 & 17.0 & 17.0 & 23.8 & 25.1 & 23.1 \\
\hline
\end{tabular}


Perfect forecasts reduce total production costs, mostly due to perfect DA wind and solar forecasts, and they reduce ACE, mostly due to perfect RT forecasts (RTSCUC and RTSCED). The reductions in production costs with perfect DA and RT VER generation forecasts from adding a FS PSH and AS PSH plant are relatively similar to the production cost savings with imperfect forecasts. Since the perfect forecasts already reduce the ACE impacts substantially compared with the imperfect forecasts, the addition of PSH does not have that much impact on reliability. While this hypothetical example does not provide realistic results, it does show that the benefits that PSH gives to reliability are only apparent when significant variable generation forecast errors are present. The production cost reductions that PSH give, however, are apparent regardless of forecast accuracy of the variable generation.

Figure 5-12 shows all three PSH units' net output overlaid on the net load (load minus wind minus solar PV) for both the perfect and imperfect forecast AS PSH scenarios. Figure 5-13 zooms in on 1 day. In the perfect forecasts scenarios, the PSH units are able to better follow the net load. The DASCUC is the model that decides whether the units are generating or pumping. When DA forecasts are accurate, the mode the PSH is operating at is more efficient. Further work should evaluate how to re-optimize PSH in RT markets. This issue is also discussed in Section 8 of this report.

\subsubsection{Fast, Unfiltered Control from Adjustable Speed PSH}

Recent initiatives in the United States have looked at how resources that have the capability to provide a faster regulation reserve response, do so. For example, FERC Order 755, "Frequency Regulation Compensation," directed the ISO/regional transmission organization (RTO) regions to implement new provisions to the regulation A/S market (FERC 2011). This included a "payfor-performance" provision. Historically, suppliers of regulation service were only paid for the capacity they held in reserve to provide regulation, not how they were actually directed by the AGC to follow the regulation need. New resources, in particular energy storage, are able to

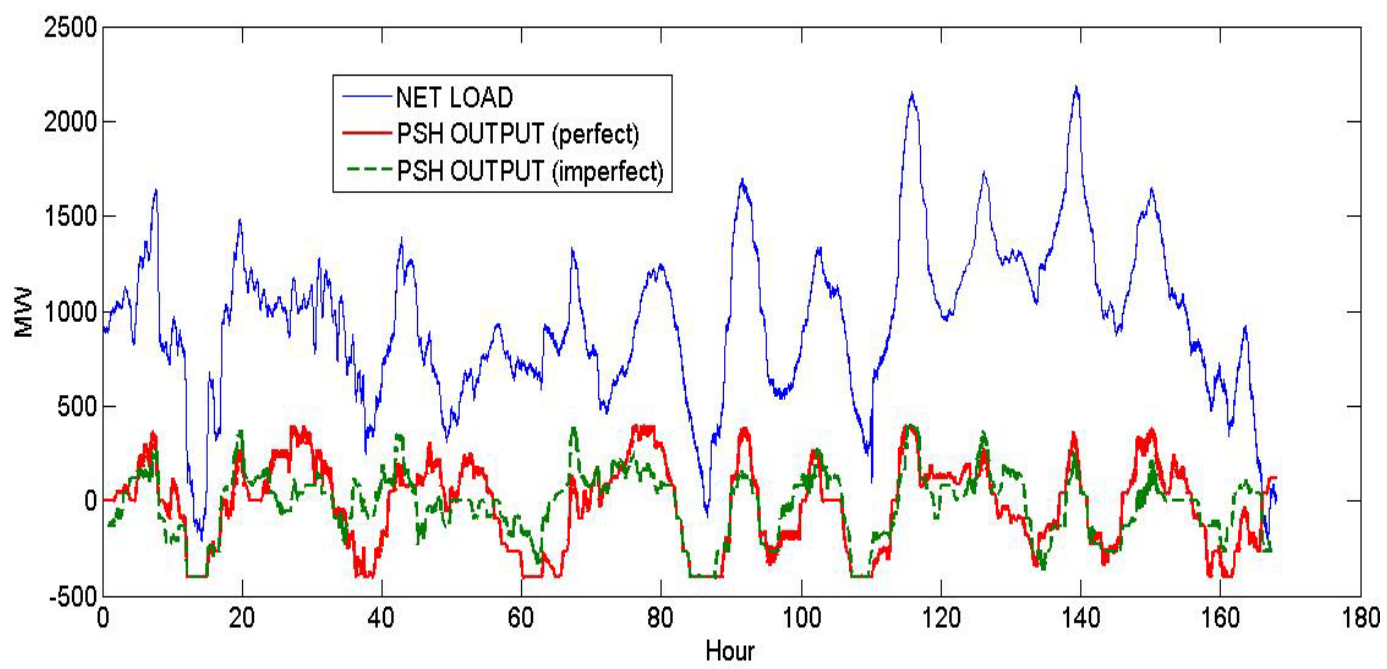

Figure 5-12 Net Load and Total PSH Output for Perfect and Imperfect Scenarios 


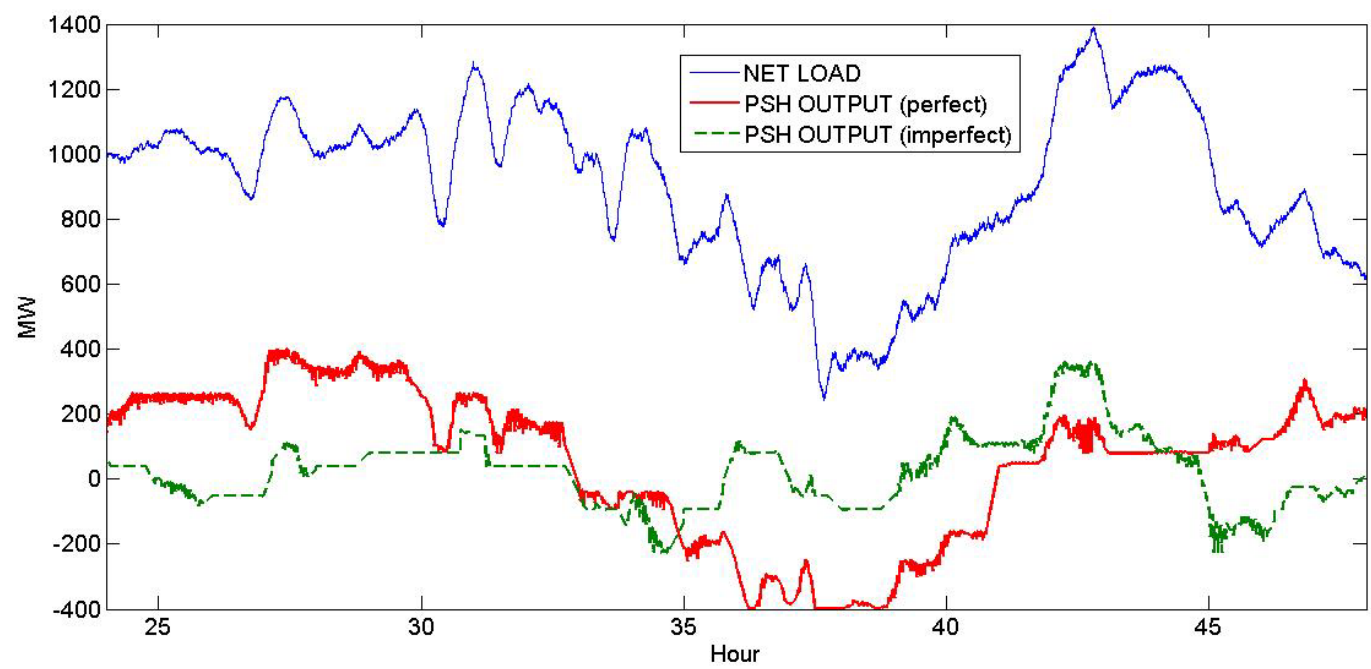

Figure 5-13 Net Load and Total PSH Output for Perfect and Imperfect Scenarios Zoomed on 1 Day

respond to the AGC signal much faster and more accurately than conventional thermal and hydro units. It has been argued that this can improve the reliability benefit. However, what led to the rulemaking was the observation that some RTOs were dispatching fast and accurate regulation resources more than slower regulation resources without providing any commensurate difference in the capacity-based compensation they would receive. The pay-for-performance, or mileage payment, was intended to address this potentially undue discrimination among different resource types.

This sensitivity analysis evaluated the reliability benefits of AS PSH providing a faster response to AGC to reflect how it would improve reliability. The simulation was identical to the April and July base cases with the three AS PSH units, with the exception that the three PSH units were following an AGC signal that opposes the instantaneous unfiltered ACE every 4 sec. Given the AS PSH large ramp rate, it is able to respond to even a 4-sec signal with significant magnitude when needed to correct the imbalance. The other plants all follow the AGC signal that is opposing the filtered, integrated ACE. The DASCUC, RTSCUC, and RTSCED have no knowledge of the fact that the AS PSH is following this signal, and so it does not change its decision of the most optimal regulation resources. Table 5-13 presents the results of this sensitivity analysis.

Table 5-13 Study of PSH Providing Fast Unfiltered AGC Regulation Response

\begin{tabular}{|l|r|r|r|r|}
\hline & \multicolumn{2}{|c|}{ April } & \multicolumn{2}{c|}{ July } \\
\cline { 2 - 5 } & \multicolumn{1}{|c|}{ Normal } & \multicolumn{1}{c|}{ Raw ACE } & \multicolumn{1}{c|}{ Normal } & \multicolumn{1}{c|}{ Raw ACE } \\
\hline Total production cost (\$ million) & 3.032 & 2.941 & 5.021 & $\$ 4.924$ \\
\hline Number of CPS2 violations & 45 & 44 & 15 & 14 \\
\hline CPS2 score (\%) & 95.5 & 95.6 & 98.5 & 98.6 \\
\hline AACEE (MWh) & 2,644 & 1,992 & 2,593 & 1,233 \\
\hline$\sigma_{\text {ACE }}(\mathrm{MW})$ & 23.06 & 20.00 & 20.18 & 12.17 \\
\hline
\end{tabular}


In both weeks, production costs are reduced and reliability is improved. CPS2 violations are reduced by 1 in both cases. Since the CPS2 criteria are based on a 10-min average of ACE, it is expected that allowing AS PSH, or other capable resources, control the raw ACE will not have a significant impact on reducing CPS2 violations. However, it was able to reduce the AACEE and $\sigma_{\mathrm{ACE}}$ substantially. In the July week, AACEE and $\sigma_{\mathrm{ACE}}$ were reduced by $50 \%$ and $40 \%$, respectively. Improvements in these metrics could lead to improved CPS1 scores as well as general overall improvement in frequency deviations on the interconnection. Figure 5-14 compares the output of one AS PSH unit while pumping and on AGC with the normal 3-min integral control and the raw unfiltered ACE input. When the AGC gives a signal opposing the raw, unfiltered ACE, the PSH unit adjusts output more frequently.

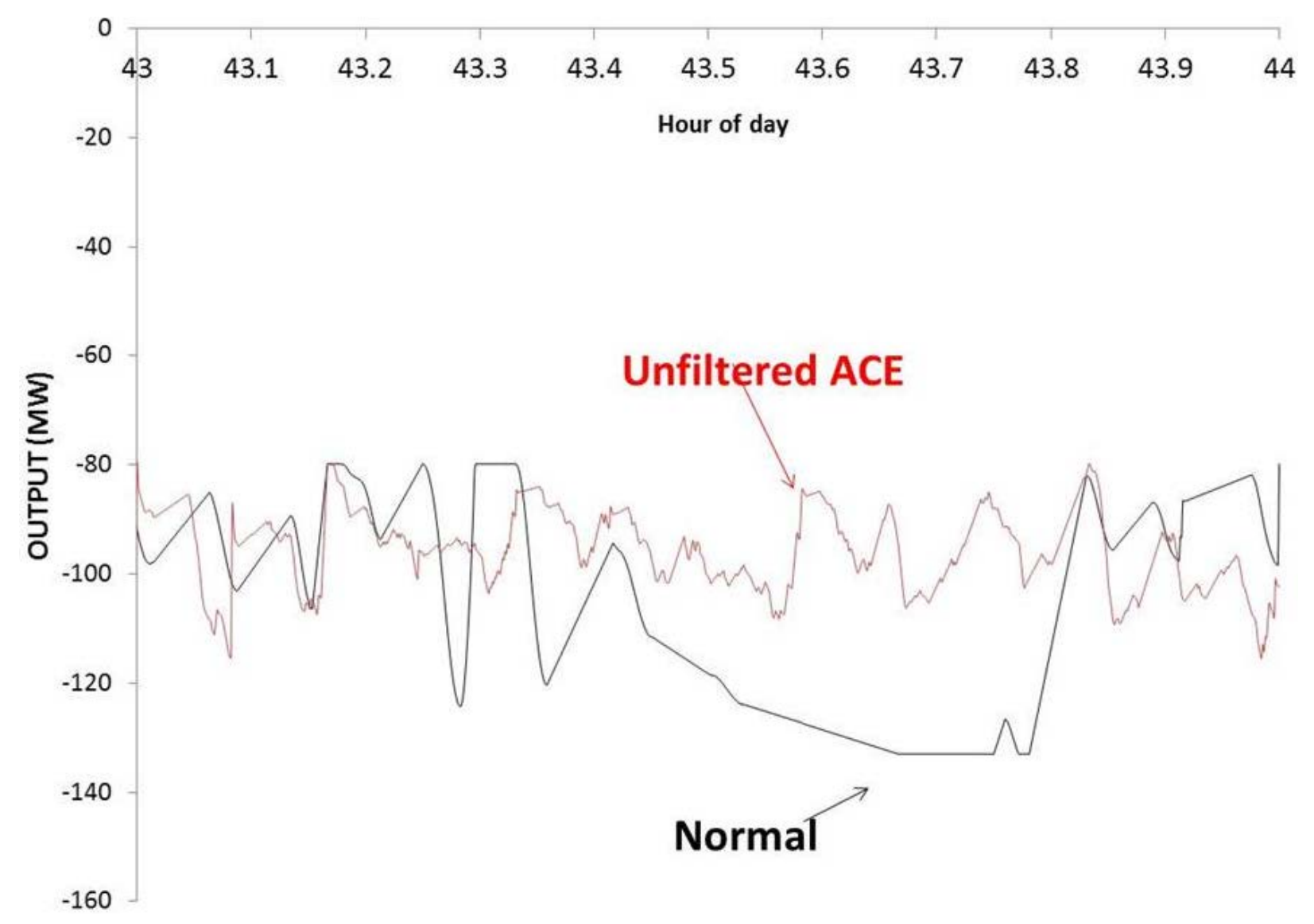

Figure 5-14 Comparison of Output from AS PSH during Normal AGC and Control Opposing Unfiltered ACE

The reduction in total production costs when allowing PSH to provide a faster control is not expected and should be studied further. Note that these costs do not include any wear-and-tear cost increases or general maintenance cost issues; only production costs. In the above simulations, what was occurring was that the PSH brought ACE back to zero quickly, allowing for the other regulating units to be closer to their optimal point and not needing to regulate as much. These units were then not ramp constrained in future dispatch runs, and the economic dispatch model made better solutions since cheaper units were not as restricted with their ramp 
rates. This result consistently happened again and again in both of the April and July cases. As far as production costs, there is no other factor that could influence a difference, since the exact same resources, variable generation output, and load are all being used. This type of result can support the idea that using this type of control for selected units that have extremely fast ramp rates can help further reduce production costs by limiting the AGC from causing other slower units to be too far from their optimal point and difficult to get back.

\subsection{Summary and Conclusions}

The analysis of this section explored how conventional and advanced PSH can assist in reducing total system production and improving steady-state reliability in high temporal detail. The FESTIV model was used to simulate the BANC system for two time periods; one with highly volatile variable generation and relatively low load in April, and one with reduced variable generation but significant load in July. In both time periods, the conventional FS PSH was able to reduce the total production costs. When adding the AS PSH rather than the conventional FS PSH plant, production costs are reduced even more. These results bolster those of Section 4, and show that analysis of the detailed realistic simulation of power system operations at multiple timescales results in PSH and advanced PSH providing tremendous benefits to systems of this size to reducing production costs.

The FS PSH was able to reduce the amount of CPS2 violations in both time periods, and the AS PSH was able to reduce the violations even further. In both cases, the CPS2 score was already above the required level (although load forecast errors and conventional generator performance were not modeled). The July time period was able to get more benefit from the PSH and AS PSH as its higher costs led to the dispatch selecting PSH more often to provide AGC regulation. The standard deviation and total amount of imbalance were reduced in the July period, but not always in the April period. It is possible that the ability to re-optimize the operational mode of PSH could better prepare the system when very large DA variable generation forecast errors would otherwise leave the PSH in the wrong operating mode. Overall, it can be seen that conventional FS PSH provides some improvement to steady-state reliability, and that AS PSH provides even greater improvement to steady-state reliability.

This study also looked at a few other sensitivities. Several additional simulations were run to see how much variable generation and variable generation forecast errors impacted the results of how PSH brought value to the system. These studies demonstrated that when steady-state reliability is very good (i.e., less than three CPS2 violations), it is hard for the PSH to truly improve the steady-state reliability. This was seen in a scenario with no variable generation, and in one with variable generation but with all variable generation forecasts being perfectly predicted. On the other hand, these studies showed that even without variable generation or without variable generation forecast errors, PSH plants still provide great benefits in reducing overall production costs.

Lastly, simulations were run to study how AS PSH plants can provide benefit if they were to follow a raw, unfiltered ACE signal, which with their extremely fast power ramp rate, would be a very possible opportunity. This type of study is relevant to recent industry developments that are evaluating the benefits of other limited energy storage resources to provide this type of 
service. The results showed that this type of control had a negligible effect in reducing the number of CPS2 violations. However, the total imbalance occurring and the standard deviation of that imbalance were significantly reduced with just the three AS PSH units providing this fast control. Another outstanding result is the reduction in total production costs even further when allowing AS PSH to provide this control. This result, not as intuitive as the reduction in ACE impacts, was caused by the PSH units allowing other ramp-constrained units to stay closer to their most optimal points. These resources were not being asked by the AGC to move too far and were therefore less constrained from their ramp rates when the dispatch model chose the least cost options to meet the expected load demands. Further studies should evaluate this effect and this type of control should be taken advantage of in operations if these studies show these results consistently.

\subsection{References and Bibliography}

Chang, T.-P., H.-H Ko, F.-J. Liu, P.-H Chen, Y.-P Chang, Y.-H Liang, and Y.-H. Chen, 2012, “Fractal Dimension of Wind Speed Time Series,” Applied Energy 93:742-749.

Ela, E., M. Milligan, and B. Kirby, 2011a, Operating Reserves and Variable Generation. NREL/TP 5500-51978, National Renewable Energy Laboratory, Golden, Colo., Aug.

Ela, E., M. Milligan, and M. O’Malley, 2011b, “A Flexible Power System Operations Simulation Model for Assessing Wind Integration,” 2011 Institute of Electronic and Electronics Engineers (IEEE) Power and Energy Society General Meeting, July 24-28, 2011, Detroit, Mich.

Ela, E., and M. O’Malley, 2012, "Studying the Variability and Uncertainty of Variable Generation at Multiple Timescales,” IEEE Transactions on Power Systems 27:3:1324-1333.

ENTSO-E (European Network of Transmission System Operators for Electricity), 2009, UCTE Operational Handbook Policy 1, Load-Frequency Control and Performance, March.

FERC (Federal Energy Regulatory Commission), 2011, Frequency Regulation Compensation in the Organized Wholesale Power Markets, Order No. 755, FERC Statutes and Regulations, Oct 20.

Ferris, M., 2005, MATLAB and GAMS: Interfacing Optimization and Visualization Software, Mathematical Programming Technical Report 98-10, University of Wisconsin Computer Sciences Department, Madison, Wis.

GAMS (GAMS Development Corporation), 2012, GAMS: The Solver Manuals, Version 24.0, Washington, D.C.

Harrouni, S., 2010, “Fractal Analysis to Quantify Wind Speed Fluctuations," in Proceedings of the 3rd Conference on Nonlinear Science and Complexity, July 28-31, Ankara, Turkey. 
Hummon, M., A. Weekley, K. Searight, and K. Clark, 2013, “Downscaling Solar Power Output to 4-Seconds for Use in Integration Studies,” 3rd International Solar Power Integration Workshop, Oct. 20-22, London, United Kingdom (NREL/CP-6A2-60335).

Hurst, D., and J.C. Vassilicos, 2007, "Scalings and Decay of Fractal-generated Turbulence,” Physics of Fluids 19(3).

Ibanez, E., G. Brinkman, M. Hummon, and D. Lew, 2012, "Solar Reserve Methodology for Renewable Energy Integration Studies Based on Subhourly Variability Analysis: Preprint,” prepared for 2nd Annual International Workshop on Integration of Solar Power into Power Systems, November 12-13, Lisbon, Portugal (NREL/CP-5500-56169). Available at www.nrel.gov/docs/fy12osti/56169.pdf. Accessed Jan. 2013.

Jaleeli, N., L.S. VanSlyck, D.N. Ewart, L.H. Fink, and A.G. Hoffmann, 1992, “Understanding Automatic Generation Control,” IEEE Transactions on Power Systems 7:3:1106-1122.

Kroese, D.P., and Z.I. Botev, 2013, “Spatial Process Generation,” pp. 1-41 in Lectures on Stochastic Geometry, Spatial Statistics and Random Fields, Volume II, V. Schmidt (editor), Springer-Verlag.

Lew, D., G. Brinkman, E. Ibanez, A. Florita, M. Heaney, B.-M Hodge, M. Hummon, G. Stark, J. King, S. Lefton, N. Kumar, D. Agan, G. Jordan, and S. Venkataraman, 2013, The Western Wind and Solar Integration Study Phase 2, NREL/TP-5500-55588, National Renewable Energy Laboratory, Golden, Colo.

Morales, R., T. Di Matteo, R. Gramatica, and Aste, T., 2012, “Dynamical Generalized Hurst Exponent as a Tool To Monitor Unstable Periods in Financial Time Series,” Physica A: Statistical Mechanics and Its Applications 391(11):3180-3189.

NERC (North American Electric Reliability Council), 2012, 2012 CPS2 Bounds. Available at http://www.nerc.com/docs/oc/rs/2012\%20CPS2\%20Bounds\%20Report\%20Final\%28Update201 20821\%29.pdf.

NREL (National Renewable Energy Laboratory), Wind Integration Datasets. Available at http://www.nrel.gov/wind/integrationdatasets.

TEPPC (Western Electricity Coordinating Council [WECC] Transmission Expansion Planning Policy Committee), 2011, TEPPC 2010 Study Program 10-Year Regional Transmission Plan, Salt Lake City, Utah, Sept.

TEPPC, 2012, Appendix C: Matrix of Assumptions - 2011 TEPPC Study Program. Available at http://www.wecc.biz/Lists/Calendar/Attachments/4084/2022_CommonCase_InputAssumptions. docx. 


\section{Section}

6

\section{CHEERS Pumped Storage Modeling and Analysis}

\subsection{General Description of CHEERS}

A team of DOE national laboratories led by Argonne developed the Water Use Optimization Toolset (WUOT). This is a suite of advanced, integrated analytical tools designed to help managers and planners increase the efficiencies of hydropower resources while enhancing their environmental performance. Toolset modules project and optimize several aspects of water and hydropower management. These include water inflow forecasting, seasonal reservoir water management, DT and RT operations, and the health of the environment. WUOT development and ongoing enhancements are funded and supported by the DOE EERE Water Power Program. The WUOT project is described in more detail in Gasper et al. (2014).

The tool suite is being tested and demonstrated by using data from hydropower sites that are representative of different operational and environmental conditions across the United States. WUOT has been demonstrated at the Colorado River Storage Project (CRSP), which is operated by the Bureau of Reclamation in the U.S. Department of the Interior. CRSP power and energy resources are marketed and scheduled by the Western Area Power Administration. WUOT has also been demonstrated at the Oroville-Thermalito Complex, which is owned and operated by the California Department of Water Resources. A toolset demonstration was recently initiated at the Conowingo Project and Muddy Run pumped storage power plants that are owned and operated by Exelon Power. A kickoff meeting with Seattle City Light for a fourth WUOT demonstration was conducted in August 2013. The fifth WUOT demonstration has not started. Late in fiscal year 2014, WUOT will optimize the operation of SMUD hydropower facilities.

Each WUOT module can be run as an integrated component of the toolset or used independently in stand-alone mode. This study uses the CHEERS tool in stand-alone mode to optimize the DA scheduling. CHEERS results will also be used by analysts to evaluate the financial viability of both advanced gas turbine (GT) and PSH technologies. Although CHEERS unit-level operations can be driven by many different objectives, applications to date have shaped operations primarily via power market price signals that are subject to environmental operating criteria. Price drivers include both energy prices and one or more A/S prices.

CHEERS uses a network of nodes, connected by links that transport commodities through a modeled system. Depending on the configuration of the network, commodities contained within and passing through nodes in a network may be stored, joined with other flows, bought and sold in one or more markets, or converted into other commodities. In the case of a hydroelectric 
generator, a CHEERS conversion node is used to represent water under pressure flowing through a turbine to produce electrical energy. Given a user-specified network and objective function, the CHEERS software generates a set of mixed-integer linear equations that are solved by using a commercial optimization software package. For this study, model results were exported into an Excel spreadsheet that makes economic computations and produces statistical summaries that are displayed as both graphs and tables.

As discussed in Section 6.4.3, CHEERS results were also input into a routine that computes various financial metrics that are used to evaluate the costs, benefits, and risks associated with constructing a new power plant.

In this study, CHEERS optimized DA scheduling for two hypothetical PSH plants, each one using a different PSH technology. For PSH runs, CHEERS models water flows and storage levels at both upper and lower reservoirs. It also models electricity production and the sale of both energy and A/S to a hypothetical market. Because hypothetical PSH projects considered in this study were assumed to be closed systems, the use of other WUOT tools would add very little or no additional insights or value to the analysis; therefore, these other toolset components were not used for this study.

This analysis also compared the financial costs and income streams of PSH plants with those of GT technologies. Therefore, CHEERS optimized the operations of hypothetical GT technologies too; CHEERS simulates GT conversion processes and computes the flow of both natural gas and electricity. In GT model runs, water flows do not apply, but natural gas flows, consumption, and purchase costs are computed.

\subsection{Objective of the CHEERS Study}

The objective of this CHEERS PSH analysis was to gain insights into the comparative advantages of different PSH technologies from the perspective of investing in capacity expansion. The financial performance of different technologies was measured in terms of net operating revenues weighed against the cost to construct and maintain a power plant. Revenues streams include sales of energy and A/S in a hypothetical U.S. electricity market. Since there are many uncertainties about future market drives and costs, sensitivity analyses were also conducted to measure any potential financial implications, both good and bad.

The hydropower technologies analyzed included both FS PSH and AS PSH. In addition to PSH, investors can also choose other technologies. Therefore, the financial competitiveness of PSH is compared and contrasted with an efficient and very flexible new GT technology. Because financial considerations and economic efficiency are the primary factors that drive a utility or merchant investor to construct a new power plant, in all cases, a range of long-term profitability was analyzed for each technology.

\subsection{Approach}

The basic approach employed by this study simulates the interaction of a power plant with an electricity market in which energy and A/S are bought and sold. The A/S considered for this 
study were regulation up, regulation down, spinning reserve, and non-spinning reserve. The CHEERS model determines power plant operations at the unit level, meaning that the quantities of energy and A/S provided by each individual unit are determined by the model in each time step. The model is configured to maximize the total net revenues generated by the plant over the course of each simulation run.

Figure 6-1 shows the CHEERS topology that was constructed for this project for optimizing PSH operations. It consists of an upper reservoir, lower reservoir, four pump-generator units (PT1 through PT4), and a series of market nodes (M1 through M5) for buying and selling services. The same network structure was used to model both the FS PSH and AS PSH technologies. However, the values for the parameters that represent both operating characteristics and operational flexibility were different for these two technologies.

Since profitability is of primary interest for the study, a full year's worth of simulation runs were performed to capture seasonal price patterns and a large sample of relative price differences among energy and ancillary value streams. The full year of simulations was broken down into 365 individual, DA (24-h) runs, each with a 1-h time step.

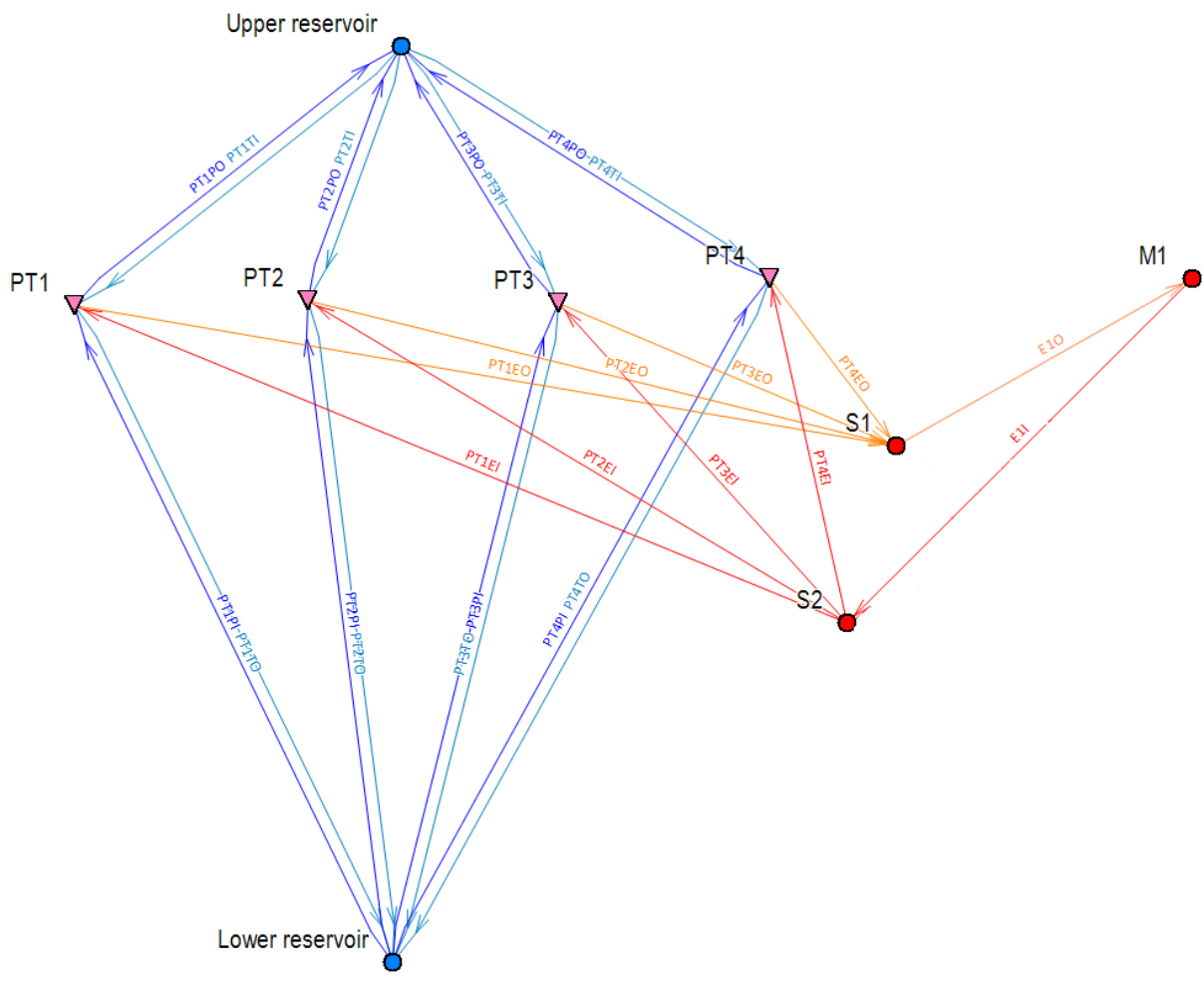

Figure 6-1 CHEERS Pumped Storage Model Topology 
CHEERS optimized PSH operations by using historical CAISO price vector inputs to drive operations. Data for energy and A/S were obtained from CAISO for the year 2011. Modeling GT operations also required energy prices for natural gas; these prices were obtained from the DOE Energy Information Administration (EIA) State Energy Data System (SEDS) database (EIA undated). To be consistent with energy and ancillary CAISO prices, SEDS monthly natural gas prices for the State of California in 2011 were used to compute fuel expenses for GT technologies.

Under actual DA scheduling, next-day market clearing prices are uncertain. To simulate this situation, we based our DA PSH unit commitments and operating levels on hourly projections of DA prices. The realized plant revenues were then calculated by applying the actual prices to the unit commitment schedule. A detailed description of the projection method used to generate these DA price forecasts is given in Section 6.3.4. We also modeled operations under several different long-term market price outlooks that span a 30-year time horizon. This approach provides a range of plausible financial outcomes.

We computed technology profitability on the basis of the assumption that future DA prices are known with certainty. Although in actuality, no forecast is perfect, these computations provide an upper profitability bound and insights on the value of improving the accuracy of market price forecasting.

The CHEERS model was constructed to allow comparisons of each of the three technologies being studied (FS PSH, AS PSH, and GT) under identical market conditions. Using these conditions ensured that the comparisons between technologies would be fair, since each one was able to buy and sell into the market at the same prices. Details of the models used for each technology type are given in Sections 6.3.1, 6.3.2, and 6.3.3.

The CHEERS approach differs from the one used by PLEXOS, in which the entire grid is optimized and prices are determined by the model. In one sense, the CHEERS approach is more simplistic, since it does not fully capture all of the system dynamics and interactions of a technology operating in a power grid. For example, it was assumed that both the sales and purchases of energy and services from any of the hypothetical power plants would not affect market prices. The use of static prices instead of ones that decrease as a function of the technology's participation level may result in an overstatement of the estimated financial viability of an optimized technology. We realize that the result based on this assumption may not theoretically be accurate, but we also postulate that the error introduced by the assumption would be small. The capacity of a modeled technology is tiny in comparison with the capacity of the entire WI and would thus presumably have a small impact on system prices. The use of strategic bidding behavior could potentially diminish price feedbacks. Also this analysis is, in part, a comparative analysis, and all the technologies operate under the same set of assumptions, and so have similar inaccuracies and errors that tend to go in the same direction.

On the other hand, CHEERS has a more detailed representation of the PSH than do most gridscale models. Although grid-scale models enable extremely useful insights regarding system operations under a wide range of conditions, these types of models also have limitations and inaccuracies. Due to the extremely complex nature of the grid, grid modelers must, out of 
necessity, make many simplifying assumptions about how the grid operates. For example, the complex operating criteria for water resources within the WI are not explicitly modeled. Actual WI water operations consider not only power, but also a complex set of legal water rights/agreements among individuals, states, and nations (i.e., Canada, United States, and Mexico); flood control; irrigation; municipal and industrial uses; environmental protection; and others. Hydropower is often given a low priority or the lowest priority in the multi-water-use arena. Also, the market structures within the WI are complex, with their prices based on interactions among numerous autonomous decision makers. The modeling of A/S prices as they relate to autonomous decision making is a particularly challenging task. Grid modelers make simplifying assumptions about how market interactions occur and about the level of "grid visibility" that participants have.

Analyzing a PSH plant as part of a larger grid and as an isolated plant that responds to historical market prices provides two different perspectives. Each one provides different insights on the financial and economic value of PSH.

\subsubsection{Fixed-Speed Pumped Storage Model}

The FS model represents a hydroelectric power plant with an upper reservoir, four pump/turbine units, and a lower reservoir. The model uses a closed-loop configuration, meaning that water flows in both directions between the upper and lower reservoirs, but no water enters or exits the system as a whole. This representation ignores both evaporation and rainwater impacts on the reservoir, both of which are assumed to be small and offsetting.

The storage capacities, areas, and relative heights of the upper and lower reservoirs were chosen to provide an average hydraulic head of approximately $600 \mathrm{ft}$ and a total energy storage capacity of $12 \mathrm{~h}$ when all turbine units are operating at full output.

The four FS pump/turbine units are modeled by using a typical set of efficiency data obtained from MWH. In CHEERS, the generation output of each turbine unit is modeled by using a piecewise linear approximation that relates the water flow through the turbine (in cubic feet per second or cfs) to the electricity output of the turbine (in MW). These curves were computed by using typical efficiency data and assuming an average operating head of $600 \mathrm{ft}$. Each turbine unit has the following characteristics:

- Maximum generation capacity: 27.5 MW,

- Turbine water flow at maximum generation: 564.6 cfs,

- Minimum output: 8.9 MW,

- Turbine water flow at minimum generation: 211.7 cfs, and

- Generation rough zone: 10.9-17.3 MW (247.0-352.9 cfs). 
Since the model contains four turbine units, the total generation capacity of the overall plant is 110.2 MW. Efficiency curves are discussed in Section 6.3.2.

The FS pumping units are also modeled by assuming an average head of $600 \mathrm{ft}$. Obviously, for FS pumping technology, the pump can only be in an off state or an on state (operating in maximum pumping mode); no intermediate operating points are technically possible. Each pumping unit has the following characteristics:

- $\quad$ Pumping states: either 0 MW or maximum power consumption of 112.4 MW,

- $\quad$ Maximum pumping power: 28.1 MW, and

- $\quad$ Pump water flow at maximum pumping: $459.1 \mathrm{cfs}$.

At each time step, for each pump/turbine unit, the model allows either pumping or generation, but it does not allow both at the same time. However, the model can operate some of the four units in pump mode while others are in generation mode, thereby allowing a kind of hydraulic short-circuit operation (assuming separate penstocks).

The FS configuration of the CHEERS model optimizes the quantities of energy bought and sold on the market and the sales of A/S during each hourly time step. In generation mode, energy is sold into the market, and the sale of all four A/S is also possible. However, the model is configured to disallow both turbine set point and regulation operations in rough zones. Rough zone operations lead to increased mechanical vibrations and stresses that shorten the operating life of a turbine. In pumping mode, energy is purchased from the market in order to transport water from the lower to the upper reservoir. One disadvantage of FS pumping technology is that some A/S cannot be provided in pumping mode, because only a single operating point is possible. In particular, both regulation up and regulation down are impossible in pumping mode, since the pump unit is unable to operate at levels other than "off” or the full pumping state. However, it is possible to sell spinning and non-spinning reserve in pumping mode.

\subsubsection{Adjustable Speed Pumped Storage Model}

For consistency with the FS model, the AS model also includes an upper reservoir, four pump/turbine units, and a lower reservoir. The reservoir configurations are identical to those of the FS model.

The operating characteristics of the AS pump/turbine units were also based on the efficiency data obtained from the firm MWH. Again, an average head of $600 \mathrm{ft}$ was assumed for both generation and pumping mode. Each turbine unit has the following characteristics:

- Maximum generation capacity: 28.0 MW,

- Turbine water flow at maximum generation: $565.1 \mathrm{cfs}$,

- $\quad$ Minimum output: 7.7 MW, 
- Turbine water flow at minimum generation: $176.6 \mathrm{cfs}$, and

- $\quad$ Generation rough zone: 13.6-15.7 MW (282.5-317.8 cfs).

When compared with FS technology; the AS turbine has slightly higher maximum generation, lower minimum generation, and a smaller rough zone. Also, the turbine efficiency curve is somewhat flatter in the high-efficiency range. The plant has a maximum generation capacity of 112.0 MW.

A major difference between FS and AS pumping units is that the AS units can operate at a range of different pumping speeds and levels of power consumption, thereby providing additional flexibility to plant operators. Each AS pumping unit has the following characteristics in pump mode:

- Maximum pumping power consumption: 28.1 MW,

- Pump water flow at maximum pumping: $459.1 \mathrm{cfs}$,

- Minimum pumping power consumption: 18.5 MW, and

- $\quad$ Pump water flow at minimum pumping: $282.5 \mathrm{cfs}$.

The plant has a maximum pumping capacity of 112.4 MW.

Generation efficiency curves for both FS PSH and AS PSH, along with rough zones, are shown in Figure 6-2. Rough zones are denoted by the shaded rectangles in the middle range. (The red rectangle is the AS rough zone, and the blue rectangle is the FS rough zone.) When compared with the FS unit, the AS unit has a number of advantages in terms of both efficiency and operational flexibility. For example, the AS efficiency curve is higher and slightly flatter than the FS curve across the entire operating range. Also, the AS rough zone is considerably smaller than the FS rough zone, and the AS unit has a lower minimum operating point.

Again, to maintain consistency with the FS case, simultaneous pumping and generation by a single unit is not allowed. However, the model can operate some of the four units in pump mode while others are in generation mode, thereby allowing a kind of hydraulic short-circuit operation.

Identical to FS PSH plants, AS PSH plants can sell both energy and A/S while operating in generation mode. However, in pumping mode, AS PSH plants can also sell regulation up services and regulation down services in addition to spinning and non-spinning reserves. This difference between FS and AS pumping units is another important one. A summary of possible $\mathrm{PSH}$ A/S contributions that were assumed for the CHEERS analysis is provided in Table 6-1. 


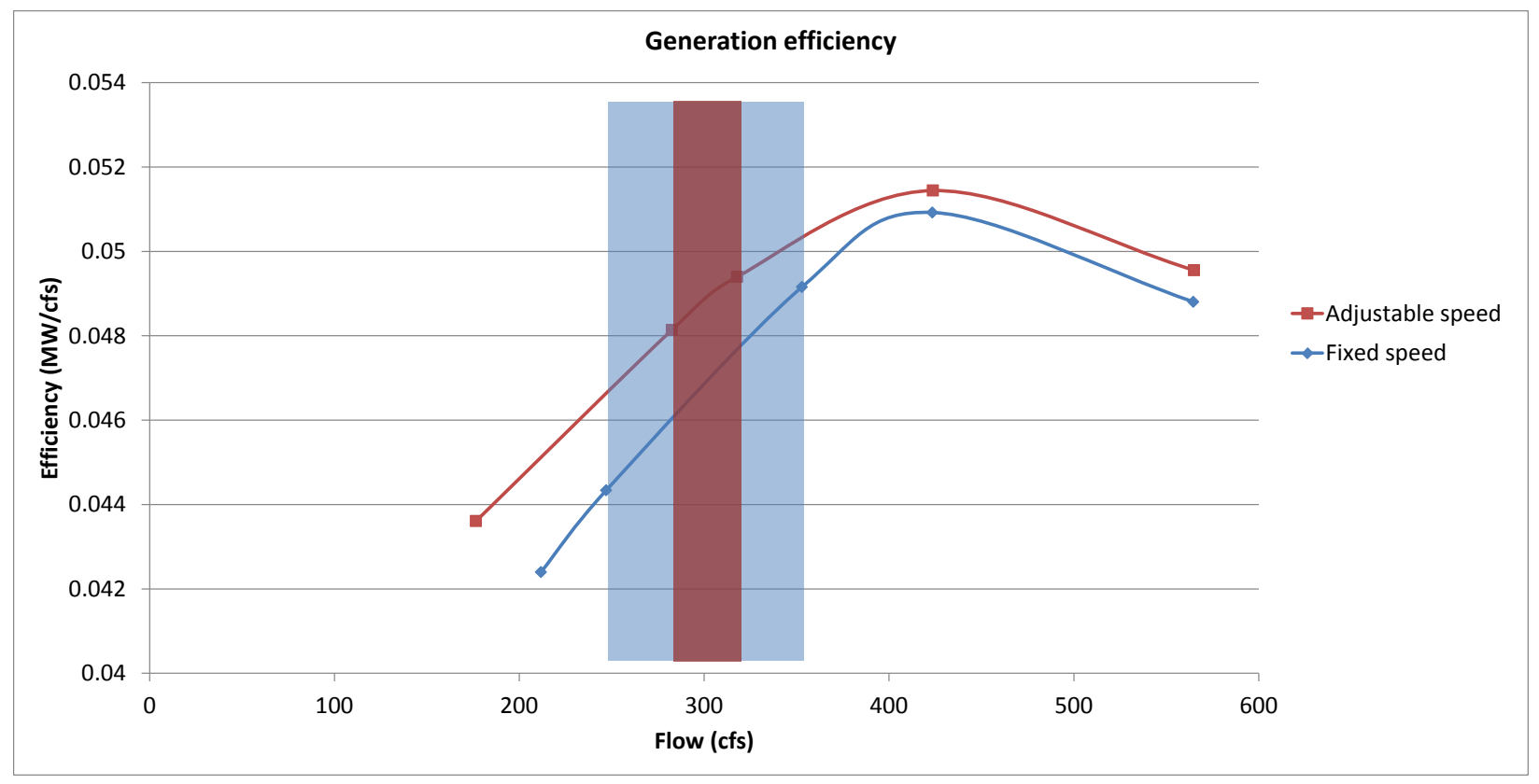

Figure 6-2 Generation Efficiency Curves for Pumped Storage Models

Table 6-1 CHEERS Assumptions for Ancillary Services of FS and AS PSH Plants

\begin{tabular}{|c|c|c|c|c|}
\hline Technology & Spin & Non-Spin & Regulation Up & Regulation Down \\
\hline \multicolumn{5}{|l|}{ FS PSH } \\
\hline Pump & $\begin{array}{l}\text { Pump power } \\
\text { capacity }\end{array}$ & $\begin{array}{l}\text { Max gen power + } \\
\text { current pump } \\
\text { power }\end{array}$ & - & - \\
\hline Generation & $\begin{array}{l}\text { Max gen power- } \\
\text { current gen power }\end{array}$ & $\begin{array}{l}\text { Max gen power- } \\
\text { current gen } \\
\text { power }\end{array}$ & $\begin{array}{l}\text { Max gen power- } \\
\text { current gen power } \\
\text { (avoiding rough } \\
\text { zones) }\end{array}$ & $\begin{array}{l}\text { Current gen power } \\
\text { - min gen power } \\
\text { (avoiding rough } \\
\text { zones) }\end{array}$ \\
\hline \multicolumn{5}{|l|}{ AS PSH } \\
\hline Pump & $\begin{array}{l}\text { Current pumping } \\
\text { level }\end{array}$ & $\begin{array}{l}\text { Max gen power }+ \\
\text { current pump } \\
\text { power }\end{array}$ & $\begin{array}{l}\text { Current pump } \\
\text { power - min pump } \\
\text { power }\end{array}$ & $\begin{array}{l}\text { Max pump power- } \\
\text { current pump } \\
\text { power }\end{array}$ \\
\hline Generation & $\begin{array}{l}\text { Max gen power- } \\
\text { current gen power }\end{array}$ & $\begin{array}{l}\text { Max gen power- } \\
\text { current gen } \\
\text { power }\end{array}$ & $\begin{array}{l}\text { Max gen power- } \\
\text { current gen power } \\
\text { (avoiding rough } \\
\text { zones) }\end{array}$ & $\begin{array}{l}\text { Current gen power } \\
\text { - min gen power } \\
\text { (avoiding rough } \\
\text { zones) }\end{array}$ \\
\hline
\end{tabular}

“-" = not applicable 


\subsubsection{Gas Turbine Model}

The GT model configuration differs significantly from the ones used by the two pumped storage models, because it does not use reservoirs or purchase electrical energy from the market. However, as mentioned previously, the GT model includes the same set of energy and A/S prices in order to enable a neutral economic and financial comparison between GT and pumped storage technologies. The modeled plant consists of a single GT unit, which purchases natural gas fuel at market prices, uses this fuel to run the turbine, and sells the resulting energy and A/S. The market prices used are from the EIA SEDS for 2011 for California (EIA undated). In the CHEERS model, these prices varied on a monthly basis.

To further enable a reasonable comparison with modern pumped storage technologies, the GT characteristics were selected to represent a modern, efficient GT unit that a utility might realistically consider building in the near future. The turbine was chosen to have a $20 \%$ minimum generation level (denoted here as GT/20). In addition, an older GT plant was modeled for comparison; this plant has a 50\% minimum generation level (i.e., GT/50). The characteristics of the GT plants are consistent with the ones used in EIA's 2012 Annual Energy Outlook (AEO). Technical parameters for GT technologies are presented in Table 6-2.

Table 6-2 Technical Parameters of GT Technologies

\begin{tabular}{|c|c|c|c|c|c|}
\hline $\begin{array}{c}\text { Gas Turbine } \\
\text { Type } \\
\text { (\% minimum } \\
\text { generation } \\
\text { level) }\end{array}$ & $\begin{array}{c}\text { Maximum } \\
\text { Generation } \\
\text { (MW) }\end{array}$ & $\begin{array}{c}\text { Minimum } \\
\text { Generation } \\
\text { (MW) }\end{array}$ & $\begin{array}{c}\text { Variable } \\
\text { Operations } \\
\text { and } \\
\text { (Btu/kWh) }\end{array}$ & $\begin{array}{c}\text { Maintenance } \\
\text { (O\&M) Cost } \\
\text { (\$/MWh) }\end{array}$ & $\begin{array}{c}\text { Startup Cost } \\
\text { (\$/start) }\end{array}$ \\
\hline GT/20 & 96.0 & 19.2 & 8,550 & 10.19 & 910 \\
\hline GT/50 & 96.0 & 48.0 & 10,450 & 15.18 & 910 \\
\hline
\end{tabular}

\subsubsection{Day-Ahead Price Forecasts and Uncertainty}

When schedulers make DA scheduling decision conditions, they are not certain about future market prices, so they use price forecasts. Currently, schedulers typically base their forecasts on many factors, such as expected weather conditions, projected loads, the season of the year, supply resource availability, and historical observations. The CHEERS PSH analysis methodology mimics this business process by using price forecasts instead of actual CAISO observed values. A relatively simple price forecasting routine was created and implemented specifically for this CHEERS application. This forecasting routine uses an econometric approach to project DA prices for energy, regulation up, regulation down, spinning reserves, and nonspinning reserves. Although DA schedules are based on projected prices, net financial operating gains are based on actual prices. Also, DA schedules are not adjusted in either HA or RT markets and are therefore dispatched at DA scheduled levels. These assumptions lead to an underestimation of the value of modeled technologies because, in this modeling exercise, we made no attempt to adjust operations in response to RT price signals. We will make this 
refinement in a subsequent study. However, we did make sensitivity model runs based on the assumption that future market prices are known with certainty.

\section{Energy Price Forecast Model}

For each hour of the next day, the model makes an initial price projection by computing the average hourly price that had occurred during the past week (using separate calculations for weekdays and weekends). For example, the energy forecast price for Wednesday at 1 a.m. is initially set to be equal to the average energy price that occurred at $1 \mathrm{a} . \mathrm{m}$. during the past five weekdays. Identical computations are made for all other hours of the day. For projections made for a weekend day, an identical process is implemented, except hourly averages are based on past weekend price observations. Projected prices are then adjusted to reflect next-day weather conditions.

Price adjustments are based on next-day atmospheric temperatures for three large cities in different parts of California: Los Angeles, San Francisco, and Sacramento. Next, the algorithm generates a least-squares linear regression equation that correlates peak daily energy prices over the past two weeks to a temperature index. This index is a weighted average of both maximum and minimum temperatures for the three aforementioned cities, whereby the weights vary by city and by temperature range. Note that the minimum temperature weights are significantly smaller than the maximum temperature weights. The linear regression equation is then used to project the maximum energy price for the next day based on maximum and minimum temperatures for the forecast day. A similar approach is used to project the minimum energy price for the next day. However, minimum daily prices are linked to a minimum temperature index.

Once next-day maximum and minimum energy price are projected, the daily energy price range is computed. Then hourly energy prices are projected. The projection method employed shapes the daily price profile by using an index that ranges from zero to one based on the average hourly price profile. The index indicates the relative difference between the daily minimum and maximum price such that the index for the hour with the lowest price is set to be zero and the hour with the highest hourly price has an index value of one. A price that equals the average of the minimum and maximum has an index value of 0.5 . To obtain a projected energy price for any hour, the daily minimum projected price is added to the product of the daily energy range (i.e., maximum minus minimum projected price) and the hourly price shaping index.

\section{Regulation Up and Spinning Reserves Price Forecast Model}

Regulation up price projections are simply based on historical hourly average daily profiles for weekdays and weekend days. No adjustments are made for atmospheric temperature, since the statistical relationship between atmospheric temperature and prices appears to be weak. On the other hand, there is a very strong historical relationship between regulation up and spinning reserve prices. The regulation prices are consistently higher than the spinning reserve prices. Therefore, the methodology employed by the price forecast routine generates a least-squares linear regression equation that correlates hourly spinning reserve to regulation up prices for the past week; that is, it covers 168 observations. Spinning reserve price projections for the next day are then estimated via the regression equation. 


\section{Regulation Down and Non-spinning Reserves Price Forecast Model}

Both regulation down and non-spinning reserve price projections are simply based on hourly average daily profiles for weekdays and weekend days. Non-spinning reserves are typically less than \$1/MW. However, on some days (typically when energy prices spike during peak-load hours), there is also a spike in non-spinning reserve prices. At some point, the price forecasting routine may be updated to better capture these price spikes.

\section{Energy Forecast Error-Summary Table}

Table 6-3 gives the average absolute error of the forecast prices (relative to the actual prices) by month.

Table 6-3 Absolute Errors of Price Forecast

\begin{tabular}{|l|c|c|c|c|c|}
\hline \multirow{2}{*}{ Month } & \multicolumn{5}{|c|}{ Absolute Average Error (\$/MW) } \\
\cline { 2 - 6 } & Energy & Spinning & $\begin{array}{c}\text { Non- } \\
\text { spinning }\end{array}$ & $\begin{array}{c}\text { Regulation } \\
\text { Up }\end{array}$ & $\begin{array}{c}\text { Regulation } \\
\text { Down }\end{array}$ \\
\hline January & 2.1 & 2.4 & 0.2 & 2.6 & 0.9 \\
\hline February & 7.2 & 2.3 & 0.2 & 2.5 & 1.3 \\
\hline March & 5.4 & 4.1 & 0.1 & 4.5 & 2.0 \\
\hline April & 8.3 & 7.2 & 0.1 & 8.8 & 4.6 \\
\hline May & 6.9 & 4.4 & 0.3 & 4.7 & 4.9 \\
\hline June & 5.9 & 3.9 & 0.7 & 4.1 & 2.5 \\
\hline July & 5.5 & 3.9 & 1.4 & 4.0 & 3.6 \\
\hline August & 4.3 & 2.9 & 1.2 & 2.6 & 2.2 \\
\hline September & 6.8 & 2.2 & 0.9 & 2.3 & 2.3 \\
\hline October & 4.8 & 2.6 & 0.8 & 2.5 & 2.9 \\
\hline November & 6.1 & 2.2 & 1.0 & 2.3 & 2.5 \\
\hline December & 9.4 & 1.3 & 0.5 & 1.4 & 1.5 \\
\hline Annual & 6.1 & 3.3 & 0.6 & 3.5 & 2.6 \\
\hline
\end{tabular}

Although energy price forecasts are imperfect in absolute terms, the daily price pattern is less volatile than are absolute price levels; therefore, it can be predicted more accurately. However, A/S price patterns can change significantly from day to day.

\subsection{Results}

In order to understand the relative performance of the three technologies being considered for this study, CHEERS optimization runs were performed for each of them.

\subsubsection{Hourly Operations}

To illustrate typical results of the CHEERS model in detail, this section illustrates hourly plant operations for two days in 2011: January 19 and July 27. Operational plots are provided for all three technology types (AS PSH, FS PSH, and GT) in Figures 6-3 through 6-8. Since the 
operational plots of the four (identical) pump-turbine units in the pumped storage plants are typically similar, only the plots for Unit 1 are shown here. Each plot shows the hourly operations of each turbine (and pump, for the pumped storage plants), giving the generation set point, A/S levels, and pumping load (if applicable). Average generation levels are also computed by CHEERS. These are based on a generator's set point plus the increase in energy produced when the plant is used to serve regulation up. Likewise, they account for the decrease in energy produced below the set point when the plant is used to serve regulation down. Also shown are both projected and actual hourly energy and A/S prices.

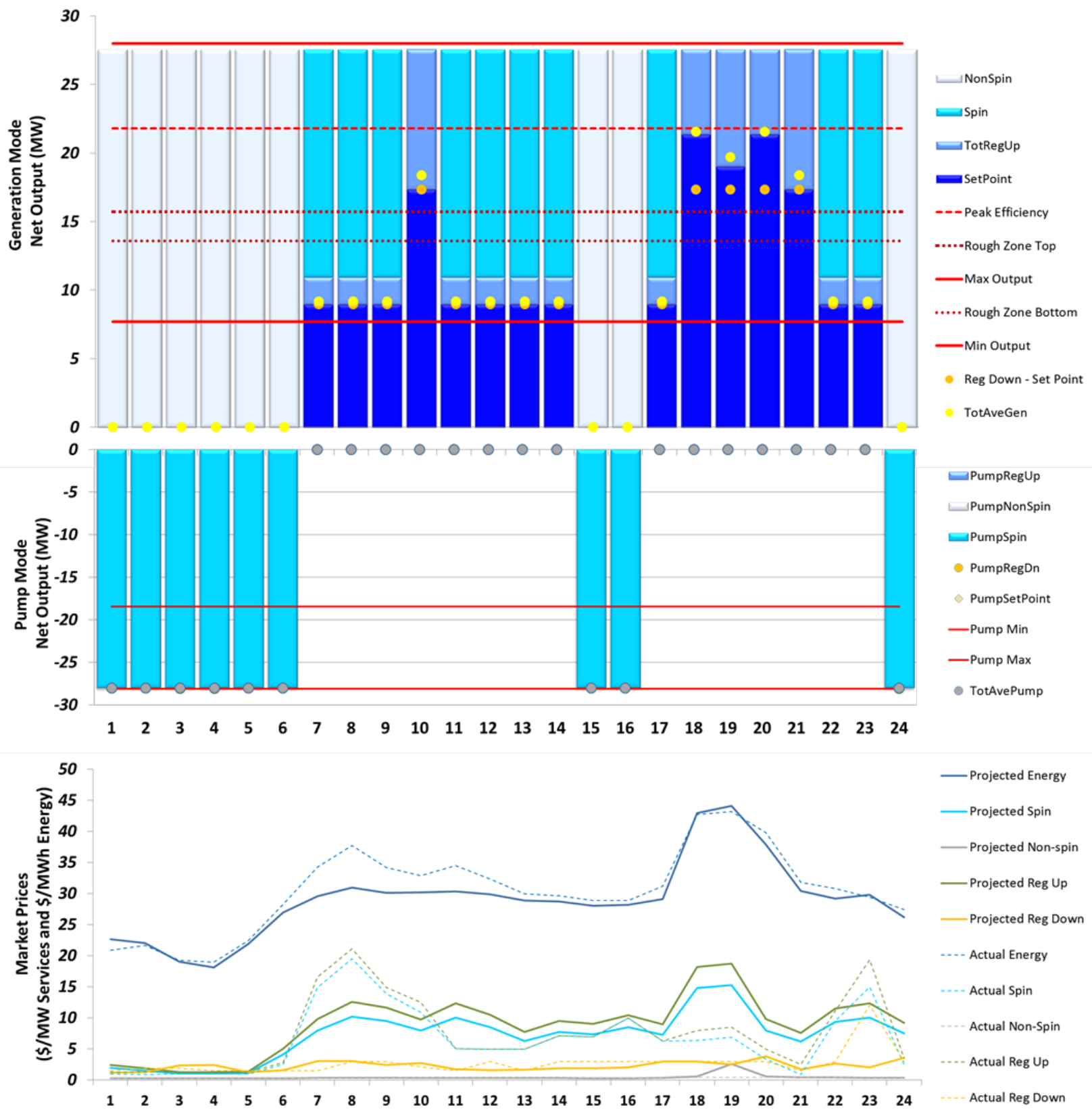

Figure 6-3 Hourly Operations of FS PSH and Projected Prices for Unit 1 on January 19 (Wednesday), 2011 


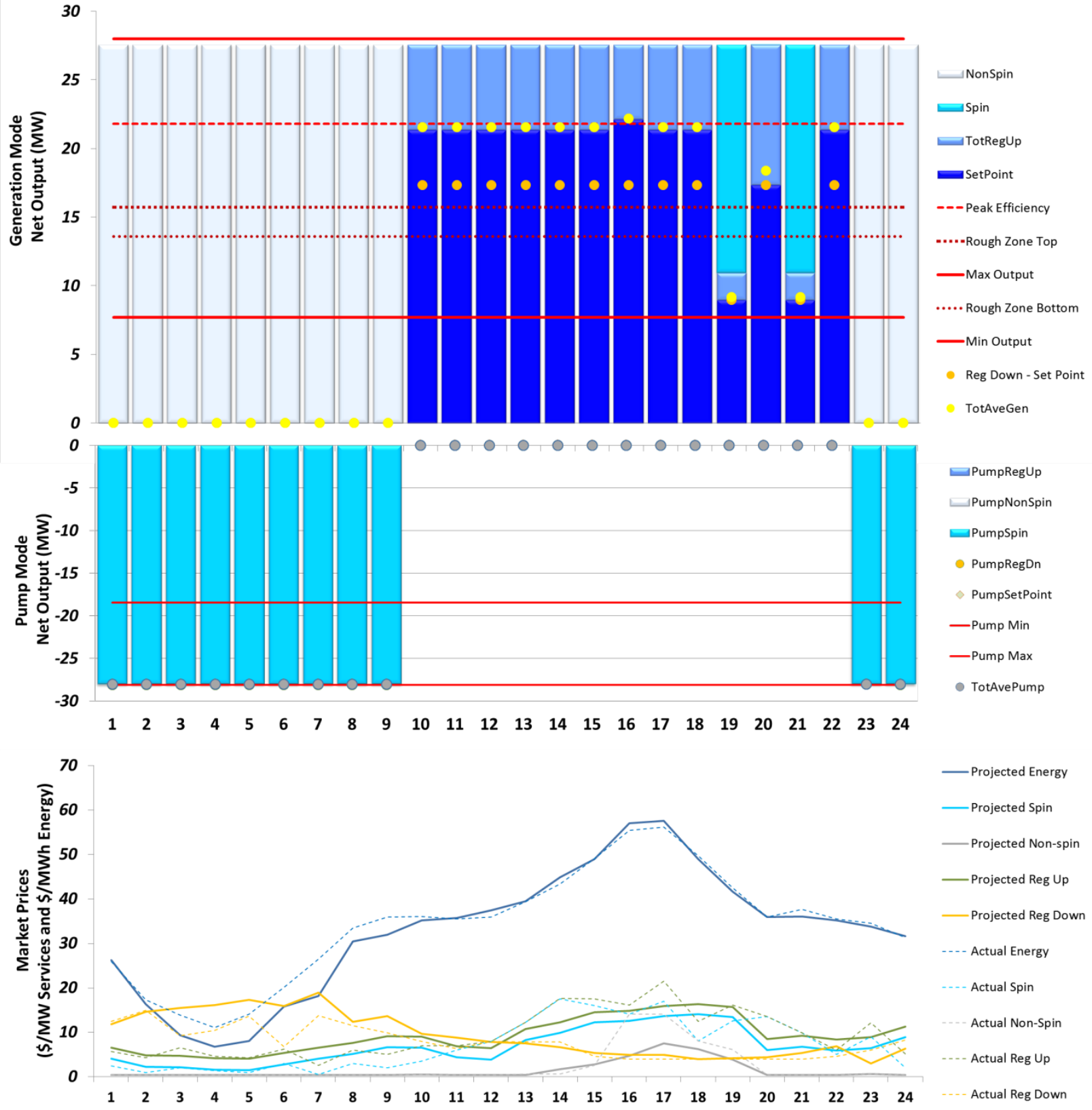

Figure 6-4 Hourly Operations of FS PSH and Projected Prices for Unit 1 on July 27 (Wednesday), 2011 


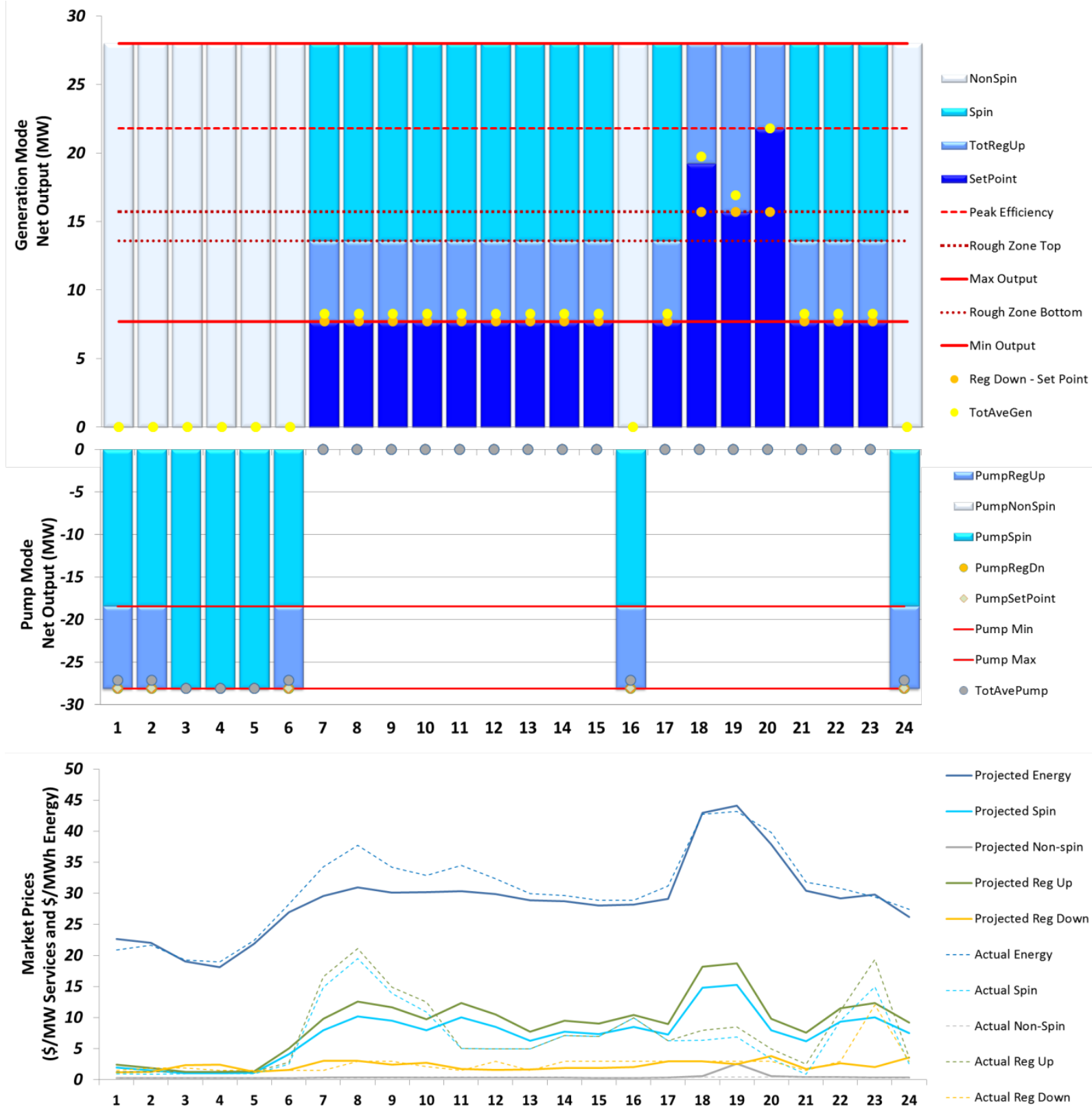

Figure 6-5 Hourly Operations of AS PSH and Projected Prices for Unit 1 on January 19 (Wednesday), 2011 


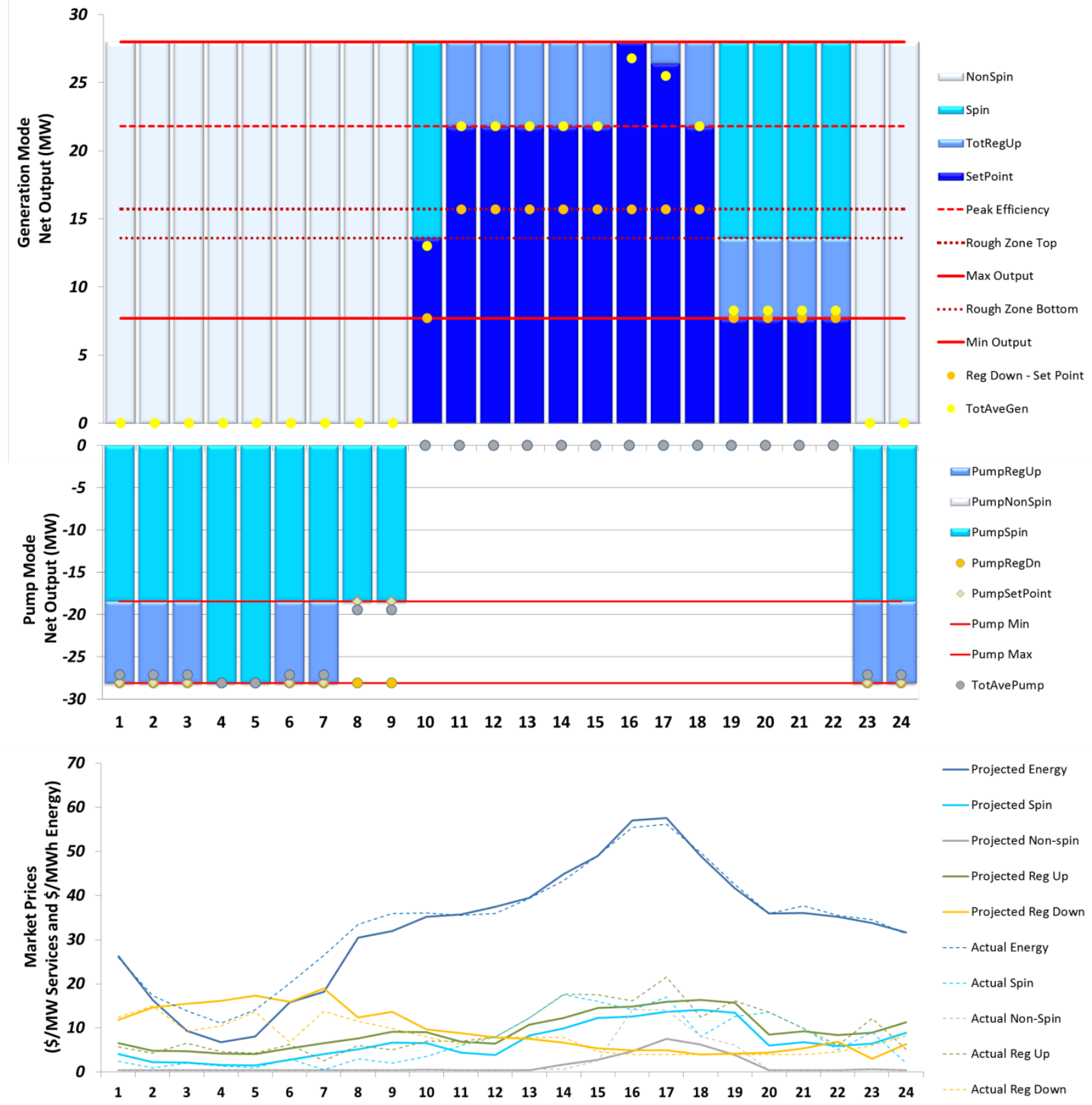

Figure 6-6 Hourly Operations of AS PSH and Projected Prices for Unit 1 on July 27 (Wednesday), 2011 


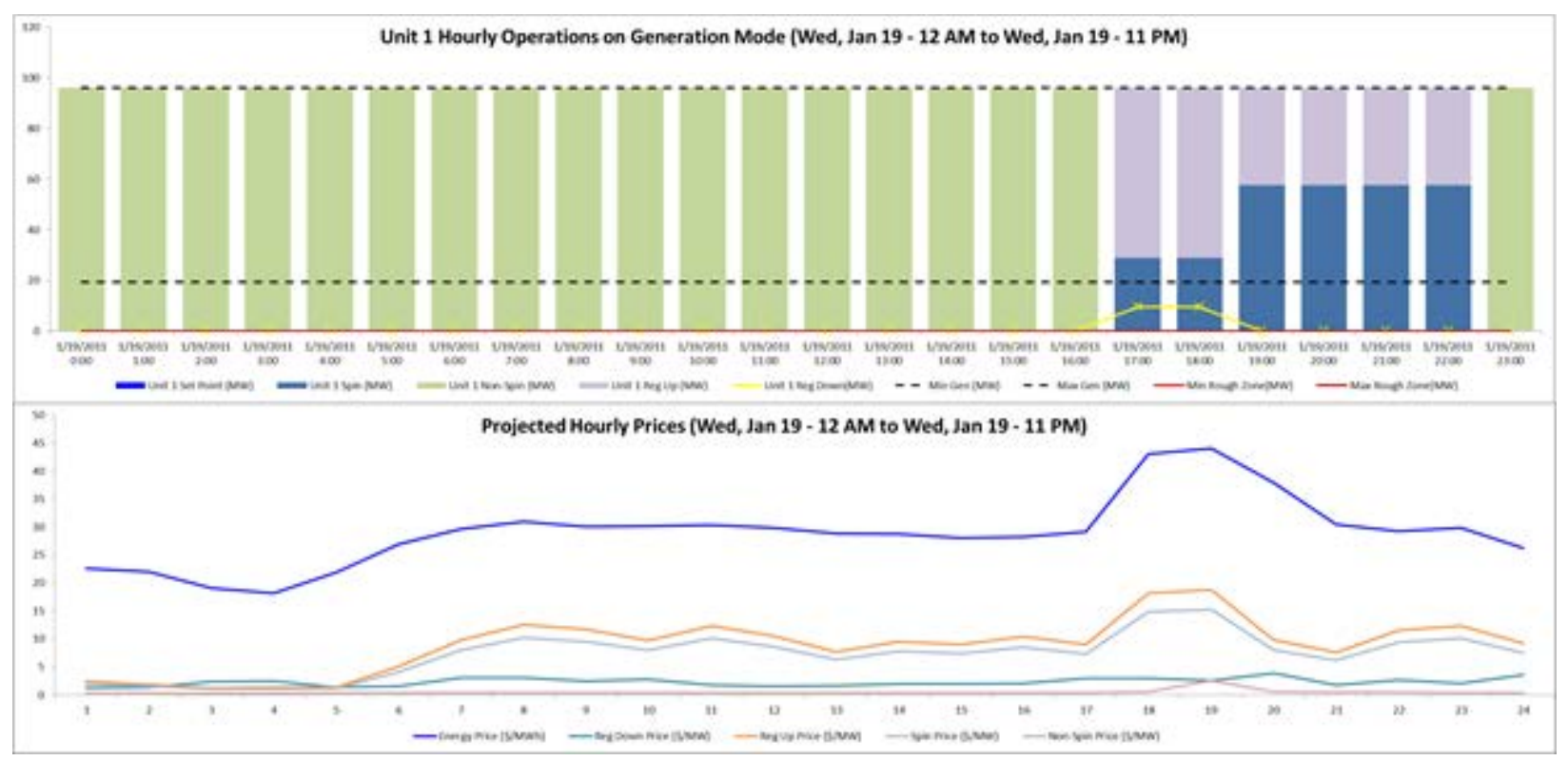

Figure 6-7 Hourly Operations of GT on January 19 (Wednesday), 2011

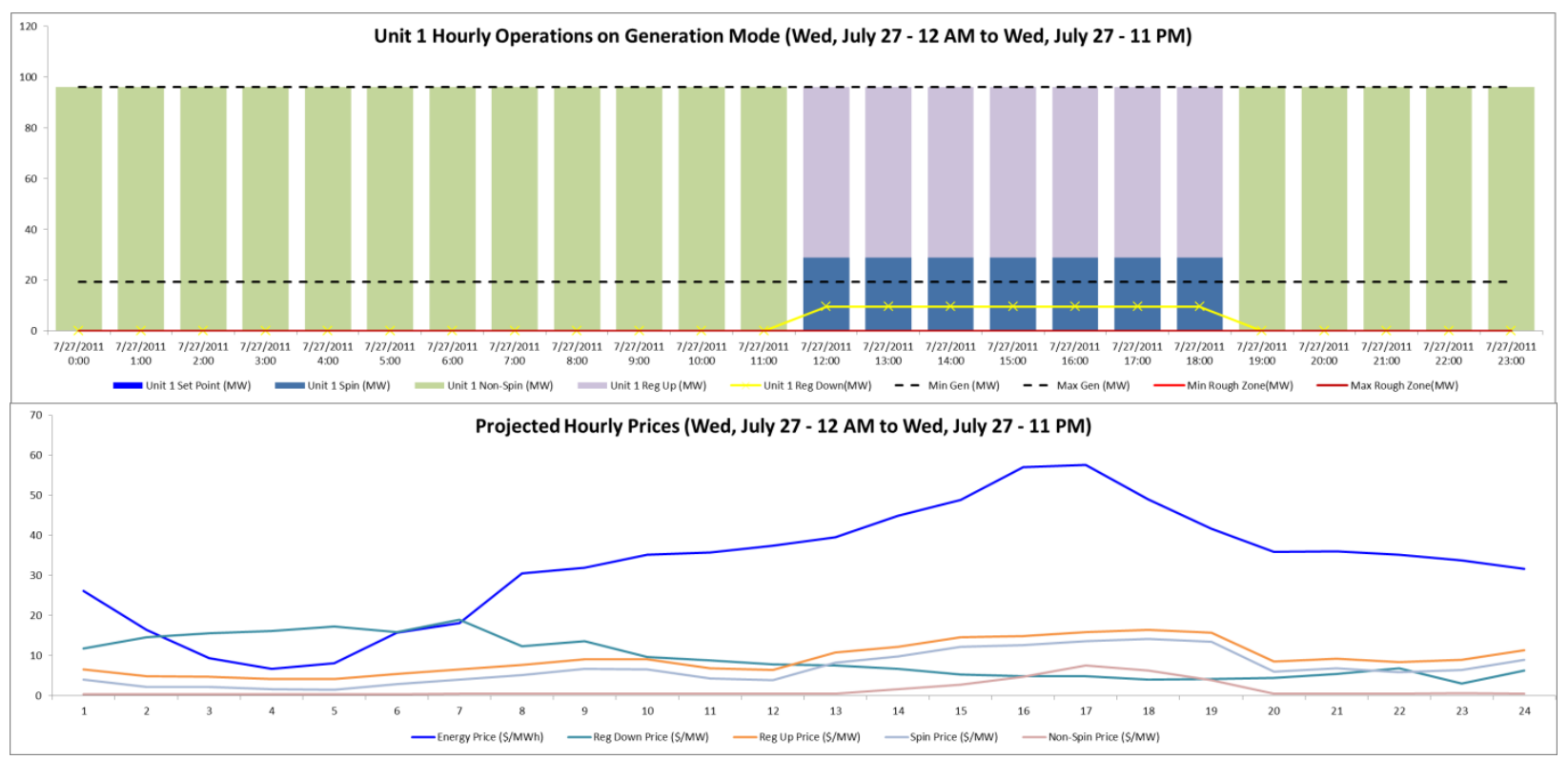

Figure 6-8 Hourly Operations of GT on July 27 (Wednesday), 2011

\section{Discussion of Hourly Operations}

The plots show a number of interesting operational behaviors in CHEERS model runs and highlight important differences among the three technologies being considered. For both pumped storage technologies, energy arbitrage behavior is clearly evident: The units generally operate in pumping mode when prices are low and in generation mode when they are high. While both FS and AS technologies can effectively capture revenues from energy arbitrage, the plots show the 
advantages that AS units have with regard to being able to provide A/S while operating in pumping mode. In both examples, the AS PSH often provides regulation services up with a pump set point at the pumping capacity. Also note that the AS pumping profile on July 27 involved pumping at the minimum level (18.5 MW) with the simultaneous selling of spinning reserve and regulation down services, and that regulation down service is achieved by increasing the pumping load on the system. The sale of regulation down while in pumping mode is advantageous for two reasons. First, the plant earns revenue for selling the service. Second, extra water is pumped into the upper reservoir, since regulation down causes an increase in pumping load. The average pumping level is higher (i.e., larger negative net output) than the pump set point. The extra water will later be converted to additional revenues when it is used to generate energy. The CHEERS model indicates that the operational capability of selling regulation down in pumping mode is valuable, since the AS units deploy it. FS units, in contrast, cannot provide any regulation services in pumping mode and thus miss the opportunity to benefit from the sale of regulation services.

The GT operations indicate a relatively simple operating trend. The GT unit generally operates at maximum capacity and sells the maximum amount of regulation down, when energy and regulation down prices are sufficiently high. At all other times, the unit remains off and sells only non-spinning reserve.

\subsubsection{Annual Operating Net Revenue Analysis}

Annual net revenue results are summarized in Table 6-4. Here net revenues are defined as the sum of energy and A/S revenues, minus the cost of fuel (in the GT cases) or electricity used for pumping (in the PSH cases). GT scenarios were run with two different values for the minimum generation capacity of the GT unit: 20\% of maximum capacity (i.e., 20 in the Minimum Output Level column) and 50\% of maximum capacity (i.e., 50 in that column).

Table 6-4 CHEERS Annual Net Revenue Results

\begin{tabular}{|l|c|l|c|c|c|c|c|}
\hline \multirow{2}{*}{ Technology } & $\begin{array}{c}\text { Minimum } \\
\text { Output } \\
\text { Level } \\
\mathbf{( \% )}\end{array}$ & $\begin{array}{c}\text { Dispatch } \\
\text { Price } \\
\text { Driver }\end{array}$ & $\begin{array}{c}\text { Energy } \\
\text { Production } \\
\mathbf{( G W h )}\end{array}$ & $\begin{array}{c}\text { Energy } \\
\text { Sales } \\
\text { Revenue } \\
\mathbf{( \$ 1 , 0 0 0 )}\end{array}$ & $\begin{array}{c}\text { Total A/S } \\
\text { Revenue } \\
\mathbf{( \$ 1 , 0 0 0 )}\end{array}$ & $\begin{array}{c}\text { Total } \\
\text { Operating } \\
\text { Cost } \\
\mathbf{( \$ 1 , 0 0 0 )}\end{array}$ & $\begin{array}{c}\text { Net } \\
\text { Operating } \\
\text { Revenue } \\
\mathbf{( \$ 1 , 0 0 0 )}\end{array}$ \\
\hline \multirow{2}{*}{ AS PSH } & 27.5 & Projection & 324 & 11,274 & 5,551 & 7,851 & 8,973 \\
\cline { 3 - 8 } & Actual & 320 & 11,524 & 6,266 & 7,287 & 10,503 \\
\hline \multirow{2}{*}{ FS PSH } & \multirow{2}{*}{32.4} & Projection & 347 & 12,019 & 4,571 & 8,191 & 8,191 \\
\cline { 3 - 8 } & Actual & 340 & 12,156 & 5,104 & 7,637 & 9,623 \\
\hline \multirow{2}{*}{ GT } & 20.0 & Projection & 84 & 3,138 & 5,511 & 5,994 & 2,655 \\
\cline { 3 - 8 } & Actual & 74 & 2,692 & 5,352 & 5,375 & 2,670 \\
\hline \multirow{2}{*}{ GT } & 50.0 & Projection & 5 & 265 & 953 & 368 & 851 \\
\hline
\end{tabular}


An examination of the CHEERS simulation data reveals the following observations.

The AS PSH plant has consistently higher net operating revenues (by about 9\%) than the FS PSH plant. This is due to several factors, including the ability of the AS units to sell regulation services in pumping mode, as well as the units' higher efficiency. As discussed in Section 6.4.1, the ability of AS units to sell regulation in pumping mode is a significant advantage, and the yearly revenue figures support this claim.

The price forecast error has significant financial implications for both PSH technologies since it reduces net operating profits by about 15\%, mainly as a result of higher pumping costs and lower A/S revenues. The implications of forecast error are most likely overstated for two reasons. First, the forecasting methodology is simplistic and could be improved. Secondly, it was assumed that no operational adjustments could be made in real time in response to actual price signals. Therefore, actual operating net revenues could be somewhere between the two extremes.

The total energy generation of the FS plant is higher than that of the AS plant due to a complex interaction of several factors in the optimization. One contributing factor is that the FS plant cannot sell regulation services in pumping mode and must pump only at maximum pumping power or not at all. In contrast, the AS plant sometimes pumps at minimum pumping power while simultaneously selling regulation down services, resulting in higher net revenues but also in a smaller amount of total water being pumped back into the upper reservoir.

For the GT technologies studied, there is a large difference in net revenue between the modern GT/20 plant and the older GT/50 plant. The net revenue of the GT/20 case is about three times higher than the net revenue of the GT/50 case. This difference is attributed to several factors. First, the GT/20 plant has significantly lower variable operations and maintenance (O\&M) costs than does the GT/50 plant (\$10.19/MWh for GT/20 versus $\$ 15.18 / \mathrm{MWh}$ for GT/50). Second, the GT/20 plant has a more efficient heat rate than does the GT/50 plant $(8,550 \mathrm{Btu} / \mathrm{kWh}$ for GT/20 versus 10,450 Btu/kWh for GT/50).

When these considerations are taken into account, it is interesting to compare the overall net operating revenue of the GT/20 plant with the AS and FS pumped storage plants. For these comparisons, we consider normalized profitability (profit [\$] per kilowatt of installed capacity per year $[\mathrm{kW}-\mathrm{yr}])$ to fairly compare the technologies:

- $\quad$ AS pumped storage: $\$ 80-94 / \mathrm{kW}-\mathrm{yr}$,

- $\quad$ FS pumped storage: $\$ 74-87 / \mathrm{kW}-\mathrm{yr}$,

- GT (20\% minimum output level): \$28/kW-yr, and

- $\quad$ GT (50\% minimum output level): \$9/kW-yr.

The first number in the range (lower value) is based on model runs that use projected prices. The second number (higher value) is based on model runs that use actual prices. The differences in results obtained for GT/20 and GT/50 reflect the large impact of GT plant technology. Note that 
most GT plants today seldom operate below $50 \%$ of their installed capacity. Therefore, our results suggest that pumped storage may be a more profitable technology. However, improvements in GT technology will continue to expand the operating range of these plants, and operations closer to $20 \%$ capacity may become commonplace in the near future. Since the GT/50 technology is less efficient, has higher variable O\&M costs, and is more expensive to build, it was eliminated from more detailed analyses.

Because energy prices have been so volatile in the past and are expected to change in the future, we performed a sensitivity analysis on 2011 prices. Figure 6-9 shows net annual operating revenues as a function of market prices for energy and A/S. For this analysis, we simply multiplied all hourly prices by a multiplier and reran CHEERS with the adjusted prices. The relationships are nearly linear; that is, doubling all of the market prices approximately doubled the net revenue estimate.

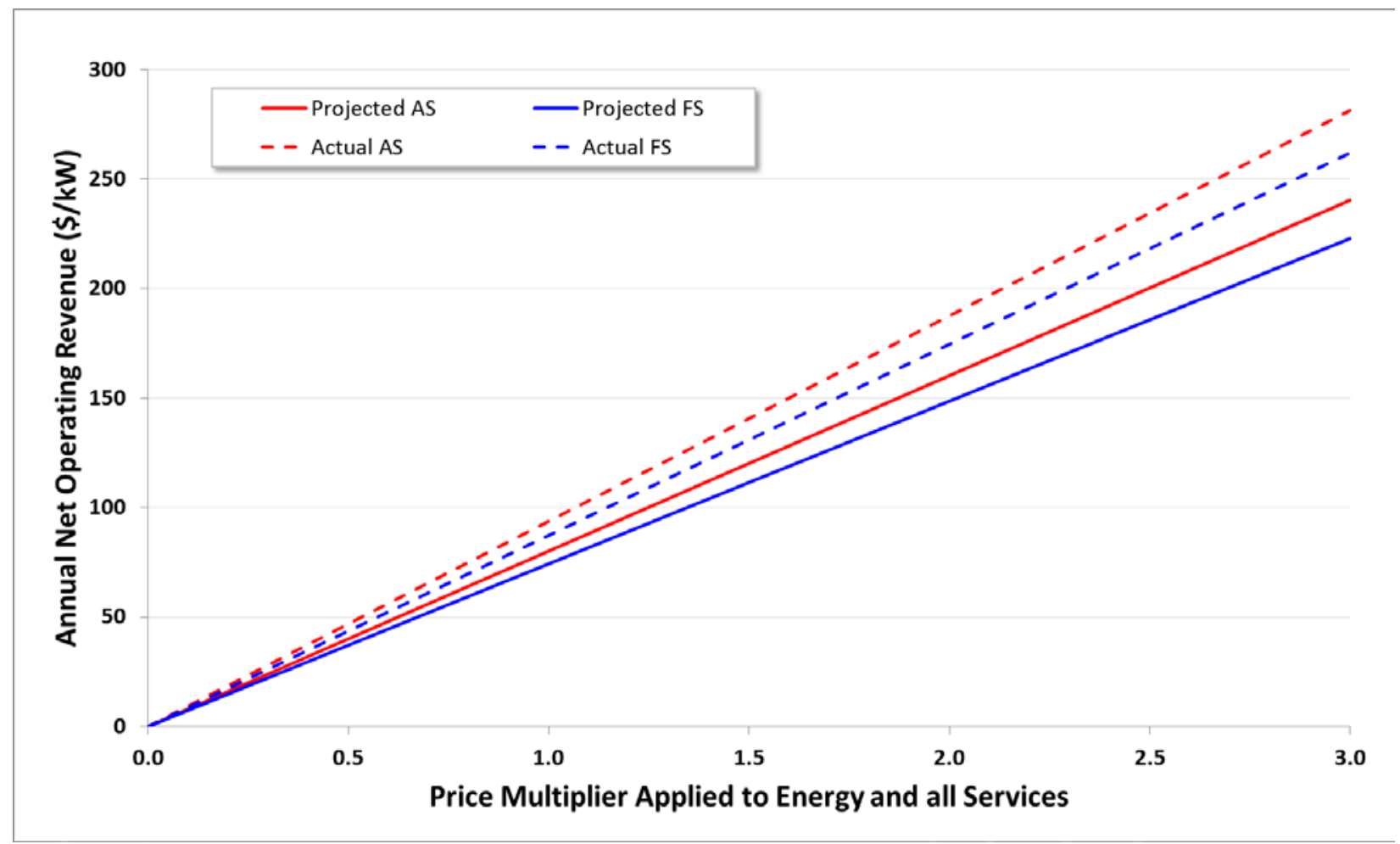

Figure 6-9 Annual Net Operating Revenue as a Function of Energy and Ancillary Services Prices

CHEERS model runs were also performed based on the assumption that the newly constructed technologies would participate only in the energy market or in a market that had only an energy product. Under these circumstances, the technologies would not supply A/S and thus only energy revenues would be received. Table 6-5 summarizes costs and revenues when the energy price signals used were the same as those used for the previous runs but zero prices were used for A/S. 
Table 6-5 CHEERS Annual Net Revenue Results without an Ancillary Services Market

\begin{tabular}{|c|c|c|c|c|c|c|c|}
\hline Technology & $\begin{array}{c}\text { Minimum } \\
\text { Output } \\
\text { Level } \\
(\%)\end{array}$ & $\begin{array}{c}\text { Dispatch } \\
\text { Price } \\
\text { Driver }\end{array}$ & $\begin{array}{c}\text { Energy } \\
\text { Production } \\
\text { (GWh) }\end{array}$ & $\begin{array}{c}\text { Energy } \\
\text { Sales } \\
\text { Revenue } \\
(\$ 1,000)\end{array}$ & $\begin{array}{c}\text { Total A/S } \\
\text { Revenue } \\
(\$ 1,000)\end{array}$ & $\begin{array}{c}\text { Total } \\
\text { Operating } \\
\text { Cost } \\
(\$ 1,000)\end{array}$ & $\begin{array}{c}\text { Net } \\
\text { Operating } \\
\text { Revenue } \\
(\$ 1,000)\end{array}$ \\
\hline \multirow{2}{*}{ AS PSH } & \multirow{2}{*}{27.5} & Projection & 307 & 11,213 & 0 & 6,720 & 4,493 \\
\hline & & Actual & 305 & 11,557 & 0 & 6,074 & 5,483 \\
\hline \multirow{2}{*}{ FS PSH } & \multirow{2}{*}{32.4} & Projection & 298 & 10,904 & 0 & 6,521 & 4,383 \\
\hline & & Actual & 298 & 11,246 & 0 & 5,894 & 5,352 \\
\hline GT & 20.0 & Projection & 25 & 1,508 & 0 & 1,335 & 174 \\
\hline
\end{tabular}

Without A/S, net operating revenue is about 50\% less for AS PSH and about 55\% less for FS PSH. For the GT/20 technology, net operating revenues are only $7 \%$ of the amount with A/S. This result illustrates the importance of A/S on net operating profit. On the other hand, strong arguments suggest that A/S levels (or levels of similar types services, such as ramping) and thus prices will increase substantially in the future as the penetration of variable resources gets higher. Therefore, a sensitivity analysis on the assumed prices of A/S was done. Figure 6-10 shows the result for this sensitivity analysis, in which energy prices were held constant, but a price multiplier was applied to all A/S prices in each hour. A price multiplier of zero is equivalent to the no A/S model runs, and a multiplier of 2.0 doubles the price of A/S while energy prices remain the same.

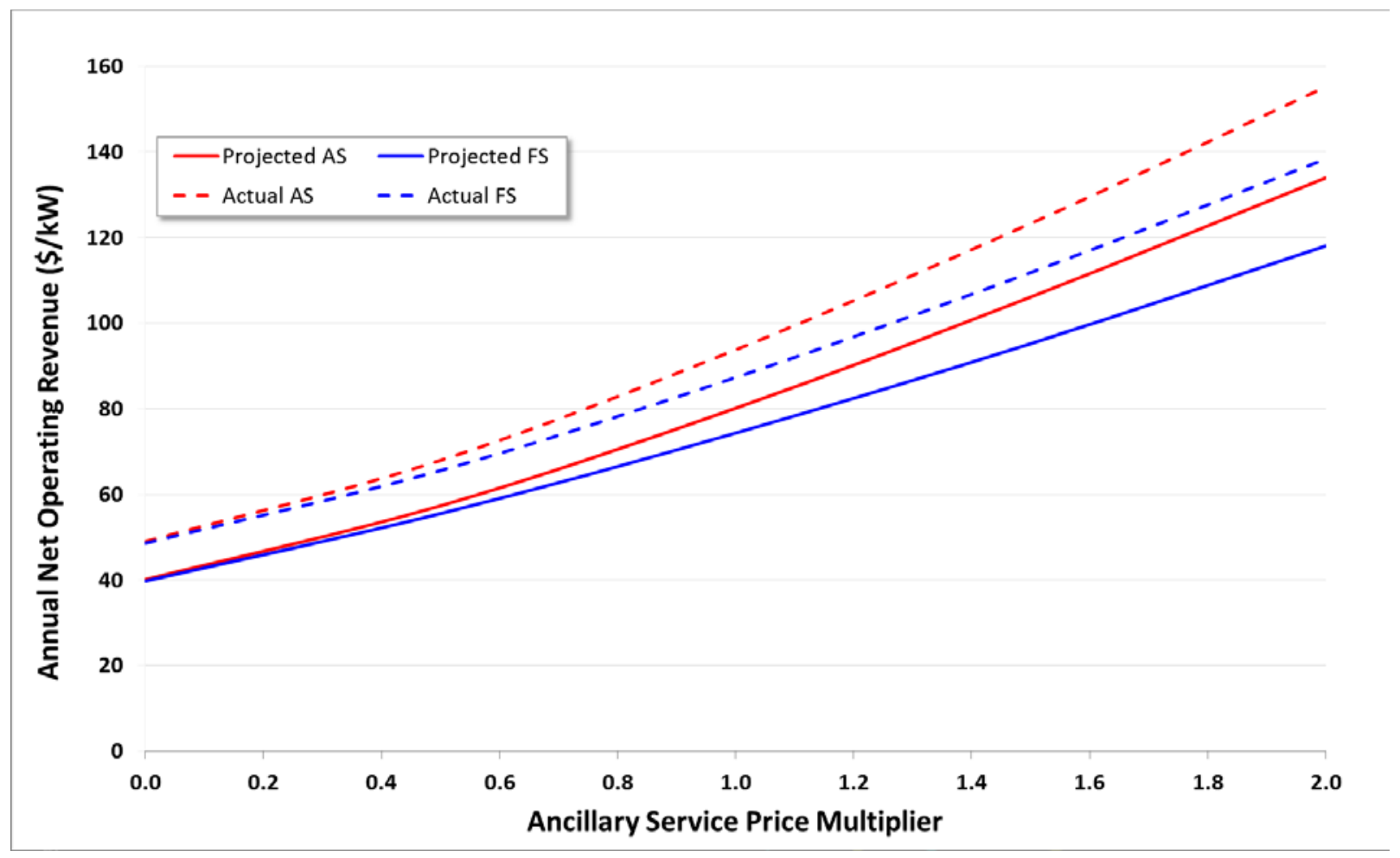

Figure 6-10 Annual Net Operating Revenue as a Function of Ancillary Services Prices 
When A/S prices are zero, there is little difference in the net revenues for the AS and FS technologies. The gap widens as the prices of A/S increase, however. This result illustrates that the key advantage of AS technology is its ability to provide regulation services in pump operating mode. In order to justify new AS construction, the financial benefits (i.e., net revenue gap) of the AS technology must be equal to or greater than the higher cost of building AS technology over building FS technology. AS technology should also be competitive with new advanced GT technologies. A detailed discussion of cost and benefit trade-offs is presented in the Section 6.4.3.

\subsubsection{Comparative Net Present Value Analysis}

To make a business decision on whether to construct a new power plant, one must consider a set of candidate technologies and plausible net revenue and expenditure streams throughout the book life of each candidate. To support project manager investment decisions, CHEERS and a financial model can be used to compare potential investment returns for various technologies. This section illustrates this modeling capability, and it shows the results of net present value (NPV) computations for both FS PSH and AS PSH technologies and for the advanced GT/20 technology under a large set of modeling assumptions. CHEERS study results discussed in the previous sections were used to compute and approximate net operating revenue streams over time. Estimated annual costs were then subtracted from sales revenues as a function of time. Costs include expenses to build a power plant, fixed O\&M costs, outlays for fuel and energy purchases, costs for unit starts, and variable O\&M costs.

NPV calculations were performed under different scenarios to determine the sensitivity of project returns to different capital costs, loan interest rates, market price forecast accuracies, and future natural gas price outlooks. Project returns were measured in terms of NPV (in millions of dollars) over 30 years of plant operation. Financial spreadsheet NPV calculations also depend on technology capacity factors (i.e., utilization rates) that were derived from generation levels and capacities presented in the previous section. Since the lifetime of the GT/20 technology is less than the 30-year analysis period, we assumed that the technology would be replaced at the same site after 20 years of operation and thus additional capital expenditures would be incurred.

Maximum potential net returns for AS PSH, FS PSH, and GT/20 mirror the results found in Section 6.4.2. The possible NPV returns for generic AS PSH plants under most outlooks are higher than those returns for generic FS PSH and GT/20 plants. In general, maximum project NPV returns for AS PSH plants were the highest, followed by returns for FS PSH plants, then GT/20 plants. However, maximum potential losses were also the highest for AS PSH. This technology therefore offers the highest potential reward but also carries the most risk.

\section{Methodology}

The methodology employed for the comparative NPV analysis is tailored for investors that need information about the relative financial gains and associated risks of constructing and operating new generating facilities. The comparative NPV analysis involves the computation of costs under a set of funding assumptions for three generic plant types: FS PSH, AS PSH, and GT/20. Both costs and benefits are computed annually over the study period, which starts with project planning, continues through power plant construction, and ends after 30 years of plant operation. 
Generic plant assumptions are incorporated into the detailed NPV analysis to examine project development costs, capital investments, and debt and equity funding provisions. Projections from technology-specific models are used, along with other generic plant assumptions, to drive income, cash flow, and balance sheet projections. The resulting earnings, cash flow, and other financial projections are used to estimate annual technology NPV returns over the study period.

Table 6-6 highlights major project base case scenario assumptions for each plant technology. Technology assumptions for generic plant types were developed for technologies to come on-line in 2022. Adjustments to project timetables and costs reflect the assumed total 8-year project development and construction phase for PSH (4 years for development, and 4 years for construction) and the shorter 2-year construction timeframe for the GT/20 plant. Therefore, an investor in PSH technologies must begin to spend sooner than a GT investor would to achieve the same "plant on-line" date.

The durations of time taken for development and construction for each generic plant type were based on industry conventions. PSH project construction costs were provided by MWH. Cost numbers for both GT technologies are consistent with those used by the EIA in AEO 2013 (EIA 2013).

As mentioned, based on the relatively low net operating revenues of the GT/50 technology, this option was screened from further analyses. The removal of this technology is further justified by the information contained in Table 6-6. It shows that a GT/50 plant is more expensive than a new GT/20 plant in terms of both construction and operating costs.

Table 6-6 Assumptions for Comparative Economic Analysis

\begin{tabular}{|l|c|c|c|c|}
\hline \multicolumn{1}{|c|}{ Project Assumption } & FS PSH & AS PSH & GT/50 & GT/20 \\
\hline Plant start-up (on line) target year & 2022 & 2022 & 2022 & 2022 \\
Project development duration (no. of years) & 8 & 8 & 2 & 2 \\
Project construction duration (no. of years) & 4 & 4 & 1 & 1 \\
Construction cost (\$/kW) & 2,000 & 2,200 & 910 & 632 \\
Annual fixed O\&M cost (\$/kW) & 14.57 & 14.57 & 7.21 & 6.92 \\
Installed project capacity (MW) & 110 & 112 & 96 & 96 \\
Plant book life (no. of years) & 50 & 50 & 20 & 20 \\
\hline
\end{tabular}

Project costs for each plant technology were assumed to be financed with the same mix of $25 \%$ equity $/ 75 \%$ debt, with loans split three ways and the same repayment and interest terms for each plant type. Project funding assumptions are provided in Table 6-7. 
Table 6-7 Project Financing Assumptions

\begin{tabular}{|l|c|}
\hline \multicolumn{1}{|c|}{ Project Funding Assumption } & $\begin{array}{c}\text { Plant } \\
\text { Type }\end{array}$ \\
\hline Equity (\% project costs) & 25 \\
Debt (\% project costs) & 75 \\
\hline Loan 1 (\% debt) & 30 \\
Loan 2 (\% debt) & 50 \\
Loan 3 (\% debt) & 20 \\
\hline Annual interest on Loan 1 (\%) & 4.5 \\
Annual interest on Loan 2 (\%) & 4.3 \\
Annual interest on Loan 3 (\%) & 4.0 \\
\hline Repayment period for Loan 1 (no. of years) & 20 \\
Repayment period for Loan 2 (no. of years) & 15 \\
Repayment period for Loan 3 (no. of years) & 10 \\
\hline
\end{tabular}

These assumptions for project and funding costs were used to drive detailed project analyses that were subsequently incorporated into the financial statement forecasting models. Assumptions for revenues, energy costs, and O\&M costs were developed using the CHEERS model for the initial operating year.

\section{Results of the Comparative NPV Analysis}

When project managers compare potential project returns of PSH and GT plants, they recognize the need to examine sensitivities to both revenues and costs over time. On the cost side, their concern could be the potential impact on project returns that could result from rising or falling capital costs and loan interest rates. The potential for multiple factors to influence project returns highlights the level of investment risk and the uncertainty associated with project outcomes. To address these concerns, different project scenarios were tested to illustrate how power plant technologies respond to changing factors. Test runs varied one factor at a time to determine potential NPV return sensitivities.

\section{Capital Cost Scenarios (Initial 2011 Market Prices with 2.35\% Inflation)}

Because constructing a new PSH is very capital intensive, the levels of base capital costs and of potential capital cost overruns are of major concern to project managers. NPV model runs were thus carried out over a range of capital cost assumptions based on their percentage variance from the base case capital costs for each technology type.

The first set of model runs measured the impact of capital costs assuming that 2011 nominal prices for fuel, energy, and A/S were set to be equal to historic values and to increase at a general inflation rate of $2.35 \%$ annually throughout the analysis period. Results when an annual discount rate of $4.28 \%$ was used are illustrated in Figure 6-11. It shows that the NPV project returns for all three technologies examined are less than zero. When participating in the A/S (as shown by the continuous lines), net losses are about $\$ 20$ million under the base capital cost (i.e., $0 \%$ change) assumptions. Returns decline further as capital costs increase because of the greater debt funding and subsequent debt service thereby decreasing annual net income and net cash flows. 
PSH technologies have greater down-side risks than does the GT/20 technology if capital cost overruns are incurred. On the other hand, PSH technologies have a potential for larger net profits if capital costs are lower than the base capital cost assumption. Investors must weigh these higher risks against the potential for larger profits.

The CHEERS model aggressively sold A/S from each of the modeled technologies. Therefore, additional model runs were performed to explore PSH and GT/20 project returns if there were no A/S sales and revenues. These model runs serve as an NPV floor. As shown in Figure 6-11, NPVs are negative for both PSH technologies and the GT/20 technology when participation in ancillary markets is excluded from model runs. The figure also shows that the NPV spread between the two PSH technologies without A/S is much larger than that between the two scenarios that have PSH A/S sales. Also, the AS PSH technology is always more expensive over the range of capital costs modeled. Therefore, the higher efficiency curve, smaller rough zone, and lower minimum output level are not sufficient to justify the higher AS PSH capital costs. The primary financial justification for spending higher capital costs for AS PSH is because it can provide regulation service in pumping mode.

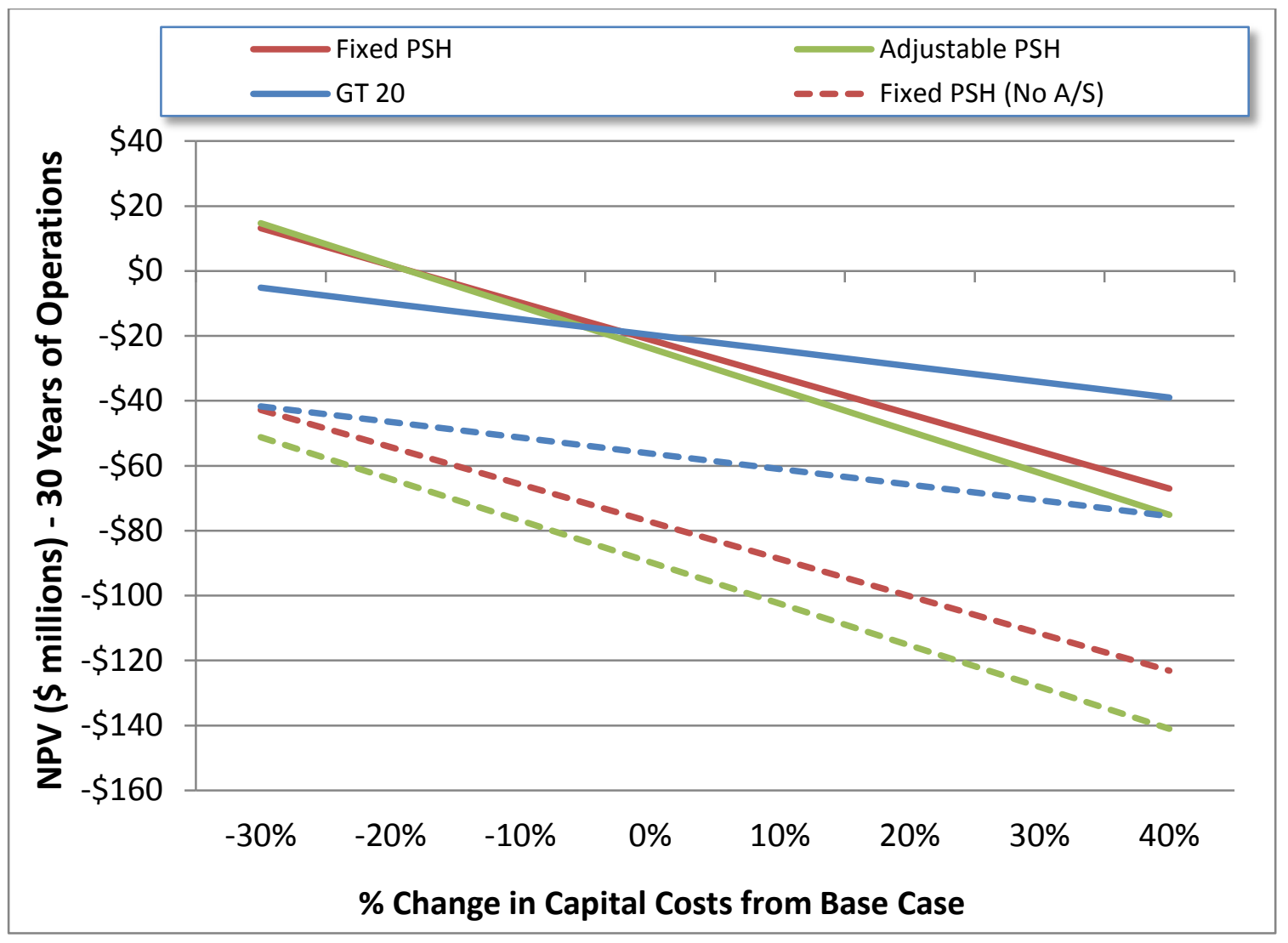

Figure 6-11 Projecting NPV as a Function of Capital Costs Based on 4.28\% Discount Rate 
Energy price spreads have generally trended downward over time due to lower natural gas prices and because natural gas units are typically on the margin during both on-peak and off-peak hours. In past decades, off-peak prices were generally set by nuclear or coal-fired technologies, which resulted in relatively larger spreads. This illustrates the importance of monetizing A/S to enhance the returns of PSH plants. It also shows that the construction of new PSH power plants cannot be financially supported by relying solely on energy arbitrage; that is, price spreads are not sufficiently large to justify new construction.

A parallel set of scenario runs for PSH technologies were conducted to illustrate the potential impact of DA market price forecast error and static scheduling on the range of potential outcomes. As noted in Section 6.3.4, we used a simplistic forecasting algorithm and did not allow operational changes in HA and RT markets. Therefore, scenarios were constructed based on perfect price forecasts such that forecasts were identical to the prices that actually occurred. Although consistently perfect price forecasts have never been accomplished, these "actual" price scenarios serve as an NPV upper bound. The continuous lines with the label "(Act)" in Figure 612 show that both AS and FS technologies are at the breakeven point (i.e., an NPV of zero) when future prices are known with certainty. The two dashed lines labeled "(Pro)" in the graph are NPV results for model runs with projected prices that assume forecast errors and inflexible schedules.

Figure 6-13 shows results when PSH technologies do not participate in A/S markets. Even without any forecast errors, NPVs are always below zero when A/S are not sold. Investors may find that the results would be somewhere between the NPV values represented by the continuous and dashed lines in Figures 6-12 and 6-13.

\section{Testing Impact of Fuel Prices on Capital Cost Scenarios}

Historically, market prices for natural gas, energy, and A/S have been very volatile yet have greatly affected power plant project costs and returns. These factors warrant a close review with regard to their potential NPV outcomes. To investigate the impact of fuel prices on NPVs, runs were performed for the various natural gas price outlooks.

\section{Capital Cost Scenarios with 35\% Lower Energy and Ancillary Services Prices}

Figure 6-14 shows model runs based on the assumption that all fuel, energy, and A/S prices were $35 \%$ lower than they were in the previous runs. The runs approximate the natural gas price drop from 2011 to 2012. Lower market price levels result in negative project NPV returns for both PSH and GT20 plants. However, the potential losses are much greater for PSH technologies, with the AS technology having the largest losses across the entire range of capital costs examined. This result suggests market prices need to remain at roughly 2011 levels (in terms of constant 2011 dollars) or higher for the financial viability of all three tested technologies to be maintained. However, new construction may also be financially viable at lower market prices if the market in which it operates also provides capacity payments. 


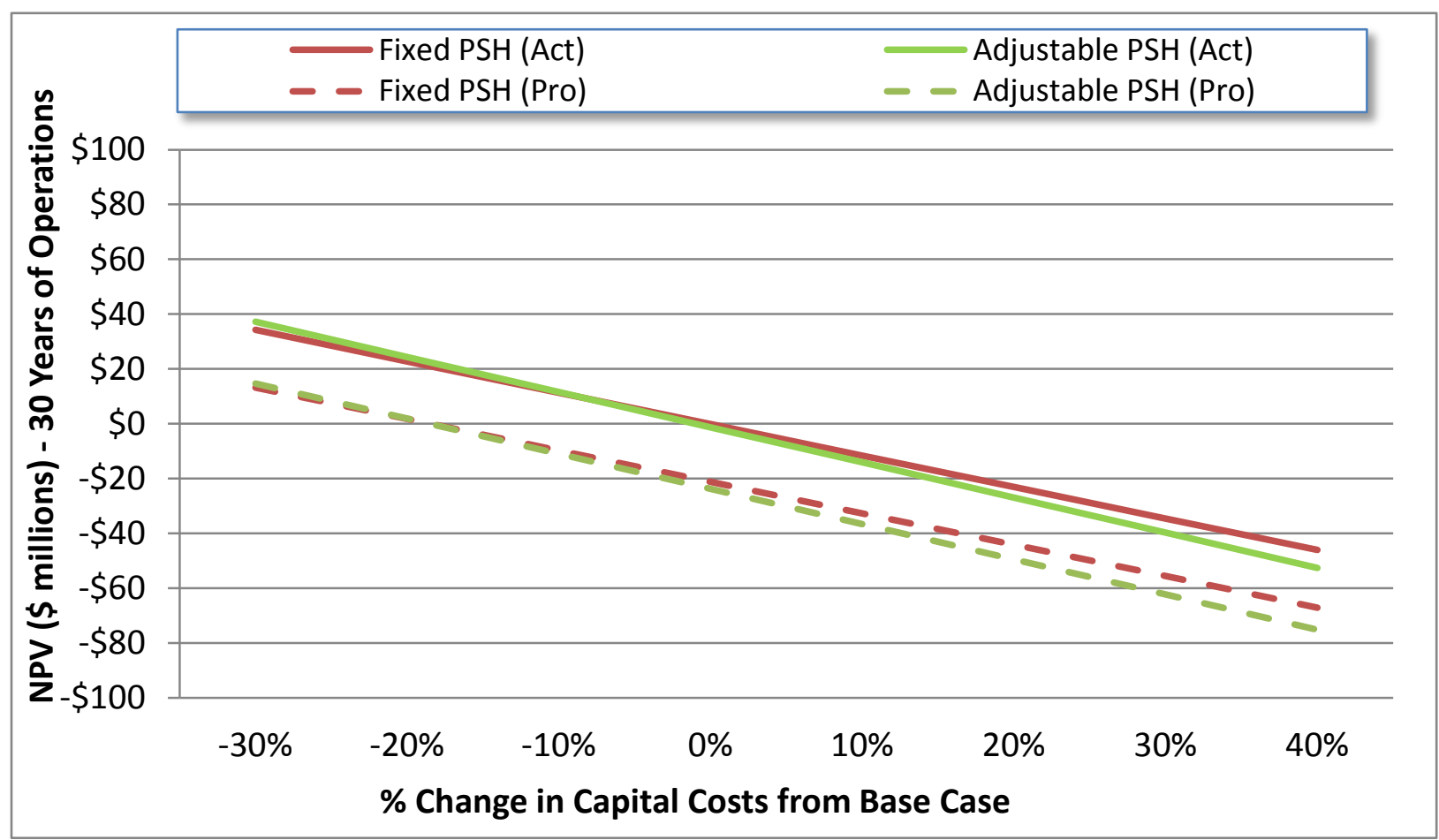

Figure 6-12 Projecting PSH NPV as a Function of Capital Costs: Comparison Using Perfect (Act) versus Imperfect (Pro) Forecasts with PSH Participation in Ancillary Services Markets

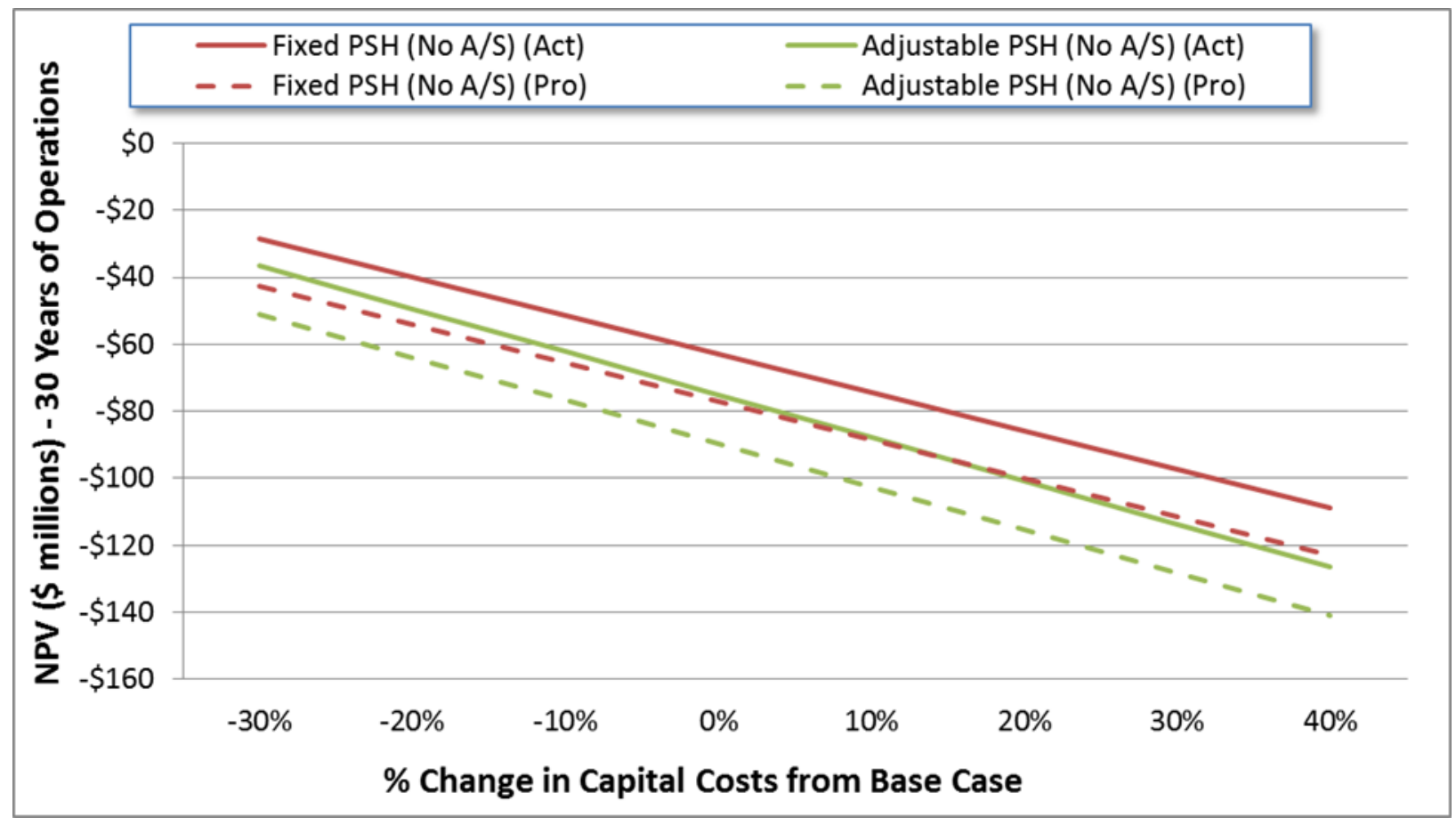

Figure 6-13 Projecting PSH NPV as a Function of Capital Costs: Comparison Using Perfect (Act) versus Imperfect (Pro) Forecasts without PSH Participation in Ancillary Services Markets 


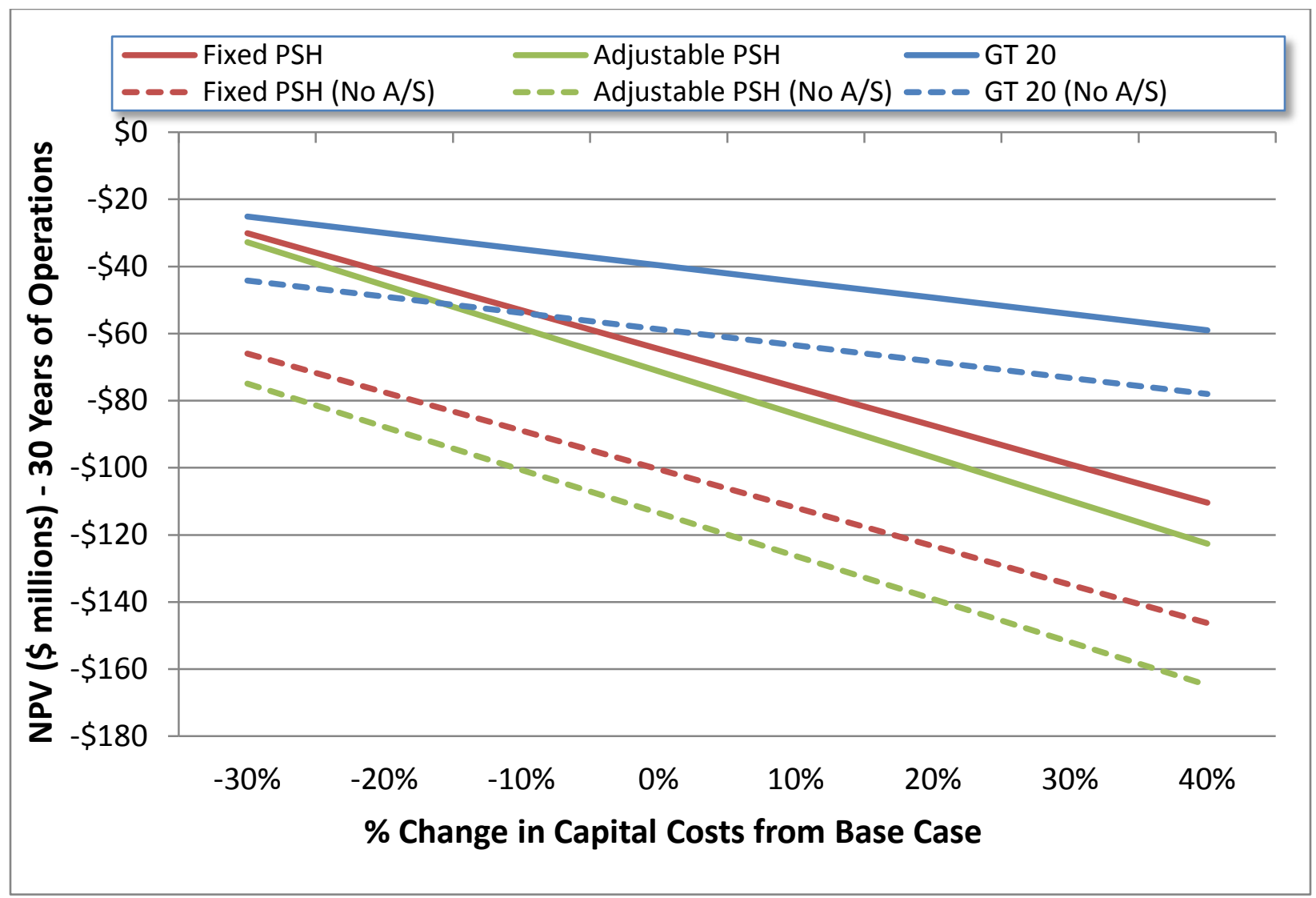

Figure 6-14 Projecting NPV as a Function of Capital Costs Based on 35\% Lower Energy and Ancillary Services Prices

As shown in Figure 6-15, adding the assumption of perfect price forecasting to the above scenario resulted in higher NPV results for both FS and AS PSH plants, but results were still below profitability.

\section{Capital Cost Scenarios with 35\% Higher Energy and Ancillary Services Prices}

Scenarios were also run based on the assumption that all energy and A/S prices were 35\% above 2011 levels, which is about equal to the natural gas price increase in nominal dollars forecasted for California between 2011 and 2029 predicted in the AEO 2013 (EIA 2013) reference scenario. As shown in Figure 6-16, project returns shift to positive NPVs for all plant types in all capital cost scenarios tested when participation in A/S markets (continuous line plots) is assumed. The highest potential returns are for AS PSH plants, followed closely by FS PSH plants and then by GT20 plants. However, without A/S sales, all technologies have negative NPVs throughout the range of capital cost scenarios tested. The figure also shows that without A/S sales, FS PSH always outperforms AS PSH throughout the range of capital cost scenarios. In addition, at lower capital costs, the GT/20 technology has larger losses than do the PSH technologies, but when capital costs are higher, it has smaller losses. 


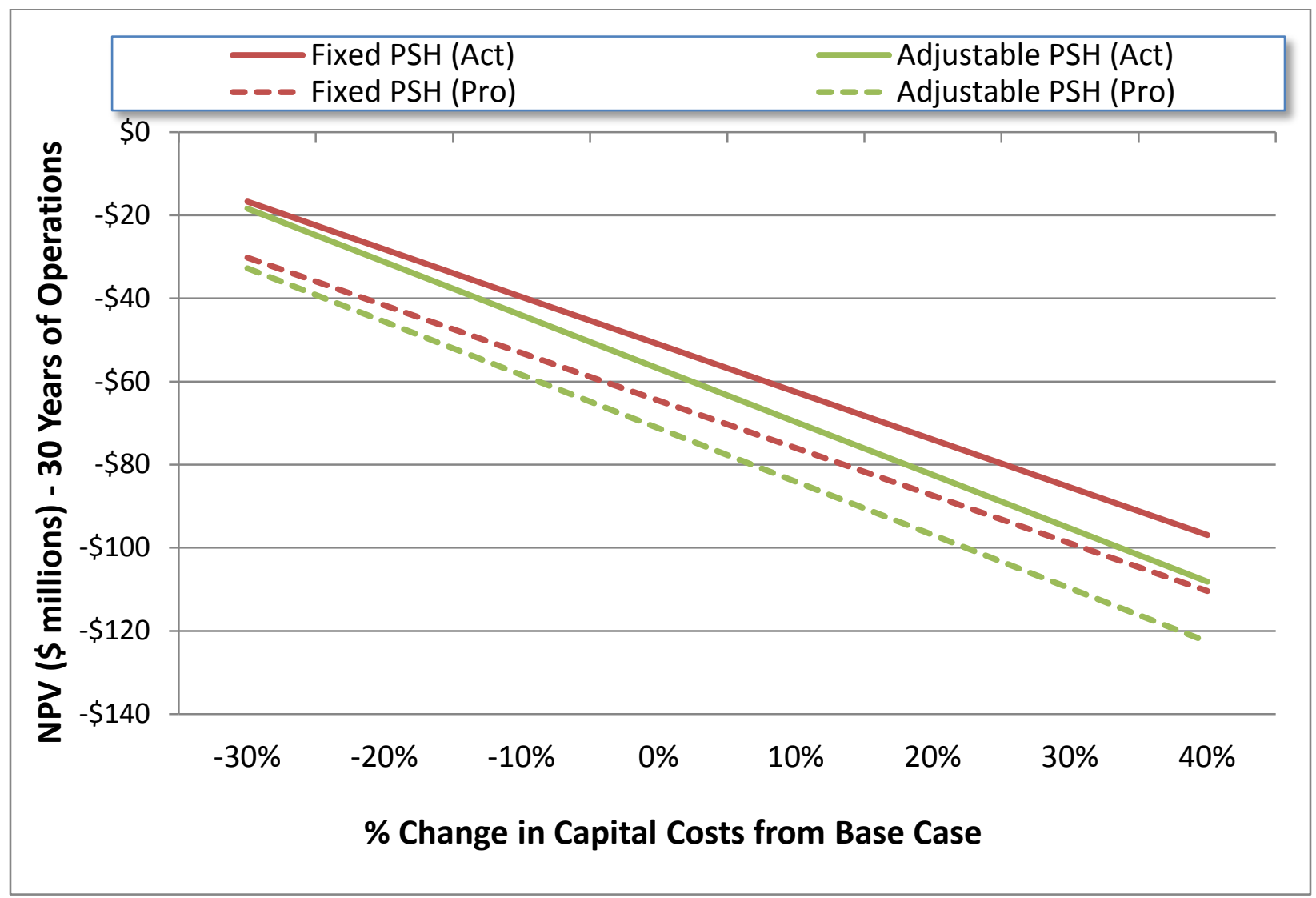

Figure 6-15 Projecting NPV as a Function of Capital Costs Based on 35\% Lower Energy and Ancillary Services Prices: Comparison Using Perfect (Act) versus Imperfect (Pro) Forecasts

As shown in Figure 6-17, under perfect price forecasting scenarios where RT adjustments could be made to maximize revenues, both FS PSH and AS PSH plants generated NPVs roughly \$30 million higher than those under imperfect price forecasting scenarios. Under perfect forecasting scenarios, NPVs for both PSH technologies remained positive under all of the capital cost cases tested. This illustrates the benefits of better price forecasts and of the flexibility to quickly respond to changing market conditions that reflect evolving grid needs.

The scenarios just discussed illustrate how the financial viability of new plants is closely linked to energy and A/S prices. This suggests the need for in-depth forecasts of sustainable, mid-cycle, and long-term prices in order to analyze project returns for PSH and GT20 plants. It also illustrates the important need to determine future revenues and monetization of PSH ancillary revenues.

\section{Natural Gas, Energy, and Ancillary Price Projections Vectors}

The wide range of NPV outcomes discussed above highlights the risk inherent in spending large sums of capital on new PSH construction over a period of several years based on long-term prices, which historically have been both very volatile and difficult to accurately project. It is 


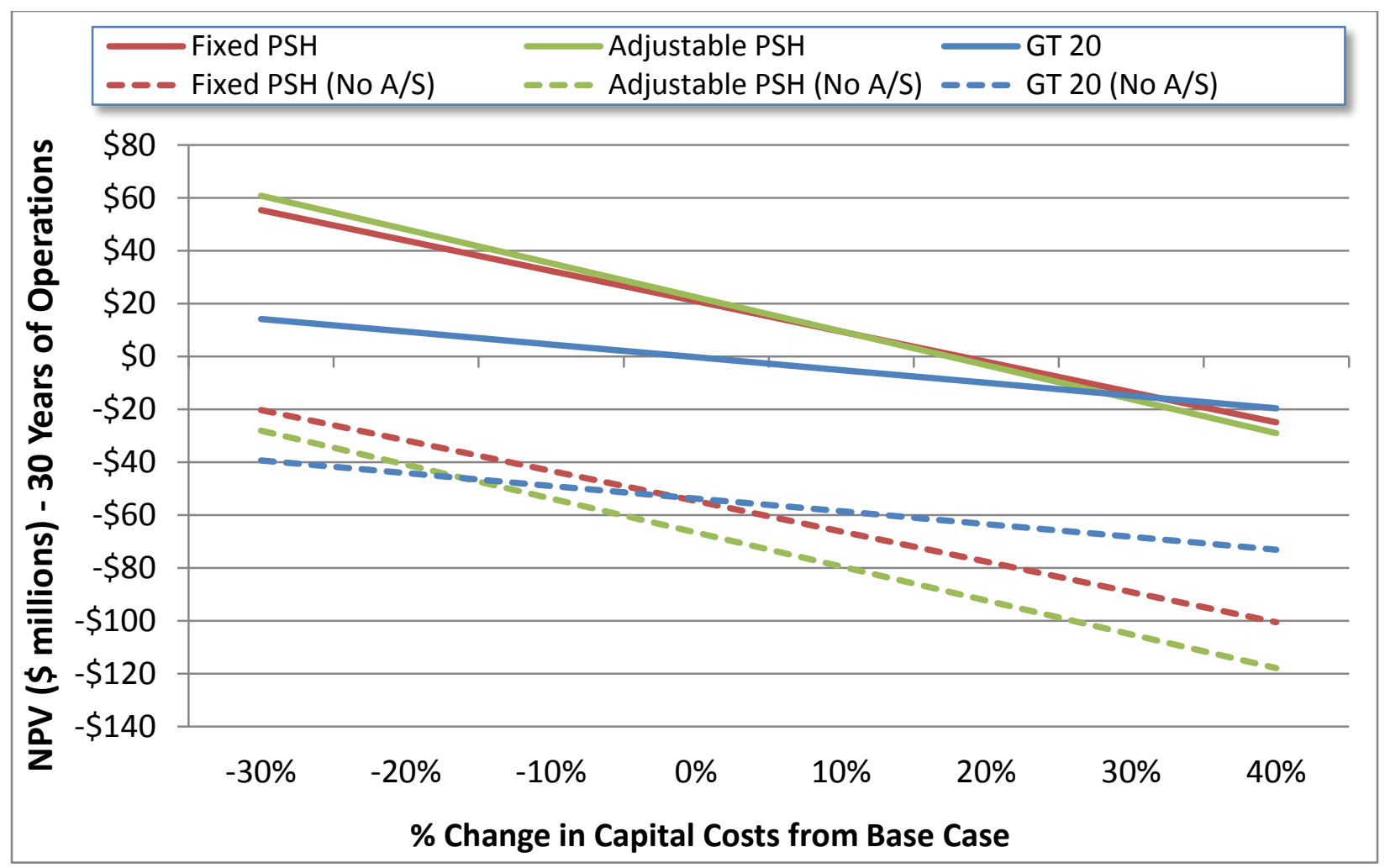

Figure 6-16 Projecting NPV as a Function of Capital Costs Based on 35\% Higher Energy and Ancillary Services Prices

highly unlikely that any future price outlook will simply parallel the rate of inflation, which was assumed in the three previous sensitivity analyses. We therefore used natural gas price projections developed for AEO 2013 (EIA 2013) shown in Figure 6-18 and assumed that both energy and A/S prices would change at the same rate over time.

Projections of energy and ancillary prices could, of course, be based on more sophisticated methodologies that incorporate many factors (such as load growth, plant retirement, portfolios of new construction, the interplay among energy and ancillary prices, variable resource locations and geographical diversity, market rules and market mitigation, and the transmission system topology). We also recognize that the probability of any of the EIA outlooks and associated prices coming into fruition is infinitesimal. However, our analysis does provide a broader range of potential outcomes that leverages modeling results from EIA extensive projection analyses. It also provides a NPV comparison among a set of capacity expansion technologies, all of which use the same set of assumptions. Identical to the previous examples, revenue and energy cost estimates derived from the CHEERS model for the first operating year were escalated each year for 30 years at an annual inflation rate of $2.35 \%$ for each plant type and then discounted at an annual rate of $4.28 \%$. 


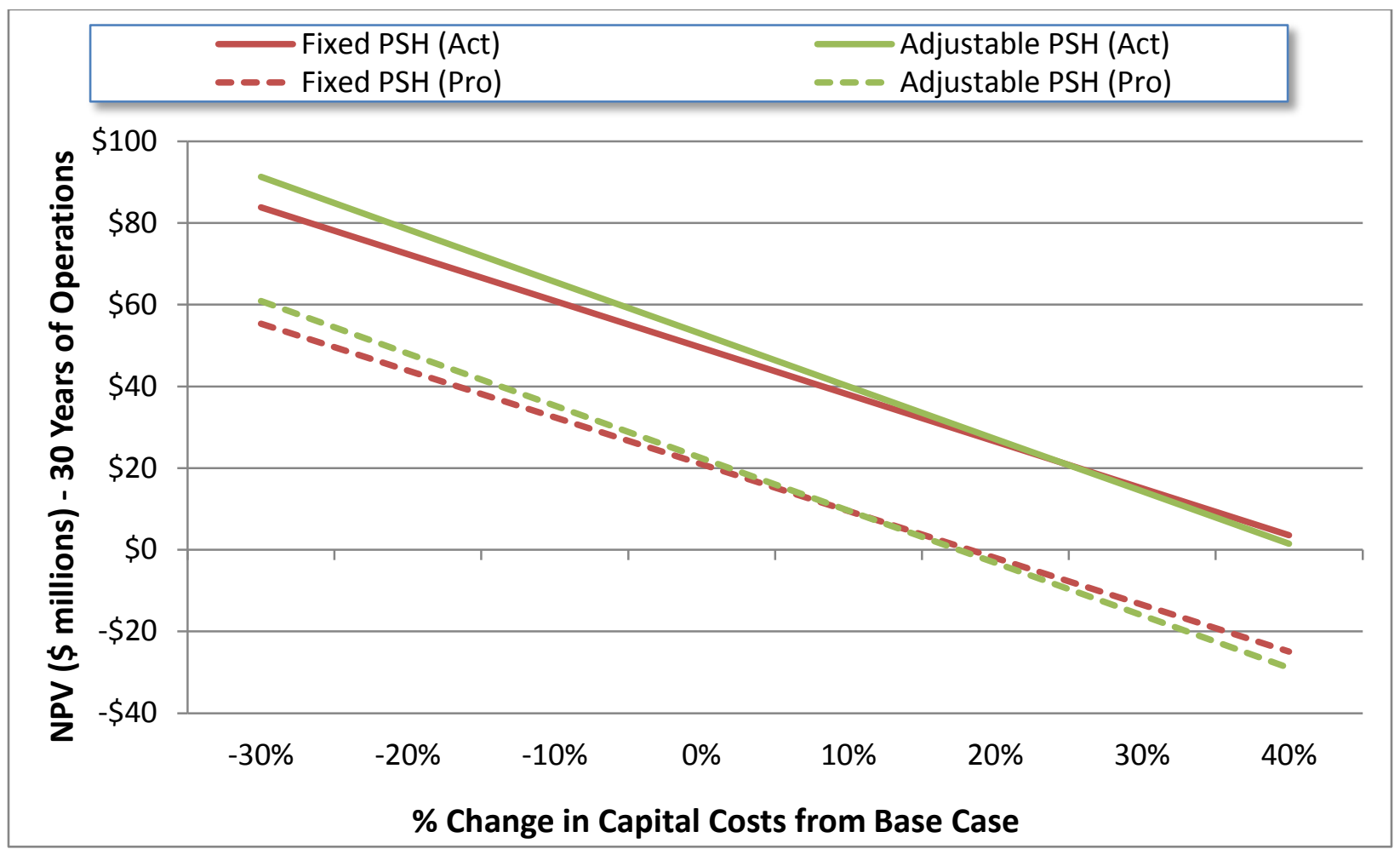

Figure 6-17 Projecting NPV as a Function of Capital Costs Based on 35\% Higher Energy and Ancillary Services Prices: Comparison Using Perfect (Act) versus Imperfect (Pro) Forecasts

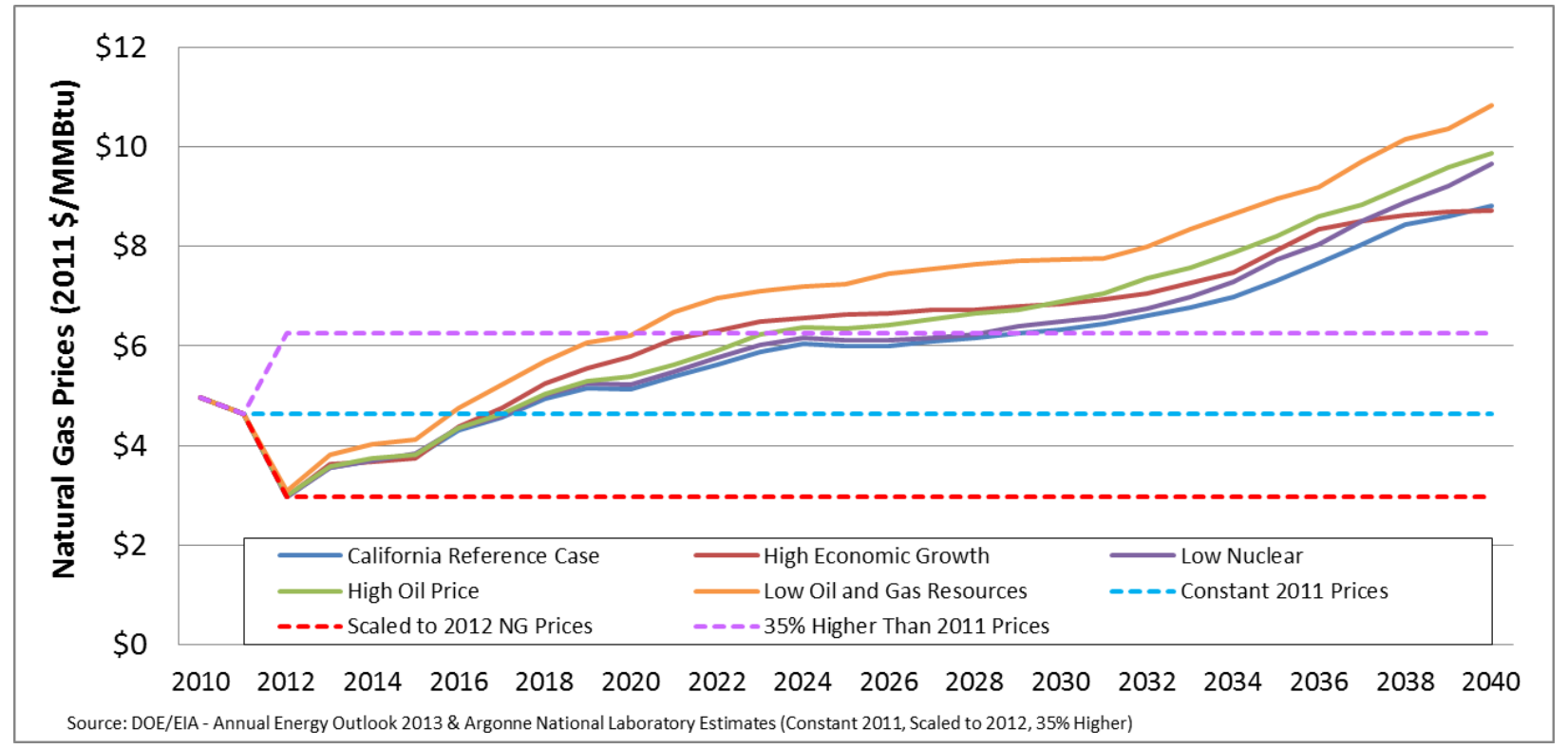

Figure 6-18 EIA 2013 AEO Natural Gas Price Projections 


\section{Capital Cost Scenarios (California Reference Natural Gas Case)}

Based on the scenarios evaluated above, the California reference case developed for AEO 2013 (EIA 2013) was adopted as the base case pricing outlook. Here we show the sensitivity of NPV computations to capital cost and loan interest cost scenarios. Figure 6-19 shows that after the California reference case natural gas pricing outlook is applied, changes in capital costs resulted in positive NPVs for PSH and GT20 plants when they participated in the A/S market. AS PSH plants yielded the highest NPVs, followed closely by FS PSH plants and then by GT20 plants. Without A/S, only the FS PSH technology had a positive return when capital costs were $30 \%$ lower than the base. Figure 6-20 illustrates the potential upside from effectively forecasting pricing and PSH operating responses. A perfect forecast would yield an additional \$25 million to \$45 million in terms of NPV.

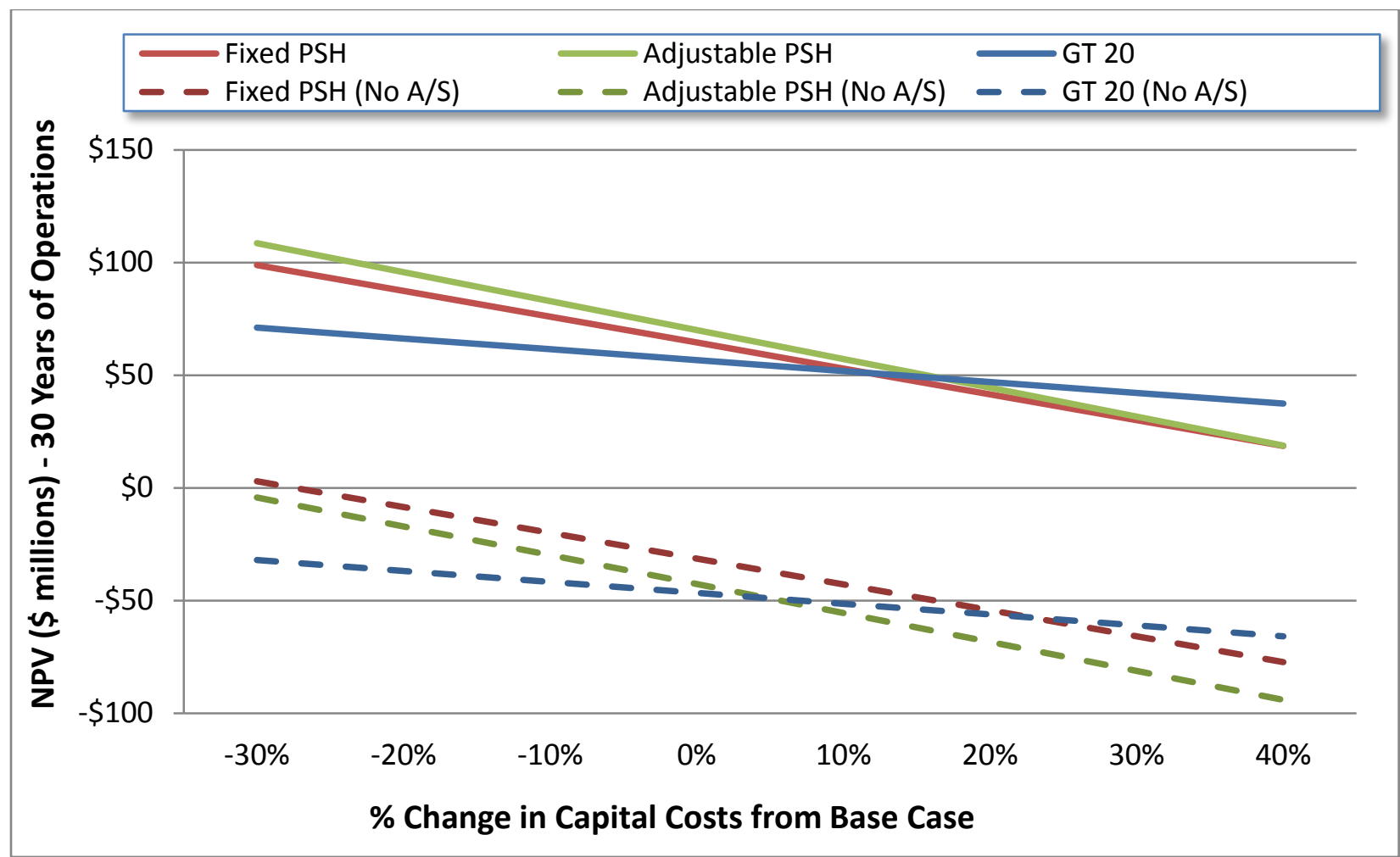

Figure 6-19 Projecting NPV as a Function of Capital Costs Based on California AEO Baseline Projection

\section{Testing Impact of Changes in Loan Interest Rates}

Changes in loan interest rates can also affect potential project returns. Tests of changes in interest rates charged on loans borrowed to fund project costs produced results that mirrored other scenarios. As shown in Figure 6-21, higher loan interest rates predictably lowered project returns for all technology types due to higher debt service costs and related decreases in annual free cash flows. Project returns as measured by NPVs were highest for AS PSH plants under different interest rate scenarios, followed by FS PSH plants and GT/20 plants. 


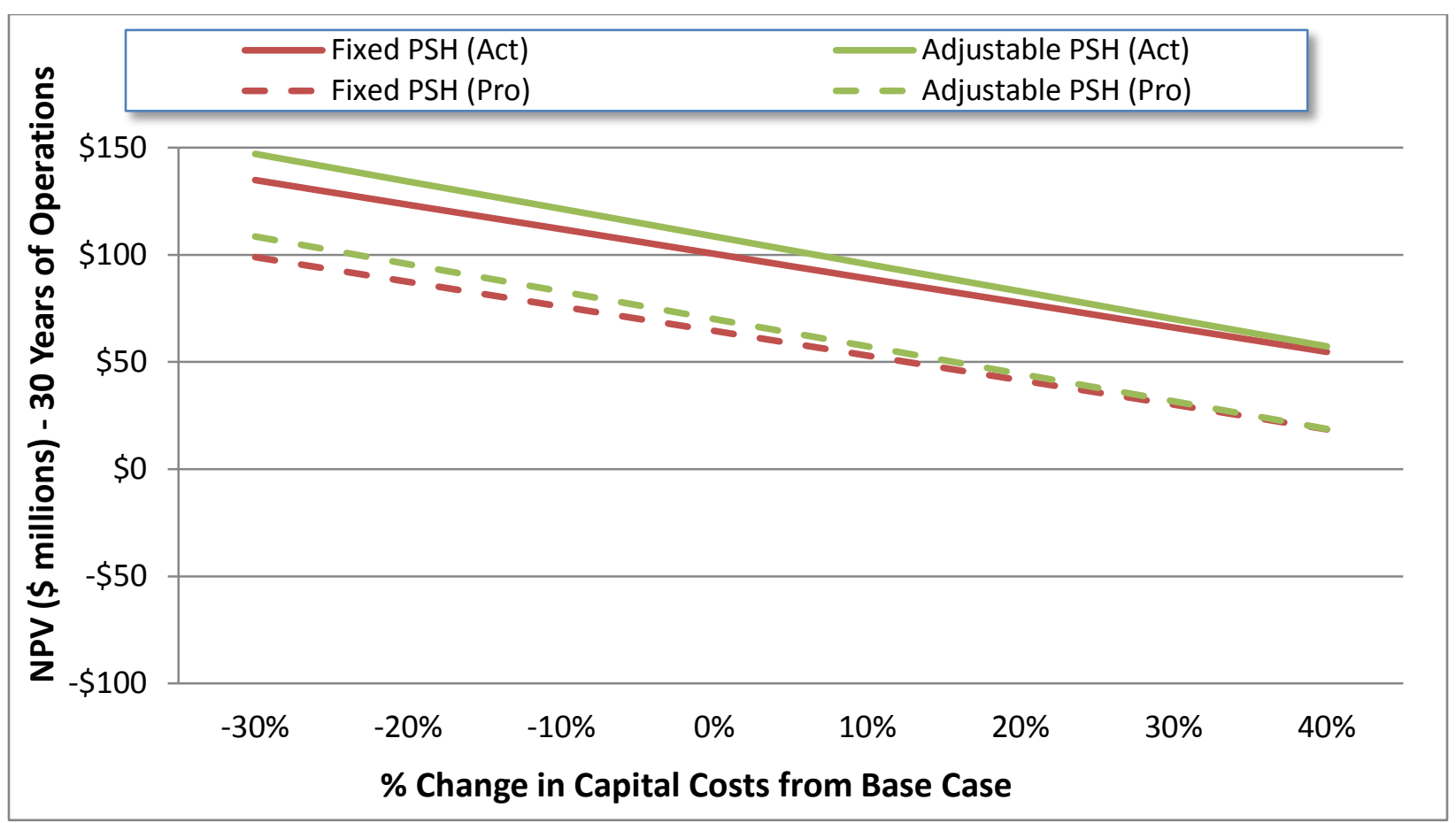

Figure 6-20 Projecting NPV as a Function of Capital Costs Based on California AEO Baseline Projection: Comparison Using Perfect (Act) versus Imperfect (Pro) Forecasts

\section{Sensitivity of NPVs to Price Vectors}

As stated previously, future prices are uncertain, and the assumption that all market prices will follow natural gas prices is very simplistic. Therefore, we performed a sensitivity analysis on assumed A/S prices. Figure 6-22 shows the NPV for a range of A/S price multipliers for the California AEO baseline scenario, with both the capital and the interest rate held at base assumption levels. It shows that with forecast uncertainty, both AS and FS technologies break even when A/S are roughly cut in half. At the lowest multiples, the FS technology is more profitable. However, multiples of 0.7 and greater result in higher net profits for the AS technology. With improved forecasting methodologies, the breakeven point is at a multiple of less than 0.1 for both technologies.

\section{Sensitivity of NPVs to Natural Gas Price Vectors}

Changes in fuel pricing outlooks based on scenarios from AEO 2013 (EIA 2013) (Figure 6-18) reveal a similar pattern, in which project returns, such as NPVs, are greater for AS PSH plants, followed by FS PSH plants and GT20 plants. As shown in Figures 6-23 and 6-24, NPVs for AS PSH and FS PSH plants increase as a function of a higher natural gas pricing outlook. Without $\mathrm{A} / \mathrm{S}$ revenues, only the greenhouse gas (GHG in figure) scenario yields a positive NPV. 


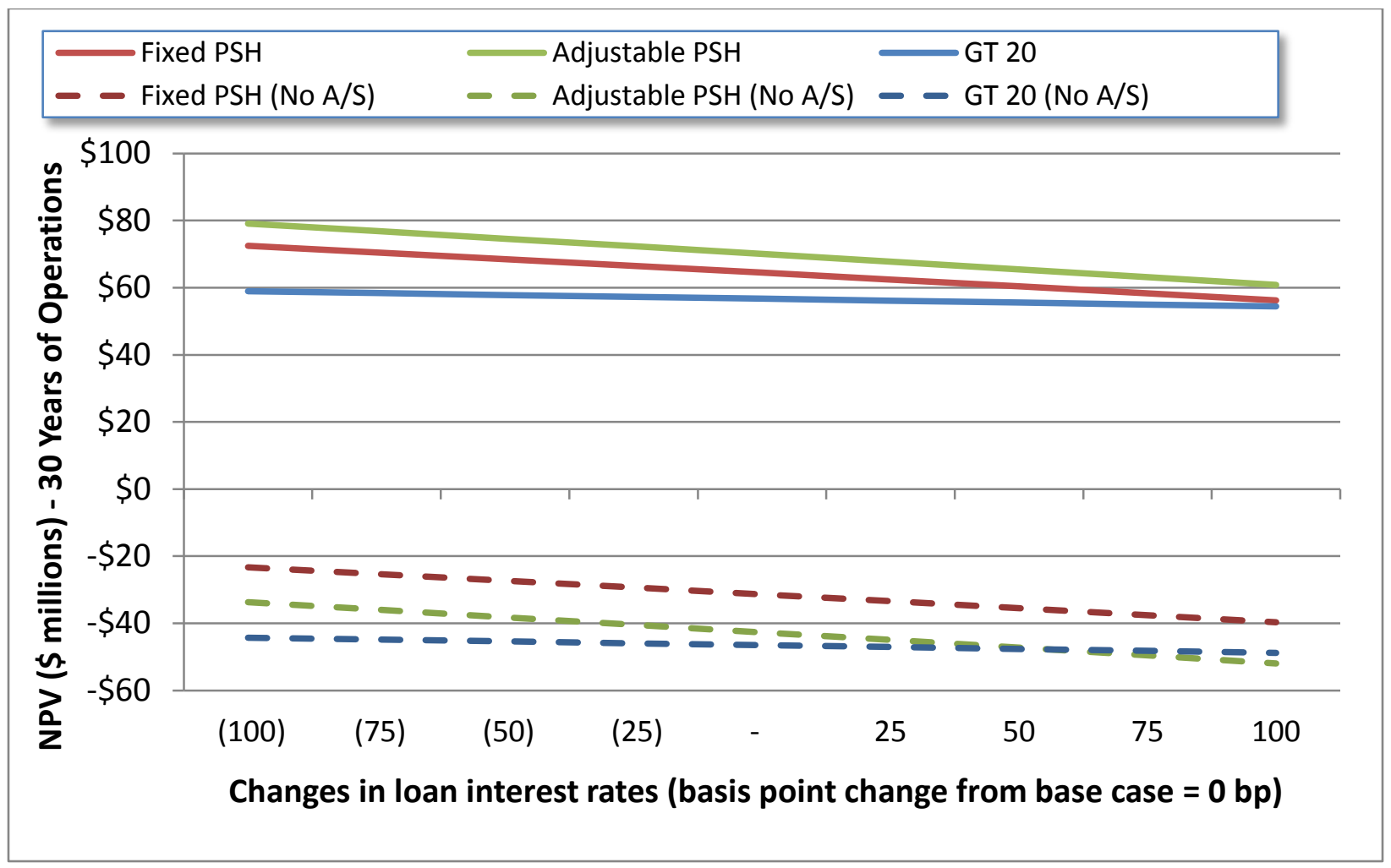

Figure 6-21 Sensitivity of Project NPV to Changes in Interest Rate Based on California AEO Baseline Projection

Figures 16-25 and 16-26 also illustrate the potential upside in NPV that would result if plant operators could perfectly forecast future pricing and respond with timely operating adjustments, producing higher NPVs for both PSH technologies under most of the pricing scenarios tested. In instances where prices were too low, resulting in negative NPVs, perfectly forecasted pricing assumptions reduced the potential impact of negative NPV returns.

\subsection{Conclusions}

The CHEERS study compared the economic performance of AS PSH, FS PSH, and GT technologies in a wide range of possible future scenarios. Results show that, in general, PSH technologies are competitive with advanced GT technologies and have higher NPVs under most, but not all, plausible future scenarios tested. While PSH technologies are associated with higher potential financial gains than are GT technologies, PSH technologies are also riskier investments that could result in potentially higher losses. The testing of capital cost variances for plants revealed that PSH technologies have greater downside risks than does GT technology if capital cost overruns are incurred. Changes in loan interest rates produced similar results, in which rising interest rates lowered project returns as higher debt service costs reduced operating profits and net cash flows. Conversely, PSH technologies have the potential for larger net profits over GT technologies if capital costs decline. 


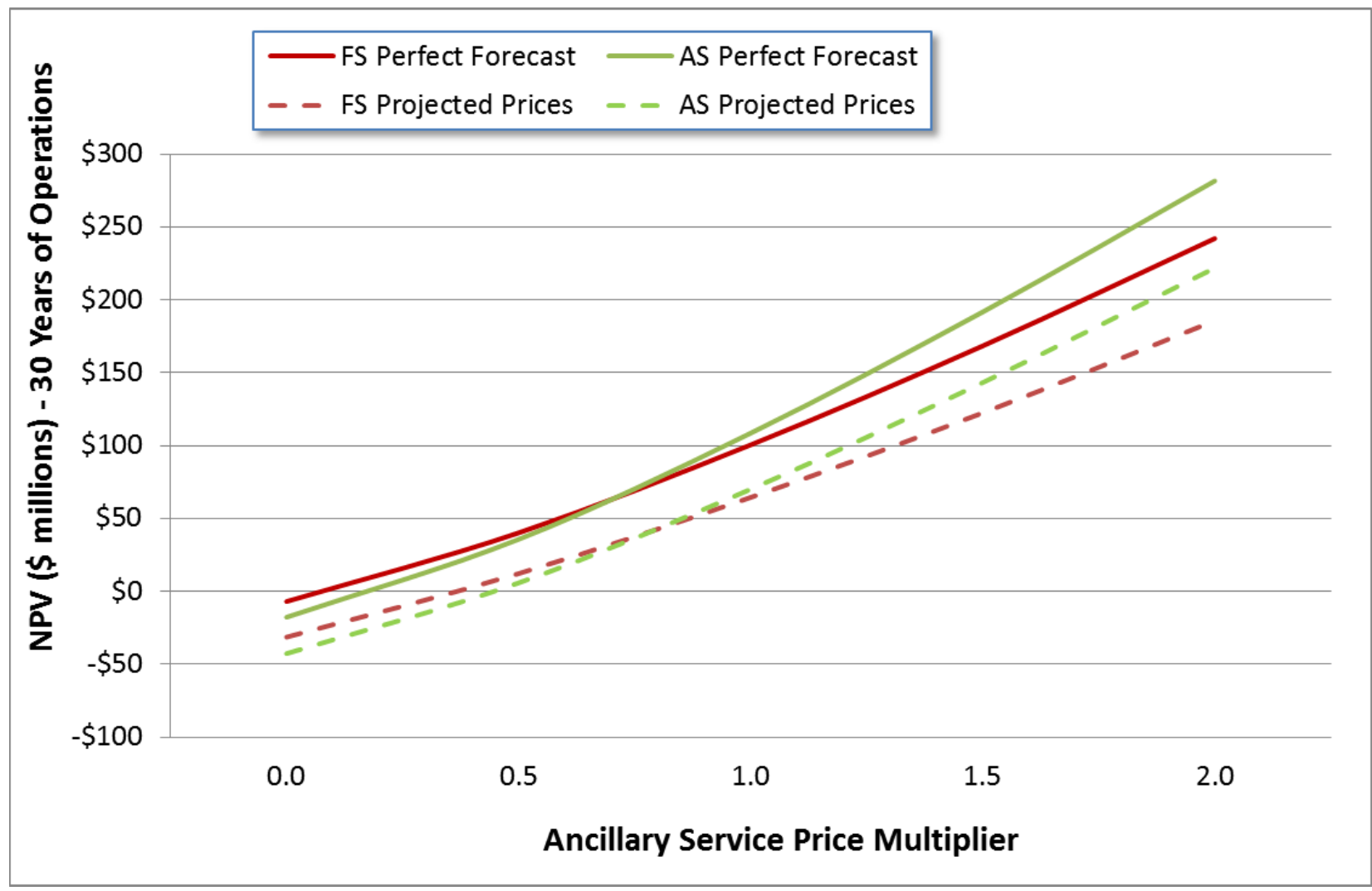

Figure 6-22 Sensitivity of Project NPV on Changes in Ancillary Services Prices Based on California AEO Baseline Projection, with Base Capital Cost and Base Interest Rate

The CHEERS results also highlight the advantage that AS PSH has over conventional FS PSH technologies, especially when market prices are high. In particular, when there are high A/S prices, the economics of AS PSH further improve over those of other technologies. Greater AS PSH revenues are due to better efficiencies, a narrower rough zone, and the ability to serve A/S in pump operating mode. Tests of hourly operations illustrate the ability of AS PSH to sell regulation services in the pumping mode, which is the key factor in offsetting higher AS PSH construction costs. When it is assumed that A/S prices are always zero (e.g., no market), there is little difference in net revenues between AS and FS technologies. However, the gap widens as the price of A/S increases, illustrating that the key advantage of AS technology is its ability to provide regulation services in pump operating mode.

Recognizing the potential sensitivity of project returns to capital costs, market conditions, and the accuracy of market price forecasts, we developed scenarios to test the implications of these factors. Results of these scenario runs highlighted four key observations. First, revenue recognition for A/S is essential to support profitable operations for PSH plants. Second, favorable (rising) natural gas prices are needed to support revenue growth and subsequent plant profitability. Third, higher project costs (such as capital costs and loan interest costs) can have a large negative impact on plant returns and result in lower NPVs over time. Lastly, DA price forecast errors can significantly erode the profitability of PSH technologies. 


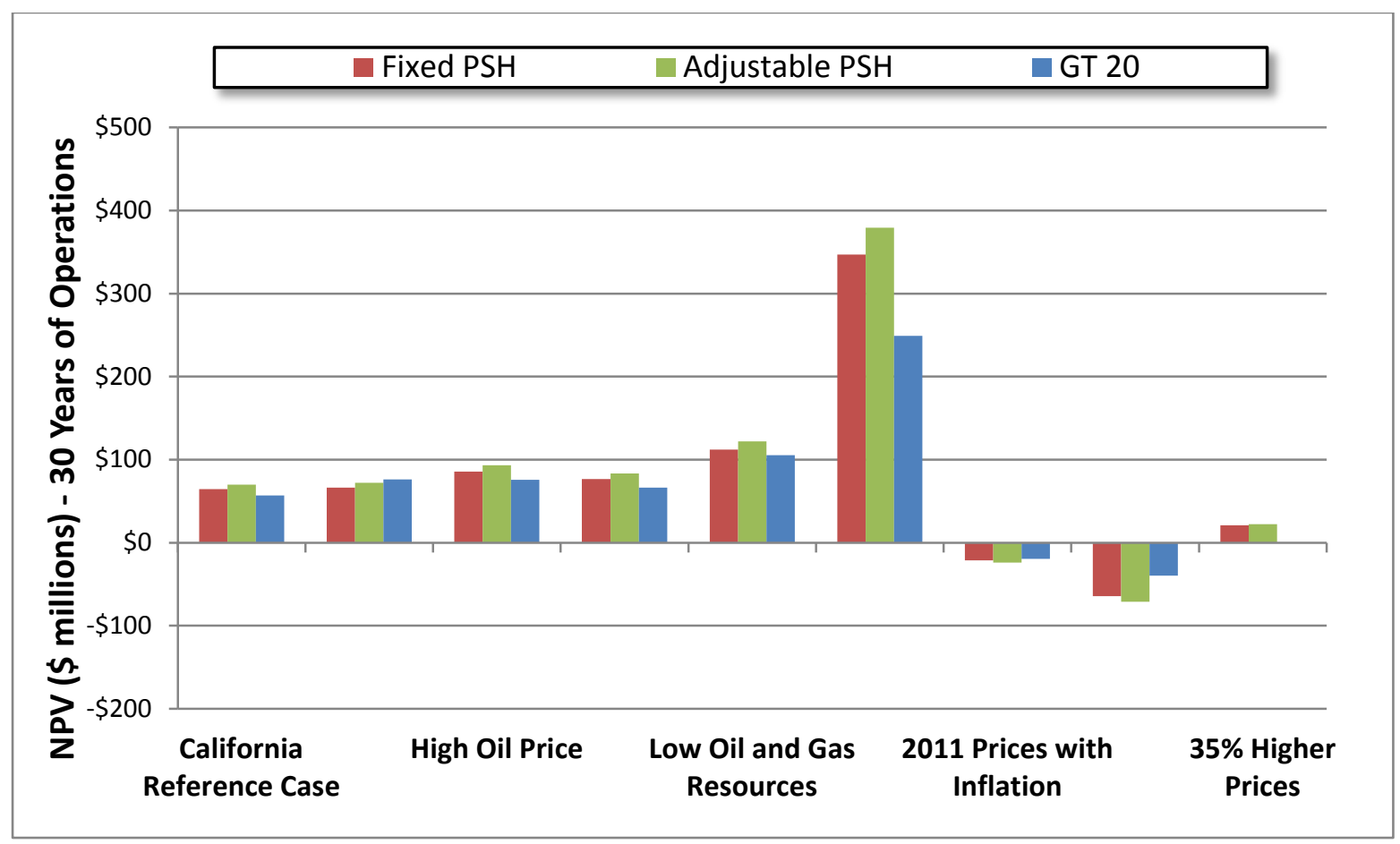

Figure 6-23 Technology NPV under Various Price Scenarios Assuming Participation in Ancillary Services Markets

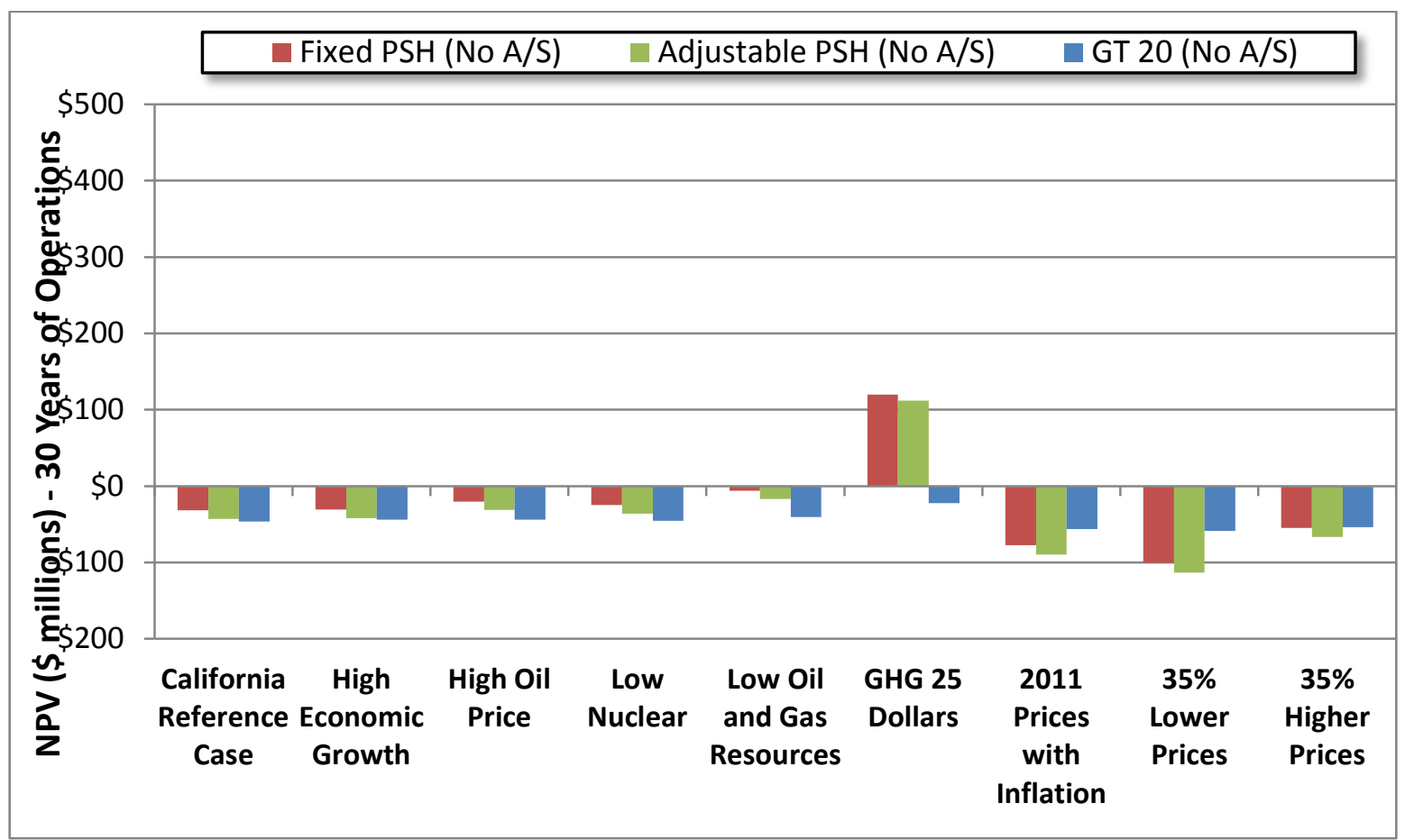

Figure 6-24 Technology NPV under Various Price Scenarios Assuming No Participation in Ancillary Services Markets 


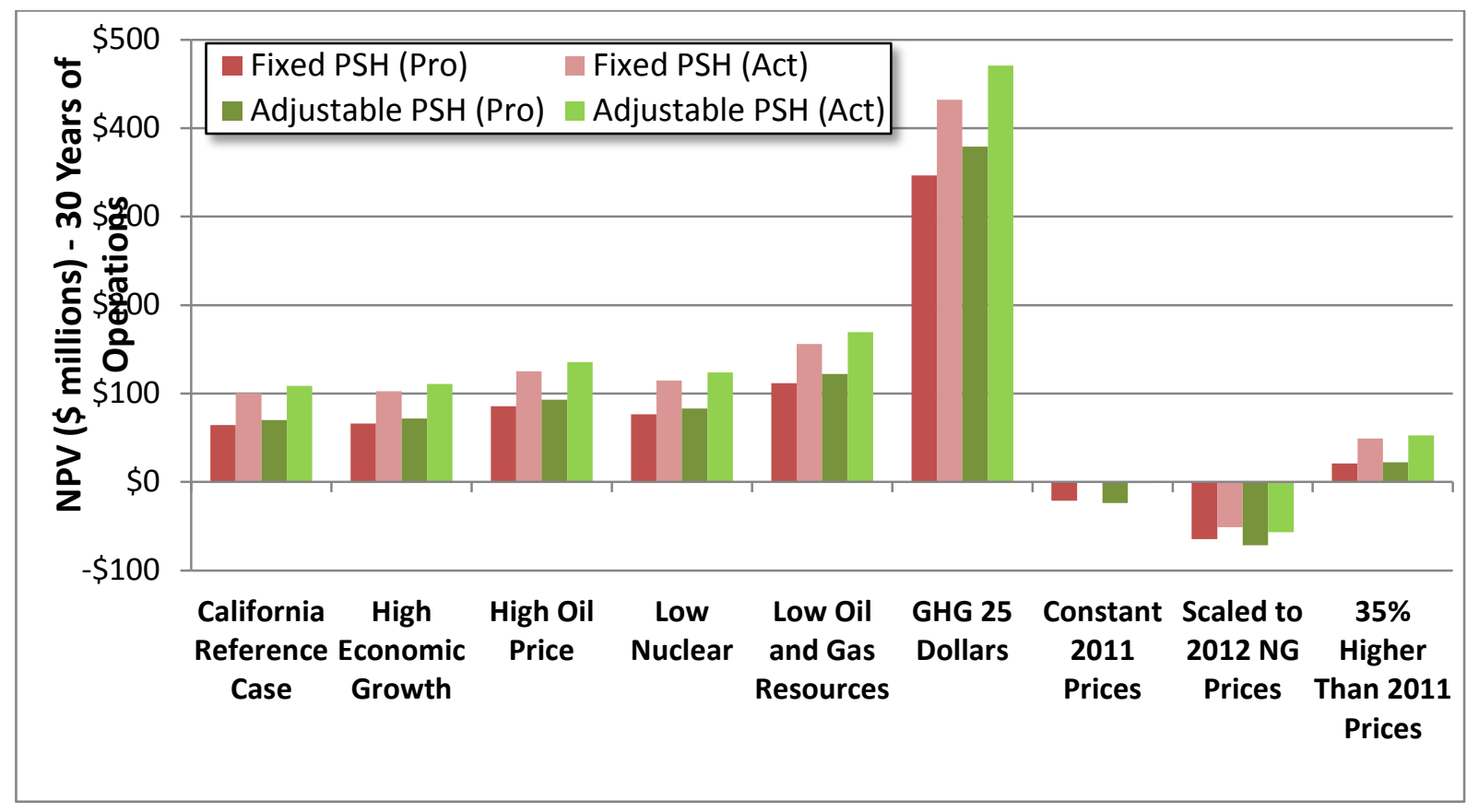

Figure 6-25 Technology NPV under Various Price Scenarios Assuming Participation in Ancillary Services Markets: Comparison Using Perfect (Act) versus Imperfect (Pro) Forecasts

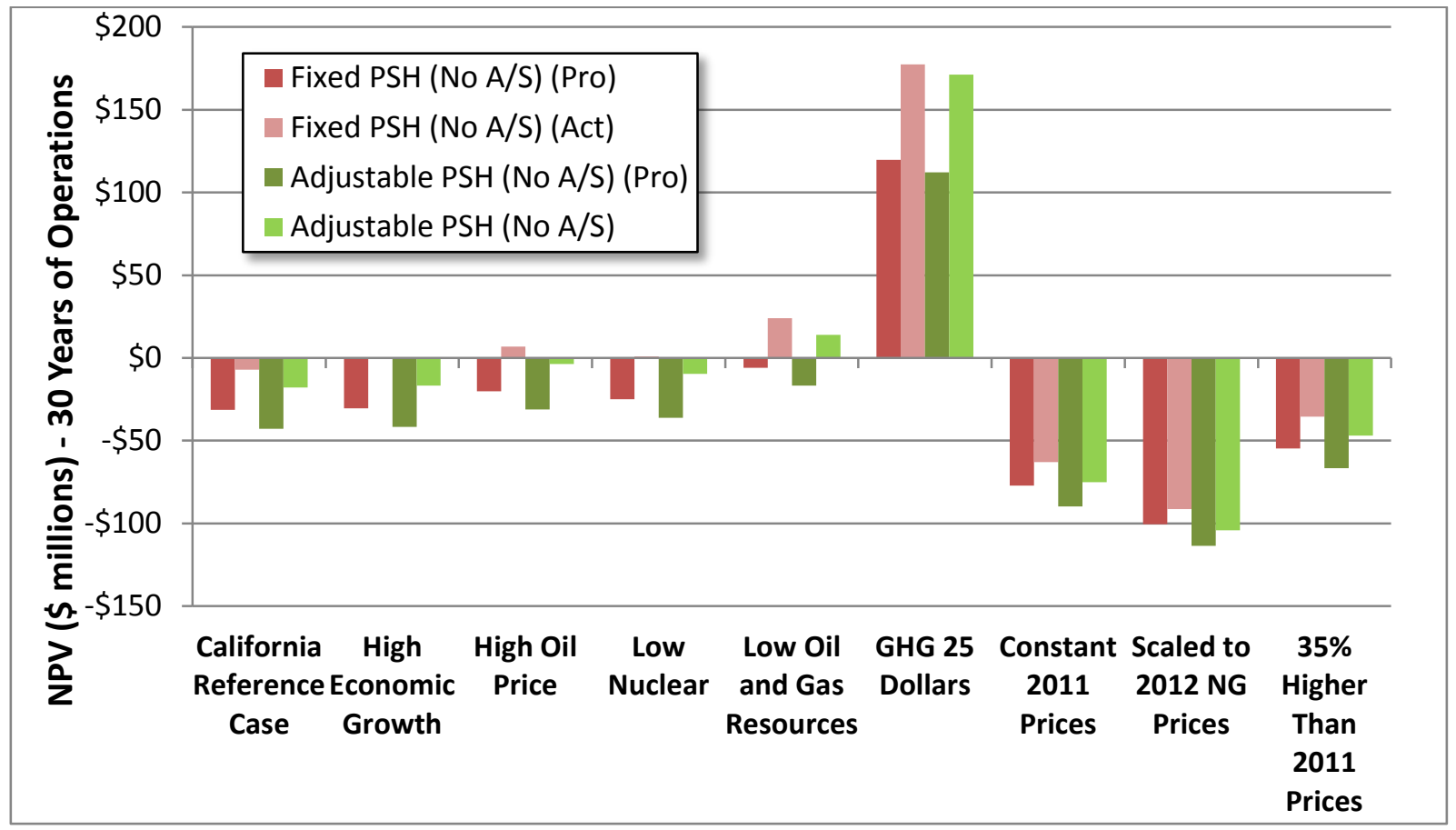

Figure 6-26 Technology NPV under Various Price Scenarios Assuming No Participation in Ancillary Services Markets: Comparison Using Perfect (Act) versus Imperfect (Pro) Forecasts 
Analyses highlight the value and importance of good mid-tem and long-term forecasts of market prices when the economics of PSH and other technologies are being evaluated.

\subsection{References}

Gasper, J., et al., 2014, Water Use Optimization Toolset Project: Development and Demonstration Phase Draft Report, ANL/EVS-14/5, Argonne National Laboratory, Argonne, Ill.

EIA (Energy Information Administration), undated, State Energy Data System, U.S. Department of Energy, http://www.eia.gov/state/seds/ accessed May 1, 2013.

EIA, 2012, Annual Energy Outlook 2012, DOE/EIA-0383(2012), U.S. Department of Energy, http://www.eia.gov/forecasts/aeo/pdf/0383(2012).pdf accessed Jun 10, 2012.

EIA, 2013, Annual Energy Outlook 2013, DOE/EIA-0383(2013), U.S. Department of Energy, http://www.eia.gov/forecasts/aeo/pdf/0383\%282013\%29.pdf accessed Feb 13, 2013. 
This page intentionally left blank. 


\section{Section}

7

\section{Value of PSH in the Power System}

PSH plants are versatile facilities that provide many benefits to the power system in which they are located. The following sections provide a qualitative and quantitative assessment of PSH benefits.

\subsection{PSH Services and Contributions}

Table 7-1 lists key PSH services and contributions, as identified by the project team. PSH plants, like all energy storage technologies, are net consumers of energy, so the amount of electricity they generate is smaller than the amount they consume for pumping. Despite that net energy loss, the energy generation of PSH plants is still very valuable because these plants can time-shift large quantities of energy based on price differentials between the peak and off-peak hours or store and time-shift excess renewable energy generation for later use. In addition to generating energy, PSH plants provide a variety of A/S necessary for power system operation, such as operating reserves, and they support the transmission grid.

While some of the PSH services need to be scheduled and coordinated with grid operators, most of the contributions listed in Table 7-1 are inherently provided by PSH plants during their normal operation. Typical services that need to be scheduled and coordinated by the operator include energy generation/pumping levels and the provision of operating reserves, such as regulation and spinning reserves. Therefore, the optimization of PSH operation typically focuses on the coordination of energy and reserve services.

The value of PSH services and contributions to the grid depends on many factors, including the technology's location in the system, capacity mix of other generating technologies, level of renewable energy penetration within the power system, shape of consumer electricity demand (the load profile), and topology and available capacity of the transmission network. For example, two identical PSH plants in different locations may have very different values for the power system. This is true for both regulated utilities and restructured market environments. A PSH plant located in a "load pocket" has a much higher value than one located in an area with a significant amount of flexible generating capacity and a strong transmission network. Similarly, in an electricity market environment, two similar PSH plants located in different electricity markets may receive very different revenues for their services, depending on the respective market clearing prices for these services in each market. Sometimes even the differences among different zones within the same market are great. These differences indicate that the valuation of PSH projects is very site-specific and depends heavily on the conditions within a particular power system or electricity market. For this reason, the analysis performed in this study did not attempt to evaluate any specific PSH project, rather it assessed the value of aggregated PSH 
Table 7-1 PSH Services and Contributions

\begin{tabular}{|l|l|}
\hline No. & \multicolumn{1}{|c|}{ PSH Contribution } \\
\hline $\mathbf{1}$ & Inertial response \\
\hline $\mathbf{2}$ & Governor response, frequency response, or primary frequency control \\
\hline $\mathbf{3}$ & Frequency regulation, regulation reserve, or secondary frequency control \\
\hline $\mathbf{4}$ & Flexibility reserve \\
\hline $\mathbf{5}$ & Contingency spinning reserve \\
\hline $\mathbf{6}$ & Contingency non-spinning reserve \\
\hline $\mathbf{7}$ & Replacement/supplemental reserve \\
\hline $\mathbf{8}$ & Load following \\
\hline $\mathbf{9}$ & Load leveling/energy arbitrage \\
\hline $\mathbf{1 0}$ & Generating capacity \\
\hline $\mathbf{1 1}$ & Reduced environmental emissions \\
\hline $\mathbf{1 2}$ & Integration of variable energy resources (VERs) \\
\hline $\mathbf{1 3}$ & Reduced cycling and ramping of thermal units \\
\hline $\mathbf{1 4}$ & Other portfolio effects \\
\hline $\mathbf{1 5}$ & Reduced transmission congestion \\
\hline $\mathbf{1 6}$ & Transmission deferral \\
\hline $\mathbf{1 7}$ & Voltage support \\
\hline $\mathbf{1 8}$ & Improved dynamic stability \\
\hline $\mathbf{1 9}$ & Black-start capability \\
\hline $\mathbf{2 0}$ & Energy security \\
\hline
\end{tabular}

capacity within each of the power systems modeled during the study. The results obtained from the analysis are representative for the power systems modeled, for the assumed quantities and type of PSH capacity operating within the system, for the assumed level of renewable energy penetration, and other scenario assumptions and modeling parameters. Clearly, the value of PSH services and contributions may be different in other power systems or electricity markets, depending on their capacity mix and operating conditions and on other characteristics.

\subsection{Value of PSH Services and Contributions}

In existing electricity markets in the United States, PSH plants can obtain revenues for only a handful of services they provide to the system. In most markets, they can bid their services, and if the offers are accepted by the market operator, they receive revenue for energy generation, regulation reserve, spinning reserve, and non-spinning reserve. The provision of black-start capability is typically arranged through a long-term contract. Currently, in most existing markets, there are no established mechanisms to provide revenues for other services and contributions of PSH to the power grid. In contrast to competitive electricity markets, the traditional regulated utilities do not have established revenue streams for specific PSH services. There the system operator typically optimizes the operation of PSH plants to minimize total system production costs. Therefore, in both traditional and restructured market environments, most of the PSH services are not explicitly monetized, and since PSH plants, during their operations, typically provide multiple services at the same time, it is rather difficult to distinguish the specific value of 
certain services and contributions (e.g., inertial response, voltage support, transmission deferral, energy security). For these services, this report provides a description of the service or contribution, the benefits to the system, and the value of that service in qualitative terms. The analysis includes primarily the results from the PLEXOS simulations, but it also contains insights gained from the PSS ${ }^{\circledR} E$, FESTIV, and CHEERS simulations.

\subsubsection{Inertial Response}

Inertial response describes the phenomena associated with Newton's second law of motion, expressed as $\mathrm{F}=\mathrm{m} \times$ a, or force equals mass times acceleration, to be precise. Rotating generators move with angular motion rather than linear motion, but the principle of inertia is the same. In a power system, frequency must be maintained within a narrow band around its nominal value, which is $60 \mathrm{~Hz}$ in the United States. To maintain constant frequency, the amount of mechanical power produced by the generators is closely controlled to match the power being consumed by the loads. Any imbalance causes an accelerating torque that (a) increases the speed of the rotating machines, and thus the frequency, if the total generator mechanical power is greater than the load power or (b) decreases the frequency if the total mechanical power is less than the load power. The rate at which the frequency changes depends on the mass of the rotating machines, described mathematically by their inertia.

Figure 7-1 shows a simulation of an event in which a large generator is tripped, thus creating a deficiency in mechanical power. The deficiency causes the frequency to decay at a rate that depends on the amount of the deficiency and the total system inertia. The frequency decay is arrested by the response of the governors of the remaining generators, which act to increase the mechanical power produced by their turbines or other prime movers. However, this increase in mechanical power takes time. In the example simulation shown next, the governor response was insufficient, and the second level of protection - the tripping of load (load shedding) — was required to arrest the frequency decay. Tripping of load is obviously undesirable; hence, slowing the rate of decay in frequency is desirable because it gives the governors of the remaining on-line machines time to respond. A higher system inertia increases the minimum frequency reached, called the nadir, and it reduces the need for load shedding. Note that as the system size increases, the size of individual generators compared to the total interconnection load decreases. In this case, the loss of a single machine is generally not a problem. As the system gets larger, the rate of frequency decay becomes slower, and the amount of frequency decay, the nadir, increases. For large systems such as the Eastern and Western U.S. grids, a significant change in frequency usually occurs only when events cause part of the system to become isolated from the interconnection.

Most renewable generation (except for hydroelectric generation) is connected to the grid through power electronic converters. This generation does not have a rotating inertia characteristic. Therefore, with the increasing penetration of renewable generation, the total inertia of the power system decreases, leading to concerns that frequency decay rates for power imbalance events will increase and that the frequency nadir reached for such events will be lower. This is of particular concern with regard to wind generation, which tends to be high when system load is low and is thus more likely to be a significant part of the total on-line generation. 
This situation has led to the consideration of inertial response as an A/S. With conventional rotating machines, such inertial response was inherently available due to the physics of the device. Hence generator owners were not paid for this service. Wind generator manufacturers are now offering control emulation of inertial response in their wind turbines, for example, by using some of the kinetic energy in the rotating turbines to transiently supply additional generation to arrest the initial frequency decay following a system imbalance event that causes a drop in frequency. Some system operators are now considering requiring such controls. However, at this time, we know of no system operator in the United States that is actually measuring or paying for this service.

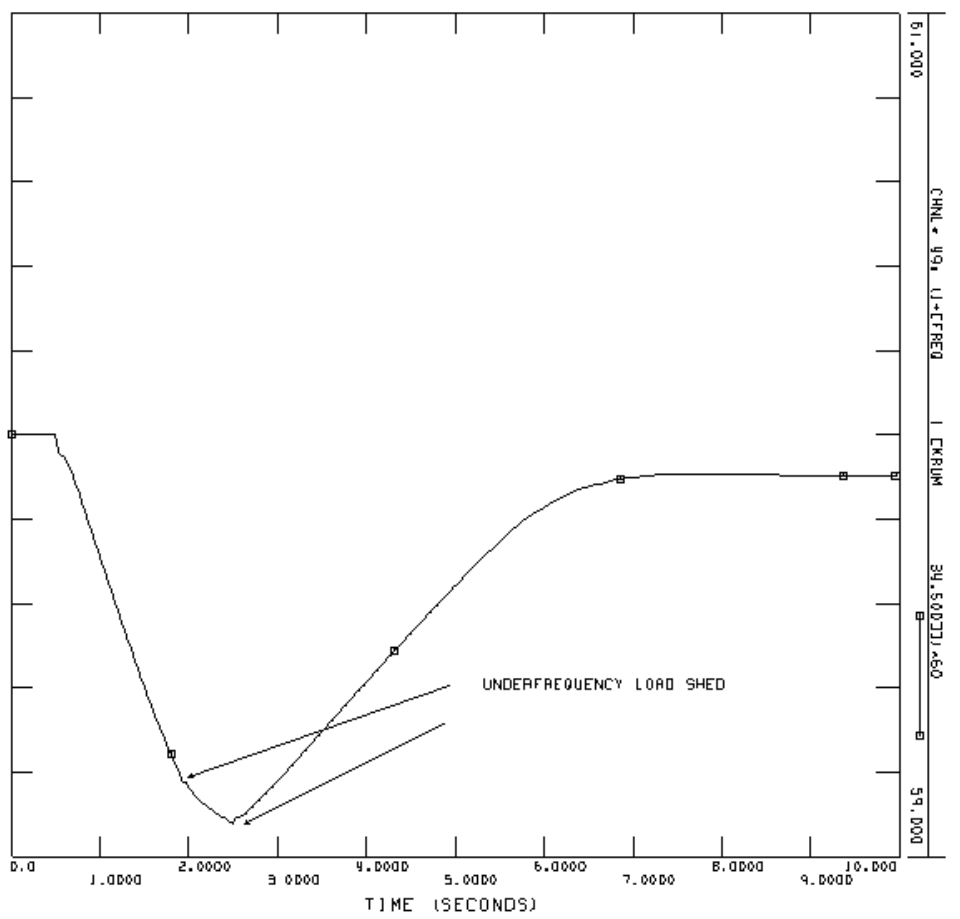

Figure 7-1 Response of System Frequency to a Loss of Generation Event

The advanced pump storage technologies have the ability to supply inertial response. The ternary units employ conventional generators and hence have characteristics similar to those of conventional generators that are similar in size. The AS units employ power electronics, so their controls and capabilities can be designed to mimic the capabilities of a conventional generator having a similar size and can also, if required, be designed to display an increased inertial response capability.

\subsubsection{Primary Frequency Control}

As noted in Section 7.2.1, an imbalance between the amount of mechanical power produced by the generators and the power being consumed by the loads will lead to a change in the speed of 
the rotating machines and thus the frequency. If the total generator mechanical power is greater than the load power, the frequency will increase, and if the total mechanical power is less than the load power, the frequency will decrease. There are two primary sets of automatic control to limit the deviation in frequency: primary frequency control and secondary frequency control.

Primary frequency control, which is often called governor control or governor response, is discussed in this section. Secondary frequency control is described in Section 7.2.3. Conventional generators (conventional steam turbine, GT, nuclear, and hydro plants) are operated with operating governors. These governors have the same overall characteristic as those shown in Figure 7-2. Speed is measured and compared to a reference, usually referred to as a load/speed reference. The error signal is supplied to the governor. Proportional control is used, with the inverse of the gain referred to as the governor droop. The speed governor and speed control mechanism control the flow of energy to the turbine - for example, by opening the control valve of a steam turbine to increase power or by opening the gates of a hydro turbine. The difference between mechanical power and electrical power produces accelerating (or decelerating) power, which results in an increase (or decrease) in speed as it is affected by the inertia of the machine.

For maintaining a stable load division between parallel units, the governors are provided with a speed/droop characteristic. For example, a 5\% governor droop or regulation means that a 5\% frequency deviation causes a $100 \%$ change in the valve position or power output. Figure 7-3 illustrates this concept for two units.

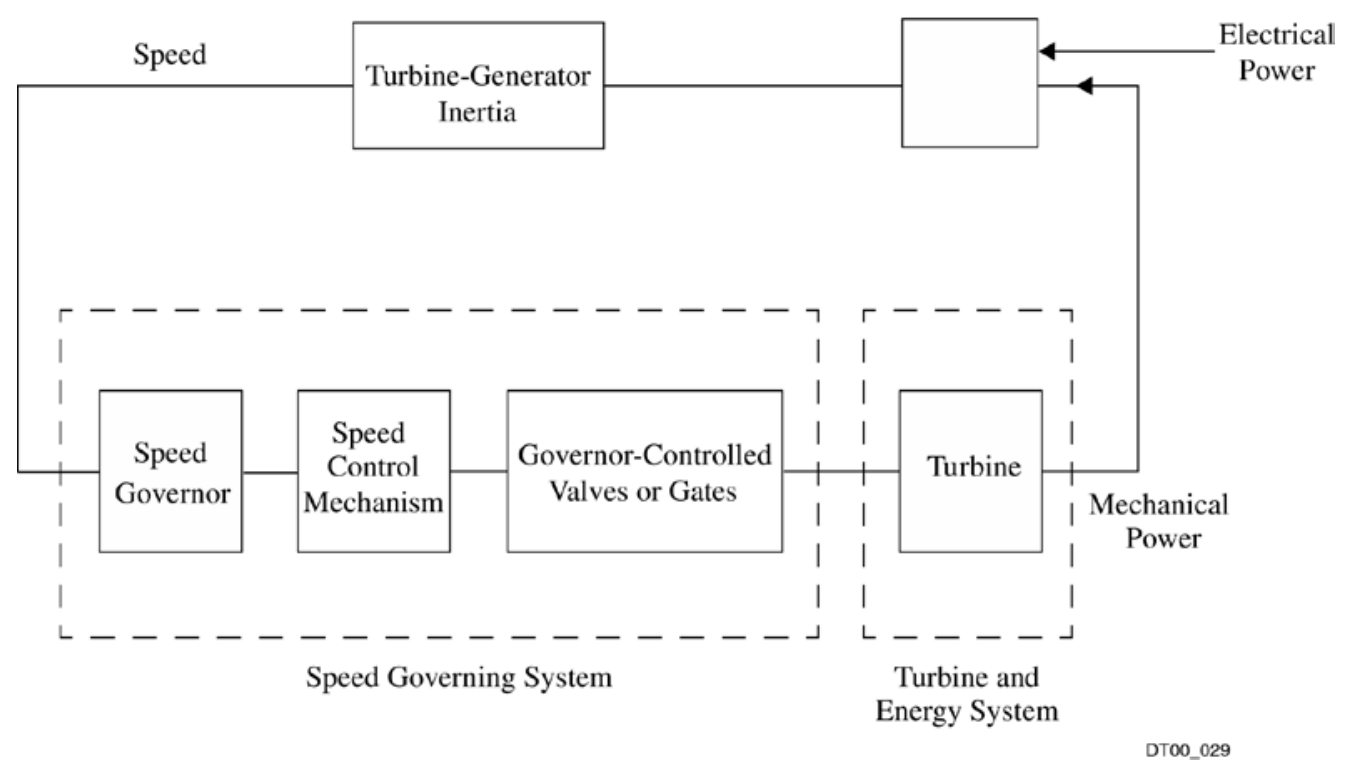

Figure 7-2 Speed Governor and Turbine in Relationship to Generator 


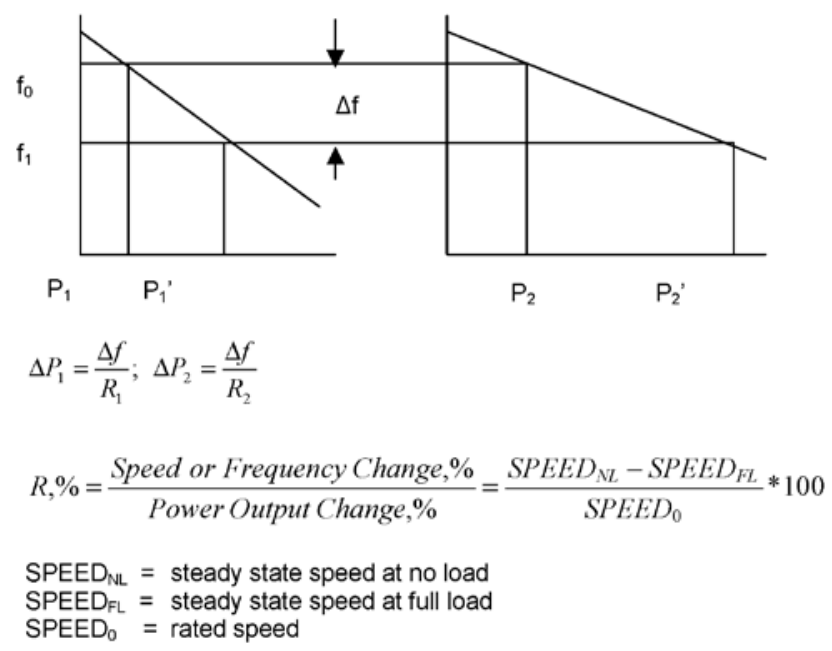

Figure 7-3 Speed/Droop Characteristic

Such control is a requirement of the generators in U.S. systems. However, there is concern that the amount of primary frequency regulation is decreasing. The two primary causes for this are the increasing number of units operating at their full output limits (and hence having no ability to increase in the event of a drop in frequency) and the increasing amount of renewable generation. As noted, most renewable generation (e.g., wind) is connected to the grid through power electronic converters. Renewable generation is also typically operated at its maximum output and thus does not have the ability to increase in the event of a drop in frequency.

In general, primary frequency control has been a required service and not a market-based one. This could change if concerns about the amount of available primary frequency regulation continue.

The advanced pumped storage technologies have the ability to supply primary frequency regulation. Their ability to supply such services in both the pumping and generating mode of operation is superior to that of conventional pumped storage units, which supply primary frequency regulation only when in generating mode.

\subsubsection{Operating Reserves}

Electric power systems, in their operation, typically maintain several types of operating reserves, such as regulation, contingency, replacement/supplemental, load following, and flexibility reserves. Operating reserves are an important part of the A/S that are necessary for the operation of a power system.

The purpose of the regulation reserve, also known as frequency regulation or secondary frequency control, is to adjust the power output of generating units in response to frequency deviations. Regulation reserve can be provided by generating units that participate in AGC, which is an automatic form of secondary frequency control that sends signals to generating units every 4 to 6 sec to adjust their power output in order to oppose small deviations in system 
frequency. Regulation actions can be both up and down, depending on whether the power needs to be injected or removed from the system to correct the frequency.

Contingency reserve provides a rapid response (typically within $10 \mathrm{~min}$ ) to system contingencies, such as the outages of generation units or transmission lines. Contingency reserve can be provided by (1) generating units that are synchronized to the grid but that operate at lower than full capacity (spinning reserve) or by (2) quick-start units (non-spinning reserve). Certain demand response actions, such as a controlled reduction in load that can be achieved within 10 min, can also serve as contingency reserve.

The replacement or supplemental reserve is provided by standby generators (or reductions in load), and it serves to (a) replace the generating capacity on outage after the contingency event and (b) restore contingency reserves to their normal operating values.

Load following reserve increases or decreases the power output of generating units in order to follow longer-term (hourly) changes in electricity demand. Similarly, because of the increasing share of variable renewable resources in power systems, the so-called flexibility reserves currently are introduced to compensate for the variability and uncertainty of VERs and to correct BA exchanges (reduce energy imbalances).

Detailed PLEXOS simulation results that quantify PSH provisions of different operating reserves, as well as the system requirements for these reserves, are presented in Section 4 (Tables 4-10 and 4-11 for WI simulations, Tables 4-22 and 4-23 for California simulations, and Tables 4-39 and 4-40 for SMUD simulations). The results are presented for both the Base and High Wind renewable energy scenarios. Considering the fact that the combined capacity of FS and AS PSH plants will represent less than 3\% of the total WI system capacity in 2022, one can see that PSH plants provide a significant amount of operating reserves to the system, especially in cases when both FS and AS PSH plants operate in the system.

Figures 7-4 and 7-5 illustrate the contributions of PSH plants to the operating reserves of the WI and California power systems in 2022, under the Base and High Wind renewable energy scenarios. Note that PSH contributions to operating reserves increase significantly with the addition of AS PSH plants to the system.

There is a significant increase for the regulation-down and flexibility-down reserves, because the AS PSH can provide these services in the pumping mode of operation as well. These reserves are particularly needed during the times when there is little flexibility in the power system. An example is during the night, when electricity demand is low and mostly base-load generating units are operating with their power outputs at or near their minimum operating capacity. Under such conditions, there may not be enough flexible capacity in the system to be used to compensate for large variations in wind generation. Rapid increases in wind generation may pose a particular challenge, because conventional generating units may not be able to reduce their power output if they are already operating at their minimum capacity, and some units may need to be shut down. On the other hand, the demand response may also be limited during the night, especially because the action would require an increase in electricity consumption to 


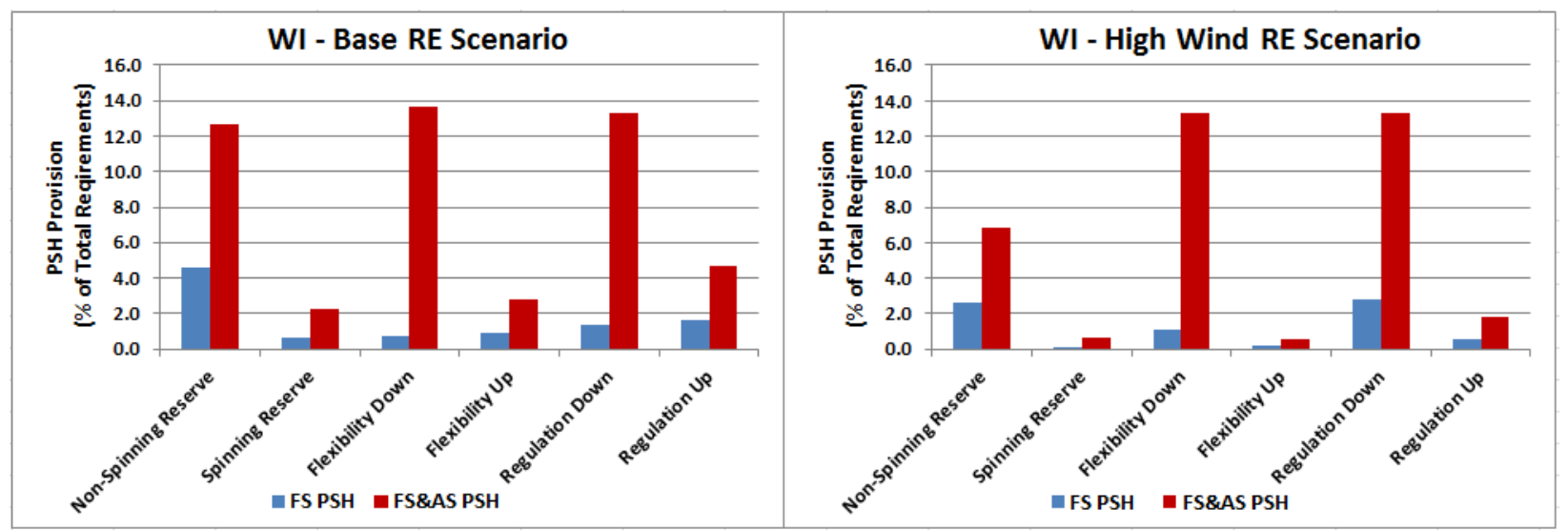

Figure 7-4 PSH Contributions to WI Operating Reserves in 2022
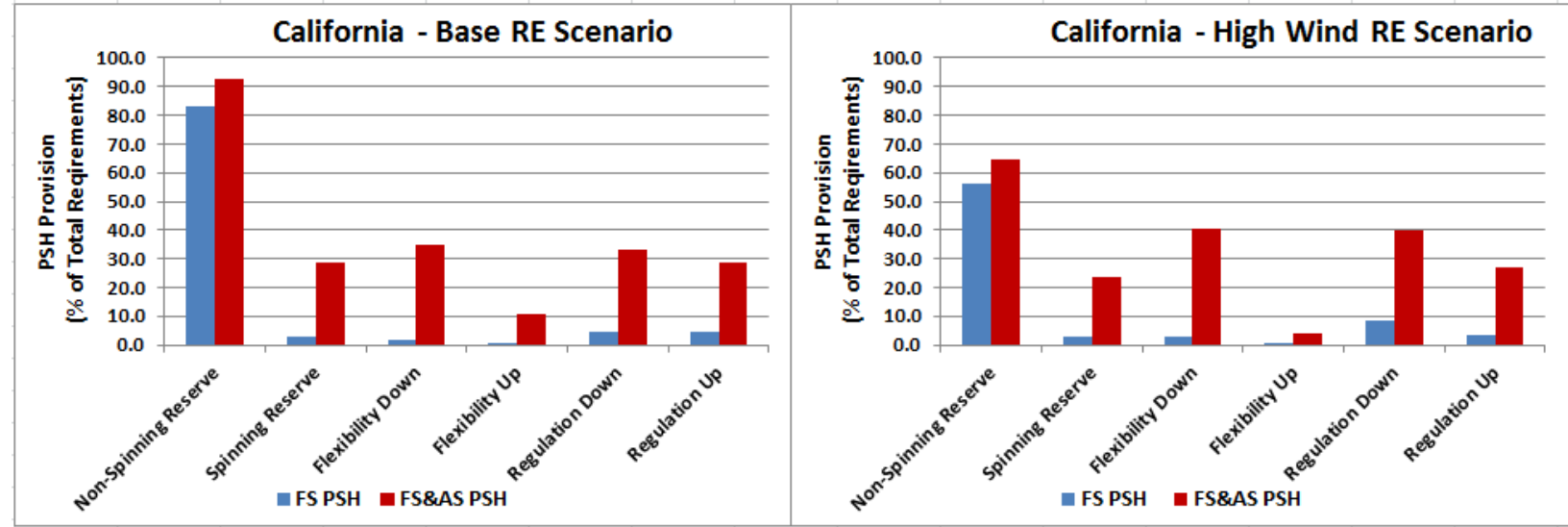

Figure 7-5 PSH Contributions to California Operating Reserves in 2022

accommodate the increase in wind generation. Under such circumstances, the variable pumping capabilities of AS PSH plants can give the system the flexibility needed to accommodate larger quantities of wind generation, reduce curtailments, and avoid shutdowns of conventional generating units.

Tables 4-32 through 4-35 in Section 4 show the monetary value of PSH contributions to operating reserves in California in 2022. PLEXOS simulations for California were performed by using a market-based approach that allowed for individual pricing and revenue analysis of A/S. Based on the PLEXOS simulations of the California system in 2022, Table 7-2 summarizes annual revenues of PSH plants for the provisions of operating reserves. 
Table 7-2 PSH Revenues for Provisions of Operating Reserves in California in 2022

\begin{tabular}{|c|c|c|c|c|}
\hline \multirow[b]{2}{*}{ Operating Reserve } & \multicolumn{2}{|c|}{ Base Renewable Scenario } & \multicolumn{2}{|c|}{$\begin{array}{l}\text { High Wind Renewable } \\
\text { Scenario }\end{array}$} \\
\hline & $\begin{array}{c}\text { FS PSH } \\
(\$ 1,000)\end{array}$ & $\begin{array}{c}\text { FS \& AS PSH } \\
(\$ 1,000)\end{array}$ & $\begin{array}{c}\text { FS PSH } \\
(\$ 1,000)\end{array}$ & $\begin{array}{c}\text { FS \& AS PSF } \\
(\$ 1,000)\end{array}$ \\
\hline Non-spinning reserve & 7,557 & 8,563 & 5,246 & 6,184 \\
\hline Spinning reserve & 1,218 & 8,588 & 1,515 & 6,208 \\
\hline Flexibility down & 389 & 5,728 & 1,626 & 14,934 \\
\hline Flexibility up & 43 & 731 & 80 & 412 \\
\hline Regulation down & 4,562 & 20,360 & 19,511 & 49,885 \\
\hline Regulation up & 4,436 & 7,935 & 4,144 & 8,528 \\
\hline Total & 18,205 & 51,905 & 32,122 & 86,151 \\
\hline
\end{tabular}

By taking into account the provisions of operating reserves by PSH in 2022, expressed through capacity (MW) provided for each reserve service in each hour of the year, the average hourly monetary values ( $\$ / \mathrm{MWh}$ ) of different types of operating reserves in 2022 can be calculated (Table 7-3). Note that regulation down is the highest value service, followed by regulation up and flexibility down. Non-spinning reserve is the lowest value service, averaging only about \$1/MWh. When the calculated values of these reserve services are used as proxies for their market prices, the prices of different operating reserves are higher when only FS PSH plants operate in the system, and lower when both FS and AS PSH plants operate. This illustrates the impact of AS PSH capacity, which offers a significant additional ability to provide system reserves, thus affecting the prices for these reserves in the market.

Table 7-3 Average Hourly Prices of Operating Reserves in California in 2022

\begin{tabular}{|l|c|c|c|c|}
\hline \multirow{2}{*}{\begin{tabular}{|l} 
Operating Reserve \\
\cline { 2 - 5 }
\end{tabular}} & \multicolumn{2}{|c|}{$\begin{array}{c}\text { High Wind Renewable } \\
\text { Scenario }\end{array}$} \\
\cline { 2 - 5 } & $\begin{array}{c}\text { FS PSH } \\
\text { (\$MWh) }\end{array}$ & $\begin{array}{c}\text { FS \& AS PSH } \\
\text { (\$/MWh) }\end{array}$ & $\begin{array}{c}\text { FS PSH } \\
\text { (\$/MWh) }\end{array}$ & $\begin{array}{c}\text { FS \& AS PSH } \\
\text { (\$/MWh) }\end{array}$ \\
\hline Non-spinning reserve & 1.07 & 1.08 & 1.10 & 1.13 \\
\hline Spinning reserve & 5.44 & 3.49 & 6.13 & 3.07 \\
\hline Flexibility down & 8.28 & 5.22 & 11.53 & 7.72 \\
\hline Flexibility up & 3.31 & 2.14 & 3.08 & 2.06 \\
\hline Regulation down & 26.68 & 16.11 & 51.75 & 28.33 \\
\hline Regulation up & 27.05 & 7.16 & 28.78 & 7.10 \\
\hline
\end{tabular}

The revenues of PSH plants for the provisions of operating reserves can be also expressed per kilowatt of PSH capacity. Table 7-4 shows that the average annual revenues are highest for the provisions of regulation-down service. 
Table 7-4 Average Annual PSH Revenues for Operating Reserves in California in 2022

\begin{tabular}{|c|c|c|c|c|}
\hline \multirow[b]{2}{*}{ Operating Reserve } & \multicolumn{2}{|c|}{ Base Renewable Scenario } & \multicolumn{2}{|c|}{$\begin{array}{l}\text { High Wind Renewable } \\
\text { Scenario }\end{array}$} \\
\hline & $\begin{array}{c}\text { FS PSH } \\
(\$ / \mathrm{kW}-\mathrm{yr})\end{array}$ & $\begin{array}{c}\text { FS \& AS PSH } \\
\text { (\$/kW-yr) }\end{array}$ & $\begin{array}{c}\text { FS PSH } \\
(\$ / \mathrm{kW}-\mathrm{yr})\end{array}$ & $\begin{array}{l}\text { FS \& AS PSF } \\
(\$ / \mathrm{kW}-\mathrm{yr})\end{array}$ \\
\hline Non-spinning reserve & 2.88 & 1.94 & 2.00 & 1.40 \\
\hline Spinning reserve & 0.46 & 1.94 & 0.58 & 1.40 \\
\hline Flexibility down & 0.15 & 1.29 & 0.62 & 3.37 \\
\hline Flexibility up & 0.02 & 0.17 & 0.03 & 0.09 \\
\hline Regulation down & 1.74 & 4.60 & 7.43 & 11.27 \\
\hline Regulation up & 1.69 & 1.79 & 1.58 & 1.93 \\
\hline Total & 6.93 & 11.73 & 12.23 & 19.47 \\
\hline
\end{tabular}

As illustrated in Figure 7-6, the average annual revenues per kilowatt of PSH capacity are higher for cases when both FS and AS PSH operate in the system.

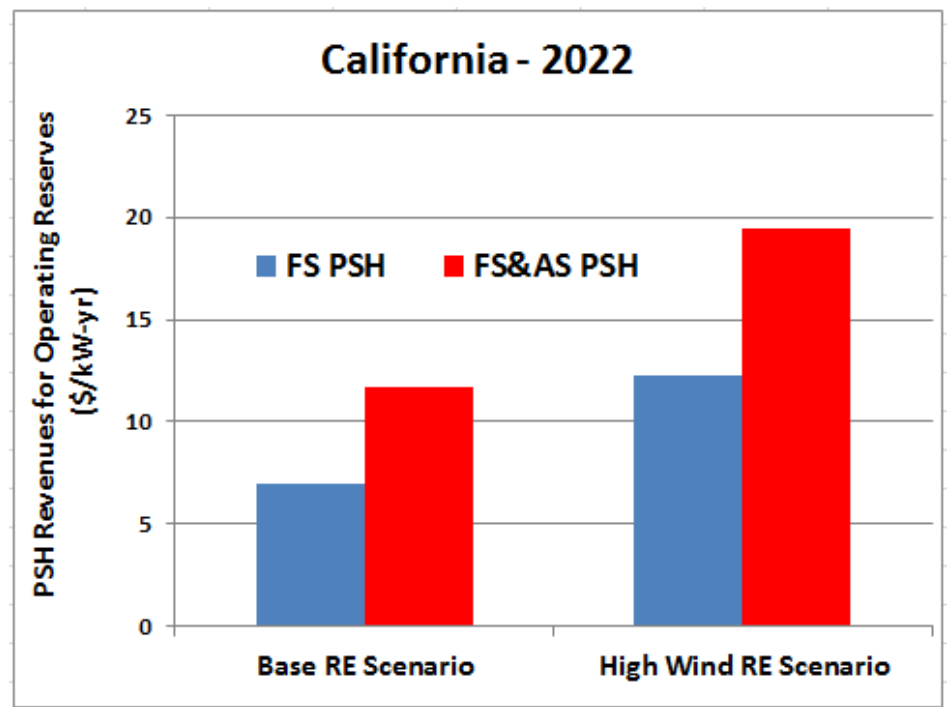

Figure 7-6 Average Annual PSH Revenues for Operating Reserves per Kilowatt of PSH Capacity

The other way in which a PSH plant contributes to regulation reserves in the power system is by improving the energy imbalance in the system. This was analyzed by using the FESTIV model; details of those simulations are presented in Section 5. Note that in FESTIV, all simulation stages (including unit commitment, dispatch, and the deployment of flexible reserves) provide the AGC submodel with information on how to use all these resources to correct the ACE. However, the contribution of regulation reserve is generally the largest with regard to reducing the ACE in the system. 
Tables 7-5 and 7-6 show the impacts of FS and AS PSH plants on improving the reliability and reducing energy imbalance in the BANC system. A case without a PSH plant operating in the system served as the reference case. The tables show that FS and AS PSH reduce the number of CPS2 violations and improve the CPS2 score in a week in April and a week in July in 2022, but the effects are more significant during July. The July results are also better with regard to the absolute amount of ACE and the standard deviation of ACE. These results illustrate how PSH provisions of regulation reserve improve system reliability, which allows a BA to better meet steady-state reliability standards.

Table 7-5 Impacts of PSH on ACE and Steady-State Reliability in Third Week of April 2022 (Balancing Authority of Northern California - BANC)

\begin{tabular}{|l|c|c|c|}
\hline \multicolumn{1}{|c|}{ Parameter } & No PSH & With FS PSH & With AS PSH \\
\hline Total production cost (\$ million) & 3.449 & 3.169 & 3.032 \\
\hline Number of CPS2 violations & 49 & 47 & 45 \\
\hline CPS2 score (\%) & 95.1 & 95.3 & 95.5 \\
\hline Absolute ACE in energy (AACEE) $(\mathrm{MWh})$ & 2,583 & 2,620 & 2,644 \\
\hline$\sigma_{\text {ACE }}(\mathrm{MW})$ & 23.8 & 25.1 & 23.0 \\
\hline
\end{tabular}

Table 7-6 Impacts of PSH on ACE and Steady-State Reliability in Third Week of July 2022 (Balancing Authority of Northern California - BANC)

\begin{tabular}{|l|c|c|c|}
\hline \multicolumn{1}{|c|}{ Parameter } & No PSH & With FS PSH & With AS PSH \\
\hline Total production cost (\$ million) & 5.394 & 5.101 & 5.021 \\
\hline Number of CPS2 violations & 40 & 16 & 15 \\
\hline CPS2 score (\%) & 96.0 & 98.4 & 98.5 \\
\hline AACEE $(\mathrm{MWh})$ & 3,201 & 2,736 & 2,593 \\
\hline$\sigma_{\text {ACE }}(\mathrm{MW})$ & 29.3 & 21.3 & 20.2 \\
\hline
\end{tabular}

\subsubsection{Energy Arbitrage}

Energy arbitrage refers to the operation of energy storage facilities that generate electricity when the demand and/or electricity prices are high and consume electricity when the demand and/or prices are low. Energy arbitrage is primarily driven by economic reasons and is beneficial in both traditionally regulated utilities and in restructured, competitive market environments. In regulated utilities, energy arbitrage reduces overall system production costs by offloading highcost peaking units during hours of high demand and by increasing the use of low-cost base load units during hours of low demand. Because this type of operation reduces the net system load during peak hours and increases the load during off-peak hours, it is also often referred to as load leveling or load shifting. In competitive markets, for which the electricity prices are typically calculated on hourly basis, energy arbitrage helps reduce high electricity prices during peak hours while taking advantage of low prices during off-peak hours for charging the energy storage (e.g., to pump water for PSH plants). The energy arbitrage operation of energy storage facilities in competitive markets is primarily driven by price differentials between the peak and off-peak 
hours. The price spread should be large enough to cover the cycle efficiency losses of the energy charging/discharging process and provide a certain amount of revenue. For this reason, energy arbitrage is also often referred to as price arbitrage.

PLEXOS simulations of the California system in 2022 were performed by using the marketbased approach, which allows for detailed analysis of the value of energy arbitrage based on the LMPs of electricity in each hour of the year. Note that PLEXOS simulations assumed the co-optimization of energy and A/S, so the results for energy arbitrage are likely to be lower than they would be if the PSH operations were optimized to maximize energy arbitrage revenues only. Table 7-7 summarizes the key PLEXOS results for the Base and High Wind renewable scenarios. Note that the capacity factors of PSH plants are significantly higher under the High Wind renewable scenario. The net revenues from energy arbitrage are also greater under the High Wind renewable scenario; however, not in proportion to the increase in PSH energy generation. This is because the value of energy generation is affected by the lower average LMP prices observed under the High Wind renewable scenario.

Table 7-7 Results for PSH Energy Arbitrage Revenues in California in 2022

\begin{tabular}{|c|c|c|c|c|}
\hline \multirow[b]{2}{*}{ Parameter } & \multicolumn{2}{|c|}{ Base Renewable Scenario } & \multicolumn{2}{|c|}{$\begin{array}{l}\text { High Wind Renewable } \\
\text { Scenario }\end{array}$} \\
\hline & FS PSH & FS \& AS PSH & FS PSH & FS \& AS PSH \\
\hline PSH capacity (MW) & 2,626 & 4,425 & 2,626 & 4,425 \\
\hline Energy generation (GWh) & 2,725 & 5,313 & 5,299 & 9,456 \\
\hline Pumping energy (GWh) & 3,840 & 6,856 & 7,501 & 12,521 \\
\hline PSH capacity factor (\%) & 11.85 & 13.71 & 23.04 & 24.39 \\
\hline Energy revenue $(\$ 1,000)$ & 102,302 & 181,554 & 147,285 & 217,302 \\
\hline Pumping cost $(\$ 1,000)$ & 65,768 & 164,508 & $-13,229$ & 25,045 \\
\hline Net revenue $(\$ 1,000)$ & 36,534 & 17,046 & 160,514 & 192,257 \\
\hline Net revenue $(\$ / \mathrm{kW}-\mathrm{yr})$ & 13.9 & 3.9 & 61.1 & 43.4 \\
\hline
\end{tabular}

The high penetration of variable energy resources (wind and solar) under the High Wind renewable scenario keeps the average LMPs rather low and even negative at times when there are curtailments of excess variable generation. The cost of pumping energy for FS PSH plants under the High Wind renewable scenario is negative because it is mostly supplied by the excess VER generation that would have been curtailed. It also shows that the capacity of existing FS PSH plants would not be sufficient for the high level of renewable resources in the system. With the addition of AS PSH plants, the overall pumping cost under the High Wind renewable scenario becomes positive, but its relatively low value indicates that the PSH pumping energy is still mostly composed of the VER energy that would have been curtailed.

Figure 7-7 illustrates the annual net revenues from energy arbitrage, and Figure 7-8 shows the net revenues per kilowatt of PSH capacity. Under the High Wind renewable scenario, the 


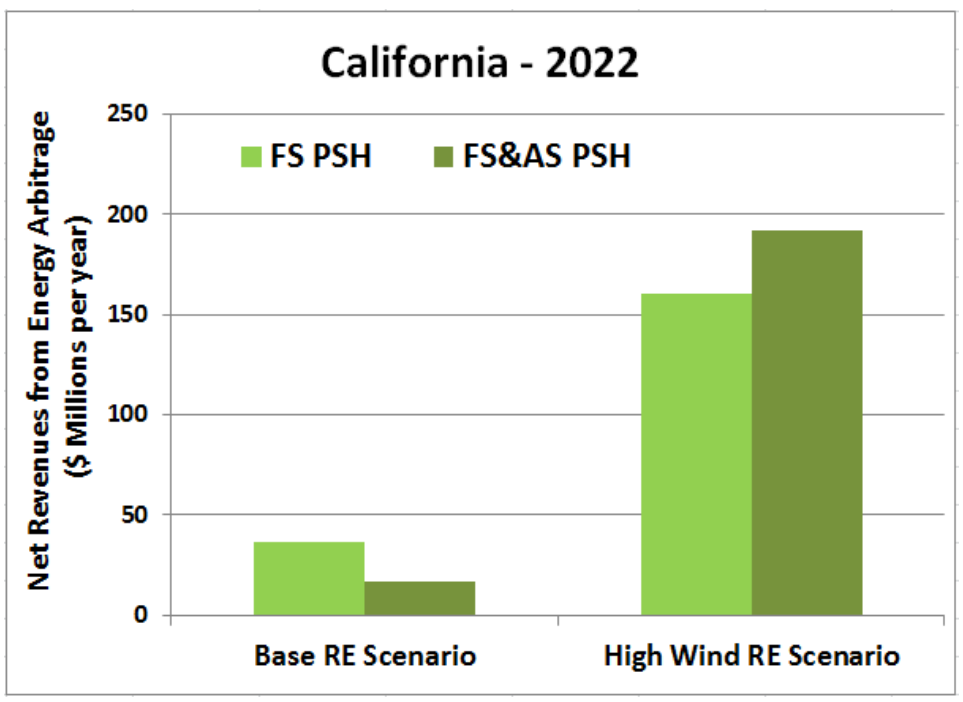

Figure 7-7 Annual Net Revenues from Energy Arbitrage in California in 2022

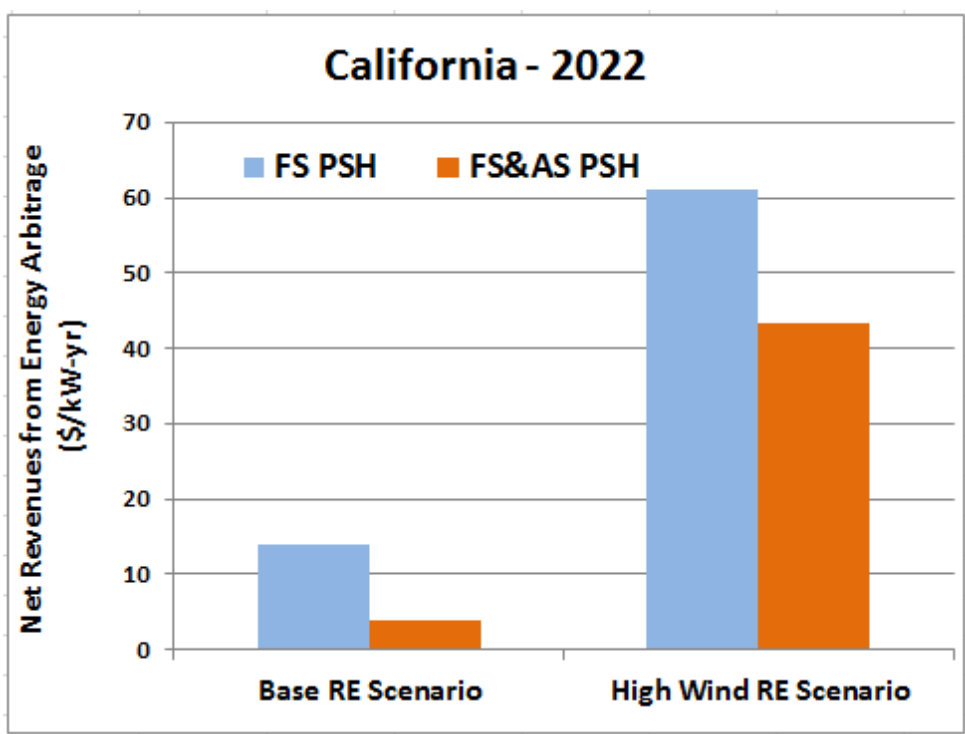

Figure 7-8 Net Revenues from Energy Arbitrage per Kilowatt of PSH Capacity

addition of AS PSH plants increases the total annual net revenues from energy arbitrage. However, the net revenues per kilowatt of PSH capacity are smaller because of the much larger PSH capacity in the system.

In the case of PLEXOS simulations for the WI and SMUD footprints, for which the cost-based approach was used, energy arbitrage benefits are included under the reduction of overall system production costs. The WI simulations for 2022 show that the addition of three proposed AS PSH plants - Swan Lake, Iowa Hill, and Eagle Mountain — could reduce the annual system 
operating cost by about $\$ 144$ million, or $1.1 \%$ of the total WI production cost under the Base renewable scenario, and by about $\$ 229$ million, or $1.8 \%$ of the total WI production cost under the High Wind renewable scenario.

The SMUD simulations for 2022 show that the addition of the proposed AS PSH Iowa Hill plant could result in an annual production cost savings of about $\$ 23$ million, or $8.6 \%$ of the total SMUD production cost under the Base renewable energy scenario, and in savings of about $\$ 51$ million, or $16.45 \%$ of the total SMUD production cost under the High Wind renewable scenario.

Detailed three-stage PLEXOS simulations for four typical weeks in different seasons of 2022 also show similar production cost savings (Table 7-8). Under the High Wind renewable scenario, the average production cost savings over the four typical weeks (in January, April, July, and October) amount to about 3.6\% of the total production cost for the WI, about $7.27 \%$ for California, and about $14.31 \%$ for SMUD. The production cost savings determined from the three-stage simulations are comparable to the production cost savings from the annual PLEXOS simulations. Note, however, that in three-stage simulations, the total system production costs in RT simulations (5-min time step) are higher than those in the DA simulations (hourly time step). The higher production costs are found in RT simulations because of the finer resolution of the analysis. RT simulation analyses capture the impacts of sub-hourly thermal dispatch at less economical loading points and the commitment cost for generating units, such as CTs, that help accommodate sub-hourly variability and the uncertainty of the load and of renewable generation.

Table 7-8 Production Cost Savings Due to PSH Capacity (Average for 4 weeks in 2022, based on PLEXOS three-stage simulations)

\begin{tabular}{|l|c|c|c|}
\hline \multirow{2}{*}{$\begin{array}{c}\text { High Wind } \\
\text { Renewable Scenario }\end{array}$} & \multicolumn{2}{c|}{ Production Cost Savings (\%) } \\
\cline { 2 - 4 } & $\begin{array}{c}\text { Western } \\
\text { Interconnection }\end{array}$ & California & SMUD \\
\hline FS PSH & 2.01 & 5.01 & - \\
\hline FS \& AS PSH & 3.60 & 7.27 & 14.31 \\
\hline
\end{tabular}

"_" = not applicable

Similar results for production cost savings were obtained from FESTIV simulations performed for the SMUD system. FESTIV simulates all timeframes of power system scheduling, from DA to 4-sec control of all power plants in the system. The operating costs are a result of detailed unit commitment, dispatch, and control of all generating resources in the system, and they are a direct result of the actual output of each unit as directed by the AGC. FESTIV simulations of the BANC system were performed for two weeks (third week of April and third week of July in 2022) for the High Wind renewable scenario. The impacts of adding a 400-MW FS PSH plant and AS PSH plant were examined (Table 7-9). 
Table 7-9 Production Cost Savings Due to PSH Capacity in BANC (Third week in April and in July in 2022, based on FESTIV simulations)

\begin{tabular}{|l|c|c|c|c|}
\hline \multirow{2}{*}{$\begin{array}{c}\text { High Wind } \\
\text { Renewable } \\
\text { Scenario }\end{array}$} & \multicolumn{4}{|c|}{ Production Cost Savings } \\
\cline { 2 - 5 } & $\begin{array}{c}\text { Week in April 2022 } \\
\text { Production Cost }\end{array}$ & $\begin{array}{c}\text { Production Cost } \\
\text { Savings } \mathbf{( \$ 1 , 0 0 0 )}\end{array}$ & $\begin{array}{c}\text { Production Cost } \\
\text { Savings (\%) } \\
\text { Savings } \mathbf{( \$ 1 , 0 0 0 )}\end{array}$ & $\begin{array}{c}\text { Production Cost } \\
\text { Savings (\%) }\end{array}$ \\
\hline FS PSH & 280 & 8.1 & 293 & 5.4 \\
\hline AS PSH & 417 & 12.1 & 373 & 6.9 \\
\hline
\end{tabular}

The monetary values for production cost savings that were obtained from FESTIV simulations were similar in the weeks in April and July, but the relative reductions were more significant in April due to lower total system operating costs in that month (because of lighter loads and a larger share of renewable generation). The results show that production cost savings are greater when AS PSH technology is used. This is because of the flexibility of AS PSH operation in the pumping mode, which allows for the more efficient operation of other generating units. The results also show that the cost savings (as percentage of total production cost) are more significant when the PSH capacity is in a smaller power system or when it covers a larger portion of the system load.

\subsubsection{Generating Capacity}

The size of PSH plants is typically on the order of several hundred megawatts, which provides a significant amount of flexible capacity to the power system. There are several PSH projects operating that have more than 1,000 MW of installed capacity. Having a large amount of generating capacity that can be quickly dispatched to meet peak demands, compensate for large swings in VER generation, or provide contingency reserves for outages of other generating units has a positive impact on system reliability.

Because the contributions of PSH capacity to the better integration of VERs and to contingency reserves are also discussed in other subsections, this subsection focuses mainly on the value of PSH capacity in providing peaking power. Since PSH plants are very flexible in their operation, they can be quickly dispatched and ramped up to meet peak demands, thus replacing or reducing the need for high-cost peaking thermal capacity. The startup times of PSH plants are very short; the plants can be up and running at full power output in several minutes. These operating characteristics of PSH plants match or exceed the capabilities of thermal alternatives that are typically used for peaking purposes, such as gas-fired CTs. In addition to their larger unit size, PSH plants have one more advantage over alternative sources of thermal peaking capacity: They can also operate in pumping mode. By switching from pumping mode to generating mode, $\mathrm{PSH}$ plants can basically double the amount of dispatchable capacity that they provide to the system. A practical use of this capability is illustrated by the well-known CAISO "duck chart," which shows the potential impacts of large amounts of solar and wind generation on CAISO system loads in the future. The CAISO duck chart illustrates that there will be a need for about 14,000 MW of ramping capacity to compensate for a drop in solar energy generation that occurs for $3 \mathrm{~h}$ in late afternoon/early evening. A 1,500-MW PSH plant that operates in pumping mode during 
the peak solar generation hours and switches to generating mode as the solar generation decreases and net system load increases in the evening can provide a total of 3,000 MW of dispatchable capacity and cover a large portion of the 14,000-MW ramping needs.

The value of PSH capacity can be determined from the long-term system expansion studies by calculating the avoided costs for the construction of alternative generating capacity. The longterm integrated resource planning analysis may show that adding a $\mathrm{PSH}$ plant to the system reduces the need for the construction of other generating units, while providing the same level of reliability of system operation. The value of PSH capacity can be then determined by comparing the expansion cases with and without PSH capacity and calculating the differences in the total system construction costs for other generating units. This type of analysis is rather complex and outside the scope for this study.

Another method of estimating the value of PSH capacity is to consider the value of peaking capacity in the existing capacity markets. Several electricity market operators in the United States have established capacity markets to increase the reliability of system operation. These capacity markets are typically run as auctions for acquisitions of new generating capacity for the next several years (typically 3 to 5 years). The resulting market clearing prices for generating capacity have been fluctuating and relatively low in recent years. This situation has mainly been due to the impact of large offerings of cheap demand response capacity, which is also eligible for providing capacity bids. Figure 7-9 illustrates forward capacity market clearing prices for capacity auctions by ISO New England (ISONE) and PJM. CAISO imposes a 1-year forward reserve requirement on load serving entities (LSEs) but does not have a centralized capacity market to help LSEs meet the reserve requirement. More details on capacity markets and capacity payments in existing electricity markets in the United States are provided in Section 8.3.

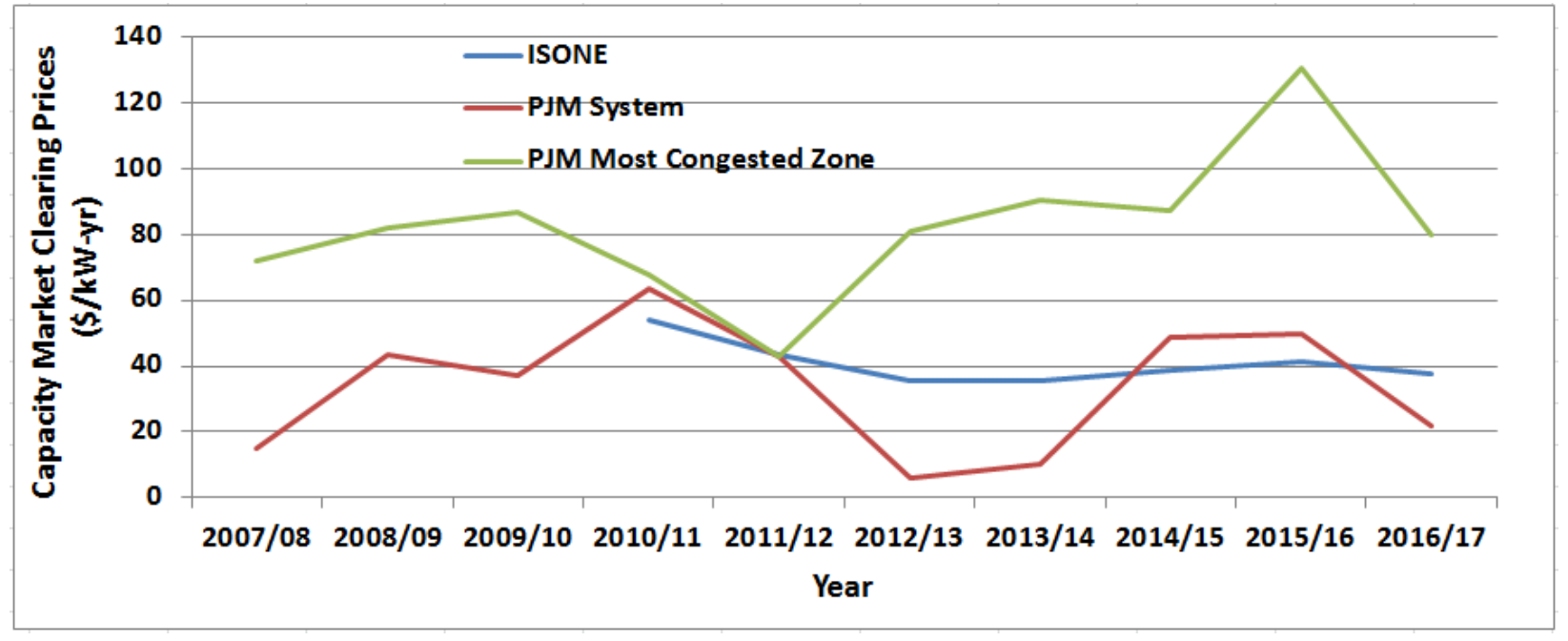

Figure 7-9 Forward Capacity Market Clearing Prices for ISONE and PJM 


\subsubsection{Emission Reductions}

The impacts that PSH plants may have on pollutant emissions depend primarily on the fuel mix of generating units in the power system in which they operate. While PSH plants typically offload high-cost peaking units, thus reducing the system emissions during peak hours, they may increase system emissions during the off-peak hours because they are adding their pumping load to the system. The increase in emissions during the off-peak hours depends on the type of generating units that are used to supply the pumping power. For example, if coal units will be increasing their generation to supply pumping power to PSH plants, the pollutant emissions may increase significantly. On the other hand, if gas units are on the margin during the off-peak hours and they are used to supply the pumping power, the increase in emissions will be smaller. The least amount of increase in emissions will occur if mostly renewable resources are used to supply the pumping power. In many parts of the United States, wind power happens to be slightly stronger during the night than during the day, and when there is a higher level of wind penetration, a significant amount of wind energy may be available for PSH pumping.

Pollutant emissions for the WI, California, and SMUD footprints were calculated by using the PLEXOS model. Details of those simulations are presented in Section 4. Simulations were performed for the base and high-wind renewable energy scenarios for cases with (1) no PSH plants in the system, (2) the existing FS PSH plants in the system, and (3) the existing FS and proposed new AS PSH plants in the system. Key findings of the simulations are illustrated in Figures 7-10, 7-11, and 7-12.

Simulation results for the WI (Figure 7-10) show an increase in pollutant emissions under the Base renewable scenario, but the operation of PSH plants decreases overall system emissions under the High Wind renewable scenario. This decrease is primarily due to (1) the higher percentage of wind energy that is available for PSH pumping and (2) PSH's impact on reducing the curtailments of wind energy. These two factors offset the increased emissions of conventional thermal generating units.

The results for California (Figure 7-11) show a decrease in $\mathrm{CO}_{2}$ and $\mathrm{NO}_{\mathrm{x}}$ emissions and an increase in $\mathrm{SO}_{2}$ emissions under both the Base and High Wind renewable energy scenarios. The results for California are different from those for the WI because of the differences in the generation mixes of these two systems.

The most significant reductions in emissions are found for the SMUD system (Figure 7-12). The introduction of the proposed AS PSH Iowa Hill plant reduces pollutant emissions in the SMUD system under both renewable energy scenarios. 


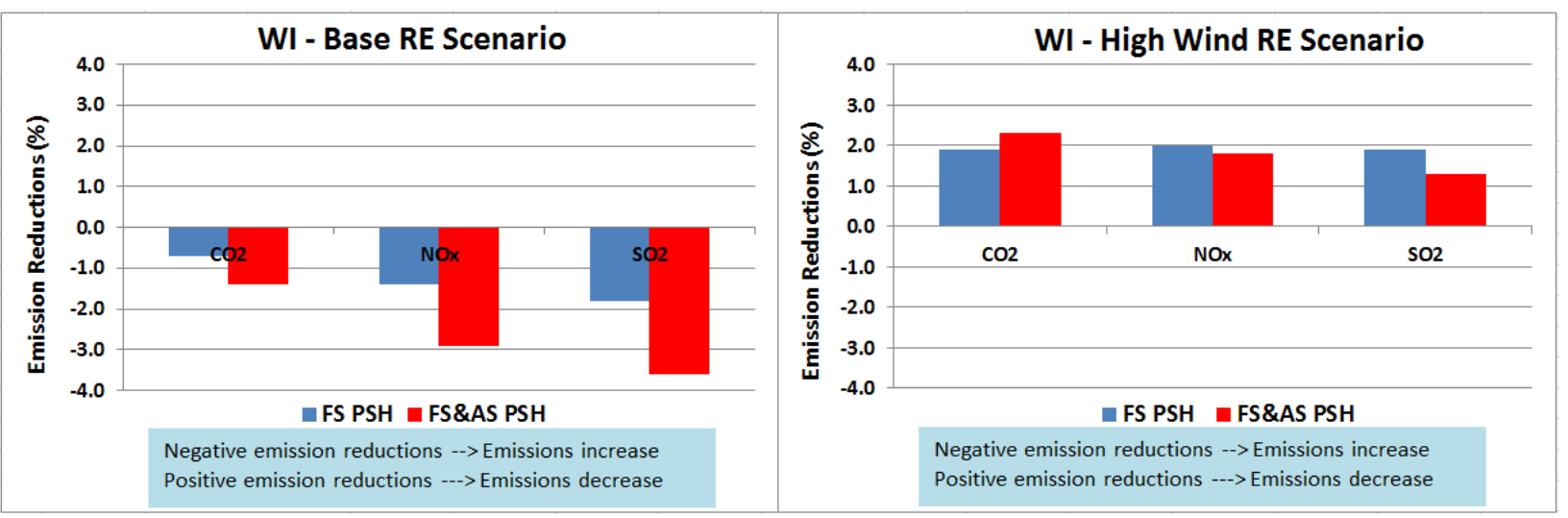

Figure 7-10 Emission Reductions Due to PSH Capacity in the WI in 2022

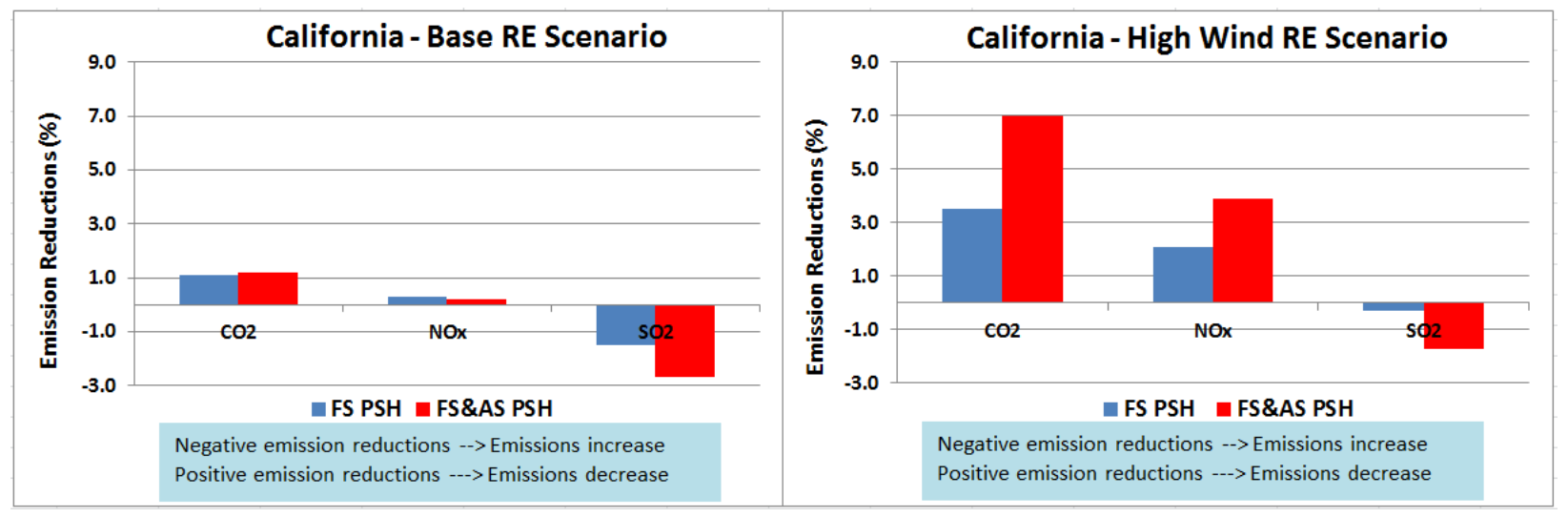

Figure 7-11 Emission Reductions Due to PSH Capacity in California in 2022

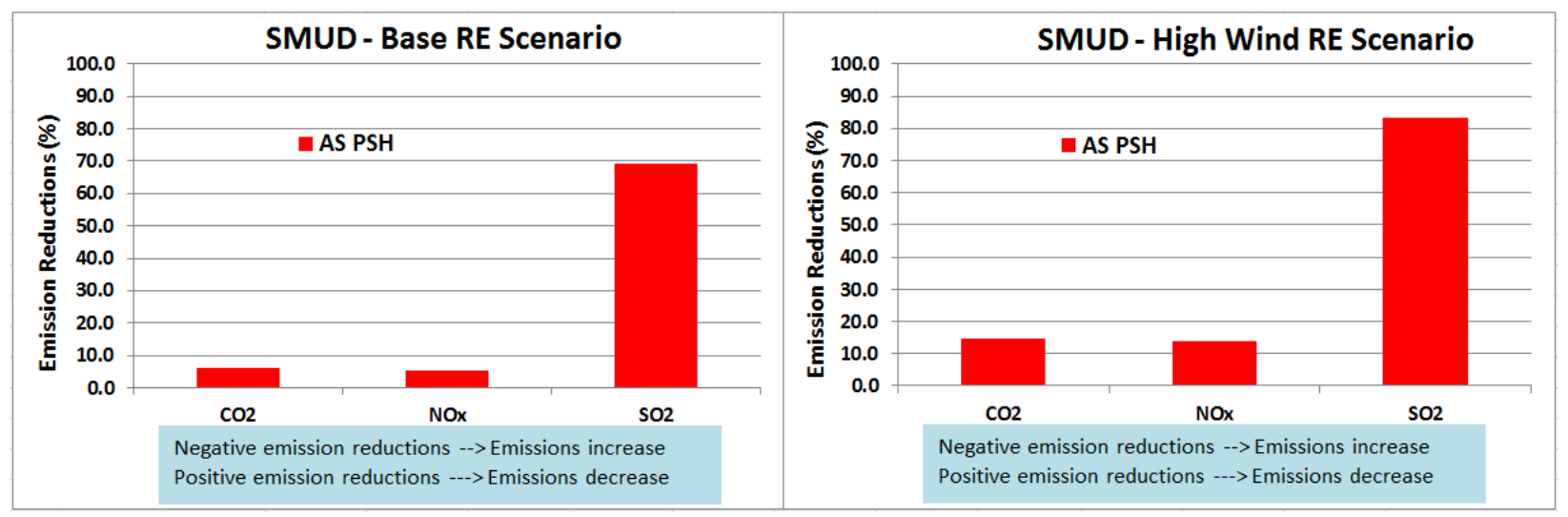

Figure 7-12 Emission Reductions Due to PSH Capacity in the SMUD System in 2022 


\subsubsection{Integration of Variable Energy Resources}

Energy storage technologies, such as PSH plants, support, in many ways, the integration of VERs into the power system. PSH plants can store the excess wind and solar power generated at times when the amount generated exceeded system needs, and they can use it to generate electricity in hours of high demand. This process is usually referred to as "shifting renewable energy generation.” By shifting the excess generation of wind and solar power, PSH plants effectively reduce curtailments of these resources and allow more renewable energy to be used in the system. This has a positive effect on system emissions and saves conventional fuels. Even at the current, relatively low penetration of wind energy (less than 10\% in most areas), many power systems occasionally experience a surplus of wind energy generation during the night, which requires either curtailing wind energy or shutting down conventional generators. The hours with excess wind energy are typically characterized by very low electricity prices, with LMPs going down to zero or even being negative. A larger use of PSH capacity would add a significant amount of pumping load in those hours and thus avoid wind energy curtailments and negative electricity prices.

PSH plants also enable a larger penetration of VERs in the power system by providing a large quantity of very flexible system capacity that can be used to compensate for the variability and uncertainty of VER generation. In addition, the operating characteristics of PSH plants, which have quick ramping capabilities and can provide large quantities of operating reserves to the system, make them ideally suited for supporting VER generation.

This section focuses on the impacts of PSH plants on reducing the curtailments of VER generation. The impacts of PSH plants on system operating reserves are covered in Section 7.2.3.

PLEXOS simulation results for the WI under the Base renewable scenario show that the FS PSH plants reduce curtailments of VER generation by $565 \mathrm{GWh}$, or about $29 \%$ of total curtailments if there are no PSH plants operating in the system. With both FS and AS PSH plants operating in the WI system, the curtailments are reduced by $958 \mathrm{GWh}$, or about $50 \%$ of total curtailments. The amount of curtailed VER generation under the High Wind renewable scenario is much greater; it is 56,885 GWh if there are no PSH plants operating in the system. The FS PSH plants reduce this curtailment by $8,482 \mathrm{GWh}$, or $15 \%$. When both FS and AS PSH plants are operating in the system, the curtailments are reduced by $12,675 \mathrm{GWh}$, or $22 \%$. Assuming a $30 \%$ capacity factor, the savings of 12,675 GWh roughly corresponds to an average annual generation of almost 5,000 MW of wind capacity.

In California, under the Base renewable scenario, the curtailments of VER generation are reduced from $155 \mathrm{GWh}$ if no PSH plants are operating to $46 \mathrm{GWh}$ (70\% reduction) if FS PSH plants are operating in the system and to $14 \mathrm{GWh}$ (91\% reduction) if both FS PSH and AS PSH plants are operating. Under the High Wind renewable scenario, the curtailments are reduced from $618 \mathrm{GWh}$ in the case without PSH plants to $380 \mathrm{GWh}$ (39\% reduction) in the case with FS PSH plants operating and to $275 \mathrm{GWh}$ (55\% reduction) in the case with both FS PSH and AS PSH plants operating. 
The results for the SMUD footprint show that the addition of the AS PSH Iowa Hill plant reduces renewable curtailments from 19 to $1 \mathrm{GWh}$ (95\% reduction) under the High Wind renewable scenario. There are no curtailments of VER generation under the Base renewable scenario.

\subsubsection{Reduced Cycling of Thermal Generating Units}

The flexibility of PSH capacity, its fast ramping characteristics, and its load-leveling operation create a flatter net load profile for thermal generating units, allowing them to operate in a steadier mode and thus reducing the need for their ramping and frequent startups and shutdowns.

\section{Reduced Startup Costs}

Since startups and shutdowns of thermal generating units involve substantial operating costs and increase the wear and tear on the units, reducing the number of unit startups results in a significant savings in system operating costs.

Tables 7-10 and 7-11 provide PLEXOS results for the number of thermal starts and total startup costs for the WI, California, and SMUD systems under the Base and High Wind renewable scenarios, respectively. Under both renewable scenarios, the number of starts and startup costs of thermal generators are reduced substantially as more PSH capacity is introduced into the system.

Table 7-10 Reduction in Thermal Startup Costs Due to PSH Capacity under the Base Renewable Scenario

\begin{tabular}{|l|c|c|c|c|c|c|}
\hline \multirow{2}{*}{$\begin{array}{c}\text { Base Renewable } \\
\text { Scenario }\end{array}$} & $\begin{array}{c}\text { Western Interconnection } \\
\text { The. of } \\
\text { Starts }\end{array}$ & $\begin{array}{c}\text { Startup Cost } \\
\text { (\$ million) }\end{array}$ & $\begin{array}{c}\text { Number of } \\
\text { Thermal } \\
\text { Starts }\end{array}$ & $\begin{array}{c}\text { Startup Cost } \\
\text { (\$ million) }\end{array}$ & $\begin{array}{c}\text { No. of } \\
\text { Thermal } \\
\text { Starts }\end{array}$ & $\begin{array}{c}\text { Startup Cost } \\
\text { (\$ million) }\end{array}$ \\
\hline No PSH & 37,804 & 153 & 18,514 & 56 & 1,812 & 5 \\
\hline With FS PSH & 31,797 & 130 & 14,646 & 46 & - & - \\
\hline With FS \& AS PSH & 27,548 & 109 & 12,134 & 36 & 828 & 3 \\
\hline
\end{tabular}

"-" = not applicable.

Table 7-11 Reduction in Thermal Startup Costs Due to PSH Capacity under the High Wind Renewable Scenario

\begin{tabular}{|c|c|c|c|c|c|c|}
\hline \multirow[b]{2}{*}{$\begin{array}{l}\text { High Wind } \\
\text { Renewable } \\
\text { Scenario }\end{array}$} & \multicolumn{2}{|c|}{ Western Interconnection } & \multicolumn{2}{|c|}{ California } & \multicolumn{2}{|c|}{ SMUD } \\
\hline & $\begin{array}{c}\text { No. of } \\
\text { Thermal } \\
\text { Starts }\end{array}$ & $\begin{array}{c}\text { Startup Cost } \\
\text { (\$ million) }\end{array}$ & $\begin{array}{c}\text { No. of } \\
\text { Thermal } \\
\text { Starts }\end{array}$ & $\begin{array}{c}\text { Startup Cost } \\
\text { (\$ million) }\end{array}$ & $\begin{array}{c}\text { No. of } \\
\text { Thermal } \\
\text { Starts }\end{array}$ & $\begin{array}{c}\text { Startup Cost } \\
\text { (\$ million) }\end{array}$ \\
\hline No PSH & 40,852 & 176 & 17,862 & 54 & 2,159 & 5 \\
\hline With FS PSH & 36,024 & 161 & 14,351 & 44 & - & - \\
\hline With FS \& AS PSH & 31,925 & 145 & 11,864 & 35 & 773 & 2 \\
\hline
\end{tabular}

"-" = not applicable. 
If both FS PSH and AS PSH units are operating in the system, the annual thermal startup cost savings for WI amounts to $\$ 44$ million (about $28.6 \%$ reduction in total startup costs) under the Base renewable scenario and to \$31 million (about 17.7\% savings) under the High Wind renewable scenario. Figure 7-13 illustrates the reductions in thermal startup costs due to PSH capacity in the WI.

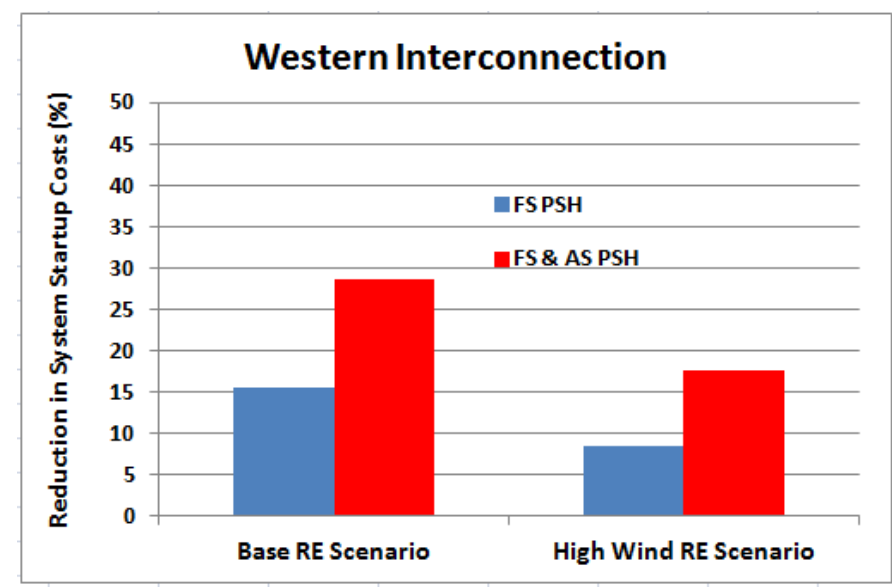

Figure 7-13 Reduction in Thermal Startup Costs Due to PSH Capacity in the WI in 2022

In the case of California, under both renewable energy scenarios, the savings in startup costs amounts to about \$10 million if only the existing FS PSH plants are operating in the system and to about \$20 million if both FS PSH and AS PSH plants are operating. This is illustrated in Figure 7-14.

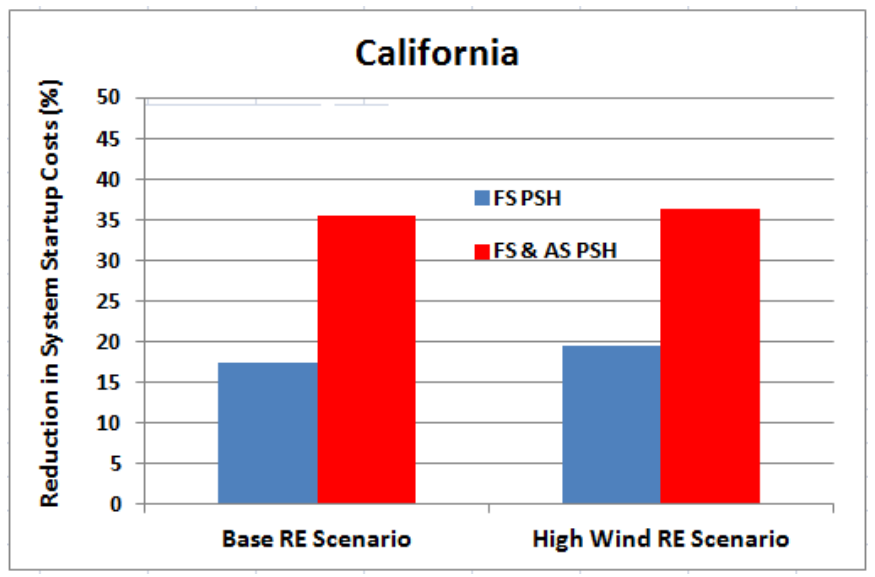

Figure 7-14 Reduction in Thermal Startup Costs Due to PSH Capacity in California in 2022 
In the case of SMUD, the addition of the AS PSH plant (Iowa Hill) reduces annual startup costs by about $\$ 2$ million under both renewable energy scenarios. As a percentage of total system startup costs in 2022, the cost savings ( $\$ 2$ million) represents about $45 \%$ of the total startup costs under the Base renewable scenario and about $42 \%$ under the High Wind renewable scenario. This is illustrated in Figure 7-15.

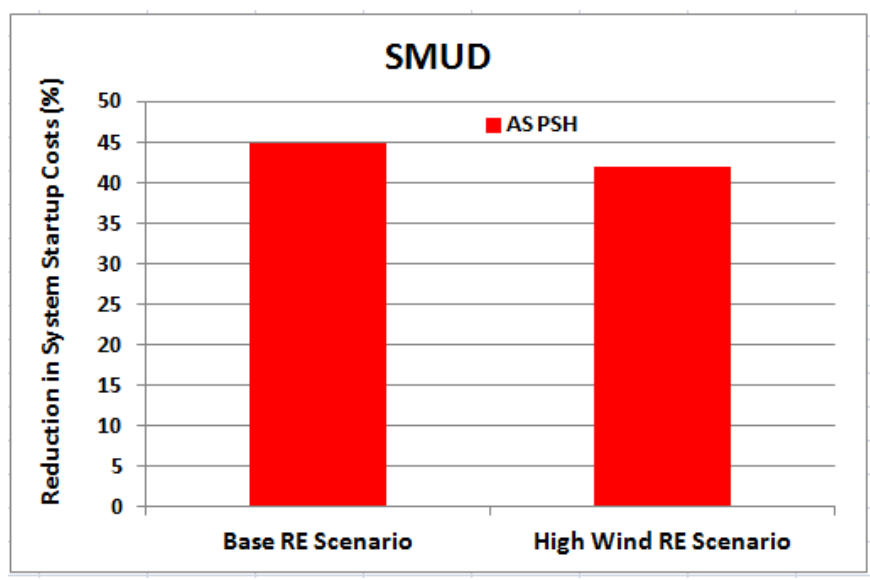

Figure 7-15 Reduction in Thermal Startup Costs Due to PSH Capacity in SMUD in 2022

\section{Reduced Thermal Generator Ramping}

Figures 7-16 through 7-18 show the results for reductions in thermal generator ramping (both up and down) in the WI, California, and SMUD systems. Detailed PLEXOS simulation results are presented in Section 4.

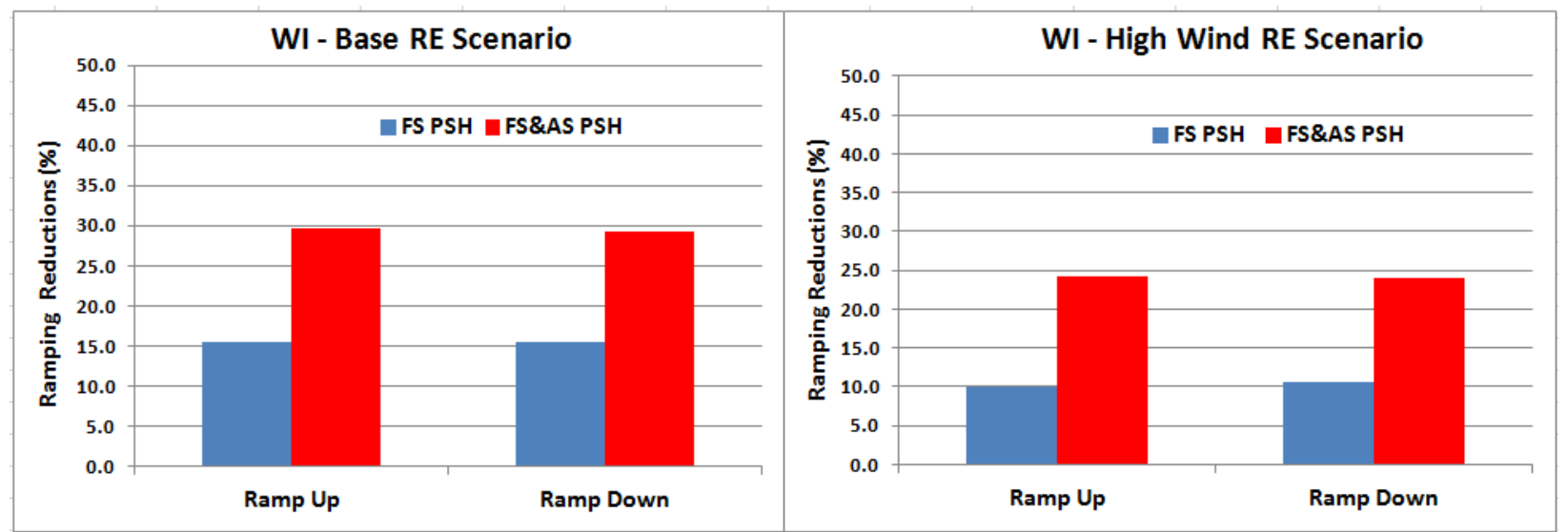

Figure 7-16 Reductions in Thermal Capacity Ramping Needs in the WI in 2022 Due to PSH Capacity 


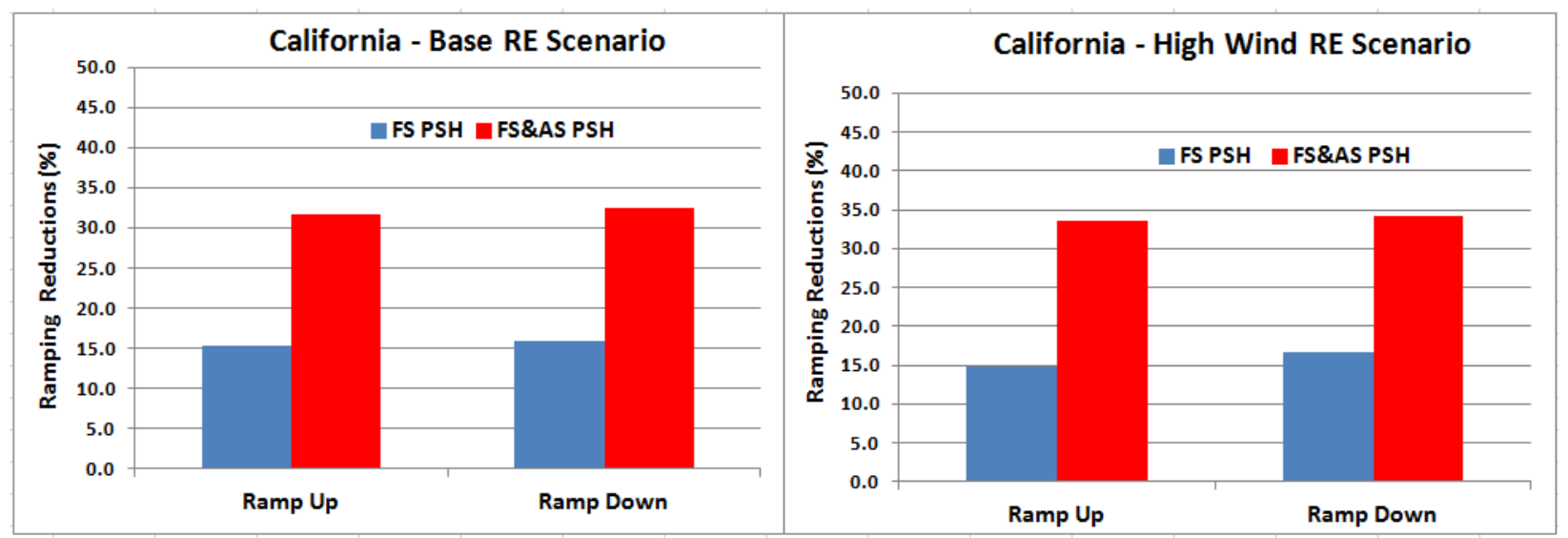

Figure 7-17 Reductions in Thermal Capacity Ramping Needs in California in 2022 Due to PSH Capacity
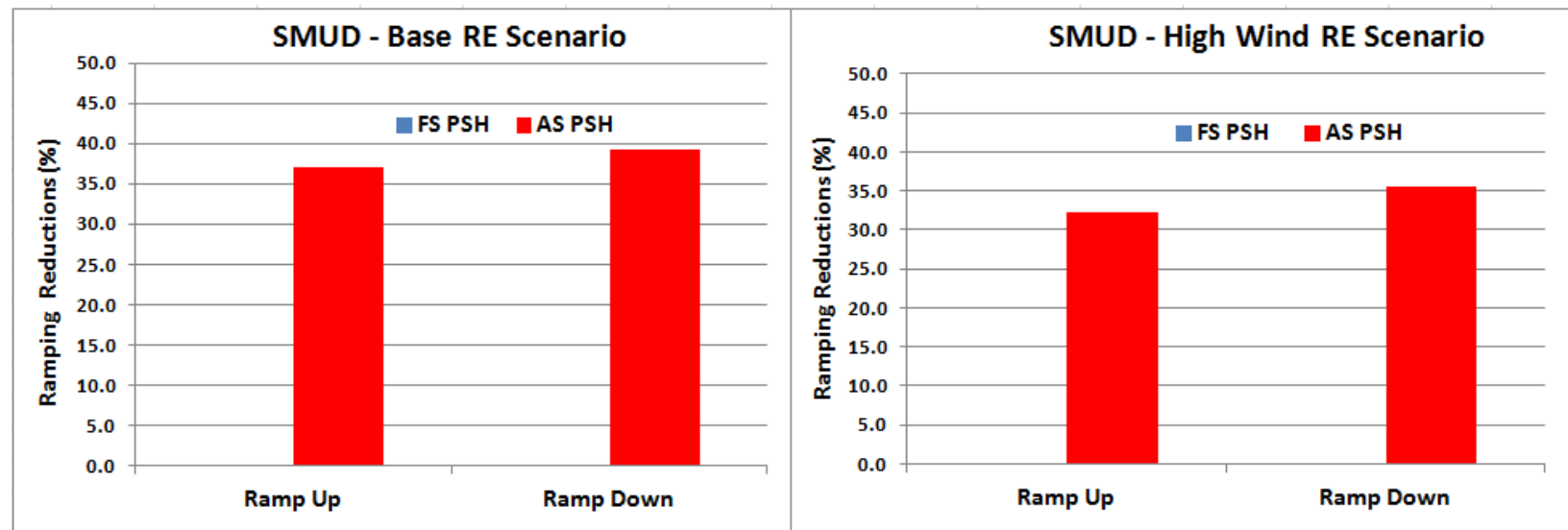

Figure 7-18 Reductions in Thermal Capacity Ramping Needs in SMUD in 2022 Due to PSH Capacity

PLEXOS simulations for the WI in 2022, under the Base renewable scenario, show that FS PSH plants reduce the ramp-up needs of thermal generators by 1,786 GW and reduce their ramp-down needs by 2,560 GW. If both FS PSH and AS PSH plants are operating in the system, the ramp-up needs of thermal generators are reduced by 3,420 GW, and the ramp-down needs are reduced by $4,817 \mathrm{GW}$.

Similarly, the results for California in 2022 under the High Wind renewable energy scenario show that FS PSH plants reduce the ramp-up needs of thermal generators by $531 \mathrm{GW}$ and reduce their ramp-down needs by $945 \mathrm{GW}$. If both FS PSH and AS PSH plants are operating in the system, the ramp-up needs of thermal generators are reduced by 1,214 GW, and their ramp-down needs are reduced by $1,943 \mathrm{GW}$.

In the case of the SMUD, the proposed AS PSH plant (Iowa Hill) reduces ramp-up needs by $136 \mathrm{GW}$ and reduces ramp-down needs by $197 \mathrm{GW}$ under the Base renewable scenario, and it reduces them by $119 \mathrm{GW}$ and $174 \mathrm{GW}$, respectively, under the High Wind renewable scenario. 
Table 7-12 shows the results obtained from three-stage PLEXOS simulations of four typical weeks in different seasons of 2022, using the 5-min time step in RT simulations. The results are similar to those presented previously from PLEXOS annual simulations using the hourly time step. Note that in the three-stage simulations, the RT simulations show higher ramping needs than those found in the DA simulations. This is because the RT simulations capture the intrahourly variability of VER generation, which is not captured in DA simulations that use an hourly time step. The higher ramping needs of thermal generators in RT simulations indicate that they need to ramp up more to meet the sub-hourly variability and uncertainties of load and renewable generation.

Table 7-12 Reduction in Thermal Ramping Needs Due to PSH Capacity (Average for four weeks in 2022, based on PLEXOS three-stage simulations)

\begin{tabular}{|l|c|c|c|c|c|c|}
\hline \multirow{2}{*}{$\begin{array}{c}\text { High Wind } \\
\text { Renewable } \\
\text { Scenario }\end{array}$} & \multicolumn{2}{|c|}{ Western Interconnection } & \multicolumn{2}{c|}{ California } & \multicolumn{2}{c|}{ SMUD } \\
\cline { 2 - 7 } & $\begin{array}{c}\text { Ramp-Up } \\
\text { Need (\%) }\end{array}$ & $\begin{array}{c}\text { Ramp-Down } \\
\text { Need (\%) }\end{array}$ & $\begin{array}{c}\text { Ramp-Up } \\
\text { Need (\%) }\end{array}$ & $\begin{array}{c}\text { Ramp-Down } \\
\text { Need (\%) }\end{array}$ & $\begin{array}{c}\text { Ramp-Up } \\
\text { Need (\%) }\end{array}$ & $\begin{array}{c}\text { Ramp-Down } \\
\text { Need (\%) }\end{array}$ \\
\hline FS PSH & 5.44 & 8.25 & 9.76 & 15.10 & - & - \\
\hline FS \& AS PSH & 23.25 & 24.86 & 33.05 & 64.16 & 22.06 & 22.87 \\
\hline
\end{tabular}

$"{ }^{\prime \prime}=$ not applicable.

\subsubsection{Other Portfolio Effects}

In addition to reduced cycling and ramping of thermal generating units and associated reduced startup and wear and tear costs, PSH plants also have other positive portfolio effects, such as enabling thermal generating units to operate at higher efficiencies. Because the operation of PSH plants tends to reduce peak loads and fill the off-peak valleys, their load leveling effect produces a flatter net load for thermal generating units, allowing them to operate for a longer time with a higher power output, and reduces ramping up and down. The steadier operation of thermal generators at power output levels close to their nominal capacity results in more efficient operation and lower heat rates. Lower heat rates, in turn, mean a better fuel-to-electricity conversion efficiency, which translates to fuel savings. In addition, the flatter load profile for thermal generating units allows for an easier dispatching and unit commitment process. These indirect portfolio effects and savings are captured in the PLEXOS simulations presented in Section 4 and represent a part of the total production costs savings for the system.

In competitive market environments, where generators bid their energy and A/S, the operation of PSH plants may also have an impact on the revenues of other generators in the system. As shown in Section 4 (Figure 4-10), PSH plants may affect the LMPs and resulting market clearing prices for electricity that are used in market settlements. While their operation reduces peak electricity prices, the reductions in curtailments of VER generation may have an even more pronounced effect and significantly raise the off-peak prices due to PSH pumping loads.

PLEXOS simulations for California show that the total net revenue (defined as the generation and reserve revenue minus the generation cost) of all generators in the system increases if more 
PSH plants are introduced into the system. This is the case under both the Base and High Wind renewable scenarios. The increase in net revenue is mostly due to increases in LMPs during the pumping hours, which yield higher generation revenues.

Net revenues are smaller under the High Wind renewable scenario than the Base renewable scenario because of the lower average level of LMPs in the High Wind renewable scenario.

Under the Base renewable scenario, reserve revenues represent less than $10 \%$ of total market revenues (energy revenue plus reserve revenue). However, reserve revenues increase to 25\% of total market revenues under the High Wind renewable scenario due to the greater needs for flexibility and regulation reserves.

\subsubsection{Reduced Transmission Congestion}

The transmission congestion price is an indicator of the amount of congestion in the transmission grid. The lower transmission congestion prices found in cases with PSH plants indicate that they can help mitigate transmission congestion.

PLEXOS simulations of the WI show that under the Base renewable scenario, average transmission congestion prices decrease from \$4/MWh if no PSH plants are operating in the system to \$2/MWh if both FS PSH and AS PSH plants are operating. Because simplified transmission expansion planning was done under the High Wind renewable scenario, no significant reductions in transmission congestion prices were observed under that scenario. However, under both the Base and High Wind renewable scenarios, the interface with the significant congestion price reduction was the P27 Intermountain Power Project DC line, which is located in the vicinity of the existing Castaic PSH plant and the proposed Eagle Mountain PSH plant.

In PLEXOS simulations of California for the Base renewable scenario, the average transmission congestion prices decrease from \$3.51/MWh if no PSH plants are operating in the system to \$0.4/MWh if FS PSH plants are operating and to \$0.24/MWh if both FS PSH and AS PSH plants are operating in the system. Under the High Wind renewable scenario, the average transmission congestion prices in California decrease from \$1.79/MWh if no PSH plants are operating to $\$ 0.56 /$ MWh if FS PSH plants are operating and to \$0.37/MWh if both FS PSH and AS PSH plants are operating in the system. The lower transmission congestion prices found under the High Wind renewable scenario are a result of the transmission expansion that took place under this scenario. Again, under both the Base and High Wind renewable scenarios, the interface with the significant congestion price reduction was the P27 Intermountain Power Project DC line located near the existing Castaic plant and the proposed Eagle Mountain PSH plant.

\subsubsection{Transmission Deferral}

High transmission congestion prices typically indicate that there is not enough transmission capacity in the system; therefore, there is a need to strengthen the grid in certain areas by adding new transmission lines or circuits. In many cases, the large dispatchable capacity of PSH plants can be used to inject or remove power from the grid, as needed in a particular situation, in order 
to influence the power flows and reduce transmission congestion. Thus, a strategically located PSH plant may defer the need for construction of new transmission capacity.

PLEXOS simulation results for the Base renewable scenario demonstrate that PSH plants help reduce transmission congestion for some interfaces in southern California. A significantly congested interface, the P27 Intermountain Power Project DC line, experiences the greatest congestion price reduction under the Base renewable scenario. This interface also attains the greatest congestion price reduction under the High Wind renewable scenario, even though this scenario incorporated transmission expansion planning.

\subsubsection{Voltage Support}

In electric power systems, system voltages must be controlled to within a tight band, typically $\pm 5 \%$, around the nominal value so that both the customer's and the power system's equipment can function properly. System voltages are controlled by controlling the supply of reactive power. Reactive power can be supplied by the generators or by other system devices, such as capacitor banks, synchronous condensers, and power-electronic-based devices like static VAR compensators (SVCs). Reactive power is typically absorbed by loads and is also required by AC systems to transmit the power from the generators to the loads.

However, voltage control is a relatively local issue. While frequency control is a system objective since the frequency very quickly becomes the same throughout the interconnection, voltage control is a local objective. It is not possible to ship reactive power over long distances, since large voltage drops occur and the reactive power gets "used up" as additional reactive losses (and also causes additional real power losses). Note that reactive power must also be absorbed by generators and devices such as reactors to control high voltages under some conditions, but this is generally not as much of a concern as supplying reactive power to improve low voltages. The control of high voltages is usually only a concern for systems with large amounts of underground cables, such as large cities, or systems with very long high-voltage transmission lines.

Therefore, reactive power must be supplied relatively close to where it is needed. However, it is a challenging service to supply via a market mechanism, due to concerns that local providers may have market power. Conventional generators have the ability to supply reactive power as part of their general design. Traditionally, the system operators have specified certain reactive power requirements for such generators and required that these units control their terminal voltages in a coordinated manner to maintain system voltages. Conventional machines use automatic voltage regulators to adjust the field voltage of the generators to provide this voltage control. Typically, there is not a specific reimbursement for the supply of reactive power or voltage control capabilities; however, several system operators are investigating market mechanisms related to reactive power and voltage control.

The advanced PSH technologies have the ability to supply voltage control. The ternary units employ conventional generators and hence have capabilities similar to those of any conventional generator of the same size. The AS units employ power electronics, and their controls and 
capabilities can be designed to mimic the capabilities of a conventional generator of a similar size and, if required, to have additional capabilities.

\subsubsection{Power System Stability}

Most of the large generators in a power system are synchronous machines. Stability is defined in terms of the ability to maintain synchronism. This report is based on the following definition of "stability" from the IEEE/CIGRE Joint Task Force on Stability Terms and Definitions (IEEE/CIGRE 2004):

Power system stability is the ability of an electric power system, for a given initial operating condition, to regain a state of operating equilibrium after being subjected to a physical disturbance, with most system variables bounded so that practically the entire system remains intact.

Disturbances play an important role in defining the dynamic behavior of the system. The system may be subject to disturbances of small or large magnitude. Small disturbances occur continuously in the routine operation of a power system. For example, new loads come on line or increase their demands, while other loads do the opposite. A large disturbance involves more severe changes, such as the loss of a large generator or load or the trip of a transmission line following a short circuit (fault). Stability is often classified according to the size of the disturbance.

“Transient stability,” also called "rotor angle stability,” is defined as the "ability of synchronous machines of an interconnected power system to remain in synchronism after being subjected to a disturbance” (IEEE/CIGRE 2004). It is often also called “first swing stability," because generally, if machines survive the first swing (i.e., remain in synchronism), subsequent swings will be of less magnitude (if not, the problem is generally damping; see small-signal stability discussion that follows). In some cases, systems can become unstable due to transient stability on the second or subsequent swings, which is sometimes due to the coincidence of models of oscillations, although this is uncommon.

The dynamic response of the system involves large excursions in generator rotor angles (and related significant speed deviations). The excursions in angle depend on both the pre-disturbance operating condition and the type and severity of the fault. Following a disturbance, the rotor angle of a nearby machine increases relative to the angle of other machines in the system. For this machine to remain stable, its angle must reach some maximum value and then "turn around" and begin to decrease, with subsequent oscillations being of lesser magnitude. The angle eventually settles at a steady-state value that, although usually not the same as the initial value, is relatively close to the initial value and maintains a constant position with respect to the rotor angles of other synchronous generators in the power system.

"Small-signal stability," sometimes also referred to as "dynamic stability," is "concerned with the ability of the power system to maintain synchronism under small disturbances" (IEEE/CIGRE 2004). Instability can be present in two forms: (1) a steady increase in rotor angle due to a lack of sufficient synchronizing torque or (2) rotor angle oscillations of increasing 
magnitude due to a lack of damping. Many factors may influence the response of the system to small disturbances. Dominant factors are heavily loaded transmission systems due to, for example, high power transfers. Fast response excitation systems and poorly tuned controls are also known to be important factors in stability performance. The types of power system oscillations can include (1) local mode oscillations, usually associated with units at a generating station or a group of units at nearby stations oscillating with respect to the remainder of the system, and (2) inter-area mode oscillations, associated with large groups of generating units oscillating with respect to each other or with respect to the remainder of the system.

These stability problems are investigated by using dynamic simulation programs in both power system planning and operations. Stability may limit system operations; for example, it may limit the power transfers that can occur across a given interface.

Stability is very system-dependent because it is very influenced by the synchronous machines and their controls. The addition of advanced pumped storage at a particular location could have either a beneficial or a negative impact on the stability performance of the system as a whole, similar to the addition of a conventional unit at the same location. The ternary units employ conventional generators and hence have similar characteristics with respect to the stability as other conventional generators. The AS units employ power electronics, so their controls and capabilities can be designed to improve their performance under particular disturbances, as compared to the capabilities of a conventional generator of similar size. These improvements would be very much a function of the design and the constraints/requirements of a particular location.

The system operators require that all generators be able to maintain stability under prescribed conditions. In general, there is no market for stability; that is, you do not get paid for being "more stable" than the plant next door. However, if the addition of a plant can be shown to increase the transfer capability across a stability-limited interface, then that contribution to the economic operation of the system is recognized by the tariffs of many power system operators.

\subsubsection{Black-Start Capability}

Although modern power systems are very reliable, extreme events can occur and can lead to partial or total blackout. In the case of a widespread blackout, system restoration must begin from generating units that have the ability to start themselves. These units, called black-start units, are then used as the kernels to start the restoration process by energizing first the transmission lines connected to these units and emanating power outward towards the critical system load. The black-start sequence will likely occur simultaneously at several generating units independently, and these independent islands of generation and load will later be synchronized to restore the original power system. It is clear that units that have black-start capability perform an essential function, and most tariffs recognize this A/S.

Generally, hydroelectric units, particularly pumped storage units, are good candidates for providing black-start capabilities, depending on their design. Advanced pump storage technologies may be able to supply black-start capability. The ternary units employ conventional generators and therefore have capabilities similar to those of other hydroelectric units, and they 
could be designed to have black-start capability. Since AS units employ power electronics, it would not be easy for them to offer black-start capability. Power electronics generally require an external source of power, which would not be available under black-start conditions. The potential manufacturer of the AS unit would need to be consulted to determine if controls and capabilities could be designed to give AS units black-start capability.

\subsubsection{Energy Security}

By virtue of its operational flexibility and reliability, PSH capacity acts as an enabler of other renewable energy resources (especially variable ones like wind and solar), helping them integrate into the power system. While providing a backbone for higher penetration levels for VERs, PSH plants also allow for better use of domestic wind and solar energy resources, reduce their curtailments, and increase the reliability of system operations by counterbalancing their variability. In addition, PSH plants provide a large amount of backup capacity that can be quickly dispatched during outages of large thermal units, thereby improving the reliability and resiliency of system operations.

A higher reliance on domestic renewable energy sources typically means less dependency on imported fuels. Although the use of imported fuels in the power sector is not a significant issue in the United States, it is one of major concern in many other countries. Nevertheless, a larger share of renewable electricity generation will have positive effects on de-carbonization of the electric sector, and it may also reduce the use of fossil fuels in other energy sectors. For example, greater electrification of the transportation sector in the future will reduce the need for fossil fuels and contribute to the sector's de-carbonization, especially if a larger share of the electricity for electric vehicles comes from clean renewable resources.

\subsection{References}

IEEE/CIGRE (Institute of Electrical and Electronics Engineers/International Council on Large Electric Systems), Joint Task Force on Stability Terms and Definitions, 2004, "Definition and Classification of Power System Stability,” in IEEE Transactions on Power Systems 19(2):13871401, May. 
This page intentionally left blank. 


\section{Section}

8

\section{Treatment of PSH in Electricity Markets}

Pumped hydro storage is the most common form of energy storage available in the power system today. Much of the nation's 22 GW of pumped hydro storage began in the mid to late 1970s (ASCE 1993), ${ }^{6}$ in response to dramatic increases in the price of oil and natural gas and to a concern about the security of our nation's power supply (Denholm et al. 2010). This concern was so strong that it led to the Powerplant and Industrial Fuel Use Act, which restricts the use of oil and gas in new power plants (EIA 2009a). Utilities that had expected to bring many new coal and nuclear plants on line to meet base-load demand were left with limited options to provide loadfollowing and peaking services. This situation led the utilities to actively evaluate pumped hydro - as well as other - storage technologies as alternatives to fossil-fueled intermediate-load and peaking units. The economic analysis and justification of new energy storage facilities during this period were based on a direct comparison of the energy and capacity provided by energy storage to that provided by an equivalently sized fossil plant (choosing the lower net-cost option). Any additional operational benefits energy storage can provide were largely ignored. ${ }^{7}$ Growth projections for energy storage during this period included significant increases in the use of several storage technologies (Boyd et al. 1983). However, most of the PSH development, along with the interest in and deployment of other emerging storage technologies, ended in the 1980s, in response to a dramatic reduction in the price of natural gas, increased efficiency and reduced costs offered by flexible combined-cycle and simple-cycle natural GTs, and the repeal of the Powerplant and Industrial Fuel Use Act in 1987. While estimates from the 1970s found combined-cycle GT (CCGT) units and PSH units to have similar costs, by the early 2000s, it was estimated that PSH units would cost about twice as much as CCGT units. As a result, the increase in the net cost of PSH limited its economic competitiveness versus gas-fired generators. ${ }^{8}$ Furthermore, the growth of gas-fired generation, coupled with the limited build-out of nuclear and coal, has greatly reduced the source for low-cost, off-peak electricity for charging storage. Finally, the simplistic treatment of the economic benefits of energy storage technologies, including how restructured markets address capacity costs, is also a limiting factor. Collectively, these factors have restricted deployment of utility-scale energy storage in the United States. In addition to PSH, storage deployment has been limited to a single 110-MW compressed-air

6 There was also significant research and development in a variety of other storage technologies, including several battery types, capacitors, flywheels, and superconducting magnetic storage (DOE 1977).

7 See, for example, EPRI (1976), in which the proposed method for comparing energy storage to conventional alternatives is based solely on the value of energy and firm capacity value, without any quantification of operational benefits.

8 PHS also takes longer to build (increasing the risk for investors), requires additional permits, and is typically located farther from load centers, which requires more transmission than gas-fired generators. PHS may also face greater environmental opposition (Strauss 1991). 
energy storage facility, and a variety of small projects, including batteries and flywheels at less than 20 MW of capacity. ${ }^{9}$

Today, PSH is still typically used to pump water during low-load nighttime hours and to generate electricity with the stored water during peak daytime afternoon hours. However, the significant increase in wind and solar generation, which add to variability and uncertainty, is increasing the need for flexibility from the rest of the power system resources (generators, loads, and storage). Simultaneously, restructuring of electricity markets is making it more transparent what types of flexibility are needed, specifying how that flexibility will be compensated, and establishing markets for various resources (and technologies) to compete to supply the required response. These changing factors can both help storage by explicitly valuing the flexibility that storage brings to the power system and sometimes create challenges for storage when market rules do not fully recognize the unique characteristics and benefits of storage technologies. Regional differences, especially between restructured and regulated areas, can also affect how storage is valued.

The goal of this section is to present the ways in which PSH resources are currently treated in electricity markets and in power system operations. It focuses on restructured areas that are operated by ISOs and RTOs. It compares and contrasts current practices with some recent studies that look at more innovative techniques. Based on the understanding gained from this comparison, it lists recommendations and suggests enhancements on how PSH is treated that could result in more economical and reliable PSH operations in the future. Some of these recommendations are tested and quantified by using the simulation tools available for this project, as documented in other parts of this report.

The basic economics of power system operation are the same in both regulated and restructured market areas. The lowest-cost generators are scheduled to reliably serve the expected load, and then they are operated to meet the actual load based on security-constrained unit commitment and economic dispatch. In regulated areas, generator marginal costs are used as input to the optimization process, while in restructured market areas, generator bid prices are used as input. In well-run markets, without the presence of market power, the bid-based offers should be close to marginal costs. Our focus is on restructured markets because information on the exact market rules and system performance are publically available for restructured areas but not as readily available for regulated areas, for which confidential bilateral arrangements are common. The operational impacts on loads and conventional generators are similar in regulated and restructured market areas, so the results from focusing on one area can be extended to the other.

However, one important difference between regulated and restructured areas is how the storage and demand response resources are compensated for their service. To illustrate this issue, consider a hypothetical storage facility so large that it could completely flatten the system net load. Generation would operate at a constant level; it would charge storage during the night when

9 To place these values in perspective, between 1993 and 2008, more than $320 \mathrm{GW}$ of conventional capacity was constructed in the United States. Except for the completion of previously started PSH facilities and a few demonstration projects, no significant storage capacity was added. The total U.S. utility storage capacity of about $20 \mathrm{GW}$ in 2008 was less than 2\% of the total installed generation capacity (EIA 2009b). 
the load declined, and it would rely on storage to serve load when it rose above the average level during the day. Conceivably this system could be economical, since lower-cost base-load generation could be continuously operated at its most efficient point and provide all of the required energy. Expensive peaking generation could be completely eliminated. If the generation savings exceeded the cost of storage (capital, losses, and maintenance), this system might be economically attractive in a regulated environment. This solution would not be economical for PSH in a simple market area, however, because generators and storage are paid based on the marginal cost of energy (i.e., prices) in each hour. While the difference between on-peak and offpeak prices might have been sufficient to justify storage before it was installed, the storage project would collapse the price difference as soon as it started to operate. On-peak and off-peak prices would be the same (or they would differ, at most, by the storage project's efficiency loss) because the marginal generation would be the same during all hours based on the flat net load seen by the base-loaded generators. Loads would see the same benefit (elimination of high-cost peaking generation) in both the regulated and restructured areas (as long as the storage facility was able to operate), but the storage project itself would go out of business if it relied on the energy arbitrage payments to recover its capital costs. ${ }^{10}$

Regulated and restructured regions also differ in how they compensate investors. In regulated areas, the utility explains the need for new resources. If new facilities are approved by the state public utility commission (PUC), they are built, either by the utility or an independent power producer (IPP). Capital costs are typically recovered through the utility rate base over decades of time, and cost recovery is essentially guaranteed for the investor. ${ }^{11}$ In restructured areas, investors assume the capital cost recovery risk based on the expected income from the energy and A/S markets. Some ISOs and RTOs also administer capacity markets, but these provide limited cost recovery for a relatively short period, as discussed in Section 8.1.

\subsection{Energy Arbitrage and Ancillary Services}

Net generation and load must be balanced instantaneously and continuously to maintain power system reliability. This balance is achieved through a combination of unit commitment and the economic dispatch of generation (and, to some extent, load) and A/S to compensate for fluctuations that are faster than economic dispatch can follow (Hirst and Kirby 1997). This situation is true in both regulated and restructured areas, but restructured areas typically specify the economic dispatch and A/S characteristics more explicitly. Restructured areas, for example, typically operate sequential energy markets that clear DA hourly, HA hourly, and every 5 min in RT markets. Regulated areas typically perform the same balancing function but are not as explicit or as public in defining the scheduling process and resulting prices. Because electricity is a RT product for which production and consumption occur simultaneously, the production cost and electricity price vary with the consumption quantity, resulting in the ability for storage to engage in energy arbitrage.

10 Loads could actually see a greater benefit in the market area than in the regulated area, since all energy cleared in the market would be priced at the margin. The pumped storage plant would reduce the cost of all on-peak energy rather than only saving the cost of energy produced by the peaking plant itself.

11 Details vary — often significantly — from region to region, but the basic concept is similar. 
Both energy arbitrage and A/S require the flexible control of real power that storage can provide. Energy arbitrage involves charging storage at times when energy is plentiful and inexpensive and returning that energy to the power system when it is scarce and expensive. Energy arbitrage can be done in vertically integrated, regulated regions based on the marginal cost of generation, or it can be done in restructured market regions based on energy market prices. Time frames can be as long as seasonal to as short as every 5 min, with daily arbitrage being most common. For an energy arbitrage transaction to be economically viable, the ratio of the cost of the charging energy to the cost of energy while the storage is discharging must exceed the round-trip efficiency of the storage project. For a storage project to be economically viable, there must be a sufficient number of viable arbitrage transactions to cover the capital and operating costs of the project. $^{12}$ Daily arbitrage provides about 130 times as many potentially profitable transactions as does seasonal arbitrage, assuming weekday operations and two seasonal transactions per year. Sub-hourly energy markets provide many more arbitrage opportunities, but there is no regular sub-hourly price cycle similar to the usual daily price cycle. Sub-hourly energy arbitrage opportunities require responding to RT power system and energy market conditions. They also require payments to be settled at the sub-hourly level, which, as is discussed later, not all markets currently do. The length of the cycle also determines the required ratio of energy storage (MWh) to power capability (MW). Seasonal cycling might require charging and discharging for several weeks at a time, requiring perhaps 250 MWh of storage for each MW of capacity. Daily cycling might require $8 \mathrm{~h}$ of charging and discharging, or $8 \mathrm{MWh}$ of storage capacity for each MW of capacity. Sub-hourly transactions might bring the ratio closer to $1 \mathrm{MWh}$ of storage for each MW of capacity.

A/S typically refer to active power operating reserves, voltage support, and black-start services. ${ }^{13}$ Operating reserves involve resources that are standing by, ready to inject energy into the power system when a major disturbance occurs (contingency reserves), or constantly injecting or removing energy from the power system to compensate for the variability of loads, conventional generators, and renewables (regulating and following reserves). Figure 8-1 shows different categories of operating reserves and why and when they are needed (Ela et al. 2011). Operating reserves can be characterized by their response speed (ramp rate and start time), response duration, frequency of use (continuously or only during rare events), direction of use (up or down), and type of control (control center activation, autonomous, or automatic, among others). Some operating reserves are used to respond to routine variability of the generation or the load. These variations occur on different time scales (from seconds to days), and different control strategies can be required depending on the speed of the variability. Other operating reserves are needed to respond to rare, unexpected events, such as the tripping of a generator.

12 This is referring to the energy storage capability rather than the power handling capability of the project. Both capabilities (energy and power) contribute to the cost of an energy storage project.

13 Black-start (the ability to supply energy to the power system after a blackout) and reactive power/voltage control are also $\mathrm{A} / \mathrm{S}$ that storage may be able to supply. 


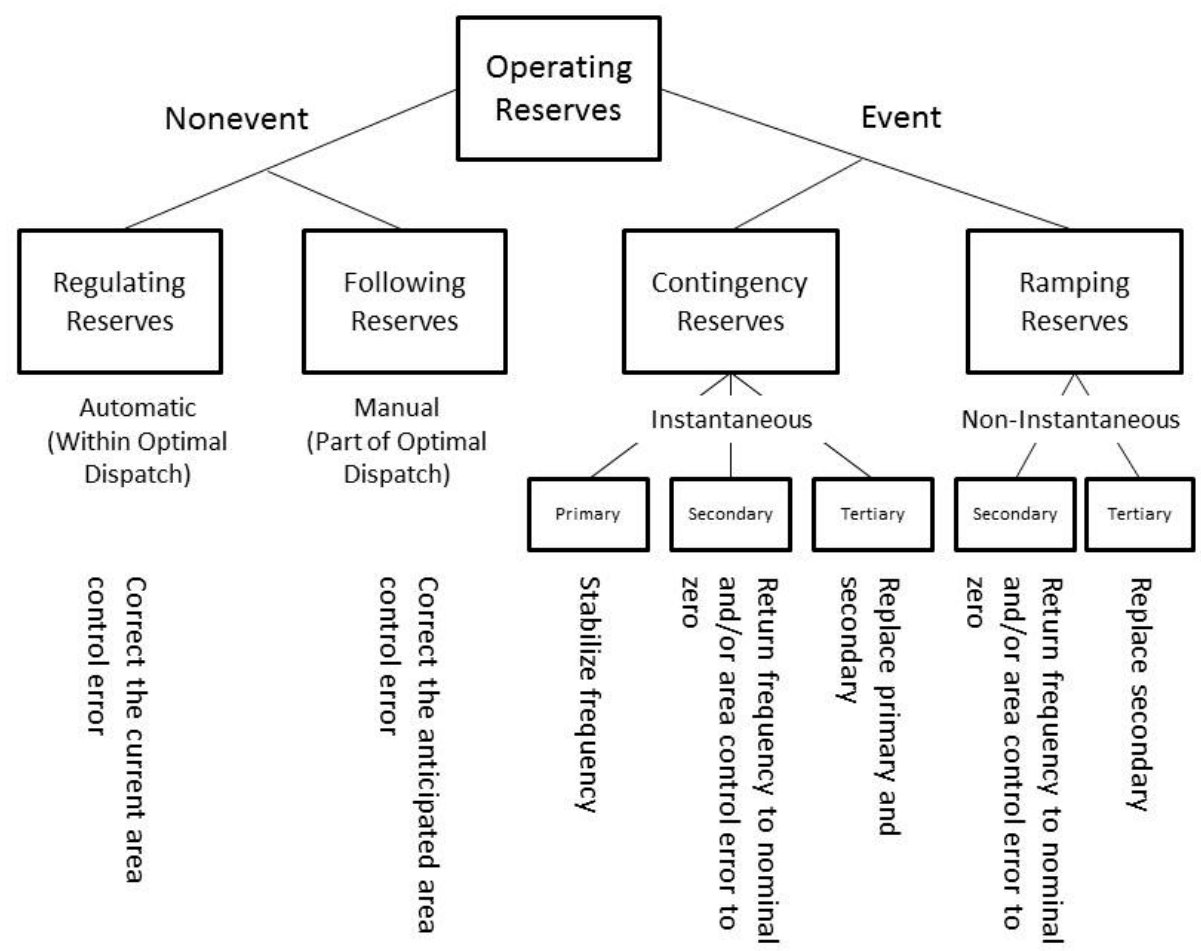

Figure 8-1 Operating Reserves, Showing Why and When They Are Needed (Ela et al. 2011)

Another way to classify the operating reserves could be based on whether they are deployed during normal conditions or event conditions. Normal conditions can be based on both variability and uncertainty, but they take place continuously. Event conditions occur whether they can be predicted or not. The standby costs and deployment costs for each reserve category differ based on how frequently they are used. This distinction, along with the technical requirements, may allow certain technologies to be more suitable for different operating reserve types than other technologies. The capability and capacity of A/S are typically sold to the system operator on an hourly or 5-min basis, but the A/S response is then under the direct control of the system operator. Table 8-1 summarizes the definitions/uses of each reserve category and other common terms used in the industry that typically refer to the same reserve category.

Of the services that have been mentioned, two have A/S markets associated with them: regulating reserve and contingency reserve. Following and ramping reserves are not defined as separate products in current market designs. Regulating and contingency reserves are two A/S that support frequency control. FERC (2011) defines regulation as "the capability to inject or withdraw real power by resources capable of responding appropriately to a system operator's automatic generation control (AGC) signal in order to correct for actual or expected area control error (ACE) needs.” It operates on time scales below the shortest energy dispatch interval and is 
Table 8-1 Operating Reserve Definitions and Common Terms

\begin{tabular}{|c|c|c|}
\hline Name & Use & Other Common Terms \\
\hline $\begin{array}{l}\text { Operating } \\
\text { reserve }\end{array}$ & $\begin{array}{l}\text { Any capacity available for assistance in active power } \\
\text { balance. }\end{array}$ & \\
\hline $\begin{array}{l}\text { Non-event } \\
\text { reserve }\end{array}$ & $\begin{array}{l}\text { Capacity available for assistance in active power balance } \\
\text { during normal conditions, or those that occur continuously. }\end{array}$ & \\
\hline $\begin{array}{l}\text { Regulating } \\
\text { reserve }\end{array}$ & $\begin{array}{l}\text { Capacity available during normal conditions for assistance in } \\
\text { active power balance to correct the current imbalance that } \\
\text { occurs, is faster than economic dispatch optimization, is } \\
\text { random, and requires an automatic centralized response. }\end{array}$ & $\begin{array}{l}\text { Regulating reserve, } \\
\text { regulation, load } \\
\text { frequency control, } \\
\text { secondary control }\end{array}$ \\
\hline $\begin{array}{l}\text { Following } \\
\text { reserve }\end{array}$ & $\begin{array}{l}\text { Capacity available during normal conditions for assistance in } \\
\text { active power balance to correct future anticipated imbalance, is } \\
\text { not faster than economic dispatch optimization, and does not } \\
\text { require an automatic centralized response. }\end{array}$ & $\begin{array}{l}\text { Load following, } \\
\text { following reserve, } \\
\text { schedule reserve, } \\
\text { dispatch reserve, } \\
\text { balancing reserve }\end{array}$ \\
\hline $\begin{array}{l}\text { Event } \\
\text { reserve }\end{array}$ & $\begin{array}{l}\text { Capacity available for assistance in active power balance } \\
\text { during infrequent events that is more severe than the } \\
\text { balancing needed during normal conditions. }\end{array}$ & \\
\hline $\begin{array}{l}\text { Contingency } \\
\text { reserve }\end{array}$ & $\begin{array}{l}\text { Capacity available for assistance in active power balance } \\
\text { during infrequent events that is more severe than the } \\
\text { balancing needed during normal conditions and is used to } \\
\text { correct instantaneous imbalances. }\end{array}$ & $\begin{array}{l}\text { Contingency reserve } \\
\text { (spinning and non- } \\
\text { spinning reserve) }\end{array}$ \\
\hline $\begin{array}{l}\text { Ramping } \\
\text { reserve }\end{array}$ & $\begin{array}{l}\text { Capacity available for assistance in active power balance } \\
\text { during infrequent events that is more severe than the } \\
\text { balancing needed during normal conditions and is used to } \\
\text { correct non-instantaneous imbalances. }\end{array}$ & Ramping reserve \\
\hline $\begin{array}{l}\text { Primary } \\
\text { reserve - } \\
\text { contingency }\end{array}$ & $\begin{array}{l}\text { Portion of contingency reserve that is automatically } \\
\text { responsive to instantaneous active power imbalance and } \\
\text { stabilizes system frequency. }\end{array}$ & $\begin{array}{l}\text { Primary control reserve, } \\
\text { frequency responsive } \\
\text { reserve, governor droop }\end{array}$ \\
\hline $\begin{array}{l}\text { Secondary } \\
\text { reserve - } \\
\text { contingency }\end{array}$ & $\begin{array}{l}\text { Portion of contingency reserve that is not automatically } \\
\text { responsive to the instantaneous active power imbalance and } \\
\text { corrects frequency to nominal and/or ACE to } 0 .\end{array}$ & $\begin{array}{l}\text { Secondary control } \\
\text { reserve, spinning } \\
\text { reserve }\end{array}$ \\
\hline $\begin{array}{l}\text { Tertiary } \\
\text { reserve - } \\
\text { contingency }\end{array}$ & $\begin{array}{l}\text { Portion of contingency reserve that is available for } \\
\text { assistance in replacing primary and secondary reserve used } \\
\text { during a severe instantaneous event so that they are } \\
\text { available for a subsequent instantaneous event that occurs } \\
\text { in the same direction. }\end{array}$ & $\begin{array}{l}\text { Tertiary control reserve, } \\
\text { replacement reserve, } \\
\text { supplemental reserve }\end{array}$ \\
\hline $\begin{array}{l}\text { Secondary } \\
\text { reserve - } \\
\text { Ramping }\end{array}$ & $\begin{array}{l}\text { Portion of ramping reserve that is used to correct the } \\
\text { imbalance of a severe non-instantaneous event and corrects } \\
\text { the frequency to nominal and/or ACE to } 0 \text {. }\end{array}$ & Ramping reserve \\
\hline $\begin{array}{l}\text { Tertiary } \\
\text { reserve - } \\
\text { ramping }\end{array}$ & $\begin{array}{l}\text { Portion of ramping reserve that is available for assistance in } \\
\text { replacing secondary reserve used during a severe non- } \\
\text { instantaneous event so that eventually secondary reserve is } \\
\text { available for a subsequent event that occurs in the same } \\
\text { direction. }\end{array}$ & $\begin{array}{l}\text { Replacement reserve for } \\
\text { ramping reserve }\end{array}$ \\
\hline
\end{tabular}


used to compensate for the random, minute-to-minute variations in aggregate system load that are too fast to be followed by the economic dispatch of the energy-producing generators (see Figure 8-2; Kirby 2006).

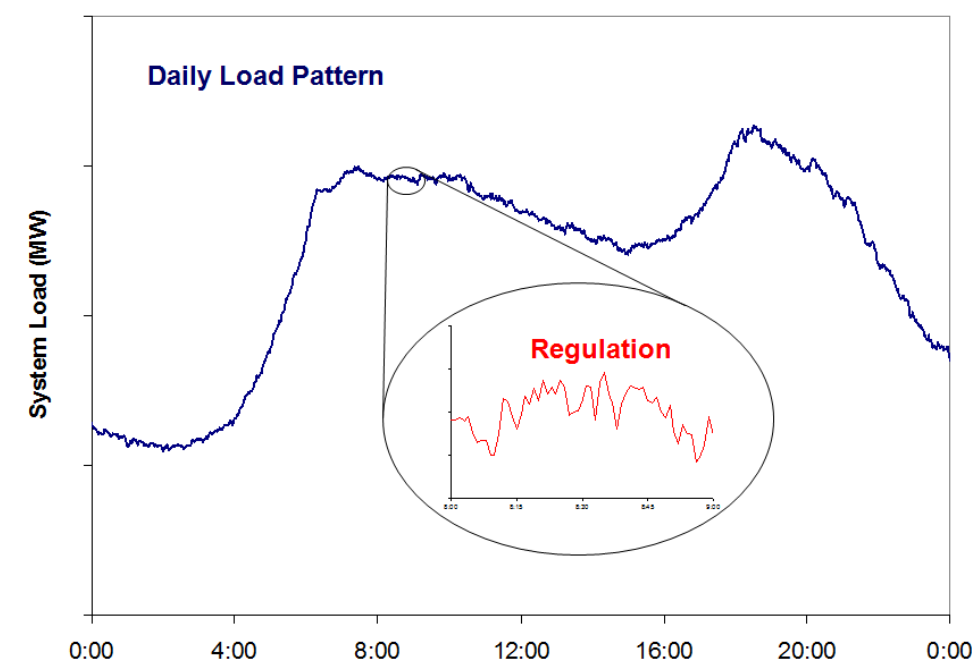

Figure 8-2 Regulation Compensates for Random Minute-to-Minute Variations in Net System Load (Kirby 2006)

FERC (2007) describes spinning reserve as that "needed to serve load immediately in the event of a system contingency. Spinning Reserve Service may be provided by generating units that are on-line and loaded at less than maximum output and by non-generation resources capable of providing this service.” Frequency response, or primary frequency response, is the autonomous rapid response from a turbine-governor of conventional generation or rapid response from demand response. The response is directly in opposition to changing frequency and is needed to arrest the initial frequency decline during generation outages (or frequency rise during large losses of load or pumped storage units in pump operation). Secondary frequency response, which is closer to the FERC-described spinning reserve, is then used to bring frequency back to its nominal level (e.g., $60 \mathrm{~Hz}$ in the United States) or to bring the ACE back to zero. The response duration is typically about 10 min but may be more than an hour for rare, serious events (see Figure 8-3; Kirby et al. 2008). While regulation is adjusted continuously based on the AGC cycle (e.g., 2 to $8 \mathrm{sec}$ ), spinning reserve is called upon relatively infrequently (e.g., every few days in some areas, and once a week or less often in other areas). ${ }^{14}$

14 Large wind and solar fluctuations have characteristics that are similar to those of conventional generation contingencies: Large events are relatively rare. It may be appropriate to use contingency reserves, or additional contingency-like reserves, to compensate for high wind and solar penetration. This may be desirable because contingency reserves are typically lower cost than regulation reserve, the typical alternative. 


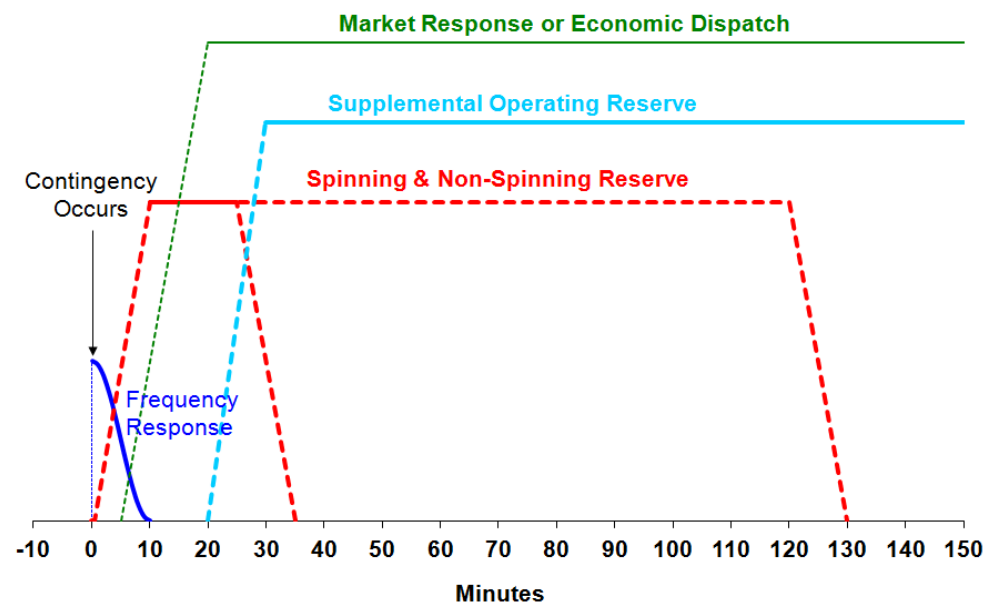

Figure 8-3 Contingency Reserves Compensate for the Sudden Failure of a Large Generator or Transmission Line (Kirby et al. 2008)

Markets value flexibility through energy and A/S prices. Table 8-2 shows 11 years of average annual A/S prices from five market areas. Although the prices vary from year to year, they do follow a pattern in which regulation is the most expensive service, followed by spinning reserve, non-spinning reserve, and replacement reserve. For storage, the variability in energy prices is more important than the absolute value. Figure 8-4 shows the average daily pattern for energy (DA hourly priced at the CAISO reference bus) and A/S for CAISO from 2011. There was a \$28/MWh difference between the average daily high and low DA hourly energy prices at the reference bus in 2011 that storage could potentially exploit. Of course, there is significant volatility from day to day as well, but the yearly average shows that the daily pattern is consistent. The HA and 5-min markets show similar patterns, but with greater day-to-day volatility.

The daily pattern in A/S prices should be considered as well. As discussed elsewhere in this report, the ability of storage and especially PSH to provide A/S depends on the technical capabilities of the plant. Conventional FS pumped storage plants typically cannot provide regulation when they are pumping or idle. The plant must be generating and operating above minimum load and below full load so that it has room to move up and down in response to the system operator's AGC signal. AS PSH plants, however, can provide both regulating and following reserve while in pumping mode (see Appendix A). These AS plants can similarly supply spinning reserve when generating below full load or when idling in condensing mode with the turbine spinning in air. Some regions allow FS pumped storage plants to provide spinning reserve when pumping. All PSH plants can provide non-spinning reserve when idle if they are able to synchronize and load within 10 to $30 \mathrm{~min}$, depending on the A/S requirement. The A/S daily price pattern is important because spinning reserve and non-spinning reserve are typically at their lowest values overnight, when energy is inexpensive and storage is likely to be charging. 
Table 8-2 Average Ancillary Services Prices from Each ISO/RTO from 2002 through 2012

\begin{tabular}{|c|c|c|c|c|c|c|c|c|c|c|c|}
\hline \multirow{2}{*}{$\begin{array}{c}\text { ISO/RTO } \\
\text { and Service }\end{array}$} & \multicolumn{11}{|c|}{ Annual Average Price (\$/MWh) per Year } \\
\hline & 2002 & 2003 & 2004 & 2005 & 2006 & 2007 & 2008 & 2009 & 2010 & 2011 & 2012 \\
\hline \multicolumn{12}{|c|}{ CAISO (California) (Reg = up + down) } \\
\hline Regulation & 26.9 & 35.5 & 28.7 & 35.2 & 38.5 & 26.1 & 33.4 & 12.6 & 10.6 & 16.1 & 10.0 \\
\hline Spinning & 4.3 & 6.4 & 7.9 & 9.9 & 8.4 & 4.5 & 6.0 & 3.9 & 4.1 & 7.2 & 3.3 \\
\hline Non-spinning & 1.8 & 3.6 & 4.7 & 3.2 & 2.5 & 2.8 & 1.3 & 1.4 & 0.6 & 1.0 & 0.9 \\
\hline Replacement & 0.90 & 2.9 & 2.5 & 1.9 & 1.5 & 2.0 & 1.4 & - & - & - & - \\
\hline \multicolumn{12}{|c|}{ ERCOT (Electric Reliability Council of Texas) (Reg = up + down) } \\
\hline Regulation & - & 16.9 & 22.6 & 38.6 & 25.2 & 21.4 & 43.1 & 17.0 & 18.1 & 31.3 & 9.2 \\
\hline Responsive & - & 7.3 & 8.3 & 16.6 & 14.6 & 12.6 & 27.2 & 10.0 & 9.1 & 22.9 & 9.1 \\
\hline Non-spinning & - & 3.2 & 1.9 & 6.1 & 4.2 & 3.0 & 4.4 & 2.3 & 4.3 & 11.8 & 6.7 \\
\hline \multicolumn{12}{|c|}{ NYISO (New York ISO) (East) } \\
\hline Regulation & 18.6 & 28.3 & 22.6 & 39.6 & 55.7 & 56.3 & 59.5 & 37.2 & 28.8 & 11.8 & 10.4 \\
\hline Spin & 3.0 & 4.3 & 2.4 & 7.6 & 8.4 & 6.8 & 10.1 & 5.1 & 6.2 & 7.4 & 6.0 \\
\hline Non-spinning & 1.5 & 1.0 & 0.3 & 1.5 & 2.3 & 2.7 & 3.1 & 2.5 & 2.3 & 3.9 & 3.8 \\
\hline 30-min & 1.2 & 1.0 & 0.3 & 0.4 & 0.6 & 0.9 & 1.1 & 0.5 & 0.1 & 0.1 & 0.3 \\
\hline \multicolumn{12}{|c|}{ MISO (Midcontinent ISO) } \\
\hline Regulation & - & - & - & - & - & - & - & 12.3 & 12.2 & 10.8 & 7.8 \\
\hline Spinning & - & - & - & - & - & - & - & 4.0 & 4.0 & 2.8 & 2.3 \\
\hline Non-spinning & - & - & - & - & - & - & - & 0.3 & 1.5 & 1.2 & 1.4 \\
\hline \multicolumn{12}{|c|}{ ISONE (ISO New England) (Reg + "mileage") } \\
\hline Regulation & - & - & 54.6 & 30.2 & 22.7 & 12.7 & 13.8 & 9.3 & 7.1 & 7.2 & 6.7 \\
\hline Spinning & - & - & - & - & 0.3 & 0.4 & 1.7 & 0.7 & 1.8 & 1.0 & 1.7 \\
\hline 10-min & - & - & - & - & 0.1 & 0.3 & 1.2 & 0.5 & 1.6 & 0.4 & 1.0 \\
\hline 30-min & - & - & - & - & 0.0 & 0.1 & 0.1 & 0.1 & 0.4 & 0.3 & 1.0 \\
\hline
\end{tabular}

“-" = not applicable

A flexible plant can maximize profits not only by responding to the expected daily pattern of energy and A/S prices but by changing how it responds on the basis of how energy and each of the A/S prices change in real time (Kirby 2012)

\subsection{Capacity Markets and Payments}

Capacity adequacy has been a challenge in restructured electricity markets for a long time. In theory, in a perfect market in equilibrium, the prices of energy and A/S should be sufficient to cover the capital and operating costs of the optimal mix of capacity. This requires that prices rise to levels well above the marginal cost of the most expensive generation during periods of scarcity. However, scarcity pricing tends to be inadequate due to limited demand response and to regulatory intervention, such as price or bid caps. The price of energy and reserves alone may therefore not be sufficient to trigger an adequate expansion of new generation capacity. The problem may be exacerbated by noncompetitive markets with large incumbent generation companies that could exercise market power. Limited liquidity in long-term markets also makes 


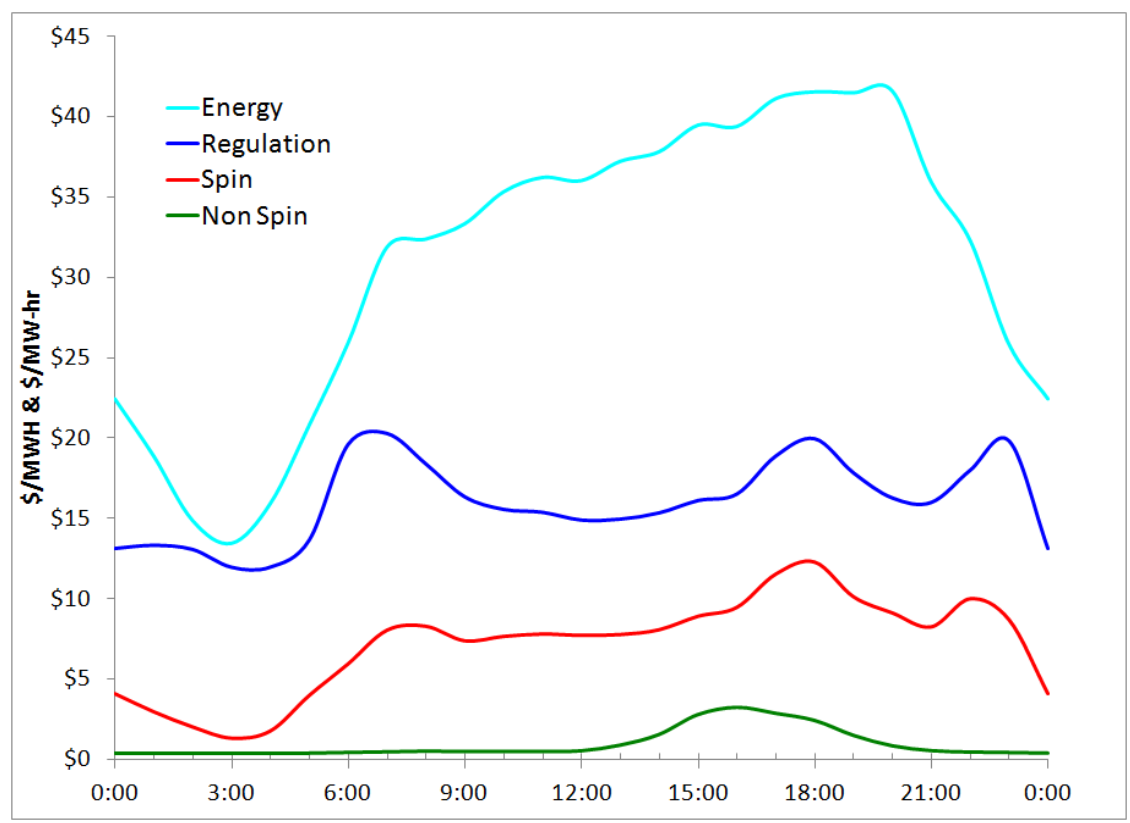

Figure 8-4 CAISO Average Hourly 2011 Prices for Energy (Reference Bus) and Ancillary Services

it difficult for investors to hedge the substantial risks in generation investment with high capital costs and long construction periods. Several different incentive mechanisms have been proposed and implemented to address the capacity adequacy problem (Botterud and Doorman 2008).

Some ISOs and RTOs in the United States established capacity markets to assure that there will be sufficient capacity (generation, storage, and demand response) available, at the right locations, to meet forecasted demand plus reserve requirements. The fear is that near-RT energy and A/S markets may not provide sufficient incentives on their own so that market participants can develop enough resources to meet requirements at all times. There is also concern by some, like the PJM independent market monitor (Bowring 2008), that generators have generally not earned sufficient revenues to recover the fixed costs of building new plants. These regions claim that waiting for actual energy and A/S prices to reflect the need for additional capacity is impractical because it takes significant time to build new generation, storage, and demand response facilities. ISONE and PJM operated 1-year forward capacity markets 3 years ahead. CAISO imposes a 1-year forward planning reserve requirement on load-serving entities LSEs but does not have a centralized capacity market to help LSEs meet the requirement. New York ISO (NYISO) operates a monthly capacity market.

Bilateral capacity transactions are also possible in regions where a capacity obligation is placed on the LSEs. LSEs can rely on the ISO/RTO's capacity market to meet their obligation. Alternatively, an LSE may be willing to enter into a capacity contract with a resource for an extended period, even if the ISO/RTO enforces the capacity requirement for only one year at a time. The LSE would be self-supplying its capacity obligations to the ISO/RTO. This could provide a resource with a longer contractual commitment than the 1-year payment that is set 
3 years in advance. This may lower the cost for both the resource and the LSE. The resource still needs to meet all of the ISO/RTO's physical, location, financial, performance, and penalty obligations for qualification and performance.

In theory, forward capacity markets should incentivize investment in needed new resources by providing them with an assured income to cover all or part of their capital cost in exchange for the resource being available to meet the power system's energy and reserve needs. In actuality, capacity markets, where they exist, are for a limited duration (1 year at most for each auction cycle), are for a limited future commitment (3 years in advance, at most, for each auction cycle), and provide limited compensation. Auctions typically clear at well below the cost of new entry (CONE) for a new combustion turbine (typically the lowest-cost benchmark capacity resource). There are several reasons that market clearing prices are typically lower than the CONE. New combustion turbine generators may offer their capacity at lower-than-full capital cost because they are expected to be more efficient and flexible than existing generators and thus make a profit in the energy and A/S markets. Existing resources, with sunk capital costs, may be willing to be "price takers" in the capacity market, offering their capacity at very low cost. Older retiring generators may be willing to remain available for less cost than the CONE. Moreover, demand response resources may also offer capacity at lower cost.

Additional factors reduce the capacity payment benefits, especially for PSH. Capacity obligations and capacity markets are supposed to reduce RT energy price volatility. This may be good for loads, but it can be bad for storage, which profits from the on-peak/off-peak price spread. Similarly, ISONE explicitly reduces the capacity payment when a resource profits from high spot energy prices, based on the theory that the capacity obligation was supposed to mitigate energy price spikes, and a resource should not be doubly compensated when a spike occurs. ${ }^{15}$ Lastly, capacity markets are typically location-specific. The highest prices are often found in congested areas where it may not be possible to locate PSH.

\section{ISONE}

ISONE operates a 1-year forward capacity auction 3 years in advance for a period lasting from June 1 through May 31 of the following year. The purpose is to attract new resources to constrained regions. The market process starts 5 years in advance, and resources that expressed interest in qualifying to supply capacity and resources are qualified by 4 years in advance. Each forward capacity auction begins in February, which is 3 years and 3 months before capacity is required. New resources can lock in a successful capacity price for 5 years (indexed to inflation); all other resources are limited to 1-year commitments. ISONE also has a capacity price floor that is set at $60 \%$ of the established CONE. Every auction so far has cleared at the floor price 16 (ISONE 2013a,b).

15 The hourly LMP is compared with a proxy generator with a 22,000-Btu/kWh heat rate that burns ultra-low-sulfur No. 2 oil or DA gas. The capacity payment is reduced by the amount of profit the proxy unit would have made.

16 All zones for all years have cleared at the floor price, except for the Boston zone during the 20162017 seventh forward capacity auction, for which insufficient capacity was offered. 
A resource having a capacity supply obligation must offer into both the DA energy market and RT energy market at an amount (in MW) equal to or greater than its capacity supply obligation whenever the resource is physically available. Resources are penalized approximately $1 \%$ for each hour of unavailability during shortage events. Table 8-3 shows the results for the seven ISONE forward capacity auctions held to date.

Table 8-3 Forward Capacity Market Clearing Prices (\$/kW per Month) for ISONE and PJM

\begin{tabular}{|l|c|c|c|c|c|c|c|c|c|c|}
\hline & \multicolumn{10}{|c|}{ Years } \\
\cline { 2 - 11 } Provider & $\mathbf{0 7 - 0 8}$ & $\mathbf{0 8 - 0 9}$ & $\mathbf{0 9 - 1 0}$ & $\mathbf{1 0 - 1 1}$ & $\mathbf{1 1 - 1 2}$ & $\mathbf{1 2 - 1 3}$ & $\mathbf{1 3 - 1 4}$ & $\mathbf{1 4 - 1 5}$ & $\mathbf{1 5 - 1 6}$ & $\mathbf{1 6 - 1 7}$ \\
\hline ISONE & & & & 4.50 & 3.60 & 2.95 & 2.95 & 3.21 & 3.43 & 3.15 \\
\hline $\begin{array}{l}\text { PJM } \\
\text { system }\end{array}$ & 1.24 & 3.63 & 3.10 & 5.30 & 3.57 & 0.50 & 0.84 & 4.08 & 4.14 & 1.81 \\
\hline $\begin{array}{l}\text { PJM most } \\
\text { congested } \\
\text { zone }\end{array}$ & 6.01 & 6.81 & 7.22 & 5.66 & 3.57 & 6.76 & 7.52 & 7.29 & 10.86 & 6.66 \\
\hline
\end{tabular}

\section{PJM}

The PJM forward capacity market is similar to ISONE's: a one-year obligation running from June 1 through May 31 of the following year set three years in advance. PJM does have a price elasticity curve to adjust the amount of capacity procured based on the market prices. It does not have a capacity price floor. PJM uses capacity price units of \$/MW per day, but they were converted to $\$ / \mathrm{kW}$ per month for Table 8-3 to facilitate comparison with ISONE. Capacity prices for most of PJM ( 55\%) are more volatile than those for ISONE because there is no floor to the capacity price. Prices in congested zones are somewhat higher (PJM 2013).

\section{NYISO}

NYISO has a reserve requirement and a monthly centralized capacity market but no forward market. Monthly prices for 2012-2013 averaged $\$ 9.42 / \mathrm{kW}$ per month for the New York City zone, $\$ 3.25 / \mathrm{kW}$ per month for Long Island, and $\$ 2.70 / \mathrm{kW}$ per month for the rest of the NYISO balancing area (NYISO 2013).

\section{MISO}

MISO has a reserve requirement but no forward capacity market. MISO recently conducted its first annual capacity market for the 2013-2014 year. The voluntary annual capacity auction replaces MISO's former monthly auction process and includes the ability to self-supply or to opt out of the auction clearing process. The systemwide clearing price for the 2013-2014 planning year was only $\$ 0.03 / \mathrm{kW}$ per month (MISO 2013).

\section{CAISO}

CAISO imposes a 1-year forward reserve requirement on LSEs, but it does not have a centralized capacity market to help LSEs meet the requirement. However, the State of California does have a very comprehensive capacity procurement process to help LSEs meet CAISO's capacity targets. Every 2 years, the California Public Utilities Commission conducts a long-term procurement 
plan proceeding to review and adopt the 10-year-capacity procurement plans of the investorowned utilities (IOUs).

\subsubsection{Capacity Market Considerations}

Currently implemented capacity markets do not provide long-term firm coverage of all PSH capital costs. Potential payments are lower and more volatile, and commitments cover a few years at most. Still, capacity markets can help cover some of the PSH capital costs.

\subsection{Treatment of PSH in Electricity Markets}

In the United States, nearly $66 \%$ of the electricity is consumed within restructured electricity markets. Deregulation started in the United States in the late 1990s with a FERC Notice of Proposed Rule Making, followed by FERC Order 888, Promoting Wholesale Competition through Open Access Non-discriminatory Transmission Service (FERC 1996a) and FERC Order 889, OASIS: Open Access Same-Time Information System and Standards of Conduct (FERC 1996b). These two orders established the basic principles for wholesale electricity markets and ISOs and RTOs, which are the entities that grew out of Order 2000 (FERC 1999). It also established the mechanisms for A/S, the system operator's code of conduct (which ensures equal treatment for IPPs and utility-owned generation and was finalized with Order 2004 in November 2003; see FERC 2003a), and the energy market structure. DA and RT markets were introduced. FERC Order 2003, Standardization of Generator Interconnection Agreements and Procedures (FERC 2003b) established the large generator interconnection procedure (LGIP) and large generator interconnection agreement (LGIA), which standardize requirements and procedures for interconnecting utility-owned and IPP generators, further leveling the playing field. This was followed by FERC Order 2006 (A\&B), Standardization of Small Generator Interconnection Agreements and Procedures (FERC 2005a, FERC 2006), which established similar but less complex small generator integration procedure (SGIP) and small generator interconnection agreement (SGIA) requirements. FERC Orders 661 and 661-A, Interconnection for Wind Generators (FERC 2005b,c) extended the LGIA/LGIP to establish interconnection requirements for wind generators. More recent FERC orders continue to refine the restructured wholesale market structure, as follows:

- $\quad$ Order 890: OATT Reform - February 2007.

- Order 1000: Transmission Planning and Cost Allocation by Transmission Owning and Operating Public Utilities - July 2011. The order requests cost allocation procedures for transmission plans that cross multiple transmission areas.

- $\quad$ Order 745: Demand Response Compensation in Organized Wholesale Energy Markets - March 2011. The order requests demand response resources that participate in markets to have special compensation schemes.

- Order 755: Frequency Regulation Compensation - October 2011. The order requests ISO and RTO administrators to implement pay for performance procedures in markets for regulating reserve. 
- Order 764: Integration of Variable Energy Resources - June 2012. The order requests that balancing area authorities offer 15-min scheduling to their market participants and that variable generators offer specific resource data for forecasting purposes.

- Order 784: Third Party Provision of Ancillary Services - July 2013. The order requests that revisions be made to the sale of $\mathrm{A} / \mathrm{S}$ at market-based rates in all jurisdictional service areas.

Figure 8-5 shows the ISO and RTO regions in North America. In the United States, these markets have evolved in similar directions, to a large extent following the principles proposed in the standard market design (Hogan 1998). This design reflects a pool-based market where there is a two or three-settlement system for forward and RT markets, with co-optimized energy and A/S, LMPs for energy, and financial transmission rights markets in place for hedging. Energy is sold in forward (e.g., DA hourly markets) and balanced in HA and 5-min RT markets with locational marginal prices. Financial transmission rights (FTRs) are a hedging instrument put in place to collect the locational differences in energy prices. In some U.S. markets, capacity markets are also put in place to incentivize investment in installed capacity and to ensure peaking units can recover fixed costs, as discussed.

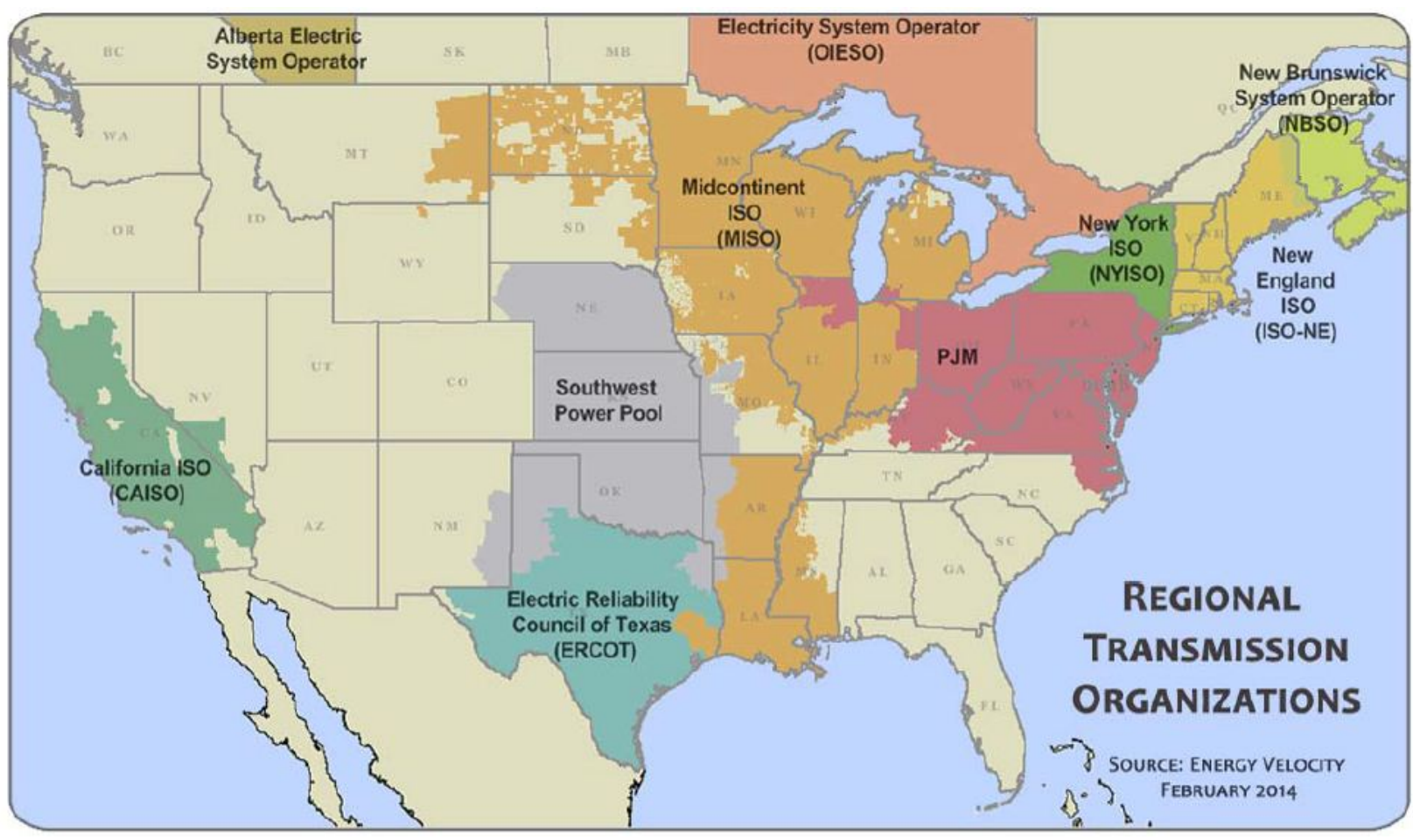

Figure 8-5 RTO and ISO Regions in North America (Source: FERC 2014)

To support the scheduling of energy in power systems, operators also require A/S. In the United States, ISOs and RTOs obtain several active power A/S through markets that are cooptimized with energy procurement. Current A/S markets typically include regulation, spinning, 
non-spinning, and sometimes supplemental reserve. Two additional services - following and frequency response - are being considered as explicit A/S that may be appropriate for market procurement by several RTOs (Ela et al. 2012a). While following reserve has been getting attention as a new payment source (Navid and Rosenwald 2012), primary frequency response is not incentivized in any of the market regions to date (Ela et al. 2012b). Voltage support and black-start are A/S that are required for system reliability but have not proved to be amenable to dynamic market procurement. Instead these services are obtained through interconnection requirements (voltage support and reactive power) and through longer-term contracts (blackstart).

Power plants are large, capital-intensive resources that take considerable time to permit and build. The decision to build a power plant must be made well before the plant is needed. Some regions rely on high prices, including administratively set scarcity prices, in the energy market itself to provide the necessary incentives for new generation. Other regions operate explicit capacity markets to assure that sufficient generation will be available to meet the expected load. Regions with capacity markets find that the capacity prices tend to be limited to the cost of a new combustion turbine, since the capacity markets consider only the fixed costs of assuring an adequate power supply and do not consider the delivered cost of energy. Capacity market auctions can result in lower prices than combustion turbine installation costs when demand response participates or if there is surplus capacity in the system.

\subsubsection{Mechanisms for Pricing and Settlement Calculations}

Prices for energy and A/S are calculated in similar ways throughout all of the restructured regions in the United States. This report refers to these prices as LMP and A/S clearing prices (ASCPs) for energy and A/S, respectively. The concept in the United States is for uniform marginal pricing. Marginal pricing reflects the cost of serving the next increment of demand, whether the demand is for energy or for A/S. The prices differ depending on the location on the system. For energy, the prices may differ at every bus bar. For A/S, there are typically fewer location requirements, and prices are usually the same throughout the market region, or there may be some zonal differences when large interfaces are constrained.

The LMP is mathematically represented as the dual value of the nodal energy injection constraints. It includes components for energy, transmission congestion, and transmission electrical losses (Shahidehpour et al. 2002). The general equation is:

$$
L M P_{n}=\lambda_{r e f}-\sum_{l=1}^{\text {Lcong }} S F_{n, l} * \mu_{l}+\left(D F_{n}-1\right) * \lambda_{r e f}
$$

where:

$\lambda_{\text {ref }}=$ the shadow price of energy at the reference bus,

$S F=$ the shift factor of the bus $n$ contribution to the flow on line $l$, 
$\mu_{l}=$ the shadow price for the transmission constraint of line $l$, and

$D F_{n}=$ the delivery factor (i.e., how much energy from bus $n$ gets delivered to the reference bus after electrical losses).

In a lossless system without transmission congestion, the price at every bus will be the same. When transmission congestion is apparent, it causes more expensive resources to be needed on one side of the constraint, as the cheaper units are constrained by the transmission limits. This causes the price to be higher where the expensive unit is needed and lower where the cheaper unit is located. This is typically calculated for large systems by using a DC power flow (i.e., a linearized approximation of the full power flow equations). Finally, prices are also higher at locations that are closer to the load, even without transmission congestion. This is because the energy injected by generation closer to the load will have fewer transmission losses. Therefore, an injection of $1 \mathrm{MW}$ is worth more when it is closer to the load than when it is farther away from it, where more energy is lost on the transmission lines.

Calculating ASCP is in some ways very similar to calculating LMP. We discuss only the A/S related to active power operating reserve, so voltage control and reactive power support are ignored; in practice in the United States, these do not have dynamic markets. ASCP is mathematically defined as the dual value of the associated operating reserve requirement constraint. It is essentially equal to the total cost increase of the system if an incremental amount of operating reserve is required. The costs involved with operating reserve are a combination of bid-in costs and lost opportunity costs. Lost opportunity costs are those associated with a resource's lost chance to make a profit in another market, and are part of the calculated ASCP when energy and $\mathrm{A} / \mathrm{S}$ are co-optimized in the market. Lastly, A/S markets also have a pricing hierarchy (Oren 2001). This is in place since some A/S are more important than others, and there are incentives in place so that market participants will always want to provide the most valuable $\mathrm{A} / \mathrm{S}$.

Most ASCPs are paid to market participants for their capacity to provide that A/S. The payments typically were not modified on the basis of how the market participant performed the $\mathrm{A} / \mathrm{S}$, as long as it was satisfactory. Recently, there has been motivation to incentivize market participants based on the speed and accuracy of their response. FERC Order 755 is directing the pay for performance scheme for regulating reserve. Resources that provide more "mileage" when they are providing regulating reserve are compensated. This often helps the participants that can provide regulating reserve at faster speeds. It is therefore possible that conventional and advanced PSH can benefit from some of the new rulings on the regulating reserve markets in the ISOs.

These pricing methods are designed to encourage resources to offer their true costs for energy and true capabilities for A/S. The ISO or RTO is responsible for solving an optimization problem to minimize the total costs to meet the energy and A/S demands, while meeting numerous generation and reliability constraints. In a well-functioning market, this should also place each market participant in a position to make the most profit. However, due to some issues (e.g., nonconvex costs, commitment constraints, and out-of-market reliability rules), the ISO may direct a market participant to provide an energy and A/S quantity that leads to losses for the 
participant. When this happens, the ISO will have rules to ensure that the market participant does not receive a negative profit. The market participant is given a "make-whole payment" to ensure that it does not lose money. Since PSH is not fully optimized and does not have explicit fuel “costs," the make-whole payment rules might not fully apply. However, if PSH is fully optimized by the market and ends up losing money from the resulting schedule by paying more during pumping periods than it makes during generation periods, make-whole payments might be necessary.

The prices will be paid to resources with the additional make-whole payments after actual power data are measured. Sometimes, there are penalties in place for market participants that stray too far from their directed energy or A/S schedules. Although they can vary depending on the market region, they do provide further incentive to ensure a reliable operation. Many of the markets will settle resources on an hourly resolution, even if the RT dispatch is conducted by using fiveminute schedules and prices. This can be an issue for a pumped storage plant if it attempts to earn value for arbitrage on sub-hourly prices.

\subsubsection{Need for Flexibility and Storage}

Power systems must have a lot of flexibility in order to operate reliably. The increased variability and uncertainty of wind and solar generation increase the need for flexibility even more. Capacity is required to meet the maximum net load. Ramping capability is required to follow the daily net load fluctuations and is supplied through sub-hourly scheduling (5-min scheduling) when there is an abundance of ramp capability. A dedicated ramp or following service with separate payments for ramp services may be required if the economic energy supply generation does not inherently have sufficient ramping capability. MISO and CAISO are considering implementing dedicated following service products (Navid and Rosenwald 2012; Abdul-Rahman et al. 2012).

Regulation is required to match the short-term variability. Contingency reserves are required to respond to sudden failures of large generators and transmission lines. All of this flexibility is absolutely required for reliability purposes. Specific resources and specific technologies are not required, however. Markets have proven to be very effective at obtaining the required flexibility at the lowest cost from a host of available resources and technologies. Storage has technical capabilities that closely match the power system's need for flexibility, but storage must deliver that flexibility at a cost that is lower than the cost of the alternatives in order to be economically successful.

Regions differ in their energy scheduling practices. Regions that only allow hourly energy scheduling from generators institutionally block the system operator from accessing the sub-hourly physical flexibility that the committed generators have. Meeting ramping requirements in hourly-only scheduling regions with capital-intensive solutions, like new dedicated storage projects, can be financially risky because market rules may change. 


\subsubsection{PSH Scheduling in Energy and Ancillary Services Markets}

ISO and RTO markets inherently optimize the scheduling of conventional generators. A generator can offer energy at its production cost (along with operational limits, such as minimum load, start time, and minimum run time), and the generator will be scheduled to run whenever the market clearing price exceeds the generator's production cost. Further, the ISO and RTO markets co-optimize A/S and energy such that the generator only has to offer its physical capabilities and costs in order for the ISO or RTO to schedule the generator's provision of each of the services to maximize the generator's profit (while also minimizing the system's total costs). In most markets, storage is not similarly optimized by the system operator. The majority of the ISOs in the United States require that pumped storage choose the generation and pumping mode time frames in advance of the DA market (O'Neill 2011). ${ }^{17}$ So in effect, the bids of pumping and the bids of generating are considered independently of one another. The ISO can then select whether the plant should be committed or not at that operation mode and the energy and A/S schedules associated with its operation mode. However, the ISO cannot decide if the plant should be generating or pumping. The exception is PJM, which currently allows for a full, simultaneous consideration of both pumping and generating mode (Ward 2011). PJM will solve the DA unit commitment and the mode of the PSH plant so that the solution minimizes costs for the 24-hour period and ensures that the desired storage level of the PSH plant at the end of the period is achieved. None of the ISOs that we know about (including PJM) allow for the full optimization of generation and pumping modes in the RT market. They do, however, allow for the PSH plants to adjust whether they would prefer to be chosen for generation and pump mode as real time approaches.

Failing to optimize storage may harm both the storage owners and the system, since sub-optimal operation can result in lower profits for storage and higher overall system costs that are ultimately paid for by the loads. One reason that ISOs do not optimize storage is that it is computationally very difficult and requires additional data sets. PJM states that the solution time for their system optimizer was increased 5 to 10 times by the addition of a single PSH plant (Ward 2011). Also, in today's market regions, with small penetrations of variable generation, the times when generation and pumping are needed tend to follow consistent daily patterns (generation in peak load periods and pumping at night). When there are higher penetrations of variable generation (when the marginal costs and thus the prices have much more volatility throughout the day), it will become more important to use the unique characteristics of PSH with full optimization.

\subsubsection{Market versus System Value}

As discussed, energy markets in the United States generally establish LMPs, the prices awarded to all successful bidders, for each time interval on the basis of the bid price of the highest-priced successful bidder. This common practice is mostly effective at selecting the least-cost generation mix and mirrors the security-constrained marginal cost-based economic dispatch used in nonrestructured areas. The practice of choosing the "least-cost" set of suppliers becomes difficult when market participants with long inter-temporal requirements, like PSH, are being considered.

17 Our communications with system operators confirmed that this is still common practice. 
Energy storage plants are often unable to capture, through market payments, all the benefits they bring to other power system users. ${ }^{18}$ In addition, with the current market rules for energy and A/S payments, energy storage can collapse its own market value. The result is that storage is not built, and the loads also suffer from this market failure. The market collapses when storage is large enough to influence the market price of electricity. For example, storage might be used to meet peak demand that would otherwise be served by combustion turbines. A large enough storage project might completely displace the combustion turbines, allowing the market clearing price to drop from the expensive price that would have existed had the combustion turbines operated (e.g., \$100/MWh) to a cheaper price set by a combined-cycle plant (e.g., \$60/MWh). This appears to be very good for the loads but not good for the storage plant. Figure 8-6 provides an example from a Colorado system study (Denholm et al. 2013). The Colorado power system was modeled for a full year with increasing amounts of storage. The system value (blue diamonds and solid blue line) was determined by comparing the total system production cost with and without the storage project. Benefits were calculated as total savings divided by the storage system capacity ( $\$ / \mathrm{kW}$ per year). Naturally the benefits are high for a small storage project, and they decline per unit of storage as the size of the storage project increases. Total benefits always increase with increased storage, but the benefits per unit of storage size decline. The dashed blue line presents the incremental storage benefits. This would be used to determine how much storage to build. For example, if storage could be built and operated for $\$ 20 / \mathrm{kW}$ per year, it would not be wise to build 1,200 MW of storage, even though the total system value

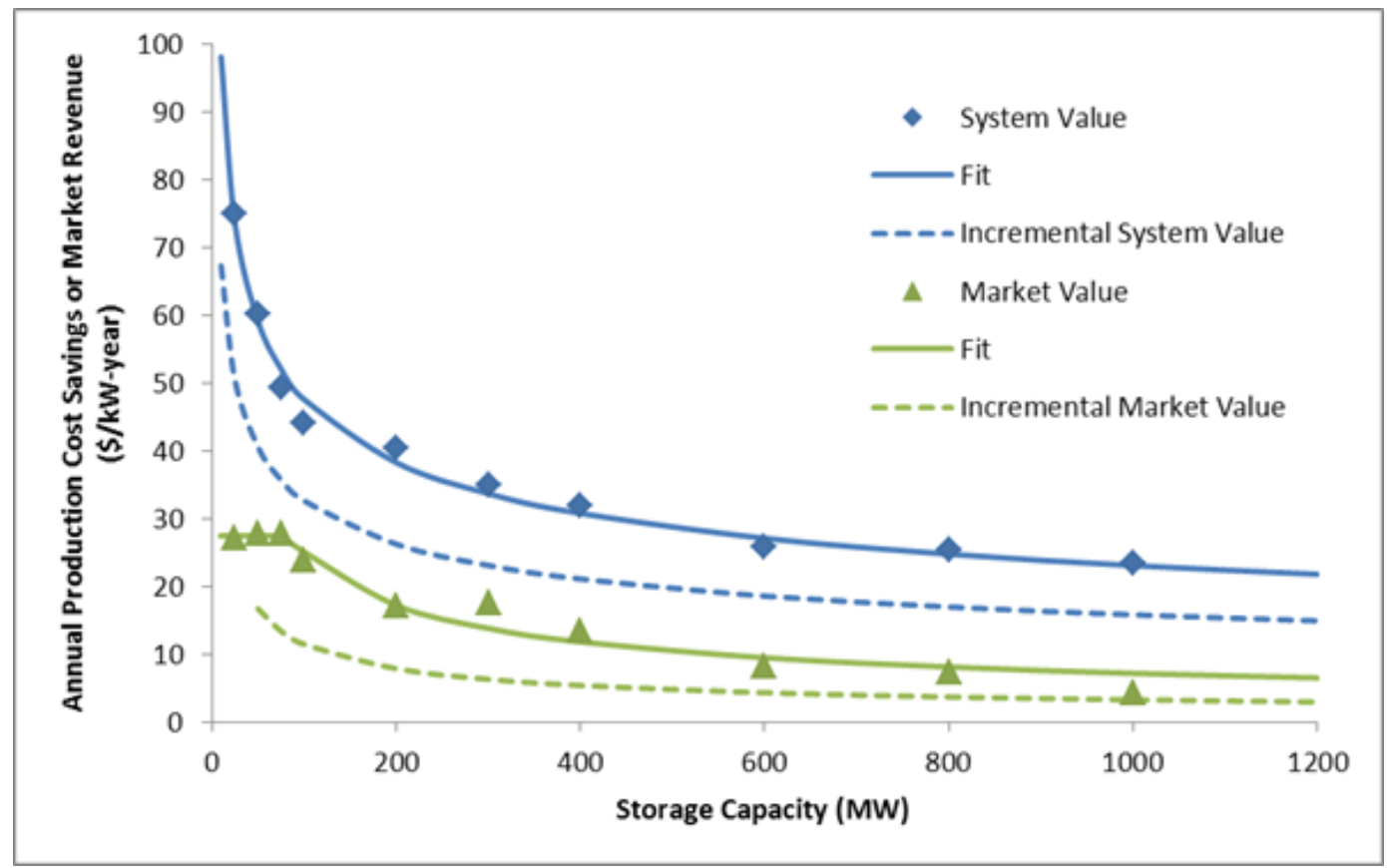

Figure 8-6 Market and System Value of Energy Storage as a Function of Total Storage Capacity in the System (Denholm et al. 2013)

18 Theoretically, a storage plant might engage in bilateral transactions with retail loads for mutual benefits; however, in actual practice, this has not proven to be practical under current regulatory and market conditions. 
realized from the 1,200 MW of storage in the example system is about $\$ 22 / \mathrm{kW}$ per year. Instead, only about $400 \mathrm{MW}$ of storage would be built, because the incremental value of additional storage above $400 \mathrm{MW}$ is below the cost of $\$ 20 / \mathrm{kW}$ per year. ${ }^{19}$

In a vertically integrated, regulated environment, the utility and the regulator might decide to build the 400-MW storage plant because the benefit to ratepayers would exceed the cost. The situation in a market area is very different. Because the storage project suppresses the on-peak energy price whenever it operates in generation mode, the market profit it makes during each transaction decreases. The larger the storage project, the greater the price impact. The solid green line shows the total market value, while the dashed green line shows the incremental market value for the full year. Again, it is the incremental value that is important when deciding how much storage to build. The market would support only about $50 \mathrm{MW}$ of storage at $\$ 20 / \mathrm{kW}$ per year.

The market structure itself determines how much of the total value can be captured by the storage project and how much is retained by the loads. In a perfect world, the loads themselves (or the load-serving entities) might invest in storage so that they could capture the full system value. In practice, that situation is unlikely, and the benefit is foregone. This problem is somewhat similar to that experienced when new transmission lines that alleviate congestion inherently eliminate the congestion differential that might be used to finance them. That is one reason that transmission remains a regulated asset. Treating storage as a regulated asset, based on the benefit for all loads, is an interesting idea that may be worth exploring.

\subsection{Market Design Issues Affecting the Value of PSH}

As a follow-up to the recent EPRI (2013) report, we have identified an additional list of topics related to electricity market design that might be limiting the system operator from extracting the full value of PSH or limiting PSH from achieving the maximum revenue. Each of these should be evaluated further. They are provided in Table 8-4.

\subsection{Conclusions}

Much of the nation's 22 GW of PSH was initiated during the mid to late 1970s. Projects were economically justified for daily energy arbitrage based on high cost of peaking oil and natural gas fired generation, low cost coal and nuclear power during the off-peak periods, and capital costs that were similar to those of combined cycle plants. Today, with natural gas on the margin much of the time and with the increased efficiency and decreased relative capital costs associated with combustion turbines and combined-cycle plants, energy arbitrage is typically not sufficient to justify new pumped storage plants. However, storage provides additional flexibility benefits for the power system, and the need for that flexibility is getting even larger as a result of the increase in variable and uncertain wind and solar generation. Moreover, restructuring has led FERC to explicitly define A/S, which help quantify and price the flexibility requirements.

19 The incremental cost of storage would be compared with the incremental value. 
Table 8-4 Market Design Topics and Pumped Storage

\begin{tabular}{|c|c|}
\hline Issue & Description and Current State \\
\hline $\begin{array}{l}\text { Full optimization in } \\
\text { DA markets }\end{array}$ & $\begin{array}{l}\text { To allow the DA market to schedule the PSH mode of operation based on } \\
\text { minimizing costs over the full time horizon. The length of the time horizon } \\
\text { may be important as well. Currently, PJM is the only market that does this. }\end{array}$ \\
\hline $\begin{array}{l}\text { Full optimization in } \\
\text { RT markets }\end{array}$ & $\begin{array}{l}\text { To allow the RT market to schedule the PSH mode of operation based on } \\
\text { minimizing costs and information that has been updated since the DA market. } \\
\text { Currently, no market performs this in the RT commitment models. }\end{array}$ \\
\hline $\begin{array}{l}\text { Lost opportunity } \\
\text { costs based on } \\
\text { multiple hours for } \\
\text { A/S clearing prices }\end{array}$ & $\begin{array}{l}\text { Since PSH depends greatly on its optimal operation over long periods of at } \\
\text { least a day, the lost opportunity costs of the resources are highly complex. If } \\
\text { by providing A/S in } 1 \mathrm{~h} \text {, it loses an opportunity to provide energy in another, } \\
\text { those pricing mechanisms should be accounted for. }\end{array}$ \\
\hline $\begin{array}{l}\text { Make whole } \\
\text { payments for PSH } \\
\text { operation }\end{array}$ & $\begin{array}{l}\text { If the PSH plants are fully optimized in the market, they should be given } \\
\text { guarantees that if they follow schedules given by the ISO, they will be "made } \\
\text { whole". This should apply if they end up paying more during pumping than } \\
\text { they gain from generating. }\end{array}$ \\
\hline $\begin{array}{l}\text { Settlements based } \\
\text { on sub-hourly time } \\
\text { intervals }\end{array}$ & $\begin{array}{l}\text { If settlements are made on a sub-hourly level, the PSH plant will have } \\
\text { opportunities to utilize fast response to meet real-time pricing swings that } \\
\text { can greatly benefit the system. With hourly settlements, the PSH plant has } \\
\text { little incentive to follow prices within the hour; it has incentive only to follow } \\
\text { the average hourly price. Only a few ISOs settle sub-hourly, but all calculate } \\
\text { sub-hourly prices as part of the RT dispatch. }\end{array}$ \\
\hline $\begin{array}{l}\text { Pay for performance } \\
\text { for regulating } \\
\text { reserve }\end{array}$ & $\begin{array}{l}\text { PSH plants can benefit from providing superior regulating reserve when the } \\
\text { response is needed. By paying for the performance of regulating reserve, they } \\
\text { can earn more revenues than if they were paid the same as are the slow- } \\
\text { moving regulating resources. All of the ISOs and RTOs have modified rules for } \\
\text { FERC Order } 755 \text { and are beginning to implement the market design } \\
\text { modifications. }\end{array}$ \\
\hline $\begin{array}{l}\text { A market and pricing } \\
\text { for primary } \\
\text { frequency response }\end{array}$ & $\begin{array}{l}\text { Primary frequency response is a service that is not necessarily incentivized in } \\
\text { current markets. It could be an additional revenue stream for PSH, since } \\
\text { conventional PSH and especially advanced PSH can provide primary frequency } \\
\text { response well. }\end{array}$ \\
\hline $\begin{array}{l}\text { A market and pricing } \\
\text { for following reserve }\end{array}$ & $\begin{array}{l}\text { Following service is being proposed in MISO and CAISO and discussed more } \\
\text { broadly throughout the industry. It can bring additional revenues to PSH } \\
\text { plants, especially AS PSH plants since they can provide it during both } \\
\text { generation and pumping modes. }\end{array}$ \\
\hline $\begin{array}{l}\text { A market and pricing } \\
\text { for voltage control }\end{array}$ & $\begin{array}{l}\text { There are currently no markets for voltage control in the United States; there } \\
\text { are only cost-recovery mechanisms. A pricing mechanism for voltage control } \\
\text { could bring additional revenues to PSH and advanced PSH. }\end{array}$ \\
\hline $\begin{array}{l}\text { Capital cost } \\
\text { compensation }\end{array}$ & $\begin{array}{l}\text { Without a firm long-term commitment, financing high-capital-cost, low- } \\
\text { operating-cost, long-lived resources is difficult, regardless of how worthwhile } \\
\text { a project is for rate payers. Existing capacity markets, where they exist, cover } \\
\text { only a portion of capital costs and offer only annual commitments, at most. } \\
\text { Treating PSH as a regulated, rate-based, transmission-like resource under } \\
\text { system operator control might be beneficial. }\end{array}$ \\
\hline
\end{tabular}


FERC's encouragement of ISOs and RTOs, which now serve two-thirds of the nation's load, has led to the establishment of energy and A/S markets that monetize the value of flexibility. Storage can compete with generators and demand response to provide the flexibility that a system operator requires to maintain reliability. In this context, there is a need to evaluate the benefits that energy storage offers against the benefits of generation and demand response alternatives. One characteristic of storage is its charging capability, which can be used to provide load for excess variable generation. This can be very valuable during off-peak hours (e.g., at night), when system loads are low, most conventional thermal generating units are base load units at their minimum (must-run) capacities, and demand response options are limited.

ISOs and RTOs co-optimize the provision of energy and A/S from generators. Generators simply offer their capabilities (maximum load, minimum load, ramp rate, start time, etc.) and bid costs and let the system operator determine how much energy and how many A/S they should provide in each market interval. This maximizes the generator's profit while simultaneously minimizing power system costs. Unfortunately, this same concept is not yet typically fully extended to the charging and discharging of storage. Storage project operators typically must guess what their best charging and discharging schedules are and then let the power system operator optimize the energy and A/S within that predefined schedule.

Vertically integrated, regulated, nonmarket areas require the same types of flexibility to maintain power system reliability. The lack of markets can make it more difficult to quantify the value of storage, especially for a third party proposing a new project, because the data on power system production costs are typically proprietary. Still, vertically integrated areas currently have the potential to offer several advantages for storage projects. Vertically integrated utilities may be able to obtain regulatory approval for long-term contracts based on their expected benefits for electricity consumers over decades. Markets seldom offer such assurances, so the developer must assume the risk, which typically increases project costs. Similarly, a vertically integrated utility and its regulator may invest in a storage project that flattens on/off peak energy price differentials or that reduces A/S prices if those benefits exceed the project cost. In contrast, in a market environment, the price collapse would eliminate the storage project's economic incentive and thereby deny consumers the project's benefits. Lastly, the system operator in a vertically integrated utility can fully optimize the use of a storage project for energy arbitrage and A/S over all time frames; a market-based system operator, however, may be restricted by bidding and scheduling practices that were designed to co-optimize conventional generators but that do not consider the multi-interval benefits of storage.

\subsection{References and Bibliography}

Abdul-Rahman, K., H. Alarian, M. Rothleder, P. Ristanovic, B. Vesovic, and B. Lu, 2012, "Enhanced System Reliability Using Flexible Ramp Constraint in CAISO Market," Proceedings of the IEEE Power and Energy Society General Meeting, San Diego, Calif., July.

Aoki, K., et al., 1987, "Unit Commitment in a Large-Scale Power System Including Fuel Constrained Thermal and Pumped-Storage Hydro,"IEEE Transactions on Power Systems, vol. 2, no. 4, pp. 1077-1084. 
ASCE (American Society of Civil Engineers), 1993, "Compendium of Pumped Storage Plants in the United States,” Task Committee on Pumped Storage of the Hydropower Committee, Energy

Division, ASCE, New York, N.Y.

Baslis, C.G., and A.G. Bakirtzis, 2011, "Mid-Term Stochastic Scheduling of a Price-Maker Hydro Producer with Pumped Storage,” IEEE Transactions on Power Systems, vol. 26, no.4, pp. 1856-1865.

Black, M., and G. Strbac, 2007, "Value of Bulk Energy Storage for Managing Wind Power Fluctuations,” IEEE Transactions on Energy Conversion, vol. 22, no.1, pp. 197-205.

Botterud A., and G. Doorman, 2008, "Generation Investment and Capacity Adequacy in Electricity Markets,” IAEE Newsletter, No. 2:11-15.

Bowring, J.E., 2008, Hearing on the Current and Future Wholesale Electricity Markets, testimony of Joseph E. Bowring, Independent Market Monitor for PJM, Pennsylvania PUC, pp. 7-11, Oct. 23.

Boyd, D.W. O.E. Buckley, and C.E. Clark, 1983, “Assessment of Market Potential of Compressed-Air Energy-Storage Systems,” Journal of Energy 1983 7:549-556.

Castronuovo, E.D., and J.A. Peças Lopes, 2004, “On the Optimization of the Daily Operation of a Wind-Hydro Power Plant,” IEEE Transactions on Power Systems, vol. 19, no. 3, pp. 15991606.

Connolly, D., et al., 2011, "Practical Operation Strategies for Pumped Hydroelectric Energy Storage (PHES) Utilising Electricity Price Arbitrage,” Energy Policy 39(7):4189-4196.

Deane, J.P., B.P. Ó Gallachóir, and E.J. McKeogh, 2010, “Techno-economic Review of Existing and New Pumped Hydro Energy Storage Plant,” Renewable and Sustainable Energy Reviews 14(4):1293-1302.

Deb, R., 2000, “Operating Hydroelectric Plants and Pumped Storage Units in a Competitive Environment,” The Electricity Journal 13(3):24-32.

Denholm, P., E. Ela, B. Kirby, and M. Milligan, 2010, The Role of Energy Storage with Renewable Electricity Generation, NREL/TP-6A2-47187, Jan.

Denholm, P., J. Jorgenson, M. Hummon, T. Jenkin, D. Palchak, B. Kirby, O. Ma, and M. O’Malley, 2013, The Value of Energy Storage for Grid Applications, NREL/TP-6A20-58465, May.

Ding, H., Z. Hu, and Y. Song, 2012, "Stochastic Optimization of the Daily Operation of Wind Farm and Pumped-Hydro-Storage Plant,” Renewable Energy 48:571-578. 
DOE (U.S. Department of Energy), 1977, DOE Interagency Coordination Meeting on Energy Storage, CONF 7709116.

Ela, E., M. Milligan, and B. Kirby, 2011, Operating Reserves and Variable Generation, NREL/TP-5500-51928, National Renewable Energy Laboratory, Aug.

Ela, E., B. Kirby, N. Navid, and J.C. Smith, 2012a, "Effective Ancillary Services Market Designs on High Wind Power Penetration Systems," in Proceedings of the IEEE PES General Meeting, July.

Ela, E., A. Tuohy, M. Milligan, B. Kirby, and D. Brooks, 2012b, “Alternative Approaches for a Frequency Responsive Reserve Ancillary Service Market,” The Electricity Journal 25(4):88102, May.

EIA (Energy Information Administration), 2009a, Repeal of the Powerplant and Industrial Fuel Use Act (1987). Available at http://www.eia.doe.gov/oil_gas/natural_gas/analysis_ publications/ngmajorleg/repeal.html. Accessed Dec. 2009.

EIA, 2009b, Electric Power Annual, 2009 (data for 2008). Available at http://www.eia.doe. gov/cneaf/electricity/epa/epa_sprdshts.html. Accessed Dec. 2009.

EPRI (Electric Power Research Institute), 1976, Assessment of Energy Storage Systems Suitable for Use by Electric Utilities, EPRI-EM-264, July.

EPRI, 2013, Quantifying the Value of Hydropower in the Electric Grid: Final Report, Palo Alto, Calif., Feb. Available at http://www1.eere.energy.gov/water/pdfs/epri_value hydropower_electric_grid.pdf.

FERC (Federal Energy Regulatory Commission), 1996a, Order 888: Promoting Wholesale Competition Through Open Access Non-discriminatory Transmission Services by Public Utilities; Recovery of Stranded Costs by Public Utilities and Transmitting Utilities, April. Available at http://www.ferc.gov/legal/maj-ord-reg/land-docs/rm95-8-00v.txt.

FERC, 1996b, Order 889: Open Access Same-Time Information System (Formerly Real-Time Information Networks) and Standards of Conduct, April. Available at http://www.ferc.gov/legal/ maj-ord-reg/land-docs/rm95-9-00k.txt.

FERC, 1999, Order 2000: Regional Transmission Organizations, Dec. Available at http://www. ferc.gov/legal/maj-ord-reg/land-docs/RM99-2A.pdf.

FERC, 2003a, Order 2004: Standards of Conduct for Transmission Providers, Nov. Available at http://www.ferc.gov/legal/maj-ord-reg.asp.

FERC, 2003b, Order 2003: Standardization of Generator Interconnection Agreements and Procedures, July. Available at http://www.ferc.gov/legal/maj-ord-reg.asp. 
FERC, 2005a, Order 2006-A: Standardization of Small Generator Interconnection Agreements and Procedures. Available at http://www.ferc.gov/legal/maj-ord-reg.asp, November.

FERC, 2005b, Order 661: Interconnection for Wind Energy, June. Available at http://www.ferc.gov/whats-new/comm-meet/052505/E-1.pdf.

FERC, 2005c, Order 661-A: Interconnection for Wind Energy, Dec. Available at http://www.ferc.gov/EventCalendar/Files/20051212171744-RM05-4-001.pdf.

FERC, 2006, Order 2006-B: Standardization of Small Generator Interconnection Agreements and Procedures. Available at http://www.ferc.gov/legal/maj-ord-reg.asp, July.

FERC, 2007, Order 890: Preventing Undue Discrimination and Preference in Transmission Service," Feb. Available at http://www.ferc.gov/whats-new/comm-meet/2007/021507/E-1.pdf.

FERC, 2011, Order 755: Frequency Regulation Compensation in the Organized Wholesale Power Markets, Oct. Available at https://www.ferc.gov/whats-new/comm-meet/2011/102011/E28.pdf.

FERC, 2014, Regional Transmission Organizations (RTO)/Independent System Operators (ISO), updated April 2, 2014. Available at http://www.ferc.gov/industries/electric/indus-act/rto.asp, accessed May 2014.

Garcia-Gonzalez, J., et al., 2008, "Stochastic Joint Optimization of Wind Generation and Pumped-Storage Units in an Electricity Market,” IEEE Transactions on Power Systems, vol. 23, no. 2, pp. 460-468.

Gordon, J.L., 2009, "Parametric Analysis of Pump-Turbine Sites," presented at Electrical Power and Energy Conference (EPEC), sponsored by Institute of Electrical and Electronics Engineers (IEEE), Montreal, Quebec, Canada, Oct. 22-23.

Hirst, E., and B. Kirby, 1997, "Creating Competitive Markets for Ancillary Services," ORNL/CON-448, Oak Ridge National Laboratory, Oct.

Hogan, W., 1998, Competitive Electricity Market Design: A Wholesale Primer, John F. Kennedy School of Government, Harvard University, Cambridge, Mass., Dec.

ISONE (ISO New England), 2013a, Forward Capacity Market Frequently Asked Questions. Available at http://www.iso-ne.com/support/faq/fwd_cap_mkt/.

ISONE, 2013b, Section III, Market Rule 1, Standard Market Design. Available at http://www.iso-ne.com/regulatory/tariff/sect_3/mr1_sec_13-14.pdf.

Kanakasabapathy, P., and K. Shanti Swarup, 2010, "Bidding Strategy for Pumped-Storage Plant in Pool-Based Electricity Market,” Energy Conversion and Management 51(3):572-579. 
Kirby, B., 2006, Demand Response for Power System Reliability: FAQ, ORNL/TM 2006/565, Oak Ridge National Laboratory, Oak Ridge, Tenn., Dec.

Kirby, B., J. Kueck, T. Laughner, and K. Morris, 2008, Spinning Reserve from Hotel Load Response: Initial Progress, ORNL/TM 2008/217, Oak Ridge National Laboratory, Oct.

Kirby, B., M.J. O’Malley, O. Ma, P. Cappers, D. Corbus, S. Kiliccote, O. Onar, M. Starke, and D. Steinberg, 2011, Load Participation in Ancillary Services: Workshop Report, U.S. Department of Energy, Office of Energy Efficiency and Renewable Energy and Office of Electricity Delivery and Energy Reliability, Dec.

Kirby, B., 2012, “Co-optimizing Energy and Ancillary Services from Energy Limited Hydro and Pumped Storage Plants,” in Proceedings of HydroVision International, Louisville, KY, July.

Koutnik, J., J. Foust, C. Nicolet, R. Saiju, and B. Kawkabani, 2010, "Pump-Storage Integration with Renewables - Meeting the Needs Using Various Concepts,” in Proceedings of HydroVision International, Charlotte, N.C., July 27-30.

Lu, N., J.H. Chow, and A.A. Desrochers, 2004, "Pumped-Storage Hydro-Turbine Bidding Strategies in a Competitive Electricity Market,” IEEE Transactions on Power Systems, vol. 19, no. 2, pp. 834-841.

McDaniel, G.H., and A.F. Gabrielle, 1966, “Dispatching Pumped Storage Hydro,” Power IEEE Transactions on Apparatus and Systems, vol. 5, pp. 465-471.

Miller, R., and M. Winters, 2010, "Opportunities in Pumped Storage Hydropower: Supporting Attainment of Our Renewable Energy Goals,” presented at NorthWest Hydrological Association Annual Conference.

MISO (Midcontinent ISO), 2013, 2013/2014 MISO Planning Resource Auction Results. Available at https://www.misoenergy.org/Library/Repository/Report/Resource\%20Adequacy/AuctionResults/ 2013-2014\%20MISO\%20Planning\%20Resource\%20Auction\%20Results.pdf accessed Jan 2014.

MWH, 2009, Technical Analysis of Pumped Storage and Integration with Wind Power in the Pacific Northwest, report prepared by MWH for U.S. Army Corps of Engineers, Northwest Division, Hydroelectric Design Center, Aug.

Navid, N., and G. Rosenwald, 2012, "Market Solutions for Managing Ramp Flexibility with High Penetration of Renewable Resource,” IEEE Transactions on Sustainable Energy 3(4): 784-790, Oct.

NHA (National Hydropower Association), 2010, Pumped Storage Hydropower, summary report on a summit meeting convened by Oak Ridge National Laboratory, NHA, and Hydropower Research Foundation, Washington, D.C., Sept. 20-21. 
NHA, 2012, Challenges and Opportunities for New Pumped Storage Development, NHA Pumped Storage Development Council. Available at http://www.hydro.org/wpcontent/uploads/2012/07/NHA_PumpedStorage_071212b1.pdf.

NYISO (New York ISO), 2013, Installed Capacity, View Spot Auction Summary. Available at http://icap.nyiso.com/ucap/public/auc_view_spot_detail.do.

O’Neill, R., 2011, Recent ISO Software Enhancements and Future Software and Modeling Plans, Staff Report, Federal Energy Regulatory Commission, Nov.

Oren, S., 2001, “Design of Ancillary Service Markets,” in Proceedings of 34th Hawaii International Conference on System Sciences, Maui, HI, Jan. 3-6.

PJM, 2013, Reliability Pricing Model (RPM). Available at http://www.pjm.com/markets-andoperations/rpm.aspx.

Schill, W.-P., and C. Kemfert, 2011, "Modeling Strategic Electricity Storage: The Case of Pumped Hydro Storage in Germany,” Energy Journal-Cleveland 32(3):59.

Shahidehpour, M., H. Yamin, and Z. Li, 2002, Market Operations in Electric Power Systems: Forecasting, Scheduling, and Risk Management, John Wiley \& Sons, New York, N.Y.

Singh, H., and A. Papalexopoulos, 1999, "Competitive Procurement of Ancillary Services by an Independent System Operator,” IEEE Transactions on Power Systems 14(2):498-504, May.

Steffen, B., 2012, “Prospects for Pumped-Hydro Storage in Germany,” Energy Policy 45:420_ 429, June.

Stoft, S., 2002, Power System Economics, John Wiley \& Sons, New York, N.Y.

Strauss, P.L., 1991, “Pumped Storage, the Environment and Mitigation,” Waterpower 91, New York, N.Y.

Suul, J.A., K. Uhlen, and T. Underland, 2008, "Variable Speed Pumped Storage Hydropower for Integration of Wind Energy in Isolated Grids: Case Description and Control Strategies,” paper in Proceedings of Nordic Workshop on Power and Industrial Electronics, NORPIE 2008, Espoo, Finland, June 9-11.

Tsai, C.-C., Y. Cheng, S. Liang, and W.-J. Lee, 2009, “The Co-Optimal Bidding Strategy of Pumped Storage Unit in ERCOT Energy Market," in Proceedings of North American Power Symposium (NAPS) 2009, Starkville, Miss., Oct. 4-6.

Ummels, B.C., E. Pelgrum, M. Gibescu, and W.L. Kling, 2009, “Comparison of Integration Solutions for Wind Power in the Netherlands,” IET Renewable Power Generation 3(3):279-292, Sept. 
Ward, M., 2011, "Resource Commitment and Dispatch in the PJM Wholesale Electricity Market,” presented at the Federal Energy Regulatory Commission Staff Technical Conference on Increasing Real-Time and Day-Ahead Market Efficiency through Improved Software, Washington, D.C., June 28.

Yang, C.-J., and R.B. Jackson, 2011, “Opportunities and Barriers to Pumped-Hydro Energy Storage in the United States,” Renewable and Sustainable Energy Reviews 15(1):839-844. 


\section{Section}

\section{9}

\section{Financial Analysis and Business Models for Assessing PSH}

While the dynamic operation models developed by the project team to simulate advanced PSH technologies are important technical tools, economic and business analyses are critical for developing new PSH projects. Section 8 highlighted a broad range of market issues that affect the development of PSH projects and discussed potential solutions for aligning the compensated value of PSH with its inherent value within the bulk power grid.

Amid these market issues, financial modeling and business analyses must be revised to reflect the value of energy storage and $\mathrm{A} / \mathrm{S}$ for PSH plants. In addition to updating project revenues in financial modeling, we must be aware of the business factors that influence the financial viability of a project. This section reviews these factors, including the type of owner, contracting strategy, and delivery type.

Two financial models were developed. They were designed to help planners review factors that influence PSH financial viability in both cost-based (utility) scenarios and market-based (IPP) scenarios and assess how changes to the business models affect a project's viability. By examining PSH business models, one can determine changes that could be made to both the inputs and the overarching framework that would remove barriers and impediments to PSH development in the United States. Recommendations on how to reduce barriers to development through changes to business models are presented at the end of this section.

This section provides an overview of how to create business models to assess the financial benefit of PSH projects. In addition, it discusses the methodology for the business models created as a part of this study and presents sample results from case studies that use these models.

\subsection{Modeling the Economic versus the Financial Potential of PSH Facilities}

In addition to demonstrating the technical advantages of advanced PSH facilities, developers need to consider the economic and financial potentials of PSH facilities and weigh net benefits against costs. Economic and financial models provide different ways of assessing the merits of a project in monetary terms. In theory, an economic model evaluates the project from the perspective of society as a whole (although in practice, some benefits do not lend themselves to quantification or monetization). A financial model (also known as a business model or pro forma) evaluates the project from the perspective of the owner. It is important to differentiate 
between the two models because they serve different purposes when evaluating a potential development.

The main purpose of an economic analysis is to compare mutually exclusive alternatives that would meet the proposed project's objectives. This type of analysis typically involves comparing the proposed PSH project to alternatives, such as meeting the need for increased capacity and energy services through alternative thermal plants. Typically, economic analyses are made without considering inflation, interest during construction, financing costs, or financing mechanisms. They use "constant” (present-year) values as opposed to nominal values. Real escalation rates (above the expected inflation rate) can be used, especially for fuel costs. A discount rate should be selected in consultation with the client. The results are expressed in metrics such as NPV, economic internal rate of return (EIRR) and benefit/cost ratio (BCR).

The main purpose of a financial analysis is to compare various financing packages in an attempt to maximize financial viability. Financial models consider projected revenues, inflation, interest during construction, debt coverage ratios, grants, bonds, taxes, depreciation, etc. The model considers "nominal" (future-year) values. The results are expressed in metrics such as return on equity (ROE) and financial internal rate of return (FIRR). The electricity tariff level required to make the project financially viable may also be an output.

It is prudent for a developer to conduct both economic and financial analyses. For example, an economic analysis will assess whether a PSH project is more economically viable than a thermal plant would be. As an alternative or in addition, a developer might also use an economic model to select a preferred installed capacity for a power plant.

After selecting the preferred alternative from the economic analysis, a developer typically uses a financial model to compare different financing options for one alternative or to select the preferred financing plan that yields the most attractive modeling metrics.

\subsection{Scope of Present Study}

This section discusses the financial model developed as part of the study (see Section 9.5 for a description of the modeling methodology). The goal of this model is to provide a template for performing a financial analysis, using the inputs for PSH costs and revenues provided by the users. In this study, the financial model is used as an example — along with some preliminary, generic data for PSH plant costs and revenues - to illustrate how operation and revenue modeling feeds into the business model, which ultimately dictates the final decision on whether to invest in a project or not. In addition, this section discusses the shortcomings of various business models and gives recommendations for improvement.

Note that this report does not cover economic modeling. It is assumed that developers will prepare economic models with assistance from engineering design consultants. This financial model assumes that results from economic modeling already indicated that a PSH plant should be developed and that they aided in the selection of plant capacity. 


\subsection{Study Terms and Definitions}

The subsections that follow define some economic and financial terms used in Section 9. Additional definitions of technical terms are provided in Appendix A.

\subsubsection{Glossary of Economic and Financial Terms}

Benefit/Cost Ratio (BCR). The present worth of the benefits accumulated over the life of the project divided by the present worth of the project costs accumulated over the life of the project.

Debt Service Coverage Ratio (DSCR). The ratio of operating income to debt payments.

Discount Rate. The time value of money used to convert or aggregate costs and benefits occurring at various times to a common point in time.

Financing Cost. The cost that captures the debt repayment and interest expenses associated with the investment.

Gross Profit Margin. The annual gross profit divided by the annual revenue, expressed as a percentage. It is calculated as an annual value and reported as an average (averaged over the first 30 operating years) annual value, that is, as a summary metric.

Internal Rate of Return (IRR). The discount rate at which the net present value is zero.

Investment Cost. The project cost, including the construction cost, development and owner's costs, and final design and construction management costs. It does not include the cost of financing the project.

Independent Power Producers (IPPs) and Electric Wholesale Generators (EWGs). Generating plants as defined in FERC Order 888.

Net Present Value (NPV). The present value of the total benefits minus the present value of the total costs.

Nominal Values (nominal dollars, nominal discount rate). Values that include the effects of expected or historic inflation. A cost in nominal dollars is expressed in terms of the cost in the year it is spent. A benefit in nominal dollars is expressed in terms of the benefit in the year it is realized.

Operating (earnings before income and taxes or EBIT) Profit Margin. The annual net income divided by the annual revenue, expressed as a percentage. It is calculated as an annual value and reported as an average (averaged over the first 30 operating years) annual value, that is, as a summary metric.

Present Value. This value provides a means to determine and compare total costs or benefits over time. A series of annual values in dollars should not be totaled because the dollar values in 
different years are not equivalent. The discount rate is used to adjust dollar values over time to a chosen base year's values.

Real (or Constant Dollar) Values. Values adjusted to eliminate the effects of expected or historic inflation.

Return on Equity (ROE). The annual net income divided by the annual equity, expressed as a percent. It is calculated as an annual value and reported as an average (averaged over the first 30 operating years) annual value, that is, as a summary metric.

Return on Investment (ROI). The annual net income divided by the sum of the annual equity and debt, expressed as a percent. It is calculated as an annual value and reported as an average (averaged over the first 30 operating years) annual value, that is, as a summary metric.

Spread Value. The difference between on-peak and off-peak electricity prices.

\subsection{Background on PSH Development and Business Models}

Because a broad range of market issues can affect PSH projects and the different types of potential PSH owners and developers, there is consequently a need to discuss different business models and their impact on the financial viability of a PSH project. The business model determines how project costs and benefits are allocated over time. PSH facilities are developed by different types of owners (see subsection 9.4.1) who have different business models and distinct economic, competitive, and regulatory challenges. Furthermore, the type of PSH development affects the project's financial viability because it affects cost and schedule. These concepts are discussed in more detail in the following text.

\subsubsection{Owner Types}

Prior to the advent of deregulation of the U.S. electric power industry, plants were owned either by IOUs or public power companies. Since deregulation, per FERC Order 888, plant ownership has general been considered to fall into two main categories: (1) regulated utilities and (2) IPPs. The second group, IPPs, also covers nonutility generators (NUGs, EWGs, and nonregulated utilities fully subject to market prices). Regulated utilities can be subdivided into several different types including IOUs, publicly owned (federal, municipal) utilities, utility cooperatives, and (in some countries but not the United States), nationalized utilities. Note that some states have not adopted legislation to allow deregulation, and in those states, IOUs remain regulated. The type of ownership affects the financial assessment of a project and can also influence the O\&M philosophies associated with it.

To evaluate potential PSH plants, regulated IOUs must consider not only technical, economic, and financial factors but also potential regulatory treatment from state utility regulators and FERC. Analyses of this topic require financial modeling to address utility-specific accounting treatments that would drive future earnings and cash flows from the PSH plant.

Regulated IOUs use cost-based business models and receive a guaranteed electricity tariff as established in the rate base by regulators. Because of this, they are not exposed to market risk in 
the way that IPPs are, and the cost of equity is usually lower for IOU projects than for IPP projects. As a result of the lower cost of equity, the financial structure tends to be more heavily weighted with equity. In the energy sector, IOUs tend to be more receptive than IPPs to investments with long return periods. For longer-term projects, regulated utilities can benefit from regulatory and utility accounting measures that allow for the deferral of capital expenditures and related depreciation in their financial statements until after the plant commences operations and begins generating revenue. Special accounts, such as construction work in progress (CWIP) accounts, can be used to reflect deferred capital expenditures and additions to plant assets on the balance sheet. Other provisions, such as an allowance for funds used during construction (AFUDC), can also apply to address pre-startup funding measures.

For market-based companies such as IPPs or non-regulated IOUs, potential PSH developers must account for costs of construction in each year as they are incurred. PSH plants for IPPs and other non-regulated firms must be profitable on a stand-alone basis, with revenues dictated by market pricing and bilateral contracts with power end-users. While IOUs may be burdened by lengthy regulatory reviews to justify tariff rates for power generation, IPPs are subject to more pricing volatility that is driven by local market demand and supply factors, some of which can be seasonal. Financing terms for stand-alone PSH projects may also be an added challenge and they may require parent IPPcompany support to avoid potentially higher financing charges from lenders.

IPPs use market-based business models. IPPs are exposed to the volatility of competitive energy markets, which often leads them to favor low-risk projects because the return on project investment is not guaranteed. IPPs tend to favor projects that are not capital-intensive and that have short construction times and quick returns. In the energy sector, this outlook has traditionally favored the development of gas-fired power plants. For IPPs, the debt/equity ratio is typically between $80 / 20$ and 70/30. Projects with more risk usually require more equity financing.

\subsubsection{Development Types}

There are four main development types: greenfield, brownfield, rehabilitation, and expansion.

1. A greenfield project refers to a new project built on an undeveloped site and would include a new bulk power transmission interconnection.

2. A brownfield project refers to a new project built on a developed site, such as a concept that uses an existing dam built for flood control or an existing storage reservoir for a conventional hydro project. (An example is Raccoon Mountain on the TVA system, which uses an existing reservoir as a lower reservoir.) Another possibility is to use an existing mine as an upper or lower reservoir. PSH projects can also be incorporated into various types of storage and canal projects.

3. A rehabilitation project is one that is at an existing plant. It may include unit overhauls with new, redesigned pumps and turbines and upgraded (also referred to as uprated) components. Upgrading a conventional hydropower unit to a reversible PSH 
unit would also fall into this category, as would converting an existing FS PSH unit to an advanced technology like an AS PSH unit. A rehabilitation project is much more systematic and extensive in scope than are typical repairs and maintenance activities.

4. An expansion is the addition of a new unit (or units) to an existing hydropower plant. Some hydropower plant designs include considerations for future expansion, such as extra space in the powerhouse sufficient for an additional unit.

\subsubsection{Contracting Strategies}

The design and construction of a PSH facility represents a significant capital investment and requires specialized hydropower and transmission expertise. The purpose of the contracting strategy is to establish the philosophy, approach, and processes for successful implementation of all parts of the project. PSH projects typically fall into the category of a "megaproject," such that they can be broken into subprojects, with all project components closely integrated from concept through construction. A PSH project can be implemented in many ways; there is no "one size fits all" solution for the project. The right contracting strategy is the one that best aligns with the overall business drivers for the project, is realistic, and balances business drivers with technical and commercial challenges. Obtaining stakeholder buy-in on the contract strategy is critical. Final budgets and schedules must be based on the final strategy.

The implementation of a particular contracting strategy is the last chance to allocate risk between the parties. The contracting schedule directly affects the cost, quality, and safety of the construction and the commissioning date, and it affects long-term operations. The contracting strategy mitigates risks, identifies performance guarantees and warranties needed from equipment suppliers, recognizes environmental and government regulations that could constrain design and construction, and accommodates potential performance bonding challenges due to the length and size of the project.

Risks associated with any construction contract include any action or event that causes (1) delays in meeting the completion schedule, (2) increases in the agreed-upon amount of the contract, or (3) less-than-expected performance. Risks that might be involved in constructing a PSH project include schedule impacts caused by circumstances beyond the control of the contractor. These could be (1) delayed or interrupted project funding; (2) delayed turnover of work areas from one contractor to the next; (3) delayed delivery of equipment supplied by others; (4) labor disputes (strikes); (5) delayed delivery or review of drawings; (6) revisions in the construction sequence due to other changes (disruption or ripple affect); (7) failure to issue extensions of time promptly, causing contractors to speed up other work to make up for lost time (acceleration); (8) differing site conditions (primarily a geologic risk of encountering subsurface conditions that would not reasonably be expected by a competent contractor performing similar work); or (9) forces majeures (floods, etc.). Other risks involve design changes, market conditions, outside influences (including agency and third-party demands), and misunderstandings among involved parties.

While it is not possible to eliminate all risks, with thorough planning and careful assignment, the magnitude of risks can be mitigated and managed. The contracting strategy identifies appropriate 
ways to divide the scope of work among contracts and select contract delivery types in order to minimize risk.

\subsubsection{Division of Scope}

Many factors influence the decision process for defining the scope of work and packaging the contract work. The general rule of thumb is that the larger the package is, the less amount of administrative oversight would be required. However, larger packages result in less owner control over the project and potentially greater impacts from risks. The extreme scenario for this approach to the division of scope would be a single performance-type contract, whereby the provider would have full responsibility for all design, procurement, and construction aspects of the project.

Considering the opposite extreme, smaller scope-of-contract packages result in increased coordination and oversight by the owner but also give the owner greater control and offer less risk. In this case, the extreme example would be task-based labor and procurement contracts, whereby each provider would have responsibility for only one task or a few very similar tasks.

The contracting strategy must maintain the desired level of control and limit risks yet provide for orderly execution with limited interference so that each provider can use its skills to deliver the project as intended.

\subsubsection{Delivery Types}

Delivery types refer to the manner in which construction, equipment procurement, and equipment installation items are packaged into various construction, supply, and installation contracts. The key point in presenting this information is that the type of contract and the contract terms will have an impact on the contractors' and suppliers' prices and thus will consequently affect the expected and total cost of the project. For cases in which a contract type allocates risk to the contractor or supplier, the result will be a higher contract price, but the owner could reduce the risk reserve in the project budget.

Multiple types of delivery can be applied to contract packages of varying size and scope. Five delivery types (three traditional and two alternatives) are listed here and described in the subsections that follow. The alternative delivery types are newer than the traditional delivery types; they emphasize a collaborative approach among the parties involved, including owners, designers, contractors, major suppliers, and/or stakeholders. (The alternative contract types can also be combined with the traditional delivery types.)

Traditional delivery types are as follows:

- Design-bid-build (DBB)

- Design-build (DB) or engineer, procure, and construct (EPC)

- Construction management at risk (CMAR)

Alternative delivery types are as follows: 
- $\quad$ Public private partnership (P3)

- Integrated project delivery or alliance contract

Engineer, procure, and construction management (EPCM) is a form of project delivery management that integrates elements of the types just listed. It is the general model used for PSH and large, complex civil works projects undertaken by an owner (such as a utility) that can carry the risk allowance. The EPCM is more of a project delivery management model rather than a delivery type. Within EPCM, the main civil works would be delivered under a modified DBB project delivery mode. The main electrical and mechanical (E\&M) equipment will be furnished under an equipment supply contract similar to a DB or an EPC, where the procurement is based on a performance and requirements specification. The main civil works would first be designed to a "tender" level (not a "final" design) sufficient for a civil contractor bidding on a unit price basis. In parallel with the main civil tender design and procurement, the main E\&M specifications and tender documents are prepared, the E\&M tender is advertised, proposals are received, and the contract is awarded to the successful vendor. When the main E\&M vendor is selected, the vendor designs the equipment and furnishes information to the main civil designer. The detailed and final civil design can then be prepared, but this occurs when the main civil contractor is already engaged and performing preliminary work on site. The unit price remuneration facilitates compensation to the main civil works contractor for variations between the tender design and the final design. In addition, a number of other smaller contracts for various project elements (such as early site preparation works, access infrastructure, transmission facilities, and site services) may be contracted on a DBB, DB, or EPC basis. All of this is integrated by the owner and an owner's engineer, and the owner and the owner's engineer carry out an EPCM process in a progressive fashion as the project advances.

An alternative approach to that just described would be to procure the entire project delivery under a single EPC-type contract. However, due to the size and risk associated with a large hydropower project, identifying and procuring a single point of responsibility EPC contractor could be difficult. This approach would be taken if there was a need for a single source of responsibility for project delivery, which might be required due to financing conditions or the owner's risk tolerance. In such a situation, all of the functions just described above for the EPC model would be performed internally by the EPC contractor, with limited input and control by the owner.

The principal drivers for selecting the delivery type(s) for a project typically include legal requirements, financing obligations, the owner's risk profile, the competitive environment, and the need for specialty contractors. Public entities are generally subject to procurement rules that may limit delivery mechanism options and encourage the DBB approach, with the intent being to obtain the lowest cost for the project.

In terms of the owner's risk profile, while the normal objective of risk allocation during development of procurement strategies is to assign project risks to the party deemed most capable of mitigating the risks, some owners demand that all risks (or at least as much risk as is legally possible) be allocated to others. This approach always results in a higher cost for the work, since risk carries cost, but it allows owners that need to fix final costs to do so at an earlier 
stage. Further to paying a premium for such risk transfer, contractors may seek legal recourse in any event. Certain risks, such as regulatory and geotechnical risks, are especially difficult to transfer to a contractor.

Balancing risk between owners and contractors allows the owners to incorporate the contingencies into their own budgets as opposed to having contractors and suppliers incorporate the contingencies into their prices. Inevitably, some of an owner's risk contingencies would be expended. However, when risk contingencies are incorporated into contractor pricing, the owner always pays the full amount of the contractors' and suppliers' risk contingencies and does not realize savings from unrealized risks.

The following subsections give brief descriptions of the various forms of contracts that were previously identified

\section{Design-Bid-Build}

DBB is a conventional project delivery approach in which the owner (or owner's engineer) prepares detailed plans and specifications, prequalified contractors furnish bids, bids are evaluated, and a construction contract is awarded to the most-qualified bidder. The owner carries the risk of errors associated with the design. The DBB contractor is responsible to the owner for procurement and construction and contracts separately with providers for these components. While the DBB contractor manages these providers on behalf of the owner, the schedule, cost, and quality risk are held, in large part, by the owner. DBB contracts balance risk between the owner and the contractor more evenly than do the other delivery types. DBB contracts can be fixed-price contracts or unit-rate contracts. For large hydropower projects constructed under the EPCM management model, for which the civil contract is established before or in parallel to the equipment design, compensation is generally by unit rates to allow a basis for variation in quantities to account for the final equipment design or other possible uncertainties associated with the project (e.g., geotechnical and related excavation and civil quantity uncertainties).

Most U.S. and international PSH and other hydroelectric projects have employed this contracting approach, although the DB and EPC forms of contract are beginning to have some traction, especially internationally. Regulatory agencies, such as the U.S. Army Corps of Engineers (USACE), FERC, and state environmental agencies, require a certain level of specificity before they will issue permits. The DBB form of contract provides such specificity before the contract is finalized for the construction phase.

\section{Design-Build or Engineering, Procurement, and Construction Management}

Under a DB or EPC 20 project delivery approach, the owner or owner's engineer would prepare performance specifications and preliminary design documents (typically 5\% to 30\% complete with respect to the final design) that define the project scope constraints, quality standards, and

20 Note that although DB and EPC do not mean exactly the same thing, they are often used interchangeably in casual situations. The DB model generally allows for some input from the risk-sharing owner during the design and delivery of the project. In the case of EPC, input from the owner is very limited, and risk is borne disproportionately by the EPC contractor. The International Federation of Consulting Engineers (FIDIC; acronym is for the French name) can be contacted for additional information. 
bid documents. The selected firm would complete the design during the contract performance period. This method is typically used to cap the total construction cost and transfer risks (e.g., schedule risk) from the owner to the contractor.

Depending on the project conditions, DB and EPC can offer cost and time savings because one DB team is working together throughout design and construction. However, DB and EPC minimize the involvement of the owner (and other stakeholders), thus reducing the owner's ability to influence the ultimate project. To maximize the benefits of a DB or EPC contract, owner-issued performance specifications are preferred over prescriptive-type specifications. Performance-type specifications allow for the optimization of the benefits that are attained as a result of the coordination of the designer, contractor, and vendor. DB and EPC contracts are typically written as fixed-price contracts.

An additional drawback of a DB or EPC form of contract for domestic PSH contracts is the regulatory environment, as previously mentioned. The time benefit gained through this contracting approach is often lost during the permitting process, because these processes cannot be completed until after the DB contract is awarded and the design is finalized. This drawback limits the owner to negotiating any changes that are needed as a result of the permitting process with the single contractor holding the contract, as opposed to negotiating with multiple bidders, which occurs during the DBB or EPCM process.

Most DB contracts tend to be a hybrid blend of DBB and DB types of contracts, consisting of both prescriptive and performance specifications.

\section{Construction Management at Risk}

Under the CMAR method, the owner typically selects the CMAR firm, which will later serve as the project general contractor, at the outset of or early in the design stage. After conducting a selection process that focuses on qualifications and fees, the owner executes an initial CMAR contract with the selected CMAR firm. As the design progresses, the CMAR firm provides construction management services to the owner, such as reviews of the constructability of the design, construction scheduling, and project cost estimates. At some point during the design stage, the owner and the CMAR firm negotiate a guaranteed maximum price (GMP) for the project. When the contract is amended to include the GMP, the CMAR contract becomes a costplus contract with a GMP, and the CMAR firm assumes responsibility for performing the work, including the work done by project subcontractors. The owner pays the CMAR firm the actual cost of the work plus the agreed-upon CMAR fee up to the GMP; change orders resulting from scope changes and unanticipated site conditions encountered during construction may increase the final contract cost (Cunha 2014). In comparison with DB or EPC, CMAR places more project control and, consequently, more risk with the owner.

The CMAR model has a number of similarities with EPCM up to the point at which the owner and the CMAR firm negotiate the GMP. In the case of EPCM, the entity providing the EPCM service does not take the construction price risk; the EPCM acts on behalf of the owner to monitor the construction execution process, performs construction engineering during the course of construction, and assists the owner in negotiating claims. 
The CMAR form of contract is not generally used on domestic or international PSH (or other hydroelectric) projects, because it introduces another party into the overall process. Most owners prefer self-performing contractors (typical of those engaged through a DBB or DB process) in order to save the markup.

\section{Public Private Partnership}

In the P3 model, the owner partners with another entity that brings financing to the project. In exchange for bringing some portion of the financing, the partner looks to recover its investment plus a return on its investment through a number of methods, including self-performing the construction, operations, and maintenance; leasing the facilities back to the owner; and sharing revenue during operations. The P3 model definitions are broad, but all variations shift risk and control away from the owner to the partner. The performance criteria for a P3 contract may be briefer than the criteria typical for a DB or EPC contract; certain criteria may be set to the condition of the project at a time that is years beyond the project's initial construction (e.g., at the end of a concession period, if there is one).

P3 contracting has gained popularity in the United Kingdom and Canada over the last two decades. In the United States, government agencies have begun considering this approach as a way to move forward on infrastructure projects, since traditional funding sources have dried up in recent years. There are no known applications of the P3 model to PSH projects, but it is currently being used by BC Hydro for its John Hart Hydroelectric Project on Vancouver Island in Canada.

\section{Alliance Contract}

A project alliance is a business strategy whereby the objectives of the owner, designers, contractors, and major suppliers in a project are aligned. Alliance contracts, negotiated during the implementation stage, have the potential to deliver quality and price benefits without having the conflicting risk/reward system inherent in traditional types of delivery. In alliances, all parties are bound to a risk/reward scheme in which they all share savings or losses, depending on the project's success.

Such contracts are often split into stages, whereby there is an exit strategy for the parties if the project would cease to be viable. In addition, as the design develops, it may become necessary to change partners or to add specialty contractors/suppliers into the contracting arrangement.

With traditional delivery types, the transfer of risk to other parties can lead to increases in the project costs and claims, because contractors seek a higher return on investment for assuming a higher level of risk under the contracts. Alliance contracting enables the owner, designers, contractors, and suppliers to adapt their behavior to focus on project objectives. Note that although there are success stories associated with alliance contracting, the success largely depends on the individuals who are in the companies involved in the alliance.

\subsection{Modeling Methodology}

Financial modeling was carried out for two types of owners: (1) a regulated IOU and (2) an IPP or non-regulated IOU. They were selected because they represent the two main categories of 
project ownership. The two models demonstrate the differences in the financial frameworks of the two types of owners and how these differences affect the project's viability. The objective of the models is to provide a tool that PSH planners can use as a start for conducting their financial analyses. The models were designed to be transparent and flexible, so that inputs can be customized to specific projects, assumptions can be varied to perform sensitivity analyses, and the model framework itself can be edited as needed to reflect the unique environment of each project. The basic inputs and financial assessment framework are described as follows.

The financial models for this study represent project financing (as opposed to corporate financing). Project financing is for long-term infrastructure projects, where debt and equity are paid back from the cash flow generated by the project. Project financing is typically accounted for off the balance sheet, while corporate financing is on the balance sheet, and the corporation holds a general liability for the amount of the loan. Project financing assumes financing on a non-recourse basis, where the security is essentially the physical project itself. This is a relatively high-risk form of financing and is typically associated with uncertain revenue streams and long loan periods. Risks specific to PSH include these:

- The site-specific nature of the projects (each one can have unique "unknowns”),

- Construction risk and relatively long construction periods,

- Capital-intensive nature,

- Water management constraints,

- Difficulty of achieving transparency in the pricing of output, and

- Environmental sensitivities (permitting and licensing).

Since PSH projects are unique from each other, the model must allow for site-specific and plantspecific factors. These are incorporated in the input tab of the Microsoft Excel-based model. Excel was chosen as the model platform because it is transparent, widely used, and familiar to many. The inputs and assumptions in the financial model are designed to be adjusted in order to reflect unique projects and to perform sensitivity analyses.

Key inputs for the financial model are outputs from the production cost and revenue modeling associated with this study. This modeling has been done in each of these three software tools: FESTIV, CHEERS, and PLEXOS. The models can use either cost-based or market-based approaches in their analyses. The outputs from these models flagged as inputs for the financial model include the following (all values are average annual values):

- Energy sales,

- Capacity revenue (if applicable),

- Pumping costs, and 
- $\mathrm{A} / \mathrm{S}$ revenue:

- Regulation up,

- Regulation down,

- Spinning reserve, and

- Non-spinning reserve.

Examples of hourly and average energy, capacity, and A/S revenues were presented in Section 8, on electricity markets.

From the perspective of modeling the ownership type, many of the basic assumptions and framework are the same in the IPP and IOU models. Both models consider debt and debt repayment on a quarterly time step, while the cash flow is summarized on an annual time step. The following inputs and assumptions are captured in the financial model; the default values are listed, where applicable:

- $\quad$ Price basis. The cost and revenue estimates have a first quarter of 2013 price basis.

- Escalation. An annual escalation rate of $2.35 \%$ is assumed for the construction cost, and $2.0 \%$ is applied to the revenues and O\&M costs.

- Project life. This is the amount of time that a project is expected to be functional before requiring major rehabilitation. Project life may also refer to the license period, or the duration during which the developer will maintain financial interest in the project. For hydropower projects, the civil works are typically assumed to have a project life of 50 years for the purposes of the financial analysis. The E\&M equipment is typically assumed to have a life of 30 years, at which point replacement or refurbishment would likely be required. For the purposes of calculating the annual depreciation for a large-scale PSH project, 50 years is appropriate. Note, however, that there will be at least one major overhaul and possible replacement and upgrade of the motor/generator, pump/turbine, and various major auxiliary equipment during the 50-year project life.

- Depreciation. Depreciation is assessed differently for an IPP and IOU. IOUs under utility regulatory accounting may be allowed to defer the accrual of project construction costs until the plant is deemed operational. This allows IOUs to also defer the annual accrual of related depreciation until the first operating year.

- Project funding. Project funding assumptions include the debt-to-equity ratio; the loans that make up the debt, including the type (fixed principal or fixed payment); and the schedule for financial closure. With regard to equity and debt, each source typically prefers that its own share be as low as possible. Lenders want debt to be low 
enough to ensure that they will be steadily repaid (at a minimum). Equity investors want to leverage debt financing to increase the IRR on equity. Lenders often require the DSCR to be within a certain range (e.g., 1.75 to 2.25 ).

- Loan terms. The interest and repayment period are defined for each of the loans that make up the project debt.

- Project capacity. The rated project capacity is assumed to be 1,000 MW (based on being rated as a generation facility).

- Capacity factor. This provides information about the use of the installed project capacity over a year. It represents the average annual generation divided by the product of the installed plant capacity and the hours per year $(8,760)$.

- Cycle efficiency. This relates the pumping energy that is required to the energy that is generated with the same volume of water. It is calculated by dividing the energy generated by the energy consumed and is expressed as a percentage. It is always less than $100 \%$, as it takes more energy to pump the water to the upper reservoir than the amount that can be generated when the water is released back to the lower reservoir.

- Construction costs. This cost is assumed to be $\$ 2,000 / \mathrm{kW}$. It excludes the transmission interconnection cost.

- Construction cost schedule. This shows the distribution of construction costs by annual allocations inputted by the model user.

- Additional expenses. The additional expenses captured in the model include the development costs, owner's costs, and final design and construction management costs.

- On-line year. The on-line year, which triggers revenue generation, O\&M costs, and debt repayment, is assumed to be 2022. The model user can determine start/end years for project phases and related construction, design, and management costs.

- O\&M costs. The annual O\&M cost is assumed to be on the order of $1 \%$ of the total construction cost, with an additional cost every 5 years for more extensive O\&M work that may take place. The incremental cost is assumed to be equal to the annual maintenance cost. During the last year of development, there is an assumed O\&M cost equal to $150 \%$ of the typical annual O\&M cost; this reflects work done prior to commissioning the plant. While there was no difference in the O\&M costs of IOUs and the O\&M costs of IPPs, the annual cost is tied to organizational objectives and philosophies and risk perspectives. This being so, an IPP might have lower O\&M costs than a utility.

- $\quad$ Taxes. The tax treatment for a PSH plant is highly project-specific. For the purposes of this concept model, a generic tax assumption was used (25\%). However, when a 
specific project is being advanced, a tax advisor would determine how the project should be taxed based on the actual patterns for the project, any federal and state exemptions, tax credits, lease arrangements, etc.

The main difference between the IOU and IPP models is that an IOU has more options available for deferring costs in the financial statement/analysis. In the IOU financial model, interest during construction can be deferred until the first year of project operation. (Whether or not a specific project has this option depends on the loan terms for the IOU.) An IPP, however, must pay the interest on the loans during the construction period. For an IPP, the depreciation expense on capital expenditures prior to plant startup is also expensed and not deferred until the first operating year.

\subsubsection{Overview of the PSH Financial Model}

The financial model is set up with standard financial analysis worksheets and several supplementary worksheets that provide space for additional assumptions and inputs, as follows:

- Introduction. This provides an in-file overview of the contents of the model, with descriptions and guidance on worksheet functions and interactions.

- PSH_Inputs. This worksheet represents the first step that model users can take to insert PSH project inputs and assumptions for base-case, higher-return, and lowerreturn scenarios. Users can change the input values to reflect a specific project concept. The worksheet also includes a sensitivity variable drop-down option menu, where users can select one variable to test under the higher-return or lower-return scenario assumptions while keeping all other variables under the base-case scenario assumptions.

Supplementary worksheets represent the next step in financial modeling: taking assumption inputs from the PSH_Inputs worksheet in order to conduct PSH project-specific analysis. The analysis can cover the following:

- PSH-CostDist. This worksheet is used to define the cost distribution during the development period based on assumptions inserted in the PSH Project Data section of the PSH_Inputs worksheet. Model users must allocate annual project costs per phase (construction, development, final design) in cells I11 to S77 in the PSH-CostDist worksheet.

- PSH-Debt. This worksheet outlines the equity contributions and loan repayment by quarter based on assumptions inserted in the PSH Project Funding and PSH Project Loan Terms sections of the PSH_Inputs worksheet and based on output from the PSH-CostDist worksheet.

- PSH-Capex-PPE. This worksheet provides an analysis of capital expenditures and related depreciation expenses based on assumptions inserted in the PSH Operating 
Costs, PSH Project Depreciation, and PSH Capital Expenditures sections of the PSH_Inputs worksheet.

Standard financial analysis worksheets then incorporate assumptions from the PSH_Inputs worksheets and the supplementary PSH-project worksheets. The financial analysis worksheets have consolidated financial statements that allow model users to add data from company financial statements in addition to PSH project-specific line items. Each worksheet has a PSHonly financial statement that follows the consolidated company financial statement. The standard financial analysis worksheets include these:

- Income. This worksheet provides an income statement that includes revenues, costs, and earnings estimates that were developed from the PSH Project Revenues and PSH Operating Costs sections of the PSH_Inputs worksheet and from output from supplementary worksheets.

- Cash Flow. This worksheet provides estimates on the cash generated from operations, from investing activities, and from financing activities that were developed from income statement estimates and from output from supplementary worksheets.

- Balance Sheet. This worksheet provides estimates for balance sheet changes that arise from income and cash flow estimates.

As a final step, financial model outputs and analytical results are collected and summarized to facilitate project review. Worksheets include these:

- PSH_Results. This provides a summary of the high-level model metrics for the base case, lower-return, and higher-return scenarios with a macro routine (Ctrl-R) that will re-run the base-case, higher-return, and lower-return scenarios after changing inputs or assumptions.

- Chart_CashFlow. This provides a graphic summary of the cash flow.

- Chart_Debt. This provides a graphic summary of the project investment, including debt and equity.

\subsection{Case Studies}

A generic 1,000-MW PSH plant was evaluated by using the two owner models: IOU and IPP. The key characteristics of these two ownership types were provided in Section 9.4, while the generic parameters used for the financial modeling of a hypothetical PSH plant are described further in the sections that follow. The financial model that was developed during the study was then used to demonstrate the sensitivity of key financial metrics. Six sample sensitivity cases are described below. These demonstrate the sensitivity of the financial metrics and also provide an example of how the financial model can be used for various analyses. 


\subsubsection{Base Case}

A set of base-case modeling assumptions for a generic PSH plant was established to illustrate the functionality of the PSH financial model. Base-case inputs for PSH plant revenues and pumping costs were based on the results from the CHEERS model runs, while other financial model assumptions were based on typical values as provided in Table 9-1. In addition, two other sets of modeling assumptions were established for higher-return and lower-return scenarios. These modeling assumptions employ illustrative, generic values; the users of the PSH financial model are expected to use their own project-specific inputs.

Table 9-1 Model Assumptions

\begin{tabular}{|lccc|}
\hline \multicolumn{1}{|c}{ Model Assumptions } & Base & Higher & Lower \\
& Case & Return & Return \\
\hline PSH project data & & & \\
\hline Year that project starts & 2014 & 2014 & 2014 \\
Year that construction starts & 2018 & 2018 & 2018 \\
Year project is on-line & 2022 & 2022 & 2022 \\
Installed project capacity (MW) & 1,000 & 1,000 & 1,000 \\
Capacity factor (\%) & 20 & 22 & 18 \\
Cycle efficiency (\%) & 80 & 82 & 80 \\
Construction cost (\$/kW) & 2,000 & 1,700 & 2,300 \\
Development and owner's costs (\% of total cost?) & 8 & 6 & 8 \\
Final design and construction management costs (\% of total cost?) & 5 & 4 & 5 \\
\hline Annual revenues & & & \\
\hline Energy arbitrage revenues (\$ million) & 61.3 & 80.9 & 44.2 \\
Average energy sales price (\$/MWh) & 35.0 & 42.0 & 28.0 \\
A/S, regulation up (\$000/MW capacity) & 20.0 & 30.0 & 15.0 \\
A/S, regulation down (\$000/MW capacity) & 7.0 & 10.5 & 5.3 \\
A/S, spinning reserve (\$000/MW capacity) & 23.5 & 35.3 & 17.6 \\
A/S, non-spinning reserve (\$000/MW capacity) & 2.0 & 3.0 & 1.5 \\
\hline Annual operating costs & & & \\
\hline Pumping energy (\$ million) & 30.7 & 23.0 & 33.1 \\
Average pumping energy (\$MWh) & 14.0 & 9.8 & 16.8 \\
Regular annual O\&M (\$ million) & 20.0 & 17.0 & 23.0 \\
O\&M startup (\$ million) & 30.0 & 25.5 & 34.5 \\
5-year major O\&M (\$ million) & 20.0 & 17.0 & 23.0 \\
\hline
\end{tabular}

For the financial model runs, a general baseline annual inflation rate of $2.35 \%$ was used. A separate annual escalation rate for construction costs was added to reflect expected cost increases during construction. For revenues, a real (above inflation) annual escalation rate was also added to reflect revenue fluctuations above or below the expected inflation rate. For this study, a 2\% real escalation rate was used. 


\subsubsection{Base-Case Results}

Using the base-case assumptions shown in Table 9-1, the PSH financial model was run for 30 operating years, with the debt and equity funding assumptions in Table 9-2. Model projections for income, cash flow, and balance sheet over the 30-year operating history were used to calculate base-case results shown in Table 9-3 for both the IOU and IPP financial model versions.

Table 9-2 Default Loan Attributes

\begin{tabular}{|l|c|c|c|}
\hline \multicolumn{1}{|c|}{ Generic PSH Base Case } & Loan 1 & Loan 2 & Loan 3 \\
\hline \% of debt component & 30 & 50 & 20 \\
\hline Loan repayment (no. of years) & 20 & 15 & 10 \\
\hline Interest rate (\%) & 4.50 & 4.25 & 4.00 \\
\hline
\end{tabular}

Table 9-3 Base-Case Results

\begin{tabular}{|l|c|c|}
\hline \multicolumn{1}{|c|}{ Base case Results } & IOU & IPP \\
\hline Construction cost (\$ million) & 2,000 & 2,000 \\
Total investment cost (\$ million) & 2,688 & 2,688 \\
DSCR (annual average \%) & 127 & 117 \\
NPV (\$ million) & 33.0 & 44.8 \\
BCR (no unit) & 1.03 & 1.04 \\
IRR (\%) & 4.6 & 4.7 \\
30-year average ROI (\%) & 5.0 & 3.9 \\
30-year average ROE (\%) & 5.2 & 3.5 \\
\hline
\end{tabular}

A series of sensitivity analyses were performed for the IOU model. The results are presented in the following sections.

\subsubsection{Sensitivity Case 1: Construction Cost}

The financial model illustrates how construction costs remain a key concern for PSH project managers, since variances in construction costs can have a large impact on project return metrics. For example, the generic model has a sample base-case PSH construction cost of $\$ 2,000 / \mathrm{kW}$ of installed capacity. The model tested a $20 \%$ variance in construction costs with PSH construction costs ranging from $\$ 1,600 / \mathrm{kW}$ in the higher-return scenario to $\$ 2,400 / \mathrm{kW}$ in the lower-return scenario. Increasing construction costs by $20 \%$ to $\$ 2,400 / \mathrm{kW}$, while keeping all other variables unchanged, reduced the NPV from \$33 million in the sample base case to a negative NPV of $\$ 325$ million in the lower-return scenario. Conversely, decreasing construction costs by $20 \%$ to $\$ 1,600 / \mathrm{kW}$ of installed project capacity increased the NPV from \$33 million in the sample base case to \$391 million in the higher-return scenario. Under the same scenarios, the IRRs shifted from $4.6 \%$ in the base case down to $1.8 \%$ in the higher-construction-cost case and up to $8.6 \%$ in the lower-construction-cost case. Results are shown in Table 9-4. 


\subsubsection{Sensitivity Case 2: Interest Rates}

Loan interest rates are a key component of the project financing plan; changes in interest rates influence project return metrics. Model users can adjust assumptions for loan amounts, interest rates, and repayment period lengths in the PSH-Inputs worksheet. For illustration purposes, the generic model assumed a $75 \%$ debt/25\% equity funding mix, with debt split into three loans. Sensitivity Case 2 used the model to examine the potential impact of interest rates rising or falling by 100 basis points or $1 \%$ (100 basis points $=1 \%$ ). The scenario results in Table 9-5 illustrate how changes in loan interest rates can affect project returns. An increase in loan interest rates by 100 basis points decreases the project NPV to a loss of $\$ 145$ million, from a base-case NPV of $\$ 33$ million. Likewise, decreasing each of the loans' interest rates by 100 basis points increases the project NPV to $\$ 288$ million.

\subsubsection{Sensitivity Case 3: Revenues from Energy and Ancillary Services}

There are uncertainties related to the projected annual revenues expected from energy arbitrage and A/S. This sensitivity analysis can be easily done in the model by changing the expected annual revenues for each service. Table 9-1 shows the assumptions that were made for each revenue stream under the base-case, higher-return, and lower-return scenarios. The results for these three cases are shown in Table 9-6. For these runs, all other baseline assumptions, including the annual inflation rate of $2.35 \%$ and the real escalation rate of $2.0 \%$, were kept the same.

\subsubsection{Sensitivity Case 4: Real Escalation Rates for All Revenues}

Over the 30-year operation period, changes in expected annual revenue real escalation for both energy arbitrage and A/S revenues can greatly influence project return metrics. Recognizing this sensitivity, the income statement allows for changes in annual revenue growth in any one year during the PSH plant's 30-year operating mode. Model users can adjust the annual revenue growth assumptions in the income growth assumptions section of the income worksheet to test the periodic variance in annual revenue growth.

Table 9-7 illustrates how a change in annual revenue escalation rates can affect the project's return metrics. Increasing annual revenue real (above general inflation) escalation rates from $2.0 \%$ to 3.0\% can increase the project NPV from a base-case value of $\$ 33$ million to $\$ 503$ million. Conversely, when annual revenue escalation rates are reduced to $1.75 \%$ in this case, the project NPV becomes negative.

IRRs mirror NPV results, rising from a base-case IRR of $4.6 \%$ to $8.2 \%$ after assuming a $3.0 \%$ annual revenue escalation and decreasing to $0.8 \%$ after assuming a $1 \%$ annual revenue escalation. 
Table 9-4 Results for Sensitivity Case 1, Construction Cost

\begin{tabular}{|c|c|c|c|c|c|c|c|c|c|}
\hline & & & & & $\begin{array}{l}\text { Base } \\
\text { Case }\end{array}$ & & & & \\
\hline Construction Cost (\$/kW) & 1,600 & 1,700 & 1,800 & 1,900 & 2,000 & 2,100 & 2,200 & 2,300 & 2,400 \\
\hline Change from Base Case (\%) & -20 & -15 & -10 & -5 & 0 & +5 & +10 & +15 & +20 \\
\hline \multicolumn{10}{|l|}{$\begin{array}{l}\text { PSH profit margins (average for } 30 \text { years } \\
\text { of operation) }\end{array}$} \\
\hline$\%$ PSH gross profit margin & 73 & 73 & 73 & 73 & 73 & 73 & 73 & 73 & 73 \\
\hline \% PSH operating (EBIT) profit margin & 46 & 44 & 43 & 41 & 39 & 38 & 36 & 34 & 33 \\
\hline \multicolumn{10}{|l|}{ PSH financing metrics } \\
\hline Total PSH investment cost (\$ million) & 2,151 & 2,285 & 2,420 & 2,554 & 2,688 & 2,823 & 2,957 & 3,092 & 3,226 \\
\hline Total PSH debt funding cost (\$ million) & 2,353 & 2,500 & 2,647 & 2,794 & 2,941 & 3,088 & 3,235 & 3,383 & 3,530 \\
\hline PSH (DSCR) (annual average \%) & 186 & 169 & 153 & 140 & 127 & 116 & 106 & 97 & 88 \\
\hline \multicolumn{10}{|l|}{$\begin{array}{l}\text { Project return metrics ( } 30 \text { years of } \\
\text { operation) }\end{array}$} \\
\hline PSH NPV (\$ million) & 391.4 & 301.8 & 212.2 & 122.6 & 33.0 & $(56.6)$ & $(146.2)$ & $(235.8)$ & $(325.4)$ \\
\hline PSH BCR (no unit) & 1.49 & 1.36 & 1.24 & 1.13 & 1.03 & 0.95 & 0.87 & 0.79 & 0.73 \\
\hline PSH IRR (\%) & 8.6 & 7.4 & 6.4 & 5.4 & 4.6 & 3.8 & 3.1 & 2.4 & 1.8 \\
\hline PSH 30-year average ROI (\%) & 5.5 & 5.3 & 5.2 & 5.1 & 5.0 & 4.9 & 4.8 & 4.7 & 4.7 \\
\hline PSH-30-year average ROE (\%) & 6.4 & 6.1 & 5.8 & 5.5 & 5.2 & 4.9 & 4.6 & 4.3 & 4.0 \\
\hline
\end{tabular}


Table 9-5 Results for Sensitivity Case 2, Interest Rates

\begin{tabular}{|c|c|c|c|c|c|c|c|c|c|}
\hline & & & & & $\begin{array}{l}\text { Base } \\
\text { Case }\end{array}$ & & & & \\
\hline Interest Rate Change (\%) & -1.00 & -0.75 & -0.50 & -0.25 & 0.00 & +0.25 & +0.50 & +0.75 & +1.00 \\
\hline $\begin{array}{l}\text { Change in No, of Basis Points from Base Case } \\
(100 \text { basis points }=1 \%)\end{array}$ & -100 & -75 & -50 & -25 & 0 & +25 & +50 & +75 & +100 \\
\hline \multicolumn{10}{|c|}{ PSH profit margins (average for 30 years of operation) } \\
\hline \% PSH gross profit margin & 73 & 73 & 73 & 73 & 73 & 73 & 73 & 73 & 73 \\
\hline \% PSH operating (EBIT) profit margin & 39 & 39 & 39 & 39 & 39 & 39 & 39 & 39 & 39 \\
\hline \multicolumn{10}{|l|}{ PSH financing metrics } \\
\hline Total PSH investment costs (\$ million) & 2,688 & 2,688 & 2,688 & 2,688 & 2,688 & 2,688 & 2,688 & 2,688 & 2,688 \\
\hline Total PSH debt funding costs (\$ million) & 2,714 & 2,770 & 2,827 & 2,884 & 2,941 & 3,000 & 3,058 & 3,117 & 3,177 \\
\hline PSH (DSCR) (annual average \%) & 133 & 132 & 130 & 129 & 127 & 126 & 124 & 123 & 122 \\
\hline \multicolumn{10}{|l|}{ Project return metrics (30 years of operation) } \\
\hline PSH NPV (\$ million) & 288.2 & 215.7 & 149.3 & 88.6 & 33.0 & $(17.8)$ & $(64.3)$ & $(106.7)$ & $(145.4)$ \\
\hline PSH BCR (no unit) & 1.25 & 1.19 & 1.14 & 1.09 & 1.03 & 0.98 & 0.93 & 0.88 & 0.83 \\
\hline PSH IRR (\%) & 5.5 & 5.2 & 5.0 & 4.8 & 4.6 & 4.4 & 4.2 & 4.0 & 3.8 \\
\hline PSH 30-year average ROI (\%) & 4.8 & 4.8 & 4.9 & 4.9 & 5.0 & 5.1 & 5.1 & 5.2 & 5.3 \\
\hline PSH-30-year average ROE (\%) & 5.4 & 5.3 & 5.3 & 5.2 & 5.2 & 5.1 & 5.1 & 5.0 & 5.0 \\
\hline
\end{tabular}


Table 9-6 Results for Sensitivity Case 3, Revenues from Energy and Ancillary Services

\begin{tabular}{|l|c|c|c|}
\hline \multicolumn{1}{|c|}{$\begin{array}{c}\text { Results for Changes to } \\
\text { Revenue Assumptions }\end{array}$} & $\begin{array}{c}\text { Base } \\
\text { Case }\end{array}$ & $\begin{array}{c}\text { Higher } \\
\text { Return }\end{array}$ & $\begin{array}{c}\text { Lower } \\
\text { Return }\end{array}$ \\
\hline Construction costs (\$ million) & 2,000 & 2,000 & 2,000 \\
Total investment costs (\$ million) & 2,688 & 2,688 & 2,688 \\
DSCR (annual average \%) & 127 & 236 & 56 \\
NPV (\$ million) & 33.0 & 878.2 & -524.2 \\
BCR (no unit) & 1.03 & 1.88 & 0.48 \\
IRR (\%) & 4.6 & 12.3 & -0.8 \\
30-year average ROI (\%) & 5.0 & 5.8 & 4.6 \\
30-year average ROE (\%) & 5.2 & 7.2 & 2.6 \\
\hline a Changed revenue assumptions for energy and A/S (\$/MWh and \\
\$000/MW capacity)
\end{tabular}

\subsubsection{Sensitivity Case 5: Ancillary Revenues}

Uncertainties related to the projected annual revenues expected from A/S were tested separately. This sensitivity analysis can be easily done in the financial model by changing the expected annual revenues for each A/S. Table 9-1 shows the assumptions that were made for each A/S revenue stream under the base-case, higher-return, and lower-return scenarios. The results for these three cases are shown in Table 9-8. For these runs, all other baseline assumptions, including the annual inflation rate of $2.35 \%$ and the real escalation rate of $2.0 \%$, were kept the same.

\subsubsection{Sensitivity Case 6: Real Escalation Rates for Ancillary Revenues}

The uncertainty of future A/S prices creates significant uncertainty regarding the economic attractiveness of this generic PSH project. Testing sample higher-return and lower-return scenarios for revenues for each service in our generic financial model has also produced wide variances in project return metrics (Table 9-9). This was done by changing the expected annual real escalation rate for $\mathrm{A} / \mathrm{S}$ only. This illustrates how $\mathrm{A} / \mathrm{S}$ values can alter project return metrics and reinforce the need to further quantify the potential value of $\mathrm{A} / \mathrm{S}$ and revenue potential for future PSH projects.

\subsection{Recommendations}

The role of PSH projects in the U.S. market has changed in response to the increased penetration of variable renewable resources. PSH projects are often operating to maximize the dependable capacity from variable renewables and provide $\mathrm{A} / \mathrm{S}$ to support interconnected bulk transmission grid reliability and stability. PSH projects can provide a fast response at the utility scale. However, as discussed in Section 8 on energy markets, many of these services are not 
Table 9-7 Results for Sensitivity Case 4, Real Escalation Rates for All Revenues

\begin{tabular}{|c|c|c|c|c|c|c|c|c|c|}
\hline & & & & & $\begin{array}{l}\text { Base } \\
\text { Case }\end{array}$ & & & & \\
\hline Escalation Rate $^{\mathrm{a}}(\%)$ & 1.00 & 1.25 & 1.50 & 1.75 & 2.00 & 2.25 & 2.50 & 2.75 & 3.00 \\
\hline $\begin{array}{l}\text { Change in Basis Points from Base Case } \\
\text { (100 basis points = 1\%) }\end{array}$ & -100 & -75 & -50 & -25 & 0 & +25 & +50 & +75 & +100 \\
\hline \multicolumn{10}{|l|}{$\begin{array}{l}\text { PSH profit margins (average for } 30 \text { years of } \\
\text { operation) }\end{array}$} \\
\hline$\%$ PSH gross profit margin & 73 & 73 & 73 & 73 & 73 & 73 & 73 & 73 & 73 \\
\hline \% PSH operating (EBIT) profit margin & 31 & 33 & 35 & 37 & 39 & 41 & 43 & 44 & 46 \\
\hline \multicolumn{10}{|l|}{ PSH financing metrics } \\
\hline Total PSH investment costs (\$ million) & 2,688 & 2,688 & 2,688 & 2,688 & 2,688 & 2,688 & 2,688 & 2,688 & 2,688 \\
\hline Total PSH debt funding costs (\$ million) & 2,941 & 2,941 & 2,941 & 2,941 & 2,941 & 2,941 & 2,941 & 2,941 & 2,941 \\
\hline PSH (DSCR) (annual average \%) & 81 & 92 & 103 & 115 & 127 & 141 & 155 & 169 & 185 \\
\hline \multicolumn{10}{|l|}{ Project return metrics ( 30 years of operation) } \\
\hline PSH NPV (\$ million) & $(334.1)$ & $(250.6)$ & $(161.8)$ & $(67.4)$ & 33.0 & 139.8 & 253.5 & 374.5 & 503.2 \\
\hline PSH BCR (no unit) & 0.67 & 0.75 & 0.84 & 0.93 & 1.03 & 1.14 & 1.25 & 1.37 & 1.50 \\
\hline PSH IRR (\%) & 0.8 & 1.8 & 2.7 & 3.7 & 4.6 & 5.5 & 6.4 & 7.3 & 8.2 \\
\hline PSH 30-year average ROI (\%) & 4.0 & 4.3 & 4.5 & 4.8 & 5.0 & 5.2 & 5.4 & 5.7 & 5.9 \\
\hline PSH-30-year average ROE (\%) & 3.5 & 4.0 & 4.4 & 4.8 & 5.2 & 5.6 & 5.9 & 6.3 & 6.6 \\
\hline
\end{tabular}

${ }^{a}$ Changed annual escalation rate for all revenue items (energy arbitrage and $A / S$ ). 
Table 9-8 Results for Changes to Ancillary Services Revenue Assumptions

\begin{tabular}{|c|c|c|c|}
\hline Results for Changes to A/S Revenue Assumptions $^{\mathrm{a}}$ & Base Case & Higher Return & Lower Return \\
\hline Construction cost (\$ million) & 2,000 & 1,700 & 2,300 \\
\hline Total investment cost (\$ million) & 2,688 & 2,285 & 3,092 \\
\hline DSCR (annual average \%) & 127 & 202 & 90 \\
\hline NPV (\$ million) & 33.0 & 609.1 & -255.0 \\
\hline BCR (no unit) & 1.03 & 1.61 & 0.74 \\
\hline IRR (\%) & 4.6 & 9.7 & 1.9 \\
\hline 30-year average ROI (\%) & 5.0 & 5.6 & 4.7 \\
\hline 30-year average ROE (\%) & 5.2 & 6.7 & 4.1 \\
\hline
\end{tabular}

Table 9-9 Results for Sensitivity Case 6, Real Escalation Rates for Ancillary Revenues

\begin{tabular}{|c|c|c|c|c|c|c|c|c|c|}
\hline & & & & & $\begin{array}{l}\text { Base } \\
\text { Case }\end{array}$ & & & & \\
\hline Real Escalation Rates for A/S Revenues (\%) & 1.00 & 1.25 & 1.50 & 1.75 & 2.00 & 2.25 & 2.50 & 2.75 & 3.00 \\
\hline $\begin{array}{l}\text { Change in Basis Points from Base Case } \\
(100 \text { basis points }=1 \%)\end{array}$ & -100 & -75 & -50 & -25 & 0 & 25 & 50 & 75 & 100 \\
\hline \multicolumn{10}{|l|}{$\begin{array}{l}\text { PSH profit margins (average for } 30 \text { years of } \\
\text { operation) }\end{array}$} \\
\hline \% PSH gross profit margin & 70 & 71 & 72 & 72 & 73 & 74 & 74 & 75 & 76 \\
\hline \% PSH operating (EBIT) profit margin & 33 & 35 & 36 & 38 & 39 & 41 & 42 & 44 & 45 \\
\hline \multicolumn{10}{|l|}{ PSH financing metrics } \\
\hline Total PSH investment costs (\$ million) & 2,688 & 2,688 & 2,688 & 2,688 & 2,688 & 2,688 & 2,688 & 2,688 & 2,688 \\
\hline Total PSH debt funding costs (\$ million) & 2,941 & 2,941 & 2,941 & 2,941 & 2,941 & 2,941 & 2,941 & 2,941 & 2,941 \\
\hline PSH (DSCR) (annual average \%) & 99 & 105 & 112 & 120 & 127 & 136 & 144 & 153 & 163 \\
\hline \multicolumn{10}{|l|}{ Project return metrics ( 30 years of operation) } \\
\hline PSH NPV (\$ million) & $(194.2)$ & $(142.5)$ & (87.5) & (29.1) & 33.0 & 98.9 & 169.1 & 243.6 & 322.9 \\
\hline PSH BCR (no unit) & 0.81 & 0.86 & 0.91 & 0.97 & 1.03 & 1.10 & 1.17 & 1.24 & 1.32 \\
\hline PSH IRR (\%) & 2.4 & 2.9 & 3.5 & 4.0 & 4.6 & 5.1 & 5.7 & 6.3 & 6.9 \\
\hline PSH 30-year average ROI (\%) & 4.4 & 4.6 & 4.7 & 4.8 & 5.0 & 5.1 & 5.3 & 5.4 & 5.6 \\
\hline PSH-30-year average ROE (\%) & 4.2 & 4.5 & 4.7 & 5.0 & 5.2 & 5.4 & 5.7 & 5.9 & 6.1 \\
\hline
\end{tabular}


currently compensated financially. ${ }^{21}$ The A/S that are acknowledged with market products vary by ISO and RTO.

PSH's other role — to operate for energy arbitrage — leads to a smoothing of prices between off-peak and on-peak hours, such that PSH operation can greatly reduce price differentials (see Section 8 on energy markets for more discussion) and, consequently, their revenues. While these market-related barriers significantly affect the financial viability of a PSH project, they are discussed in Section 8 on electricity markets, along with recommendations to reduce or eliminate these barriers.

As demonstrated in the financial modeling completed as part of this study, developing a new, financially viable PSH project will be a challenge. While this report focuses on a generic case study with associated sensitivity analyses, its results highlight the overarching issue facing largescale energy storage, where the monetized benefits under current market conditions are not always enough to justify the required investment. Lenders often seek a fast return with lower capital costs, but PSH requires financing for a long-lived project with high capital costs and low operating costs.

As mentioned in Section 8, treating PSH as a regulated, rate-based resource under system operator control may help reduce this barrier. In addition, providing tax credits for energy storage projects, similar to providing an investment tax credit or production tax credit, would reduce the burden of the initial capital investment.

\subsection{References and Bibliography}

Bodell, T., 2010, “Why We Can’t Avoid Avoided Cost,” Electric Light \& Power. Available at http://www.elp.com/articles/print/volume-88/issue-2/columns/why-we-can-t-avoid.html.

Cunha, G.A., 2014, Construction Management at Risk, M.G.L. c. 149A, $\S \S 1-13$, Inspector General of Massachusetts. Available at http://www.mass.gov/ig/public-design-andconstruction/alternative-construction-methods/construction-management-at-risk-m-g-l-c-149a-113.html, accessed Jan. 30, 2014.

Doty, G.N., D.L. McCree, and F.D. Doty, 2010, "Projections of Levelized Cost Benefit of GridScale Energy Storage Options,” in Proceedings of Energy Sustainability 2010, ES2010-90377, American Society of Mechanical Engineers.

eLab, 2013, New Business Models for the Distribution Edge: The Transition from Value Chain to Value Constellation. Available at www.rmi.org/new_business_models.

EPRI (Electric Power Research Institute), 2013, Quantifying the Value of Hydropower in the Electric Grid: Final Report, EPRI Report 1023144, Feb.

21 Conditions are beginning to change in this regard, as evidenced by FERC Order 784, Third-Party Provision of Ancillary Services; Accounting and Financial Reporting for New Electric Storage Technologies, issued July 18, 2013 (FERC 2013). 
FERC (Federal Energy Regulatory Commission), 2013, Order 784: Third-Party Provision of Ancillary Services; Accounting and Financial Reporting for New Electric Energy Storage Technologies, July 18. Available at http://www.ferc.gov/whats-new/comm-meet/2013/071813/E22.pdf.

FERC, 2011, Order 1000: Final Rule on Transmission Planning and Cost Allocation by Transmission Owning and Operating Public Utilities. Available at http://www.ferc.gov/whatsnew/comm-meet/2011/072111/E-6.pdf.

HydroVision, 2008, Hydro Finance Handbook, July.

Gulliver, J.S., and R.E.A. Arndt, 1991, Hydropower Engineering Handbook, Chapter 9, McGraw-Hill.

McDermott, K., 2012, Cost of Service Regulation in the Investor-Owned Electric Utility Industry: A History of Adaptation, Edison Electric Institute. Available at http://www.eei.org/ issuesandpolicy/stateregulation/Documents/COSR history_final.pdf.

NETL (National Energy Technology Laboratory), 2008, Recommended Project Finance Structures for the Economic Analysis of Fossil-Based Energy Projects, DOE/NETL-401/090808, U.S. Department of Energy, Sept.

Sandia National Laboratories, 2011, Quantifying the Value of Hydropower in the Electric Grid: Role of Hydropower in Existing Markets, SAND Report 2001-1009, Jan.

Sandia National Laboratories, 2012, Project Report: A Survey of Operating Reserve Markets in U.S. ISO/RTO-Managed Electric Energy Regions, SAND Report 2012-1000, Sept.

World Bank, 2000, Financing of Private Hydropower Projects, World Bank Discussion Paper No. 420 (WDP420), July. 


\section{Section}

\section{0}

\section{Key Findings and Conclusions}

This study involved numerous simulations and model runs across various time scales. The key findings and conclusions derived from the various analyses are summarized in this section.

\subsection{Advanced Technology Modeling}

\subsubsection{Development and Testing of Dynamic PSH Models}

The project team reviewed the hydroelectric turbine-governor simulation models now being used in the United States and concluded that they accurately represent the dynamic behavior of conventional hydro and pumped storage units. However, the team also determined that for new advanced PSH technologies, such as AS and ternary units, there are no dynamic models currently available in the United States. Yet such models are needed to conduct transmission interconnection and system dynamic performance studies for new PSH projects that employ these technologies. At present, there are about 50 proposed pumped storage projects in the United States in various stages of the planning and FERC licensing process (see Figure 2-3). Many of these projects are considering the use of AS technology, such as DFIMs. Dynamic models for the AS and ternary units must be developed to fill the hydropower industry's and the PSH project developers' need for them.

The project team developed dynamic vendor-neutral models for AS and ternary units. The models (block diagrams and transfer functions) are described in several reports that are publicly available. The models were integrated into the Siemens PTI's PSSE software and added to the PSSE library of dynamic models. They are also available for integration into other software tools.

These dynamic models of AS and ternary PSH units were used by the project team to conduct various power system dynamic performance studies and to analyze the dynamic behavior of these technologies and their impact on the power system. Analyses of conventional FS and advanced AS PSH technologies and their dynamic responses focused on various system disturbances (including over- and under-frequency events due to a sudden loss of load or generation in the power system) and on changes in the power generated by variable renewable energy sources. The analyses showed that compared with conventional FS PSH plants, advanced PSH technologies provide greater flexibility and faster response times to system events.

The tests showed that the new models performed well and can be used for the typical dynamic simulation analyses required for transmission planning and interconnection studies. The tests also demonstrated the new capabilities of these models, such as using AS and ternary PSH plants 
to provide regulation service in pump mode. For all scenarios and disturbances, the newly developed AS PSH and ternary unit models performed as expected and allowed the advantages of the advanced PSH technology (specifically, the ability of AS and ternary pumps to participate in secondary frequency control) to be demonstrated.

\subsubsection{Power and Speed Control of AS PSH}

Conventional single-speed pumped storage plants employ synchronous machines. The input to the governor controls is speed, and the gate position is controlled to adjust power. The machine's speed is not controlled; speed is locked to the system frequency because the machine is synchronous.

However, in a pumped storage plant employing a DFIM, there are two controllable variables: gate position and speed, since the speed of the machine is no longer locked to system frequency. In steady state, the controls select the optimal relationship between gate position and speed to get the desired power. In principle, there are three basic control approaches:

1. The electrical power is controlled by the power converter, and the rotating speed is controlled by the turbine-governor adjusting the gate position;

2. The rotating speed is controlled by the power converter, and the electrical power is controlled by the turbine-governor adjusting the gate position; and

3. A combination of these two approaches.

Since the power converter can be adjusted much more quickly (it takes tenths of a second) than the gate position (it takes seconds), the project team labeled the first control strategy as "fast power control" and the second strategy as "fast speed control." It can be shown that in a general sense, both approaches work, although the transient responses of the units to events occurring on the system are very different.

\subsubsection{Mode Change Times of PSH Technologies}

One of the characteristics of PSH technologies is their fast ramping capabilities, which allow them to very quickly ramp up to full capacity or ramp down to standstill. Fast ramping is available in both the generating and pumping mode of operation. Moreover, a PSH plant can very quickly (in several minutes) transition from full power generation to pumping with full capacity. This type of flexibility is very advantageous for compensating the variability of loads and variable renewable generation in the system. By being able to change its mode of operation from generating to pumping in few minutes, a PSH plant practically doubles its effective dispatchable capacity. Ternary generating units, which have a motor/generator and separate pump and turbine on the same shaft, are especially quick in changing their mode of operation because the pump and turbine are rotating in the same direction and can operate at the same time (hydraulic short circuit), thereby eliminating the need to stop the turbine and reverse the rotation to transition from pumping to generating and vice versa. 
This advantage of ternary units is illustrated in Figure 10-1, which gives typical startup and transition times of different PSH technologies. The transition time from generating mode to pumping mode for a reversible pump/turbine ranges from 4 to $8 \mathrm{~min}$, even for units employing advanced technologies. The transition time for ternary units is much less: on the order of 0.5 to $0.75 \mathrm{~min}$.

The time for a reversible pump/turbine to transition in the opposite direction, from pumping mode to generating mode, ranges from 1.5 to $5 \mathrm{~min}$, while the transition time for the ternary units is again significantly less, on the order of 0.5 to $1 \mathrm{~min}$.

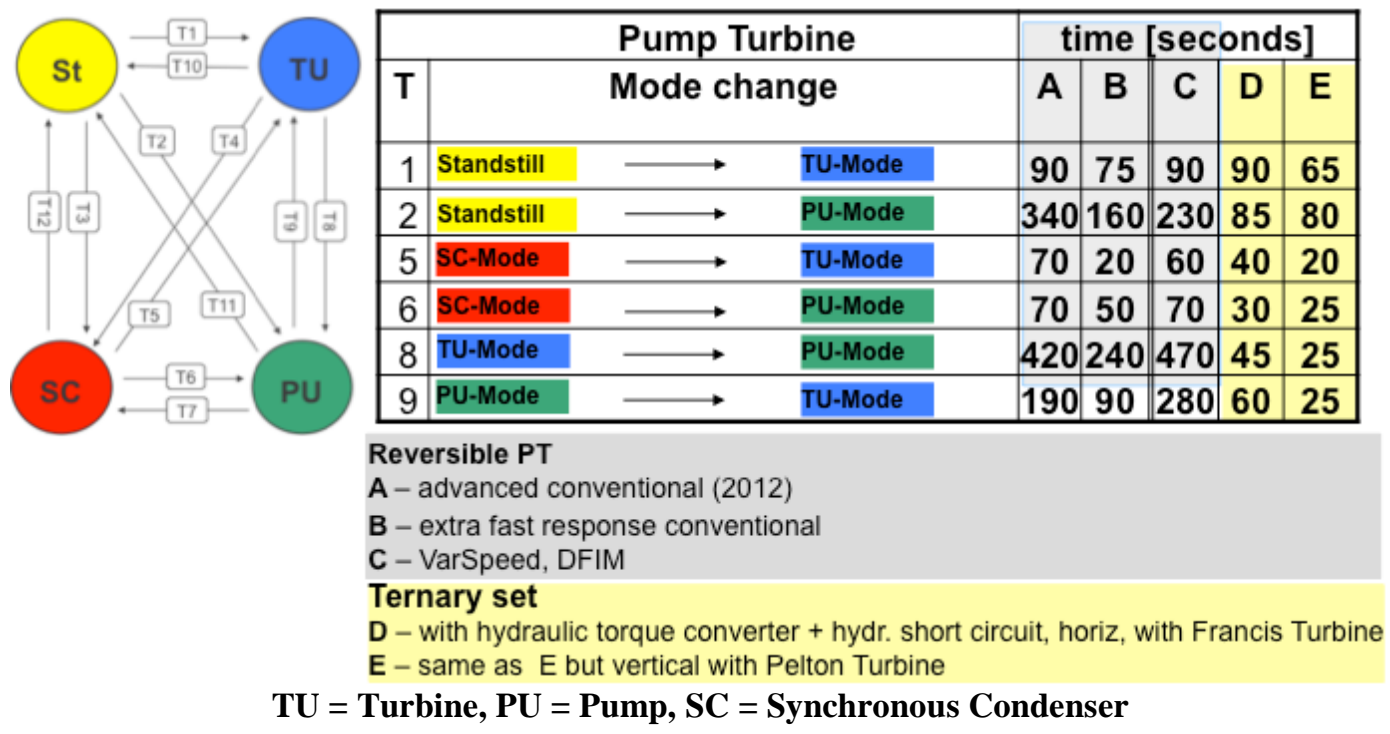

Figure 10-1 Mode Change Times for Various Advanced Pumped Storage Technologies (Source: Fisher et al. 2012)

These fast transition times provided by PSH technologies are very advantageous for the power system. For example, consider a pumped storage unit operating in pumping mode at night, when a large amount of wind-powered generation is occurring. If there is a significant and fast drop in the wind energy, the ability of the pumped storage plant to transition quickly from pumping (and thus a system load) to generating could have a large impact with regard to mitigating any resultant frequency deviations experienced by the system.

\subsubsection{Additional Capabilities Provided by Advanced PSH Technologies}

Although conventional FS PSH technology is one of the most flexible technologies currently available, AS PSH technologies provide even more flexibility. Some of the additional capabilities they provide are summarized here:

- Have more flexible and efficient operation in the generation mode than do conventional FS PSH technologies; 
- Have a minimum unit power output of $30 \%$ or lower;

- Increase the efficiency and lifetime of the turbine at partial loads by operating at optimal speed;

- Employ turbines driven by the induction machine that can operate, even at no load, without significantly reducing the lifetime of the turbine;

- Have frequency regulation capabilities that are also available in the pumping mode of operation;

- Have electronically decoupled control of active and reactive power, which provides more flexible voltage support;

- Have power systems with improved dynamic behavior and stability in case of grid disturbances and with fewer frequency drops in case of generator outages; and

- Better compensate for the variability of renewable energy sources because they:

- Have a more flexible and quicker response in generating (turbine) mode,

- Have variable power in pumping mode to counterbalance the variability of wind power, and

- Are an excellent source of frequency regulation during off-peak hours.

\subsection{Production Cost Simulations with PLEXOS Model}

Energy Exemplar's PLEXOS model was used to perform production cost and revenue simulations for the Base and High Wind renewable energy scenarios with and without FS and AS PSH plants modeled in the system. The DA simulations were performed on an hourly basis for the entire year 2022 for all cases. However, higher-resolution PLEXOS three-stage simulations with a 5-min simulation time step were performed in each case for four typical weeks in year 2022: the third week in January, April, July, and October.

The analysis focused on three areas: WI, California, and SMUD. In the WECC TEPPC database, the load region SMUD represents BANC, which includes SMUD, the MID, Roseville Electric, and Redding Electric Utility. The simulation footprints for California and SMUD were developed by extracting them from the WI simulation footprint.

Both cost-based and market-based approaches were used in the analysis. The cost-based approach was applied for the simulation of the entire WI and for the SMUD footprint, and the market-based approach (as a bid-based electricity market) was applied for the simulation of the California footprint. 


\subsubsection{Annual Simulation Results}

The following subsections present some of the key results obtained from the annual PLEXOS simulations of the WI, California, and SMUD for three cases: (1) without any PSH plants, (2) with existing FS PSH plants, and (3) with existing FS and additional AS PSH plants. All three cases were run for the Base and High Wind renewable energy scenarios.

\section{Production Cost Savings}

Table 10-1 summarizes the savings in total system production cost in 2022 that can be attributed to PSH capacity. The production cost savings are greater when there is a higher penetration of renewable energy resources in the system.

The simulation results for WI show that existing FS PSH plants reduce the total system operating cost in 2022 by about $1.1 \%$ (about $\$ 167$ million) under the Base renewable energy scenario, or about 2\% (about \$248 million), under the High Wind scenario. The addition of three proposed AS PSH plants (Eagle Mountain, Iowa Hill, and Swan Lake North) could further reduce the total production cost in the WI by an additional $1 \%$, or $\$ 144$ million, under the Base renewable energy scenario and by an additional $1.8 \%$, or $\$ 229$ million, under the High Wind scenario. Percentagewise, even larger cost savings could be achieved in California, where the FS and AS PSH capacity reduces total system operating costs by $3.4 \%$, or $\$ 171$ million, under the Base renewable scenario, and by a total of 9.1\%, or \$376 million, under the High Wind scenario.

Table 10-1 Production Costs Savings in 2022 Due to PSH Capacity

\begin{tabular}{|c|c|c|c|c|c|c|}
\hline \multirow[b]{2}{*}{$\begin{array}{l}\text { Production Cost } \\
\text { Savings Due to } \\
\text { PSH Capacity (\%) }\end{array}$} & \multicolumn{2}{|c|}{ Western Interconnection } & \multicolumn{2}{|c|}{ California } & \multicolumn{2}{|c|}{ SMUD } \\
\hline & $\begin{array}{c}\text { Base } \\
\text { Renewable } \\
\text { Scenario }\end{array}$ & $\begin{array}{c}\text { High Wind } \\
\text { Renewable } \\
\text { Scenario }\end{array}$ & $\begin{array}{c}\text { Base } \\
\text { Renewable } \\
\text { Scenario }\end{array}$ & $\begin{array}{c}\text { High Wind } \\
\text { Renewable } \\
\text { Scenario }\end{array}$ & $\begin{array}{c}\text { Base } \\
\text { Renewable } \\
\text { Scenario }\end{array}$ & $\begin{array}{c}\text { High Wind } \\
\text { Renewable } \\
\text { Scenario }\end{array}$ \\
\hline With FS PSH & 1.14 & 1.96 & 2.18 & 4.52 & - & - \\
\hline With FS \& AS PSH & 2.11 & 3.77 & 3.36 & 9.12 & 8.62 & 16.45 \\
\hline
\end{tabular}

" $-"$ = not applicable.

Results for the SMUD area show that the addition of the proposed AS PSH Iowa Hill plant could result in annual production cost savings of about $\$ 23$ million, or 8.6\% of the total SMUD production cost under the Base renewable energy scenario, and in savings of about $\$ 51$ million, or $16.45 \%$, under the High Wind scenario.

\section{Energy Arbitrage}

PLEXOS simulations of the California system in 2022 were performed by using the marketbased approach, which allows for a detailed analysis of the value of energy arbitrage based on the LMPs of electricity in each hour of the year. Note that PLEXOS simulations were performed using the co-optimization of energy and A/S, so the results for energy arbitrage are likely lower than if the PSH operations were optimized to maximize energy arbitrage revenues only. A 
summary of key PLEXOS results for the Base and High Wind renewable energy scenarios is presented in Table10-2.

Table 10-2 Results for PSH Energy Arbitrage Revenues in California in 2022

\begin{tabular}{|l|c|c|c|c|}
\hline \multirow{2}{*}{\begin{tabular}{c}
\multirow{2}{*}{$\begin{array}{c}\text { Energy Arbitrage } \\
\text { Revenues }\end{array}$} \\
\cline { 2 - 5 }
\end{tabular}} & \multicolumn{2}{|c|}{ Base Renewable Scenario } & \multicolumn{2}{c|}{$\begin{array}{c}\text { High Wind Renewable } \\
\text { Scenario }\end{array}$} \\
\cline { 2 - 5 } & FS PSH & FS \& AS PSH & FS PSH & FS \& AS PSH \\
\hline PSH capacity (MW) & 2,626 & 4,425 & 2,626 & 4,425 \\
\hline Energy generation (GWh) & 2,725 & 5,313 & 5,299 & 9,456 \\
\hline Pumping energy (GWh) & 3,840 & 6,856 & 7,501 & 12,521 \\
\hline PSH capacity factor (\%) & 11.85 & 13.71 & 23.04 & 24.39 \\
\hline Energy revenue (\$1,000) & 102,302 & 181,554 & 147,285 & 217,302 \\
\hline Pumping cost (\$1,000) & 65,768 & 164,508 & $-13,229$ & 25,045 \\
\hline Net revenue (\$1,000) & 36,534 & 17,046 & 160,514 & 192,257 \\
\hline Net revenue (\$/kW-yr) & 13.9 & 3.9 & 61.1 & 43.4 \\
\hline
\end{tabular}

The capacity factors of PSH plants are significantly higher under the High Wind renewable energy scenario. The net revenues from energy arbitrage are also greater under the High Wind renewable energy scenario, but not as much as the PSH energy generation. This is because the value of energy generation is affected by the lower average LMP prices under the High Wind scenario.

The high penetration of variable energy resources (wind and solar) under the High Wind scenario keeps the average LMPs low and even negative when there are curtailments of excess variable generation. The cost of pumping energy for FS PSH plants under the High Wind scenario is negative because it is mostly supplied by the excess VER generation that would have been curtailed. It also shows that the capacity of existing FS PSH plants would not be sufficient for the high level of renewable resources in the system. With the addition of AS PSH plants, the overall pumping cost under the High Wind scenario becomes positive, but its relatively low value indicates that the PSH pumping energy is still mostly made up of the VER energy that would have been curtailed.

Table 10-2 also shows that under the High Wind scenario, the addition of AS PSH plants increases the total annual net revenues from energy arbitrage; however, the net revenues per kilowatt of PSH capacity are smaller because of the much larger PSH capacity in the system.

\section{Operating Reserves}

Figures 10-2 and 10-3 illustrate the contributions of PSH plants to operating reserves in the WI and California power systems in 2022. The results are presented for both the Base and High Wind renewable energy scenarios. Considering that the combined capacity of FS PSH and AS PSH plants represents less than 3\% of the total WI system capacity in 2022, it can be seen that PSH plants provide a significant amount of operating reserves to the system, especially in cases 


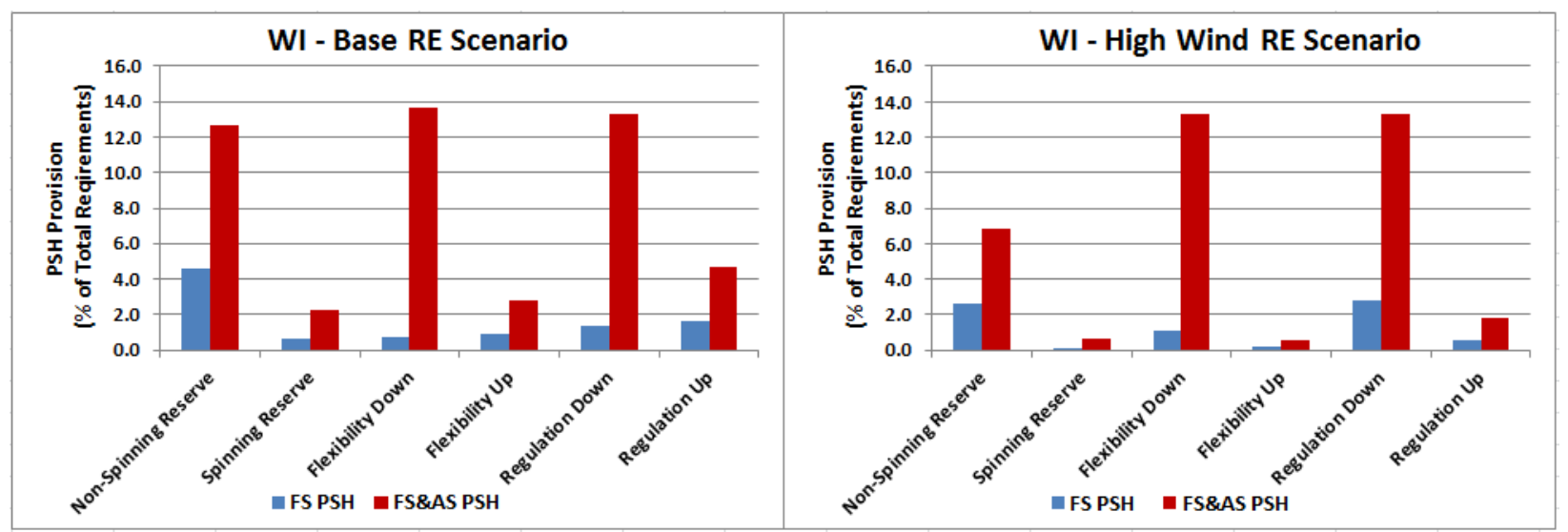

Figure 10-2 PSH Contributions to WI Operating Reserves in 2022

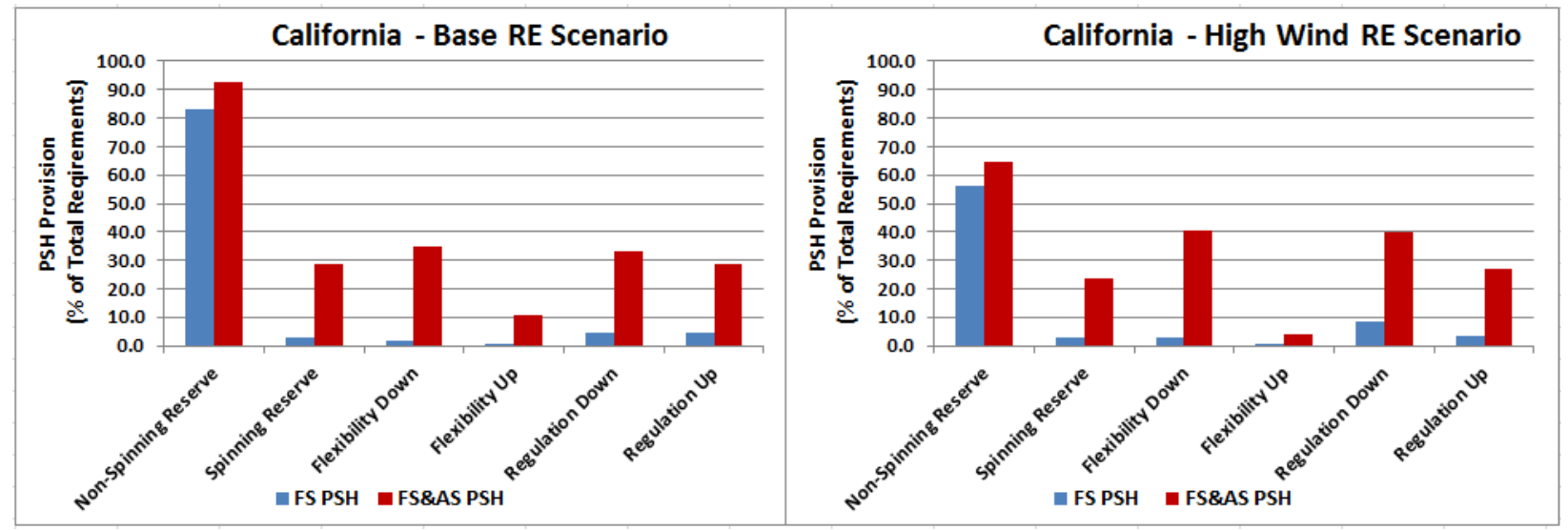

Figure 10-3 PSH Contributions to California Operating Reserves in 2022

when both FS PSH and AS PSH plants are operating. It can also be seen that PSH contributions to operating reserves increase significantly with the addition of AS PSH plants to the system.

There is an especially large increase for the regulation-down and flexibility-down reserves, because the AS PSH facility can provide these services in the pumping mode too. These reserves are especially needed during times when there is little flexibility in the power system. For example, during the night, the electricity demand is low and mostly base-load generating units are in operation, with their power outputs at or near their minimum operating capacity. Under such conditions, there may not be any flexible capacity in the system to compensate for large variations in wind generation. Rapid increases in wind generation may pose a particular challenge because conventional generating units may not be able to reduce their power output if they are already operating at their minimum capacity, and some units may need to be shut down. On the other hand, the demand response may also be limited at night, especially because the action would require an increase in electricity consumption to accommodate the increase in wind generation. Under such circumstances, the variable pumping capabilities of AS PSH plants can 
give the system the flexibility it needs to accommodate larger quantities of wind generation, reduce curtailments, and avoid shutdowns of conventional generating units.

With regard to the monetary value of PSH contributions to operating reserves, PLEXOS simulations for California were performed by using a market-based approach, which allowed for individual pricing and revenue analysis of A/S. A summary of PSH total annual revenues for provisions of operating reserves is provided in Table 10-3.

Table 10-3 PSH Revenues for Provisions of Operating Reserves in California in 2022

\begin{tabular}{|c|c|c|c|c|}
\hline \multirow[b]{2}{*}{ Operating Reserve } & \multicolumn{2}{|c|}{ Base Renewable Scenario } & \multicolumn{2}{|c|}{$\begin{array}{l}\text { High Wind Renewable } \\
\text { Scenario }\end{array}$} \\
\hline & $\begin{array}{c}\text { FS PSH } \\
(\$ 1,000)\end{array}$ & $\begin{array}{c}\text { FS \& AS PSH } \\
(\$ 1,000)\end{array}$ & $\begin{array}{l}\text { FS PSH } \\
(\$ 1,000)\end{array}$ & $\begin{array}{c}\text { FS \& AS PSF } \\
(\$ 1,000)\end{array}$ \\
\hline Non-spinning reserve & 7,557 & 8,563 & 5,246 & 6,184 \\
\hline Spinning reserve & 1,218 & 8,588 & 1,515 & 6,208 \\
\hline Flexibility down & 389 & 5,728 & 1,626 & 14,934 \\
\hline Flexibility up & 43 & 731 & 80 & 412 \\
\hline Regulation down & 4,562 & 20,360 & 19,511 & 49,885 \\
\hline Regulation up & 4,436 & 7,935 & 4,144 & 8,528 \\
\hline Total & 18,205 & 51,905 & 32,122 & 86,151 \\
\hline
\end{tabular}

Taking into account the provisions of operating reserves by PSH in 2022, expressed through megawatts of capacity provided for each reserve service in each hour of the year, the average hourly monetary values (\$/MWh) of different types of operating reserves in 2022 were calculated. The results showed that the regulation down is the highest-value service, followed by regulation up and flexibility down. The non-spinning reserve is the lowest-value service, averaging only about $\$ 1 / \mathrm{MWh}$. Taking the calculated values of these reserve services as proxies for their market prices, the results showed that the prices of different operating reserves are higher in cases when only FS PSH is operating in the system and lower if both FS and AS PSH plants are operating. This result illustrates the impact of AS PSH capacity, which offers significant additional capability for providing system reserves, thus affecting the prices for these reserves in the market.

The revenues of PSH plants for the provision of operating reserves can also be expressed per kilowatt of PSH capacity. The results in Table 10-4 show that the average annual revenues are highest for the provisions of regulation down service. 
Table 10-4 Average Annual PSH Revenues for Operating Reserves in California in 2022

\begin{tabular}{|l|c|c|c|c|}
\hline \multirow{2}{*}{\multicolumn{1}{|c|}{ Operating Reserve }} & \multicolumn{2}{c|}{} & \multicolumn{2}{c|}{$\begin{array}{c}\text { High Wind Renewable } \\
\text { Scenario }\end{array}$} \\
\cline { 2 - 5 } & $\begin{array}{c}\text { Base Renewable Scenario } \\
(\mathbf{\$} / \mathbf{k W}-\mathbf{y r})\end{array}$ & $\begin{array}{c}\text { FS \& AS PSH } \\
(\mathbf{\$} / \mathbf{k W}-\mathbf{y r})\end{array}$ & $\begin{array}{c}\text { FS PSH } \\
(\mathbf{\$} / \mathbf{k W}-\mathbf{y r})\end{array}$ & $\begin{array}{c}\text { FS \& AS PSH } \\
(\mathbf{\$} / \mathbf{k W}-\mathbf{y r})\end{array}$ \\
\hline Non-spinning reserve & 2.88 & 1.94 & 2.00 & 1.40 \\
\hline Spinning reserve & 0.46 & 1.94 & 0.58 & 1.40 \\
\hline Flexibility down & 0.15 & 1.29 & 0.62 & 3.37 \\
\hline Flexibility up & 0.02 & 0.17 & 0.03 & 0.09 \\
\hline Regulation down & 1.74 & 4.60 & 7.43 & 11.27 \\
\hline Regulation up & 1.69 & 1.79 & 1.58 & 1.93 \\
\hline Total & 6.93 & 11.73 & 12.23 & 19.47 \\
\hline
\end{tabular}

As illustrated in Figure 10-4, the average annual revenues per kilowatt of PSH capacity are higher for cases when both FS PSH and AS PSH plans operate in the system.

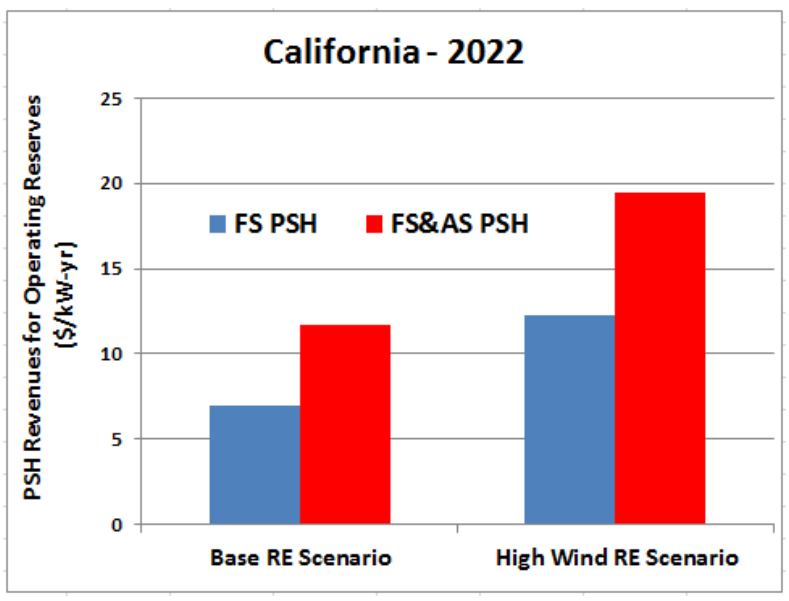

Figure 10-4 Average Annual PSH Revenues for Operating Reserves per Kilowatt of PSH Capacity

\section{Integration of Variable Energy Resources}

PLEXOS simulation results for WI under the Base renewable energy scenario show that the FS PSH plants reduce curtailments of VER generation by 565 GWh, or about $29 \%$ of total curtailments if there were no PSH plants operating in the system. With both FS and AS PSH plants operating in the WI system, the curtailments are reduced by $958 \mathrm{GWh}$, or about $50 \%$ of total curtailments. The amount of curtailed VER generation under the High Wind scenario is much greater and amounts to 56,885 GWh in the case without PSH plants operating in the system. The FS PSH plants reduce this curtailment by 8,482 GWh, or 15\%. When both FS and AS PSH plants are operating in the system, the curtailments are reduced by $12,675 \mathrm{GWh}$, or 
$22 \%$. Assuming a $30 \%$ capacity factor, the savings of $12,675 \mathrm{GWh}$ roughly corresponds to an average annual generation of almost 5,000 MW of wind capacity.

In California, under the Base renewable energy scenario, the curtailments of VER generation are reduced from $155 \mathrm{GWh}$ if there are no PSH plants operating, to $46 \mathrm{GWh}$ (70\% reduction) if FS PSH is operating in the system, and to $14 \mathrm{GWh}$ (91\% reduction) if both FS and AS PSH are operating. Under the High Wind scenario, the curtailments are reduced from $618 \mathrm{GWh}$ if there are no PSH plants operating, to $380 \mathrm{GWh}$ (39\% reduction) if FS PSH is operating in the system, to 275 GWh (55\% reduction) if both FS and AS PSH are operating.

The results for the SMUD footprint show that the addition of the AS PSH Iowa Hill plant reduces renewable energy curtailments from 19 to 1 GWh (95\% reduction) under the High Wind renewable energy scenario. There were no curtailments of VER generation under the Base renewable energy scenario.

\section{Reduced Cycling of Thermal Generating Units}

The flexibility of PSH capacity, its fast ramping characteristics, and its load leveling operation creates a flatter net load profile for thermal generating units, which allows them to operate in a steadier mode, thus reducing the need for their ramping and frequent startups and shutdowns.

\section{Reduced Startup Costs}

Because startups and shutdowns of thermal generating units involve substantial operating costs and increase their wear and tear, a reduction in the number of unit startups can result in significant savings in system operating costs. PLEXOS results show that under both renewable energy scenarios, the number of starts and the startup costs of thermal generators are reduced substantially as more PSH capacity is introduced into the system.

If both FS and AS PSH plants are operating in the system, the annual thermal startup cost savings for WI amounts to $\$ 44$ million (about $28.6 \%$ of total startup costs) under the Base renewable energy scenario, and to \$31 million (about $17.7 \%$ savings) under the High Wind scenario. Figure 10-5 illustrates the reductions in thermal startup costs due to PSH capacity in the WI.

In the case of California, under both renewable energy scenarios, the savings in startup costs amounts to about $\$ 10$ million if only the existing FS PSH plants are operating in the system, and about \$20 million if both FS and AS PSH plants are operating. This is illustrated in Figure 10-6.

In the case of SMUD, the addition of the AS PSH plant (Iowa Hill) reduces annual startup costs by about $\$ 2$ million under both renewable energy scenarios. As a percentage of total system startup costs in 2022, the cost savings (\$2 million) represents about $45 \%$ of total startup costs under the Base renewable energy scenario and about $42 \%$ under the High Wind renewable energy scenario. This is illustrated in Figure 10-7. 


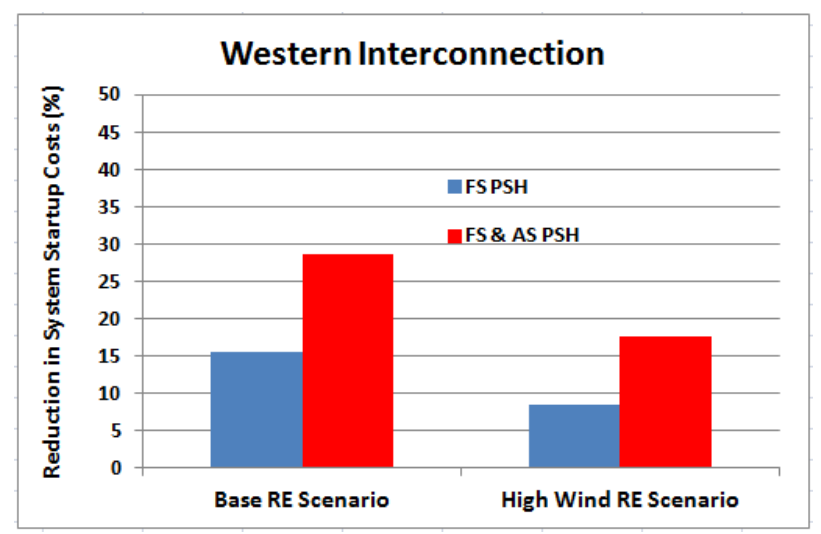

Figure 10-5 Reduction in Thermal Startup Costs Due to PSH Capacity in the WI in 2022

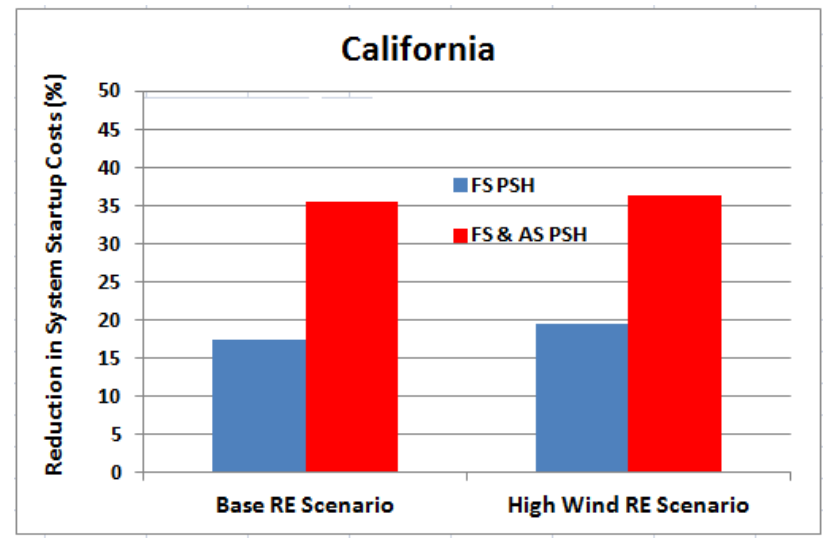

Figure 10-6 Reduction in Thermal Startup Costs Due to PSH Capacity in California in $\mathbf{2 0 2 2}$

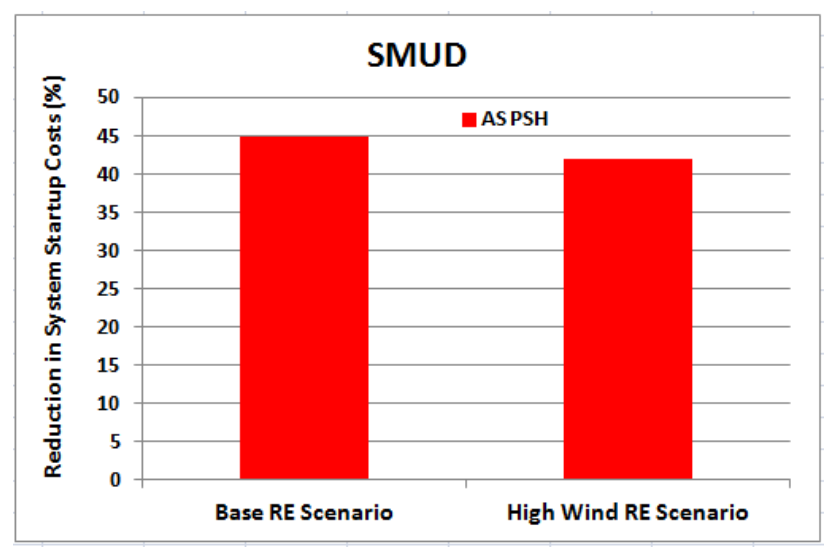

Figure 10-7 Reduction in Thermal Startup Costs Due to PSH Capacity in SMUD in 2022 


\section{Reduced Thermal Generator Ramping}

Figures 10-8 through 10-10 show the results for reductions in thermal generator ramping (both up and down) in the WI, California, and SMUD systems.
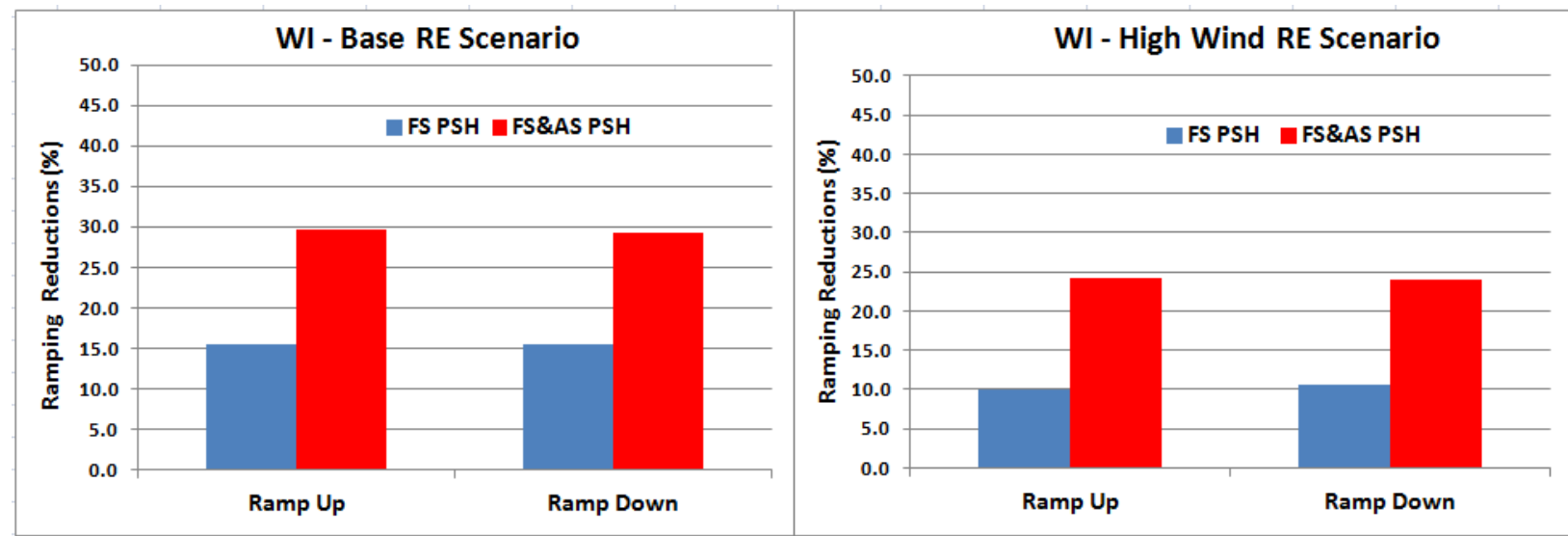

Figure 10-8 Reductions in Thermal Capacity Ramping Needs in the WI in 2022 Due to PSH Capacity
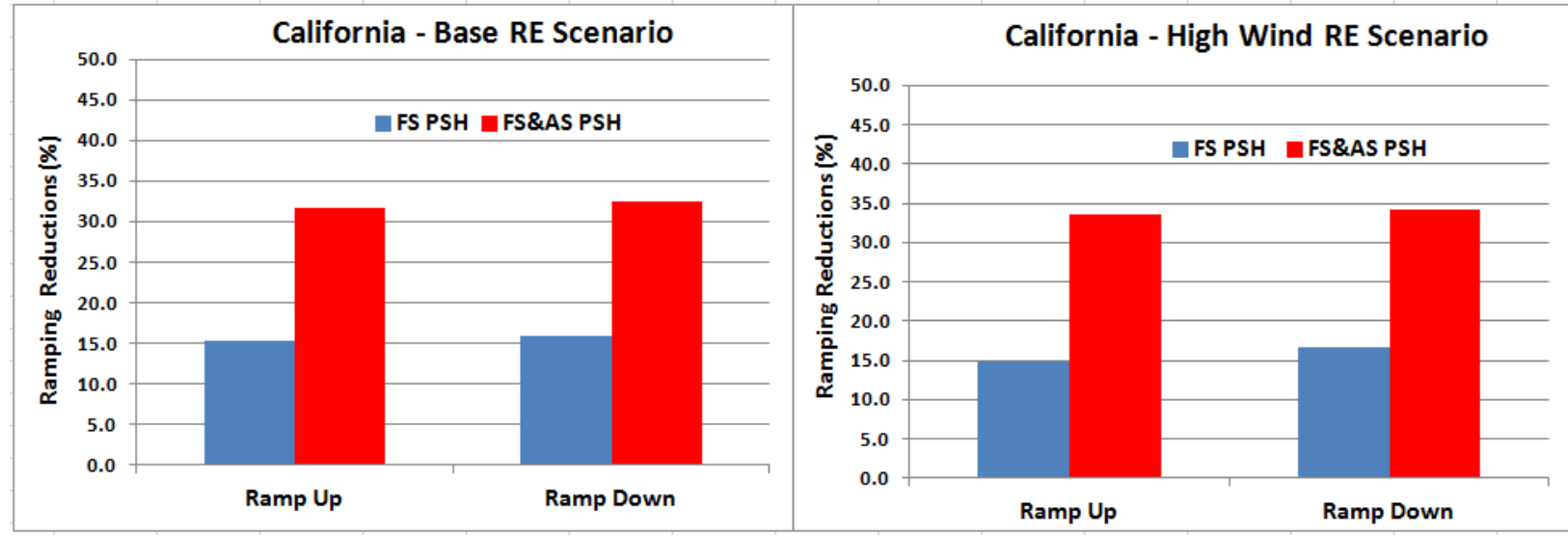

Figure 10-9 Reductions in Thermal Capacity Ramping Needs in California in 2022 Due to PSH Capacity

PLEXOS simulations for the WI in 2022 under the Base renewable energy scenario show that FS PSH plants reduce the ramp up needs of thermal generators by $1,786 \mathrm{GW}$ and reduce the rampdown needs by 2,560 GW. If both FS and AS PSH plants are operating in the system, the ramp-up needs of thermal generators are reduced by 3,420 GW, and the ramp-down needs are reduced by $4,817 \mathrm{GW}$.

Similarly, the results for California in 2022 under the High Wind renewable energy scenario show that FS PSH plants reduce the ramp-up needs of thermal generators by $531 \mathrm{GW}$ and reduce the ramp-down needs by 945 GW. If both FS and AS PSH plants are operating in the system, the 


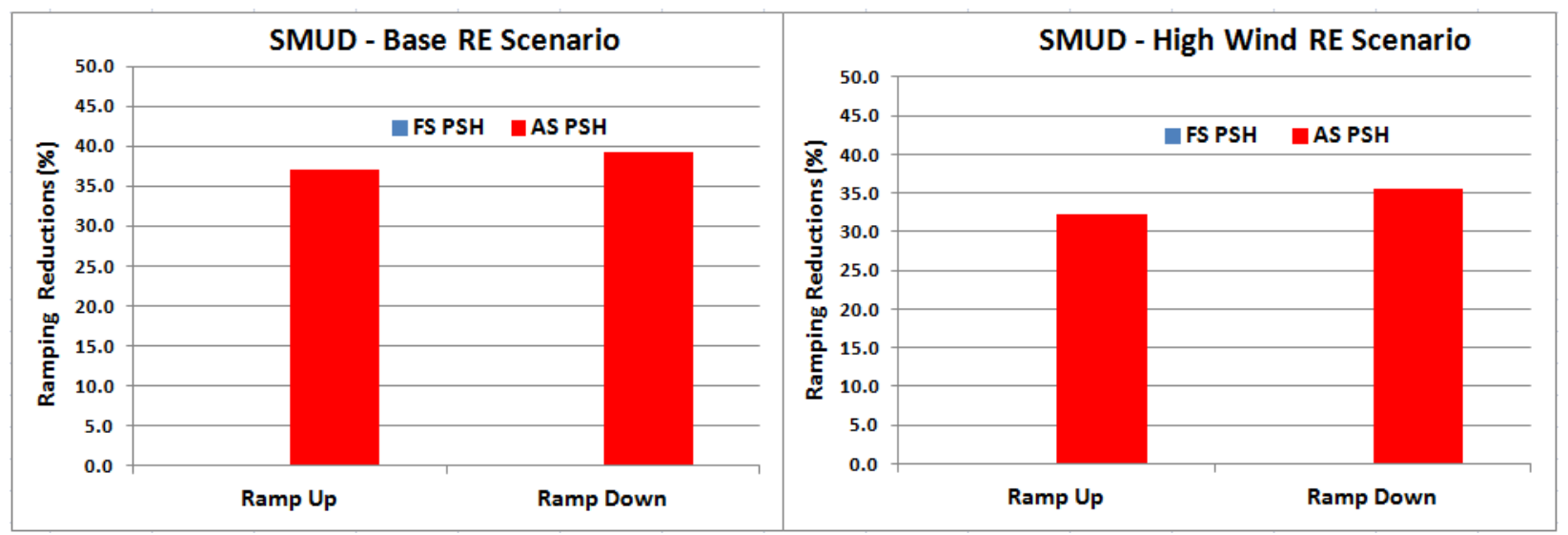

Figure 10-10 Reductions in Thermal Capacity Ramping Needs in SMUD in 2022 Due to PSH Capacity

ramp-up needs of thermal generators are reduced by 1,214 GW, and the ramp-down needs are reduced by $1,943 \mathrm{GW}$.

In the case of SMUD, the proposed AS PSH plant (Iowa Hill) reduces ramp up needs by $136 \mathrm{GW}$ and ramp-down needs by $197 \mathrm{GW}$ under the Base renewable energy scenario, and it reduces ramp-up and ramp-down needs by 119 GW and $174 \mathrm{GW}$, respectively, under the High Wind scenario.

\section{PSH Impacts on System Emissions}

Simulation results for the WI (Figure 10-11) show an increase in pollutant emissions under the Base renewable energy scenario, but the operation of PSH plants decreases overall system emissions under the High Wind scenario. This result is primarily because of the higher percentage of wind energy that is available for PSH pumping and also because the PSH plants reduce the curtailments of wind energy and thus offset the increased emissions from conventional thermal generating units.
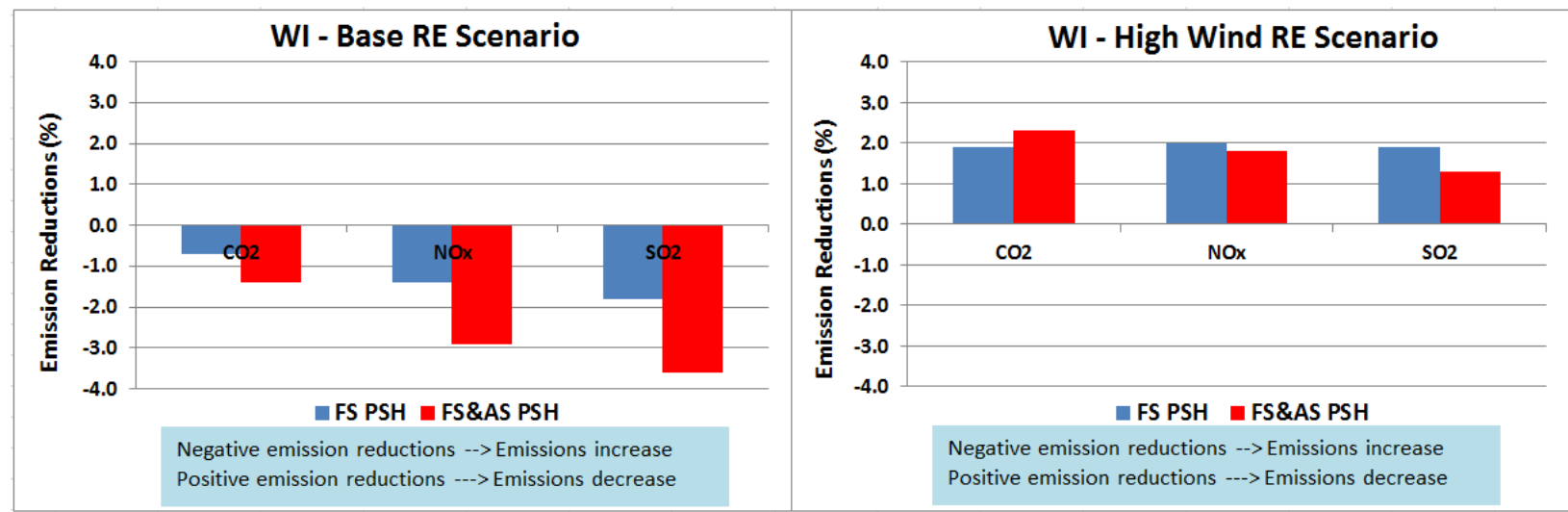

Figure 10-11 Emission Reductions Due to PSH Capacity in the WI in 2022 
The results for California (Figure 10-12) show a decrease in $\mathrm{CO}_{2}$ and $\mathrm{NO}_{\mathrm{x}}$ emissions and an increase in $\mathrm{SO}_{2}$ emissions under both the Base and High Wind renewable energy scenarios. The results for California are different than those for the WI because of the differences in the generation mix of these two systems.

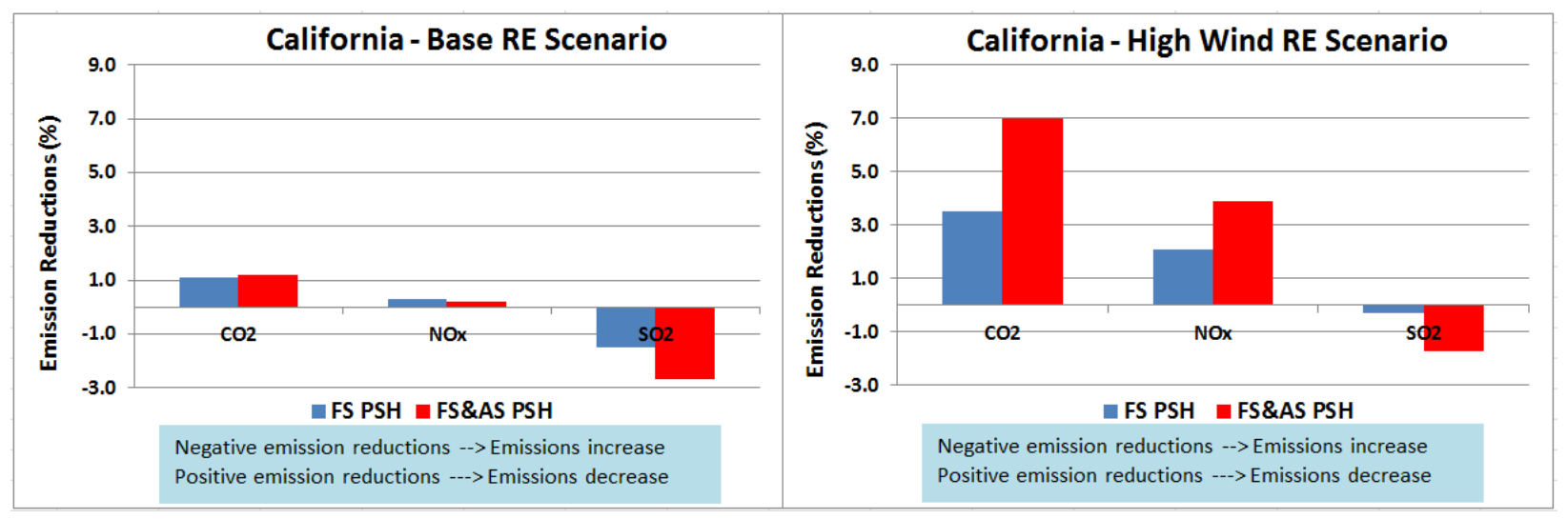

Figure 10-12 Emission Reductions Due to PSH Capacity in California in 2022

The most significant emission reductions occurred for the SMUD system (Figure 10-13). The introduction of the proposed AS PSH Iowa Hill plant reduces pollutant emissions in the SMUD system under both renewable energy scenarios.

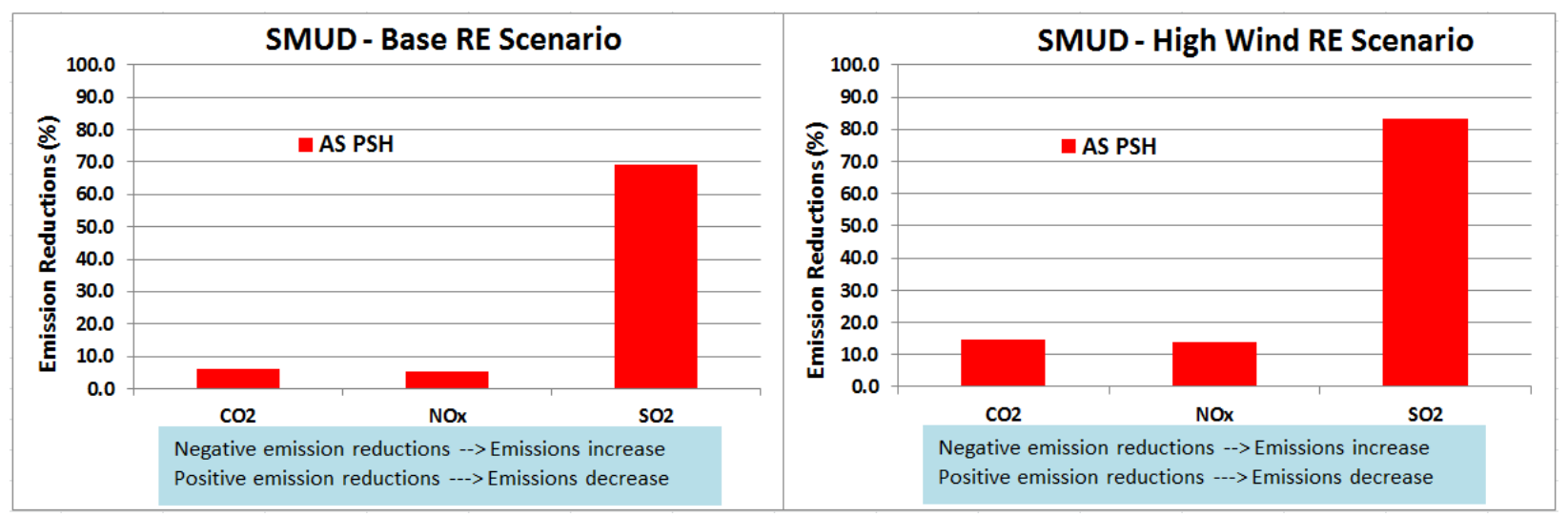

Figure 10-13 Emission Reductions Due to PSH Capacity in the SMUD System in 2022

\section{PSH Impacts on Transmission Congestion}

The transmission congestion price is an indicator of the congestion in the transmission grid. The lower transmission congestion prices that occur when PSH plants operate indicate that they help mitigate transmission congestion.

PLEXOS simulations of the WI show that under the Base renewable energy scenario, average transmission congestion prices decrease from \$4/MWh if there are $\mathrm{PSH}$ plants operating in the 
system to \$2/MWh if both FS and AS PSH plants are operating. Because transmission expansion planning was done for the High Wind scenario, no significant reductions in transmission congestion prices occur under that scenario. However, under both the Base and High Wind scenarios, the interface with the significant congestion price reduction was the P27 Intermountain Power Project DC line located in the vicinity of the existing Castaic and proposed Eagle Mountain PSH plants.

In PLEXOS simulations of California for the Base renewable energy scenario, the average transmission congestion prices decrease from \$3.51/MWh if there are no PSH plants operating in the system, to \$0.4/MWh if FS PSH plants are operating, and they decrease further to \$0.24/MWh if both FS and AS PSH plants are operating in the system. Under the High Wind renewable energy scenario, the average transmission congestion prices in California decrease from \$1.79/MWh if there are no PSH plants operating, to \$0.56/MWh if FS PSH plants are operating, and they decrease further to \$0.37/MWh if both FS and AS PSH plants are operating in the system. The lower transmission congestion prices found under the High Wind renewable energy scenario occur because of the transmission expansion planning that was done for this renewable energy scenario, which resulted in additional transmission capacity in the system. Again, under both the Base and High Wind renewable energy scenarios, the interface with the significant congestion price reduction was the P27 Intermountain Power Project DC line located in the vicinity of the existing Castaic and the proposed Eagle Mountain PSH plants.

\subsubsection{Three-Stage DA-HA-RT Simulation Results}

To capture the uncertainty of renewable energy forecasting and the intra-hourly variability of VER, as well as to evaluate system needs for operating reserves and flexible ramping capacity, three-stage DA-HA-RT sequential simulations with a 5-minute time step in RT were performed for four typical weeks in different seasons of the year. Simulations were performed for the WI, California, and SMUD footprints, and the selected weeks were the third weeks of January, April, July, and October 2022.

Table 10-5 summarizes the key results obtained from PLEXOS three-stage simulations for the WI, California, and SMUD power systems. The results shown are for the High Wind renewable energy scenario. Because SMUD plans to add an AS PSH plant (Iowa Hill) to its power system in the future, no conventional FS PSH plants were modeled in the simulations of the SMUD footprint.

The results of these detailed, high-resolution (5-min time step) simulations show that the overall production cost savings due to the operation of FS and AS PSH plants in the system amount to about $3.6 \%$ of the total production costs in the WI, amount to $7.3 \%$ in California, and reach $14.3 \%$ in the SMUD system. Although these are the average cost savings over the four typical weeks in different seasons of 2022, the average annual values can be expected to be in a similar range. PLEXOS annual simulation runs using the hourly time step also show similar results. 
Table 10-5 Summary of PLEXOS Three-Stage Results for the WI, California, and SMUD in 2022

\begin{tabular}{|l|c|c|c|c|}
\hline \multirow{2}{*}{$\begin{array}{c}\text { High Wind } \\
\begin{array}{c}\text { Renewable } \\
\text { Scenario }\end{array}\end{array}$} & $\begin{array}{c}\text { Average Cost Savings (\%) or Decrease in Ramping Needs (\%) Due to } \\
\text { PSH Capacity over the Four Simulated Typical Weeks in 2022 (\%) }\end{array}$ \\
\cline { 2 - 5 } & $\begin{array}{c}\text { System } \\
\text { Production } \\
\text { Cost Savings }\end{array}$ & $\begin{array}{c}\text { Startup and } \\
\text { Shutdown } \\
\text { Cost Savings }\end{array}$ & $\begin{array}{c}\text { Ramp-Up of } \\
\text { Thermal } \\
\text { Generators }\end{array}$ & $\begin{array}{c}\text { Ramp-Down of } \\
\text { Thermal } \\
\text { Generators }\end{array}$ \\
\hline \begin{tabular}{l} 
Western Interconnection \\
\hline With FS PSH
\end{tabular} & 2.01 & 11.21 & 5.44 & 8.25 \\
\hline With FS \& AS PSH & 3.60 & 17.71 & 23.25 & 24.86 \\
\hline California & \multicolumn{5}{|l|}{} \\
\hline With FS PSH & 5.01 & 27.58 & 9.76 & 15.10 \\
\hline With FS \& AS PSH & 7.27 & 41.67 & 33.05 & 64.16 \\
\hline SMUD & 14.31 & 10.62 & 22.06 & 22.87 \\
\hline With AS PSH &
\end{tabular}

The impacts of PSH plants on reducing startup and shutdown cost are also significant. The operation of FS and AS PSH plants in the system reduces overall startup and shutdown costs from about 11\% in SMUD to almost 42\% in California.

Similarly, the operation of both FS and AS PSH plants reduces the need for ramping of thermal generating units. Over the four typical weeks in 2022, the ramping up and ramping down of thermal units are reduced by about 25\% in the WI and SMUD areas and by more than $60 \%$ in California. This shows that PSH plants can take on a significant amount of ramping duties to counterbalance the intra-hourly variations in loads and variable renewable generation.

In the three-stage simulations, the RT simulations result in higher operating costs and ramping needs than do the DA simulations. This is because the RT simulations capture the intra-hourly variability of VER generation, which is not captured by DA simulations that use the hourly time step. The higher operating cost and ramping needs of thermal generators in RT simulations indicate that they need to ramp more to meet the sub-hourly variability and uncertainties of load and renewable generation.

\subsection{Analysis of Reliability and Costs by Using the FESTIV Model}

NREL's FESTIV model was used to analyze, in high temporal detail, how conventional and advanced PSH plants can help reduce total system production costs and improve steady-state reliability. The FESTIV model was used to simulate the BANC system for two time periods, one with highly volatile variable generation and relatively low load in April, and one with reduced variable generation but significant load in July. In both time periods, FS conventional PSH was able to reduce the total production costs. When an AS PSH plant was added rather than a conventional FS PSH plant, production costs were reduced even more. These results bolster those obtained from PLEXOS simulations. Thus, the results from analyzing detailed power system operations at multiple time scales show that PSH and advanced PSH plants provide tremendous benefits to systems of this size with regard to reducing production costs. 
The FS PSH was able to reduce the amount of CPS2 violations in both time periods, and the AS PSH was able to reduce the violations even further. In both cases, the CPS2 score was already above the required level (although load forecast errors and conventional generator performance were not modeled). More benefits from both the FS and AS PSH plants were obtained in the July time period, when the higher costs led the dispatch model to select PSH more often to provide AGC regulation. The standard deviation and total amount of energy imbalances were reduced in the July period but were not always reduced in the April period. It is possible that the ability to re-optimize the operational mode of PSH could better prepare the system when very large, DA, variable generation forecast errors would otherwise leave the PSH plant in the wrong operating mode. Overall, conventional FS PSH improves steady-state reliability some, and the improvements provided by AS PSH are even greater.

This study also looked at a few other sensitivities. Additional simulations were run to see how much variable generation and variable generation forecast errors affected the results on how PSH brought value to the system. These studies demonstrated that when steady-state reliability is very good (i.e., less than three CPS2 violations), it is hard for PSH to truly improve steady-state reliability. Evidence for this conclusion was found in a scenario with no variable generation and in a scenario with variable generation, but with all variable generation forecasts being perfectly predicted. On the other hand, these studies also showed that even without variable generation or without variable generation forecast errors, PSH plants still provide great benefits with regard to reducing overall production costs.

Lastly, FESTIV simulations were run to study how AS PSH plants could provide benefits if they followed a raw, unfiltered ACE signal. Such an opportunity is, with the plants' extremely fast power ramp rate, very possible. This type of study is relevant to recent industry developments in which the benefits of other limited energy-storage resources in providing this type of service are being evaluated. The results show that this type of control has a negligible effect on reducing the number of CPS2 violations. However, the total imbalance that occurred and the standard deviation of that imbalance were significantly reduced when just three AS PSH units provided this fast control. Another outstanding result was the further reduction in total production costs that was achieved when AS PSH plants were allowed to provide this control. This result, which is not as intuitive as the reduction in ACE impacts, was a result of the PSH units allowing other ramp-constrained units to stay closer to their most optimal points. These resources were not being asked by the AGC to move too far; therefore, they were less constrained from their ramp rates when the dispatch model chose the least-cost options to meet the expected load demands. Further studies should evaluate this effect, and this type of control should be taken advantage of in operations if these studies consistently have these results.

\subsection{Analysis of PSH Operation by Using the CHEERS Model}

The CHEERS study compared the economic performance of FS PSH, AS PSH, and GT technologies when these technologies are used to sell energy and A/S in a typical U.S. electricity market, under a range of different pricing scenarios. The CHEERS results reveal that AS PSH technology has an advantage over conventional FS PSH technology. 
CHEERS results for the overall net operating revenues of AS PSH, FS PSH, and GT plants based on 2011 California energy and ancillary prices are as follows:

- $\quad$ AS pumped storage: $\$ 80-94 / \mathrm{kW}-\mathrm{yr}$,

- $\quad$ FS pumped storage: $\$ 74-87 / \mathrm{kW}-\mathrm{yr}$,

- $\quad$ GT at 20\% minimum output level: $\$ 28 / \mathrm{kW}-\mathrm{yr}$, and

- GT at 50\% minimum output level: $\$ 9 / \mathrm{kW}-\mathrm{yr}$.

With regard to pumped storage, the first number in the range (lower value) is based on model runs that use projected prices, and the second number (higher value) is based on model runs that use actual prices.

Although most GT plants today seldom operate below 50\%, improvements in GT technology will continue to expand the operating range of these plants, and operations closer to $20 \%$ capacity may become commonplace in the future.

When capital and fixed costs are factored into the analysis, results show that in general, PSH technologies are competitive with advanced GT technologies and have higher NPVs under most, but not all, plausible futures tested. While PSH technologies show higher potential financial gains than do advanced GT technologies, PSH technologies are also riskier, with potentially higher losses. Testing capital cost variances for new projects revealed that PSH technologies have greater downside risks than do GT technologies if capital cost overruns are incurred. Changes in loan interest rates produced similar results; rising interest rates lowered project returns, as higher debt service costs reduced operating profits and net cash flows. Conversely, PSH technologies have the potential for larger net profits over GT technologies if capital costs decline.

The CHEERS results also highlight the advantage that AS PSH has over conventional FS PSH technologies, especially when market prices are high. In particular, when A/S prices are high, the economics of AS PSH further improve over the economics of other technologies. Greater AS PSH revenues are due to better efficiencies, a narrower rough zone, and the ability to serve $\mathrm{A} / \mathrm{S}$ in pumping mode. When it is assumed that A/S prices are always zero (e.g., there is no market), there is little difference in net revenues between AS and FS technologies. However, the gap widens as A/S prices increase, which illustrates that the key advantage of AS technology is its ability to provide regulation services in pumping mode.

Recognizing the potential sensitivity of project returns to capital costs, market conditions, and the accuracy of market price forecasts, scenarios were developed to test the implications of these factors. The results from these scenario runs highlight four key findings. First, revenue recognition for A/S is essential to support profitable operations of PSH plants. Second, favorable (rising) natural gas prices are needed to support revenue growth and subsequent plant profitability. Third, higher costs, such as capital costs and loan interest costs, can greatly 
negatively affect plant returns and lower NPVs over time. Lastly, DA price forecast errors can significantly erode the profitability of PSH technologies.

Analyses highlight the value and importance of market prices for energy and A/S, confirming the need for good mid-term and long-term forecasts of market prices when the economics of not only PSH but also other technologies.

\subsection{Treatment of PSH in Electricity Markets}

Much of the nation's $20 \mathrm{GW}$ of pumped hydropower storage began in the mid to late 1970s. Projects were economically justified for daily energy arbitrage based on the high cost of peaking oil- and natural-gas-fired generation, low cost of coal and nuclear power in off-peak periods, and based on pumped storage capital costs that were similar to those of combined-cycle plants. With natural gas now being on the margin much of the time, and with the increase in efficiency and decrease in relative capital costs for CTs and combined-cycle plants, energy arbitrage is typically not sufficient to justify new pumped storage plants today. However, storage does provide additional flexibility-related benefits for the power system, and the increase in variable and uncertain wind and solar generation is increasing the need for that flexibility. Moreover, restructuring has led FERC to explicitly define A/S, which helps in quantifying and pricing the flexibility requirements. FERC's encouragement of ISOs and RTOs, which now serve two-thirds of the nation's load, has led to the establishment of energy and A/S markets that monetize the value of flexibility. Storage can compete with generators and demand response to provide the flexibility that the system operator requires to maintain reliability. In this context, there is a need to evaluate the benefits that energy storage offers against the generation and demand response alternatives. One advantage of storage is its charging capability, which can be used to provide load for excess variable generation. This can be very valuable during the off-peak hours (e.g., at night), when the system loads are low. At that time, most conventional thermal generating units in operation are base-load units at their minimum ("must run") capacities, and demand response options are limited.

ISOs and RTOs co-optimize the provision of energy and A/S from generators. Generators simply offer their capabilities (maximum load, minimum load, ramp rate, start time, etc.) and bid costs; they let the system operator determine how much energy and each A/S they should provide in each market interval. This maximizes the generator's profit while simultaneously minimizing power system costs. Unfortunately this same concept is not yet typically fully extended to the charging and discharging of storage, mostly due to computational difficulties. Storage projects typically must guess at their charging and discharging schedules and only then let the power system operator optimize the energy and A/S within that predefined schedule.

Vertically integrated, regulated, non-market areas require the same types of flexibility to maintain power system reliability. The lack of markets can make it more difficult to quantify the value of storage, especially for a third party proposing a new project, because the power system production cost data are typically proprietary. Still, vertically integrated areas currently have the potential of offering several advantages for storage projects. Vertically integrated utilities may be able to obtain regulatory approval for long-term contracts based on the expected benefits for electricity consumers over decades. Restructured markets seldom offer such assurances, and the 
developer must assume the risk, which typically increases project costs. Similarly, a vertically integrated utility and its regulator may invest in a storage project that flattens peak energy price differentials on or off or that collapses $\mathrm{A} / \mathrm{S}$ prices if those benefits exceed the project cost. In a market environment, however, the price collapse would eliminate the storage project's economic incentive and thereby deny consumers the project's benefits. Lastly, the system operator in a vertically integrated utility can fully optimize the use of a storage project for energy arbitrage and A/S over all time frames; a market-based system operator, on the other hand, may be restricted by bidding and scheduling practices that were designed to co-optimize conventional generators but that do not consider the multi-interval benefits of storage.

A number of current limitations on extracting the flexibility from PSH and on the maximum revenue achievable by PSH were listed. The full optimization of PSH mode in both DA and RT markets could greatly benefit the flexibility of PSH and potentially its revenue streams. The use of inter-temporal lost opportunity costs and make-whole payments for PSH would also benefit the revenue potential of PSH. The addition of incentives for new A/S that historically had not been priced could greatly benefit PSH too. Finally, addressing the problem of covering the capital costs of capital-cost-intensive resources like PSH is extremely important. Treating PSH as a regulated, rate-based, transmission-like regulated resource under system operator control might be beneficial in cases where it can be justified.

\subsection{Financial Analysis and Business Models}

The role of PSH projects in the U.S. market has changed in response to the increased penetration of variable renewable resources. PSH projects are often operating to maximize the dependable capacity from variable renewables, and they provide $\mathrm{A} / \mathrm{S}$ to support interconnected bulk transmission grid reliability and stability. PSH projects have the ability to provide fast response at a utility scale. However, in the existing electricity markets, many of these services are not currently compensated for financially. ${ }^{22}$ The A/S that are acknowledged with market products vary by ISO and RTO.

PSH's other role — to operate for energy arbitrage—leads to a smoothing of prices between off-peak and on-peak hours, such that PSH operation can greatly reduce price differentials and, consequently, their revenues. These market-related barriers significantly affect the financial viability of a PSH project.

As demonstrated in the financial modeling completed as part of this study, developing a new, financially viable PSH project will be a challenge. Although this report focuses on a generic case study with associated sensitivity analyses, its results highlight the overarching issue facing largescale energy storage, where the monetized benefits under current market conditions are not always enough to justify the required investment. Lenders often seek a fast return with lower capital costs, but PSH requires financing a long-lived project with high capital costs and low operating cost.

22 The conditions are beginning to change in this regard as evidenced by the recently adopted FERC Order 784, Third-Party Provision of Ancillary Services; Accounting and Financial Reporting for New Electric Storage Technologies; issued July 18, 2013 (FERC 2013). 


\subsection{References}

FERC (Federal Energy Regulatory Commission), 2013, Order 784: Third-Party Provision of Ancillary Services; Accounting and Financial Reporting for New Electric Energy Storage Technologies, July 18. Available at http://www.ferc.gov/whats-new/comm-meet/2013/071813/E22.pdf.

Fisher, R.K., J. Koutnik, L. Meier, V. Loose, K. English, and T. Beyer, 2012, “A Comparison of Advanced Pumped Storage Equipment Drivers in the US and Europe,” HydroVision International. 
This page intentionally left blank. 


\section{Appendix \\ A \\ PSH Technology Characteristics}

\section{A.1 Introduction}

This appendix is a supplement to Section 2.1 of Chapter 2 and presents information about pumped storage hydropower (PSH) technologies, including single-speed, adjustable speed (AS), and ternary units. It provides background information in support of the modeling efforts described in other chapters and reports prepared during the study. The focus of this appendix drawing on experience with more than 20 pumped storage units in Japan and Europe, is on pumped storage units with AS capabilities, as well as on ternary pumped storage with hydraulic bypass.

\section{A.2 Pumped Storage Hydropower Technology}

A typical conventional PSH project consists of two interconnected reservoirs (lakes), tunnels that convey water from one reservoir to another (waterways), turbine shutoff valves, hydro machinery (a pump/turbine, a motor/generator, transformers), a transmission switchyard, and a transmission connection (see Figure A-1). The product of the total volume of water and the differential height between reservoirs is proportional to the amount of stored electricity; thus, storing 8,800 MWh in a system with an elevation change of 1,000 ft and installed capacity of 800 MW requires a water volume of about 10,000 acre-feet.

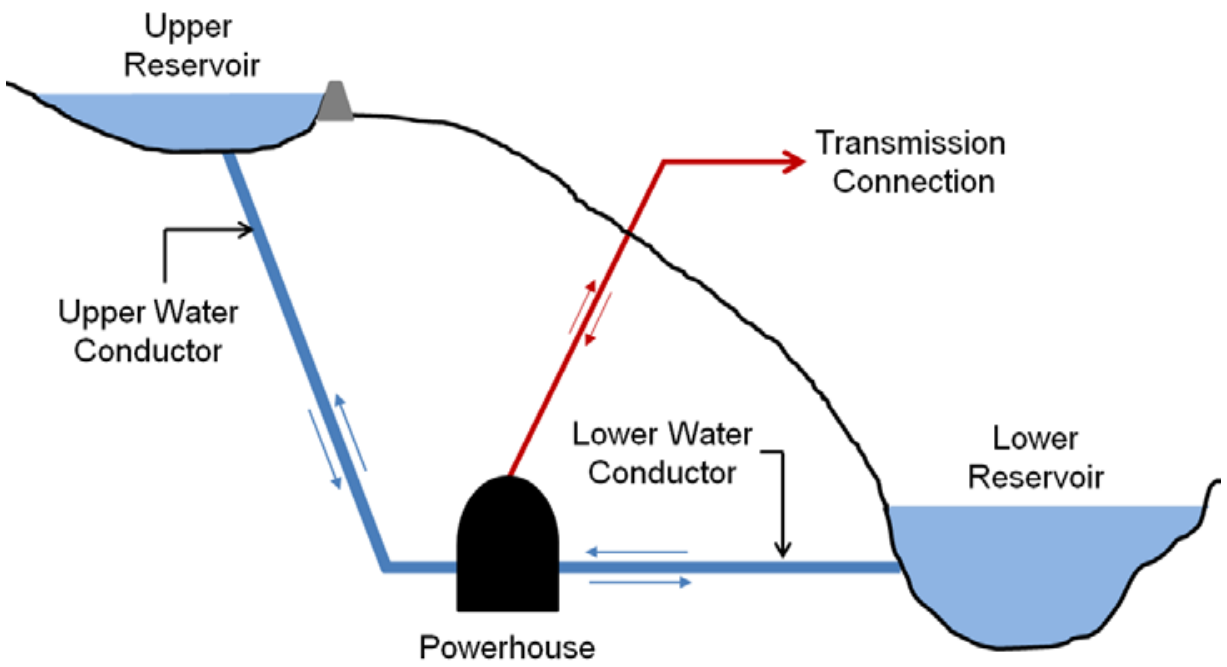

Figure A-1 Typical Pumped Storage Configuration 
There are a variety of ways that the pump storage concept can be implemented within specific geologic and hydrologic constraints. Many early pumped storage projects used existing, conventional hydro facilities to provide the necessary lower reservoir for water storage. These installations form a class of projects known as "on-stream integral pumped storage" or "pumpback pumped storage" projects. The latter uses two reservoirs located in tandem on the same river. Such a project can operate as a conventional hydro plant; however, when water flows are low or when peak demand is high, it is operated in the pumped storage mode. Although operating fewer hours per year than the dedicated PSH system, these units often fit into an effective niche and function very well and economically.

It is also possible to construct pumped storage projects that are independent of a naturally occurring river or lake. Plants of this type are often referred to as "closed-loop" pumped storage systems. In this type of plant, the upper and lower reservoirs are located "off stream.” An advantage of this approach is that there is minimal to no aquatic life interaction; this approach thus minimizes or avoids the permitting and environmental review process. The development of a closed-loop system requires that a water source be identified to provide the initial charge and water to replace losses from evaporation and leakage. Closed-loop systems may be advantageous for smaller applications with daily operating cycles.

The basic pumped storage plant consists of upper and lower reservoirs with interconnecting water tunnels; several choices exist, however, concerning which pump/turbine and motor/generator power conversion technologies to employ. Since the 1990s, more than 20 AS units have been placed in commercial operation, and several more are in design and construction. In addition, in recent years a variation of a ternary configuration with a hydraulic bypass has been constructed at the Kops II plant in Austria. Another variation providing advanced pumped storage is the converter-fed synchronous machine (CFSM), of which there is a 100-MW CFSM unit in operation at the Grimsel 2 plant in Switzerland. Nevertheless, because the dominant pumped storage technology is based on AS machines, the following discussion focuses on these units.

\section{A.2.1 Single Speed (Conventional Pumped Storage)}

With a conventional single-speed unit, pumping occurs at a fixed synchronous speed and almost fixed wicket gate opening. In pump mode, the unit cannot provide regulating service to the system. The power input is nearly constant at the input rating of the pump, and the discharge varies with the pumping head. In turbine mode, the reversible pump/turbine is used to drive the single-speed synchronous generator and deliver electric energy and regulation to the system.

\section{A.2.2 Adjustable Speed}

An AS unit has a greater generating range and a range of pumping power input and provides frequency regulation and volt-ampere reactive (VAR) control during the pumping cycle.

AS operation is possible thanks to the application of the doubly-fed induction machine (DFIM), with a three-phase sinusoidal rotor voltage and current that is provided by an 
alternating/direct/alternating current (AC/DC/AC) solid-state converter. The frequency of the rotor voltage and current are adjusted to control rotor speed.

The majority of existing AS machines use rotor excitation systems based on cycloconverter circuit topology with thyristors. However, newer units are using exciters with advanced solidstate devices. The newer excitation systems use gate turn-off thyristors (GTOs), gate commutated thyristors (GCTs), injection-enhanced gate transistors (IEGTs), or insulated gate bipolar transistors (IGBTs). In addition, some of the new units are using excitation systems that use the Voltage Source Converter systems, which have more desirable reactive power control capability.

Figure A-2 provides a side-by-side comparison that shows the basic differences between a conventional, single-speed pumped storage unit with a synchronous motor/generator and an AS unit with a doubly-fed, wound rotor induction motor/generator.

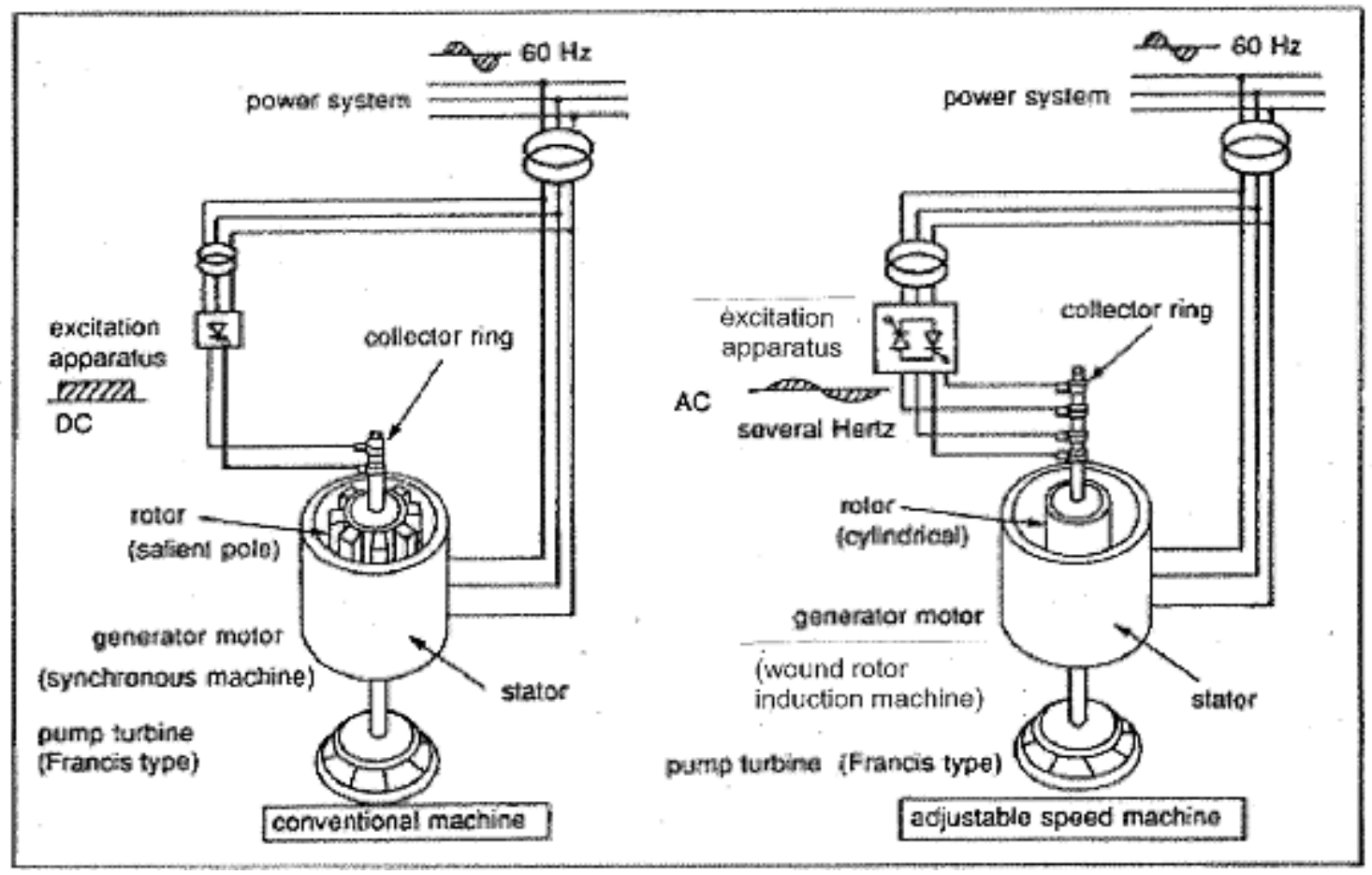

Figure A-2 Comparison of Single-Speed and AS Electrical Connections (Source: USACE 2009)

The AS capability makes it possible to change rotor and pump/turbine mechanical speed using high-speed electronic systems. By optimizing the two variables (speed and power), an AS unit can be dispatched at optimum efficiency over a large head range. Because the rotor excitation system uses robust, high-capacity, solid-state devices and high-speed computer controls, it is possible to rapidly interchange energy stored in the rotating mass of the rotor with the grid and provide the fast response needed for frequency regulation. 


\section{A.2.2.1 Conversion of Single-Speed Machines to Adjustable Speed}

In Japan, Unit No. 2 at the Yagisawa pumped storage plant was converted from single speed to AS in 1990. An evaluation of a conversion involves a study of a project's civil, mechanical, and electrical aspects. A premise in this approach is that the existing motor/generator stator and pump/turbine runner setting would not be changed. A critical cost factor in a conversion is the feasibility of reuse of the existing stator: because if the original stator can be reused, the economic cost/benefit analysis will be more favorable. When the cost to replace the original stator is included in the analysis, the cost/benefit is significantly reduced.

Major cost items to be included in a conversion effort include the following:

- New rotor with a three-phase commutator assembly;

- Excitation system with overvoltage protection and a water cooling system;

- Controls and protection;

- Electric bus and switchgear;

- $\quad$ Floor space for added equipment;

- Possible need to increase crane lift capability and clearance requirement; and

- Cost of civil structural construction to create additional space to house a new rotor excitation system with overvoltage protection and associated high-voltage bus, switchgear, transformers, filters, and auxiliary electrical and mechanical equipment.

\section{A.2.3 Ternary}

Ternary pumped storage units use a separate, synchronous motor/generator and turbine/pump on a single shaft and are operated in a single rotational direction. Because the direction of rotation of a ternary unit is the same in both the pump and generation modes, the time spent changing from one mode to another is faster than with a reversible pump/turbine unit. Ternary units can have turbines that are either the impulse (Pelton) or Francis type and can be multistage. Ternary units can also have a hydraulic torque converter coupling that connects the pump to the shaft system. The clutch allows the pump to be connected and disconnected quickly.

These units have operational capabilities similar to single-speed, reversible pump/turbine pumped storage units with synchronous motor/generators. In this context, the standard ternary unit can only provide frequency regulation and load following in the generation mode. It should be noted that, because there are separate pumps and turbines, it is possible to design each for best efficiency at the same synchronous speed.

The most notable ternary application is the Vianden project in Luxembourg, with nine ternary units. In plants such as Vianden, the faster mode change for ternary units is important; this plant provides system regulation, with multiple mode changes every day. Frequent mode changes 
(as many as 100 per day) are necessary because the ternary units-without hydraulic bypass (discussed below) — cannot provide regulation service in pump mode.

\section{A.2.3.1 Ternary Pumped Storage with Hydraulic Bypass (Hydraulic Short Circuit)}

There is a recent refinement of the ternary configuration that allows for regulation in pump mode. This added capability is achieved with the introduction of a hydraulic bypass, also known as "hydraulic short circuit" or "mixed mode." The hydraulic bypass allows the total output of the plant to be controlled by diverting a portion of the pump output back into the flow of water to the turbine.

A ternary unit with hydraulic bypass can accomplish regulation using water flow and mechanical valves, whereas with an AS unit, regulation is accomplished via rotor current electronics.

The most recently constructed ternary plant with a hydraulic bypass is the Kops II plant in Austria. This plant is located in the Alps and is installed in a large-scale water storage system with multiple reservoirs and tunnels. Kops II has three units, each rated $150 \mathrm{MW}$. When the hydraulic bypass is activated, the turbine utilizes some of the water from the pump to generate power and offset the power used by the pump. This capability allows the unit to provide a wide range of adjustable power consumption levels to the grid when it is operating in pump mode. Figure A-3 shows the ternary plant configuration of the Kops II plant.

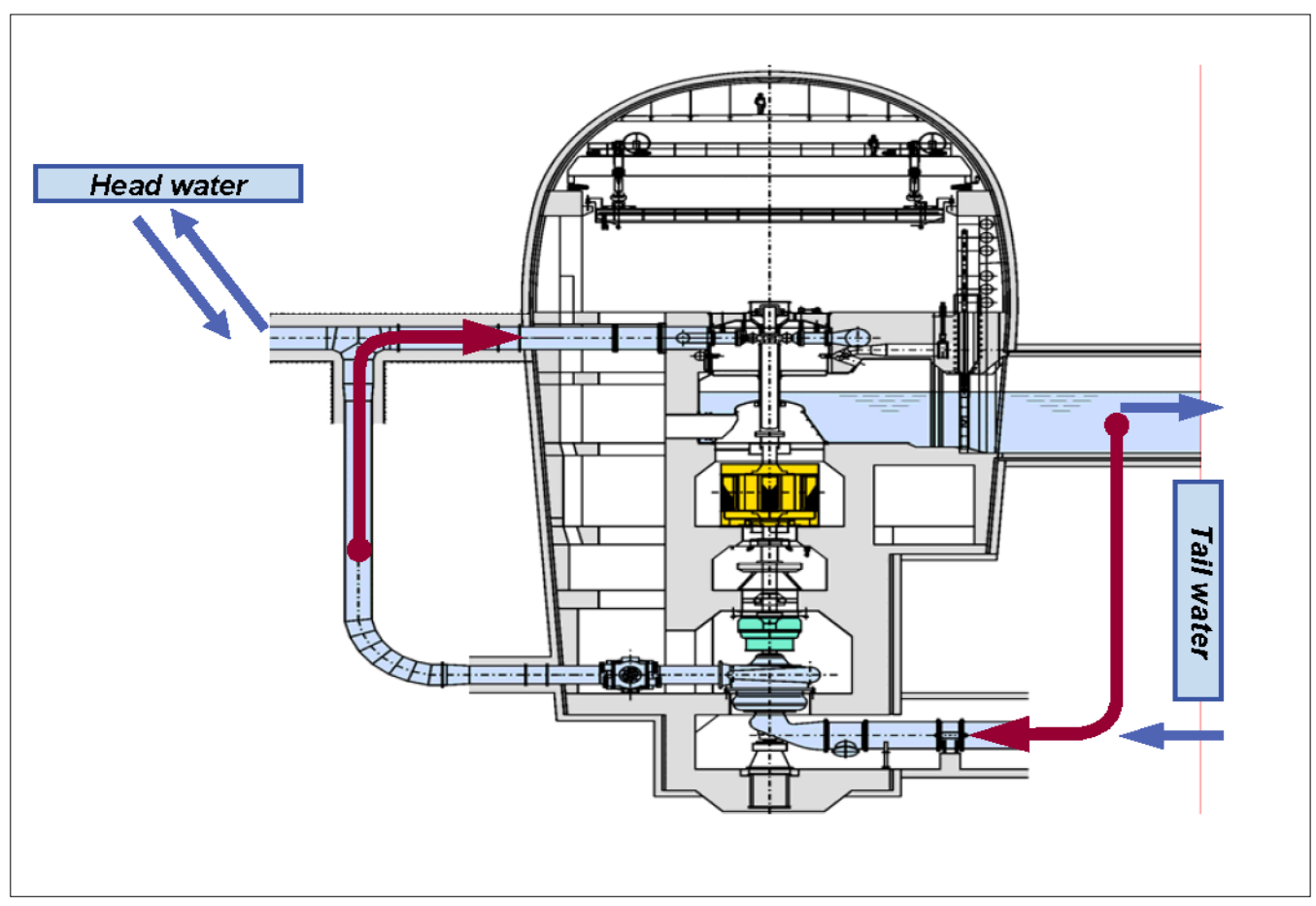

Figure A-3 Ternary Pumped Storage Plant Configuration (Source: Spitzer and Penninger 2008) 
When the transmission system requires regulation service, the plant is operated in hydraulic bypass mode, with the clutch engaged so that both the pump and turbine are operating. The net plant load as seen by the transmission system is the power being drawn by the pump motor minus the power being produced by the generator, as shown in Figure A-4. The plant optimizing algorithm sets the turbine guide vanes to obtain the desired net motor load and regulation.

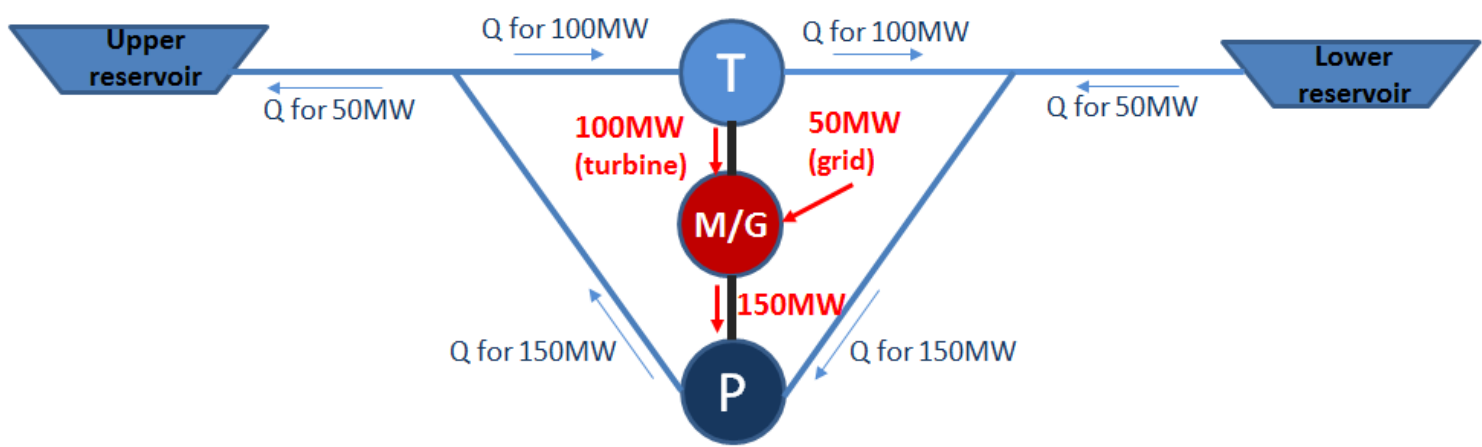

Figure A-4 Ternary Unit Operating in a Hydraulic Short-Circuit Mode

\section{A.2.4 Converter-Fed Synchronous Machine}

One manufacturer, ABB, has proposed a CFSM solution as a way to operate smaller, singlespeed pumped storage units. The CFSM solution uses a four-quadrant controller and provides power regulation in pump mode. For example, Unit 1 at the Grimsel 2 plant in Switzerland was recently commissioned with a 100-MVA AC/DC/AC converter unit. This unit was carried out as an upgrade of an existing single-speed unit. The objective was to provide power regulation capability in pump mode instead of running a unit in generation mode using valuable water at very low energy prices.

The characteristics of this project are as follows:

- $\quad$ Plant name: Grimsel 2, Unit \#1

- Utility name: Kraftwerke Oberhasli AG (KWO) Switzerland

- $\quad$ Service date: 2013

- $\quad$ Pump: $91 \mathrm{MW}$

- Generator: $85 \mathrm{MW}$

- Frequency: $50 \mathrm{~Hz}$

- Synchronous speed: 750 rpm 
- Speed range: $-20 \%$ to $+4 \%$

- Speed range: 600 to $765 \mathrm{rpm}$ (pump operation) and 0 to $765 \mathrm{rpm}$ (startup)

- Integrated gate-commutated thyristor (IGCT) voltage source converter: CFSM

The CFSM option offers several advantages, as follows:

- Speed control is possible from zero to "speed range high value."

- Unit has very fast startup time; there is no need for stator short-circuit equipment.

- Operation change from pump to turbine mode (or vice-versa) is fast.

- Startup is accomplished with watered pump/turbine.

- This option uses standard synchronous machine and transformers.

- Possibility exists to bypass the converter for efficiency improvement for operation close to the pump's or turbine's rated operating point.

- This option features grid code compliance.

- Capability exists for synchronous condenser operation without running unit (using the converter only).

- Reactive power is controlled by the converter.

\section{A.2.5 AS PSH in Japan and Europe}

Table A-1 presents information about AS pumped storage units in commercial operation in Germany, Japan, and Slovenia, and Table A-2 presents others in various stages of design and construction at locations around the world.

Manufacturers that have supplied pump/turbines, motor/generators, and rotor excitation and control systems for pumped storage plants with AS units include the following: Toshiba, Hitachi, Mitsubishi, Andritz, Alstom, Converteam/GE, ABB, and Voith. 
Table A-1 AS DFIM Pumped Storage Hydro Units

\begin{tabular}{|c|c|c|c|c|c|c|c|c|c|c|}
\hline Plant Name & Country & Utility Name & $\begin{array}{c}\text { Service } \\
\text { Date }\end{array}$ & $\begin{array}{l}\text { Pump } \\
\text { (MW) }\end{array}$ & $\begin{array}{c}\text { Generator } \\
\text { (MVA) }\end{array}$ & $\begin{array}{l}\text { Speed } \\
\text { Range } \\
(\mathrm{rpm})\end{array}$ & $\begin{array}{l}\text { Synchronous } \\
\text { Speed (rpm) }\end{array}$ & $\begin{array}{c}\text { Frequency } \\
\text { (Hz) }\end{array}$ & $\begin{array}{c}\text { Speed } \\
\text { Range } \\
(\%)\end{array}$ & AFC Type \\
\hline Narude, No. $2^{\mathrm{a}}$ & Japan & Kansai EPCo & 1987 & 18.5 & 22 & $190-210$ & 200 & 60 & $+/-5$ & Cyclo-C \\
\hline Yagisawa, No. $2^{\mathrm{b}}$ & Japan & TEPCO & 1990 & $53-82$ & 85 & $130-156$ & 150 & 50 & $+4 /-13$ & Cyclo-C \\
\hline Takami,No.2 & Japan & Hokkaido EPCo & 1993 & $44-140$ & 103 & $200-254$ & 230.8 & 50 & $+/-10$ & GTO inv \\
\hline Okawachi, No.2 & Japan & Kansai EPCo & 1993 & $331-392$ & 395 & $330-390$ & 360 & 60 & $+/-8$ & Cyclo-C \\
\hline Okawachi, No.4 & Japan & Kansai EPCo & 1995 & $240-400$ & 395 & $330-390$ & 360 & 60 & $+/-8$ & Cyclo-C \\
\hline Shiobara, No. $3^{c}$ & Japan & Kansai EPCo & 1995 & $200-330$ & 360 & $356-394$ & 375 & 50 & $+/-8$ & Cyclo-C \\
\hline Okukiyotsu No. 2 PH & Japan & EPDC & 1996 & $212-340$ & 345 & $407-450$ & 428.6 & 50 & $+/-5$ & GTO inv \\
\hline YanbaruNo. $1^{\mathrm{d}}$ & $\begin{array}{l}\text { Japan/ } \\
\text { Okinawa }\end{array}$ & EPDC & 1999 & $1.5-31.5$ & 31.5 & $423-477$ & 450 & 60 & $+/-6$ & GTO inv \\
\hline Goldistahl, No. 1 & Germany & VEAG & 2002 & $170-300$ & 351 & $300-346.6$ & 333 & 50 & $+4 /-10$ & Cyclo-C \\
\hline Goldistahl, No. 4 & Germany & VEAG & 2002 & $170-300$ & 351 & $300-346.6$ & 333 & 50 & $+4 /-10$ & Cyclo-C \\
\hline Omarugawa, No. 4 & Japan & Kyushu EPCo & 2007 & 310 & 340 & $576-624$ & 600 & 60 & $+/-4$ & Cyclo-C \\
\hline Omarugawa, No. 3 & Japan & Kyushu EPCo & 2008 & 330 & 345 & $576-624$ & 600 & 60 & $+/-4$ & GCT inv \\
\hline Omarugawa, No. 1 & Japan & Kyushu EPCo & 2010 & 330 & 350 & $576-624$ & 600 & 60 & $+/-4$ & GCT inv \\
\hline Omarugawa, No. 2 & Japan & Kyushu EPCo & 2011 & 330 & 345 & $576-624$ & 600 & 60 & $+/-4$ & Cyclo-C \\
\hline Avce, No. 1 & Slovenia & SENG & 2012 & $125-180$ & 195 & $576-636$ & 600 & 50 & $+6 /-4$ & GCT inv \\
\hline \multicolumn{11}{|c|}{$\begin{array}{l}\text { a Pilot project to test excitation and controls for a djustable speed doubly fed machine } \\
\text { b Conversion from single speed to adjustable speed } \\
\text { c Formerly named Sabigawa } \\
\text { d Seawater pilot project }\end{array}$} \\
\hline $\begin{array}{l}\text { TEPCO = Tokyo Elect } \\
\text { GTO inv = Gate Tum } \\
\text { PH = Powerhouse } \\
\text { EPDC = Electric Powe } \\
\text { VEAG = Vattenfall Eu } \\
\text { GCT inv = Gate Comr } \\
\text { SENG = Soske Elektra }\end{array}$ & $\begin{array}{l}\text { ic Power Co } \\
\text { ff Thyristor } \\
\text { Developme } \\
\text { ope Genera } \\
\text { utated Thyr } \\
\text { ne Nova Go }\end{array}$ & $\begin{array}{l}\text { mpany } \\
\text { inverter } \\
\text { nt Company (Japa } \\
\text { ion(Germany) } \\
\text { stor inverter } \\
\text { ica (Slovenia) }\end{array}$ & & & & & & & & \\
\hline
\end{tabular}

Table A-2 AS PSH Units in Various Stages of Construction and Installation

\begin{tabular}{|c|c|c|c|c|c|c|c|c|c|c|}
\hline Plant Name & Country & $\begin{array}{l}\text { Utility } \\
\text { Name }\end{array}$ & $\begin{array}{c}\text { Service } \\
\text { date }\end{array}$ & $\begin{array}{l}\text { Pump } \\
(\mathrm{MW})\end{array}$ & $\begin{array}{c}\text { Generator } \\
\text { (MVA) }\end{array}$ & $\begin{array}{c}\text { Speed } \\
\text { Range } \\
\text { (rpm) }\end{array}$ & $\begin{array}{l}\text { Synchronous } \\
\text { Speed (rpm) }\end{array}$ & $\begin{array}{c}\text { Frequency } \\
(\mathrm{Hz})\end{array}$ & $\begin{array}{c}\text { Speed } \\
\text { Range } \\
\% \\
\end{array}$ & AFC Type \\
\hline Kazunogawa, no. 3 & Japan & TEPCO & 2014 & 460 & 475 & $475-525$ & 500 & 50 & $+/-5$ & GTO inv \\
\hline Kazunogawa, no. 3 & Japan & TEPCO & 2015 & 460 & 475 & $475-525$ & 500 & 50 & $+/-5$ & GTO inv \\
\hline Kyogoku, no.1 & Japan & $\begin{array}{l}\text { Hokkaido } \\
\text { EPCo }\end{array}$ & 2015 & 230 & 230 & $475-525$ & 500 & 50 & $+/-5$ & IEGT inv \\
\hline Limmem & Europe & Axpo/Glarus & 2015 & 250 & 280 & $470-530$ & 500 & 50 & $+/-6$ & IGBT VSI \\
\hline Venda Nova/Frades & Portugal & EDP & 2015 & & 445 & & 375 & 50 & & \\
\hline Nant-de-Drance & Switzerland & Alpiq/SBB & 2016 & 154.7 & 170 & $399-459$ & 428.6 & 50 & $+/-7$ & IGBT VSI \\
\hline Tehri & India & THDC & 2015 & 250 & 259 & $214-250$ & 230.8 & 50 & $+/-8.3$ & TBD \\
\hline \multicolumn{11}{|c|}{$\begin{array}{l}\text { TEPCO = Tokyo Electric Power Company } \\
\text { GTO inv = Gate Tum-off Thyristor inverter } \\
\text { IEGT inv = Injection Enhanced Gate Transistor inverter } \\
\text { IGBT VSI = Insulated Gate Bipolar Transistor Voltage Source Inverters } \\
\text { EDP = Energias de Portugal } \\
\text { TBD = To be determined }\end{array}$} \\
\hline
\end{tabular}




\section{A.3 Pumped Storage Capabilities}

A comparison matrix of capabilities with technical characteristics for PSH plants and units is incorporated in the following tables. The matrices summarize the capabilities for the three pumped storage technologies in terms of primary (Table A-3) and secondary (Table A-4) benefits.

Table A-3 Primary Benefits of PSH Technologies

\begin{tabular}{|c|c|c|c|}
\hline $\begin{array}{l}\text { System or Plant } \\
\text { Capability }\end{array}$ & $\begin{array}{l}\text { Conventional FS PSH } \\
\text { with Single-Speed } \\
\text { Synchronous } \\
\text { Motor/Generators }\end{array}$ & $\begin{array}{l}\text { AS PSH with DFIM } \\
\text { Motor/Generators }\end{array}$ & $\begin{array}{c}\text { Ternary Type PSH with Hydraulic } \\
\text { Bypass and Single-Speed } \\
\text { Synchronous Motor/Generators - } \\
\text { Based on Kops II }\end{array}$ \\
\hline Energy arbitrage & Yes & Yes & Yes \\
\hline $\begin{array}{l}\text { Minimum unit } \\
\text { capacity rating } \\
(\mathrm{MW})\end{array}$ & 25 & 31.5 & 25 \\
\hline $\begin{array}{l}\text { Maximum unit } \\
\text { capacity rating } \\
(\mathrm{MW})\end{array}$ & $400+$ & $400+$ & $400+$ \\
\hline $\begin{array}{l}\text { Generation } \\
\text { Mode }\end{array}$ & & & Pelton turbines are used at Kops II \\
\hline Spinning reserve & Yes & Yes & Yes \\
\hline Efficiency & Less than pump mode & Changes with speed & Per the turbine design \\
\hline $\begin{array}{l}\text { Range of } \\
\text { operation (\% of } \\
\text { rated capacity) }\end{array}$ & $30 \%-110 \%$ & $20 \%-120 \%$ & $30 \%-110 \%$ \\
\hline Pump Mode & & & Francis pump \\
\hline Spinning reserve & No & Yes & Yes \\
\hline Efficiency & Per the pump design & Changes with speed & Per the pump design \\
\hline $\begin{array}{l}\text { Range of } \\
\text { operation (\%) }\end{array}$ & $\begin{array}{l}\text { Only pump at full } \\
\text { capacity }\end{array}$ & $75 \%-125 \%$ & $100 \%$ \\
\hline
\end{tabular}


Table A-4 Secondary Benefits of Pumped Storage Hydro Technologies

\begin{tabular}{|c|c|c|c|}
\hline $\begin{array}{c}\text { System or Plant } \\
\text { Capability }\end{array}$ & $\begin{array}{c}\text { Conventional FS PSH } \\
\text { with Single-Speed } \\
\text { Synchronous } \\
\text { Motor/Generators }\end{array}$ & $\begin{array}{l}\text { AS PSH with DFIM } \\
\text { Motor/Generators }\end{array}$ & $\begin{array}{l}\text { Ternary Type PSH with } \\
\text { Hydraulic Bypass and } \\
\text { Single-Speed Synchronous } \\
\text { Motor/Generators }\end{array}$ \\
\hline $\begin{array}{l}\text { Synchronize at less than } \\
\text { system frequency? }\end{array}$ & No & Yes & No \\
\hline Mode change time & Base Case & Faster $^{a}$ & Fastest \\
\hline $\begin{array}{l}\text { Change direction of } \\
\text { rotation for mode } \\
\text { change? }\end{array}$ & Yes & Yes & No \\
\hline $\begin{array}{l}\text { Hydraulic churning } \\
\text { during mode change? }\end{array}$ & Yes & Yes & No \\
\hline \multicolumn{4}{|l|}{ Generation Mode } \\
\hline Regulate frequency & Yes & Yes & Yes \\
\hline Load following & Yes & Yes & Yes \\
\hline Ramp rate & Yes & Yes & Yes \\
\hline Flywheel effect & No & Yes & No \\
\hline Reactive power & Yes & Yes & Yes \\
\hline Generator dropping & Yes & Yes & Yes \\
\hline \multicolumn{4}{|l|}{ Pump Mode } \\
\hline Shoulder pumping & No & Yes & No \\
\hline Regulate frequency & No & Yes & Yes \\
\hline Load following & No & Yes & Yes \\
\hline Ramp rate & No & Yes - fast & Yes \\
\hline Reactive power & Yes & Yes & Yes \\
\hline Load shedding & Yes, $100 \%$ & Yes, partial to $100 \%$ & Yes, $100 \%$ \\
\hline Flywheel effect & No & Yes & No \\
\hline Hydraulic churning & No & No & $\begin{array}{l}\text { Continuous in hydraulic } \\
\text { bypass mode }\end{array}$ \\
\hline
\end{tabular}

a It should be noted that pumped storage units with AS capability can provide regulation service in both pumping and generating modes, and therefore a fast mode change capability is not necessary for regulation. 


\section{A.4 Technical Characteristics of AS PSH}

The characteristics of 21 AS pumped storage units (14 operating, 7 in construction) were reviewed. The projects are located in Europe and Japan. This discussion is focused on units with a nominal rating capacity of greater than $50 \mathrm{MW}$. The smaller-sized units were excluded because it is more economical to use a four-quadrant AC/DC/AC converter connected to the motor/generator terminals. Table A-5 provides a comparison of the basic characteristics of conventional and AS pumped storage units.

Table A-5 Summary/Comparison of Single-Speed and AS Reversible Pump/Turbine Pumped Storage Units

\begin{tabular}{|l|c|c|}
\hline & $\begin{array}{c}\text { Conventional FS PSH with Single- } \\
\text { Speed Synchronous } \\
\text { Motor/Generators }\end{array}$ & $\begin{array}{c}\text { AS PSH with DFIM } \\
\text { Motor/Generators }\end{array}$ \\
\hline Synchronous Speed & \multicolumn{2}{|c|}{$\begin{array}{c}150 \text { to } 600 \mathrm{rpm} \text { for existing machines } \\
\text { Most common: } 300 \mathrm{rpm} \text { for } 50 \mathrm{~Hz} ; 360 \mathrm{rpm} \text { for } 60 \mathrm{~Hz}\end{array}$} \\
\hline $\begin{array}{l}\text { Speed adjustment range, } \\
\text { above and below } \\
\text { synchronous speed }\end{array}$ & $\begin{array}{c}\text { Not applicable (can only operate at } \\
\text { single synchronous speed) }\end{array}$ & +/-4\% to +/-10\% \\
\hline $\begin{array}{l}\text { Range of operation in } \\
\text { generating mode (\% of } \\
\text { nominal rating) }\end{array}$ & $30 \%$ to 115\% & $20 \%$ to $120 \%$ \\
\hline $\begin{array}{l}\text { Pump adjustment range } \\
\text { (\% of nominal rating) }\end{array}$ & $\begin{array}{c}\text { Not applicable (can only operate at } \\
\text { full rated pump capacity) }\end{array}$ & $75 \%$ to $125 \%$ \\
\hline
\end{tabular}

Ternary units have synchronous speeds similar to those of single-speed pumped storage units with reversible pump/turbines.

\section{A.4.1 Speed Range}

The pump/turbine of a conventional single-speed pumped storage unit is operated at a constant speed as determined by the synchronous speed of the AC motor/generator. Pump/turbines, however, are not inherently fixed-speed machines; they can operate over a speed range depending mostly on head.

In generation mode, the power output of a single-speed machine can be adjusted by the operation of wicket gates and speed governor controls; however, this method does not obtain the best levels of efficiency. With AS capability, however, speed can be adjusted in addition to the wicket gates, and an efficiency gain is possible.

In pump mode, the wicket gate position of a single-speed unit is not adjusted but fixed at a best efficiency point. In this case, the unit can only operate at rated pump power and cannot provide power system regulation services. 
Pump power is a function of discharge (flow) and head. For an AS pumped storage unit, a change in speed changes discharge and results in a power level change. The speed of an AS unit is controlled through the electronics that create the magnetic field on the rotor. By adjusting the frequency of the rotor field, the pump speed is changed. In this way, it is possible to control pump power and provide regulation service in the pump mode.

Because pump input power is proportional to the cube of rotational speed, a large pump input power range is obtained with relatively small variation in rotational speed. The pump mode input power range is sufficient to provide automatic frequency control (AFC) in the pump mode.

The range of speed adjustment is given in terms of a percentage above and below synchronous speed. The uniform speed range of existing units in commercial operation ranges from $+/-4 \%$ to $+/-8 \%$. However, there are several units that have different positive and negative speed adjustments limits; these are as follows: $+4 \% /-13 \%,+10 \% /-13 \%,+4 \% /-10 \%$, and $+6 \% /-4 \%$. With these speed ranges, it is possible to provide significant pump mode power adjustments and contribute to system regulation.

\section{A.4.2 Pump Power Rating}

Figure A-5 shows the range of pump operation for AS for Unit \#4 at the Okawachi pump storage plant. The AS unit can regulate frequency in the pumping mode over a range of 240 to $392 \mathrm{MW}$. Speed is adjustable over the range 330 to $390 \mathrm{rpm}$, which corresponds to a $+/-8 \%$ range based on a synchronous speed of $360 \mathrm{rpm}$.

\section{A.4.3 Generator Capacity Rating}

The nominal nameplate rating of generators ranges from $50 \mathrm{MW}$ up to $400 \mathrm{MW}$. Although units with greater ratings may exist, units with nameplate ratings in the $300-\mathrm{MW}$ range are the most common at present.

Figure A-6 shows the range of operation in generation mode for an AS unit at the Okawachi pump storage plant. For a single-speed unit, the rating is 395 MVA (320 MW at 81\% power factor) in generation mode, and it can operate from $160 \mathrm{MW}$ to $320 \mathrm{MW}$. For an AS unit, the operating range is $90 \mathrm{MW}$ to $320 \mathrm{MW}$, an increase of $70 \mathrm{MW}$ over the single-speed unit. Speed is adjustable over the range $330 \mathrm{rpm}$ to $390 \mathrm{rpm}$ and corresponds to a $+/-8 \%$ range based on a synchronous speed of $360 \mathrm{rpm}$.

Figure A-6 indicates that an AS motor/generator pumped storage unit has a larger range of operation in turbine mode than a single-speed unit. AS units have a reduced rough zone, improved efficiency, and the ability to operate at lower power levels. These capabilities are shown in Figure A-7; the green curve is for AS and the blue curve for fixed-speed units. 


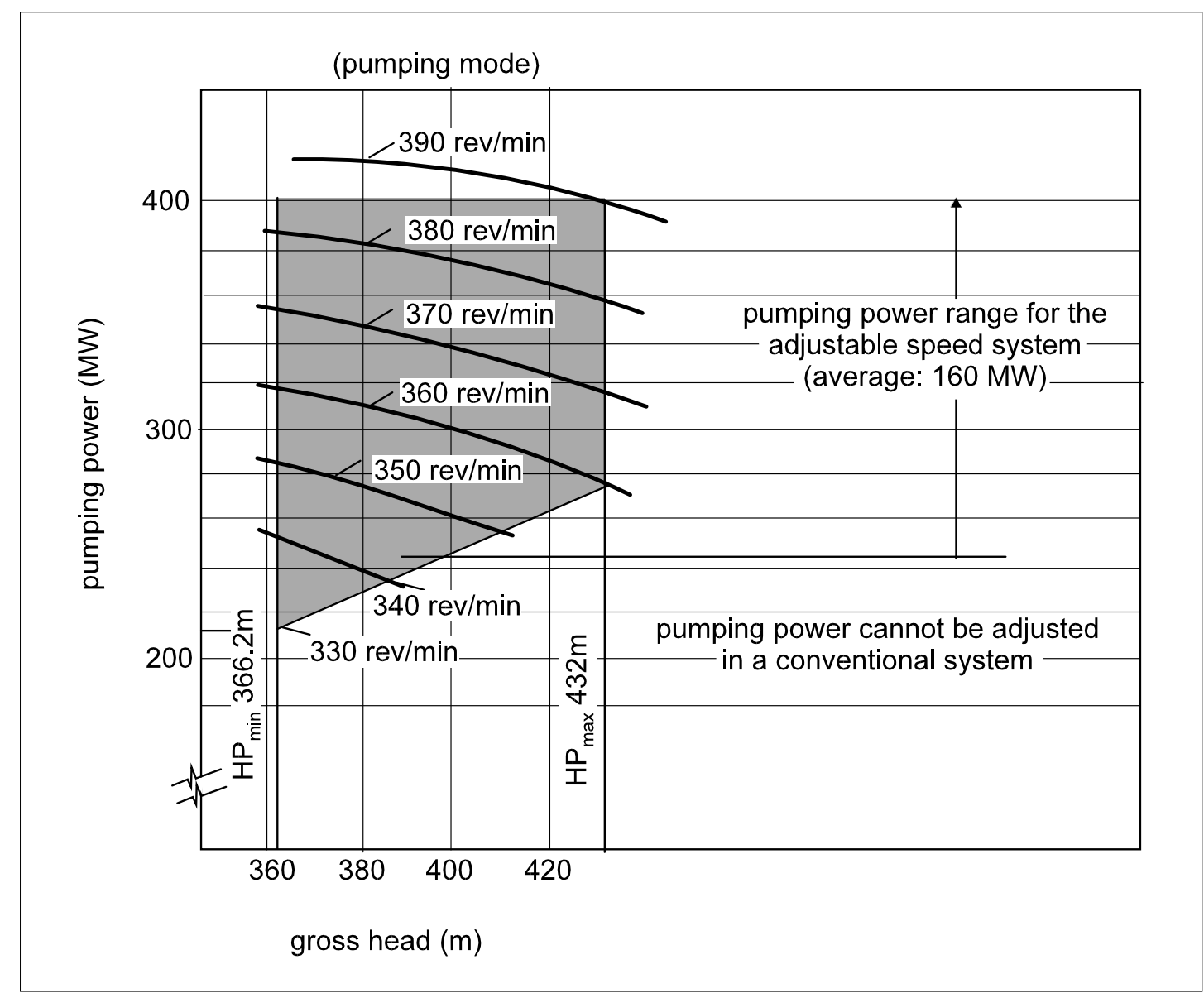

Figure A-5 Operating Range in Pump Mode (Source: USACE 2009)

(Note: $\mathrm{rev} / \mathrm{min}=$ revolutions per minute)

\section{A.5 Operating Characteristics}

A pumped storage unit operates in two distinct modes: pumping and generating. The difference in cost of pumping and generating provides the necessary cost margin (energy arbitrage) that makes the operation economically viable. Pumped storage plants also provide added value to the grid in the form of ancillary services (A/S). The need for A/S in deregulated markets is an opportunity for conventional, AS, and ternary PSH with fast response to earn revenue via the provision of $\mathrm{A} / \mathrm{S}$.

System operators and dispatchers rely on specific electric wholesale generators (EWGs) and load serving entities (LSEs) to provide the necessary A/S when system conditions require them. The increased need for regulation services is driven by the addition of wind-powered generation and solar photovoltaic (PV) capacity. Electric power system regulators have come to realize the value of $\mathrm{A} / \mathrm{S}$, and, in deregulated markets, these services are unbundled from basic operation in pump and generation modes. The Federal Energy Regulatory Commission (FERC) has recognized this aspect of system operation and created regulations and tariffs that provide revenue to those EWGs and LSEs for the provision of A/S. 


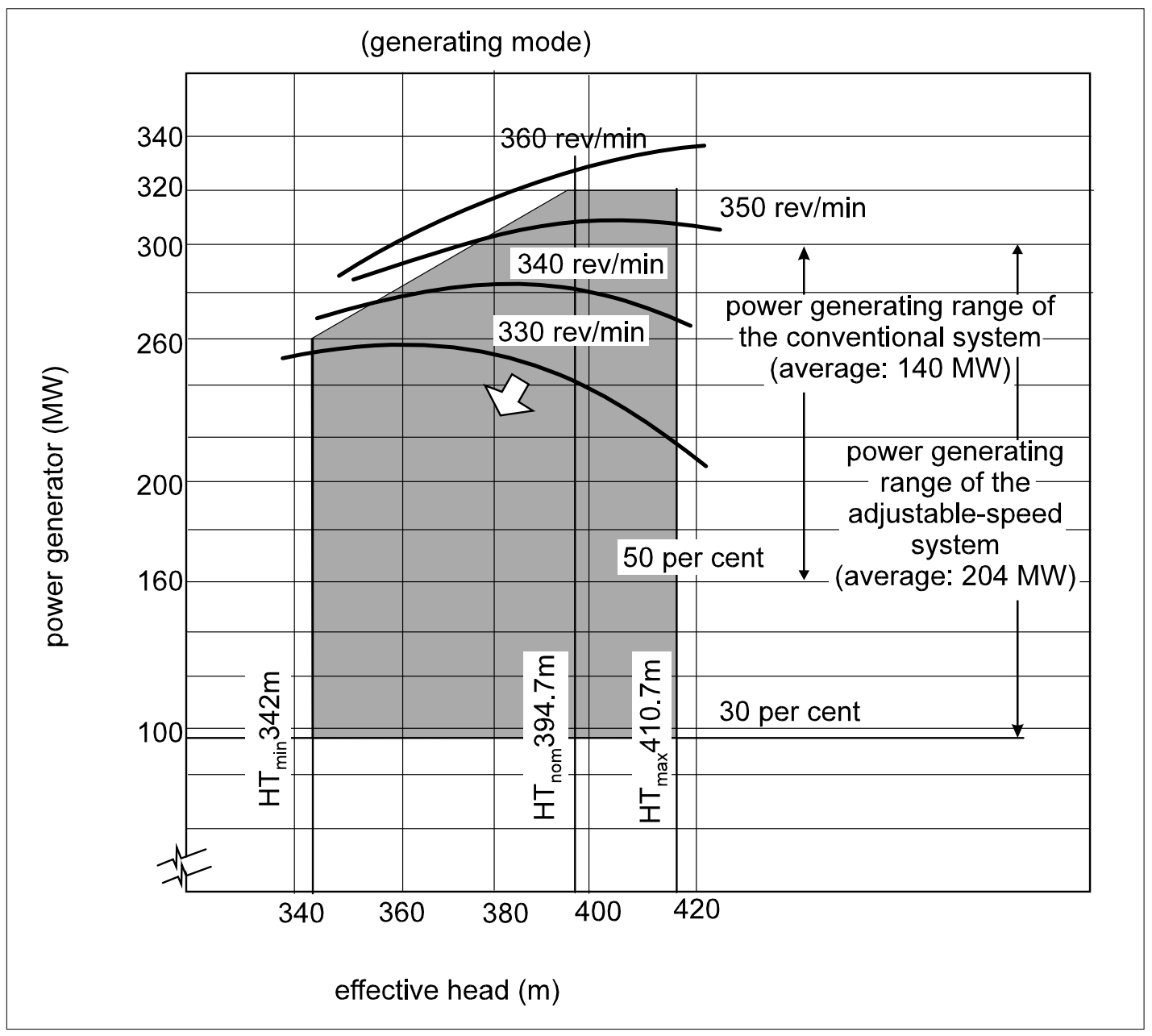

Figure A-6 Operating Range in Generation Mode (Source: USACE 2009)

\section{A.5.1 Mode Transitions}

Figure A-8 shows the mode transitions for each pumped storage technology. The mode transitions are shown with regard to the provision of A/S in pumping and generation modes. Most notable is the fact that a conventional single-speed unit cannot provide regulation services when it is operating in the pump mode. The table embedded in Figure A-8 provides the amount of time required for different types of pumped storage units to make the mode transitions.

With the advent of increasing amounts of nondispatchable renewable capacity, the need for additional regulation services is changing. If regulation services are required during the time when a single-speed unit is pumping in preparation for the next day's operation, then the unit must stop pumping, come to a stop and reverse direction, and restart as a generator. Later, the unit must stop generating and return to pump mode. 


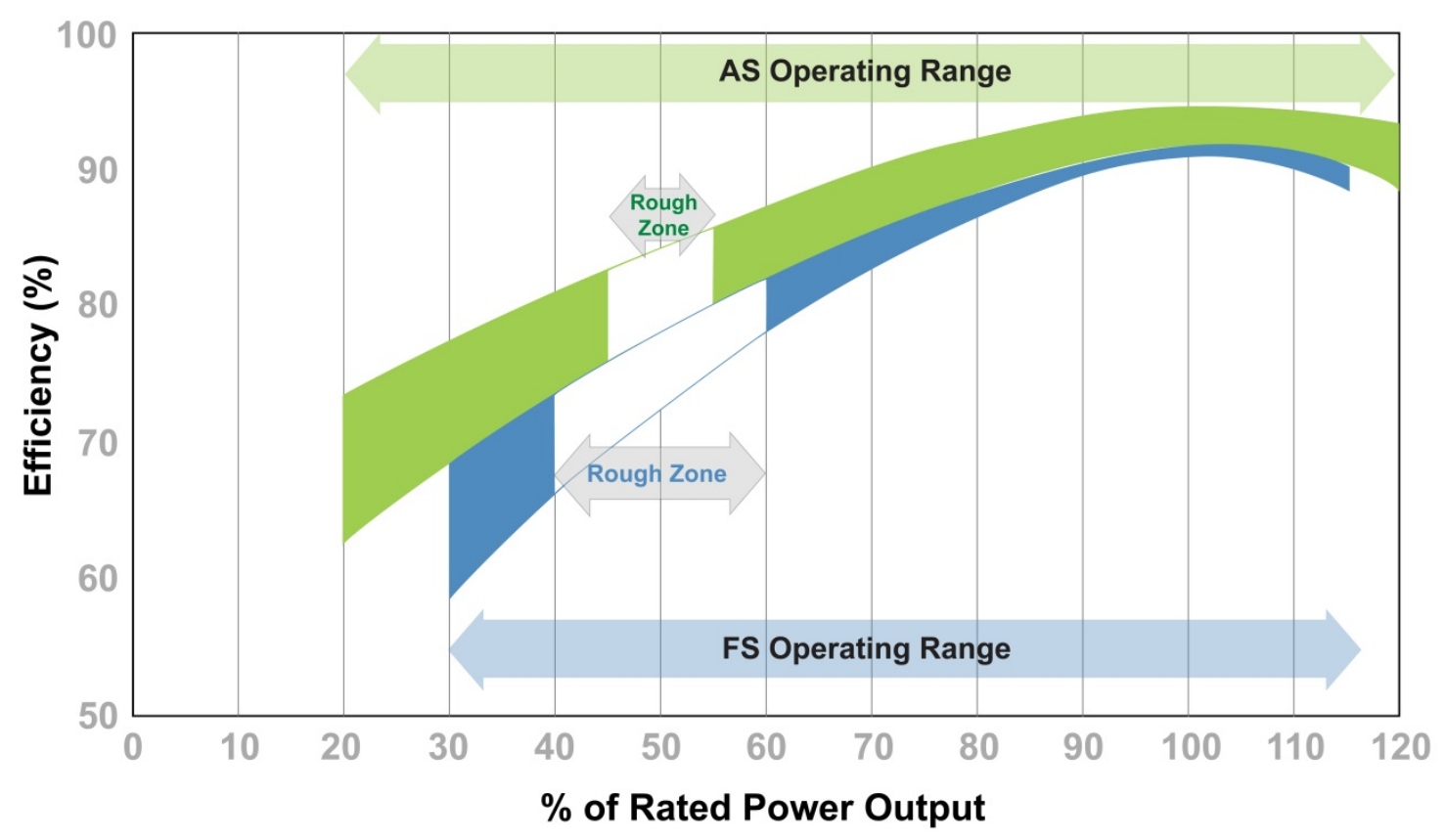

Figure A-7 Comparison of Efficiency Curves (Adapted from USACE 2009)

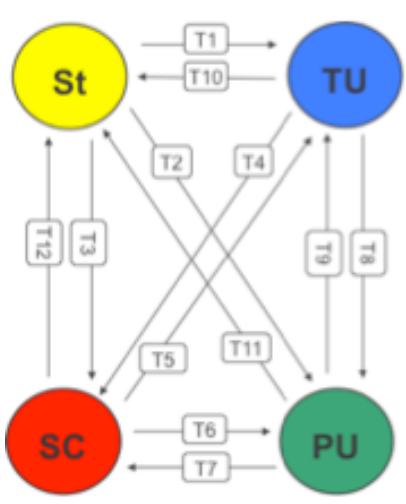

\begin{tabular}{|c|c|c|c|c|c|c|c|c|}
\hline \multicolumn{4}{|c|}{ Pump Turbine } & \multicolumn{5}{|c|}{ time [seconds] } \\
\hline$T$ & \multicolumn{3}{|c|}{ Mode change } & A & B & C & D & $\mathbf{E}$ \\
\hline 1 & Standstill & $\longrightarrow$ & TU-Mode & 90 & 75 & 90 & 90 & 65 \\
\hline 2 & Standstill & $\longrightarrow$ & PU-Mode & \multicolumn{2}{|c|}{340160} & 230 & 85 & 80 \\
\hline 5 & SC-Mode & $\longrightarrow$ & TU-Mode & 70 & 20 & 60 & 40 & 20 \\
\hline 6 & SC-Mode & $\longrightarrow$ & PU-Mode & 70 & 50 & 70 & 30 & 25 \\
\hline 8 & TU-Mode & $\longrightarrow$ & PU-Mode & \multicolumn{2}{|c|}{420240} & 470 & 45 & 25 \\
\hline 9 & PU-Mode & $\longrightarrow$ & TU-Mode & \multicolumn{2}{|c|}{19090} & 280 & 60 & 25 \\
\hline
\end{tabular}

Reversible PT

A - advanced conventional (2012)

B - extra fast response conventional

C - VarSpeed, DFIM

Ternary set

D - with hydraulic torque converter + hydr. short circuit, horiz, with Francis Turbine

$\mathrm{E}$ - same as $\mathrm{E}$ but vertical with Pelton Turbine

Figure A-8 Operating Mode Transition Times (Source: Fisher et al. 2012) 
The need to perform mode changes as quickly as possible focuses on the amount of time required to make the change. If mode changes cannot be accomplished quickly enough, then the usefulness of a conventional pumped storage unit as a provider of regulation services is reduced, and system dispatchers will turn to other generators that can be brought online quickly to provide the required regulation capacity.

In addition to frequency regulation and load following, there is often a need for reactive power support to provide voltage regulation on the high-voltage transmission grid. Pumped storage units can provide these services by operating as rotating synchronous condensers. The time it takes a unit to change from synchronous condenser to generation mode is another benchmark.

The times presented in Figure A-8 are based on measurements at various existing PSH plants. It should be noted that the specific times depend strongly on individual plant characteristics such as opening and closing times of the wicket gates, rotor inertia, converter equipment and rating, operational procedures, and further site conditions. Hence, the values provide some typical order of magnitudes, but their comparability is limited and can vary from plant to plant. The main purpose of the times in Figure A-8 is to show a rough comparison of the individual technologies based on existing examples and to illustrate the differences between reversible pump/turbine and ternary configurations. Considering future projects, the actual design of which has some major impact on plant performance and mode, changing times may be adapted to meet specific power plant and grid requirements.

As noted, the times it takes to implement mode changes for single-speed PSH units are often not fast enough to provide system operators with necessary regulation of power and frequency fluctuations associated with intermittent renewable resources. However, with AS and ternary pumped storage with hydraulic bypass, it is now possible to provide regulation service in both pumping and generating modes. Because it is possible to provide regulation services in both pumping and generating modes, the need to change modes to obtain regulation service is eliminated. This capability offers the prospect that there will be a reduction in the use of conventional single-speed hydro units to provide regulation services and reduce wear and tear on hydro turbine components. It may also reduce the need to obtain regulation services from combustion turbines or coal-fired generation.

\section{A.5.2 Primary and Secondary Response}

Power system response requirements are in two categories: primary and secondary. Primary control relates to how the system initially reacts to a sudden disturbance (such as a generator trip or loss of a major transmission circuit) during the first several seconds and is mainly a function of the inertial response, automatic excitation, power system stabilizer action, and speed governor control action. Secondary control relates to the system's response during several minutes after primary control actions and is basically a function of the automatic generation control (AGC) response to load changes and disturbance (Byrne et al. 2012). 


\section{A.5.2.1 Response Rate}

The response rates for hydro (including pumped storage) units are a function of governor settings, water column start time, machine inertia, and wicket gate response. A major factor in the response rate of a PSH plant is the water column's starting time constant (also known as the water column start time). The water column start time is associated with the acceleration time for water in the penstock between the turbine inlet and the forebay (or surge tank, if one exists). The water column start time is calculated in terms of penstock length, head, cross sectional area of the penstock, power, efficiency, and physical constants.

Figure A-9 shows the response capabilities of conventional, single-speed pumped storage plants compared with those of combustion turbine and steam turbine-driven generators (Fisher 1994).

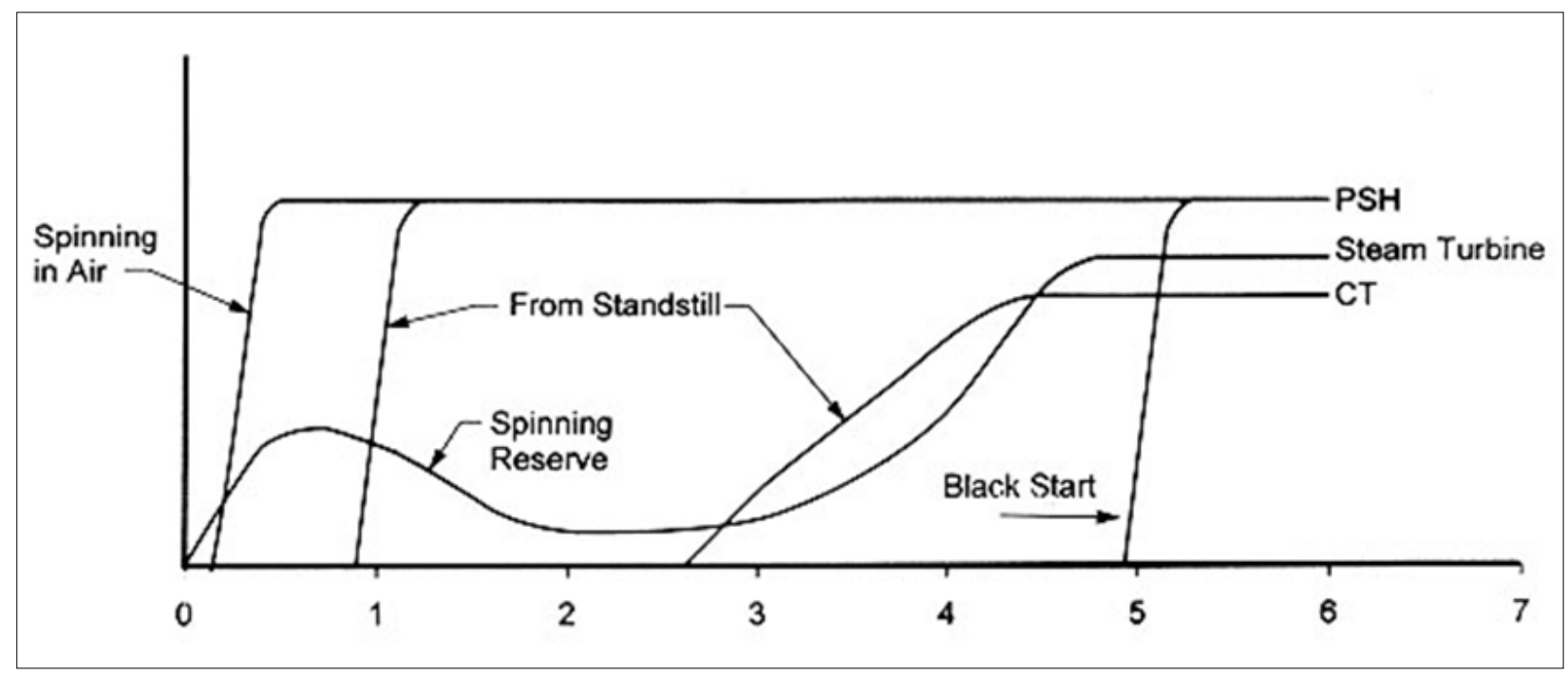

Figure A-9 Comparison of Response Capabilities (Source: USACE 2009)

The rotational speed of a conventional single-speed synchronous machine is controlled by a governor via the wicket gates (also known as guide vanes). In an AS unit, the rotational speed can be controlled either by a speed governor for wicket gate control, or by the rotor excitation voltage and current frequency, or by a combination of both.

Response times using AS pumped storage technologies in both pumping and generation modes are faster than response times using other sources of regulation services. This result occurs because changes in power are accomplished through the rotor excitation system electronics. Figure A-10 shows the response capability of a conventional, single-speed pumped storage unit as compared with a unit with AS capability.

According to an Institute of Electrical and Electronics Engineers (IEEE) Power \& Energy Society (PES) paper, the excitation system response rate for both active and reactive power for an AS unit is on the order of 10 to $30 \mathrm{~ms}$ (Sporild et al. 2000). The 10- to 30-ms value is the 
amount of time it takes the electronics to change rotor current excitation frequency. In a presentation for the Goldisthal project, the total amount of time for a step response during a change in power from zero to rated maximum, by way of the cycloconverter and associated controls, is given as $150 \mathrm{~ms}$. The 150-ms response time includes the 10- to 30-ms excitation system response time.

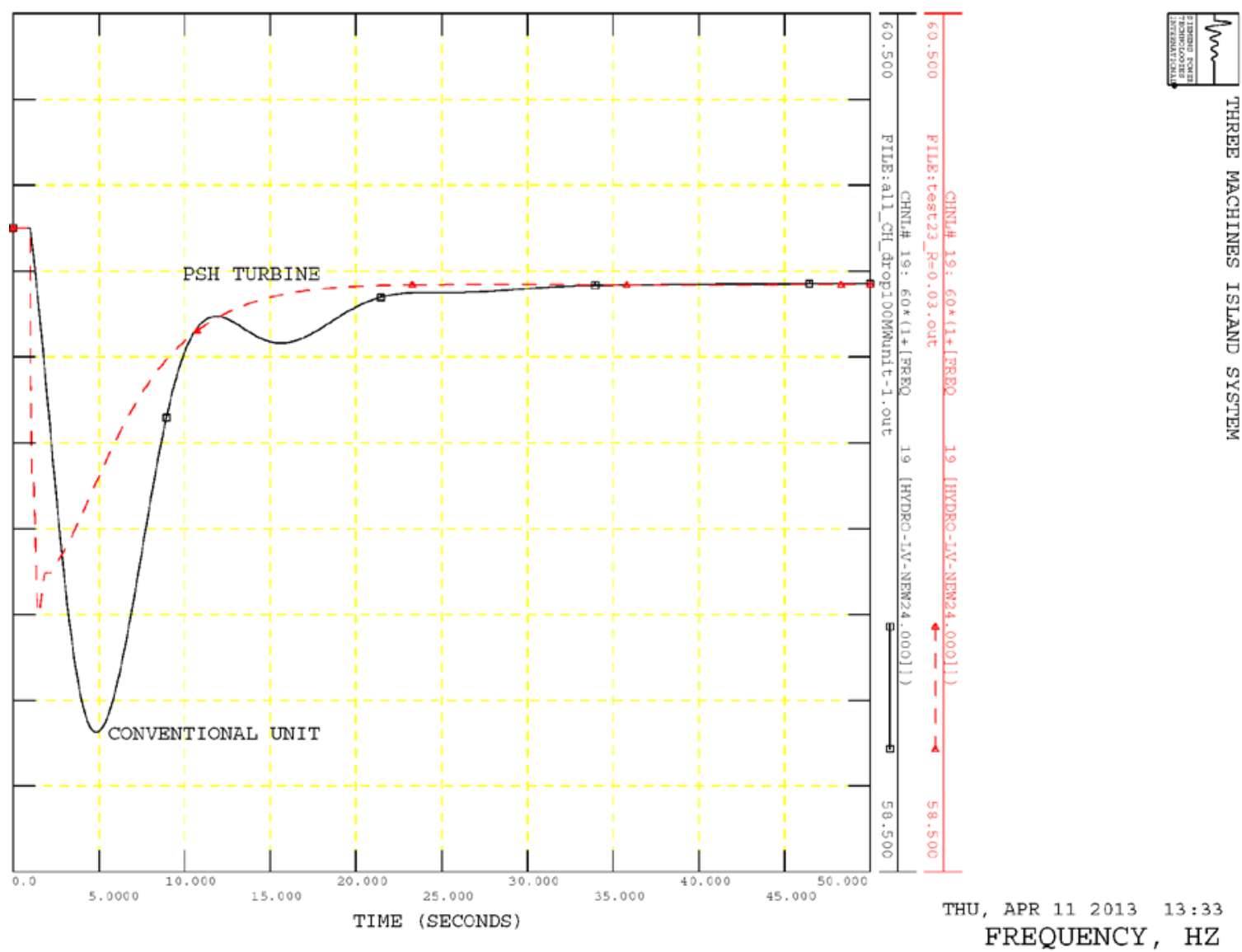

Figure A-10 Comparison of Response of AS PSH and Single-Speed PSH

The ability of an AS unit to change rotational speed via the rotor current and frequency allows active power to be supplied from (or absorbed by) the motor/generator, and thus may be used to stabilize system frequency and power level. The capability to change output rapidly through the electronic controls offers system operators the potential to use an AS unit to modulate power fluctuations associated with intermittent renewables, such as wind-powered generators and solar PV. 


\title{
A.5.2.2 Ramp Rates
}

In this section, the response rate is discussed in the context of secondary response. The ability of a conventional, single-speed pumped storage unit to change output in generation mode is called the "ramp rate," and it is measured in terms of MW per second (sec) or MW per minute (min). Conventional, single-speed pumped storage units are not able to change power output in pump mode, and therefore ramp rates are not considered when a single-speed unit is in pump mode.

The ramp rate is a revenue source for those units that participate in the AGC and load following markets. Not all units have ramp rates that can be used for AGC or load following (see also IEEE Task Force Report 2007). The most desirable units are those that have fast (high) ramp rates. Ramp rates for a pumped storage unit are determined by unit inertia, water column time constant, and wicket gate operating times. Ramping is needed to address changing (increasing or decreasing) system frequency and load conditions (NERC 2011). A/S markets typically address these transition periods as "ramp up" and "ramp down

Conventional, single-speed pumped storage units in generation mode provide normal ramping in the range of $1.7 \mathrm{MW} / \mathrm{sec}$ to a fast ramp rate of $2.1 \mathrm{MW} / \mathrm{sec}$, and emergency ramping of 9.6 MW/sec. The six single-speed, 320-MW units at the Dinorwig pumped storage plant in Wales are reported to have normal and emergency ramp rates of $22 \mathrm{MW} / \mathrm{sec}$. The plant as a whole can provide up to 1,320 MW in 12 seconds (First Hydro Co. 2014) ${ }^{23}$. In normal operation, the ramp rate for the plant is about $50.0 \mathrm{MW} / \mathrm{sec}$, as plant ramp rates are typically constrained because of waterway capacity. This plant has played a significant and positive role during fastchanging load conditions (Stalker 1994).

Ternary units have ramp rates that are similar to those of conventional, single-speed pumped storage units. However, ternary units with Francis turbines and hydraulic bypass have a ramp rate capability in pumping mode as well as in the generation mode.

AS units can have higher ramp rates as compared with the other current PSH technologies; the faster ramp rate results from the ability to interchange energy between the bulk power system and the rotating mass of the rotor via the rotor excitation system electronics. In some papers, this capability is referred to as the "flywheel effect" (see Section A.5.2.3 for additional information). In this regard, AS machines are superior to other generators, regardless of the type of "prime mover” (i.e., whether steam, hydro, combustion; or wind turbines).

Ramp rates in generation and pump modes for AS Unit 4 at the Okawachi pumped storage plant are reported in an article appearing in the Hitachi Review (Kita et al. 1995) as follows:

\author{
Ramp Response Characteristics in Generation Mode \\ Ramp up: \\ From zero to $320 \mathrm{MW}$ in $50 \mathrm{sec}$ \\ Ramp rate: $6.4 \mathrm{MW} / \mathrm{sec}$
}

23 http://www.electricmountain.co.uk/en-GB/Dinorwig 


\author{
Ramp down: \\ From $320 \mathrm{MW}$ to zero in $50 \mathrm{sec}$ \\ Ramp rate: $6.4 \mathrm{MW} / \mathrm{sec}$ \\ Ramp Response Characteristics in Pumping Mode \\ Ramp up: \\ From $246 \mathrm{MW}$ to $400 \mathrm{MW}$ in $20 \mathrm{sec}$ \\ Ramp rate: $7.7 \mathrm{MW} / \mathrm{sec}$ \\ Ramp down: \\ From $400 \mathrm{MW}$ to $246 \mathrm{MW}$ in $20 \mathrm{sec}$ \\ Ramp rate: $7.7 \mathrm{MW} / \mathrm{sec}$
}

\title{
A.5.2.3 Flywheel Effect
}

The flywheel effect is discussed here in the context of primary response. The concept of the flywheel effect is mentioned in the discussion of comments to the recent FERC rule 764 (FERC 2012). The discussion points out that a MW of reserve capacity from a fast-ramping resource provides more regulation value to the grid per MW than a slow-ramping resource. It also points out that some resources that provide generator regulation service, such as batteries and flywheels, can dampen variation much more quickly than can traditional generators. If advanced pumped storage can supply equivalent or superior regulation performance, when compared with the public utility transmission provider's default service, then this capability may represent added value.

The "flywheel" capability of AS PSH units should also make it possible to provide primary frequency response and system damping during transmission system transient disturbances. For a technical reference documenting the system damping capability of an AS machine, see Kuwabara et al. (1996). This paper describes the system damping capability of a 395-MVA AS machine at the Okawachi Pumped Storage Plant on the Kansai Electric System in Japan. In the discussion, the authors note that Unit No. 4 was in operation during the Hanshin earthquake on the morning of January 17, 1995, and they report that the machine absorbed power disturbances in random spikes.

\section{A.5.3 Efficiency}

\section{A.5.3.1 Cycle Efficiency}

Operational efficiency of a pumped storage plant is measured in terms of cycle efficiency (sometimes called "round trip" efficiency). However, multiple terms and methods are used to represent cycle efficiency. The efficiency definition includes values for these elements: pump/turbine, motor/generator, generator step-up transformer, and hydraulic losses. The ratio of energy output at the high-voltage terminals of the main power transformer to the recorded energy input (for pumping) at the high-voltage input to the main power transformer is the cycle efficiency. 
A review of the historic data for 17 large pumped storage projects in operation in the United States showed that the overall cycle efficiencies ranged from a low of $60 \%$ to a high of $80 \%$. For planning purposes, an overall cycle efficiency value on the order of $75 \%$ is often used, which includes hydraulic losses. It may be possible to achieve $80 \%$ or more in a controlled test of evacuating and refilling the reservoir within a short time, where the facility is operated at optimized output. In the traditional vertically integrated utility, plant operators had more control over system operation; however, when operated in market-based systems, pumped storage plants may be operated off of their best efficiency in response to market conditions, and best theoretical cycle efficiency may not be attained.

While cycle efficiency is a metric of overall efficiency, each component and subcomponent can be evaluated and measured individually. Table A-6 provides typical ranges of efficiency values for the water conductors, pump/turbine, motor/generator, and main power transformer. The values in the table are based on generating and pump cycles for single-speed pumped storage projects.

Table A-6 Composition of a Single-Speed PSH Plant Cycle Efficiency

\begin{tabular}{|c|c|c|}
\hline \multicolumn{2}{|c|}{ Component } & $\begin{array}{c}\text { Indicative Value } \\
\text { (\%) }\end{array}$ \\
\hline \multirow{5}{*}{ Pump cycle } & Water conductors & $98.0-98.6$ \\
\hline & Pump & $90.0-92.0$ \\
\hline & Motor & $97.8-98.3$ \\
\hline & Transformer & $99.0-99.6$ \\
\hline & Overall pump cycle & $85.4-88.8$ \\
\hline \multirow{5}{*}{$\begin{array}{l}\text { Generation } \\
\text { cycle }\end{array}$} & Water conductors & $96.8-98.0$ \\
\hline & Turbine & 76.4-91.0 \\
\hline & Generator & $97.8-98.3$ \\
\hline & Transformer & $99.0-99.6$ \\
\hline & Overall generation cycle & $71.6-87.3$ \\
\hline \multicolumn{2}{|c|}{ Hydraulic Losses and Leakage } & $98.0-99.8$ \\
\hline \multicolumn{2}{|c|}{ Operational - Both Modes } & $60.0-77.4$ \\
\hline
\end{tabular}

Water flow efficiencies through the water conductor are highly site specific. Design of a complex waterway system and selection of tunnel linings can improve the efficiency associated with the water conveyance system. Although the motor/generator and transformer tend to have a flat efficiency curve, the efficiency of a pump/turbine varies significantly with the net head and water flow; this circumstance is discussed more fully in the sections that follow. 
Overall efficiency for ternary units is somewhat better owing to the fact that the pump and the turbine are physically separate units, and therefore each can be designed for best efficiency at the selected synchronous speed.

\section{A.5.3.2 Pump Efficiency}

When depicted on a graph, operation of a single-speed, reversible Francis unit plots along a single discharge versus head pump curve. In generation mode, wicket gates are positioned to provide the least throttling effect (reducing the losses) at the prevailing head and speed.

Throttling with the wicket gates is convenient to carry out in generation mode; however, it is not used in pumping mode because it sustains hydraulic losses, causes excessive vibrations, and reduces equipment life. As confirmed by experience in Japan, pumped storage units with AS capability can be used effectively to extend the single-speed pump operating curve to a broad range of pump operation and to provide positive control over the pump discharge and input power.

The limits of the pumping range with AS machines are normally defined by cavitation (low head, high-speed operation), motor/generator output (medium to high head, high-speed operation), turbulence or reverse flow (high head, low-speed operation), and the speed range. Although these limits seem restrictive, in reality the improvement in operating range is extremely impressive, especially when considering the possibilities of how the extended range can be used to avoid cavitation or reduce input power at low heads, adjust input power, avoid reverse flow at high head operation, and control electric power frequency during the pumping mode.

Figure A-11 shows an example of the pumping operation range for AS, as compared with the operation along a single curve defined for a single synchronous speed; the single-speed pump is constrained to operate along the line identified as $140 \mathrm{rpm}$, whereas an AS pump is able to operate within a range defined by the upper and lower speeds. The ability to operate over a range, at different speeds, gives the plant operator the capability to operate at the best efficiency as the upper reservoir head changes. A "speed optimizer" is used to adjust the operating speed in pump mode.

The ability of AS machines to pump at less than full power allows operators to participate in "shoulder pumping." Shoulder pumping provides added operational flexibility and allows for the purchase of smaller blocks of power. It also allows the unit to provide load following for variable output from wind and solar PV units.

\section{A.5.3.3 Single Speed versus Adjustable Speed}

For a given conventional, single-speed PSH unit, it is not possible to have the maximum efficiency point for the pump and the turbine to occur at the same speed (see Figure A-12). In this case, the reversible, single-speed unit can be designed to achieve maximum efficiency in only one of the two modes. If the unit designed for best efficiency as a pump, then the best efficiency point in generating mode will occur at a different speed and will not be realized.

Because single-speed pumped storage units can only operate at maximum efficiency in one of the two modes, the unit can either achieve best efficiency in pump mode or best efficiency in turbine 
mode. Because more energy is input in pump mode than is output in generation mode, the water wheel is designed to operate at best efficiency in pump mode.

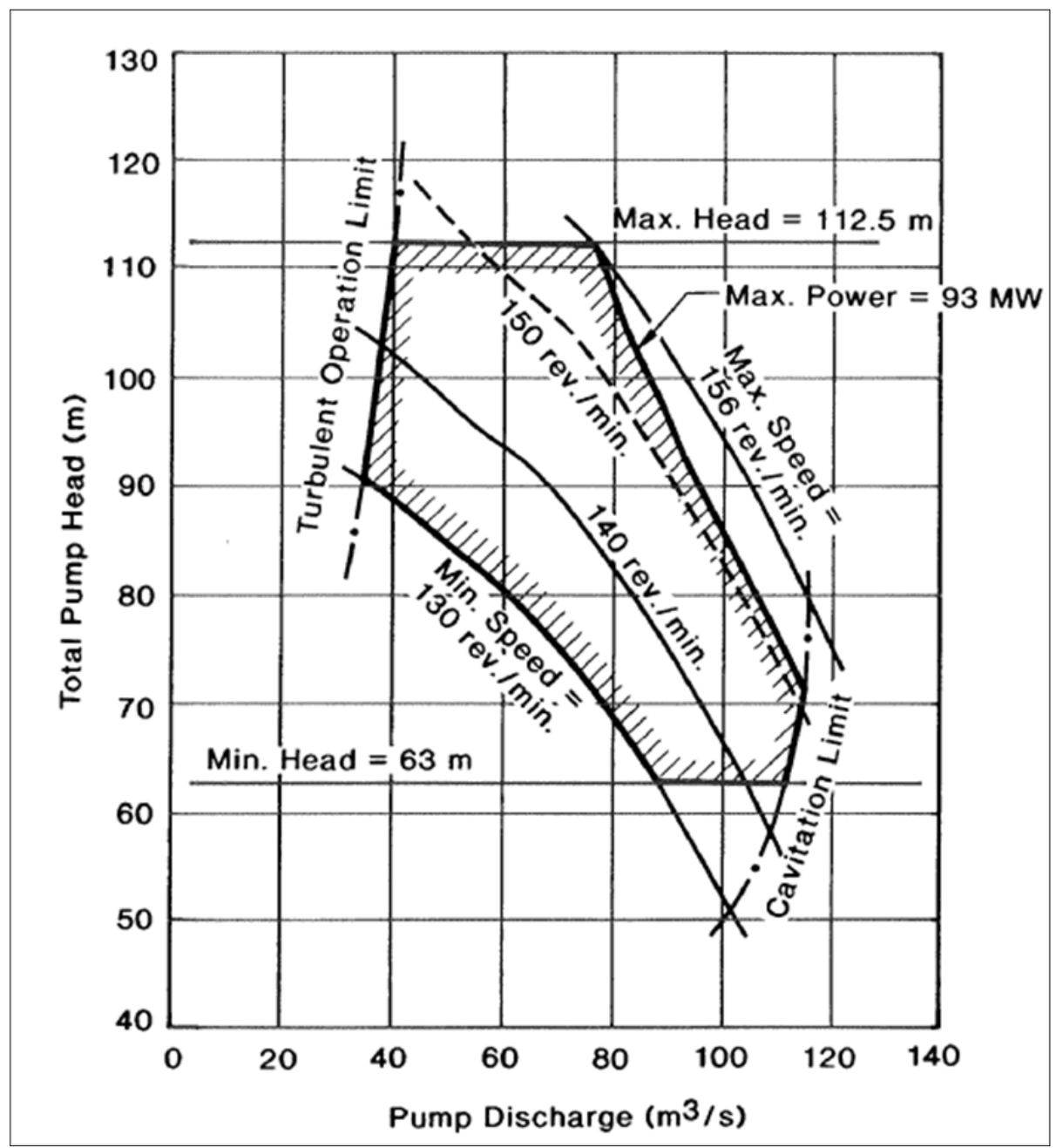

Figure A-11 Pump Mode, Discharge, and Head Operating Range (Source: USACE 2009)

With an AS machine, it is possible to achieve best efficiency in both pumping and generating modes because the speed can be selected in each operating mode. Figure A-13 provides a comparison.

The ability to operate at the best efficiency points in both the pumping and generating modes with AS results in increased energy production because the turbine can be operated at maximum efficiency in generation mode. In Japan, the minimum improvement has been estimated at 3\% per year (Furuya et al. 1992).

\section{A.5.3.4 Turbine Efficiency}

Differences in efficiency between single-speed and AS units are illustrated as a function of head (Figure A-14) and power output (Figure A-15). 


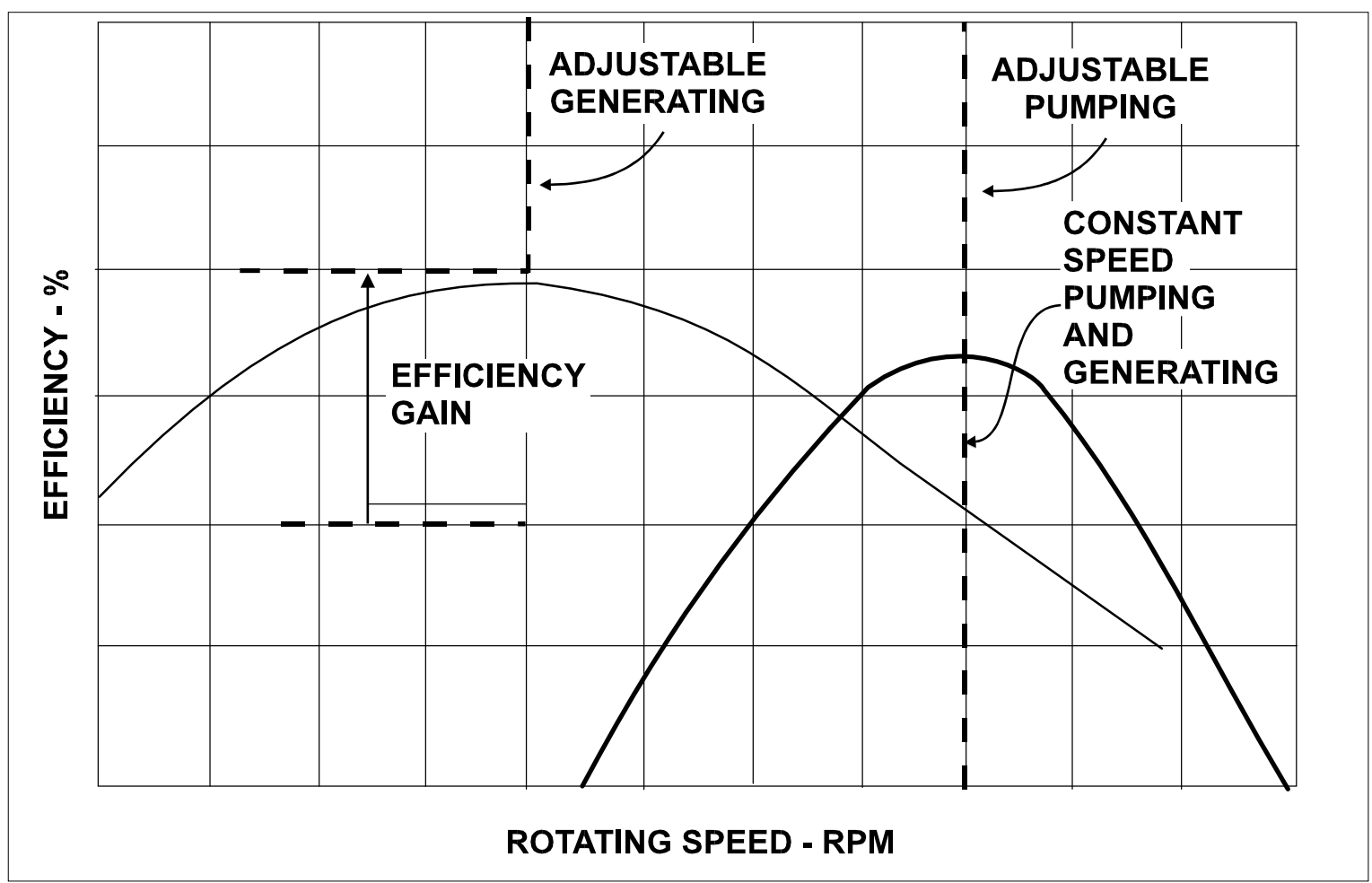

Figure A-12 Separate Efficiency Points for Pump and Generation Modes (Source: USACE 2009)

\section{A.5.4 Wear and Tear and Machine Vibration}

Hydraulic machine vibrations and draft tube surges are serious concerns, especially with fixedblade reaction units. Certain wicket gate openings can produce undesirable relationships between the angle of flow leaving the wicket gates and the entrance angle of the runner blades, resulting in the vibrations and leading edge cavitation. Francis units are also notorious for draft tube surges at partial load (between approximately 35\% to 60\% wicket gate opening). These draft tube surges can be intensive enough to cause unit shutdown if vibration monitoring equipment is installed, or serious damage if the unit is operated for a prolonged time under these conditions. There are some means available to reduce draft tube surges, the most notable among these are: air admission, providing fins in the draft tube or a combination of both. The problems with these solutions are that:

- Air admission causes a slight reduction in hydraulic efficiency.

- If atmospheric air admission is insufficient and compressed air is required, then there is an additional efficiency loss (regardless of whether the compressed air is provided by compressors or by ejectors using water from the penstock).

- Whereas fins are helpful in reducing draft tube surges, a cavitation zone typically develops on the low-pressure side of the fins, requiring frequent repairs. 


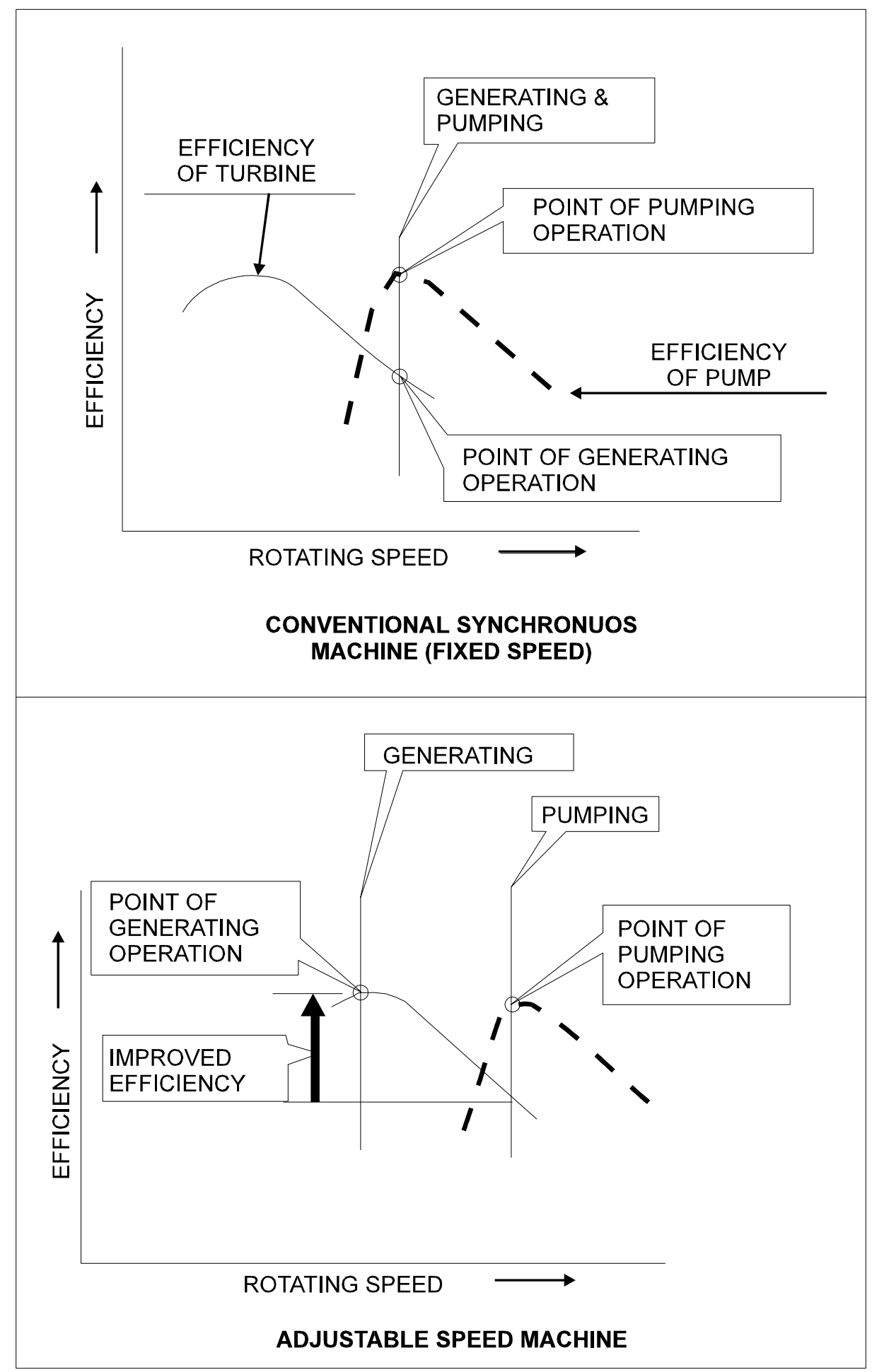

Figure A-13 Efficiency Difference for Single-Speed and AS Operation (Source: USACE 2009) 


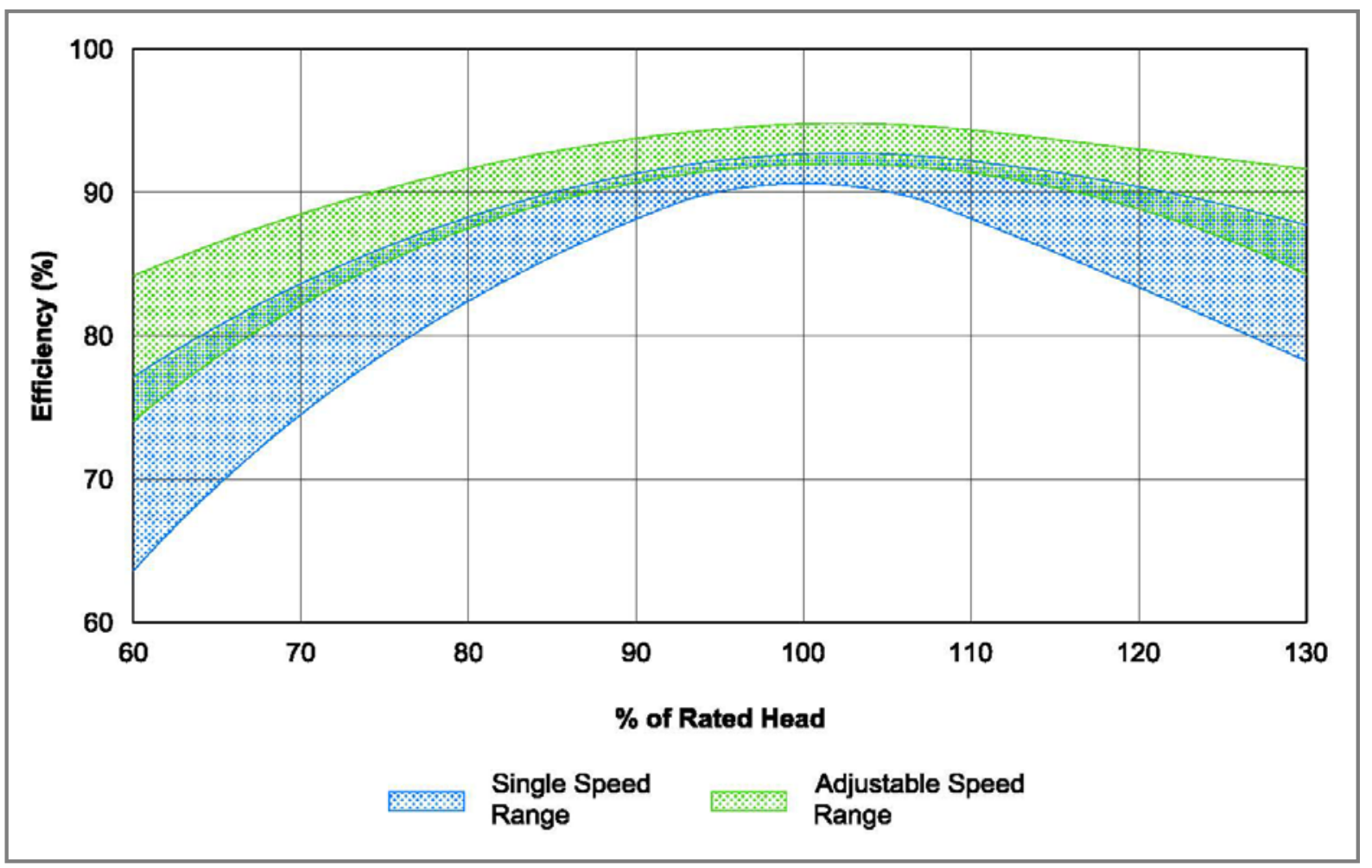

Figure A-14 Turbine Efficiency Range versus Rated Head (Source: USACE 2009)

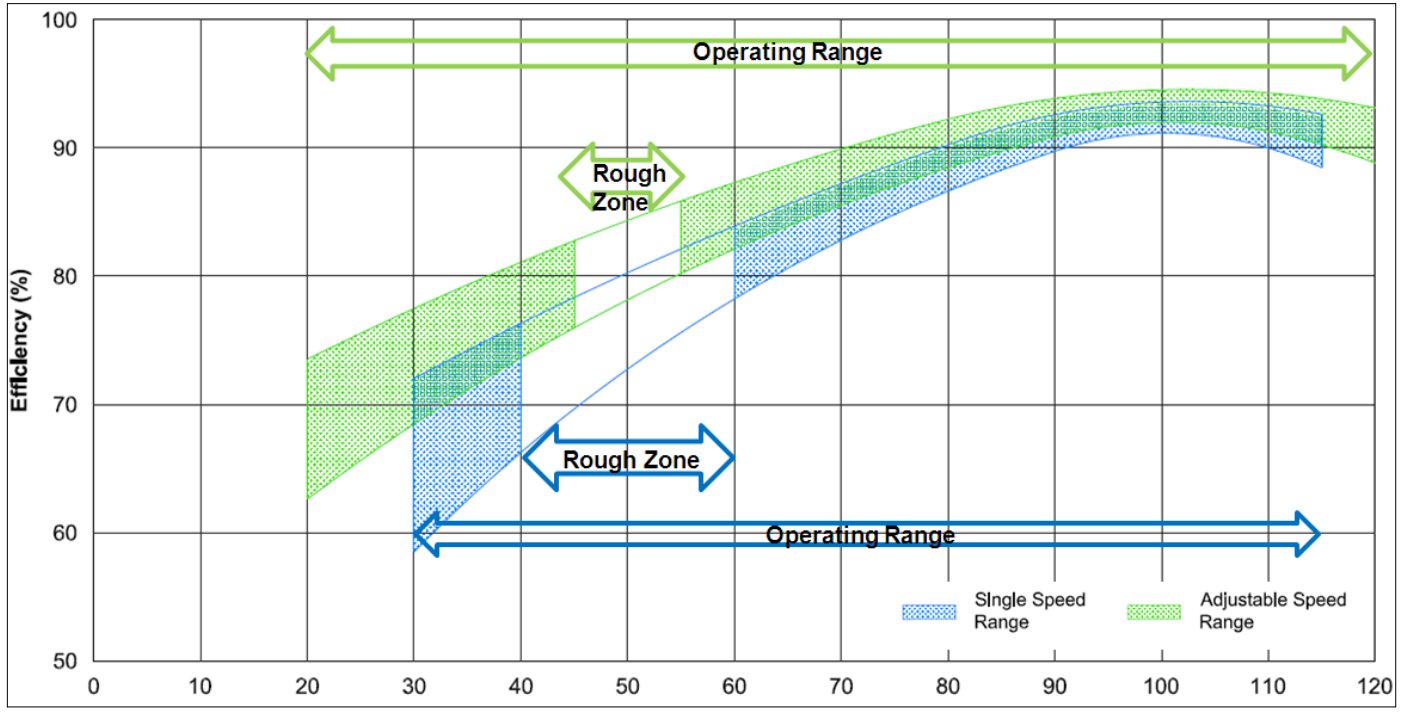

Figure A-15 Turbine Efficiency Range versus Rated Power Output (Source: USACE 2009)

Experience at the Yagisawa plant indicates that these problems can be overcome with AS. For a comparison of vibration intensities of a single-speed Francis type of pump/turbine and the same machine with AS, see Figure A-16. 


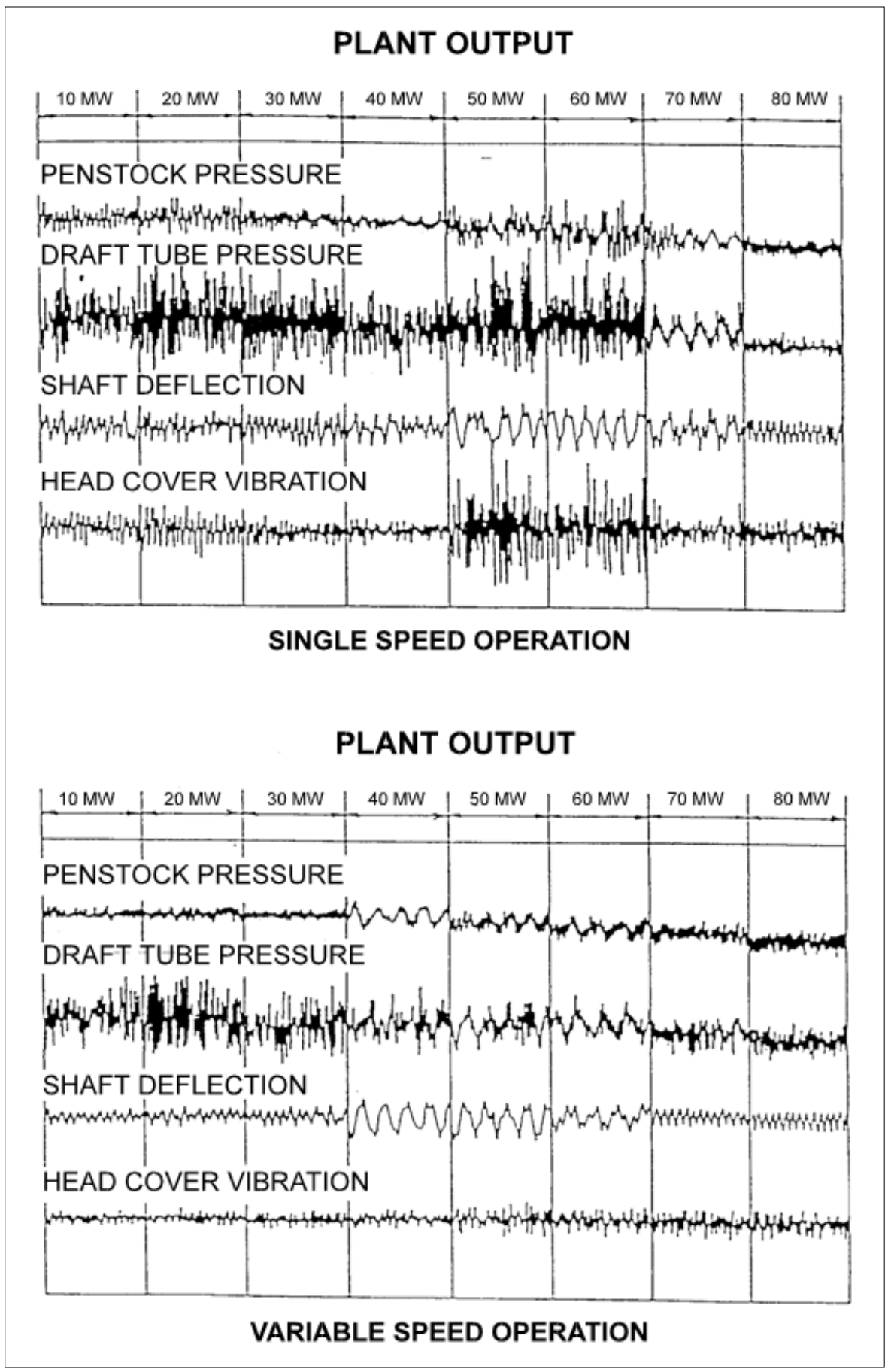

Figure A-16 Comparison of Vibrations and Pressure, Yagisawa Pumped Storage Plant (Source: EPRI 1995)

The benefits of AS in this respect are two-fold, as AS: (1) reduces vibrations in rough operation; and (2) extends the unit's operating range to include the $35 \%$ to $60 \%$ wicket gate opening range. 
These benefits result in reduced wear and tear on bearings and extended operation between maintenance shutdowns (EPRI 1995).

\section{A.5.5 Reactive Power}

Reactive power control of the bulk power transmission grid is driven by the need for voltage regulation at substation buses. The amount and type (inductive or capacitive) of reactive power capability is highly location dependent within a given system. During regular operation, a bulk power transmission grid experiences changes in substation bus voltage as system load levels change from peak to minimum, and voltages are adjusted using designated reactive power resources. In some regional systems, there are concerns about voltage instability, and the management of reactive power resources becomes critical.

Reactive power control can be provided by fixed and switchable shunt reactors and capacitor banks, and by hydro and thermal generators operating in synchronous condenser mode. With solid-state devices, such as static VAR compensators (SVCs) or static synchronous compensator (STATCOM) devices, it is possible to control the level of reactive power by switching or using thyristors to control the capacitor or reactor banks.

Both conventional, single-speed PSH and AS PSH can be operated as synchronous condensers and provide reactive power control during normal day-to-day operation. When operated as synchronous condensers, the units can supply reactive power up to the limits established by rotor heating, and they can absorb reactive power up to a limit determined by stator end-turn heating or the system stability margin. Over-excitation limiters (OELs) are used to prevent overheating.

A compressed air system is activated when a hydro unit is operated in synchronous condenser mode so that the pump/turbine can spin in air. When spinning in air, there are friction and windage losses in addition to the power required to operate air compressors. The machine is drawing a small amount of real power to overcome friction and windage losses when operating as a synchronous condenser.

It should be noted that the air compression system is required as part of the pump-motor starting process; the investment in air compressors is not directly associated with operation in synchronous condenser mode (however, there are operations and maintenance [O\&M] costs associated with operating in synchronous condenser mode). With an AS unit, it should be possible to operate at a lower speed in synchronous condenser mode and reduce windage losses.

Pumped storage units (including single-speed, AS, and ternary) can also provide reactive power support during transient events on the bulk power grid. A conventional, single-speed PSH controls and interchanges reactive power with the bulk power system via the excitation system. A single-speed synchronous machine uses a DC rectifier to establish the magnetic field on the fixed poles of the rotor. An AS machine uses an AC/DC/AC converter to provide a three-phase field on the rotor, which can provide a very fast response to voltage deviations and offers a wide reactive power range. 
The model testing report prepared by Siemens PTI, Inc., includes plots showing machine terminal voltage response for the time following a fault condition. The plots for terminal voltage of the AS machine indicate that the magnitude of voltage dip following a fault is lower for the AS machine than for a conventional, single-speed PSH unit. One manufacturer is suggesting a voltage dip-detecting function as a way to maximize the faster voltage control capability of the DFIM (Shimomura et al. 2001).

\section{A.6 Pumped Storage Design}

The design of a pumped storage plant often begins with a site that is in a desirable location and has favorable geotechnical and seismic conditions with an adequate water source or feature, possibilities for upper and lower reservoir locations, and reasonable head conditions. For the purpose of this discussion, reasonable geotechnical and seismic conditions are assumed, and thus the focus will be on the technical characteristics and facilities that contribute to a successful pumped storage plant.

\section{A.6.1 Head, Flow Rates, Waterways, and Reservoir Size}

\section{A.6.1.1 Head}

Pumped storage projects have been constructed with hydraulic heads ranging from about 100 to 2,500 ft. Most projects at the lower end of this range are either multipurpose projects, pump-back projects, or projects that use an existing lake or reservoir. The minimum practical head for an off-stream pumped storage project is generally around $300 \mathrm{ft}$, with higher heads being preferred. Some projects have been constructed with heads exceeding 3,000 ft. These higher-head projects involve the use of separate pumps and turbines, or multistage pump/turbines. Studies have also been undertaken to develop pumped storage projects with underground lower reservoirs sited 4,000 to 5,000 ft below the surface.

\section{A.6.1.2 Flow Rate}

The capacity of a project is a function of hydraulic head and flow rate. For a pumped storage project with a given head and reservoir storage volume, flow rate is determined to achieve a desired cycling time. A higher flow rate lowers the cycling time. A higher flow rate also requires a larger size for the generating and pumping units and waterway diameter. Cost-benefit optimization is generally carried out to optimize the design flow rate and, hence, the plant capacity. Design flow rate is also constrained by the head loss associated with a particular waterway diameter. For a flow required by the power plant's capacity, the diameter of waterways is optimized by balancing the loss of energy benefits resulting from higher head losses associated with smaller diameters versus the waterway construction costs associated with larger diameters.

\section{A.6.1.3 Waterways}

Figure A-17 shows the major components that make up the waterways in a typical pumped storage plant. It should be noted that not all pumped storage plants have surge tanks, and that the need for surge tanks is the result of hydraulic transient analysis as part of project design. 


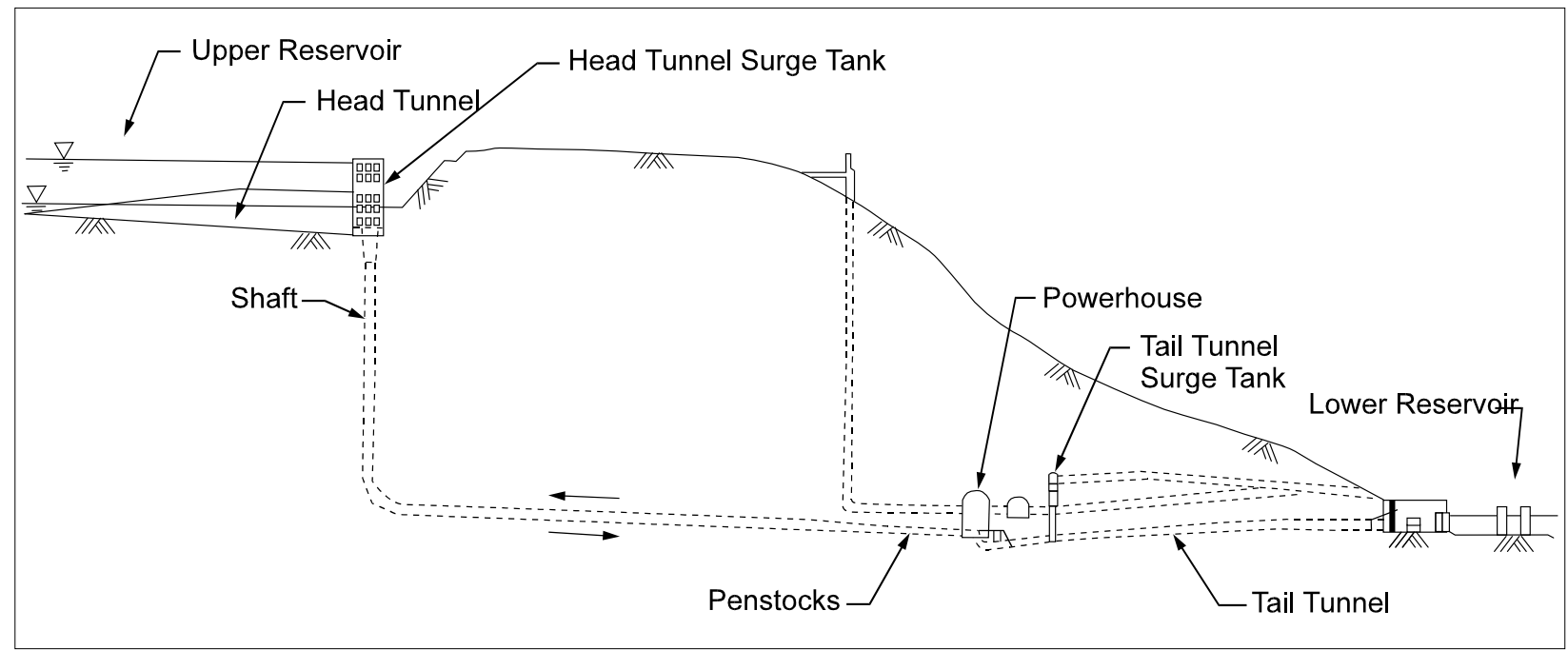

Figure A-17 Cross Section Showing Waterways (Source: EPRI 1995)

A characteristic of a successful pumped storage project is one that develops its hydraulic head with a relatively short waterway between the upper and lower reservoirs. Waterway costs are a major component of a plant's construction costs. The main factor affecting the waterway cost is the overall size of the proposed facility and the "length to head ratio" $(\mathrm{L}: \mathrm{H})$ of the waterway. Waterway length refers to the distance from the intake structure to the tailrace outlet, and the head refers to the vertical distance between the upper and lower reservoirs. The length to head metric, or $\mathrm{L}: \mathrm{H}$, is often used as a screening criterion when comparing alternative project configurations. Minimizing the length, while maintaining a sizeable head between upper and lower reservoirs, is an important metric in project optimization. Projects with lower L:H tend to have lower costs (see Figure A-18) and better cycling efficiency.

In general, the economic upper limit of the $\mathrm{L}: \mathrm{H}$ is about 10 . Although an $\mathrm{L}: \mathrm{H}$ greater than 10 may be observed for some projects, these projects may have other overriding factors that make them feasible. For example, the Helms project in California has exceptionally long waterways, but it is also a seasonal water storage project.

The L:H is also a possible indicator of the need for a surge chamber(s), shaft(s) or tank(s). A surge chamber, shaft, or tank may be required on a long waterway as a way to reduce hydraulic pressure rise during transient events, such as load rejection. The $\mathrm{L}: \mathrm{H}$ is also an indicator of response time and regulating capability. The response time and regulating capability of a unit generally decreases as the L:H increases.

Site topographic and geological characteristics control the configuration of the waterway, both in terms of horizontal and vertical alignment. The waterway profile may include surface or buried sections. High-pressure and large-diameter segments constructed as tunnels in hard rock (if available) are normally the lower-cost option. The alternatives to tunnels in rock include steel or concrete water pipes. 


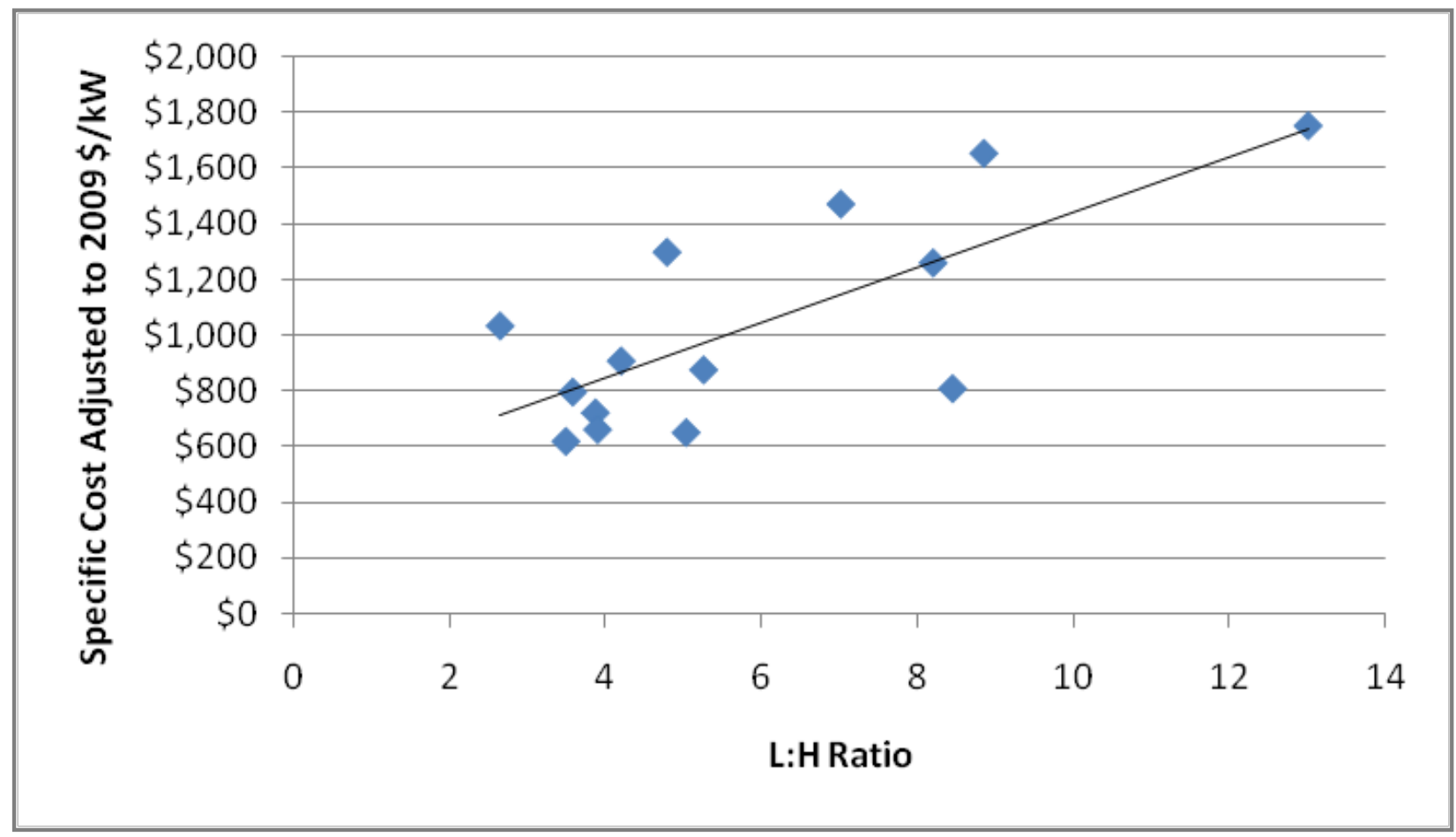

Figure A-18 Historic Capital Cost (2009 $\$ / \mathrm{kW}$ ) versus Length to Head Ratio (Source: USACE 2009)

Waterway costs are influenced by total generating capacity and prevailing head. The number and size of a given waterway are determined as a function of flow and hydraulic parameters. Given the same output specification (MW), a high-head project will have a smaller waterway cross section than a low-head project. Given the same head, higher-capacity projects will have a greater waterway flow cross section than will lower-capacity projects.

The design of the waterways is an important aspect in the performance of the project. The characteristics of the waterway determine head loss and also influence unit responsiveness in terms of ramp rate and ability to provide other A/S.

\section{A.6.1.4 Reservoir Size}

The sizes of the upper and lower reservoirs are dependent on available head, plant capacity, plant operation, and site characteristics. Site characteristics include land acquisition cost, as well as physical and geotechnical conditions. Good physical and geological site conditions are vital to upper and lower reservoir selection and design. Upper reservoirs are typically created by building a dam across a three-sided depression or a ring-dike on a plateau or by building a dam across a stream or other water feature.

A lower reservoir can be a natural lake or an existing hydro project reservoir, or one can be created by building a dam across a small stream. It is also possible to use an existing quarry or an 
underground mine. The Yanbaru Seawater Pumped Storage Plant on Okinawa uses the Pacific Ocean as a lower reservoir.

The selection of the reservoir size is dependent on the site characteristics and needs of the electric power system. Some pumped storage projects have more than 20 hours of operating storage, and some have as little as 4 hours of operating storage. Those with larger amounts of operating storage may have been planned with the objective of using the weekend to store water as part of a weekly operating regime. Pumped storage projects with limited storage were probably planned for operating on a daily cycle or to provide short-term operating reserve. In recent times, the amount of nondispatchable renewable energy sources is another determining factor in reservoir sizing.

A pumped storage project in which the upper and lower reservoirs have an operating storage volume of 10,000 acre-feet and an average head differential between the reservoirs on the order of $1,000 \mathrm{ft}$ with an $86.7 \%$ generating efficiency would have an energy content of approximately 8,800 MWh. This energy content can support an installed capacity of $880 \mathrm{MW}$ and an energy storage equivalent of up to 10 hours of operation.

Production costing models, operational simulations, and generation expansion modeling tools are used to study and estimate the reduction in system operating costs associated with increasing levels of energy storage. Typically, the savings will diminish as energy storage increases. The comparisons to be made are: (1) cost versus storage, and (2) benefit (or system operational cost savings) versus storage capacity. This comparison should lead to a point where incremental costs and benefits are equal, thus should help identify the preferred energy storage size.

\section{A.6.2 Pump/Turbine Selection}

Modern multi-unit pumped storage plants use reversible Francis turbines with wicket gates and a speed governor system. Design and selection of the pump/turbine takes into account a multitude of factors; among these are operating head, the setting in relation to the upper and lower reservoir levels, specific speed, synchronous speed, water column time constant, draft tube surging, and other factors. In the case of the advanced pumped storage plants with AS capability, there is also a need to determine the range of speed variation. The selection of synchronous speed and the range of speed adjustment are important factors in overall performance, operating cost, and revenue.

\section{A.6.3 Adjustable Speed DFIM Motor/Generator}

As mentioned previously, AS machines use a DFIM. The DFIM has a solid rotor that is built up with laminated steel sheets as compared with a synchronous machine with salient poles mounted on a spider-shaped support structure.

Stator design is similar to that of conventional synchronous single-speed motor/generators. However, the design and manufacturer of rotors for AS machines presents several major design challenges for manufacturers. Some of these include circulation of cooling air, balance, attachment of rotor coil overhang, testing, transportation, installation, and commissioning. 
Figure A-19 allows a comparison between a single-speed synchronous motor/generator and a doubly-fed induction motor/generator in a pumped storage application.

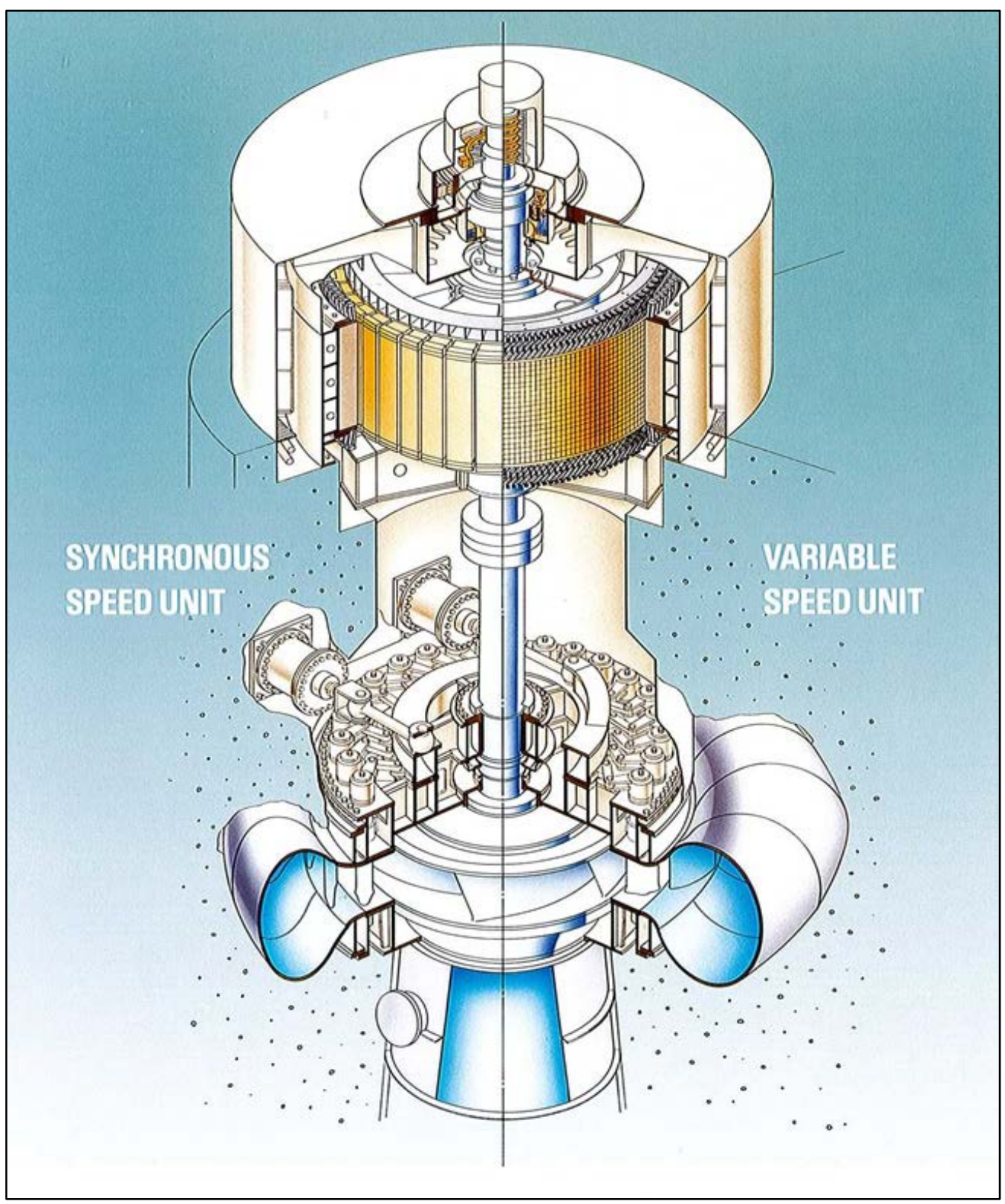

Figure A-19 Synchronous Speed and AS PSH Unit (Source: Toshiba Corp. 2000)

\section{A.6.4 Other Design Issues}

Table A-7 lists several design issues for the three types of pumped storage technologies under study. 
Table A-7 Plant Design Issues

\begin{tabular}{|c|c|c|c|}
\hline Benefits & $\begin{array}{c}\text { Conventional FS PSH } \\
\text { with Single-Speed } \\
\text { Synchronous } \\
\text { Motor/Generators }\end{array}$ & $\begin{array}{l}\text { AS PSH with DFIM } \\
\text { Motor/Generators }\end{array}$ & $\begin{array}{c}\text { Ternary Type PSH with } \\
\text { Hydraulic Bypass and } \\
\text { Single-Speed } \\
\text { Synchronous } \\
\text { Motor/Generators } \\
\end{array}$ \\
\hline Bearing life & Base & $\begin{array}{l}\text { Same as base but with } \\
\text { reduced vibration }\end{array}$ & Base \\
\hline Maintenance cost & Base & Increased & Base \\
\hline Vibrations & Base & Reduced & Base \\
\hline $\begin{array}{l}\text { Time between major } \\
\text { overhaul }\end{array}$ & Base & $\begin{array}{c}\text { May be extended because } \\
\text { of reduced vibration }\end{array}$ & Base \\
\hline Pump/turbine setting & Base & Deeper & - \\
\hline Crane capacity & Base & Greater & Base \\
\hline Floor space & Base & Greater & Base \\
\hline $\begin{array}{l}\text { Water-cooled } \\
\text { electronics }\end{array}$ & $\mathrm{SFC}^{\mathrm{a}}$ & Yes & Not required \\
\hline Pump mode starting & SFC & Rotor electronics & - \\
\hline Power house height & Base & Higher & Base \\
\hline $\begin{array}{l}\text { Rotor - overvoltage } \\
\text { protection }\end{array}$ & No & Rotor circuit & No \\
\hline Hydraulic churning & $\begin{array}{c}\text { In back-to-back mode } \\
\text { on a common } \\
\text { penstock }\end{array}$ & $\begin{array}{l}\text { In back-to-back mode on a } \\
\text { common penstock }\end{array}$ & Yes \\
\hline
\end{tabular}

${ }^{\mathrm{a}} \mathrm{SFC}=$ static frequency converter

"_" = not applicable

\section{A.7 Cost Characteristics}

Cost characteristics of pumped storage projects include capital (or construction) cost, O\&M costs, and revenue. This discussion is focused on capital costs.

Because of the overall scope and site-specific nature of pumped storage project development, capital costs are difficult to characterize and estimate. Several factors that influence the costs of a pumped storage project include site-specific geotechnical and topology conditions, size of reservoirs and dams or ring dikes, length of tunnels, surface versus underground powerhouse, type of electromechanical technology, transmission system interconnection and upgrade costs, environmental issues, permitting process, regulatory environment, business plan, and ownership structure.

In addition, a pumped storage plant has a longer development and construction period compared with most other types of thermal generation plants, often as long as 10 years or more. During the preconstruction period, many activities are undertaken in the form of preliminary engineering, permitting, environmental, regulatory, and other nonengineering items. 
For large, long-term projects-such as pumped storage-there is always some uncertainty about what is included or excluded in reported capital costs. For example, it is often not known whether costs such as engineering, administration, financing fees, and interest costs during construction, or other "soft" costs are included as project capital costs, or whether they are reported in some other way. Because these costs can be significant, any conclusions about project costs and guidelines, such as $\$ /$ kilowatt $(\mathrm{kW})$ installed, based on historic data need to be considered with care.

\section{A.7.1 Historic Capital Cost Information}

There are 36 licensed, non-federal pumped storage projects operating in the United States. Of this group, 14 are considered to be relevant to this discussion; the other 22 projects were excluded because they are pump-back schemes, or are part of a larger water supply project and not what could be called a "conventional” pumped storage project.

Historical cost data from FERC Form 1 reports and a compendium of pumped storage plants were used to evaluate the cost per $\mathrm{kW}$, and costs were adjusted to 2009 levels using Bureau of Labor Statistics data. The plants that were evaluated have capacities from 300 to 2,100 MW, with an average plant capacity of $900 \mathrm{MW}$. The number of units per plant ranged from two to eight; five of the 14 plants have four units.

\section{A.7.2 Cost Trends}

There is an expectation that, as rated plant capacity increases, there should be a corresponding decrease in cost per $\mathrm{kW}$. However, from a review of the data, this trend is not evident for the sample projects. This apparent anomaly is related to the fact that each pumped storage project has unique costs that are independent of plant and unit size; these include environmental investigations, land ownership and procurement, site-specific geotechnical and civil design engineering, number of units, project delivery method, and regional construction cost variations.

The project costs plotted against the 14 sample projects' in-service years do follow a trend, as shown in Figure A-20: project costs, expressed in constant dollar terms per $\mathrm{kW}$ of generating capacity, appear to be trending upward. This trend may be related to the regulatory environment or to site-specific factors. There is also a difference in the regulatory environment during the 1960s that changed with deregulation when FERC Rule 888 was adopted in the mid-1900s. It is also possible that the first projects developed are the most favorable, and that the later sites have less favorable characteristics and were therefore more expensive to develop. 


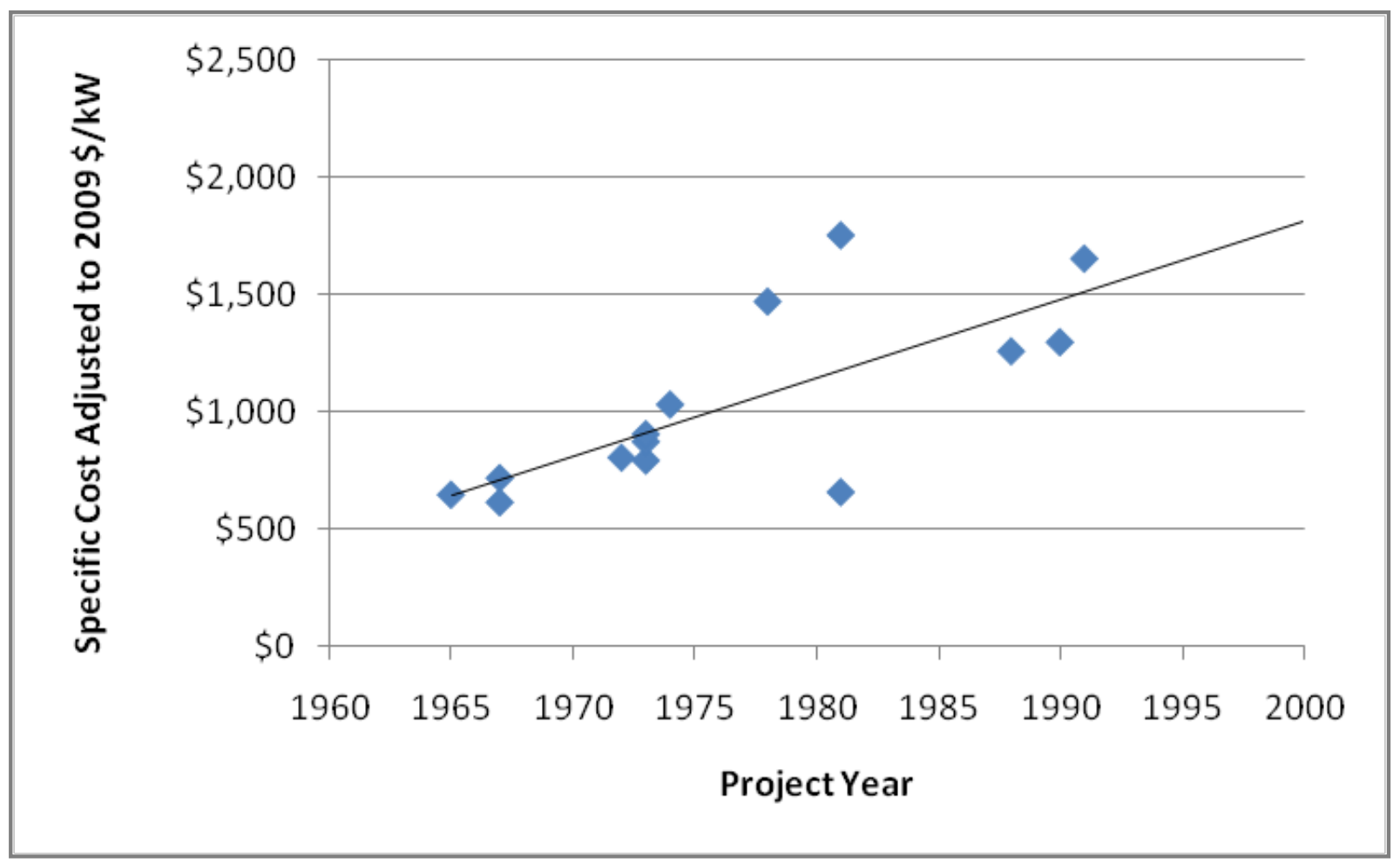

Figure A-20 Historic Capital Cost (2009 \$/kW) versus Project Year (Source: USACE 2009)

\section{A.7.3 Cost for Future Projects}

Figure A-21 shows cost ranges for greenfield pumped storage projects. The variation reflects site-specific (and other) items with large cost variability. The cost data are based on 2009 price levels known as the "overnight" costs for construction and equipment procurement, which exclude escalation to the midpoint of the construction period and are without any allowances for third-party engineering and legal costs, owner's administration, land, transportation, or financial costs (interest and other financial fees). In addition, the data used to prepare the curves have been developed to reflect bidding for construction and equipment procurement in a neutral bidding environment not impacted by market factors, and an assumed normal bid-build project delivery methodology. Inspection of the curves shows that an expected construction and equipment procurement cost of a hypothetical 1,000-MW pumped storage project is on the order of $\$ 2,000 \$ / \mathrm{kW}$ but could fall in the range of $\$ 1,750 / \mathrm{kW}$ to $\$ 2,500 / \mathrm{kW}$. 


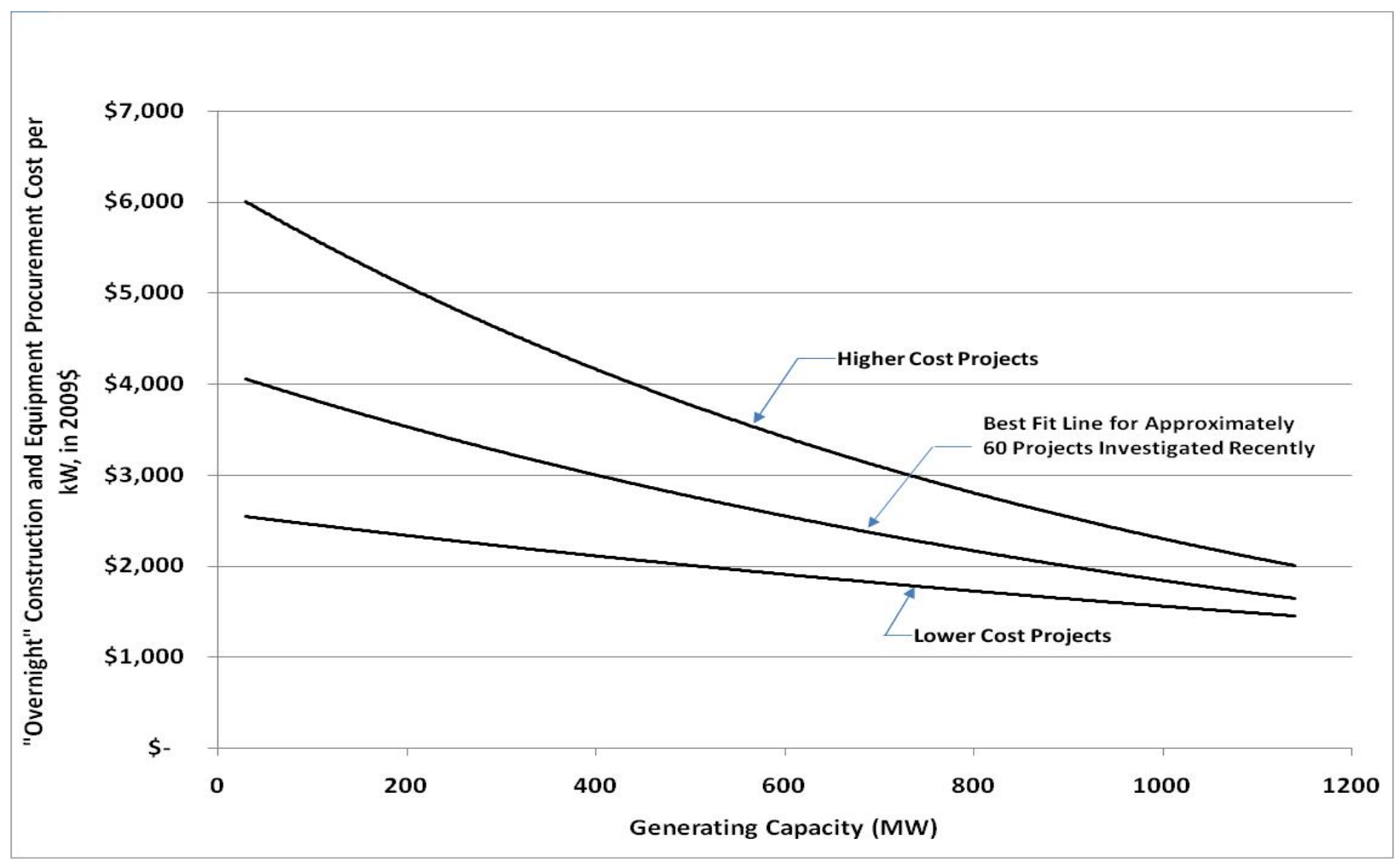

Figure A-21 Indicative Overnight Construction Cost for Greenfield Pumped Storage Projects (Source: USACE 2009)

\section{A.7.4 Incremental Cost Increase with Adjustable Speed}

The incremental cost for incorporating AS capability is mainly related to equipment and civil costs. Equipment costs include the motor/generator rotor and stator, rotor excitation system, cooling system for the solid-state devices in the rotor excitation system, rotor circuit overvoltage protection system, and smoothing reactors. The civil structural costs are for the necessary space to accommodate electrical equipment. The selection of the speed range has an impact on the civil works in the form of additional excavation and civil structural costs associated with the deeper setting of the pump/turbine. Another cost factor is the need for an overhead crane with adequate capacity to lift a rotor made with stacked laminations. The speed range also effects the cost for the rotor excitation AC/DC/AC converter. Greater speed range requires a converter with an increased MVA rating.

Pricing information from electrical equipment manufacturers suggests an incremental cost increase in the range of $50 \%$ to $125 \%$ of the cost for a conventional single-speed motor/generator. The manufacturing cost of the laminated rotor includes additional effort to test the weight distribution of the assembled rotor for proper balance. If manufacturers can reduce the effort needed for rotor assembly and testing, then costs could be reduced. Another factor in the cost is the shift from cycloconverter technology to self-commutated voltage source converter technology and the use of alternatives to the thyristor. In terms of overall PSH project cost, an incremental project cost increase in the range of $7 \%$ to $15 \%$ might be expected. 


\section{A.7.5 Ternary Pumped Storage with Hydraulic Bypass - Plant and Equipment Costs}

There is limited experience with hydraulic bypass ternary PSH plants and units. As of this writing, we are aware of one ternary pumped storage plant with hydraulic bypass units in commercial operation - Kops II in Austria. There may be others in the planning and design stages.

The cost of a ternary unit with hydraulic bypass is greater than a ternary unit without hydraulic bypass. With hydraulic bypass, there are added costs for civil works, water conductors, and valves to create the hydraulic bypass.

Power conversion equipment is similar to that used with a conventional, single-speed pumped storage unit with some major differences. Instead of a single reversible pump/turbine, the ternary plant has a separate pump and turbine with a hydraulic torque converter (clutch).

Major power conversion equipment that is used for a ternary unit with hydraulic bypass includes the following:

- Synchronous single-speed motor/generator

- $\quad$ Separate pump and turbine

- Clutch (hydraulic torque converters)

- Valves

The investment with the reversible pump-turbine is lower for the hydraulic machinery and also for the civil engineering as compared with the configuration using the classic three-machine ternary arrangement (Spitzer and Pennington 2008).

\section{A.8 References and Bibiliography}

Byrne, R.H., M.K. Donnelly, V.W. Loose, and D.J. Trudnowski, 2012, Methodology to Determine the Technical Performance and Value Proposition for Grid-Scale Energy Storage Systems, SAND2012-130639, Sandia National Laboratories, Albuquerque, N.M., pg. 43, Dec.

EPRI (Electric Power Research Institute), 1995, “TR-105542: Application of Adjustable Speed Machines in Conventional and Pumped-Storage Hydro Projects,” Nov.

FERC (Federal Energy Regulatory Commission), 2012, "Integration of Variable Energy Resources,” Section 264, Docket No. RM10-11, Order 764, 18 CFR Part 35, June 22.

First Hydro Company, 2014, http://www.electricmountain.co.uk/en-GB/Dinorwig. Accessed June 2014. 
Fisher, F., 1994, “Mt. Hope Waterpower Project,” Panel Session on Advanced Pumped Storage, IEEE-PES Winter Meeting, New York, N.Y., Feb.

Fisher, R.K., J. Koutnik, L. Meier, V. Loose, K. Engels, and T. Beyer, 2012, “A Comparison of Advanced Pumped Storage Equipment Drivers in the U.S. and Europe,” HydroVision International.

Furuya, S., S. Fujiki, T. Hioki, T. Yanagisawa, S. Okazaki, and S. Kobayashi, 1992, "Development and Achieved Commercial Operation Experience of the World's First Commissioned Converter-Fed Variable Speed Generator-Motor for a Pumped Storage Power Plant,” CIGRE (Conference Internationale des Grandes Reseaux Electriques) 11-104.

IEEE Task Force Report, 2007, “Interconnected Power System Response to Generation Governing: Present Practice and Outstanding Concerns,” Final Report, prepared by the Task Force on Large Interconnected Power System Response to Generation Governing, Power System Dynamic Performance Committee of the IEEE Power Engineering Society, April.

Kita, E, A. Bando, and T. Kuwabara, 1995, “400 MW Adjustable-Speed Pumped Storage Hydraulic Power Plant;” 4th Plant at the Kansai Electric Power Company, Okawachi Power Station, Hitachi Review, Vol. 44, No. 1, pp. 55-62.

Kuwabara, T., A. Shibuya, and H. Furuta, 1996, "Design and Dynamic Response Characteristics of 400 MW Adjustable Speed Pumped Storage Unit Four Okawachi Power Station,” pp. 376384 in IEEE Transactions on Energy Conversion, Vol. 11, No. 2, June.

NERC (North American Electric Reliability Corporation), 2011, Balancing and Frequency Control, Available at http://www.nerc.com/docs/oc/rs/NERC\%20Balancing\%20and\%20Frequency\%20Control\%2004 0520111.pdf.

Shimomura, M., Y. Xia, and J. Paserba, 2001, “Active Power Control for Preventing Voltage Instability Using an Adjustable Speed Machine," in Proceedings of the IEEE PES 2001 Summer Power Meeting, Vancouver, B.C., July.

Spitzer, F., and G. Penninger, 2008, "Pumped Storage Power Plants - Different Solutions for Improved Ancillary Services Through Rapid Response to Power Needs,” Hydro Vision 2008 Session 4H2, Sacramento, Calif., July 17.

Sporild, R., J.O. Gjerde, and T. Gjengedal, 2000, "Economic and Technical Aspects of Adjustable Speed Hydro (ASH) Machines Applied for Improved Stability in Power Networks," PES Summer Meeting, July, Vol. 4, pp. 2469-2474.

Stalker, B., 1994, personal communication between Peter Donalek (MWH) and Brian Stalker, Dinorwig plant manager, retired. 
Toshiba Corp., 2000, The World's First Commissioned Converter-fed Variable-Speed Pumped Storage System, Catalog 4502-2. Tokyo, Japan.

USACE (U.S. Army Corps of Engineers), 2009, Technical Analysis of Pumped Storage and Integration with Wind Power in the Pacific Northwest, Final Report, Aug.

\section{A.9 Selected Definitions}

Ancillary Services (A/S) - Technical within-hour power and transmission services necessary for reliable power delivery other than simple megawatt-hours. Includes spinning and non-spinning generation reserves, VAR support, within-hour load following and regulation, generation imbalance, and others. Some A/S are charged in power rates, others in transmission rates, and others are provided without specific charge.

Balancing Authority (new term for Control Area) - The responsible entity that schedules generation on transmission paths ahead of time, maintains load-interchange-generation balance within a Balancing Authority Area, and supports interconnection frequency in real time.

Balancing Reserves - A portion of the operating system that is held ready to maintain load resource balance at all times. This reserve amount includes load following, regulating reserves, generation imbalance (scheduling error), and the variability of intermittent resources.

Black-Start Capability - Black start is the recovery procedure after a total or partial shutdown of the transmission system that causes an extensive loss of supplies. Plants with black-start capability can be started individually by themselves and can be gradually reconnected to each other to restore interconnected system operation.

Capacity - The greatest amount of power a generator or system of generators can supply at its peak output. Capacity is measured in kilowatts (kW), megawatts (MW), or gigawatts (GW), where one GW is equal to 1,000 MW.

Cavitation - During pumping, cavitation refers to cavities or air and gas bubbles that are formed at low pressure (negative gage pressure) on the suction side of the pump.

Corona - Ionization of air surrounding electrical conductors due to high electric field intensity.

Downward Regulation (Reg down) - Spinning reserves ready to increase generation to compensate for a declining contribution from a nondispatchable resource such as wind or an increase in load. This reserve is in addition to the spinning reserves that stand ready to respond to contingency outages.

Energy - Where used specifically, an amount of electricity consumed over time, which may include periods of higher and lower consumption within that time frame. Energy is measured in kilowatt-hours (kWh), megawatt-hours (MWh), and also gigawatt-hours (GWh). 
Frequency Regulation - In the United States, electricity is transmitted from a power plant to an end user at a frequency of $60 \mathrm{~Hz}$. Electrical equipment designed to operate at $60 \mathrm{~Hz}$ may not operate efficiently or even safely at frequencies other than the intended frequency. Frequency of a system can vary with an imbalance between loads and generation. The power system frequency declines when loads exceed generation and increases when generation exceeds loads. Maintaining the balance between loads and generation provides frequency regulation.

Load - The total amount of electricity used at any given time or over any given period that a utility is obligated to serve, or the balancing authority area must balance, with generation.

Load Following - Balancing of loads and resources over a several-minute response time, typically 10 to 60 minutes.

Peak Load - The highest amount of electricity demand in a specific area, either for a moment, an hour, a set of hours, or another specified period. To maintain reliability, peak loads must always be less than generation capacity available to the specified area.

Power Factor - The ratio of power actually being used in an electricity circuit measured in $\mathrm{kW}$, to the power that is apparently being drawn from the power source, measured in kilovoltamperes ( $\mathrm{kVA})$. It is the cosine of the angle between the real power and apparent power vectors.

Pumped Storage Project Cycle Efficiency - Long-term energy generated divided by the longterm pumping energy input.

Pumped Storage Project Roundtrip Efficiency - Energy generated by evacuating the upper reservoir while operating at maximum output divided by the energy required to completely refill the upper reservoir, with all units operating simultaneously and continuously during the generation and pumping modes.

Ramp Rate - Rate of change of unit power level, up or down, in response to an automation generation control (AGC) signal.

Reactive Power (VARS) - A component of apparent power that does not produce any real power (watts). Reactive power is measured in units called volt-amps-reactive or VARS. An imbalance in VARS causes voltage to rise or drop across the power system.

Reserves (Operating Reserves) - In a power system, reserves provide the necessary capability in excess of that required to carry the normal total load. Electric power needed to serve customers in the event of generation or transmission system outages, adverse streamflows, delays in completion of new resources, or other factors that may restrict generating capability or increase loads. Normally provided from additional resources acquired for that purpose, or from contractual rights to interrupt, curtail, or otherwise withdraw portions of the electric power supplied to customers.

Reserve Requirements - Amounts and types of reserves that a Balancing Authority must maintain in available status to comply with North American Electric Reliability Corporation, 
Western Electricity Coordinating Council, or other regulatory requirements. Includes contingency reserves (half spinning, half non-spinning), regulating reserves, load following, generation imbalance, and contingency reserves.

Regulation - Balancing of loads and resources over a several-second response time.

Resource - Any source of power supply that can be contractually assured.

Shaping - Taking energy (or streamflows) from a generation source as it is produced, and providing, in return, energy (or water) in the amount(s) over time as requested by a customer or as required. Shaping can be accomplished with pumped storage by storing energy from intermittent resources during off-peak hours for use during the peak hours or by storing energy for later use when output from intermittent plus must-run resources exceeds the load.

Speed Droop - A governor function that changes the governor reference speed as power output changes in response to system loads.

Spinning Reserves - Generators that are turned on and synchronized with the grid, literally spinning but not connected to load or that are not operating at full capacity but held on stand-by to increase generation at a moment's notice.

Ternary Type Pumped Storage System - A type of pumped storage system that consists of a hydraulic bypass or "short circuit" with a single synchronous machine coupled to both a separate turbine and a separate pump by a torque converter or clutch.

Upward Regulation (Reg up) - Spinning reserves ready to increase generation to compensate for a declining contribution of a nondispatchable resource, such as wind, or an increase in load. This reserve is in addition to the spinning reserves that stand ready to respond to contingency outages.

Variable Generation - An electric generator that is not dispatchable and cannot store its fuel source and therefore cannot respond to changes in system demand or respond to transmission security constraints. Hydropower is variable beyond the storage capabilities of reservoirs. Wind and solar output vary with wind and sun, respectively.

Variable Resources - An electric generator that is not dispatchable and cannot store its fuel source and therefore cannot respond to changes in system demand or respond to transmission security constraints. Variable resources include wind power that cannot increase or produce generation at the command of their operators, but are only available at nature's discretion. Synonymous with nondispatchable generation.

VAR (Volt-Ampere Reactive) - A unit to measure reactive power in an AC electric power system. 
Voltage support - As with frequency, voltages must be kept within design tolerances.

Transmission system voltage control involves balancing the supply and demand of reactive power. 


\section{Acronyms}

AC

AGC

AS

$\mathrm{A} / \mathrm{S}$

CFSM

DC

DFIM

EWG

FERC

GCT

GTO

IEEE

IGBT

IEGT

$\mathrm{L}: \mathrm{H}$

LSE

O\&M

PSH

PV alternating current

automatic generation control

adjustable speed

ancillary service(s)

converter-fed synchronous machine

direct current

doubly-fed induction machine

electric wholesale generator

Federal Energy Regulatory Commission

gate commutated thyristor

gate turn-off thyristor

Institute of Electrical and Electronics Engineers

insulated gate bipolar transistor

injection-enhanced gate transistor

length to head ratio

load serving entity

operations and maintenance

pumped storage hydropower

photovoltaic

\section{Units of Measure}

$\begin{array}{llll}\mathrm{Hz} & \text { Hertz } & \text { rpm } & \text { rotations per minute } \\ \mathrm{kW} & \text { kilowatt(s) } & \text { sec } & \text { second(s) } \\ \mathrm{kWh} & \text { kilowatt-hour(s) } & \text { VAR } & \text { volt-ampere(s) reactive } \\ \mathrm{min} & \text { minute(s) } & & \\ \mathrm{ms} & \text { millisecond(s) } & & \\ \mathrm{MW} & \text { megawatt(s) } & & \\ \mathrm{MWh} & \text { megawatt-hour(s) } & & \end{array}$





\section{Argonne \\ NATIONAL LABORATORY}

\section{Decision and Information Sciences}

Argonne National Laboratory

9700 South Cass Avenue, Bldg. 221

Argonne, IL 60439-4844

www.anl.gov 